Plumes et Pinceaux

Discours de femmes sur l'art en Europe

(1750-1850) - Anthologie

Anne Lafont, avec la collaboration de

Charlotte Foucher et Amandine Gorse

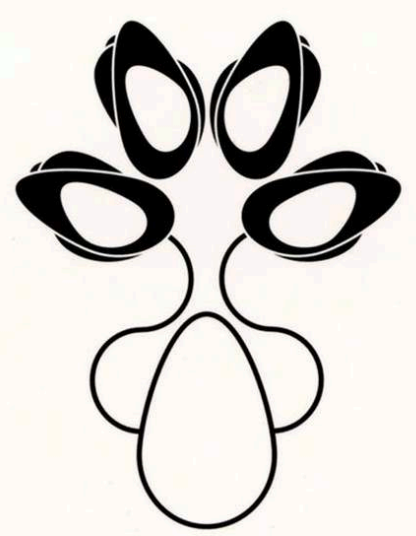

les presses du réel

Etwures en societés 


\section{Plumes et Pinceaux : Discours de femmes sur l'art en Europe (1750-1850) - Anthologie}

\section{Anne Lafont (dir.)}

Isabelle Baudino, David Blankenstein, Charlotte Foucher, Amandine Gorse, Anne Lafont, France Nerlich, Christine Planté et Fanny Reboul (éd.)

Traducteur : Anne-Laure Brisac-Chraïbi, Flore Piacentino, Jean Piétri et Évelyne Sinnassamy

DOI : 10.4000/books.inha.2907

Éditeur : Publications de l'Institut national d'histoire de l'art, Presses du réel

Lieu d'édition : Dijon

Année d'édition : 2012

Date de mise en ligne : 5 décembre 2017

Collection : Sources

ISBN électronique : 9782917902844

\section{S books}

http://books.openedition.org

Édition imprimée

Date de publication : 1 juin 2012

ISBN : 9782840664581

Nombre de pages : 520

\section{Référence électronique}

LAFONT, Anne (dir.) ; et al. Plumes et Pinceaux : Discours de femmes sur l'art en Europe (1750-1850) Anthologie. Nouvelle édition [en ligne]. Dijon : Publications de l'Institut national d'histoire de l'art, 2012 (généré le 18 décembre 2020). Disponible sur Internet : <http://books.openedition.org/inha/2907> ISBN : 9782917902844. DOI : https://doi.org/10.4000/books.inha.2907.

Ce document a été généré automatiquement le 18 décembre 2020.

(C) Publications de l'Institut national d'histoire de l'art, 2012

Conditions d'utilisation:

http://www.openedition.org/6540 
Si Germaine de Staël et Marceline Desbordes-Valmore sont connues pour leurs réflexions sur l'art, d'autres textes et pensées de femmes des années 1750-1840 en France, mais aussi en Angleterre et en Allemagne, le sont moins, ou pas du tout.

C'est un florilège de ces écrits qui est donné à lire ici : de $\mathrm{M}^{\text {me }}$ de Beaumer à Edmée de Syva, en passant par Félicité de Genlis (dont sont publiés deux textes inédits, Essai sur les arts et Catalogue pittoresque du cabinet de tableaux de Monsieur le comte de Sommariva), Élisabeth Vigée-Lebrun, Helmina von Chézy, Anne Plumptre, parmi une quinzaine d'autres. Journalistes, critiques d'art, artistes ou voyageuses curieuses et averties visitant les musées européens avec passion, elles usent de tous moyens littéraires pour faire entendre des positions esthétiques, morales, voire politiques sur l'art et son histoire. Elles portent un regard aigu, mais pourtant jamais univoque, sur les grands événements de leur temps - de la Révolution française à la conquête napoléonienne et à ses conséquences -, et sur l'art et la création artistique.

Cette publication, dirigée par Anne Lafont, Maître de conférences en histoire de l'art (université de Marne-la-Vallée) et conseillère scientifique à l'INHA, avec la collaboration de Charlotte Foucher (université Paris-I Panthéon-Sorbonne) et Amandine Gorse (université Paris Ouest Nanterre La Défense), va de pair avec deux ouvrages papier publiés aux Presses du réel. Le premier, Plumes et Pinceaux. Discours de femmes sur l'art en Europe (1750-1850), est un recueil d'essais qui paraîtra sur ce site après une barrière mobile de trois ans.

C'est le texte intégral du second de ces volumes que nous proposons ici. Il donne à entendre les voix des auteures qui, dans les années 1750-1850 en Europe, ont visité les Salons et les musées, ou ont fréquenté les ateliers d'artistes et les collectionneurs. Mais nous avons pensé que mettre à la disposition des internautes ces pages parfois inédites et très souvent difficiles à retrouver aujourd'hui constituait un formidable outil pour la recherche. Nous avons par ailleurs recherché - et trouvé, autant que faire se peut - les œuvres d'art dont parlent ces femmes : la publication en ligne nous permet alors de les donner à voir, de façon à restituer leur regard. Une bibliographie très complète accompagne également cette publication. 
SOMMAIRE

Introduction

Anne Lafont

$M^{\text {me }}$ de Beaumer (1720 ? - 1766)

Introduction

Amandine Gorse

$M^{m e}$ de Beaumer, Journal des dames, 1761-1762

[extraits choisis]

« Lettre sur les tableaux, de M.*** à M.*** » (octobre 1761)

« Arts et modes » (novembre 1761)

" Arts » (décembre 1761)

« Arts » (avril 1762)

«Arts » (novembre 1762)

$M^{\text {me }}$ de Maisonneuve (1710 ? - 1774 ?)

Introduction

Amandine Gorse

$M^{\text {me }}$ de Maisonneuve, Journal des dames, 1763-1767

[extraits choisis]

«Salon de peinture » (août-octobre 1763)

« Lettre d'une dame au sujet du dôme des Invalides » (février 1764)

« Avis divers. Gravure » (août 1765)

«Gravure » (septembre 1765)

«Gravure » (mai 1766)

«Beaux-Arts » (mars 1767)

Marie-Émilie de Montanclos (1736 - 1812)

Introduction

Amandine Gorse

$M^{m e}$ de Montanclos, Journal des dames, 1774-1777

[extraits choisis]

« Lettre à Monsieur le marquis de... sur les sculptures et peintures de Saint-Luc exposées à l'hôtel de Jabac » (octobre 1774)

« Peinture » (janvier 1775)

« Gravures » (janvier 1775)

«La Cruche cassée, conte d'après un tableau de M. Greuze » (janvier 1777) 


\section{Caroline Wuiet (1766 - 1835)}

\section{Introduction \\ Amandine Gorse}

Caroline Wuiet, Le Papillon, an VI

[extraits choisis]

«Première promenade au Salon de peinture » (7 thermidor an VI)

" Ma seconde promenade au Salon de peinture » (10 thermidor an VI)

« Troisième promenade au Salon de peinture » (11 thermidor an VI)

« Ma quatrième promenade au musée des Arts » (17 thermidor an VI)

" Ma cinquième promenade au musée des Arts » (21 thermidor an VI)

« Ma sixième promenade au musée des Arts » (8 fructidor an VI)

\section{Caroline Wuiet, Le Phénix, an VI et VII}

[extraits choisis]

« Théâtre Richelieu » (8 fructidor an VI)

"Ma huitième promenade au musée des Arts » ( $1^{\mathrm{er}}$ vendémiaire an VII $)$

"Ma neuvième promenade au musée des Arts » (7 vendémiaire an VII)

« Deuxième édition revue et corrigée de la sixième promenade au musée des Arts » (13 vendémiaire an VII)

\section{B. [Pauline Auzou (1775 - 1835) ou Albertine Clément-Hémery (1778 - 1855)]}

\section{Introduction}

Amandine Gorse

B., Journal des dames et des modes, an X-an XI [extraits choisis]

«Salon de l'an X » (15 brumaire)

Article du 30 brumaire an XI

\section{Maria Cosway (1759 - 1838)}

Introduction

Fanny Reboul

Maria Cosway, Extraits de son journal, 1802

Manuscrit, Lodi, Fondation Cosway, volume A, extraits choisis.

Mardi 22 juin $1802^{* *}$

9 juillet $1802^{* *}$

11 octobre $1802^{*}$

17 octobre $1802^{* *}$

21 décembre $1802^{* *}$ 
Maria Cosway, Lettre autobiographique adressée à William Cosway, cousin de Richard Cosway, 1830

Manuscrit, Londres, Victoria and Albert Museum, National Art Reference Library, MS (Eng.) L.961-1953.

Anne Plumptre (1760 - 1818)

Introduction

Isabelle Baudino

Anne Plumptre, Relation d'un séjour de trois ans en France, 1810

A Narrative of a Three Years' Residence in France, Principally in the Southern Departments, from the Year 1802 to 1805: Including some Authentic Particulars Respecting the Early Life of the French Emperor, and a General Inquiry into his Character, Mawman et al. (éd.), Londres.

Chapitre III

Chapitre XVII

Julie Candeille (1767 - 1834)

\section{Introduction}

Anne Lafont

Julie Candeille, Lettres à M. Girodet, 1808, 1809, 1810, 1813

Montargis, musée Girodet, extraits choisis.

26 rue Grange-Batelière, $1808 ; n^{\circ} 78$

$1809 ; n^{\circ} 21$

$1810 ; n^{\circ} 64$

$1813 ; n^{\circ} 14$

Julie Candeille, Stances irrégulières. Vers improvisés sur le tableau d'Atala pour G[irodet]

[s.d.] ; Montargis, musée Girodet, inv. Ms 967. 2. 3.

\section{Germaine de Staël (1766 - 1817)}

\section{Introduction}

Anne Lafont

Germaine de Staël, Corinne ou l'Italie, 1807

Édition établie, présentée et annotée par Simone Balayé, Paris, Gallimard, 1985, extraits choisis.

« Rome»

« Les statues et les tableaux»

Germaine de Staël, De l'Allemagne, 1814

Paris, Garnier-Flammarion, 1968, extraits choisis.

« Lessing et Winckelmann »

« Des beaux-arts en Allemagne » 
Helmina von Chézy (1783 - 1856)

Introduction

David Blankenstein

Helmina von Chézy, La Vie et les Arts à Paris depuis Napoléon I ${ }^{\text {er }}, 1804$

Essai d'une vue d'ensemble de la nouvelle école française[Leben und Kunst in Paris seit Napoleon I. Versuch einer Übersicht der neuen französischen Schule], Berlin, Akademie-Verlag, 2009, extraits choisis.

\section{Marianne Colston (1792 ? - 1865)}

Introduction

Isabelle Baudino

Marianne Colston, Journal d'un voyage en France, 1822

[Journal of a Tour in France, Switzerland \& Italy, During the Years 1819, 20, 21], Paris, Galignani, extraits choisis.

Volume I, chapitre I

Volume II, chapitre XXIII

\section{Félicité de Genlis (1746 - 1830)}

\section{Introduction}

Charlotte Foucher

Stéphanie-Félicité Du Crest, Essai sur les arts, vers 1825

[s. d.], Nancy, bibliothèque municipale, Ms 765, extraits choisis.

«Sur les beaux-arts - Avertissement »

«De la peinture »

«Des arabesques»

"Des peintres modernes"

« De la sculpture et de l'architecture »

Stéphanie-Félicité Du Crest, Catalogue pittoresque du cabinet de tableaux de Monsieur le comte de Sommariva, 1820

Nancy, bibliothèque municipale, Ms 766, p. 3-14, extraits choisis.

« Discours préliminaire sur la magnificence »

Dialogue entre Alcime et Lydanie

Marie-Camille de G. (? - ?)

\section{Introduction}

Amandine Gorse

Marie-Camille de G., Tribune des femmes, 1834

[extraits choisis]

« Beaux-arts - Salon de 1834 » 


\section{Marceline Desbordes-Valmore (1786 - 1859)}

\section{Introduction \\ Christine Planté}

Marceline Desbordes-Valmore, L'Atelier d'un peintre, 1833

L'Atelier d'un peintre : scènes de la vie privée, Paris, Charpentier, tome I, chapitre II, extraits choisis.

Marceline Desbordes-Valmore, «Un Christ 》

(poème posthume), dans (Euvres poétiques de Marceline Desbordes-Valmore, éd. Marc Bertrand, Presses universitaires de Grenoble, 1973, 2 vol. , t. II, p. 642-643.

\section{Élisabeth Vigée-Lebrun (1755 - 1842)}

\section{Introduction \\ Charlotte Foucher}

\section{Élisabeth Vigée-Lebrun, Souvenirs, 1869}

[Paris, Charpentier], Édition féministe de Claudine Herrmann, Paris, Des femmes Antoinette Fouque, 2005, tome I, p. 150-262, extraits choisis.

Élisabeth Vigée-Lebrun, Conseils pour la peinture du portrait, 1869 [Paris, Charpentier], La Rochelle, Rumeur des âges, 1997, extraits choisis.

Ce qu'on doit observer avant de commencer un portrait

Règle nécessaire

Alida de Savignac (1790 - 1847)

Introduction

Amandine Gorse

Alida de Savignac, Journal des demoiselles, 1837

Articles « Beaux-arts - Salon de 1837 », extraits choisis.

« Premier article » (mars 1837)

« Deuxième article » (avril 1837)

« Troisième et dernier article » (mai 1837)

Alida de Savignac, Journal des demoiselles, 1844

Articles « Beaux-Arts - Salon de 1844 », extraits choisis.

« Premier article » (avril 1844)

« Deuxième article » (mai 1844)

Alida de Savignac, Journal des demoiselles, 1846 Articles « Beaux-Arts - Salon de 1846 », extraits choisis.

« Premier article» (avril 1846)

« Deuxième article » (mai 1846) 
Johanna von Haza (1794 - 1849)

Introduction

France Nerlich

Johanna von Haza, Premières Impressions d'un profane à l'exposition d'art de Leipzig de l'automne 1837

[Heinrich Paris], Erste Eindrücke eines Laien auf der ersten Leipziger Kunstausstellung im Herbst 1837, Leipzig, 1838, extraits choisis.

Premier extrait

Deuxième extrait

Troisième extrait

\section{Marie d'Agoult (1805 - 1876)}

Introduction

Charlotte Foucher

Daniel Stern [Marie d'Agoult], La Presse, 1841-1842

[extraits choisis]

«La nouvelle salle de l'École des beaux-arts peinte par M. Paul Delaroche » (12 décembre 1841)

« Le portrait de Cherubini par M. Ingres » (7 janvier 1842)

«Le Salon 1842. Deuxième article » (20 mars 1842)

\section{Edmée de Syva (? - ?)}

Introduction

Amandine Gorse

Edmée de Syva, Journal des demoiselles, 1848

[extraits choisis]

«Salon de 1848 - Premier article»

"Salon de 1848 - Deuxième article »

"Salon de 1848 - Troisième et dernier article »

Bibliographie générale

Liste des cuvres évoquées 


\title{
Introduction
}

\author{
Anne Lafont
}

1 S'il nous a semblé essentiel de donner à lire ces textes, c'est qu'ils témoignent, réunis, d'une diversité d'intérêts, de points de vue et de formes que l'on ne pouvait présumer. Car, si les noms célèbres de Germaine de Staël, Élisabeth Vigée-Lebrun ou Marie d'Agoult ont traversé les siècles et ne sont pas sans évoquer un ou des moments glorieux de l'histoire culturelle française des $\mathrm{XVIII}^{\mathrm{e}}$ et $\mathrm{XIX}^{\mathrm{e}}$ siècles, il est fort peu probable que la contribution de l'une d'entre elles à la pensée sur l'art et à ce que l'on appelait les beaux-arts puisse s'ancrer dans notre mémoire commune sur quelque texte ou idée précise que ce soit. Pourtant, non seulement ces trois célébrités ont participé remarquablement à la production de discours critiques, théoriques et historiques comme on le verra dans les pages qui suivent, par les ouvrages ou extraits retenus -, mais de surcroît, nos recherches ont fait surgir de nombreuses autres auteures qui, pour la plupart, eurent une production littéraire variée, dans laquelle nous avons sélectionné des passages sur l'art. De Félicité de Genlis, nous publions deux textes inédits : Essai sur les arts et Catalogue pittoresque du cabinet de tableaux de Monsieur le comte de Sommariva (Nancy, bibliothèque municipale). De même, certaines artistes, en marge de leur œuvre, écrivirent sur l'art de leur temps ou saisirent l'autobiographie pour livrer une forme de schéma idéal de la formation d'une artiste (Maria Cosway, Élisabeth Vigée-Lebrun).

2 L'anthologie nous a semblé la modalité la plus efficace pour faire connaître ces voix méconnues et souvent inconnues, car, au-delà des travaux publiés dans le premier volume, les textes de ces femmes auteures peuvent être lus, appréciés et compris sans médiation. Leur richesse engagera certainement de nouvelles recherches que ce premier sondage n'épuise aucunement. Le second parti pris de notre sélection - imposé par ce long siècle (1750-1850) d'une modernité politique européenne en transformation, compte tenu de la redistribution des frontières et des identités nationales - tient à son ambition de panacher les discours d'auteures françaises, anglaises, italiennes et allemandes, qui côtoyèrent les institutions (les expositions publiques du Salon et le Muséum central des arts bientôt renommé musée Napoléon) et les artistes contemporains (Adélaïde Labille-Guiard, Jacques-Louis David, Angélique Mongez, François Gérard, Nisa Villers, Marguerite Gérard, Anne-Louis Girodet, Auguste 
Biard, Jean-Auguste-Dominique Ingres, Paul Delaroche... jusqu'à Rosa Bonheur). Aussi proposons-nous aux lectrices et aux lecteurs, pour la première fois traduits en français, des textes allemands de Helmina von Chézy et Johanna von Haza, et des textes anglais de Marianne Colston, Maria Cosway (certains également traduits de l'italien) et Anne Plumptre.

Nous avons opté pour une organisation chronologique plutôt que thématique car la variété des textes et des centres d'intérêts ne permettait pas de couper les discours de manière satisfaisante. En revanche, chaque auteure est présentée dans une courte introduction qui met en contexte les extraits choisis et révèle d'entrée les thèmes abordés.

Quatre fils rouges structurants peuvent être dégagés de cet ensemble, même si la pluralité des formes que prirent ces écrits aurait pu conduire à d'autres subdivisions. Les positionnements théoriques de ces femmes sur la création s'exprimèrent en effet dans des romans (Staël), des lettres (Candeille), des essais (Staël, Genlis), des mémoires (Vigée-Lebrun), des critiques de salons (d'Agoult, Savignac, Haza), des récits de voyage (Colston, Plumptre), ou encore des chroniques parisiennes pour un journal étranger (Chézy).

5 On découvrira d'abord la grande culture de nombre d'entre elles qui connaissent et apprécient l'art ancien, l'architecture, l'urbanisme, autant que la gravure, la sculpture et la peinture des écoles françaises, italienne et nordique. Cette culture étendue s'appuie sur des références théoriques, de Roger de Piles à Denis Diderot en passant par Winckelmann et l'abbé Du Bos (Genlis, Staël), mais s'inscrit également dans le domaine dynamique des savoirs à l'œuvre, des réflexions sur la pédagogie et l'éducation à finalités variables : Vigée-Lebrun, auteure d'un manuel destiné à une jeune portraitiste (réédité ici dans sa totalité) et B. (peut-être Pauline Auzou ou Albertine Clément-Hémery, comme le propose ici Amandine Gorse ${ }^{1}$ ) prônant l'instruction des femmes - en l'occurrence artistique, mais ses propos s'inscrivaient dans une prescription plus générale - en vue de leur émancipation.

6 Le deuxième aspect qui a retenu notre attention, par sa récurrence, tient à l'attention particulière que plusieurs auteures portèrent à la question des arts et de la société dans leurs relations les plus diverses : que ce soit l'étude des collections privées ou publiques (la galerie de Dresde par Staël ou la collection Sommariva par Genlis, mais aussi les spoliations dans le cadre des conquêtes napoléoniennes qui constituèrent le Muséum par Colston ou encore le musée de Lenoir par Anne Plumptre) ; les publics du Salon et la nécessaire contribution à la formation de leurs goûts par la critique (Maisonneuve, Syva); la question des commanditaires (Candeille) et notamment les stratégies de contournement de la censure via la flatterie des portraits royaux (Montanclos). 


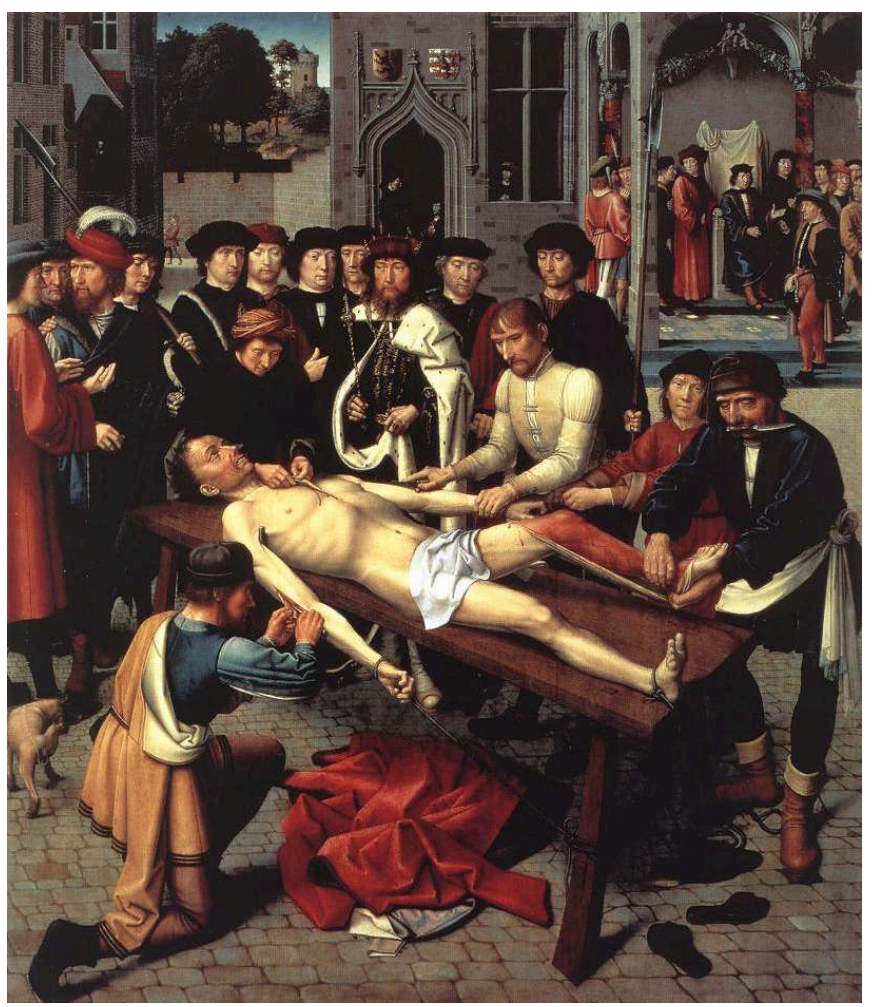

1498, huile sur toile, $182 \times 159 \mathrm{~cm}$, Bruges, Groeningenmuseum, volet de droite.

7 Une certaine dimension politique de l'art et ses parties liées aux constructions identitaires nationales semblent s'établir à cette époque qui va, approximativement pour la France, de d'Angiviller, surintendant des Bâtiments du roi, au musée de l'Histoire de France voulu par Louis-Philippe, en passant, bien sûr, par le Musée impérial de Dominique Vivant Denon. Au cours de cette période, certaines femmes auteures subirent l'expérience traumatique d'une Europe réduite en lambeaux par la violence des ambitions conquérantes de l'armée française, mais surent la dépasser et la métamorphoser en une aventure intellectuelle transnationale. Dans une conscience particulièrement aiguë des désastres de la guerre, quelques voix, dont celle de Germaine de Staël, firent valoir - même dans un schéma nord-sud exaspéré, qui conduisit aux récits nationalistes du début $\mathrm{du} \mathrm{xx}^{\mathrm{e}}$ siècle - la nécessité de s'approprier les textes sur l'art quasi inconnus des pays voisins (la Suisse, l'Allemagne, l'Angleterre). Anne Plumptre, quant à elle, au détour d'une visite dans la grande galerie du Louvre qui la mit face au Jugement de Cambyse de Gérard David (1498, Bruges, Groeningenmuseum), crut repérer en l'usage abusif de la guillotine par la Révolution le dernier avatar des mœurs cruelles de l'Ancien Régime, et établit une correspondance entre les siècles de torture passés et la facilité du peuple français à exposer et à regarder des scènes d'une violence insoutenable, à ses yeux de Britannique. Dans ces méandres si porteurs de l'art et de l'identité nationale, les bienfaits de la conquête furent loués par une autre voyageuse britannique - peut-être sensible à la situation comparable des marbres du Parthénon dans son pays : Marianne Colston soutint en effet que la restauration par la France des peintures spoliées les avait en quelque sorte sauvées de la détérioration. Quant à Johanna von Haza, elle fut celle qui complexifia le plus les relations éminemment politiques qu'entretenaient l'art et les identités sexuelles et raciales : face 
au Marché aux esclaves sur la côte d'Or africaine d'Auguste Biard (vers 1835, Hull, City Museums and Art Galleries, Wilberforce House), elle enjoignit indirectement le spectateur à faire le rapprochement entre la situation des esclaves noirs et celle des esclaves blancs - c'est-à-dire les couches les plus misérables du continent - et des femmes, « esclaves » elles aussi, que la « civilisation européenne met sur le marché sous le nom d'épouses ».

Ce qui nous amène au dernier argument prépondérant dans la sélection des textes constituant cette anthologie: les prises de position des unes et des autres quant au statut de la femme en général et de la femme artiste en particulier. Dans l'introduction du volume d'essais, les positions et les idées les plus novatrices et les plus conceptualisées sur la condition des femmes dans le domaine de la création ont été discutées : nous n'y reviendrons pas. Il s'agira seulement de pointer ici les idéologies, plus ou moins explicites, de textes apparemment moins engagés dans ce premier féminisme mais qui, au détour d'un commentaire stylistique, d'une attribution, ou encore d'une anecdote biographique, donnent à saisir un point de vue personnel sur les femmes dans les mondes de l'art.

Les opinions des unes et des autres divergent ostensiblement et, à la lecture de cette anthologie, on ne peut présumer d'une doxa. En revanche, une préoccupation partagée se manifeste, par exemple, via des propos sur une nature féminine supposée : B. croit reconnaître le sexe de son auteure à la vue de son tableau tandis que $\mathrm{M}^{\text {me }}$ de Maisonneuve limite sa recension du Salon aux œuvres dont elle pense qu'elles intéresseront ses lectrices du Journal des dames, laissant de côté les tableaux censés attirer exclusivement les hommes. Marie-Camille de G. exhorte les artistes à abandonner l'image stéréotypée de la femme objet du désir, alors que $\mathrm{M}^{\mathrm{me}}$ de Montanclos croit nécessaire de préciser, en marge de l'éloge qu'elle fait de la pastelliste et miniaturiste $\mathrm{M}^{\text {lle }}$ Navarre, que cette dernière travaille seule à ses ouvrages. Dans ce contexte hésitant, Helmina von Chézy déclare, pour sa part - et dans un paradoxe assumé -, qu'elle a « ignoré les femmes, pas seulement parce que les noms de Chaudet, [Vigée-] Lebrun, Mongez, Benoist, Romany, Lorimier, $\mathrm{M}^{\mathrm{me}}$ Kugler sont partout connus, mais aussi parce qu['elle n'est] pas d'avis que les femmes puissent amener des progrès quelconques dans l'art, même si elles touchent souvent, comme le font aussi ces artistes de mérite, une des plus agréables cordes de l'art et animent leurs toiles de la magie du sentiment ".

D'autres incongruités, mais aussi des pépites, d'autres idées, des artistes inconnus, d'autres très célèbres, des auteures toujours intéressantes surgiront au cours de la lecture de ce recueil, qui se veut à la fois un échantillon et un florilège.

NdÉ : Nous avons choisi de moderniser, le cas échéant, l'orthographe et la ponctuation des textes. Une introduction situe le travail de chaque auteure, suivie d'une brève bibliographie. Sauf mention contraire, les notes de bas de page sont des auteures elles-mêmes.

Nous avons tenté de retrouver les œuvres mentionnées, vues, commentées par les auteures, avec les informations techniques dont nous disposions (auteur, titre de l'œuvre, technique, dimensions, lieu actuel de conservation) : nous en donnons la liste à la fin de chaque rubrique (y compris pour celles non identifiées ou dont 
l'identité est incertaine à nos yeux, ou encore non localisées malgré nos recherches).

L'ensemble de cette anthologie est désormais consultable en ligne, en accès libre et gratuit, assorti d'une iconographie plus complète, de manière à s'approcher le plus possible de ce qu'ont vu dans les musées et les Salons, les femmes de l'époque.

Enfin, les notes sans mention particulière sont des auteures elles-mêmes ; les autres sont signalées par (NdÉ) (note de l'éditeur), (NdT) (note du traducteur) ou (NdA) (note de l'auteur de l'introduction).

\section{ANNEXES}

Cliquer ici pour un aperçu des œuvres d'arts observées et commentées par chaque femmes dont nous publions les textes.

\section{NOTES}

1. Voir Mechthild Fend, Melissa Hyde et Anne Lafont (dir.), Plumes et pinceaux. Discours de femmes sur l'art en Europe (1750-1850) - Volume 1, Dijon, Les presses du réel/INHA, 2012, p. 245 ; et l'introduction d'Amandine Gorse dans ce volume. 
$\mathrm{M}^{\mathrm{me}}$ de Beaumer (1720 ? - 1766) 


\title{
Introduction
}

\author{
Amandine Gorse
}

1

$\mathrm{M}^{\mathrm{me}}$ de Beaumer (1720 ?-1766), vicomtesse, fut l'une des premières éditrices du Journal des dames, un mensuel d'une centaine de pages paru entre 1759 et 1778 et spécifiquement adressé aux dames de la cour. D'origine hollandaise, elle réussit à éditer, pendant deux ans (1761-1763) et malgré les critiques de la censure, un périodique novateur qui diffusa, entre autres, de nombreux articles sur l'art. Le ton frondeur et anticonformiste qu'elle adoptait était inhabituel pour l'époque, tout comme sa personnalité déterminée et souvent audacieuse : elle s'habillait comme un homme pour négocier avec le milieu de l'édition et tenir tête à ses censeurs (GELBART 1991, p. 505). Elle s'engagea dans la défense de la cause féminine, combattit l'injustice sociale et l'intolérance religieuse, avec des idées proches de celles soutenues, plus tard, par Pierre-Augustin Caron de Beaumarchais, qu'elle eut vraisemblablement l'occasion de connaître. Elle exprima pour la première fois ses idées radicales dans un périodique publié à La Haye en 1759, Lettres curieuses, instructives et amusantes (GELBART 1991, p. 502). La protection de Louis-François de Bourbon-Conti lui permit d'être introduite à la cour où elle put profiter des relations du prince dans le milieu artistique et admirer sa collection. Toutefois, l'éditrice ne parvint pas à échapper à la censure royale et dut renoncer à la direction du Journal des dames en 1763, mettant fin à son projet d'éducation féministe (GELBART 1987 et VAN DIJK 1988, p. 134-186).

2 Dans les extraits d'articles présentés ci-dessous, le discours sur l'art de $\mathrm{M}^{\mathrm{me}}$ de Beaumer revêt essentiellement deux aspects: la promotion des femmes artistes et le commentaire de l'actualité artistique, qui prend la forme d'une correspondance fictive. Ainsi, pour l'exposition publique de 1761, elle met en scène un personnage féminin, faussement ingénu, qui convoque des notions comme la noble simplicité, le coloris, le sublime, etc. 


\section{BIBLIOGRAPHIE}

GELBART 1987

Nina Rattner Gelbart, "The Journal des dames and its female editors: politics, censorship and feminism in the old regime press", dans J. Popkin et J. Censer (éd.), Press and politics in prerevolutionary France, Berkeley, University of California Press, 1987.

GELBART 1991

Nina Rattner Gelbart, « Les femmes journalistes et la presse (XVII ${ }^{\mathrm{e}}-\mathrm{XVIII}{ }^{\mathrm{e}}$ siècles) », dans Michèle Perrot et Georges Duby (éd.), Histoire des femmes en Occident 3. XVI ${ }^{e}-X V I I I I^{e}$ siècle, sous la dir. de Natalie Zemon Davis et Arlette Farge, Paris, Plon, 1991, p. 491-512.

RIMBAULT 1988

Caroline Rimbault, La Presse féminine française au XVIII siècle, Amsterdam/Maarsen, APA-Holland University Press, 1988.

SULLEROT 1966

Évelyne Sullerot, Histoire de la presse féminine en France des origines à 1848, préf. de Jacques Godechot, Paris, Armand Colin, 1966.

VAN DIJK 1988

Suzan Van Dijk, « Le Journal des dames, 1759-1778 : les journalistes-dames et les autres », dans Traces de femmes, présence féminine dans le journalisme français du XVIII ${ }^{e}$ siècle, Amsterdam, Maarsen, APA-Holland University press, 1988, p. 134-186.

\section{ANNEXES}

Diaporama des tableaux commentés par Mme de Beaumer :

http://www.flickr.com//photos/73632227@N02/sets/72157629202782650/show/

Lire les extraits des articles de Mme de Beaumer parus dans le Journal des dames

Liste complète des œuvres d'arts commentées par Mme de Beaumer à travers ses textes édités dans Plumes et pinceaux 


\section{$\mathrm{M}^{\mathrm{me}}$ de Beaumer, Journal des dames,} 1761-1762

[extraits choisis]

\section{"Lettre sur les tableaux, de M.*** à M.*** » (octobre 1761)}

Journal des dames dédié à son excellence Madame la princesse de Gallitzin, de l'Académie des Arcades de Rome, tome III, $1^{\text {re }}$ partie, p. 72-78.

1 Vous me demandez, madame, que je vous communique mes observations sur les tableaux exposés cette année au Louvre; je n'ai que de très faibles connaissances dans l'art de la peinture; le désir cependant de vous amuser un instant me fera immoler ma vanité, car je sens qu'en ce moment elle vous est sacrifiée. Il convient bien à une femme aussi peu instruite que je le suis de parler des arts ; ce qui m'enhardit, c'est que je serai l'écho de cette nature, qui est la souveraine des artistes, le but et la récompense de leurs travaux : au reste, madame, je vous soumets entièrement mes remarques. 
1. Jacques Dumont, dit le Romain, Allégorie en l'honneur de la publication de la paix d'Aix-la-Chapelle, le 13 février 1749

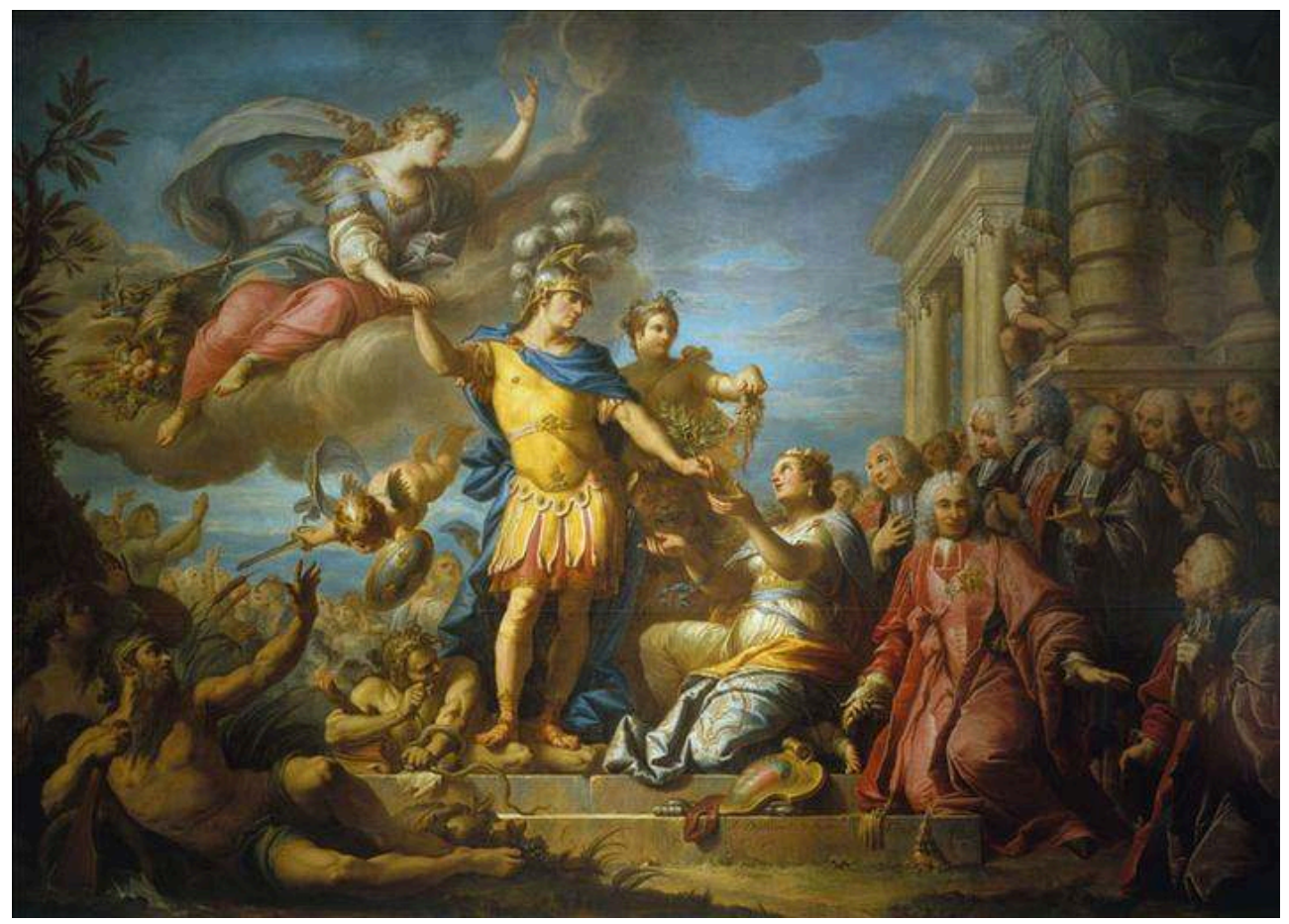

1761, huile sur toile, 320 × 430 cm, Paris, musée Carnavalet.

2 Le Tableau allégorique représentant la publication de la paix, en 1749, par M. Dumont le Romain, est d'une invention riche et poétique, on y trouve de ces belles idées du célèbre Rubens. Mais on a dit, peut-être à tort, que le coloris et l'exécution ne répondaient pas à l'invention (fig. 1).

3 La Magdeleine dans le désert, de M. Carle Vanloo, est d'une beauté séduisante, d'un ton flatteur de couleurs; quelques critiques voudraient seulement que la douleur éclatât sur ce beau visage. La censure se tait et admire, à l'aspect d'un autre ouvrage du même grand maître, qu'on peut intituler La Lecture. C'est un jeune Espagnol qui lit un roman à deux jeunes filles. Le jeune homme est de toute grâce, de toute beauté ; les filles ont de l'élégance, de la finesse dans les traits, elles se ressemblent peut-être un peu trop, la mère a interrompu son ouvrage pour écouter; une troisième petite fille dans l'âge de l'enfance fait voltiger un oiseau au bout d'un fil : cette composition enlève tous les suffrages ; rien de plus vrai, de plus agréable ; brillant coloris, dessin correct et élégant, attitudes variées, de l'âme et de la vie dans toutes ses parties; tel est, madame, ce morceau enchanteur.

4 M. Vien se fait admirer dans son tableau de Saint Germain revêtu de ses habits pontificaux et donnant une médaille à sainte Geneviève. L'évêque respire la dignité, ses vêtements déploient une noble richesse; pour la sainte, elle annonce ce qu'elle doit être un jour, c'est la candeur embellie des chastes Grâces, on ne peut voir de contours plus heureux, le caractère d'une jeune vierge plus marqué et en même temps plus flatteur ; cette dernière figure est céleste. Le même peintre a consacré aux Grâces mondaines dans un tableau d'un genre différent, qui représente une jeune Grecque entourant un vase de guirlandes de fleurs ; la noble simplicité de l'antique, cette élégante nature, si difficile à saisir, sont développées dans ce morceau si agréable; on croit être à Athènes, 
l'habillement de la Grecque est tout à fait dans le costume; on peut ajouter au ton extrêmement gracieux qui règne dans ce tableau une fraîcheur séduisante qui frappe et relève beaucoup le mérite de l'exécution.

\section{Jean-Baptiste Henri Deshays de Colleville, dit le Romain, Saint Benoît mourant reçoit le viatique}

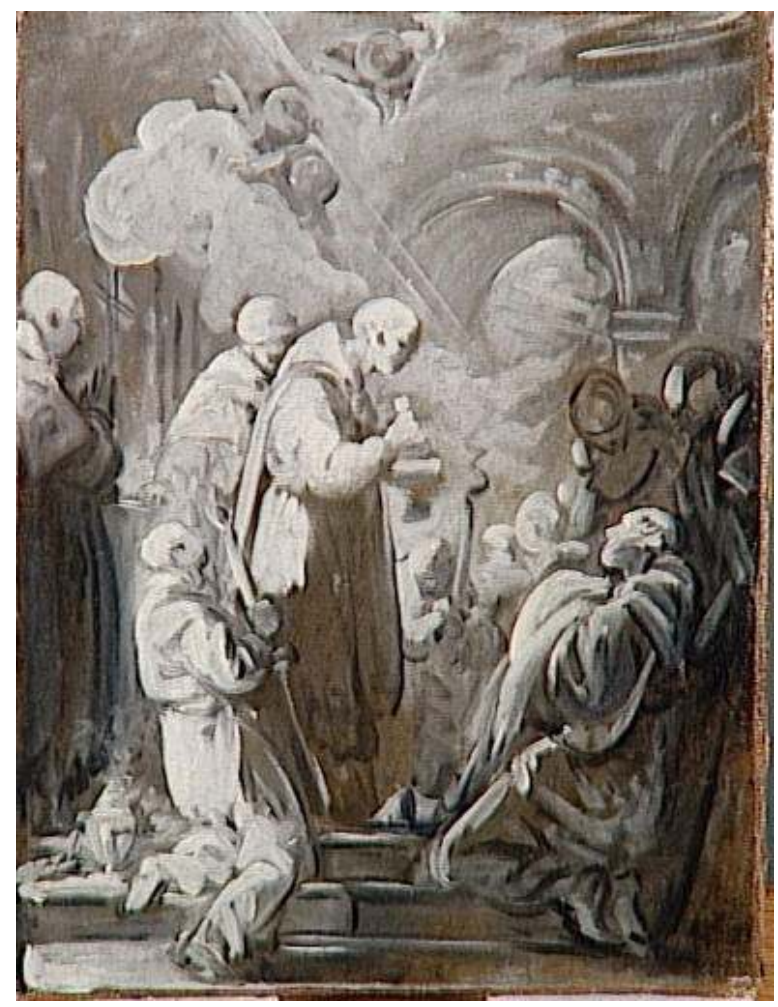

1761, huile sur toile, 292 × 191 cm, Orléans, musée des Beaux-Arts.

Saint Benoît mourant, qui s'est fait traîner aux marches de l'autel pour recevoir le viatique (fig. 2), et qui est, pour ainsi dire, tombant entre les bras de ces religieux, est d'une expression de génie qu'on ne peut assez admirer. On voit dans cette tête la ferveur de la dévotion ; la pâleur de la mort réunies, une âme remplie d'amour et de respect pour son Dieu éclatent sur ce visage expirant ; tous les autres personnages dans ce tableau sont intéressants, touchants, et en même temps variés. Ce chef-d'œuvre est de M. Deshayes ; cet ouvrage seul suffirait pour lui mériter une réputation immortelle.

6 Le Portrait du roi par M. Michel Van Loo est de toute richesse. On regarde ce tableau comme un très bel ouvrage.

$7 \mathrm{M}$. Vernet continue de se couvrir d'une nouvelle gloire par ses Marines - les dernières pourtant ont essuyé quelque critique, surtout sur les ciels et le coloris.

8 Vénus blessée par Diomède annonce un génie décidé dans M. Doyen. Ce morceau n'est pas sans défauts, mais il est allumé en quelque sorte d'un feu qui ne peut partir que d'un talent sublime. Diomède, dans une action menaçante, exhale toute sa fureur. Pallas, sa lance à la main, et protectrice du héros, inspire la peur, tant elle est bien exprimée ; Vénus n'est pas digne des autres figures. Mais, oserais-je le dire ? C'est peut-être le tableau du Salon qui soit le plus animé de la flamme du génie; sans me donner les airs de prophétesse, je puis vous assurer que ce jeune homme ira extrêmement loin et qu'il aura sa place parmi les premiers peintres de notre école française. Il y a encore de lui le 
Portrait d'une jeune Indienne, habillée à la mode de son pays, qui prouve qu'il a tous les pinceaux.

9 Il ne faut pas omettre dans nos éloges un tableau qui nous offre une bataille. Depuis le célèbre Wouwermans, je ne sache pas que nous ayons eu quelque chose de plus beau, de plus animé, de plus vigoureux ; il est de M. Cazenove, jeune peintre, dont avec raison l'on conçoit de grandes espérances.

10 La Jeune Blanchisseuse 1 de M. Greuze est d'une naïveté inimitable ; ce peintre de la nature se surpasse tous les jours lui-même; il a réuni tous ses talents dans ce tableau qu'il vient de donner, un père comptant la dot à sa fille ; on revient cent fois à ce chefd'œuvre; il est fini : la bonté et la joie paternelle, le respect de la fille pour son père et son amour pour son prétendu qu'elle tient par la main... Le petit garçon qui, conduit par un mouvement enfantin, passe sa tête sous le bras du notaire et se plaît à déranger les papiers ; tous ces personnages respirent, vivent, agissent aux yeux, la nature même ne saurait être plus vraie, plus intéressante, plus animée. M. Greuze dès ce moment peut se flatter que son nom est marqué du sceau de l'immortalité.

\section{Maurice Quentin de La Tour, Le Prince Xavier de Saxe}

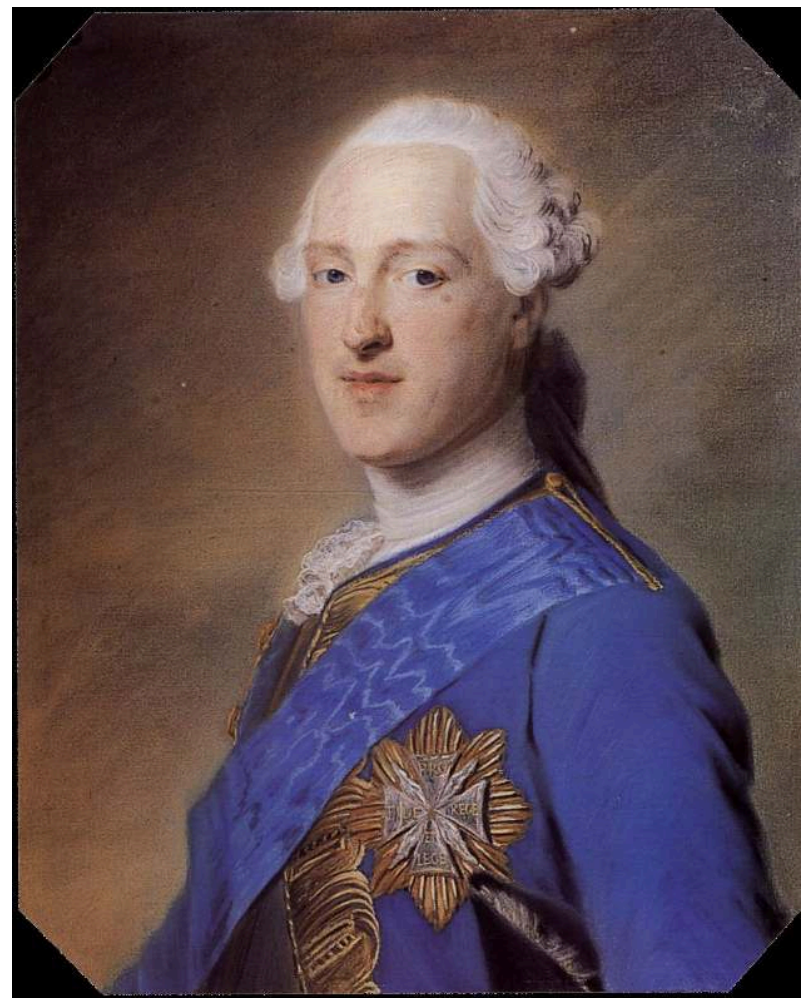

1761, pastel, 63 x 53 cm, Saint-Quentin, musée Antoine Lecuyer. 


\section{Maurice Quentin de La Tour, Portrait de M. Laideguive}

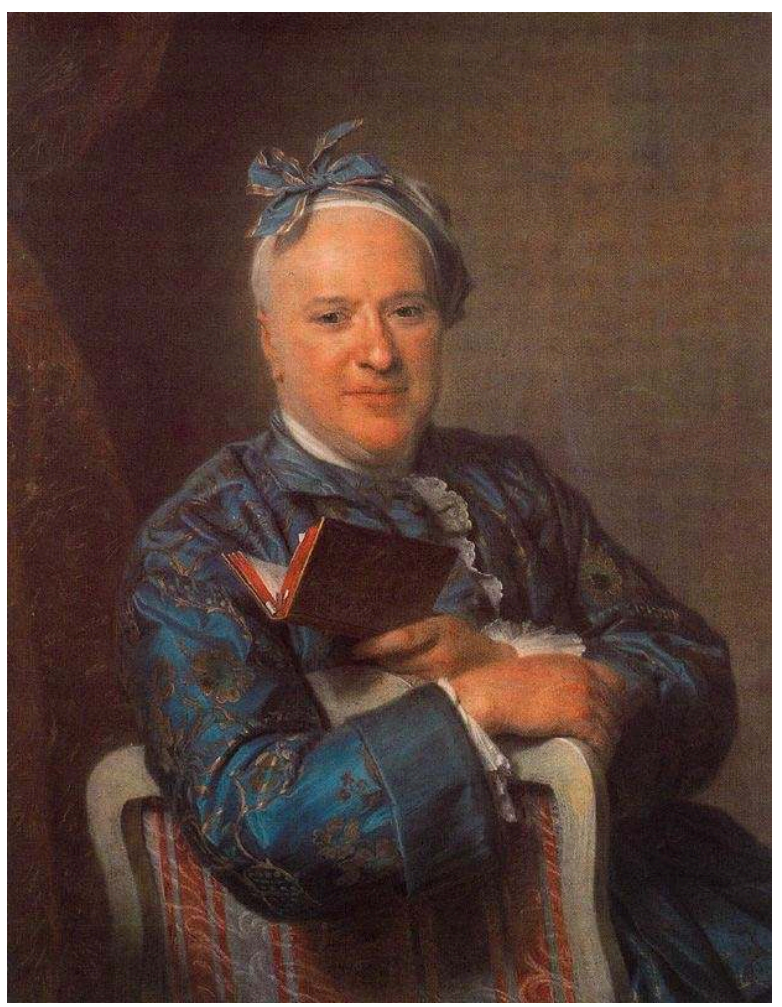

Salon de 1761, huile sur toile, Barcelone, musée d'Art moderne

11 Il y a encore des ouvrages de M. Boucher, dans lesquels on reconnaît ce pinceau frais et brillant qui a peu d'égal.

12 M. de La Tour, si célèbre par ses pastels (fig. 3 et 4), reçoit de nouveaux applaudissements dans son Portrait de M. Lai de Guive: les chairs sont d'une fraîcheur, d'une vie qu'on ne se lasse pas d'admirer; je ne parle pas des autres parties qui ne sont pas moins estimables.

Nous aurions encore à rendre justice à beaucoup d'autres tableaux, mais ces détails nous conduiraient trop loin.

14 À l'égard des sculptures, celle qui m'a paru remporter le prix est une Nymphe qui au sortir de l'eau sèche ses cheveux : il y a de l'élégance et de l'atticisme dans cette statue.

\section{«Arts et modes » (novembre 1761)}

Journal des dames dédié à son excellence Madame la princesse de Gallitzin, de l'Académie des arcades de Rome, tome III, $2^{\mathrm{e}}$ partie, p. 190-192.

$\mathrm{M}^{\mathrm{lle}}$ Girouard, demeurant rue Traversière, près la rue Saint-Honoré, peut être mise au nombre de nos artistes de réputation. Elle s'occupe à la peinture à l'huile et au pastel. Parmi les tableaux qui font honneur à son pinceau et à son crayon, les amateurs distinguent une Vénus d'une grande beauté qui désarme l'Amour; le coloris, les attitudes, le dessin, tout décèle une maîtresse dans son art. Deux autres tableaux de Vierges qui tiennent l'Enfant Jésus, le premier à l'huile et le second au pastel, ne méritent pas moins d'éloges; c'est l'expression de la Nature même : l'Enfant Jésus 
paraît respirer et les Vierges ont cette beauté simple et majestueuse qui annonce la grandeur et la dignité de la mère d'un Dieu. $\mathrm{M}^{\text {lle }}$ Girouard a encore plusieurs petits bustes qui sont faits pour orner des cabinets: toutes nos louanges doivent se réunir pour un morceau de la même main qui représente deux filles qui se font dire la bonne aventure. Les filles annoncent cette simplicité et cette innocence, l'aimable caractère de leur âge ; la vieille les regarde avec un air malin où se lit le plaisir de tromper et d'inquiéter.

$\mathrm{M}^{\text {lle }}$ Caron, quai des Morfondus, ne doit pas être oubliée dans la liste de nos femmes peintres. Elle est attachée à la peinture en pastel où elle se distingue. Nos connaisseurs lui promettent du succès. [...].

\title{
«Arts » (décembre 1761)
}

\author{
Journal des dames dédié à son excellence Madame la princesse de Gallitzin, de l'Académie des \\ Arcades de Rome, tome III, $3^{\mathrm{e}}$ partie,
} p. 281-282. $\mathrm{M}^{\mathrm{me}}$ Linto, demeurant rue Mêlée, se distingue dans la peinture en pastel. Cette dame estimable par les excellentes qualités de l'esprit et du cœur, qui caractérisent une femme respectable, loin de s'amuser aux frivolités du siècle, s'occupe, pour son plaisir, avec succès de la peinture. Elle a un cabinet décoré d'un grand nombre de tableaux, qui feraient honneur aux plus grands maîtres, tant pour la beauté du coloris que pour les attitudes naturelles; les carnations, les étoffes, les sites et les airs gracieux, tout est réuni dans ses ouvrages.

$\mathrm{M}^{\mathrm{lle}}$ Trunque, rue Neuve-Saint-Laurent, mérite aussi des éloges; cette demoiselle travaille, pour son plaisir, en miniature. Elle a tiré, en ce genre, le portrait de sa majesté prussienne et celui de la reine d'Espagne, qui ont fait honneur à son pinceau. [...].

\section{«Arts » (avril 1762)}

\section{Journal des dames dédié à Son Altesse Sérénissime $M^{\text {lle }}$ de Condé, tome I, $1^{\text {re }}$ partie,}

p. 106-107.

Si nos autels ont fumé, dans le journal de mars, de l'encens que nous offrons aux mânes des artistes célèbres, notre encens doit brûler en faveur des femmes qui se distinguent sous nos yeux par des talents reconnus, parmi lesquelles $\mathrm{M}^{\text {me }}$ de Lisle mérite de fixer les regards. Cette dame, qui réunit la beauté et le vrai mérite à l'esprit le plus éclairé et le plus aimable, a un goût exquis pour les belles-lettres, excelle dans la peinture, et a acquis un si haut degré de perfection, qu'on peut la mettre de pair avec les grands maitres. Dans le grand nombre de tableaux qu'ont travaillés son crayon et son pinceau, nous nous bornerons à parler d'un seul, qui est comme le chef-d'œuvre de ses chefsd'œuvre ; c'est une chaste Suzanne dans les bains qui est représentée d'une taille fine, déliée et majestueuse, avec une main et un bras incomparables, une jambe bien faite et le visage le plus enchanteur par sa beauté. Les grâces sont répandues avec tous les charmes sur ce beau visage et, dans toutes les attitudes de Suzanne, on aperçoit un air de sagesse, de modestie et de douceur, qui caractérise et inspire en même temps l'amour séducteur et le respect pour la vertu. Les deux vieillards sont tirés avec autant d'élégance et de perfection dans le genre qu'ils demandent, qu'il semble qu'ils vivent, 
qu'ils respirent, et que l'air frappe et embellit tous les objets; rien de plus naturel. Ce tableau ne laisse rien à désirer. C'est un monument digne de nos plus grands éloges et qui mériterait d'être donné pour modèle aux artistes qui tendent à la gloire immortelle.

\section{«Arts » (novembre 1762)}

Journal des dames dédié à Son Altesse Sérénissime Mle de Condé, tome III, $2^{e}$ partie,

p. 191-192.

Qu'il est glorieux pour notre sexe de trouver chaque mois le nom de quelque aimable artiste à consacrer. La figure intéressante, l'air libre, délicat et enjoué, ainsi que les grâces du pinceau de $\mathrm{M}^{\text {lle }}$ Chasselet, lui donnent, plus qu'à toute autre personne de son art, droit aux plus justes éloges. On ne peut trop applaudir à la vivacité de son intelligence et à la justesse de son goût. Ses têtes ont une manière et un naturel qui frappent l'œil le moins connaisseur. Elle est dans cet âge heureux où le temps est également donné à jouir et à connaître. On peut lui promettre autant d'admirateurs que de rivales. [...].

\section{ANNEXES}

Lire l'introduction à $\mathrm{M}^{\mathrm{me}}$ de Beaumer écrite par Amandine Gorse

\section{NOTES}

1. (NdA) Il s'agit en fait de l'Accordée de village de Greuze. 
$\mathrm{M}^{\mathrm{me}}$ de Maisonneuve (1710 ? 1774 ?) 


\title{
Introduction
}

\author{
Amandine Gorse
}

1 Sous la direction de Catherine-Michelle de Maisonneuve (1710 ? - 1774 ?), le Journal des dames adopta une stratégie plus modérée que celle insufflée par $\mathrm{M}^{\text {me }}$ de Beaumer, à laquelle elle succéda en 1763. En effet, la précédente éditrice avait été sommée de quitter la tête du journal après son refus de le transformer en magazine de mode. Grâce à l'orientation nouvelle et en vertu de ses relations avec la cour, $\mathrm{M}^{\text {me }}$ de Maisonneuve parvint à maintenir la publication du périodique. Elle avait pu pénétrer le cercle royal par l'intermédiaire de son frère, Jean-Baptiste (probablement Jean-Baptiste Simonnet de Maisonneuve, 1745-1819), alors attaché à la garde-robe du roi. Ce dernier lui accorda une audience le 21 juin 1765 ainsi qu'un privilège.

2 L'évolution du périodique, dont le contenu se révéla davantage en adéquation avec les pratiques de la société de cour, est sans doute due à la collaboration de deux hommes au sein de la rédaction à partir de 1766 : Charles-Joseph Mathon de la Cour et Claude Sautereau de Marsy. On note ainsi un retrait de la préoccupation féministe et le regain d'un conformisme prônant une attitude passive de la part des femmes à l'égard du rôle que les hommes leur attribuaient. Toutefois, le style précieux de certains articles permet de déceler une critique discrète et habile des sujets évoqués comme l'inégalité des droits ou les pratiques économiques du gouvernement. L'analyse des champs lexicaux par Évelyne Sullerot (SULLEROT 1966, p. 19-27) démontre l'omniprésence d'un vocabulaire sentimental alors que tout ce qui pouvait affecter la censure est ironiquement qualifié de "philosophique " : les propos gênants étaient définis comme des idées théoriques, relevant de l'imaginaire et du spéculatif.

3 Les articles sur l'art ne dérogent pas au style d'ensemble du périodique et s'inscrivent pleinement dans la littérature artistique contemporaine, alors que l'ambition éducative de $\mathrm{M}^{\text {me }}$ de Maisonneuve se manifeste par sa volonté de rendre accessible le discours sur l'art à la majorité des lectrices. Le choix des œuvres commentées reflète également l'exclusion d'un discours féministe et redéfinit ce qui est du ressort des femmes. Ainsi les thèmes évoqués font référence aux arts subalternes comme le paysage et la peinture de genre, censés intéresser les dames de la cour. Toute actualité politique, militaire, voire sociale, est en apparence évincée (VAN DIJK 1988, p. 134-186). 
4 Catherine-Michelle de Maisonneuve dirigea le Journal des dames jusqu'en 1773, avant de laisser la place à Marie-Émilie de Montanclos, baronne de Princen. À la fin de sa vie, $\mathrm{M}^{\mathrm{me}}$ de Maisonneuve bénéficia d'une pension qui lui assura un revenu constant pour les bons services qu'elle avait rendus au roi. On ne lui connaît pas d'autres écrits.

\section{BIBLIOGRAPHIE}

SULLEROT 1966

Évelyne Sullerot, Histoire de la presse féminine en France des origines à 1848, préf. de Jacques Godechot, Paris, Armand Colin, 1966.

VAN DIJK 1988

Suzan Van Dijk, «Le Journal des dames, 1759-1778 : les journalistes-dames et les autres », dans Traces de femmes, présence féminine dans le journalisme français du XVIII ${ }^{e}$ siècle, Amsterdam/Maarsen, APA-Holland University press, 1988, p. 134-186.

\section{ANNEXES}

Diaporama des tableaux et gravures commentés par Mme de Maisonneuve dans le Journal des dames de 1763 à 1767 : http://www.flickr.com//photos/73632227@N02/sets/72157629211071312/show/ Lire les extraits des articles de $\mathrm{M}^{\text {me }}$ de Maisonneuve parus dans le Journal des dames Liste complète des œuvres d'arts commentées par Mme de Maisonneuve à travers ses textes édités dans Plumes et pinceaux 


\section{$\mathrm{M}^{\mathrm{me}}$ de Maisonneuve, Journal des}

dames, 1763-1767

[extraits choisis]

\section{«Salon de peinture » (août-octobre 1763)}

p. 110-116

1 Pour encourager les talents, on a coutume de faire, tous les deux ans, l'exposition des peintures, sculptures et gravures de MM. de l'Académie royale; en conséquence, on en fit l'ouverture, suivant l'intention de Sa Majesté, par ordre de M. le marquis de Marigny, directeur des Académies et Manufactures royales, le 25 août, jour de SaintLouis, dans le grand salon du Louvre.

2 Nous ne parlerons ici que des ouvrages qui intéressent le plus les dames; en conséquence, nous commencerons par ceux de $\mathrm{M}^{\text {me }}$ Vien, académicienne : ils n'ont pas été les derniers à fixer les yeux des amateurs et des connaisseurs. Le beau défaut qu'elle a, c'est, dit-on, de savoir trop bien imiter la nature ; en effet, les yeux sont trompés lorsqu'on regarde les oiseaux. J'ai vu une dame avouer de bonne foi qu'elle les avait crus naturels et qu'il lui avait semblé que c'était des oiseaux qu'on avait attachés par les pieds pour servir de modèles, à cause de la beauté du plumage.

3 À côté, on y voyait un émouchet terrassant un petit oiseau. Ce tableau, ainsi que les autres, qui sont deux pigeons, un bouquet de roses dans un gobelet, une tige de renoncules dans un pot de terre qui a pour pendant un pot de renoncules, sont, ainsi qu'un autre représentant des fruits, en miniature. Ces tableaux ont environ un pied six pouces de large, sur un pied trois pouces de haut, plus ou moins.

On y voit de M. Carle Vanloo un tableau de sept pieds de haut, qui représente au naturel les trois Grâces enchaînées par l'Amour. Au-dessous est, du même, l'Amour faisant faire l'exercice à ses soldats. Ce tableau, dont le sujet est très nouveau, appartient à M. de Marigny. 
1. Louis-Michel Van Loo, Louis-Michel Van Loo accompagné de sa sœur Marie-Anne et travaillant au portrait de son père Jean-Baptiste Van Loo

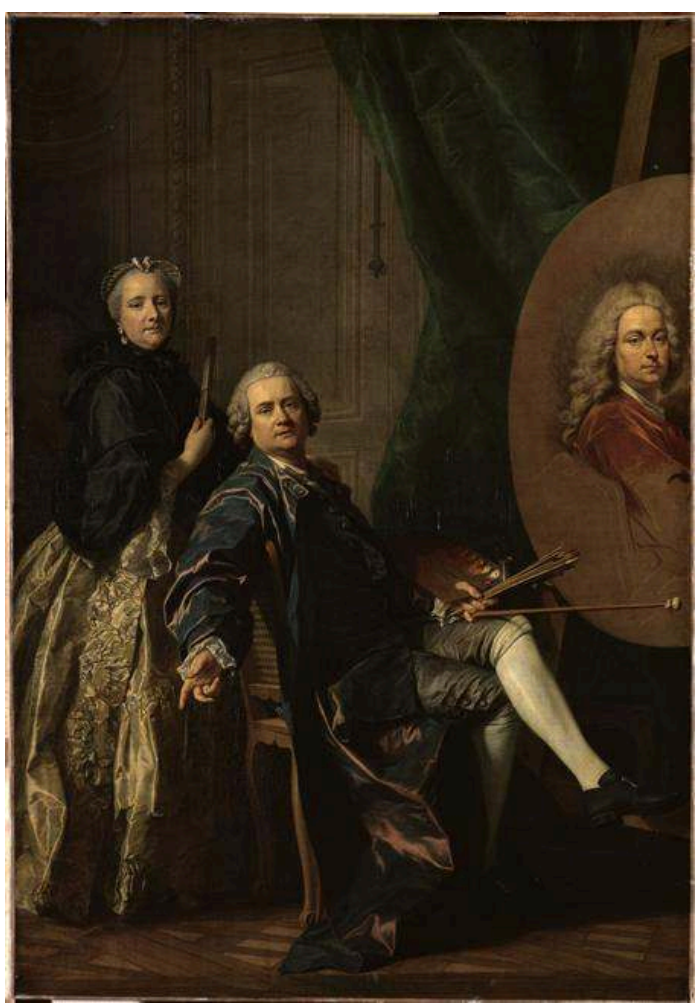

1763, huile sur toile, $245 \times 162 \mathrm{~cm}$, Versailles, musée national des châteaux de Versailles et de Trianon.

5 De M. Restout, Orphée qui descend aux enfers pour y demander Eurydice sa femme; et L'Évanouissement d'Esther de M. Michel Van Loo. Le portrait de l'auteur accompagné de sa sœur et travaillant au portrait de son père (fig. 1).

6 De M. Jeaurat, un peintre faisant chez lui le portrait d'une jeune dame.

7 De M. Pierre, une des scènes du massacre des innocents, où l'on voit une mère se poignarder de douleur, après la perte de son fils. 
2. Jean-Marc Nattier, Indienne [peut-être Portrait d'une jeune femme en vestale]

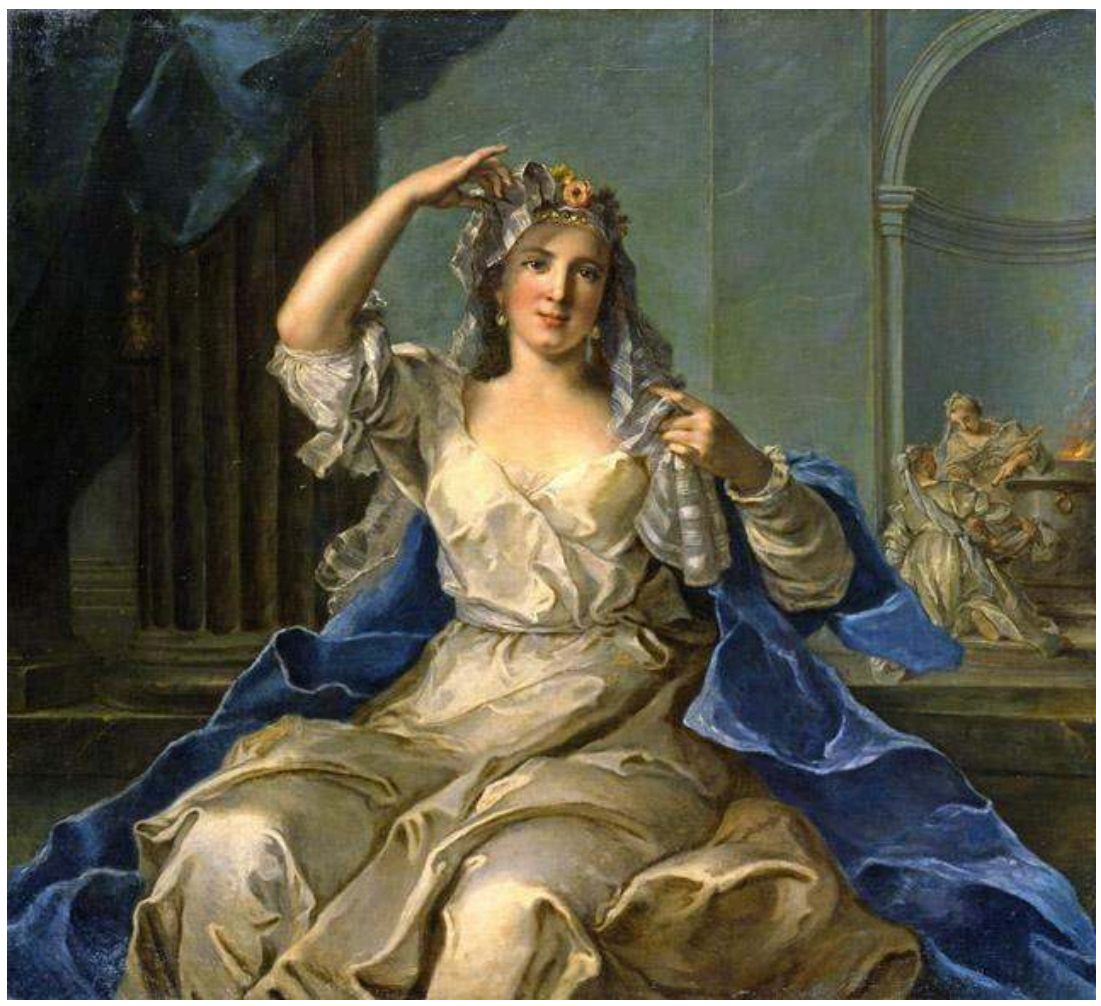

1759, Salon de 1763, huile sur toile, 115,6 x 135,9 cm, Raleigh, North Carolina Museum of art.

8 De M. Nattier, un tableau représentant une Indienne (fig. 2).

9 De M. Hallé, une Vierge avec l'Enfant Jésus. 
3. Joseph-Marie Vien, Une femme qui sort des bains

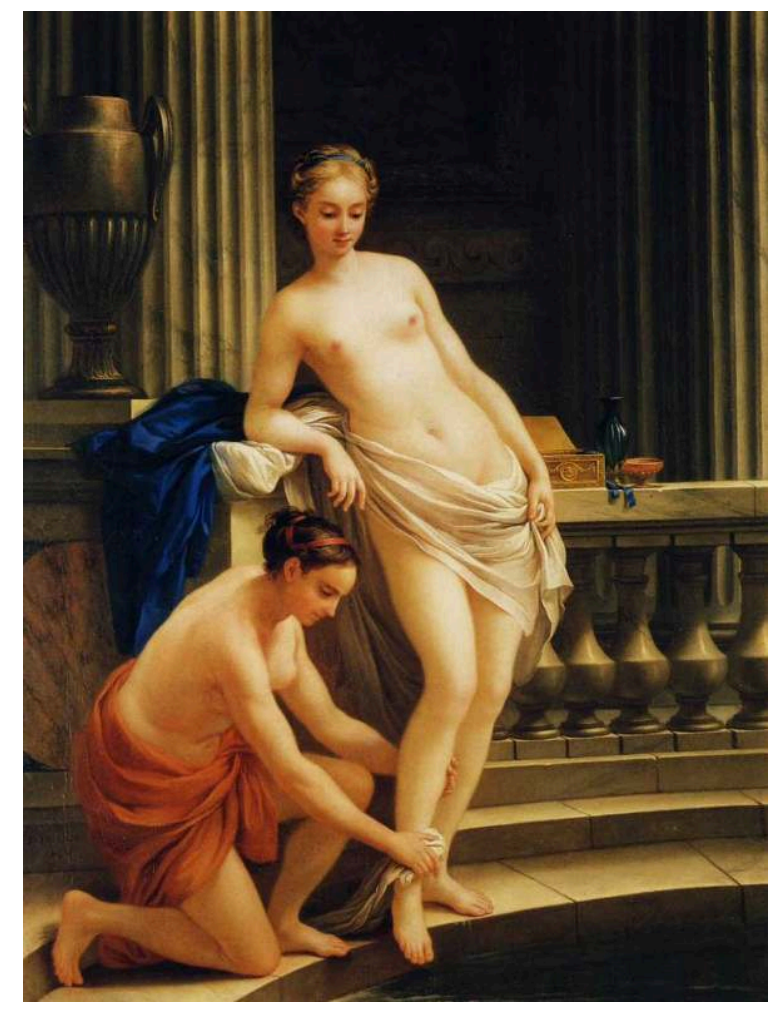

1763, huile sur toile, $95 \times 68 \mathrm{~cm}$, coll. part.

10 De M. Vien, La Marchande à la toilette; La Marchande de fleurs; Une femme qui arrose un pot de fleurs; Une femme qui sort des bains (fig. 3).

\section{Louis Jean François Lagrenée, Le Lever de l'Aurore}

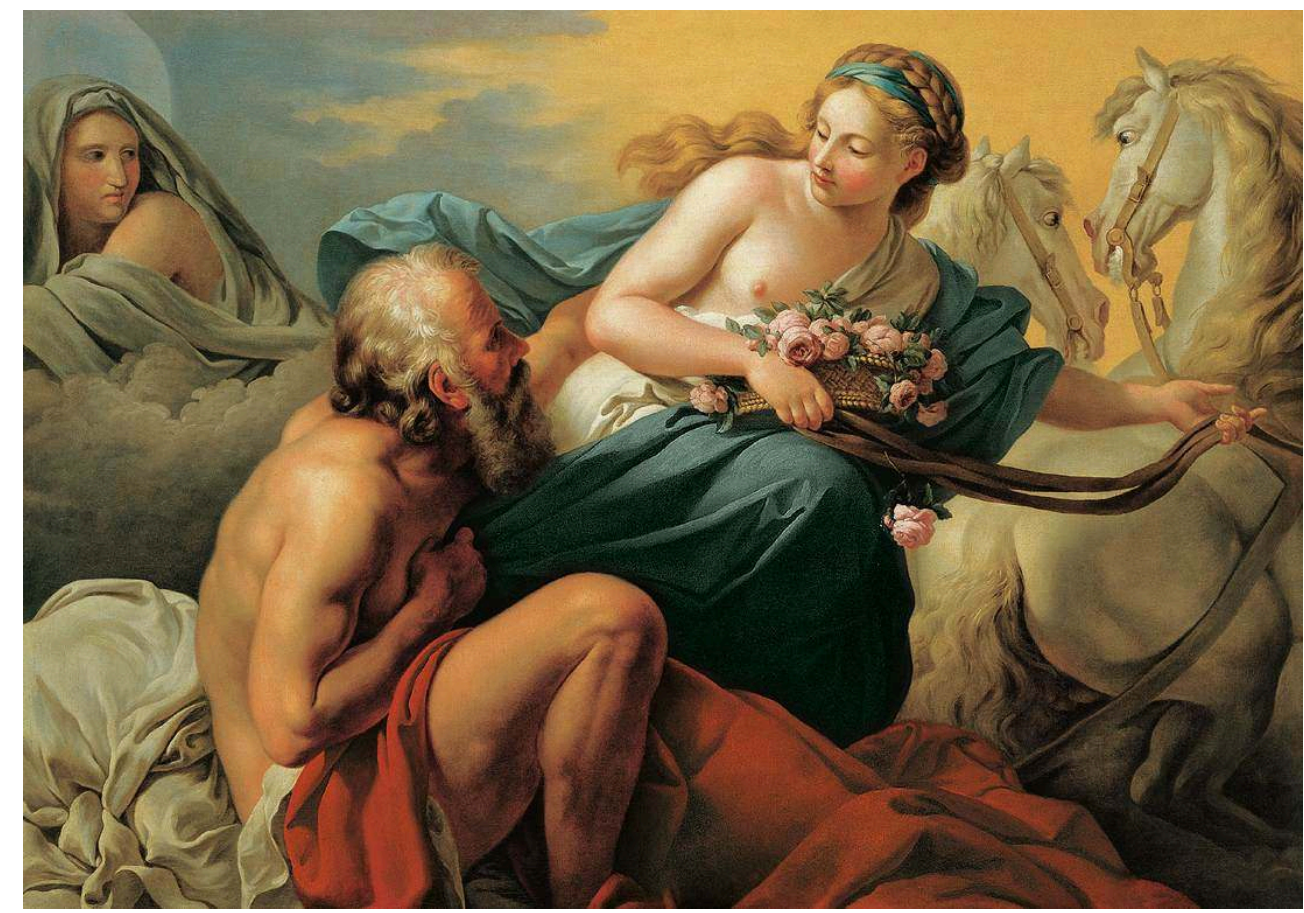

1763 , huile sur toile, $121 \times 170 \mathrm{~cm}$, Vicence, coll. part. 
11 De M. Lagrenée, Suzanne surprise au bain par les deux vieillards ; La Douce Captivité ; Le Lever de l'Aurore (elle quitte le lit du vieux Titon) (fig. 4).

De M. Deshays, Le Mariage de la Sainte Vierge; Danaé qui reçoit Jupiter en pluie d'or.

De M. Challe, Vénus endormie ; Esther évanouie aux pieds d'Assuerus.

\section{Maurice Quentin de La Tour, Portrait de la princesse Marie-Christine de Saxe}

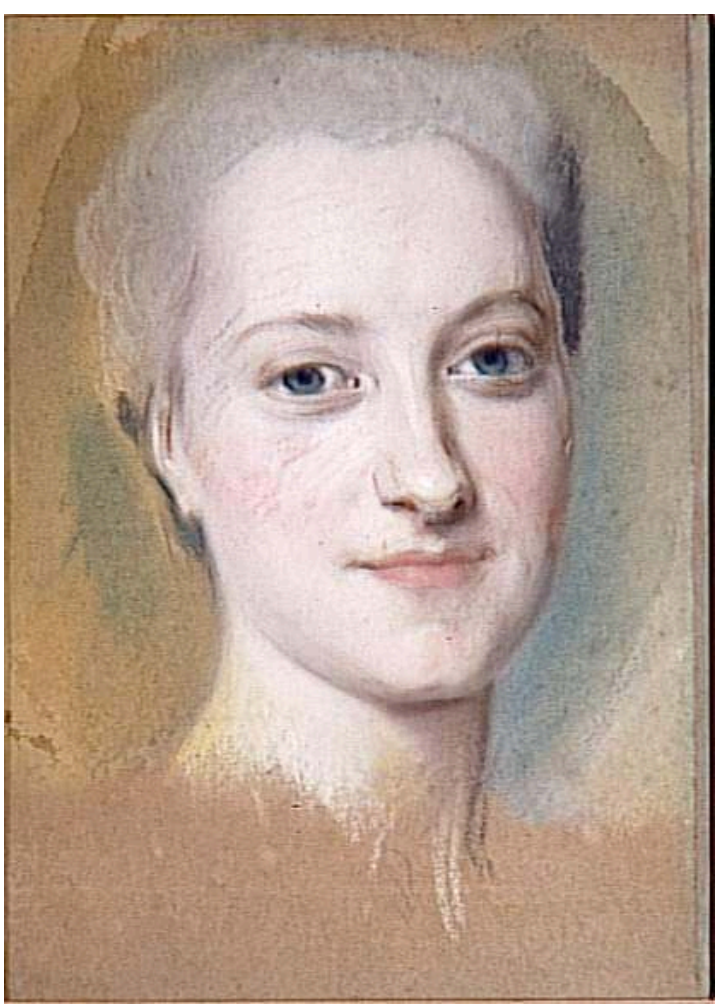

1763, dessin au pastel, 32 × 22 cm, Saint-Quentin, musée Antoine Lécuyer.

De M. de La Tour, le portrait de Madame la Dauphine, et celui de la princesse Christine de Saxe (fig. 5).

De M. Bachelier, L'Europe savante. Le roi y est représenté encourageant les Sciences et les Arts : le Louvre, qui est leur sanctuaire, termine l'horizon. 
6. Jean-Baptiste Perronneau, Portrait de $M^{\text {me }}$ de Tourolle

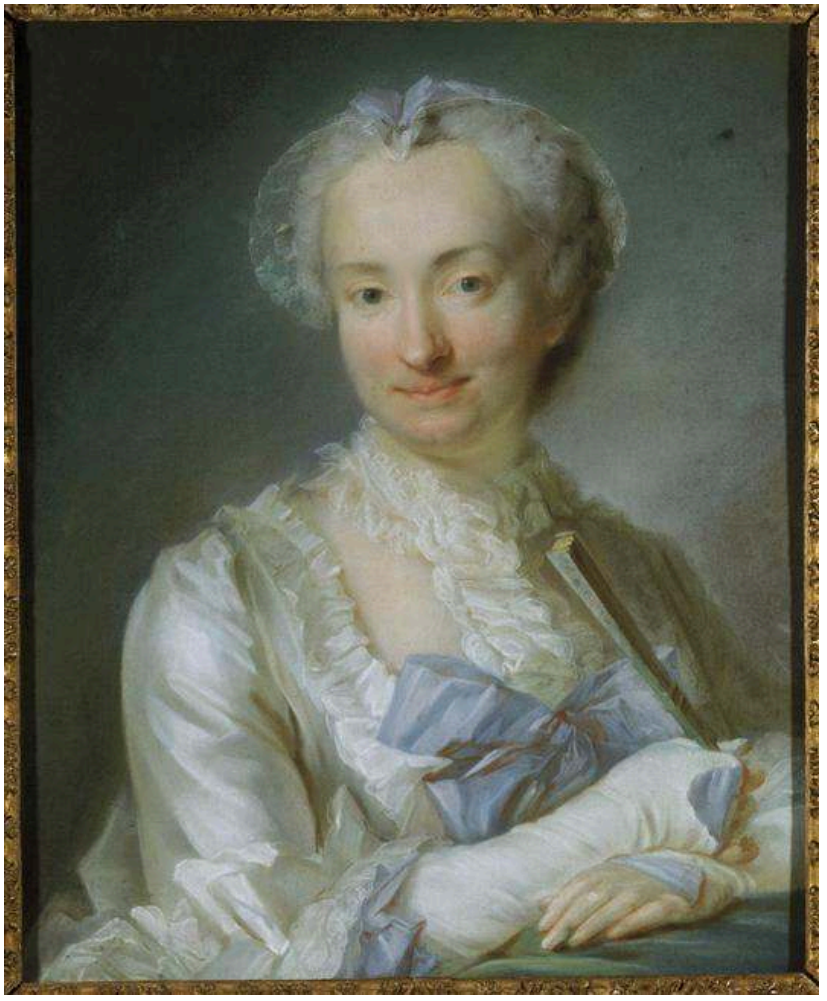

1763, dessin au pastel, 59 × 49 cm, Orléans, musée des Beaux-Arts.

17 De M. Perronneau, le portrait de $\mathrm{M}^{\text {me }}$ Perronneau faisant des nœuds; celui de $\mathrm{M}^{\text {me }}$ Trudaine de Montigny et de $\mathrm{M}^{\text {me }}$ de Tourolle (fig. 6). 


\section{Joseph Vernet, Vue du port de Rochefort}

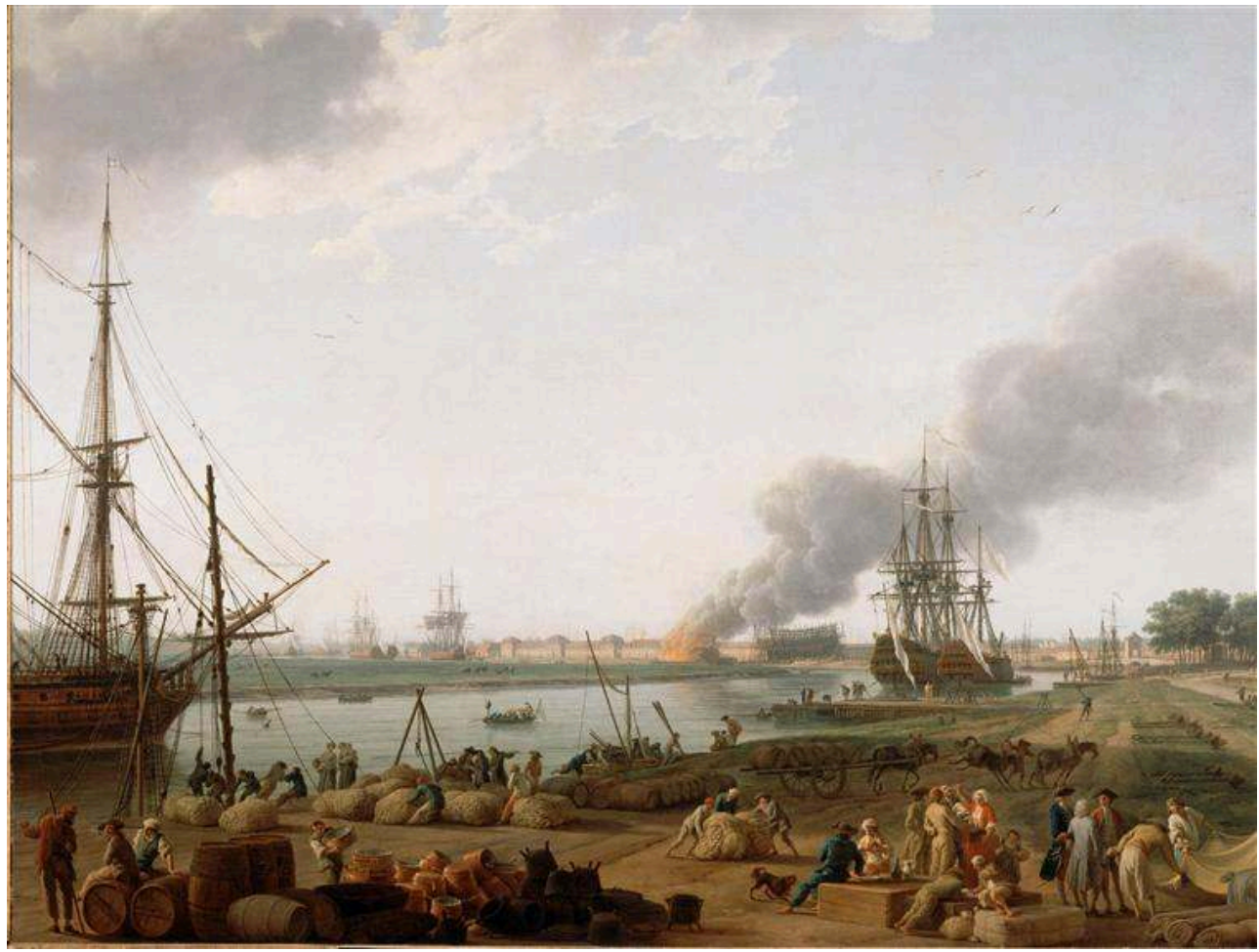

1762, huile sur toile, 165 × 263 cm, Paris, musée national de la Marine.

\section{Joseph Vernet, Vue du port de La Rochelle}

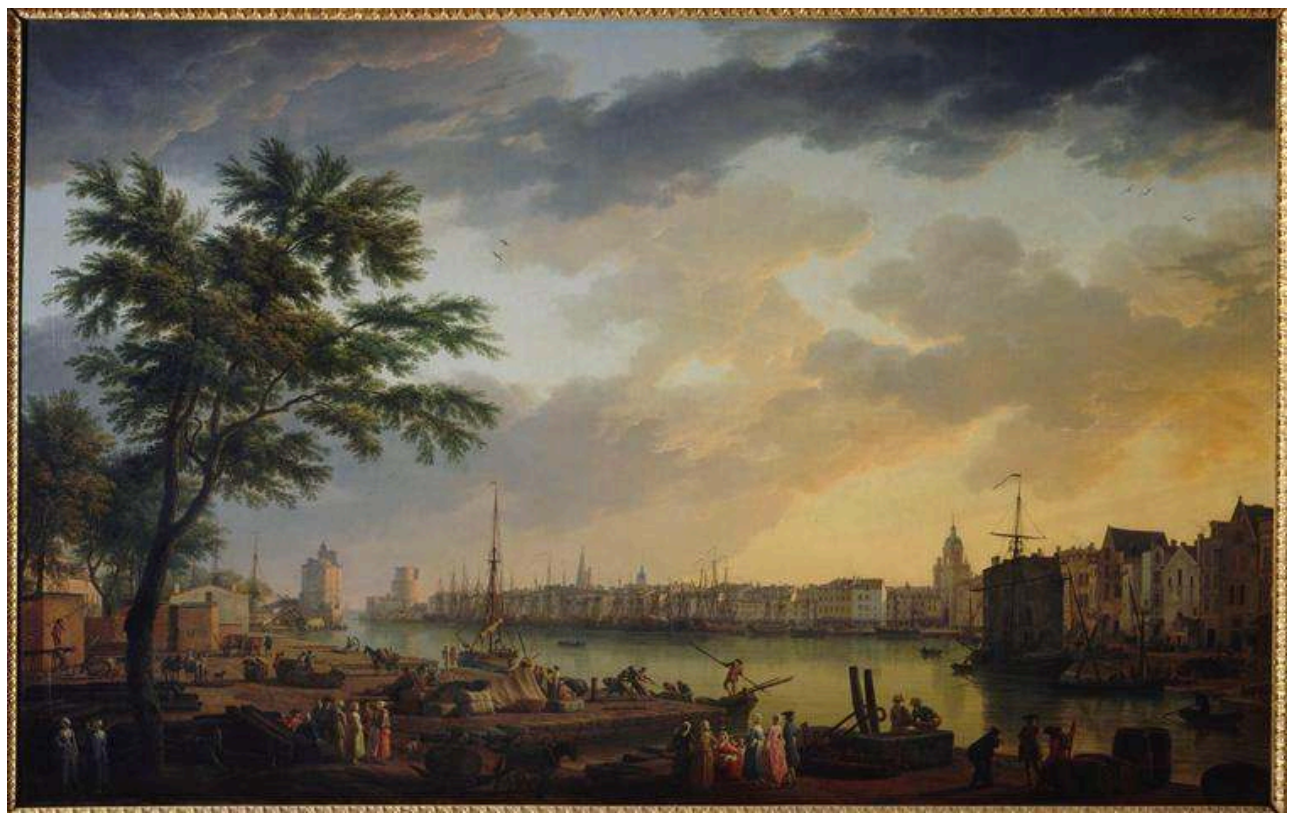

1763, huile sur toile, 165 × $263 \mathrm{~cm}$, Paris, musée national de la Marine.

18 De M. Vernet, Vue du port de Rochefort (fig. 7) et vue de celui de La Rochelle (fig. 8) : ces deux beaux tableaux sont au roi, pour servir de suite aux ports du Havre. La Bergère des Alpes, sujet tiré des Contes de M. Marmontel.

De M. Roslin, Portrait de Madame la comtesse d'Egmont, fille de Monsieur le duc de Richelieu. 
De M. de Machy, Statue équestre de Louis XV, à l'instant où on la descend sur son piédestal.

9. François-Hubert Drouais, Portrait de Madame et de Monsieur le comte d'Artois jouant ensemble [Charles Philippe de France, comte d'Artois et sa sœur, $M^{\text {me }}$ Clothilde]

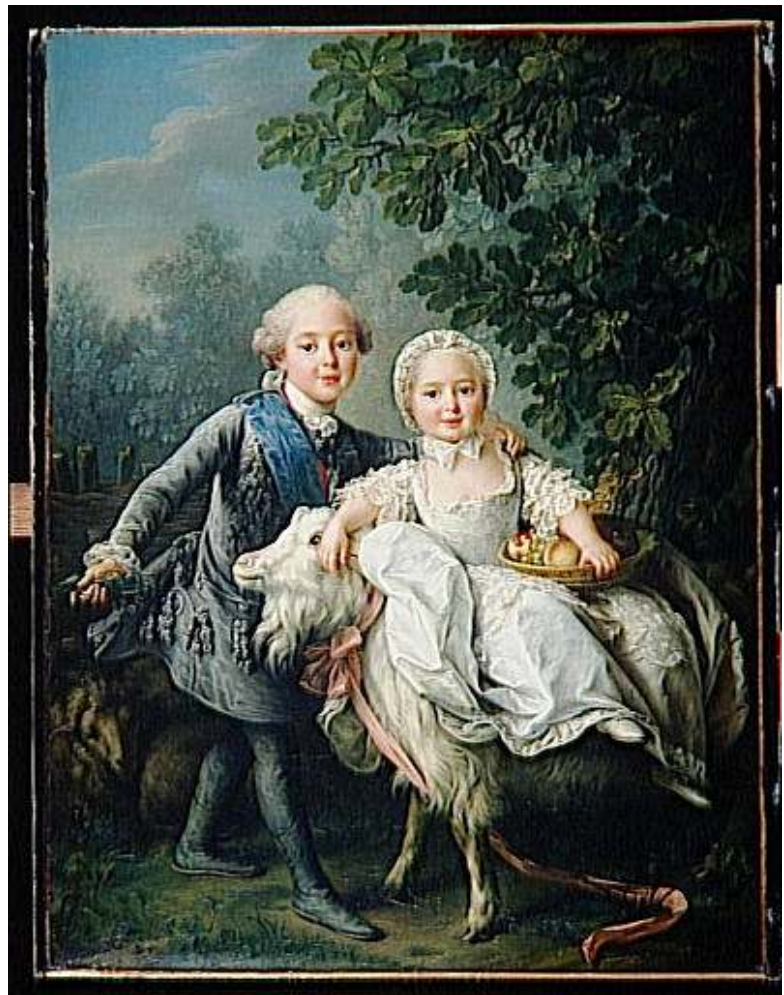

1763, huile sur toile, 129,5 × 97,5 cm, Paris, musée du Louvre.

De M. Drouais le fils, portrait de Madame et de Monsieur le comte d'Artois jouant ensemble (fig. 9); $M^{\text {lle s }}$ de Lorraine et d'Elbeuf; le portrait de Monsieur le prince d'Elbeuf se trouve dans le même tableau, dont le sujet est l'Amour enchaîné et désarmé; une petite fille jouant avec un chat. 
10. Chevalier Antoine de Favray, Dames maltaises se faisant visite

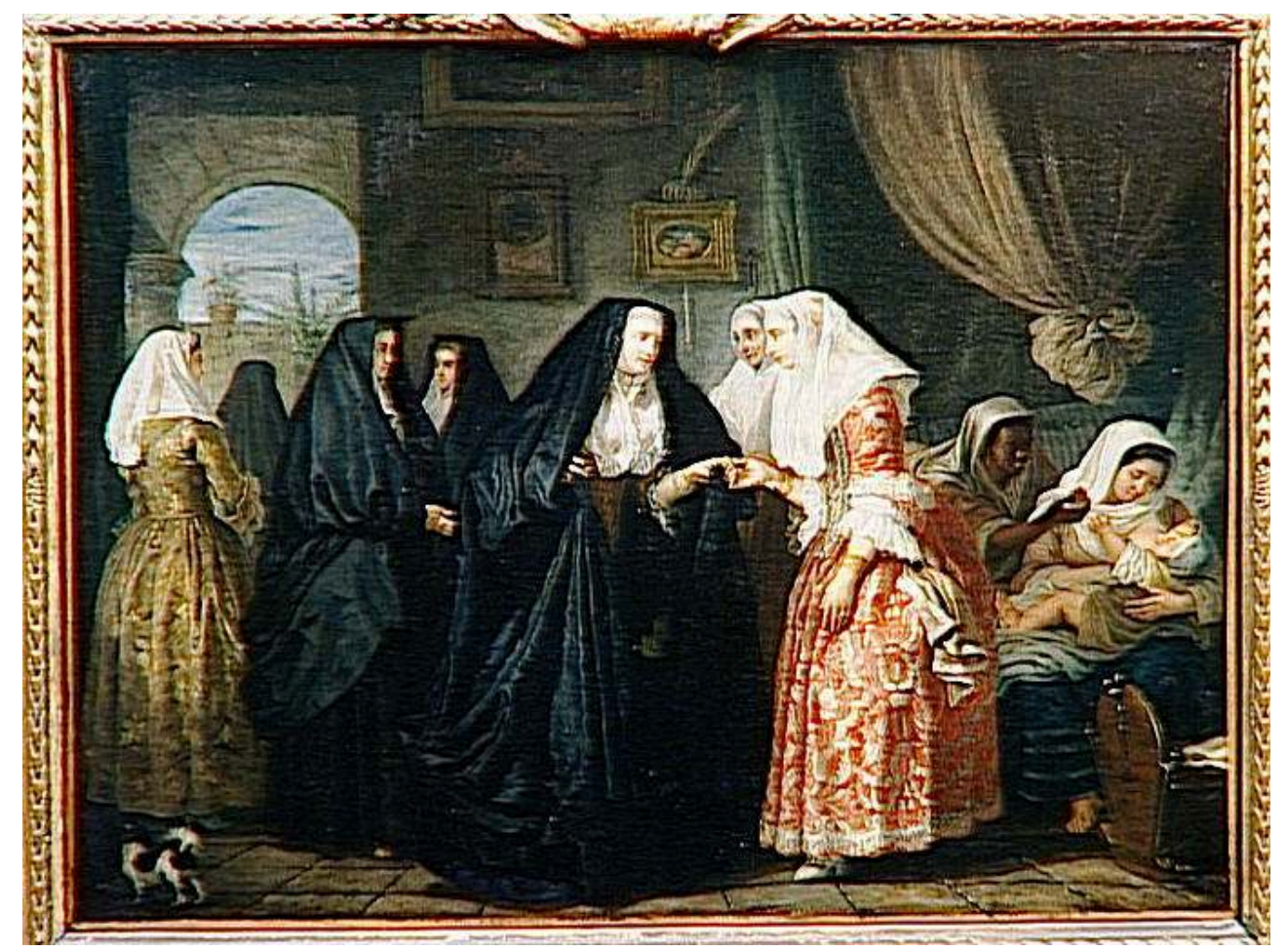

1751, huile sur toile, 49 × 63 cm, Paris, musée du Louvre. messieurs Baudoin, Brenet, Bellanger, Casanove, Parrocel, Doyen, Voiriot, Desportes, Venerant, peintres en miniatures, Millet pour le paysage, Chardin pour les fruits; Amédée Vanloo, qu'on peut nommer Le Dévot; de M. Bouchart, recteur de l'Académie. Les bornes que je me suis prescrites ne me permettent pas d'entrer dans leurs ouvrages.

De M. Favray, chevalier de Malte, des dames maltaises se faisant visite; Femmes de Maltes de différents états (fig. 10).

De M. Greuze, La Piété filiale. Une jeune fille qui a cassé son miroir; les portraits de Monsieur le duc de Chartres, de Mademoiselle, de $\mathrm{M}^{\text {lle }}$ de Pange et de $\mathrm{M}^{\mathrm{me}}$ Greuze.

De M. Guérin, portrait de Madame la comtesse de l'Isle-Bonne avec $M^{\text {lle }} \mathrm{d}^{\prime}$ Harcourt sa fille.

De M. Roland de la Porte, Les Apprêts d'un déjeuner rustique. Je ne puis oublier du même auteur un bas-relief avec la bordure imitée, représentant une tête d'empereur ; c'est un tableau unique dans le Salon.

De M. Loutherbourg, quatre tableaux représentant les quatre heures du soir.

C'est aux connaisseurs à louer ou à censurer tous ces ouvrages, ainsi que ceux de M. Lemoyne, sculpteur, a exposé un buste représentant la belle Madame la comtesse de Brionne ; elle est à côté du portrait du roi.

De M. Falconet, une figure de marbre représentant la douce Mélancolie. 
11. Louis Claude Vassé, Femme couchée sur un socle carré, pleurant sur une urne

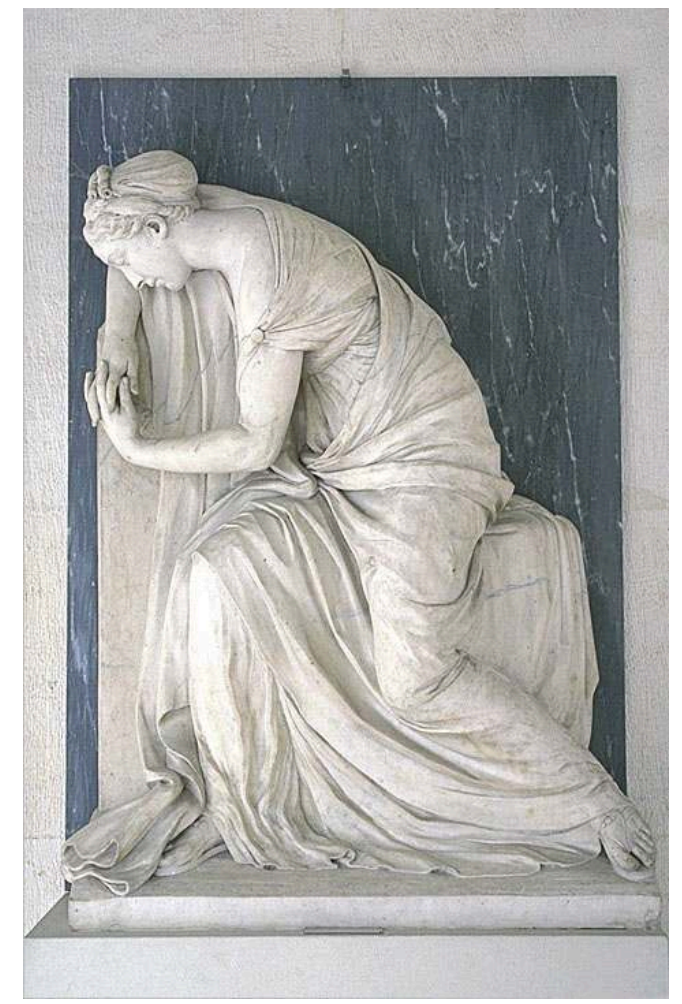

1763 (?), petite figure en plâtre, Saint-Pétersbourg, Laure Alexandre Nevski, tombeau de la Princesse de Galitzin.

De M. Vassé, une Femme couchée sur un socle carré, pleurant sur une urne ; figure qui doit faire partie du tombeau de Madame la princesse de Galitzin (fig. 11).

De M. Pajou, La Peinture.

De M. Challe, une Vierge avec l'Enfant Jésus.

De M. Caffieri, le portrait de Monsieur le prince de Condé. 
12. Nicolas-Sébastien Adam, Prométhée attaché sur le mont Caucase, un aigle lui dévore le foie [Prométhée]

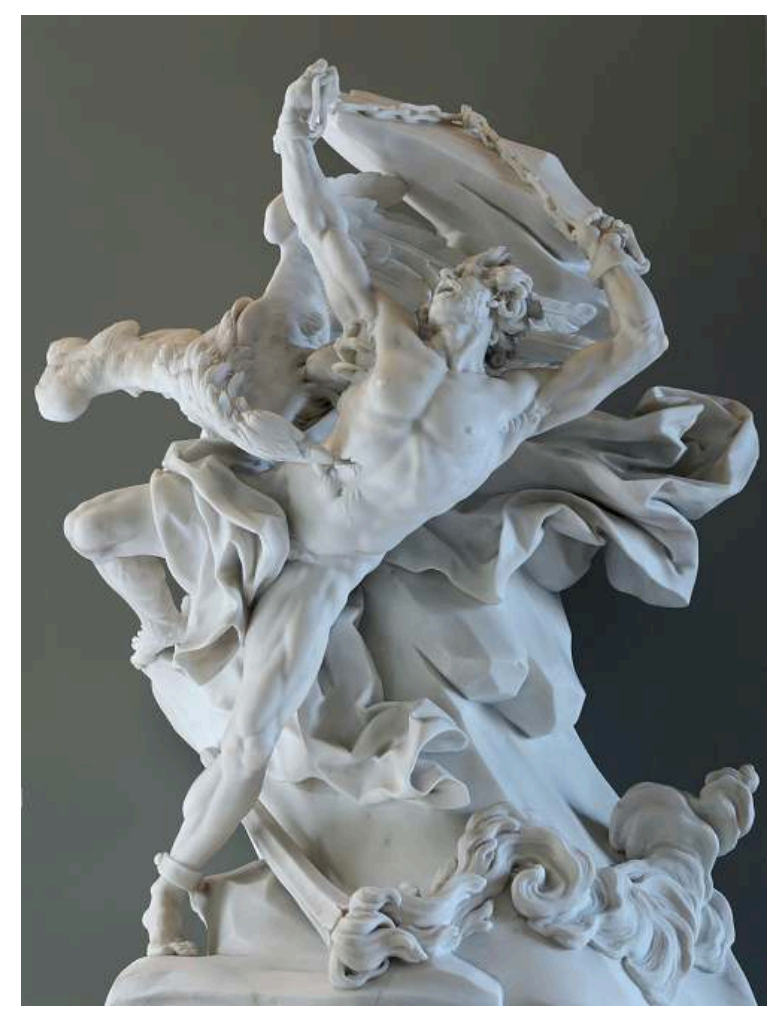

1762, sculpture, marbre, 115 cm, Paris, musée du Louvre. ils représentent Monsieur le duc
M. Mercier et M. Babil, échevins.

mire aussi les gravures de messieurs Moitte, Melini et Beauvarlet et surtout le bel ouvrage de M. Audran. C'est le portrait de Sa Majesté, exécuté en haute lisse d'après le tableau original de M. Louis-Michel Van Loo, qui fut exposé en 1761 au Salon du Louvre.

\section{«Lettre d'une dame au sujet du dôme des Invalides » (février 1764)}

p. 59-64

43 Je viens d'éprouver, Monsieur, un plaisir qui peut être senti, mais difficilement rendu, et dont il me prend envie de vous faire part autant qu'il me sera possible. C'est un 
enthousiasme qui s'est emparé de moi et de ma fille, que j'ai menée, pour la première fois, à l'hôtel des Invalides, que je n'avais jamais vu moi-même, quoique née dans la capitale dont je suis habitante. Il ne fallait pas moins qu'une fille chérie, que je n'avais pas vue depuis bien des années, arrivant d'une province la plus reculée du royaume, pour exciter ma curiosité. Ce digne monument de la grandeur de Louis XIV vient d'être regratté. Ah! monsieur, en entrant dans l'enceinte du dôme, nous sommes restées saisies d'admiration: rien de plus beau ne m'a jamais frappée. Quel ordre! Quelle décence et quelle majesté! Un jour lumineux, qui est jeté avec art, rend le coup d'œil parfait et ravissant. J'ai regardé ma fille dans ce moment de surprise; elle en était pénétrée. Le respect a retenu l'exclamation. Ce temple unique est orné de sa seule beauté : sa grandeur, son élévation et ses justes proportions n'exigent point d'autre magnificence; sa structure lui suffit. Les chapelles de côté, qui éclairent et accompagnent ce dôme superbe, ne laissent rien à désirer. Son contour, élevé par des degrés, et qui s'étend sur le sanctuaire, le couvre de majesté.

Le marbre, sur lequel on marche, a des compartiments relatifs à l'objet, ce grand roi que nous avons vu, vous et moi, dans toute sa gloire. Deux $L$ entrelacés, accompagnés de palmes et de lauriers, couronnés de lys, se reproduisent d'espace en espace. Ce sont des tableaux admirables qui, repolis et grattés, reçoivent un nouvel éclat, rappellent le moment de la construction de l'édifice, et ajoutent au plaisir qu'il nous fait. Mais, le croirez-vous, monsieur? En parcourant les chapelles de côté avec le respect dû à la maison de Dieu, j'ai senti que ce respect m'abandonnait à la vue d'une figure de sainte, dont je n'ai pu deviner le nom, qui en remplace une autre que le temps a endommagée ; elle est descendue de l'autel pour faire place à la nouvelle venue.

Quelle différence! La première joint à une belle physionomie un air de candeur qui annonce la piété : l'amour de Dieu exprimé dans son regard; son attitude, noble et simple, parle aux yeux et dit ce qu'elle représente... Mais l'autre, si j'ose le dire, déshonore l'autel où elle était encore appuyée. Figurez-vous, monsieur, une jolie créature avec des traits fins et délicats qui, en se courbant du côté droit, semble s'efforcer d'élever le bras gauche jusqu'à la gorge qu'elle presse de sa main. Elle regarde le ciel comme pour lui reprocher un sacrifice dont elle ne semble trop se souvenir. Pour moi, indignée, je n'ai vu dans cette représentation qu'une comédienne des plus expressives. Crainte de me tromper, j'ai demandé à ma fille ce qu'elle pensait de ces deux morceaux si différents : elle n'a point hésité ; l'ancienne, qui n'est que de plâtre, a eu la préférence, malgré sa caducité, sur la moderne qui paraît être de pierre. On a sans doute cru faire une vestale de ces élégantes gardiennes du feu sacré des dieux de la fable.

C'est ainsi, monsieur, que nous perdons essentiellement les idées relatives à l'objet de notre culte. Nos images se ressentent de la perversité ; le cœur et l'esprit corrompus conduisent le ciseau et expriment, non pas ce qui devait être, mais ce qui nous affecte. Ce sont des réflexions que je crois justes. Je souhaite qu'elles vous fassent naître l'envie d'aller voir le dôme des Invalides nouvellement rajeuni. Le fameux Mansart doit être encore flatté de son ouvrage; ce chef-d'œuvre si respectable vit encore en lui; il le portera comme un trophée à la vallée de Josaphat.

Je laisse, monsieur, le reste de l'édifice et ses dépendances, dont la magnificence fera dans les siècles futurs le plus grand honneur au prince et à son artiste, pour ne vous parler que de ce qui m'a plus singulièrement frappée, et de l'effet que l'enthousiasme a produit sur moi. Seriez-vous tenté de l'éprouver et d'aller voir ce que je viens de 
peindre sans principes, en suivant les différents mouvements qui m'ont agitée ? La comparaison de ces deux saintes m'a conduite aux réflexions que vous venez de voir. Un siècle apporte à l'autre des changements sensibles : nous nous peignons dans nos productions. Nos pères étaient plus simples et leurs ouvrages plus décents; de façon qu'en gagnant du côté de l'esprit par les découvertes, nous avons perdu ce point juste du vrai beau ; je veux dire cette belle et immuable simplicité qui est dans la nature, qui l'orne sans la détruire. M. Mansart, dans son genre, n'a pas négligé ce secret important. Le jour dont il pourrait disposer à son gré, il le ménage avec soin. Les deux chapelles le réfléchissent au sanctuaire et il vient se joindre à celui des croisées pratiquées dans le dôme et ce jour, que j'appelle lumineux, surprend d'autant plus que l'on ne trouve point à sa portée d'ouvertures d'où il puisse partir : celles du dôme sont trop élevées, et celles de côté sont masquées, ce semble, par des colonnes admirables; cependant son éclat ravit et n'éblouit point. La majesté essentielle du temple de Dieu y préside naturellement. Divin Mansart! Tout respire ici le feu de ton imagination, la force de ton esprit et la profondeur de ton génie.

Vous en jugerez mieux que moi, monsieur, si j'ai la satisfaction de vous persuader: alors vous m'en direz votre sentiment en homme qui connait le beau, qui l'aime et sait l'apprécier. Votre sagacité et votre goût me répondent d'un jugement de votre part qui ne sera ni flatté, ni outré.

Je suis, etc.

P.-S. On m'a dit, depuis que ma lettre est écrite, que cette sainte que je n'ai pas reconnue pouvait être sainte Thérèse.

\section{" Avis divers. Gravure » (août 1765)}

Jusqu'à présent, personne n'a entrepris de faire pour les arts ce qu'on fait pour la littérature. On annonce dans plusieurs journaux les estampes nouvelles: mais des éloges fades ou des lieux communs, employés gauchement, ne suffisent pas pour diriger dans leurs emplettes les amateurs des provinces ou des pays étrangers. Il faudrait apprécier les beautés, rendre compte des détails, indiquer même les défauts, en un mot, faire connaître les gravures et les juger : voilà ce qu'on se propose de faire à l'avenir, dans le Journal des dames. Tous ceux qui voudront y faire annoncer des nouveautés dans ce genre auront soin d'en remettre une épreuve chez Bauche, libraire, quai des Augustins, et d'en marquer le prix. On les prévient qu'on ne s'en rapportera pas à eux sur le mérite de leurs ouvrages. On en parlera sans partialité et sans fadeur; on rendra justice à la finesse, la netteté, la douceur du burin, à la variété des travaux et à leur emploi, pour distinguer les diverses étoffes et les différentes carnations, à l'accord des tons et à la perfection de la manœuvre. On s'entendra surtout sur l'esprit de la gravure, sur son effet, sur la beauté, le sentiment, la grâce, sur l'expression des passions et tout ce qu'on peut appeler la poésie d'une estampe. On espère contribuer par là à l'avantage des artistes, et peut-être au progrès du vrai goût. Du moins on ne négligera rien pour $\mathrm{y}$ réussir.

51 Les lecteurs se plaignent quelquefois de ce qu'on se sert dans les ouvrages sur les arts d'un langage presque inintelligible. C'est un défaut qu'on évitera avec soin. Ceux qui affectent ainsi de se hérisser de mots techniques ne le font souvent que pour faire 
parade d'une fausse science. Il y en a quelques-uns, à la vérité, qui sont d'une précision et d'une énergie que rien ne pourrait remplacer: mais ils sont en petit nombre, et le parti qu'on prendra, à l'égard de ceux-là, c'est d'en donner l'explication dans une note, la première fois qu'on sera obligé de s'en servir.

\section{La Blanchisseuse gravée par M. Danzel, d'après le tableau de M. Greuze}

\section{Jacques-Claude Danzel, La Blanchisseuse}

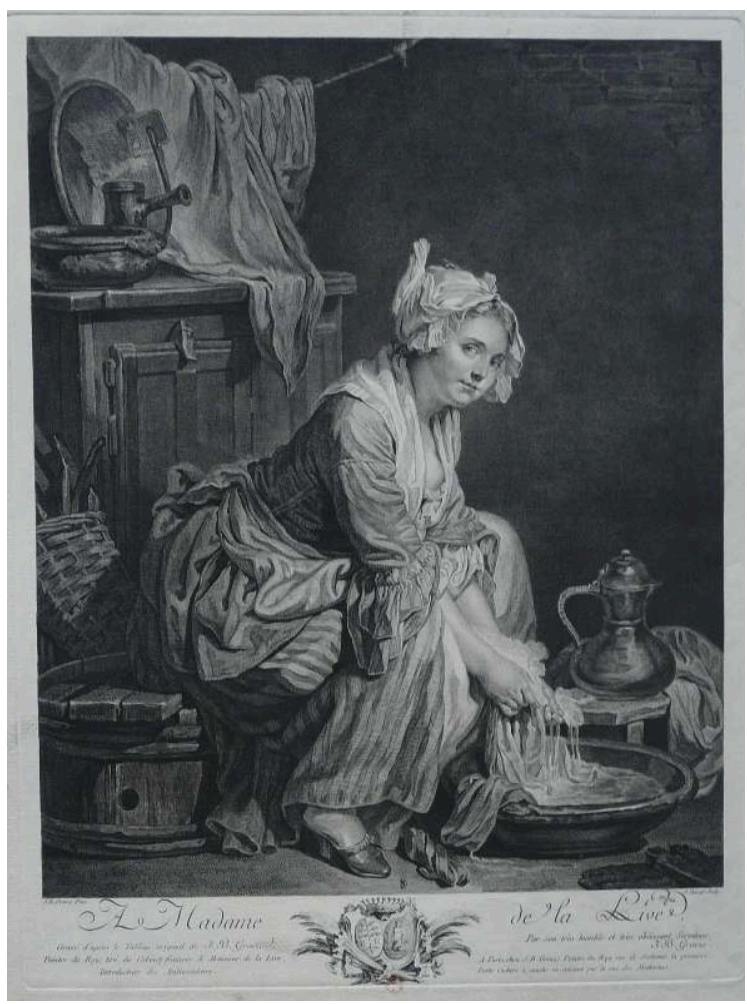

Gravée par M. Danzel, d'après une huile sur toile de M. Greuze présentée au Salon en 1759, 1765, gravure en taille douce, 39,8 × 32,3 cm, Paris, Bibliothèque nationale de France.

Cette jolie estampe parait depuis quelques jours, et l'on ne pouvait guère commencer sous de meilleurs auspices l'entreprise que nous venons d'annoncer. Le tableau de $L a$ Blanchisseuse, par M.Greuze, avait été extrêmement applaudi au Salon de 1759. Il représente une fille qui savonne du linge (fig. 13). Le jeune artiste qui l'a gravée est élève de M. Flipart. Sa planche est d'un beau fini ; on y retrouve ce sentiment fin et délicat qui est dans le tableau de M. Greuze et qu'il n'était pas aisé de saisir. Cette fille, qui mériterait par la figure d'être occupée à des choses plus intéressantes, semble être ennuyée de son état et se tourne vers les spectateurs d'un air fripon et agaçant. On voit autour d'elle des cafetières, un chaudron, du linge étendu sur une corde, etc. Le graveur a observé dans les carnations toutes ces gradations insensibles qui font le charme de la gravure. Les travaux les plus précieux sont réservés pour la tête et pour la gorge, que l'ouverture du mouchoir laisse un peu entrevoir. Les mains sont potelées; et les bras, étant moins exposés à l'air, sont d'un burin encore plus doux. Toutes les draperies sont bien caractérisées; et chacun des accessoires sert à faire valoir la figure principale. 
Quoique le sujet de cette planche paraisse froid, elle ne laisse pas de faire beaucoup de plaisir.

Une estampe est, en quelque sorte, la traduction d'un tableau. La gravure et la peinture, de même que les langues, ont des génies, et, pour ainsi dire, des idiomes différents. Il ne faut pas toujours traduire littéralement un ouvrage, ni copier un tableau d'une manière servile. Ce qui ajoute à l'effet dans le tableau y nuirait souvent dans l'estampe; et M. Greuze l'a bien compris. En faisant graver sa Blanchisseuse, il a fait quelques changements dans les choses qui auraient paru imparfaites, sans la magie des couleurs. Son estampe en est plus belle; l'harmonie générale n'est pas la même que celle du tableau; mais elle est plus convenable au génie de la gravure. C'est un mérite de plus d'avoir su plaire par deux routes différentes; et il serait bien à souhaiter que tous les graveurs en suivissent l'exemple.

Cette estampe se trouve chez M. J.-B. Greuze, peintre du roi, rue de Sorbonne, première porte cochère à gauche, en entrant par la rue des Mathurins. Prix 4 livres.

\section{« Gravure » (septembre 1765)}

Vénus et Adonis, d'après un tableau de feu M. Berthon, peintre de l'académie de SaintLuc.

Vénus et Énée, d'après un tableau de M. Boizot, de l'Académie royale de peinture.

La Charité romaine, d'après le tableau de feu $\mathrm{M}$. Coypel, premier peintre du roi.

Ces trois estampes ont été gravées par M.J. Danzel, et se trouvent chez l'auteur, rue d'Enfer, à côté du séminaire de Saint-Louis. Le prix de chacune est de 30 sols.

M. Danzel nous a demandé d'annoncer ses estampes comme des études dans l'art de graver. Cette modestie lui fait honneur et nous croyons que le public jugera de ses ouvrages plus favorablement qu'il ne le fait lui-même. On remarque avec plaisir dans ceux-ci les progrès qu'il a faits d'année en année. Son estampe de Vénus et Adonis a été gravée en 1761. La déesse appuyée sur le sein de son amant le conjure de renoncer à sa passion pour la chasse. Adonis l'écoute avec une tendresse mêlée de quelque embarras. À ses pieds est un chien de chasse qui semble par son impatience l'inviter à partir. De petits Amours retiennent les cygnes du char de Vénus et les autres chiens d'Adonis. L'effet général de cette estampe est assez bon; la figure d'Adonis est d'un burin net et hardi. Il serait à souhaiter que celles des Amours et de Vénus fussent d'un travail plus doux, plus aimable; ce contraste ferait valoir le reste de l'estampe et en rendrait le coup d'œil plus intéressant et plus flatteur.

L'estampe de Vénus et Énée, gravée l'année suivante, fait plus d'effet. Cette différence est sensible et fait bien augurer des talents de M. Danzel; le sujet est l'apothéose d'Énée. Vénus soutient le corps de son fils et les Amours lui versent de l'ambroisie dans l'oreille. Il paraît que le tableau que le graveur avait pris pour modèle était un peu froid. Vénus n'est point assez animée. Les Amours sont dans une attitude fausse. Un Triton et une Néréide qui assistent à cette cérémonie ne paraissent y prendre aucun intérêt.

61 La Charité romaine gravée en 1763 est la meilleure de ces estampes à tous égards. Le corps du vieillard est d'une manière large et vigoureuse ; la tête est noble et belle ; tous 
ses muscles sont bien rendus. Cette gravure pourrait disputer avec la plupart des tableaux du côté de la force et de l'énergie. Mais la gorge de la fille n'est pas d'un dessin bien correct et cette figure est traitée un peu durement. Il paraît que M. Danzel est sujet à tomber dans ce défaut. On ne saurait trop lui demander d'employer, dans les carnations des femmes, ce burin doux et gracieux qu'on admire dans sa Blanchisseuse d'après M. Greuze.

M. Le Bas avait autrefois gravé La Charité romaine de Coypel et nous avons eu le plaisir de comparer les deux estampes. Le vieillard de M. Danzel est d'un ton plus ferme; sa tête est plus belle; mais celui de M. Le Bas a l'air plus souffrant, et la fille a un air de compassion que M. Danzel n'a pas entièrement rendu. Cependant on ne saurait convenir que l'estampe de M. Danzel ne soit celle qui fasse le plus d'effet. Nous exhortons ce jeune artiste à marcher avec courage dans une carrière où il paraît qu'il peut aller loin, à mettre plus de variété et plus de douceur dans ses gravures, et surtout à travailler d'après de bons modèles.

\section{« Gravure » (mai 1766)}

La Jeune Fille qui pleure son serin, estampe gravée par M. Flipart, d'après le tableau de M. Greuze (fig. 14).

\section{Jean-Baptiste Greuze, Jeune fille pleurant son serin [Une Jeune fille qui pleure son oiseau mort]}

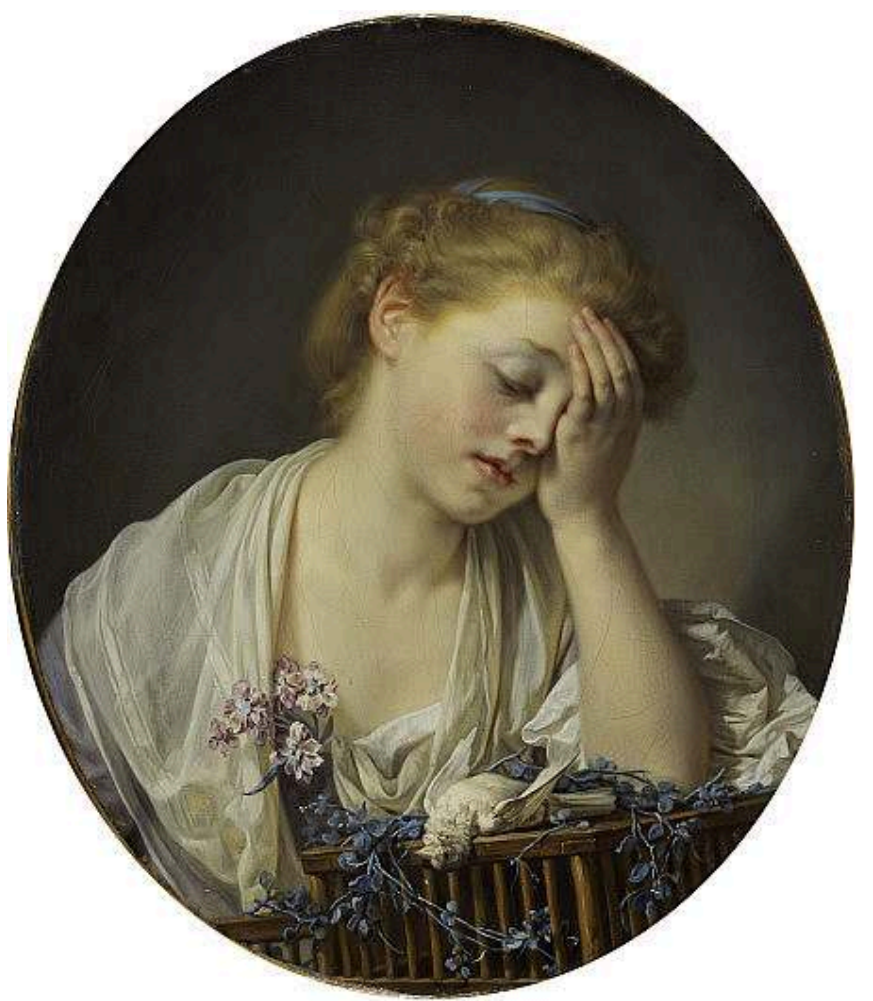

1765, huile sur toile, 52 × 45,6 cm, Édimbourg, National Galleries of Scotland.

13 pouces 8 lignes de hauteur. 9 pouces 9 lignes de largeur. 
La sensation vive et générale qu'avait excitée au dernier Salon La Jeune Fille qui pleure son serin a engagé M. Greuze à la faire graver. Ce chef-d'œuvre de grâce et de sentiments ne saurait être trop multiplié et trop répandu. On sent qu'il n'était pas possible au burin de rendre cette fraîcheur du teint, cette séduction du coloris, qu'on a tant admirées dans le tableau; une telle magie n'appartient qu'à la peinture, et M. Greuze l'avait portée au plus haut degré : mais le graveur a saisi et exprimé toutes les beautés qu'il pouvait nous transmettre. Il a approché de son modèle d'aussi près qu'il était possible. Cette estampe lui fait honneur et elle est l'une des plus intéressantes ${ }^{1}$ et des plus précieuses qui aient paru depuis longtemps.

On la trouve à Paris chez M. J.-B. Greuze, peintre du roi, rue de Sorbonne. Prix 4 livres.

On trouve aussi chez le même peintre une estampe de M. Ingouf, jeune élève de M. Flipart. Elle représente une petite fille qui tient d'un air boudeur une poupée habillée en capucin. Ce tableau de M. Greuze avait été vu avec plaisir au dernier Salon. Le prix de l'estampe est de 24 sols.

\section{« Beaux-Arts » (mars 1767)}

Le Paralytique servi par ses enfants,gravé d'après le tableau de M. Greuze, par M. Flipart, graveur du roi.

Estampes de 12 pouces de large sur 17 pouces 10 lignes de hauteur. À Paris, chez M. Greuze, peintre du roi, rue pavée Saint-André-des-Arts. Prix 16 livres.

Le tableau du Paralytique fut exposé au Salon de 1763, sous le titre de la Piété filiale. M. Greuze y avait représenté avec autant d'art que d'énergie une de ces scènes touchantes que produisent les devoirs les plus sains de la nature : c'est un vieillard entouré de sa famille attendrie, qui bénit les soins et les vertus de son fils. On sent assez ce que peut devenir un pareil sujet sous le pinceau de M. Greuze. L'impératrice de Russie ayant fait l'acquisition de ce morceau, tous les amateurs regrettaient, avec raison, qu'il fût perdu pour la France. L'estampe que j'annonce doit les consoler, du moins en partie : elle a été gravée sous les yeux de l'auteur et par un artiste habile. On espère que $M$. Greuze publiera de même sa nouvelle mariée. C'est un présent que le public semble avoir mérité par les transports et l'ivresse soutenue avec laquelle il l'a applaudie.

\section{ANNEXES}

Lire l'introduction à $\mathrm{M}^{\mathrm{me}}$ de Maisonneuve écrite par Amandine Gorse 
NOTES

1. Nous n'entrons pas dans de plus grands détails à l'égard de cette estampe. Nous avions donné la description du tableau dans notre journal de septembre 1765, et nous y renvoyons nos lecteurs. 
Marie-Émilie de Montanclos (1736 1812) 


\section{Introduction}

Amandine Gorse 
1 Marie-Émilie de Montanclos, baronne de Princen (1736-1812), reprit la direction du Journal des dames de janvier 1774 à avril 1775, avant de la céder à Louis-Sébastien Mercier. Femme de lettres à l'esprit inventif, elle eut une production littéraire abondante et, notamment, écrivit des pièces qui furent jouées à la Comédie-Française. Ses talents lui ouvrirent la porte du cercle des rédacteurs du Mercure de France, dont $\mathrm{M}^{\mathrm{me}}$ de Laisse (1742-1790) - qui collabora également au Journal des dames - faisait partie. Son mariage avec le baron de Princen lui permit de fréquenter la cour, dont elle se retira rapidement après la mort de son mari, afin de se consacrer à son œuvre.

2 Au sein du Journal des dames, Marie-Émilie de Montanclos renoua avec la verve féministe, abandonnée par la précédente rédactrice en chef, $\mathrm{M}^{\mathrm{me}}$ de Maisonneuve. S'élevant contre les allégations du rousseauisme ambiant, elle prônait pour toutes les femmes une éducation intellectuelle variée leur permettant d'entreprendre une carrière publique à l'égal des hommes. Elle-même se sépara de son second mari, Charlemagne Cuvier-Grandin de Montanclos, afin de pouvoir exercer librement ses activités littéraires et sa profession d'éditrice. Grâce à ses nombreux talents, elle put subsister lorsqu'elle perdit sa fortune, soutenue dans sa démarche par le poète ClaudeJoseph Dorat et protégée par la dauphine Marie-Antoinette. Elle modifia alors le titre du journal, qui devint Journal des dames dédié à la dauphine, par la baronne de Princen, et adopta un style enjoué et plaisant, parfois ironique dans sa défense du futur couple royal.

3 La spécificité de ses écrits résidait dans cet antagonisme stratégique qui réunissait à la fois discours critique et engagé à l'égard de la reconnaissance intellectuelle des femmes, et discours coquet où la légèreté tenait une grande place (GELBART 1991, p. 508). Dans sa lutte, elle tenta de définir le statut des femmes artistes et leur donna, grâce à son journal, un moyen supplémentaire d'expression. Sa carrière littéraire féconde lui permit, à partir de 1804, de recevoir une modeste pension impériale. Elle signa quelques articles dans La Correspondance des dames, en marge de ses œuvres en prose et en vers, de ses comédies, vaudevilles et autres opéras.

\section{BIBLIOGRAPHIE}

GELBART 1991

Nina Rattner Gelbart, « Les femmes journalistes et la presse (XVII ${ }^{\mathrm{e}}-\mathrm{XVIII}{ }^{\mathrm{e}}$ siècle) », dans Michèle Perrot et Georges Duby (éd.), Histoire des femmes en Occident 3. XVI ${ }^{e}$-XVIIII ${ }^{e}$ siècle, sous la dir. de Natalie Zemon Davis et Arlette Farge, Paris, Plon, 1991, p. 491-512.

SULLEROT 1966

Évelyne Sullerot, Histoire de la presse féminine en France des origines à 1848, préf. de Jacques Godechot, Paris, Armand Colin, 1966. 
VAN DIJK 1988

Suzan Van Dijk, « Le Journal des dames, 1759-1778 : les journalistes-dames et les autres », dans Traces de femmes, présence féminine dans le journalisme français du XVIII ${ }^{e}$ siècle, Amsterdam/Maarsen, APA-Holland University press, 1988, p. 134-186.

\section{ANNEXES}

Diaporama des tableaux illustrant les articles de Marie-Émilie de Montanclos pour le Journal des dames :

http://www.flickr.com//photos/73632227@N02/sets/72157629589691711/show/

Lire les extraits des articles de $\mathrm{M}^{\mathrm{me}}$ de Montanclos parus dans le Journal des dames

Liste complète des œuvres d'arts commentées par $\mathrm{M}^{\mathrm{me}}$ de Montanclos à travers ses textes édités dans Plumes et pinceaux 


\title{
$\mathrm{M}^{\mathrm{me}}$ de Montanclos, Journal des
} dames, 1774-1777

[extraits choisis]

\section{"Lettre à Monsieur le marquis de... sur les sculptures et peintures de Saint-Luc exposées à l'hôtel de Jabac » (octobre 1774)}

\author{
Journal des dames dédié à Madame la Dauphine par $M^{m e}$ la baronne de Princen, tome V, \\ p. 240-246. \\ À La Haye
}

1 Cette lettre est écrite par un jeune artiste ; il attribue le progrès qu'il semble faire dans l'art de la peinture aux conseils et aux bontés encourageantes du marquis de... Après lui avoir exprimé sa reconnaissance, il lui fait part des observations qu'il a faites sur les différents tableaux et morceaux de sculpture et d'architecture, exposés par messieurs les académiciens. Il regarde comme un moyen d'exciter l'émulation des artistes la permission qu'ils ont obtenue de réunir, dans un même lieu et à la vue du public, leurs divers ouvrages. Après avoir fait une énumération assez exacte de ceux qui méritent des éloges, il se permet, avec beaucoup d'honnêteté, de relever les défauts qu'il a cru apercevoir dans plusieurs autres.

2 Comme nous avons un intérêt très vif à faire connaître les talents dont notre sexe est susceptible et dont chaque jour il se montre capable, nous nous arrêterons principalement sur ce que dit l'auteur de la lettre des ouvrages de peinture sortis des mains des femmes. Les hommes trouvent toujours assez d'apologistes ; la rivalité même n'empêche point qu'ils ne se rendent justice, au lieu qu'on nous a fait très souvent le reproche fâcheux de chercher parmi nous autres femmes les occasions de ravaler les talents et les vertus de nos semblables.

3 Le Journal des dames, où on ne lit que leurs éloges, doit, il me semble, détruire cette assertion. Pour prouver de plus en plus qu'il n'est consacré qu'à la gloire de notre sexe, nous allons rendre hommage aux aimables artistes que le public a déjà couronnées dans le Salon de l'hôtel de Jabac. 


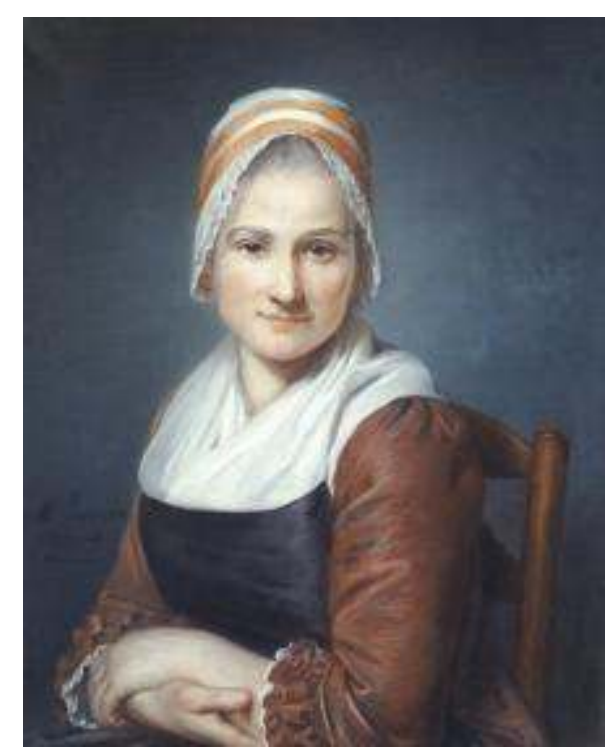

1774, pastel sur papier, $61 \times$ 49,5 cm, Washington, National Museum of Women in the Arts.

4 On a remarqué avec le plus grand plaisir plusieurs portraits en pastel de $\mathrm{M}^{\text {lle }}$ Navarre, élève du célèbre $\mathrm{M}$. de La Tour ; elle promet d'atteindre à ce beau naturel, qui distingue si bien les ouvrages de cet habile artiste. Les portraits de son aimable élève sont bien dessinés, et d'une couleur vraie (fig. 1). L'auteur de la lettre y désirerait, dit-il, un peu plus d'effets. Il trouve ses ombres un peu grises, et même faibles ; mais lorsqu'on a jeté les yeux sur une tête d'enfant de la même demoiselle, les reproches que lui fait l'auteur de la lettre ne paraissent plus fondés et ne laissent au contraire rien à désirer. $\mathrm{M}^{\text {lle }}$ Navarre réussit également dans la miniature. Elle s'est, pour ainsi dire, surpassée dans une tête d'une jeune personne, qui est de la plus grande vérité. Il faut ajouter à cela que $\mathrm{M}^{\text {lle }}$ Navarre travaille seule à ses ouvrages, et qu'ainsi ses talents peuvent être jugés exactement et donner avec raison la plus grande espérance.

$\mathrm{M}^{\text {lle }}$ Vigée a un grand nombre de portraits composés avec beaucoup de goût et de feu : le portrait de $\mathrm{M}^{\text {me }}$ de... est du ton le plus brillant et le plus séduisant ; son habillement est on ne peut plus agréable. Le même auteur a peint $\mathrm{M}^{\text {lle }}$ Dumesnil, et la voix publique l'avoue très ressemblant.

$6 \quad \mathrm{M}^{\text {lle }}$ Bocquet a beaucoup de portraits qui lui font honneur ; mais on s'est attaché surtout à celui de Madame sa mère. On voit que la tendresse de la jeune artiste a conduit son pinceau, et que son cœur voulait une ressemblance frappante : ses yeux doivent être satisfaits; on ne peut réussir davantage, aussi ce portrait a-t-il eu les plus grands éloges. 
2. Adélaïde Labille-Guiard, Portrait de madame Labille-Guiard

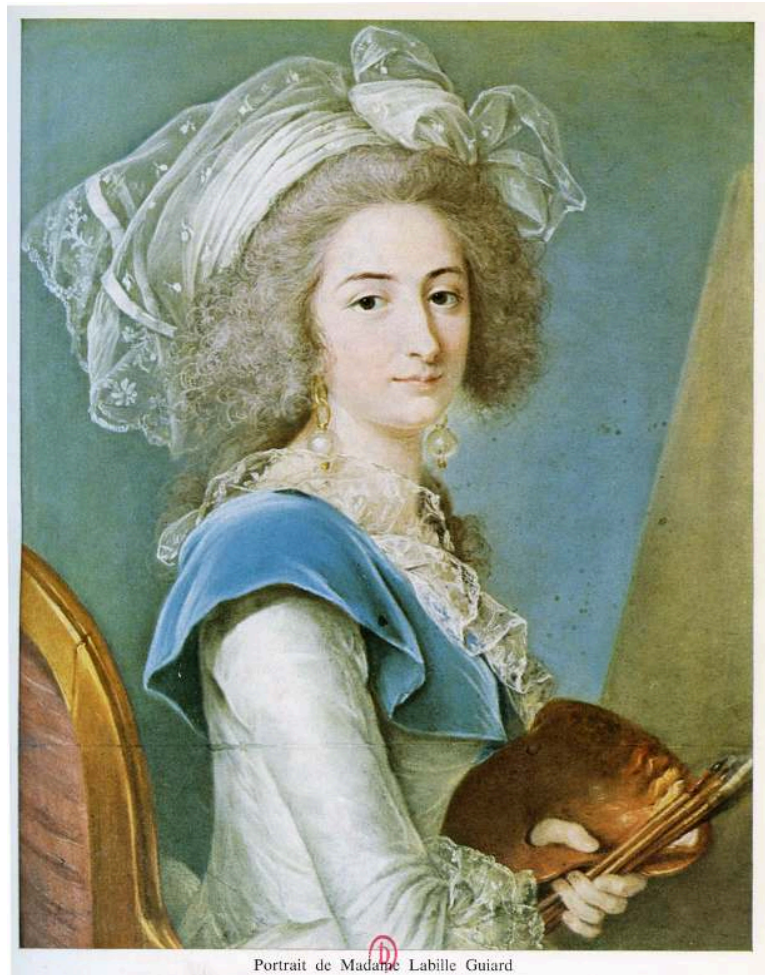

1774, miniature ovale sur ivoire, Madrid, Museo Lázaro Galdiano.

3. Adélaïde Labille-Guiard, Portrait du duc de Choiseul

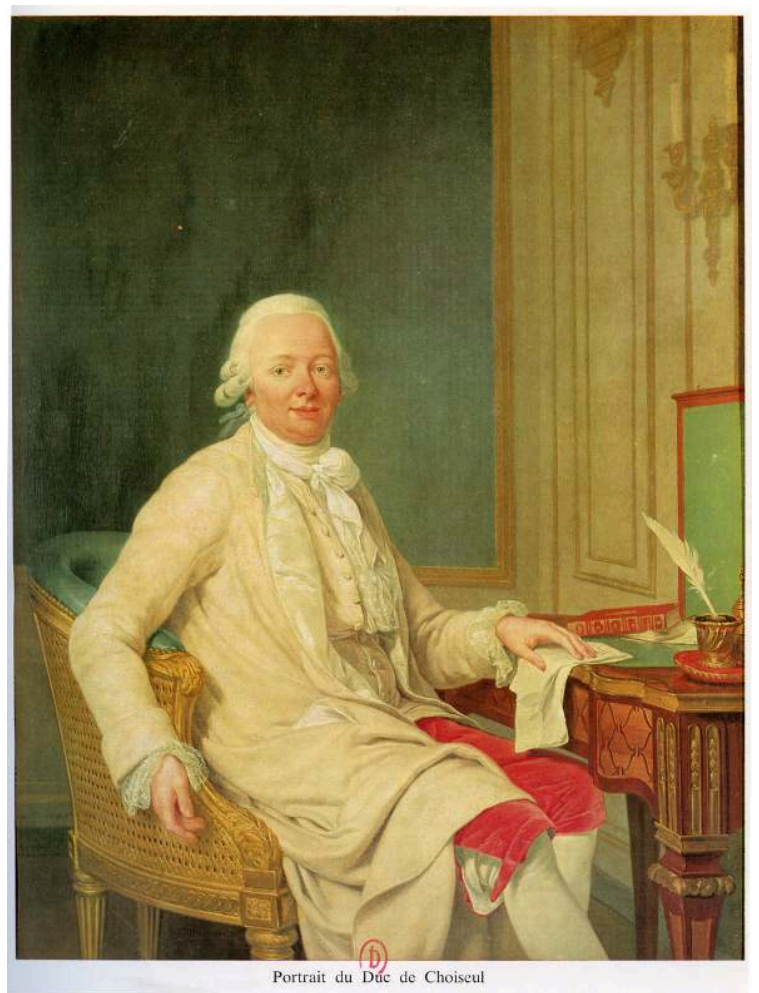

1786, huile sur toile, Paris, coll. part. 
trouvés si bien qu'on a regretté de n'en pas voir davantage. Les ouvrages de cette dame annoncent ses progrès rapides, et l'on voit qu'elle les doit à son goût, qui est naturel et sûr.

Nous sommes étonnée que l'auteur de cette lettre ait omis de parler de M. Charpentier ; les talents de cet artiste le mettent au-dessus de l'oubli et le placent au rang de ceux qui méritent de justes éloges. On a vu de lui avec plaisir plusieurs portraits, et tous d'une vérité et d'une ressemblance à rendre la nature jalouse de l'art. On a remarqué deux tableaux du même artiste; l'un est un marchand de melon et l'autre, une marchande bouquetière. Ils sont l'un et l'autre d'une riche composition; et l'on a trouvé beaucoup de vérité dans les figures.

M. Montpetit ne devait pas non plus être oublié par l'auteur de la lettre. Cet artiste ajoute à l'habileté de son pinceau l'avantage d'avoir trouvé une manière aussi agréable que nouvelle de s'en servir ; et d'ailleurs, peut-on ne pas se souvenir que cet artiste est l'auteur de l'Allégorie charmante, qui nous peint notre reine dans une rose et ombragée de lys? Rien de plus ingénieux, de plus délicat que la manière dont elle est rendue. Ce tableau réunit, dans le temps, tous les suffrages ; et chaque fois qu'on l'a revu, on lui a donné de nouveaux éloges.

\section{«Peinture » (janvier 1775)}

Journal des dames dédié à la reine par $\mathrm{M}^{m e}$ de Montanclos, baronne de Princen, tome I, p. 138-140.

Le désir de retracer, aux yeux de la postérité, l'image d'une reine qui fait le bonheur de son peuple et le charme de tous ceux qui la voient excite de plus en plus les artistes de cette capitale. Dans le nombre des habiles peintres qui ont fait le portrait de cette auguste souveraine, on doit citer, avec éloge, l'auteur du tableau qui vient d'être présenté au roi.

11 M. de Lorges, jeune artiste, semble avoir épuisé son art, pour donner à la figure de la reine toute la ressemblance que les yeux et les cœurs y cherchent. Cette princesse est représentée en pied, de grandeur naturelle et en chasseresse. Le costume est des plus élégants. Sa draperie est de satin bleu, bordée de peau de tigre, recouverte d'une espèce de soubreveste de satin blanc, aussi bordée de peau de tigre; les plis de cette draperie sont jetés avec beaucoup d'art et de goût ; la touche est largement faite.

L'ordonnance de la composition est simple ; mais la pose de la figure est noble et légère.

Cette intéressante chasseresse paraît sortir d'une forêt, que l'on aperçoit dans le fond, et rentrer dans un jardin désigné par des arbustes entourés de roses. Elle semble donner des ordres pour aller prendre son gibier. L'attitude, la forme et le coloris de ses bras sont de la plus grande beauté. Il règne généralement dans ce tableau une harmonie douce, qui fixe les regards. La manière de peindre de $\mathrm{M}$. de Lorges est précisément celle qui doit être mise en usage, lorsqu'il s'agit d'offrir aux yeux, par la magie du pinceau, la fraîcheur, le transparent et les grâces d'une jeune beauté. On ne saurait trop inviter cet artiste à se faire de plus en plus connaître par des productions de même genre que celle qui vient de lui mériter les suffrages de plusieurs académiciens, et de tous ceux qui ont vu le portrait de la reine, son dernier ouvrage. 


\section{« Gravures » (janvier 1775)}

Journal des dames dédié à la reine par $\mathrm{M}^{m e}$ de Montanclos, baronne de Princen, tome I,

p. 141-144.

14 M. Petit, marchand, rue du [illisible] ont, à Paris, a eu l'honneur de [présen]ter à Leurs Majestés et à la famille [royale] deux estampes gravées par M. Le Mire, fameux artiste, et dessinées par M. Moreau, également célèbre dans son art. [L'obj]et de ces gravures est une allégorie [relati]ve à l'avènement de Louis XVI au [trône]. Le médaillon du roi est soutenu par la Justice : la Sagesse soulage ses peu[rs] par des bienfaits que répand l'Abondance. La Vérité réclame ses droits, et est [libé]rée du joug de la fourberie et du [men]songe, qui paraissent rentrer dans [les a]bîmes du crime. Dans l'autre estampe, qui fait pendant de cette première, le médaillon de la reine [est] soutenu par [la B]onté et la Tendresse, caractérisée par le pélican qui ouvre son sein pour nourrir ses petits. Les trois Grâces ornent de fleurs le médaillon : au bas est la France, qui présente à la reine un peuple immense sous la forme de jeunes enfants qui reconnaissent leur mère. Plus bas sont la Poésie et la Peinture, qui s'empressent d'immortaliser les vertus de notre souveraine.

L'idée de ces allégories est prise dans l'esprit de tous les Français, qui chérissent et respectent les vertus de notre jeune roi et celles de son auguste épouse, mais la manière dont cette idée est rendue fait le plus grand honneur au dessin de M. Moreau et au burin délicat et hard[i] de M. Le Mire. Le portrait du roi est d'une ressemblance frappante : toutes les figures accessoires ont un caractère de vérité qui les désignerait sans le secours de leurs attributs. La Justice, surtout, porte dans ses traits une vérité noble et imposante. La Vérité est d'une candeur inexprimable. Minerve a une douce majesté, [et l'A]bondance a les contours heureux de la [bo]nté et de la fraîcheur. Auprès du médaillon de la reine, on voit les trois Grâces telles qu'elles sont dépeintes dans le temple de Cnide. Elles forment un groupe charmant et qui ne fait rien perdre de leurs charmes. La France, présentée sous la forme d'une femme couronnée, offre une beauté intéressante. Tous les enfants qu'elle présente ont des caractères différents, et tous très heureux. Il est dommage qu'au milieu de tant de perfections on ne retrouve pas ce que l'on désire le plus, la ressemblance de la reine. Si cet avantage était [four]ni à tout ce que l'on aperçoit de [bea]utés dans ces deux estampes, on [pou]rrait assurer n'avoir rien vu de plus [par]fait dans ce genre.

M. Petit, pour rendre ces gravures [auss]i flatteuses pour le public qu'elles [sont] agréables pour les connaisseurs, a imaginé d'en monter plusieurs en écran; elles sont soutenues par un sceptre dont le manche est de velours, garni de franges d'or. On ne peut sans doute présenter des étrennes plus intéressantes à une nation qui trouve son bonheur à aimer ses souverains.

\section{« La Cruche cassée, conte d'après un tableau de M. Greuze » (janvier 1777)}

Mélanges littéraires ou Journal des dames dédié à la reine par Claude Dorat, tome IV, p. 274-276. Jeune fillette, apprenez à ne jurer de rien; et, surtout ne dites point : je ne casserai jamais ma cruche. Tu me fais trembler, disait Jeanne à la jeune Alix, tu me fais trembler 
toutes les fois que je te vois partir avec ta cruche : prends bien garde, ma fille, rien n'est si fragile. Ne craignez rien, ma bonne mère, dit naïvement Alix, je ne casserai point ma cruche, et la voilà partie.

\section{Jean-Baptiste Greuze, La Cruche cassée}

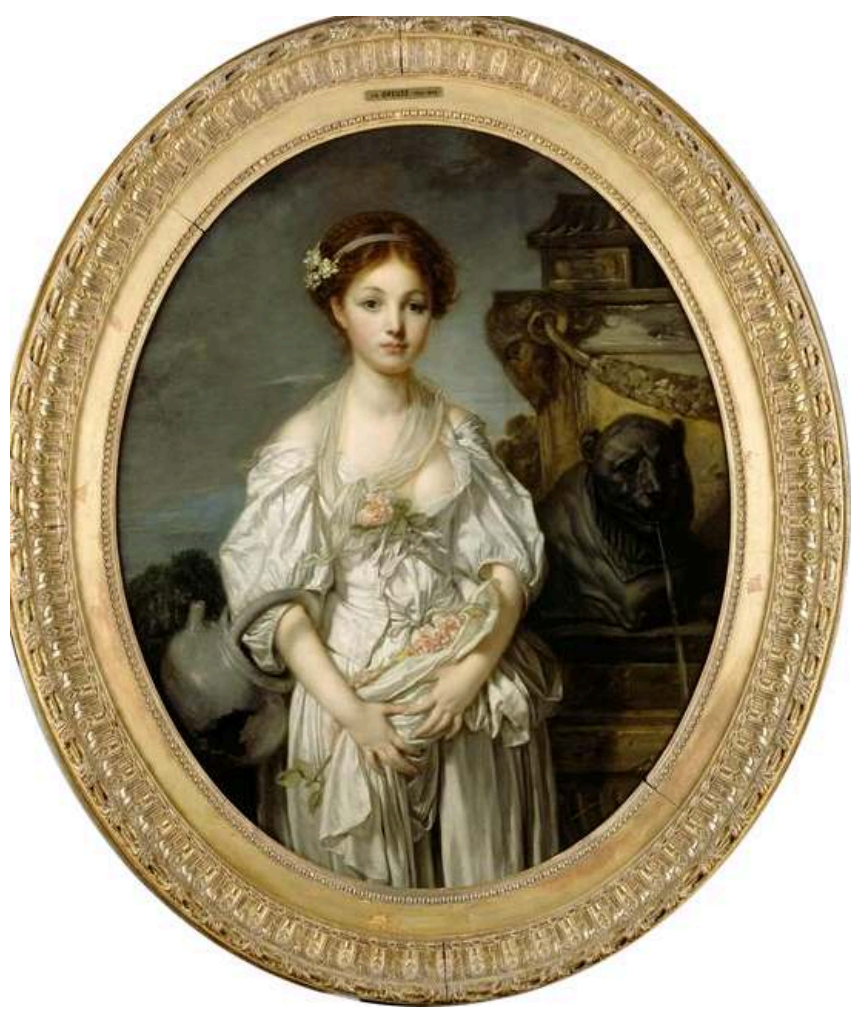

1771, huile sur toile, $109 \times 87$ cm, Paris, musée du Louvre.

Si jeunesse savait !... continue la vieille... Je me souviens encore du jour que je cassai la mienne, il y a pourtant bien des années. Ce jour-là, Thérèse cassa la sienne, et Simonette aussi. Que de cruches cassées dans le monde! Et cette enfant croit conserver la sienne! Toujours dansant, toujours sautant, tantôt sur un pied, puis sur l'autre, voyez comme elle court! Alix, Alix, gare la cruche! Effectivement, Alix, dans la prairie, bondissait comme un jeune agneau. Arrivée à la fontaine, elle remplit sa cruche gaiement en suivant la mesure d'une chanson. Les accents de sa voix font accourir mille oiseaux, car Alix entrait dans un bois ; mais s'il est des oiseaux dans les bois, il est aussi des bergers. Lucas savait qu'Alix devait passer par là ; et tandis qu'elle folâtre, ne voilàt-il pas qu'il paraît? Alix veut fuir, le pied lui manque. Alix, Alix, criait de loin mère Jeanne, la cruche, la cruche! Ah! Le méchant Lucas !... Alix se relève ; mais un corset, flexible au battement de son cœur, en trahit l'agitation. Un bouquet effeuillé, un fichu dérangé, des cheveux en désordre, et surtout, l'étonnement d'Alix, tout dirait que la cruche est cassée, quand le vase fêlé, qu'elle tient à son bras, ne prouverait pas son malheur (fig. 4).

Nota. Ces deux jolis morceaux sont tirés d'un ouvrage intitulé L'Origine des Grâces, par $\mathrm{M}^{\text {lle }} \mathrm{de}^{* * *}$; ce sont elles qui, dans beaucoup d'endroits, ont conduit la plume de l'auteur. Cette agréable collection de pièces érotiques est enrichie d'estampes charmantes, dessinées par M. Cochin le fils et gravées par M. de Saint-Aubin, deux artistes distingués par leurs talents et leurs succès. Je ne doute pas que le public 
n'accueille une production que tous les arts se sont empressés d'embellir et qui réunit la chaleur du sentiment au charme de la volupté.

\section{ANNEXES}

Lire l'introduction à $\mathrm{M}^{\mathrm{me}}$ de Montanclos écrite par Amandine Gorse 
Caroline Wuiet (1766 - 1835) 


\title{
Introduction
}

\author{
Amandine Gorse
}

1 Enfant prodige, Caroline Wuiet bénéficia, dès l'âge de cinq ans, d'une instruction approfondie grâce à la protection de la Dauphine. Elle apprit plusieurs langues, étudia la littérature sous la houlette de Pierre-Augustin Caron de Beaumarchais et de CharlesAlbert Demoutier, perfectionna sa pratique de la musique grâce à Grétry et s'initia à la peinture auprès de Jean-Baptiste Greuze. Très vite, elle montra d'étonnantes aptitudes et sa carrière fut lancée en 1778 avec la publication de ses premiers écrits.

Elle entama ensuite une longue période de voyages qui la menèrent notamment en Allemagne et en Italie, où elle fut reçue membre de l'Académie des Arcades, puis s'installa de nouveau en France sous la Terreur. Profitant des événements de Thermidor, elle sut imposer sa personnalité courageuse au sein des salons de $\mathrm{M}^{\mathrm{me}}$ Tallien, ce qui lui valut le surnom de «Lionne du Directoire » (SOUVESTRE 1859, p. 4 et 21). C'est dans ce contexte qu'elle créa en février 1798 son premier journal : Le Cercle. Seuls soixante-douze numéros parurent puisqu'il fut supprimé par un acte du Directoire le 8 Germinal an VI (28 mars 1798) en raison de ses opinions politiques trop vives (sULleRot 1966, p. 75). Affectée par cette décision, Caroline Wuiet décida de s'adresser à toutes les femmes, quelle que soit leur condition, et publia Le Papillon ou Journal des arts et des plaisirs du 7 thermidor au 21 fructidor de l'an VI (25 juillet-7 septembre 1798). Pourtant, elle ne put s'empêcher de critiquer de manière virulente les parvenues issues des nouvelles classes bourgeoises (SOUVESTRE 1859, p. 56). Cette liberté d'expression lui coûta d'être censurée à la suite de plaintes portées par ses lectrices. Mais, tenace, elle fonda le 27 fructidor an VI (13 septembre 1798) un troisième journal, Le Phénix, qui portait comme sous-titre Je renais de ma cendre. Il fut également supprimé le 14 ventôse an VII (4 mars 1799). Enfin, le manque d'abonnés eut raison de son dernier périodique, La Mouche, journal des grâces, publié entre le $1^{\mathrm{er}}$ vendémiaire et le 15 brumaire de l'an VIII (22 septembre 1799-5 novembre 1799). Parallèlement à son activité de journaliste, elle continua à rédiger des articles pour le Journal des dames et des modes et écrivit des romans comme Ésope au bal de l'opéra et Mémoires de Babioles, avant d'épouser en 1807 un colonel du génie au service du Portugal, le baron Auffdiener.

3 Dénonçant l'assignation de la femme dans les magazines de modes à un rôle de consommatrice, elle souhaitait publier un quotidien qui témoignât de son expérience 
professionnelle en tant que femme, considérant son activité de journaliste comme un métier à part entière. Dans Le Papillon et Le Phénix, elle signa neuf promenades qui relataient ses impressions sur les œuvres d'art admirées au Salon de 1798. Ce choix lui permettait à la fois d'évoquer ses déambulations physiques dans les salles d'exposition du Salon et de s'inscrire, à l'instar des premiers critiques d'art du xvIII siècle, dans un genre littéraire identifié, propre à restituer sa réception très personnelle des œuvres. Dans ses textes, Caroline Wuiet évoquait davantage ses émotions qu'elle ne rendait compte des pièces exposées par la description ou l'analyse formelle.

Malgré ses combats et son talent incontesté pour l'écriture, musicale et littéraire, le XIX ${ }^{e}$ siècle n'a retenu de sa production que quelques chansonnettes. À l'exception des Drames parisiens d'Émile Souvestre ( SOUVESTRE 1859, p.4-104), peu d'ouvrages mentionnent l'existence de Caroline Wuiet. Fortunée Briquet (BRIQUET 1804, p. 206) lui consacra une courte notice dans son Dictionnaire de 1804, tout comme l'abbé E.-J. C*** (C*** 1876) et François-Joseph Fétis (FÉTIS 1881-1889). Son travail en tant que critique d'art reste encore à étudier de manière approfondie. Les articles à venir de Heather Belnap Jensen permettront de faire le point sur la personnalité étonnante de cette féministe aristocrate.

\section{BIBLIOGRAPHIE}

BRIQUET 1804

Fortunée Briquet, Dictionnaire historique, littéraire et bibliographique des Françaises et des étrangères naturalisées en France connues par leurs écrits, ou par la protection qu'elles ont accordée aux gens de lettres..., Paris, Treuttel et Würtz, an XII-1804.

$C^{* * *} 1876$

Abbé E.-J. C ${ }^{* * *}$, Histoire des Enfants célèbres, Limoges, E. Ardant, 1876.

FÉTIS 1881-1889

François Joseph Fétis, Biographie universelle des musiciens et bibliographie générale de la musique, Paris, Firmint-Didot, 10 tomes, $2^{\mathrm{e}}$ éd., 1881-1889.

JENSEN [à paraître]

Heather Belnap Jensen, « Caroline Wuiet », dans Antoinette Fouque, Mireille Calle-Gruber et Béatrice Didier (éd.), Dictionnaire des femmes créatrices, Paris, Éditions des femmes (à paraître).

JENSEN [à paraître]

Heather Belnap Jensen, “'C.W., académicienne': Caroline Wuiet and the Woman Art Critic in PostRevolutionary France", dans Wendelin Guentner (éd.), Vanishing Acts: Women Art Critics in Nineteenth-Century France, Newark, University of Delaware (à paraître).

SOUVESTRE 1859

Émile Souvestre, Les Drames parisiens, Paris, Michel-Lévy frères, 1859, p. 4-104. 
SULLEROT 1966

Évelyne Sullerot, Histoire de la presse féminine en France des origines à 1848, préf. de Jacques Godechot, Paris, Armand Colin, 1966.

\section{ANNEXES}

Diaporama des tableaux commentés par Caroline de Wuiet dans les journaux Le Papillon et Le Phénix:

http://www.flickr.com//photos/73632227@N02/sets/72157629596051973/show/

Lire les extraits d'articles de Caroline Wuiet parus dans Le Papillon

Lire les extraits d'articles de Caroline Wuiet parus dans Le Phénix

Liste complète des œuvres d'arts commentées par Caroline de Wuiet à travers ses textes édités dans Plumes et pinceaux 


\section{Caroline Wuiet, Le Papillon, an VI}

[extraits choisis]

\section{« Première promenade au Salon de peinture » (7 thermidor an $\mathrm{VI}$ )}

Le Papillon, Journal des arts et des plaisirs, $\mathrm{n}^{\circ} 1$,

p. 5-6.

1 Quel est ce jeune adolescent qui caresse une jeune vierge ? C'est l'Amour. Ne voyezvous pas, à travers la volupté qui parcourt ses traits, ce malicieux regard qui le distingue des autres dieux? Comme l'œil fuit sur ses formes arrondies! Comme il est ramené dans les contours moelleux de ces membres délicats ! Il désire et n'ose désirer : voyez ces doigts légers, comme ils effleurent cette épaule d'albâtre! Il est embarrassé d'être heureux, il craint d'effaroucher la pudeur; les femmes trouvent le regard de Psyché plus qu'insignifiant, c'est celui de l'Innocence étonnée ; elle réfléchit au plaisir qu'elle éprouve, à la pression voluptueuse de deux bras caressants; elle ne se livre point encore, elle s'interroge. Que le voile qui la couvre est aérien! On serait fâché qu'il pût se détacher, il semble que les grâces qu'il recèle pourraient s'évaporer; je ne sais, mais cette Psyché doit ressembler à la femme qu'on a le mieux aimée, comme on doit retrouver dans son amant quelques-uns des traits de celui qu'on n'ose nommer. Gérard n'a point fait un tableau; il n'a point réuni des couleurs sur un froid tissu : ces deux adolescents sont descendus du ciel pour donner des leçons de volupté aux mortels. Il ne faut pas les regarder trop longtemps. Allons voir le citoyen Roche. Ô citoyen Roche! Que vous avez l'air d'un homme de bien; votre oisiveté peint le calme de votre conscience ; le repentir n'a point sillonné votre front : on serait tenté de baiser le petit duvet qui le couvre. On dit que cette jolie femme est la citoyenne Simon. Non pas, c'est la citoyenne Lange; ne voyez-vous pas la statue de Thalie? Chut! Le temps effacera l'inscription, et la muse sera tout ce qu'on voudra. 
1. Isabey Jean-Baptiste, Isabey et sa famille, dessiné par lui-même [La Barque d'Isabey]

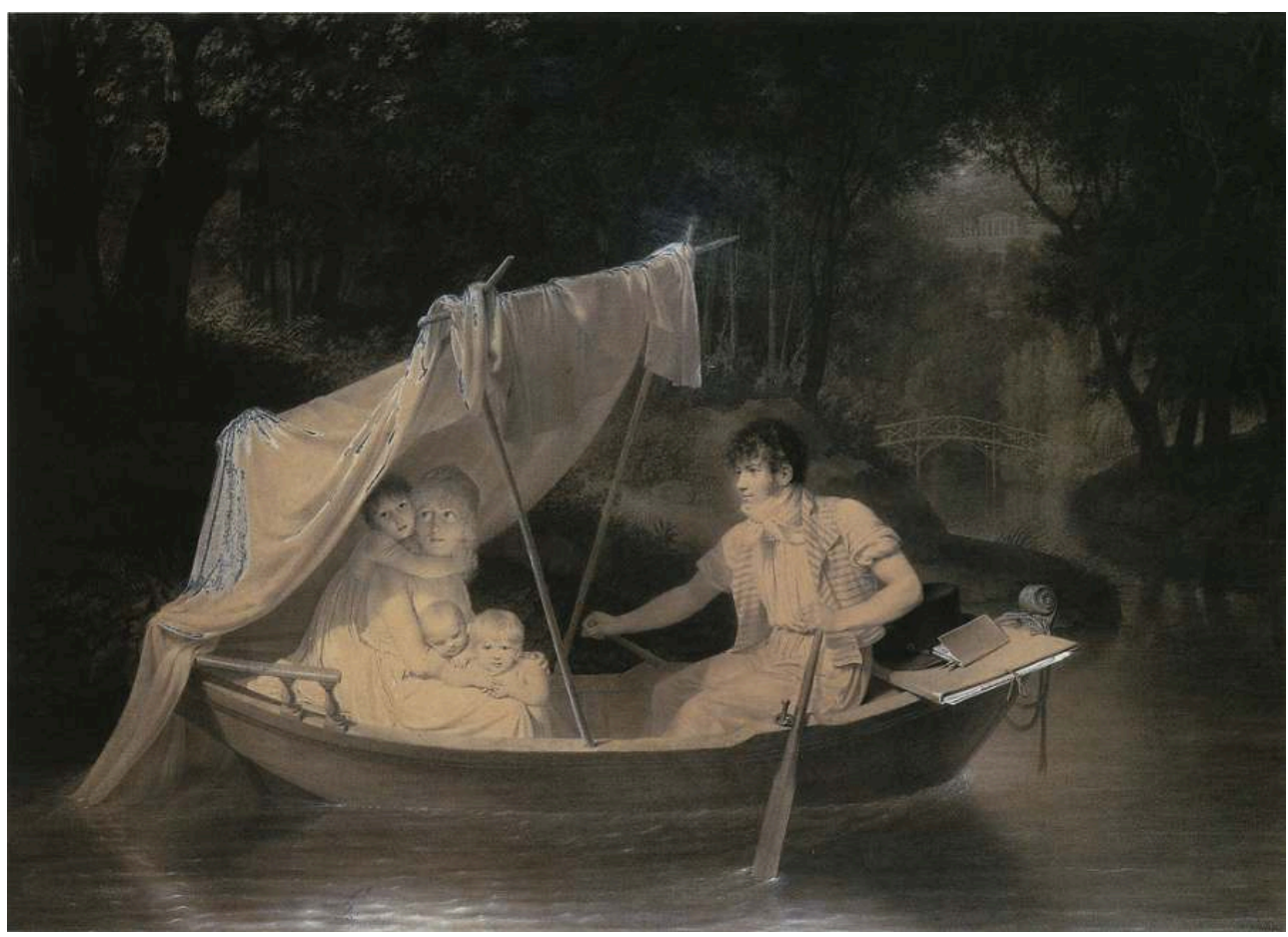

1798, dessin au crayon noir, 64,5 × 87,7 cm, Paris, musée du Louvre.

Arrêtez un moment, Isabey ; vous arriverez toujours assez tôt ; laissez-moi regarder ces jolis enfants : comme ils sont groupés (fig. 1)! Que cette demi-teinte est céleste ! Que ce paysage est frais! Comme le ciel est calme! Comme la terre est en amour! Qu'ils sont limpides, ces flots qui échappent à la rame! Isabey, tu es le secret de la nature, et l'amour de la gloire te fait commettre tous les jours une indiscrétion.

2 Voilà bien des portraits de famille, c'est une promenade aux Champs-Élysées; des artistes? Arrêtons-nous ; Grétri, mon maître, Martini, mon modèle, l'abbé de Lille, mon génie familier, Bernardin de Saint-Pierre, je vous salue tous; vous qui honorez mon pays, vous qui m'avez consolée de vivre, quand il ne me restait plus d'espoir que la mort: je reviendrai demain vous voir, et demain, je parlerai des ombres qui vous entourent.

C. $W . * * *$

\section{« Ma seconde promenade au Salon de peinture » (10 thermidor an $\mathrm{VI}$ )}

Le Papillon, Journal des arts et des plaisirs, $\mathrm{n}^{\circ} 4$,

p. 28-29.

3 Le voilà, ce Jupiter de Myron, que j'ai si souvent admiré dans mes promenades solitaires; pourquoi n'éprouvais-je plus ce sentiment? Pourquoi mon imagination refroidie ne raconte-t-elle plus à ma mémoire ses exploits, ses amours, ses vengeances? Il était au milieu des bois, dans un bosquet préservé des ouragans ; sa tête élevée parmi les rameaux paraissait dominer la terre ; les feuilles, doucement agitées, ombrageaient son front; les oiseaux chantaient pour lui rendre hommage, les papillons voltigeaient, 
s'arrêtaient sur les boucles de ses cheveux; tout paraissait s'animer de son souffle créateur. Maintenant encadré dans un bloc de pierre, ce n'est plus un dieu, ce n'est que du marbre... Pourquoi donc ai-je voulu le revoir? Depuis dix ans je ne m'en étais pas aperçue.

Quel intérêt touchant dans les traits touchants de Vincent de Paule! Qu'il est beau de l'action qu'il vient de faire! Combien de vertus dans ces rides que la piété rend quelquefois si sévères! Le reproche qu'on lui fait de trop presser l'enfant est, suivant moi, un rayon de génie ; il se défie de son adresse, il emploie la force pour le retenir ; rien est-il plus dans la nature! Le manteau n'est pas drapé ? Plus il presse les formes, plus on sent qu'il fait froid. L'enfant mort est bien mort, l'agonie ne l'a point défiguré, il n'a fait que cesser de vivre. Ce Vincent de Paule fera autant d'honneur au citoyen Stouf que le modèle a fait d'honneur à l'humanité.

C. $W . * *$

\section{«Troisième promenade au Salon de peinture » (11 thermidor an $\mathrm{VI}$ )}

Le Papillon, Journal des arts et des plaisirs, $n^{\circ} 5$,

p. 37-38.

5 J'ai longtemps combattu contre le désir de parler des ouvrages de mon sexe : c'est soulever contre moi tous les philosophes qui ne reconnaissent que l'homme dans la nature et renient Dieu dès qu'on veut leur prouver l'existence morale de la femme.

\section{Adélaïde Labille-Guiard, Portrait du peintre François-André Vincent}

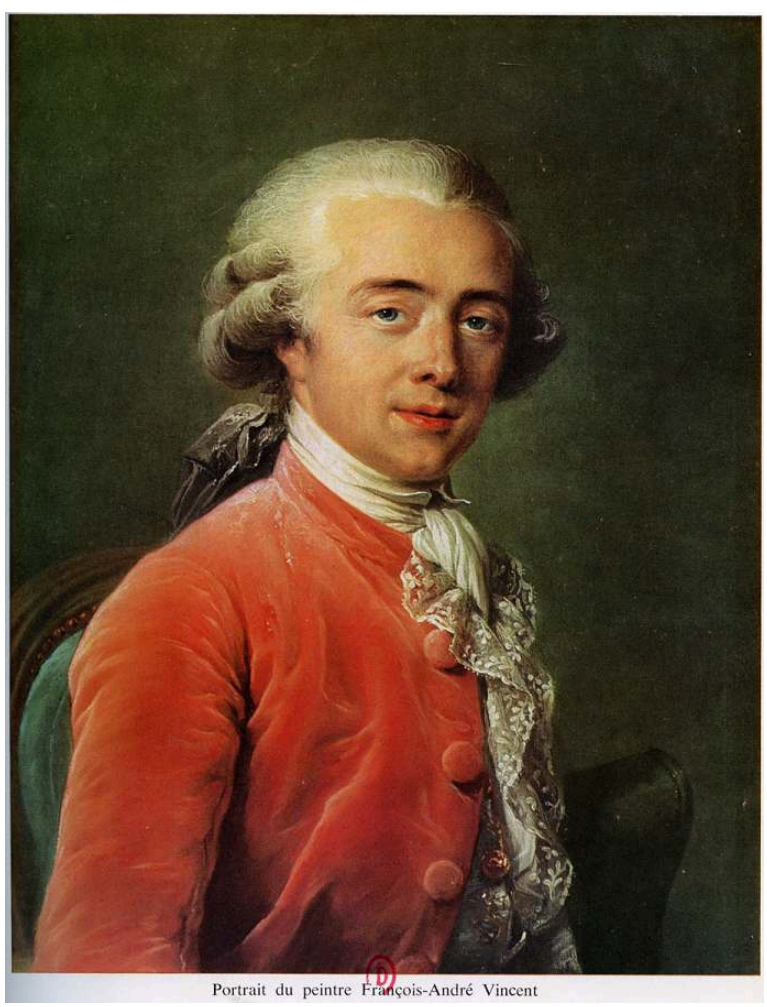

1782, pastel, 60,8 × 50 cm Paris, musée du Louvre. 
Mais voilà des portraits de la citoyenne Guiard (fig. 2) ; voilà une Hébé de la citoyenne Huin; ces fleurs viennent d'éclore sous les pinceaux de la citoyenne Coster; ce joli homme est venu se placer sous les crayons de la citoyenne Morin; une jeune Frescatane, animant l'amour des charmes de la mélodie, doit le jour à la citoyenne Lemoine; et ces paysannes de Terracine?... Vous voudriez bien, messieurs les incrédules, en être les créateurs; mais sans vous, et malgré vous, ces jolis enfants passeront à la postérité avec le nom de leur mère. J'en aurais encore d'autres à nommer, qui rivalisent avec nos génies; mais ce n'est pas savoir louer que d'intimider la modestie.

\section{Horace Vernet, Fidélité des hussards français}

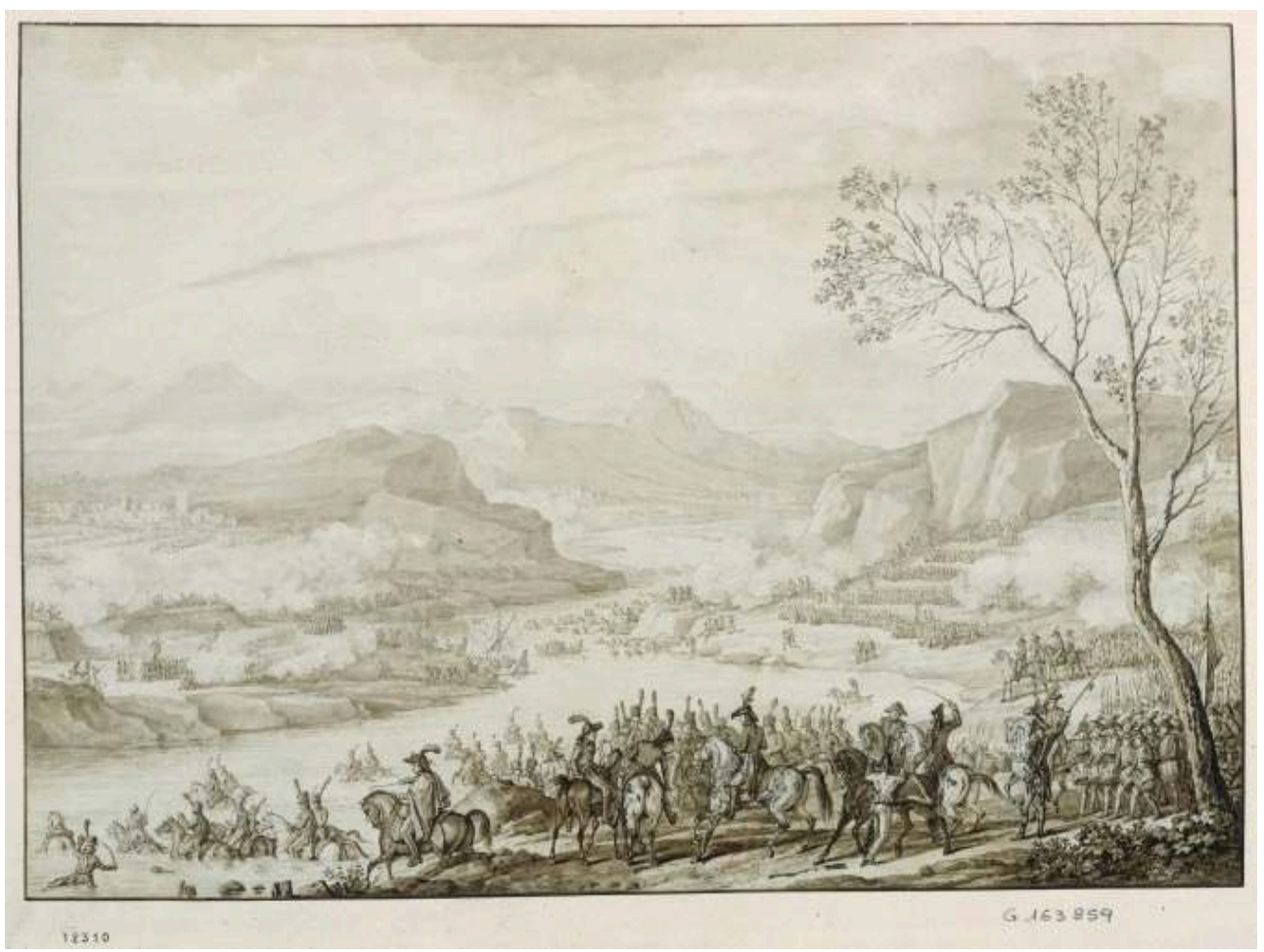

1798, dessin.

Passons aux beaux dessins de Vernet, à ce tableau si varié, si bien composé, des hussards de Berchini (fig. 3), à ce cours si précieux d'équitation, à cette Amazone... Pourquoi n'a-t-elle pas les grâces de son coursier? Le jeune peintre aimerait-il mieux les chevaux que les jeunes femmes ?... Ce serait dommage, il les ferait si jolies !... Quelle sublime composition! Que ces beautés agrestes sont effrayantes! Ces rochers dépouillés touchent aux nues; ce torrent précipité d'abîmes en abîmes fatigue les échos de ses longs mugissements; ses vagues blanchies d'écumes vont engloutir ce superbe coursier; il est porté par la terreur; les rugissements des lions retentissent dans ses flans ; il fuit la mort, et la mort ne peut l'atteindre... Je mesure l'espace, je ne respire plus, je crains, j'espère... Vernet, j'ai voulu t'admirer trop longtemps ; je m'en vais, le cœur pressé. 


\title{
« Ma quatrième promenade au musée des Arts » (17 thermidor an $\mathrm{VI}$ )
}

\author{
Le Papillon, Journal des arts et des plaisirs, $\mathrm{n}^{\circ} 11$, \\ p. 84-85.
}

7 Ce pauvre vieillard! Qui ne serait tenté de lui donner l'aumône! Il ne demande pas, il espère; les sons de sa vielle n'ont pas besoin d'être mélodieux, ils sont tristes et touchants; trois enfants le regardent avec intérêt; le plus jeune écoute, l'ainé s'attendrit et le tout petit vient d'oublier ses cerises, car son attention ne peut être partagée. Le bon chien, l'ami du malheureux, est là ; vieux et modeste comme son maître, il ne tourmente pas la pitié, il se repose et l'attend; groupe intéressant, rappelez l'amour de l'humanité dans les cœurs froids qui le repoussent, et le citoyen Liancourt n'aura plus rien à faire pour sa gloire.

8 Je l'ai bien lu dans mon livret; ce grand tableau, si long, si noir, c'est Pâris s'arrachant des bras d'Hélène; je ne me pardonnerai jamais l'écart de mon imagination; oser prendre la fille de Tindare pour une Flamande enfumée, le beau Troyen pour un tapageur, et le palais de Priam pour une tabagie. David! C'est ta faute, l'image enchanteresse de tes voluptueux amants est encore présente à ma pensée; je les vois parés de toutes les grâces de la nature, de tous les charmes de ton imagination; je souris à leurs plaisirs, je m'identifie à leur être, je me sens transportée sous ses murs qui servent d'égide à leur coupable ivresse... Détournons-nous, ce tableau trouble ma douce rêverie ; cherchons Homère, il ramènera l'illusion. Voilà des chiens, un berger, une femme qu'on croit attentive, un buste de carton sur un corps inanimé... C'est là ce vieillard qui chanta les dieux dans leur langue, qui survécut à la Grèce pour en faire la honte et l'honneur, naquit ignoré, qui mourut sans gloire ?... Eh non, c'est l'Homère du Pâris qui est ici, il fallait bien en faire un tout exprès, pour ne pas les dépareiller. ${ }_{20}$ Qu'il est joli ce buste! Et qu'il est modeste ! Est-ce Hébé ? Est-ce la pudeur? Je ne sais, mais assurément en le modelant, le sculpteur Chinard pensait à la citoyenne Récam[ier] ... Si cette remarque est indiscrète, la faute en est aux dieux qui la firent si jolie.

C. $W . * * *$

\section{« Ma cinquième promenade au musée des Arts » (21 thermidor an $\mathrm{VI}$ )}

Le Papillon, Journal des arts et des plaisirs, $\mathrm{n}^{\circ} 15$,

p. 117-118.

Vénus, charme de la nature, souveraine des plaisirs, mère de la séduction, des caprices, de la jouissance, toi qui d'une chaîne universelle rapproches tous les cœurs, toi qui donnes un ami à l'indifférence et du sens à la sagesse, Vénus ! Est-ce toi qui m'apparais, pleurant sur le corps d'Endymion? Ces chairs molles et blafardes ont-elles été formées pour l'immortalité ? Ce linge froissé a-t-il jamais recelé les tourments et la volupté ? Cette draperie grossière pouvait-elle effleurer tes épaules d'albâtre sans les déchirer? Ce paysage enfumé ne respire point de ta vie; cette rose qui paraît se flétrir de honte devait naître sous tes pas, et non sous tes ronces, ce petit Endymion, si jaune, si mesquin, qui meurt de si mauvaise grâce, a respiré l'ambroisie sur tes lèvres, a conçu l'immortalité dans tes bras. ô blasphème! Qui doit attirer toutes tes vengeances sur la 
tête du peintre coupable, nos mortelles peuvent se profaner! Mais, après les dieux, Vénus ne doit choisir que leur chef-d'œuvre. S'il est vrai que les hommes ont toujours fait les divinités à leur image, le créateur de ce tableau n'a pas été gâté par elles ; mais qu'importe? Il leur rend bien, et tout est pour le mieux.

\section{Pierre Maximilien Delafontaine, Le Patineur (portrait du graveur Jean Bertrand Andrieu)}

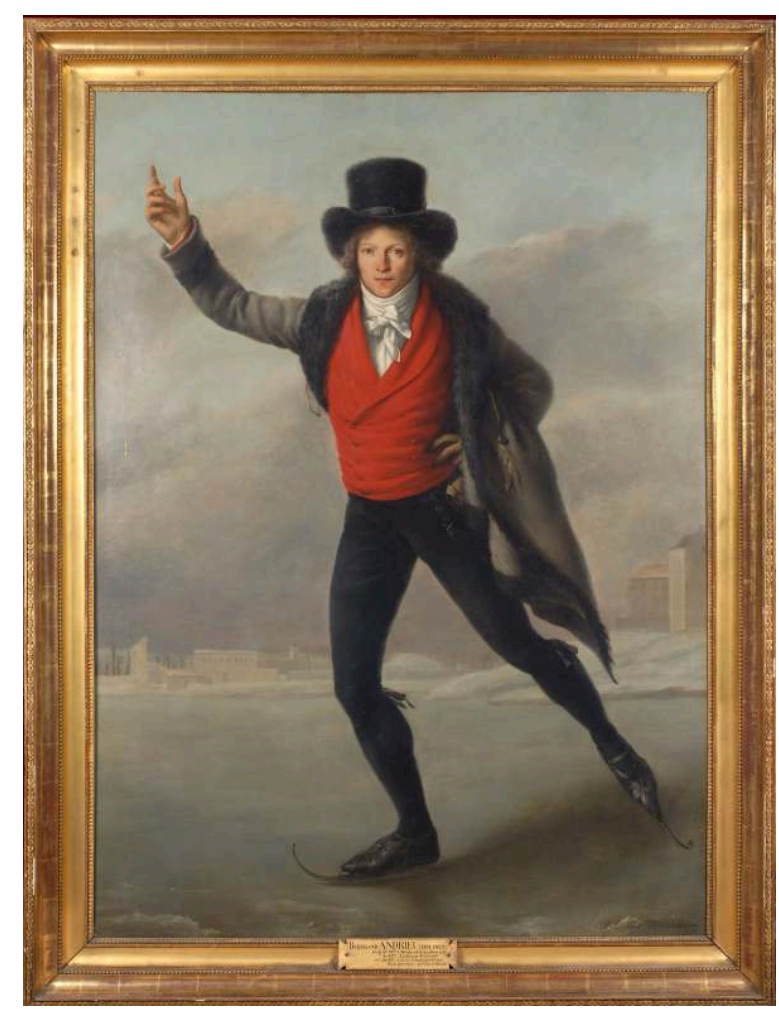

1798, huile sur toile, $179 \times 130 \mathrm{~cm}$, Paris, musée de la Monnaie.

Qu'il est bien ce patineur (fig. 4)! Que sa position est naturelle! Comme il fend l'air ! Tout a froid autour de lui ; les frimas l'environnent; ses habits sont couverts de cette neige aérienne qu'on respire pendant l'hiver. Je voudrais voir les traces de ses patins sur la glace; l'illusion serait plus complète. Le citoyen Delafontaine l'a sans doute oubliée pour laisser une remarque à faire ; c'est une mouche sur les belles formes de Vénus callipyge. Puisque j'ai froid, je veux revoir ce paysage du citoyen Coste ; je veux admirer cette porcelaine échappée aux innovations de la mode : ô comme il a bien saisi la pâture à l'agonie! Ces arbres dépouillés, ce ciel sans chaleur, cette terre sans amour ! On entend tourbillonner le vent du nord; on voit les flocons de neige se détacher des montagnes; le bûcheron veut travailler, et sa poignée va s'échapper de ses doigts engourdis... ! Après ce tableau, il faut voir son clair de lune ; le sommeil de la terre ; la douce mélancolie qu'il a répandue sur elle. Astres des êtres sensibles! Je t'ai salué de cœur et de pensées! Tu m'as rendu des souvenirs ; tu as entrouvert le petit livret de ma vie ; j'ai senti une larme brûlante sillonner mes joues! Était-ce d'ivresse ? Était-ce de regret? Je me suis retournée ; les portraits du citoyen Leguay étaient là. Je les ai fixés pour distraire mon imagination, pour la ramener aux douces émotions du présent. Qu'ils sont bien dessinés! Qu'ils sont délicieusement peints! Comme l'admiration suit heureusement toutes ces formes arrondies! J'aurais besoin de tout détailler depuis les ongles jusqu'aux cheveux livrés aux zéphyrs; mais j'ai là, sur mon sein, un petit 
portrait fait par lui, et je ne répondrais pas d'être impartiale dans mes éloges - la reconnaissance a son exaltation comme l'amour.

C. $W^{* * *}$, académicienne

\section{« Ma sixième promenade au musée des Arts » (8 fructidor an VI)}

Le Papillon, Journal des arts et des plaisirs, $\mathrm{n}^{\circ} 32$,

p. 252-253.

11 C'est parce que j'estime votre modestie et vos talents, citoyen Monsiau, que je vais être sans indulgence. Je ne vous parlerai point en peintre, mais en poète qui a étudié l'antique ; je respecterai vos pinceaux et ne tourmenterai que votre génie.

\section{Nicolas André Monsiau, Zeuxis choisissant des modèles}

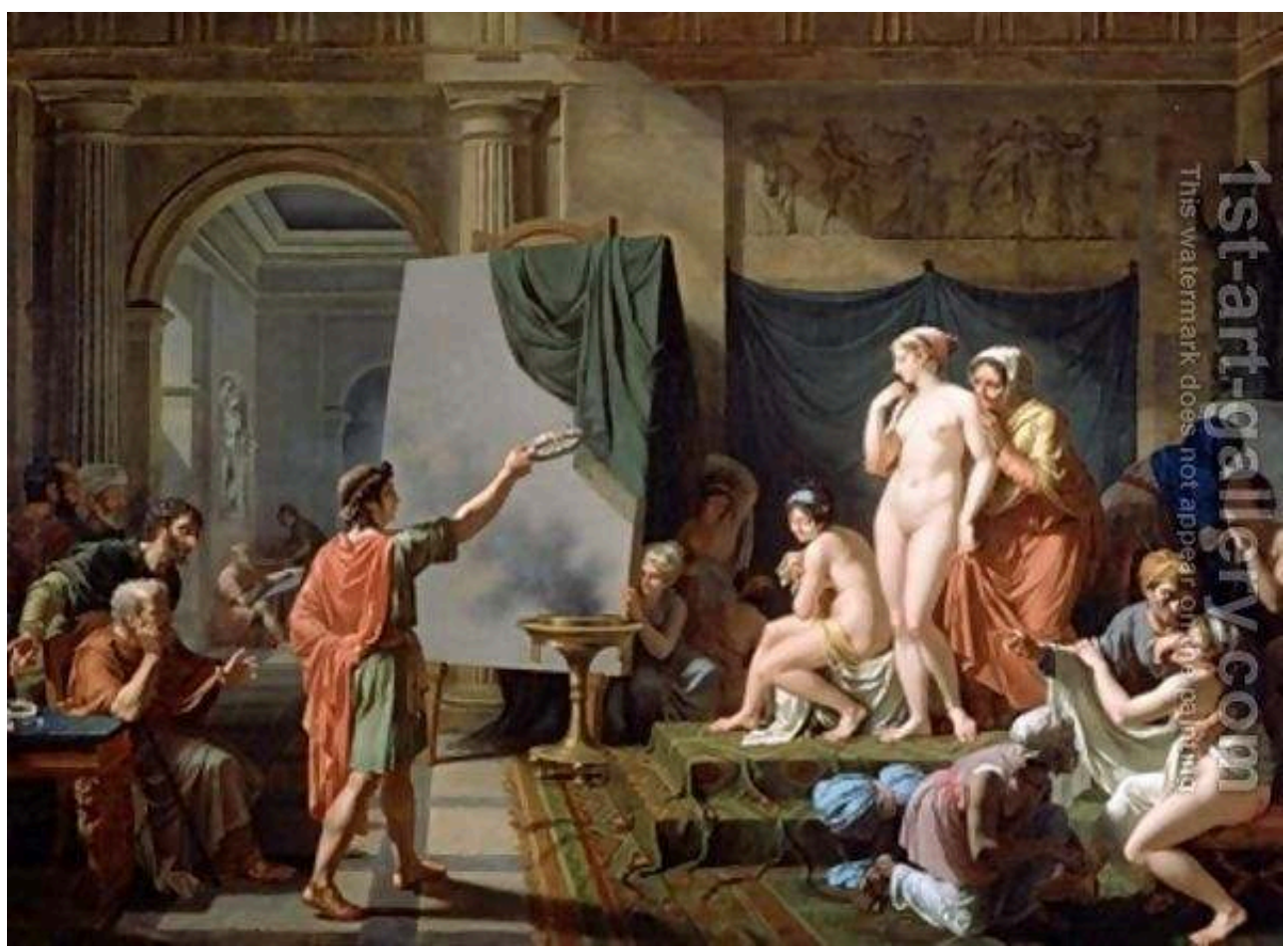

1798, huile sur toile, $96 \times 129$ cm, Toronto, Art Gallery of Ontario. 


\section{Nicolas André Monsiau, Dessin d'après le tableau de Zeuxis}

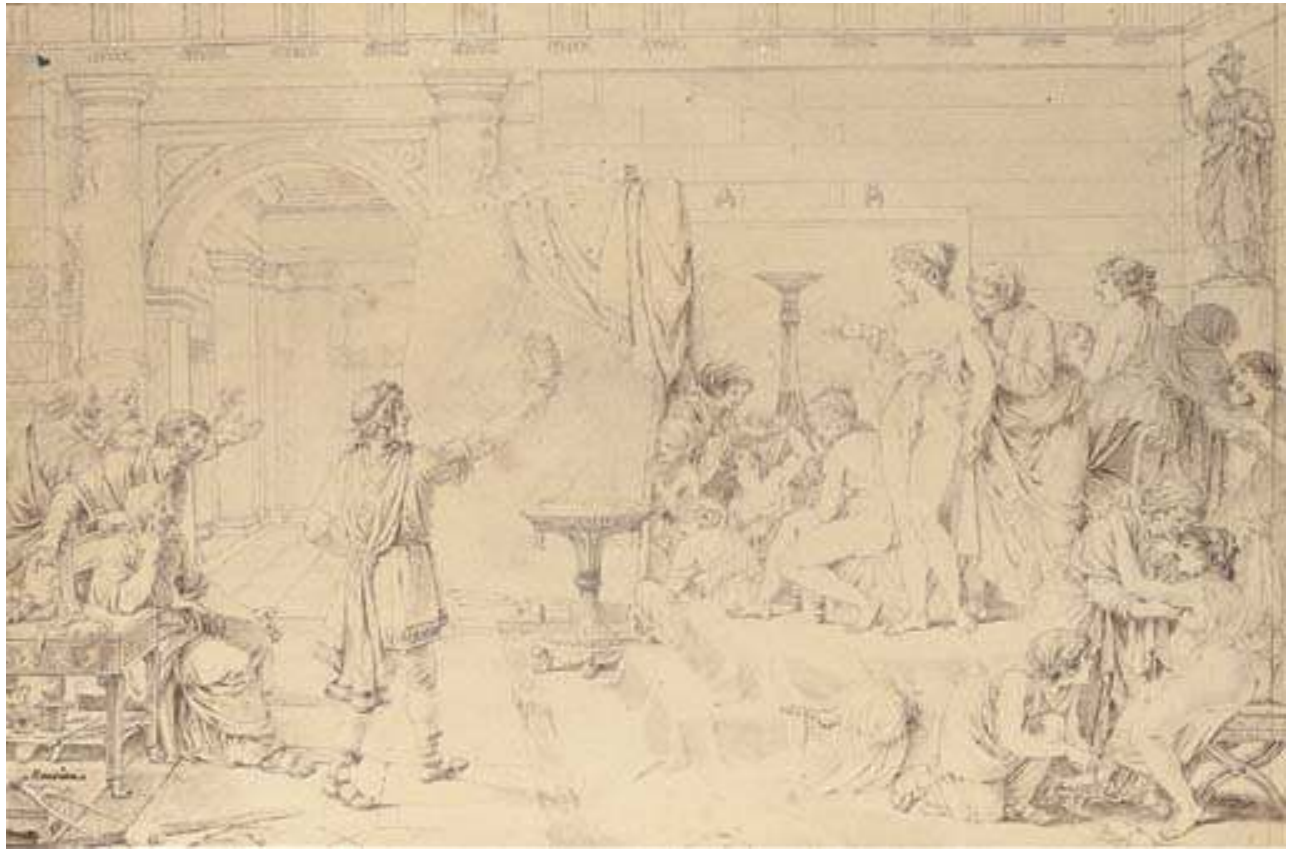

1798, dessin, mine de plomb, plume et encre brune, lavis brun, $26 \times 40 \mathrm{~cm}$, coll. part.

7. Nicolas André Monsiau, Socrate et Alcibiade chez Aspasie [Aspasie s'entretenant avec les hommes illustres]

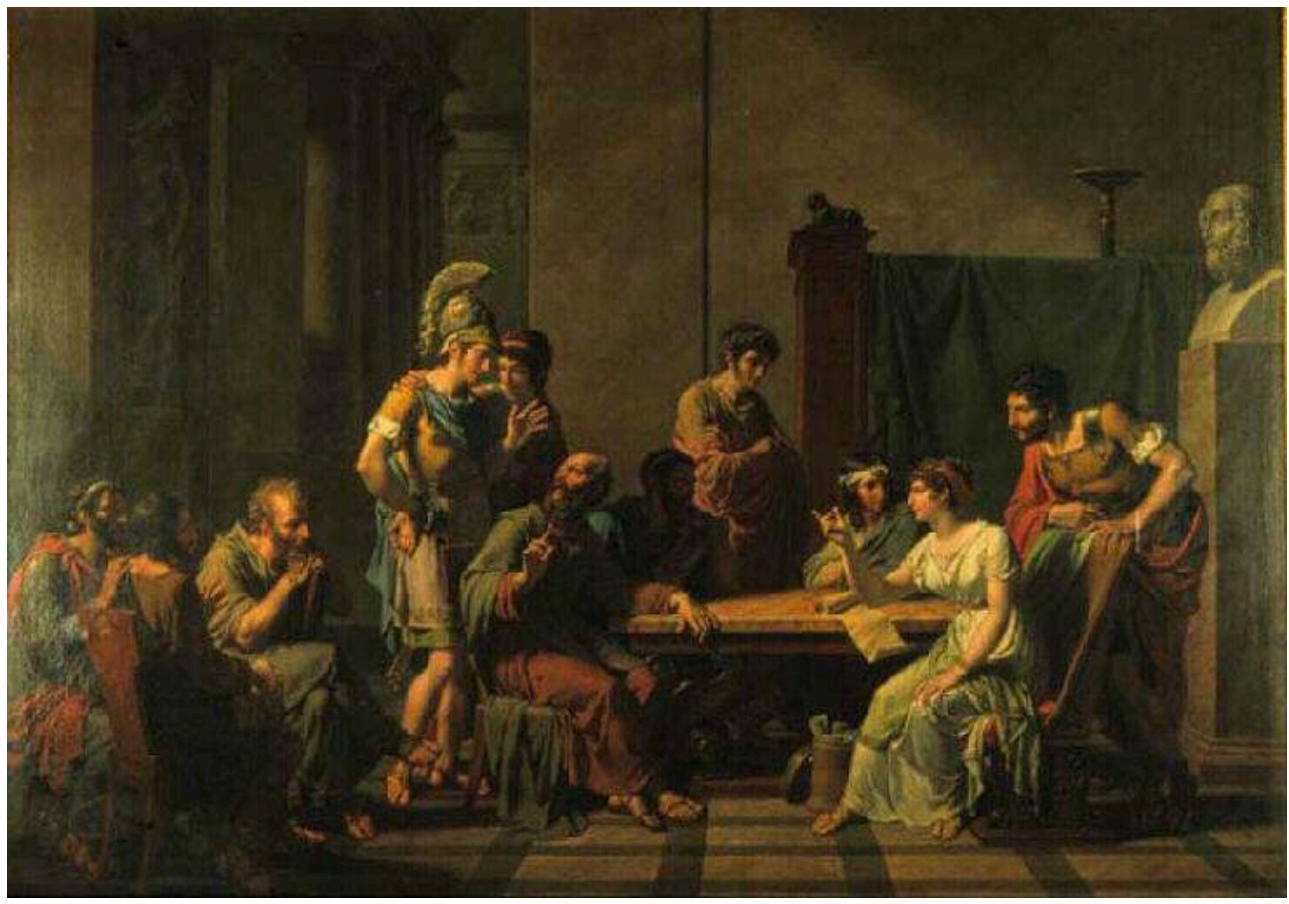

1798, huile sur toile, 146,5 x 106,5cm, Chambéry, musée des Beaux-Arts.

12 Le tableau de Zeuxis est généralement estimé, la composition en est savante, les détails sont pleins de grâce et de modestie, les chairs palpitent, les draperies dessinent, les figures parlent; on pouvait faire aussi bien, mais on ne pouvait faire mieux (fig. 5). Je n'ai vu que son dessin qui pouvait rivaliser avec lui, et peut-être cette comparaison lui 
nuirait-elle si la copie pouvait l'emporter sur le modèle (fig. 6) ; mais pourquoi le génie qui vous dictait Zeuxis vous a-t-il abandonné quand vos pinceaux ont cherché les traits d'Aspasie et d'Alcibiade (fig. 7) ? Les auriez-vous conçus dans le boudoir d'une de nos courtisanes, la caricature de la Grèce aurait-elle séduit votre imagination? Élancez votre âme de siècle en siècle; interrogez les fragments échappés à la destruction et déchirez ce tableau ; ce n'est point là ni la maîtresse de Périclès, ni son enfant adoptif ; la tête de Socrate est bien, sa position est naturelle ; mais pourquoi ce vieux manteau qui peint la misère et non la philosophie ? Diogène ou Timon auraient pu s'en affubler ; Socrate n'affectait point cette dégoûtante misanthropie qui naît de l'orgueil et répugne à la modestie : c'était un sage, vous en avez fait un cynique, et certes, rien ne se ressemble moins. Au moment où vous peignez Alcibiade, ce n'était point encore un héros, mais le plus fastueux des Grecs. Pourquoi donc ce casque lourd et mesquin ? Il ne va point combattre, il est près d'une femme qu'il aime ardemment; couronnez-le de lauriers, si vous voulez présager sa gloire. Le laurier sied aux amants et n'effarouche pas les amours. Aspasie, aussi voluptueuse que savante, était la Ninon de la Grèce, sa beauté, son luxe, sa coquetterie, tout lui servait d'éloquence ; elle étonnait les savantes, elle entraînait les sages, elle séduisait les sybarites, ses principes dirigeaient toutes les opinions politiques, parce que rien ne résiste à l'esprit qui prend le chemin du cœur. J'aurais donc voulu qu'Aspasie fût environnée de tout le luxe athénien, que sa tête, à moitié voilée, fût couverte des trésors de l'Afrique, que ses draperies eussent été tissées par les Tyriens, que sa tunique ondoyante eût été attachée sur son épaule d'ivoire par une agrafe sémillante: j'aurais voulu plus d'expression dans ses traits, plus de grâce dans toutes ses formes... Écoutez parler Alcibiade dans une lettre que j'ai enlevée au néant, elle vous donnera mieux que moi la mesure de leur existence à Athènes. [...].

C. W. ${ }^{* * *}$, académicienne

\section{ANNEXES}

Lire les extraits d'articles de Caroline Wuiet parus dans Le Phénix

Lire l'introduction à Caroline Wuiet écrite par Amandine Gorse 


\section{Caroline Wuiet, Le Phénix, an VI et VII}

[extraits choisis]

\section{« Théâtre Richelieu » (8 fructidor an VI)}

Si je parlais de la salle de Richelieu en artiste, je dirais que les loges m'ont paru écrasées, que l'ordre toscan a peu de noblesse, l'ordre corinthien peu de grâce; que le cintre de l'avant-scène n'est point assez détaché des colonnes; que la décoration de la voûte est mesquine, que le lustre est sans effet, parce qu'une seule masse de lumière éclaire moins un vaste édifice que des rayons divergeants. Je rappellerais les cirques romains, je chercherais à persuader qu'une rotonde flanquée de loges et d'amphithéâtres vaut mieux pour une salle de spectacle, qu'une église gothique ou un péristyle de temple grec; mais je parle en femme et je crois qu'il n'en est aucune dont la beauté soutienne le reflet fatigant du pinceau. Les théâtres d'Angleterre sont à peu près dans le genre de celui-ci ; mais comme le parquet est la place d'honneur, il importe peu de quelle manière les loges sont décorées. Si on les éclairait de même avec une quantité innombrable de bougies, il serait possible que cette salle fît un très bel effet. Je crois que les architectes devraient toujours sacrifier les ornements à la beauté des femmes et les environner des chefs-d'œuvre de l'art, au lieu de les éclipser par ceux de l'imagination. Si la moitié de Paris court au spectacle pour voir, assurément l'autre moitié n'y va que pour être vue. On doit toujours savoir gré au citoyen Sagerer du zèle qu'il met à justifier l'opinion publique. Ses moyens de succès augmentent de jour en jour, l'envie le désigne encore, mais ne pourra bientôt plus l'atteindre. La République des arts a, comme la nôtre, ses royalistes et ses anarchistes. C'est toujours aux pieds des plus grands arbres que se réunissent les insectes. 


\section{« Ma huitième promenade au musée des Arts " ( ${ }^{\mathrm{er}}$ vendémiaire an VII)}

Le Phénix, $\mathrm{n}^{\circ} 10$,

p. 4-5.

2 Je passais dans la galerie d'Apollon, pour voir La Mort d'Eurydice, et, très distraite, comme c'est assez mon ordinaire, je fredonnais le duo de mon maitre qui commence par Tu me l'paieras, j'en jure; tu me l'paieras, j'en jure, etc. Un éclat de rire trouble ma rêverie, je me retourne, je suis les yeux du rieur, et je les trouve fixés sur le Télémaque se séparant du Mentor en Égypte. Ô comme ma chanson allait bien à ce tableau ! Le joli fils d'Ulysse tout flanqué de membres de rapports menace Métophis qui prend assez bien la plaisanterie ; Mentor, tant soit peu dessiné d'après Saint-Pierre, prêche la paix, et un soldat de cuivre s'impatientant des oraisons porte avec audace une petite main de poupée sur le Télémaque qu'il finit par entraîner. Après avoir assez regardé les mesquines idoles et les grandes momies, je suis allée admirer le couple tant renommé parmi les divinités infernales; Eurydice, piquée par un serpent, meurt dans les bras d'Orphée ; je ne sais si l'expression du jeune époux est naturelle à l'amour ; il me semble que, doutant de son malheur, il pourrait arrêter sur les lèvres d'Eurydice son âme encore fugitive ; sa tête n'a pas assez de douleur, elle ressemble trop à celle de l'Apollon du Belvédère; son corps est purement dessiné. Celui d'Eurydice a tout l'abandon de la mort ; on pourrait désirer quelque chose de plus aérien dans les cheveux ; le paysage ne satisfait pas entièrement l'imagination; mais ce tableau joint de grandes beautés à de petits défauts ; c'est un nuage dans le ciel.

1. Jean-Baptiste François Desoria, Portrait de la citoyenne Pipelet

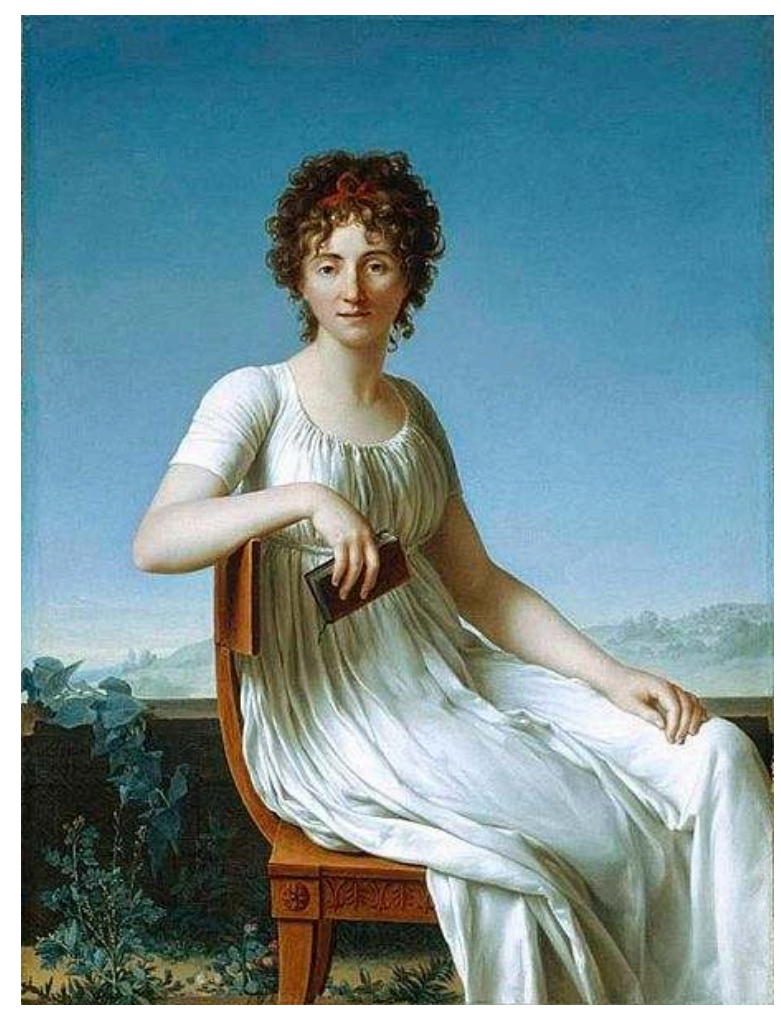

1798, huile sur toile, $130 \times 99,1 \mathrm{~cm}$, Chicago, The Art Institute. 
3 Je n'aime pas les portraits ; il me semble être à la promenade, obligée de saluer à droite, à gauche : je me suis cependant arrêtée sous celui de la citoyenne Saint-Aubin; il est parfait pour la ressemblance; pour l'expression, on ne pourrait le désirer mieux. Pourquoi donc faire un atlas de cette charmante actrice? Le ciel ne peut-il s'élever, les [illisible] hers doivent-ils presser ses épaules délicates ? C'est un reproche à faire au citoyen Bouchet : il a voulu tout sacrifier à son modèle. Je ne sais si la citoyenne Pipelet est ressemblante. J'ai vu des médailles frappées à Mytilène à l'effigie de Sapho, je me rappelais son invocation à Vénus, et les traits s'effaçaient; je ne voyais plus que l'immortalité (fig. 1).

4 Qu'elle est jolie, cette Érigone! Toutes les femmes voudraient lui ressembler, tous les hommes voudraient en rencontrer le modèle; que cet effet de lumière éclaire délicieusement ses formes angéliques, elles n'ont point encore été flétries par l'ivresse ; mais déjà ses doigts délicats pressent Bacchus sous l'épiderme du raisin, et bientôt l'enivrement de ses yeux passera dans son âme. Le ruisseau qui la caresse est d'une volupté poétique. Les draperies sont bien jetées; le corps, et surtout la tête, sont dans une position assez tourmentante ; on ne peut la regarder longtemps sans souffrir ; mais la pensée qui suit son mouvement ramène tout son être dans un état plus naturel; la grappe va devenir Dieu et la fille d'Icarius va connaître l'immortalité. Pourquoi le paysage n'est-il pas plus amoureux ? Ce cep de vigne ne pourrait-il serpenter sur des saules, sur des arbrisseaux en fleurs?

\section{François-André Vincent, L'Agriculture, nommé La Leçon de labourage}

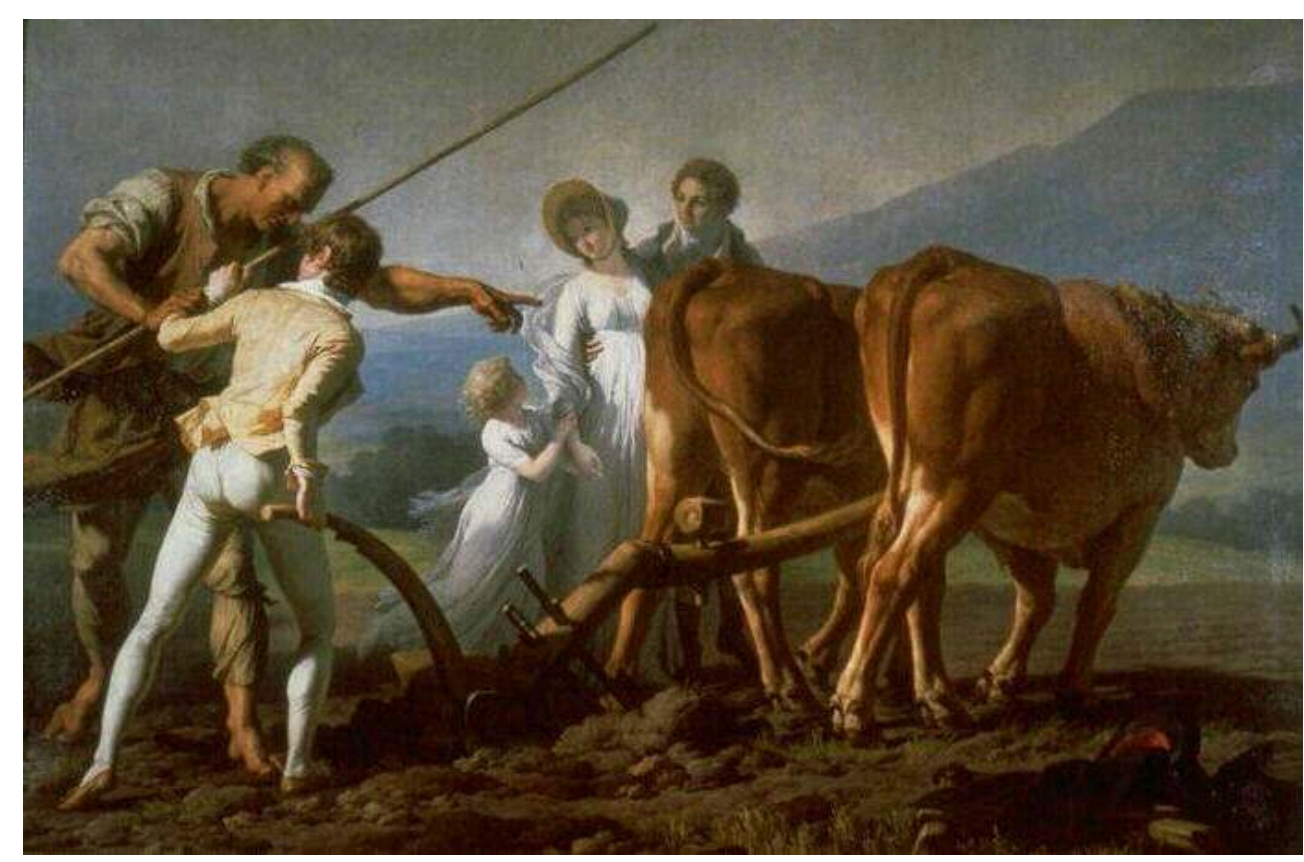

1798, huile sur toile, 213 × 313 cm, Bordeaux, musée des Beaux-Arts.

Le rocher refroidit l'imagination; sa voûte est trop claire; l'échappée de vue ne l'est pas assez : la nature devait s'embellir de l'amour de Bacchus et servir ses désirs par tous ses charmes, par toute sa séduction; l'élève de David aurait trop approché de son maître s'il avait répandu sur la terre la volupté qui est l'essence de son Érigone.

5 J'ai vu le tableau sur l'agriculture; je retournerai au musée avant d'oser prononcer (fig. 2). 


\section{« Ma neuvième promenade au musée des Arts » (7 vendémiaire an VII)}

Le Phénix, $\mathrm{n}^{\circ} 15$,

p. 3-4.

Le tableau de l'agriculture aurait eu le prix en Chine, où le labourage est l'art le plus estimé ; je ne dirai rien de sa composition, des groupes, du mélange, des couleurs. Vincent est un grand maître ; et la critique se tait devant l'immortalité.

Les infortunés qui ont pleuré sur les ronces des tombeaux s'arrêteront devant le tableau du citoyen C... et sentiront la douleur qui l'oppresse, que ses traits sont flétris, que ses yeux ont été brûlés de larmes. Il ne gémit plus; il se tait : son âme dort du sommeil du désespoir. L'adolescent auquel il montre l'urne de sa mère a bien le chagrin de son âge. Son sein est gonflé, son regard est morne ; mais on voit qu'il se consolera : et l'homme qui a perdu sa compagne ne recouvrera jamais son repos ni sa joie. Les draperies sont sévères, comme le sujet. L'échappée de jour est sombre ; la nature est en deuil ; elle pleure avec les infortunés.

3. Guillaume Guillon Lethière, Philoctète dans l'île déserte de Lemnos gravissant les rochers pour avoir un oiseau qu'il a tué

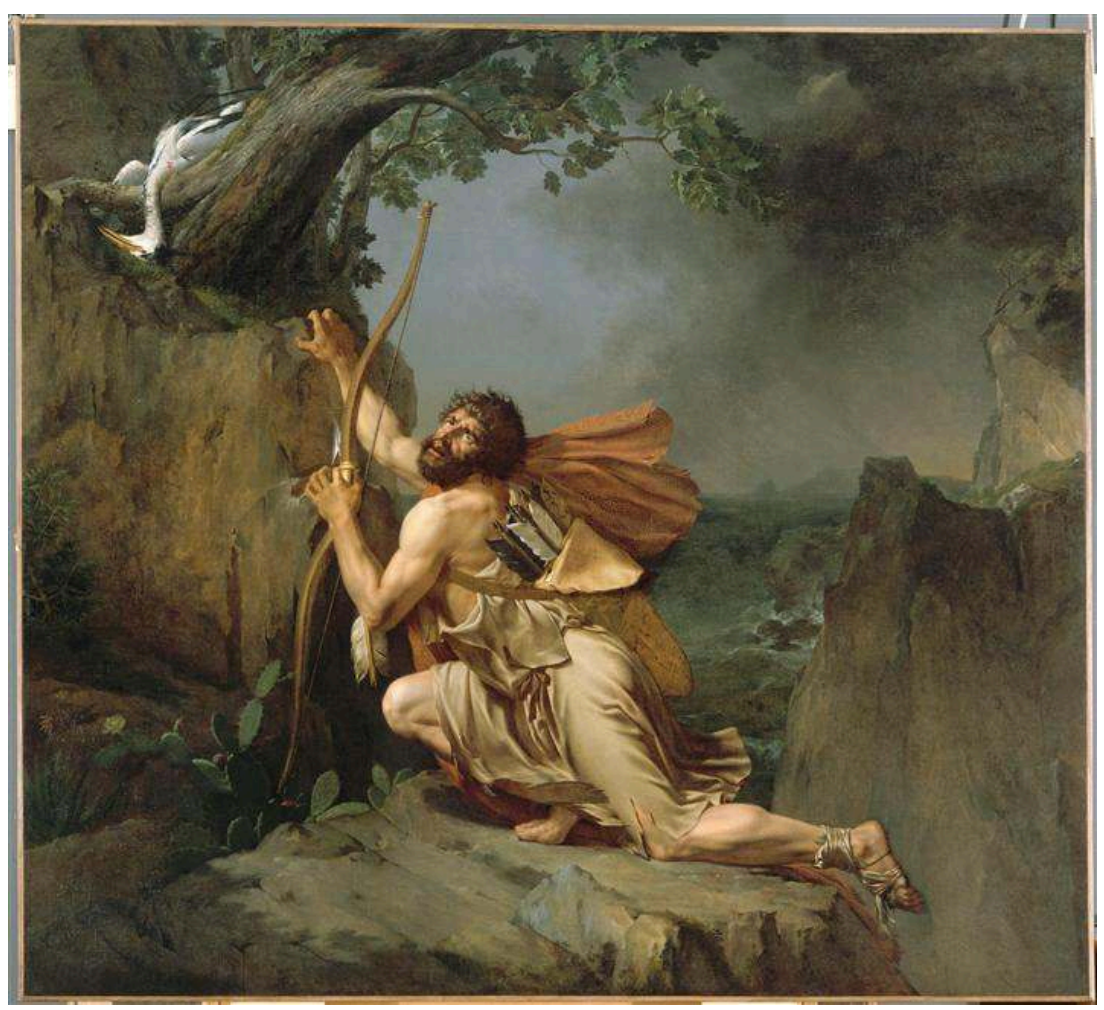

1798, huile sur toile, Paris, musée du Louvre.

Le citoyen Barbier n'avait besoin que de cet ouvrage pour sa réputation. Il pouvait laisser dans le néant son Othryade, qui n'est qu'une académie bien soignée. J'en vois encore une sous les traits de Philoctète (fig. 3). L'expression de tête est fort belle, la 
position de tête est naturelle ; le ciel ne pouvait être plus aride, la terre plus sauvage, la composition plus harmonieuse. Mais Philoctète est épuisé par la douleur; et jamais, peut-être, il ne fut plus vigoureux : tous ses muscles respirent la vie. Pourquoi cette main qui tient l'arc est-elle seule énervée? Ses doigts, légèrement détachés, n'éprouvent-ils aucune des angoisses qui torturent le reste du corps? Je n'aime point cette main, elle refroidit l'action. En regardant plus attentivement cet infortuné, on serait tenté de rendre grâce aux dieux de ce qu'il ne peut se soulever ; car il semble que sa tête pourrait se perdre dans les nues. Cette réflexion est presque générale : elle naît de l'intérêt qu'il inspire.

Le tableau d'ÆEdipe et celui d'Oreste m'ont paru d'une composition savante; on ne pouvait mieux traiter deux sujets que tous les arts paraissaient avoir épuisés: đEdipe, criminel et vertueux, traîne partout sa terreur et ses remords ; Oreste, agité par le fouet des furies, brave les remords et va connaître le crime. Dans l'un des tableaux, la sensible Antigone ramène la paix qui doit suivre le repentir. Dans l'autre, le superstitieux Pylade étouffe le cri de la nature et la déchire en voulant la venger. La tête d'EEdipe ne rappelle qu'un souvenir pénible d'inceste et celle d'Oreste exhale toute l'horreur qu'inspire le parricide; il cherche la place où il doit frapper; sa main la désigne ; Clytemnestre ne se défend pas, elle a reconnu son fils, et la mort est déjà dans son sein. L'apparition d'Agamemnon, le calme des tombeaux, font une opposition à l'horrible activité qui anime le premier plan. Ce tableau est beau, celui d'Ædipe l'est aussi ; la nature est horrible, on voit que le temple des Euménides est sur ces rochers; on entend les ouragans mugir sur ses portes d'airain; Antigone est trop froide, ses draperies ne sont pas assez froissées, ses cheveux sont trop en repos; mais après son malheureux père, quel intérêt pouvait-on répandre sur elle! C'est lui qu'il faut voir, c'est lui qu'il faut admirer; on peut faire aussi bien, je le crois; on ne pouvait faire mieux.

C. W. ${ }^{* * *}$, académicienne

\section{« Deuxième édition revue et corrigée de la sixième promenade au musée des Arts » (13 vendémiaire an VII)}

Le Phénix, $\mathrm{n}^{\circ} 21$,

p. 2-3.

Dans le temps que le Papillon n'agitait plus qu'une de ses ailes à moitié consommée, j'imaginais de le charger de ma sixième promenade au musée des Arts. Dieu sait ce que l'infortuné volatile en fit: toute la géographie d'Athènes en fut bouleversée; je ne reconnus ni le fleuve Céphise qui serpentait sous ses murs, ni le mont Hymette, ni les gymnases, ni ce temple de Vénus si célèbre dans la Grèce. Soit pitié, soit faiblesse, je respectai son agonie; mais à présent que ses cendres reposent en paix, je rends à Athènes son site voluptueux, à Aspasie sa séduction, au jeune Alcibiade son éloquence, à Socrate sa philosophie, à Monsiau son talent et à moi ma réputation; ce qui est bien quelque chose, quand on ne compte plus que sur elle pour exister. [...] 


\section{ANNEXES}

Lire des extraits d'articles de Caroline Wuiet parus dans Le Papillon

Lire l'introduction à Caroline Wuiet écrite par Amandine Gorse 
B. [Pauline Auzou (1775 - 1835) ou Albertine Clément-Hémery (1778 1855)] 


\title{
Introduction
}

\author{
Amandine Gorse
}

1 L'auteure qui se cache derrière cette initiale ne peut être clairement identifiée : il s'agirait soit de Pauline Auzou (1775-1835) soit d'Albertine Clément-Hémery (1778-1855). En effet, les deux femmes participèrent à l'élaboration du Journal des dames et des modes (1797-1839) dont sont issus les extraits présentés ci-dessous. La particularité de ce périodique résidait à la fois dans un discours général éludant tout sujet politique, mais également dans son ouverture à des collaborations diversifiées qui permirent aux femmes journalistes (Caroline Wuiet, Constance de Salm), éditrices (Albertine Clément-Hémery) et artistes (Pauline Auzou) d'écrire dans ses colonnes. Très vite, le journal devint le médium privilégié d'une observation ironique de la société où l'analyse des mœurs était façonnée par la critique littéraire et artistique. Il défendit régulièrement l'émancipation de la femme.

De 1797 à 1830, Albertine Clément-Hémery contribua à la rédaction du journal, dont elle fut également le propriétaire pendant une courte période, de 1799 à 1800 (KLEINERT 2001, p. 336-337). Un certain nombre d'éléments porte à croire qu'elle fut l'auteur des tout premiers comptes rendus du Salon présentés par le périodique. En 1802, elle possédait déjà une expérience en tant que journaliste puisqu'elle avait dirigé deux journaux : le Sans-Souci (s.d.) et Le Démocrite français, journal politique, de littérature et des spectacles (de février à mai 1799). Elle avait également exprimé ses convictions féministes à plusieurs reprises, comme dans son article du 28 avril 1797 paru dans le Journal des dames et des modes : "Quel est l'homme, ayant des lumières, qui consentirait à prendre un automate pour compagne?", ou bien dans son ouvrage Les Femmes vengées de la sottise d'un philosophe du jour ou Réponse au projet de loi de M. S.**-M.***, portant défense d'apprendre à lire aux femmes, par $M^{m e * * * *}$, publié en 1801. Possédant une bibliothèque d'environ 2600 volumes, il lui semblait primordial de défendre la solide éducation qu'elle avait reçue.

3 Ses mémoires, publiés en 1832 (Souvenirs de 1793 et 1794), nous apprennent notamment qu'elle étudia le dessin et la peinture dans l'atelier de Jean-Baptiste Regnault (1754-1829), au moment même où Pauline Auzou y fut également élève. Elle éprouvait un certain respect pour la jeune femme qu'elle considérait comme une "artiste distinguée » (CLÉMENT-HÉMERY 1832, p. 10), ce qui expliquerait pourquoi Pauline Auzou 
est citée en premier dans l'article sur le Salon de l'an X (1802). Toutefois, B. présente Pauline Auzou comme un peintre débutant, promis à une brillante carrière, alors même qu'elle exposait déjà au Salon depuis 1793 et tenait un atelier pour jeunes filles depuis 1800. Sa critique commente subtilement le style de l'artiste qui s'orienta, aux alentours de 1800 , vers la peinture de genre au détriment de la peinture d'histoire. On peut y déceler la prédilection d'Albertine Clément-Hémery pour le goût à la grecque que JeanBaptiste Regnault lui avait enseigné. L'article se termine d'ailleurs par un hommage à Regnault, dont elle défendait fermement la manière. Enfin, les thèmes abordés - la famille, l'éducation - lui étaient familiers.

Il nous semble donc peu probable que Pauline Auzou ait écrit ces articles. Comme le fit remarquer Albertine Clément-Hémery, elle se consacrait uniquement à son art : "Rien ne pouvait la distraire de ses études " (CLÉMENT-HÉMERY 1832, p. 10). En outre, il est surprenant qu'Auzou se définisse elle-même comme novice à une période où elle était reconnue comme une artiste accomplie. Les archives laissent penser que sa collaboration avec le Journal des dames et des modes se concrétisa exclusivement autour des 300 planches qu'elle dessina pour le magazine entre 1807 et 1809 (KLEINERT 2001, p. 345), cinq ans après le salon de 1802. Finalement, Pauline Auzou n'était pas une femme de lettres. Le seul ouvrage qu'on lui connaisse fut publié chez Didot en 1800 : il s'agissait de Têtes d'études destinées aux élèves de son atelier.

Quant à Albertine Clément-Hémery, elle consacra les vingt dernières années de sa vie à l'éducation des jeunes filles et à la publication de ses manuscrits tels que le Traité analytique du mélange des couleurs à l'usage des personnes qui s'occupent de la peinture orientale professée par $M^{m e}$ Clément en 1833 et l'Histoire des fêtes civiles et religieuses, usages anciens et modernes $d u$ département du Nord, par $M^{m e}$ Clément, née Hémery, l'année suivante.

\section{BIBLIOGRAPHIE}

\section{BALLASTER 1991}

Ros Ballaster et al., Women's Worlds: Ideology, Feminity and the Woman's Magazine, Londres, Macmillan, 1991.

BRUNEREAU 2000

Jeanne Brunereau, Presse féminine et critique littéraire de 1800 à 1830 : leurs rapports avec l'histoire des femmes, [Paris], Ève et Son Espace Créatif, 2000.

CAMERON 1997

Vivian P. Cameron, « Pauline Auzou », dans Delia Gaze (éd.), Dictionary of Women Artists, Londres/ Chicago, Fitzroy Dearborn Publishers, 1997, vol. 1, p. 199-201.

CAMERON 2004

Vivian P. Cameron, « Jeanne Marie Catherine Desmarquest », Dictionnaire des femmes de l'Ancien Régime, SIEFAR, 2004, en ligne, consulté le 23 octobre 2011. 
CLÉMENT-HÉMERY 1832

Albertine Clément-Hémery, Souvenirs de 1793 et 1794, Cambrai, Leisne-Daloin, 1832.

FRAISSE 1989

Geneviève Fraisse, Muse de la raison : la démocratie exclusive et la différence des sexes, Aix-enProvence, Alinéa, 1989.

KLEINERT 2001

Annemarie Kleinert, Le Journal des dames et des modes ou la Conquête de l'Europe féminine, 1797-1839, Stuttgart, Thorbecke, 2001.

SULLEROT 1966

Évelyne Sullerot, Histoire de la presse féminine en France des origines à 1848, préf. de Jacques Godechot, Paris, Armand Colin, 1966.

LACAMBRE 1981

Geneviève Lacambre, « Pauline Auzou », dans La Femme artiste d'Élisabeth Vigée-Lebrun à Rosa Bonheur, cat. expo., (Donjon Lacataye, musée Despiau-Wlerick, novembre 1981-février 1982), Mont-de-Marsan, Lacoste, 1981, p. 35-39.

Women Artists: 1550-1950 1976

Women Artists: 1550-1950, cat. expo., (Los Angeles County Museum of Art), Ann Sutherland Harris et Linda Nochlin (dir.), New York, Alfred A. Knopf, 1976.

\section{ANNEXES}

Diaporama des illustrations des articles parus dans le Journal des dames et des modes sous le pseudonyme de "B." :

http://www.flickr.com//photos/73632227@N02/sets/72157629306159528/show/

Lire des articles de B. parus dans le Journal des dames et des modes.

Liste complète des œuvres d'arts commentées par B. à travers ses textes édités dans Plumes et pinceaux 


\section{B., Journal des dames et des modes, an $\mathrm{X}$-an XI}

[extraits choisis]

\section{«Salon de l'an X » (15 brumaire)}

Journal des dames et des modes, $\mathrm{n}^{\circ} 9$, p. 67-70.

Pendant presque toute la durée de l'exposition, le Salon a fourmillé chaque jour de curieux, et cependant rien n'a été plus rare que d'y trouver les personnes que l'on aurait voulu y rencontrer. N'y aurait-il donc plus à Paris de ce que l'on appelait autrefois la bonne compagnie, ou bien la bonne compagnie actuelle se croirait-elle peu digne d'admirer et d'encourager les talents? Quoi qu'il en soit, il est affligeant de voir les dames françaises mettre si peu d'empressement à venir honorer de leurs suffrages des travaux souvent entrepris pour leur plaire, et ne s'informer que par procuration des succès de nos artistes. Il semblerait qu'on ne prend à leur gloire qu'un intérêt de curiosité très frivole et que tout le prix de leurs efforts doive se borner au stérile avantage d'alimenter, pendant de courts instants, la conversation de quelques cercles brillants et superficiels, parmi lesquels un léger signe d'admiration n'est que le songe rapide d'une constante apathie.

En jetant un coup d'œil sur quelques-unes des productions de l'exposition de cette année, nous les considérerons moins sous le rapport de l'art en lui-même que sous celui de l'opinion que l'on peut se former du goût et du génie des artistes, d'après le choix de leurs sujets et l'ordonnance de leurs tableaux. Cette manière d'en faire l'examen plaira peut-être davantage à celles de vos lectrices qui, ne professant point elles-mêmes l'art enchanteur des Rubens et des Raphaël, ne jugent de cet art que par ses effets et par les sensations plus ou moins agréables qu'il leur fait éprouver.

$\mathrm{N}^{\circ}$ 6. Deux jeunes filles lisant une lettre.

$\mathrm{N}^{\circ}$ 7. L'Amour dissipant les larmes. 
Ces deux charmants tableaux donnent la plus agréable idée du cœur et de l'esprit de $\mathrm{M}^{\text {me }}$ Auzou et font espérer qu'elle se montrera bientôt la digne élève du peintre de $L a$ Mort de Cléopâtre.

$\mathrm{N}^{\circ}$ 34. Psyché sortant des Enfers et venant d'ouvrir la boîte de fard de Proserpine, par $\mathrm{M}^{\mathrm{lle}}$ Bounieu, élève de son père.

4 Courage, mademoiselle, cette jolie Psyché vous fait encore plus d'honneur que votre bacchante de l'année dernière, et rentre davantage dans le genre qui convient au pinceau des dames.

$\mathrm{N}^{\circ}$ 36. L'Amour endormi rêve que Psyché est près de lui.

5 Ce bras levé est d'un mauvais effet ; et cet Amour n'a aucun trait de ressemblance avec le fils de Vénus.

$\mathrm{N}^{\circ}$ 65. Une jeune femme surprise par un orage.

6 L'auteur a retiré ce tableau du Salon, et il a bien fait: cette femme était tellement effrayée de l'orage qu'elle en était effrayante.

$\mathrm{N}^{\circ}$ 71. Portrait en pied du citoyen Lafond, étudiant devant une glace le rôle de Tancrède.

7 Ce n'est point que Lekain eût voulu être représenté. Ce n'est point dans cette attitude que Regnault eût peint un acteur tragique. On devine au premier coup d'œil le sexe de l'auteur de ce portrait.

$\mathrm{N}^{\circ}$ 100. Un Amour traçant un serment de fidélité sur le sable.

8 On n'en voit guère de cet âge-là ; et celui-ci semble n'avoir vieilli que sous les traits de l'amitié... Ô vous qui voulez peindre l'Amour, regardez les enfants de $\mathrm{M}^{\mathrm{me}}$ Chaudet; ne dirait-on pas qu'il est le père de tous ceux qu'a créés le pinceau frais et brillant de cette aimable artiste?

$\mathrm{N}^{\circ}$ 115. Une jeune femme embrassant son enfant.

9 Que l'on se sent disposé à embrasser avec cette jolie maman son innocent marmot! Quelle délicieuse sensation fait naître l'aspect d'une bonne mère de famille, quand tout l'éclat de la beauté rend encore plus touchantes ses vertus domestiques! Et combien

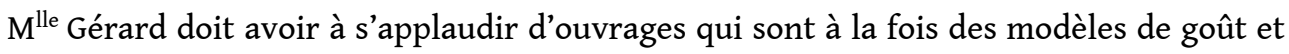
des exemples séduisants de bonnes mœurs!

$\mathrm{N}^{\circ}$ 119. Tableau représentant des bergers qui se disputent le prix du chant devant des jeunes filles.

10 L'on croirait plutôt qu'à l'imitation des callipyges, ils se disputent le prix des formes. 


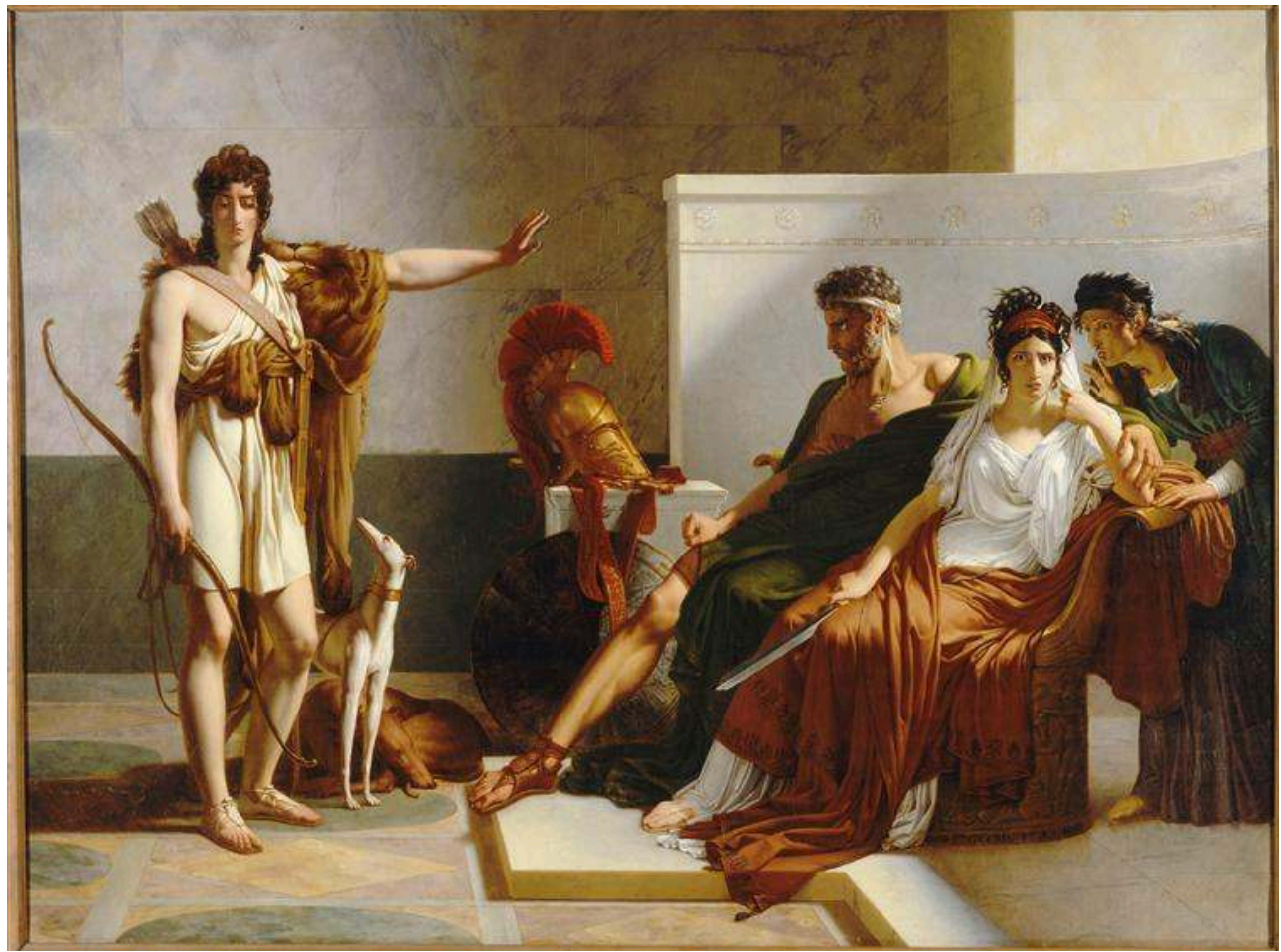

An X (1802), huile sur toile, 257 × 335 cm, Paris, musée du Louvre.

$\mathrm{N}^{\mathrm{o}}$ 121. Phèdre et Hippolyte.

11 Le souvenir du tableau de Marcus Sextus faisait attendre ce nouvel ouvrage avec une impatience que le citoyen Guérin a pleinement justifiée (fig. 1). Le choix du sujet, la simplicité de son exposition, la réunion sans confusion et sans obscurité, en une seule scène, de ce qui fait l'objet de plusieurs scènes très distinctes dans la tragédie de Racine : tout dans cette admirable composition décèle le génie et le goût exquis du jeune auteur, dont Raphaël et Titien semblent avoir guidé le pinceau.

$\mathrm{N}^{\circ}$ 207. Astyanax arraché à sa mère; par Mme Mongez, élève du citoyen David.

12 Tableau où l'on reconnaît les talents du maître et les fautes de son élève. Les yeux de cette belle Andromaque versent des larmes sans pleurer. En général, ce tableau produit sur le spectateur, qui voudrait être ému d'une scène qui devait être déchirante, l'effet que produirait Thalie chaussant le cothurne et s'armant du poignard de Melpomène.

$N^{0}$ 208. Le Duel.

13 Sujet traité de la manière la plus dramatique.

$\mathrm{N}^{\mathrm{o}}$ 210. Molière lisant le Tartuffe chez Ninon de Lenclos.

Quelle brillante époque et quels souvenirs glorieux cette imposante assemblée doit retracer aux gens de lettres! Mais aussi quelles tristes comparaisons !

$\mathrm{N}^{\circ}$ 269. Bataille du mont Tabor. Esquisse.

15 Nous engageons l'auteur, qui annonce du talent, à tâcher de mieux placer à cheval sa cavalerie. La jambe et le genou doivent être moins tendus. Mais ce défaut n'est pas étranger à nos meilleurs dessinateurs, et nous aimons à croire pourtant qu'ils ne prennent pas pour modèles nos jeunes élégants de Paris, dont les coudes en arrière, la 
poitrine en avant, les jarrets en dedans et les pieds en dehors n'annoncent pas de grands talents en équitation. Oh ! Comme il serait curieux de voir rangé en bataille tout un régiment placé à cheval à la parisienne! La belle étendue de terrain qu'il occuperait! Et comme la moindre manœuvre, sous peine d'entorse ou de dislocation, remettrait bien vite tous ces pieds et tous ces bras à leur place! À moins que Borée ou même le Zéphyr ne fît, dès le premier galop, de ce corps pimpant de cavalerie un modeste régiment de fantassins.

$\mathrm{N}^{\circ}$ 510. Un enfant dans son berceau, entraîné par les eaux de l'inondation de l'an $X$.

Une submersion plus imminente aurait rendu plus pathétique le danger que court cet enfant.

\section{Jupiter et Io.}

17 Jupiter a l'air plus précieux que divin, et semble moins amoureux d'Io que de lui-même. $\mathrm{Ne}$ ressemblerait-il pas en cela à quelques-uns de nos modernes immortels, lorsqu'ils veulent bien s'abaisser jusqu'à faire l'amour?

Éros ou l'Amour débrouillant le Chaos.

Comment l'auteur a-t-il pu espérer de donner un corps à une idée aussi vaste et en même temps aussi abstraite? Suffisait-il, pour la rendre sensible, de mettre à califourchon sur un nuage un enfant coiffé à la Titus en colère?

\section{François Gérard, Bélisaire}

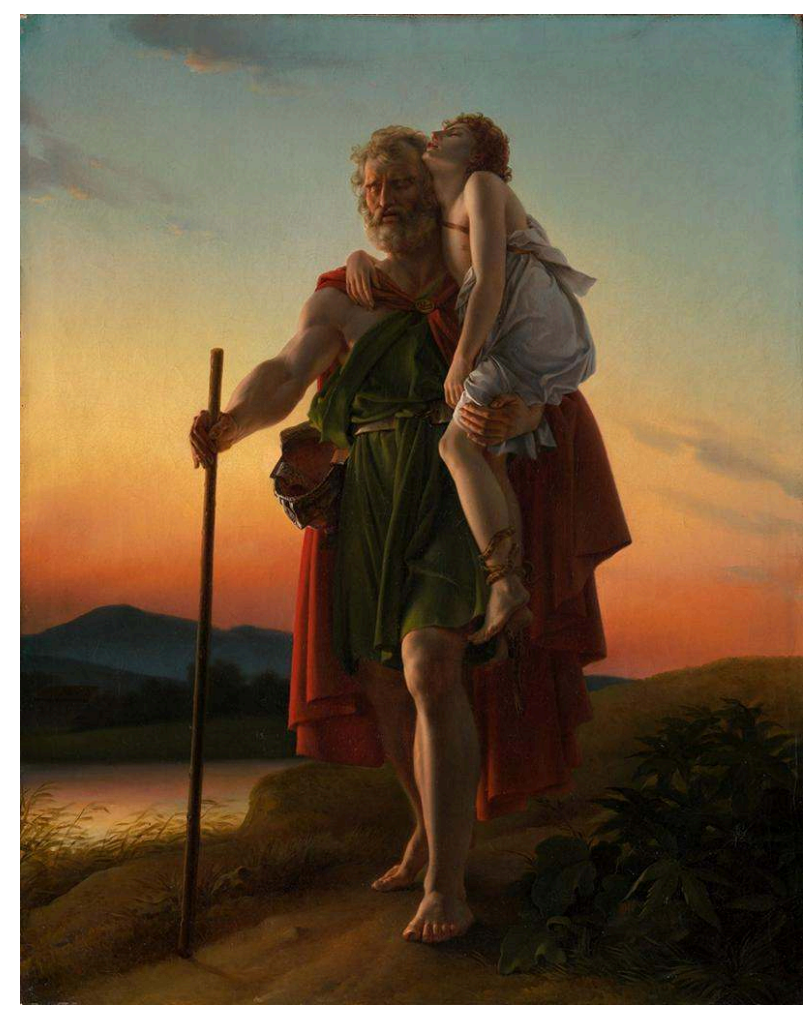

1797, huile sur toile, 91 x 74 cm, Los Angeles, J. Paul Getty Museum Collection. 
3. Anne-Louis Girodet, L'Apothéose des héros français morts pour la patrie pendant la guerre de la Liberté : les ombres des héros morts pour la patrie conduites par la Victoire viennent habiter l'Élysée aérien où les ombres d'Ossian \& de ses valeureux guerriers s'empressent de leur donner dans ce séjour d'immortalité \& de gloire la fête de la Paix \& de l'Amitié

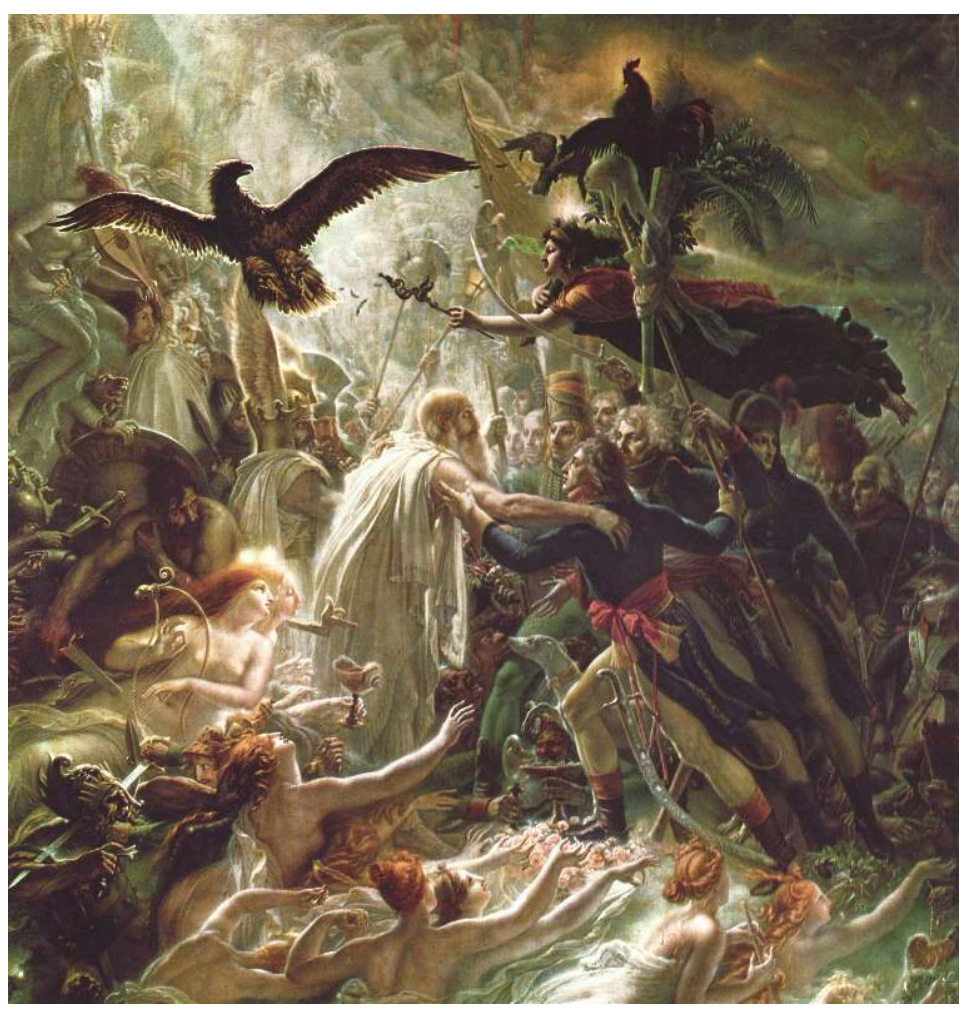

1801 (an IX), huile sur toile, 192 x 182 cm, Rueil-Malmaison, musée national des Châteaux de Malmaison etde Bois-Préau. 
4. Jean-Baptiste Isabey, Portrait du Premier consul [peut-être Le Premier Consul Bonaparte à la Malmaison]

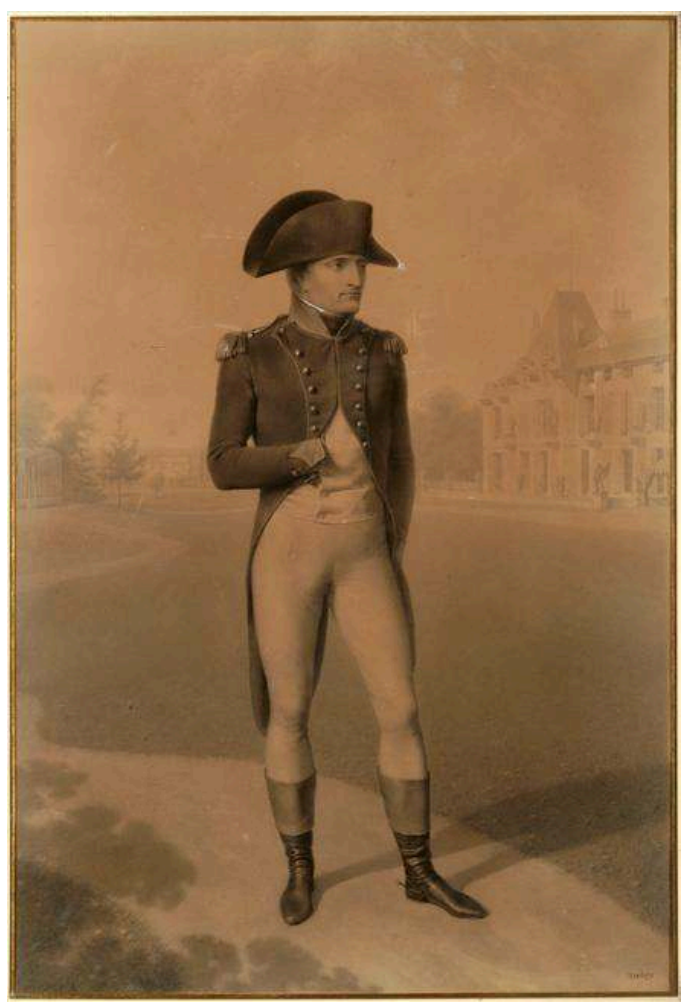

1797, crayon noir, estompe, blanc (rehaut), $69 \times 47,5$ cm, Rueil-Malmaison, musée national des Châteaux de Malmaison et de Bois-Préau.

\section{Antoine Charles Horace Vernet, Le Premier Consul passant une revue dans la cour des Tuileries}

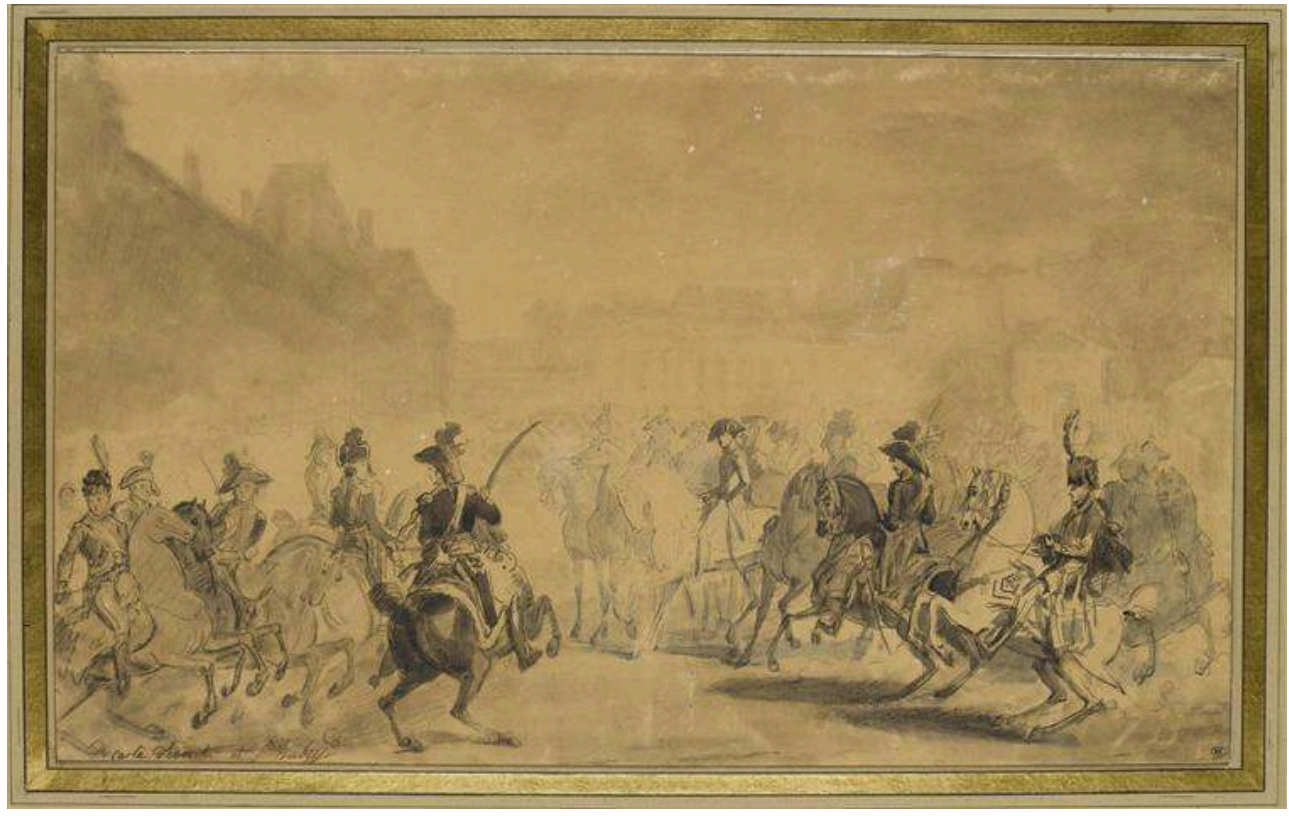

An X (1802), dessin, encre de chine, estompe, lavis gris, mine de plomb sur papier brun, 25,8 x $43 \mathrm{~cm}$, Paris, musée du Louvre. 
Le Salon n'était autrefois ouvert que tous les deux ans, et l'exposition ne durait qu'un mois. On avait jugé ce temps nécessaire aux artistes pour produire des ouvrages dignes d'y figurer. Depuis qu'on a pris le parti de l'ouvrir chaque année, de tripler la durée de l'exposition et d'y admettre trop facilement les productions les moins estimables, cette brillante galerie des peintres de l'école française est devenue successivement moins abondante en chefs-d'œuvre de l'art, et rien n'égalait surtout la peinture du Salon de l'an X, avant que le ministre de l'Intérieur eût invité nos peintres fameux à y exposer de nouveau leurs productions si justement admirées les années précédentes. Une pareille disette de bons ouvrages affligeait d'autant plus tout bon Français jaloux de la gloire de sa patrie, que l'affluence des étrangers à Paris aurait dû engager les artistes à redoubler d'efforts pour porter cette année au plus haut degré de splendeur le spectacle de notre richesse et de notre luxe en talents de toute espèce. Oh! Combien donc ne sont-ils pas estimables les artistes simples et modestes qui, s'embarrassant peu du ton et de l'étiquette du jour, n'ont pas dédaigné d'inscrire leurs noms déjà célèbres parmi des noms jusqu'alors inconnus et qui, capables de produire des chefs-d'œuvre, n'ont pas seulement pensé à calculer jusqu'à quel point le mérite de leurs ouvrages pouvait être rehaussé ou compromis par le voisinage des productions de leurs confrères! Cependant, l'invitation du ministre a tout à coup rendu cette exposition la plus brillante que l'on ait jamais vue ; et rien n'égale l'admiration et l'enthousiasme qu'ont tous obtenus et mérités le beau tableau de Dédale et Icare par Garnier, le magnifique Bélisaire de Gérard (fig. 2), les ravissantes miniatures d'Isabey, les ombres magiques des guerriers français rejoignant Ossian aux Champs-Élysées par Girodet (fig. 3), et enfin le portrait et cette belle revue du Premier consul aux Tuileries par Isabey et Vernet (fig. 4 et 5), etc.

Nous ne terminerons point cet article sans parler du superbe tableau d'Hercule et Alceste par Regnault, et sans offrir à son auteur l'hommage particulier de notre reconnaissance pour tout le plaisir que nous a fait son ouvrage. En effet,

21 Quel sujet à la fois touchant et magnanime

Fut plus digne, ô Regnault, de ton pinceau sublime !

Le fils de Jupiter, de l'antre redouté,

À ta voix est sorti, plein de gloire et de vie.

Il respire... triomphe... et Pluton, en furie,

Te redemande en vain ce héros si vanté.

Pluton perd avec lui cette épouse céleste,

La compagne d'Admète, et sa félicité.

Ton art aussi t'enlève à son pouvoir funeste :

Oui, devant toi l'enfer se ferme épouvanté :

Cet Hercule vainqueur qui lui ravit Alceste,

Avec elle a conquis ton immortalité.

\section{Article du 30 brumaire an XI}

Journal des dames et des modes, $\mathrm{n}^{\circ} 12$,

On a eu occasion de remarquer, au sujet des ouvrages exposés au Salon, que le beau sexe commençait à s'associer aux arts et à ne plus se croire étranger aux productions utiles du génie. On ne s'étonne presque plus de voir les femmes s'occuper de choses 
plus sérieuses que la musique et la danse. C'est déjà un préjugé de vaincu à leur égard ; s'il arrivait maintenant qu'on renonçât à la manie de les marier à l'âge de quatorze ans et, par conséquent, de terminer là leurs cours d'études, peut-être ne tarderait-on pas à découvrir, dans un nouveau mode d'éducation des femmes, les moyens d'utiliser cette mine inépuisable d'imagination qu'on a toujours négligé ou dédaigné d'exploiter. On sait bien que le despotisme des hommes est un grand obstacle à l'instruction des femmes. Mais l'autorité des parents est là pour surveiller leur éducation jusqu'à l'âge où leur esprit aura pris une direction déterminée.

En Angleterre, un quart des livres de morale et les trois quarts des romans sont écrits par des femmes. Mais là, il n'y a point de ridicule attaché aux occupations sérieuses du beau sexe ; là on ne confond point les prétentions ridicules d'une femme bel esprit avec l'emploi raisonnable que peut faire de son temps une mère de famille livrée à ses devoirs domestiques et qui ne se fait pas un cas de conscience de manquer un bal ou de ne pas se condamner, cinq fois la semaine, à pâlir, pendant une mortelle nuit d'hiver, autour d'une table de bouillotte.

\section{ANNEXES}

Lire l'introduction à « B. » écrite par Amandine Gorse 
Maria Cosway (1759 - 1838) 


\title{
Introduction
}

\author{
Fanny Reboul
}

1 Artiste anglo-italienne " accomplie », selon le terme de Stephan Lloyd, Maria Cosway a laissé une œuvre importante en Europe aussi bien sur le plan artistique qu'éducatif, ainsi que de nombreux témoignages sur l'art et les événements politiques dont une intéressante correspondance en anglais et en italien, et un journal tenu de 1802 à 1817 en italien.

2 Née à Florence, où ses parents tenaient un hôtel pour les touristes anglais de passage lors du Grand Tour, Maria Hadfield fut dès son enfance au contact d'artistes et ses talents furent rapidement décelés. Douée pour la musique, elle se tourna également vers la peinture, à la suite de sa rencontre avec Angelika Kauffmann (Cazzulani et Stroppa 1989). Sur ses jeunes années, sa lettre autobiographique nous apporte quelques renseignements, notamment sur son apprentissage de l'art italien par la copie des maîtres, jusqu'à son retour à Londres après le décès de son père. Son mariage en 1781 avec Richard Cosway, miniaturiste, peintre officiel du prince de Galles, fut d'abord profitable à tous deux sur le plan artistique. En effet, jusqu'à la naissance de leur fille en 1790, Maria exposa à l'Académie de nombreuses toiles, des portraits - dont celui de la duchesse du Devonshire - et des sujets mythologiques ou tirés de la littérature. Toutefois, ce mariage se révéla vite un frein à sa carrière. Cantonnée au rôle de modèle ou de maîtresse de maison, Maria poursuivit néanmoins son activité de gravure et continua à échanger avec des artistes ou des hommes politiques, tels que le général Pasquale Paoli (général corse exilé en Angleterre) ou Thomas Jefferson qui écrivit pour elle Dialogue entre mon esprit et mon cœur. Rencontré lors d'un voyage à Paris, où il était ambassadeur, en 1786, Maria entretint avec lui une relation amicale, dont témoigne une correspondance tenue jusqu'à la mort de ce dernier, en 1825.

3 Après la mort de sa fille en 1796, Maria Cosway se consacra de nouveau à la peinture et à la religion. En 1801, elle retourna à Paris et débuta le projet artistique le plus ambitieux de sa carrière : effectuer la copie et la gravure des œuvres du Musée central, futur musée du Louvre, agencées par Vivant Denon. Ce travail en commun avec Julius Griffiths s'avéra difficile, mais donna lieu à deux publications contenant chacune sept planches complètes. Pendant cette période, elle renoua certaines amitiés anciennes, notamment avec Jacques-Louis David qui la conseilla dans ses projets artistiques, ou 
Élisabeth Vigée-Lebrun; mais elle fit aussi des rencontres déterminantes comme celle de l'oncle de Bonaparte, Joseph Fesch. Le journal de Maria sur cette période est un témoignage de sa vie à Paris, de ses difficultés et de ses doutes dans son travail, ainsi que des visites qu'elle organisait pour les touristes anglais à nouveau autorisés à voyager en France, après la signature du traité de paix d'Amiens en 1802. Ce fut aussi une occasion pour elle de s'exprimer sur l'art ancien et contemporain, et également sur des sujets plus politiques. Dès 1803, grâce à Joseph Fesch, Maria put créer une école pour jeunes filles à Lyon, projet auquel elle aspirait depuis longtemps. À la fermeture de l'école en 1809, le duc de Lodi Francesco Melzi fit venir Maria auprès de lui afin d'en créer une similaire dans sa ville lombarde. Elle se consacra à cette école jusqu'à sa mort, le 5 janvier 1838, occultant ainsi en partie son activité artistique.

\section{BIBLIOGRAPHIE}

BARNETT 1995

Gérald Barnett, Richard and Maria Cosway, a biography, Tiverton/Devon, Westcountry Books, 1995.

CAZZULANI et STROPPA 1989

Elena Cazzulani et Angelo Stroppa, Maria Hadfield Cosway: biografia, diari et scritti della fondatrice del Collegio delle dame inglesi in Lodi, Lodi, L'Immagine, 1989.

GIPPONI 1998

Tino Gipponi, Maria e Richard Cosway, Turin, U. Allemandi, 1998.

LLOYD 1992

Stephen Lloyd, The accomplished Maria Cosway: Anglo-Italian artist, musician, salon hostess and educationalist (1759-1838), Msida, Malta University Press, 1992.

LLOYD 1995

Stephen Lloyd, Richard \& Maria Cosway, Regency artists of taste and fashion with essays by Roy Porter \& Aileen Ribeiro, Édimbourg, Scottish National Portrait Gallery, 1995.

Walker 1986

John Walker, "Maria Cosway, an undervalued artist", Apollo, mai 1986, p. 318-324.

\section{ANNEXES}

Lire des extraits du Journal de Maria Cosway

Lire la Lettre autobiographique adressée à William Cosway de Maria Cosway

Liste complète des œuvres d'arts commentées par Maria Cosway à travers ses textes édités dans Plumes et pinceaux 


\section{Maria Cosway, Extraits de son journal, 1802}

Manuscrit, Lodi, Fondation Cosway, volume A, extraits choisis.

\section{Mardi 22 juin $1802 * \star$}

1 J'ai travaillé toute la matinée pour retoucher les estampes. J'ai envoyé le portefeuille en maroquin avec trois numéros colorés: un pour $\mathrm{M}^{\text {me }}$ Bonaparte, un autre pour le Premier consul, et le troisième pour Fesch. J'avais demandé à les porter moi-même, mais Fesch m'a assuré qu'il s'en chargerait. J'ai donc accepté la proposition, malgré ma curiosité de les rencontrer. Après le déjeuner, je me suis rendue avec David chez $\mathrm{M}^{\mathrm{me}}$ Barthélemy où j'ai entendu quelque anecdote curieuse. Le duc d'Orléans avait offert une parcelle de son terrain pour en faire un cimetière. Quand le corps de la reine fut chargé sur la charrette et conduit en ce lieu, on l'enterra à côté du duc d'Orléans, qui était déjà inhumé à cet endroit. Ceux qui furent ennemis de leur vivant ont à présent leurs cendres mêlées. Un arbre a été planté au-dessus de la sépulture de la reine.

\section{9 juillet 1802 **}

2 David est venu me voir hier pour me donner la suite de ses instructions à propos du tableau que j'ai entrepris sous sa direction. Il m'a suggéré d'en faire une étude à partir d'un modèle réduit en cire fait à la lumière d'une bougie, ce que je fis hier soir, avant d'aller ce matin lui montrer mon travail : il m'a aussitôt dit qu'il m'attendait déjà, il avait affirmé hier soir à sa femme qu'il était sûr que j'étais en train de travailler, ce qui était vrai. En effet, je n'ai voulu recevoir personne et j'ai dessiné jusqu'à onze heures. Il a été très satisfait de ce que je lui ai montré - il faut dire qu'il a une manière admirable d'encourager les gens.

\section{1 octobre $1802^{*}$}

[à propos d'une visite à $\mathrm{M}^{\text {me }}$ Vigée-Lebrun] 


\section{1. Élisabeth Vigée-Lebrun, Portrait du prince Lubormirski}

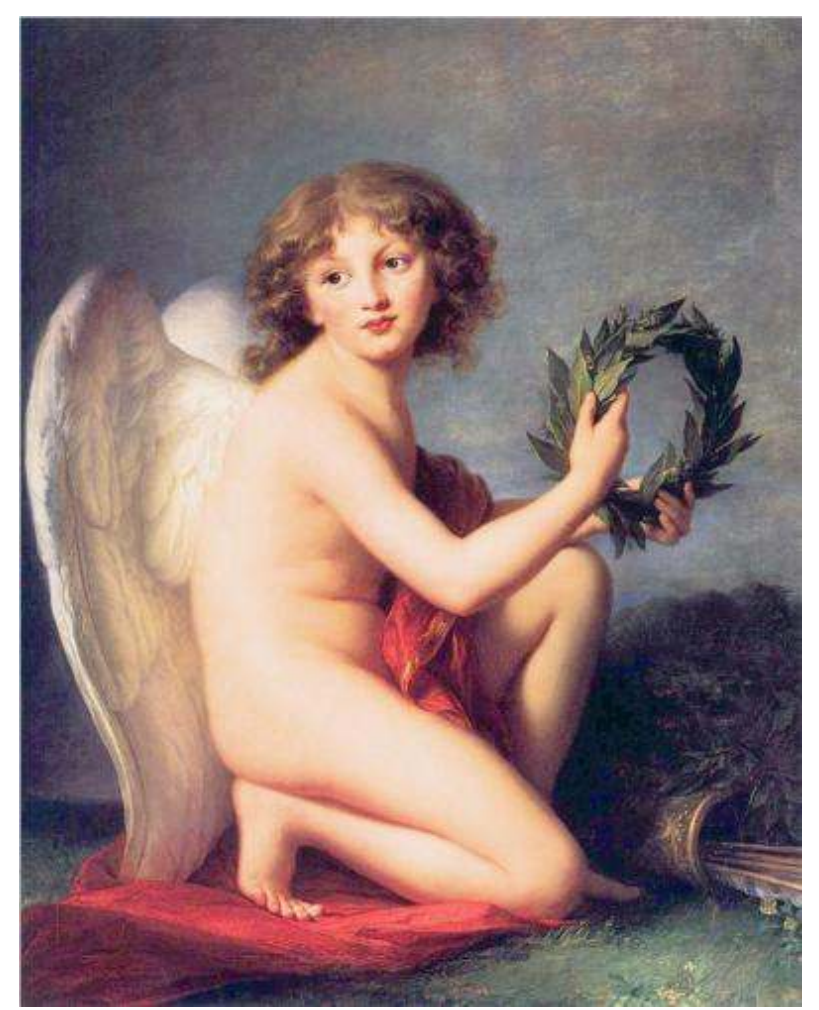

1789, huile sur toile, 105 x 83 cm, Berlin, Gemäldegalerie.

3 Elle m'a montré l'ancien portrait du prince Lubormirski - une œuvre faible, piètre, indigente, commune, mal dessinée (fig. 1). Quelque chose de français dans la composition, mais rien du point de vue de l'invention. Mais une sorte de brillance dans le travail de la matière et des couleurs. Je ne peux pas critiquer le reste de son travail : elle a l'air si sûre d'elle, et c'est aussi quelqu'un de très aimable.

\section{7 octobre $1802^{\star \star}$}

4 Puis est venu Gérard, avec qui je suis allée chez $\mathrm{M}^{\text {me }}$ Villers, qui a une belle demeure et qui est elle-même une belle femme. Je la considère comme la meilleure peintre, bien que l'on dise que David a beaucoup travaillé sur son tableau.

\section{1 décembre 1802**}

5 Alors que je travaillais à la galerie depuis trois jours, j'ai éprouvé hier une sensation extraordinaire dont je me rappellerai toujours. 


\section{Raphaël, La Transfiguration}

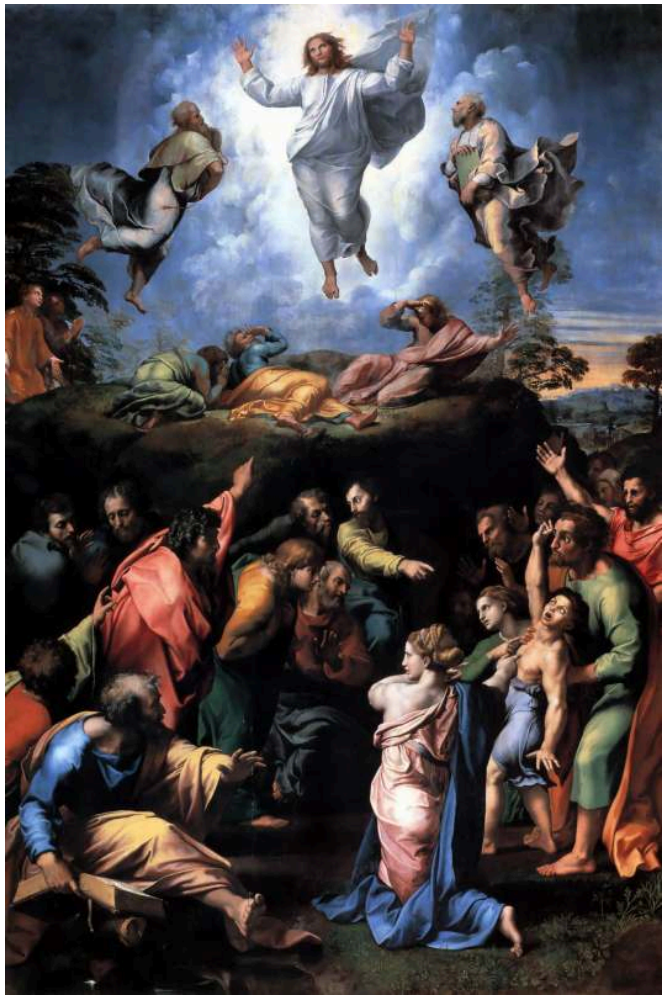

1516-1520, huile sur bois, 405 × 218 cm, cité du Vatican, musées du Vatican.

6 J'étais à mes travaux quand j'ai entendu un bruit sourd: autour de moi passaient des hommes qui portaient un grand tableau. C'était la Transfiguration (fig. 2). J'ai ressenti une émotion si forte que j'en ai presque pleuré, de respect, de plaisir, peut-être des deux à la fois. Eussent-ils porté le corps de Raphaël, je n'aurais pu être plus émue. Un tableau qui fait date dans le monde, qui a rendu célèbre un homme à travers toute la planète et qui représente une des étapes de la conquête de l'Italie. J'aurais voulu que retentissent les canons, que tout Paris fût présent, qu'il y eût une grande fête comme, à ce qu'on m'a dit, celle qui eut lieu lorsque l'Apollon fut déposé et que Bonaparte fit un discours en présence de toute l'Administration.

NB : les textes suivis d'une seule astérisque sont traduits de l'anglais; les textes suivis de deux astérisques sont traduits de l'italien.

\section{ANNEXES}

Lire la Lettre autobiographique adressée à William Cosway de Maria Cosway

Lire l'introduction à Maria Cosway écrite par Fanny Reboul 


\section{Maria Cosway, Lettre}

\section{autobiographique adressée à William Cosway, cousin de Richard Cosway, 1830}

Manuscrit, Londres, Victoria and Albert Museum, National Art Reference Library, MS (Eng.) L.961-1953.

Traduction : Anne-Laure Brisac-Chraïbi depuis l'anglais

Cher monsieur,

1 J'ai reçu votre aimable lettre de Brighton le 25 avril, alors que je passais quelques jours chez mon cousin près du lac de Côme - un séjour qui m'a fait beaucoup de bien -, et j'ai bien pensé à vous et à Lady Cosway. Je vois que vous insistez pour que je rédige mes mémoires : je vous envoie ce qui peut vous sembler nécessaire, et à ma mort vous aurez une liste complète de mes cahiers, notes de voyages et correspondance.

Mon père, Charles Hadfield, était issu d'une très riche famille de commerçants et manufacturiers de Manchester. Je me suis un peu renseignée et on m'a dit qu'il n'y a plus qu'une vieille lady encore vivante qui demeure là-bas, le dernier du nom est décédé, très riche mais sans descendant, et personne n'a pu me dire où étaient ses héritiers. Mon père, lors d'un voyage en Italie, avait eu du mal à trouver un logement décent pour les gens de passage, en particulier pour les Anglais, ce qui le conduisit à installer une vaste maison et à l'aménager un peu à l'anglaise ; cela attira tous ses compatriotes et il fut ainsi amené à ouvrir deux autres pensions, dont l'une sur les bords de l'Arno, où je suis née.

3 Je me permets de raconter une scène relative aux premiers mois de ma vie, aussi extraordinaire que méconnue. Mes parents avaient eu quatre ou cinq enfants avant moi, élevés par des nourrices en dehors de la ville. Ma mère s'y rendait fréquemment : un jour, elle trouva le bébé en pleine santé et à sa grande surprise, le lendemain, la nourrice vint lui dire qu'il était mort durant la nuit. On changea de nourrice, on changea d'endroit, et la même chose se produisit avec quatre autres enfants. À ma naissance, mon père décida de prendre une nourrice à demeure avec une gouvernante 
qui ne les lâchait pas des yeux, elle et le bébé. Un jour, cette femme arriva dans la nurserie, me prit dans ses bras et dit: «Ma petite mignonne créature, j'en ai envoyé quatre au Ciel, j'espère bien en faire autant avec toi. » La gouvernante, interloquée, se précipita chez mon père, une enquête fut menée en bonne et due forme, la nourrice affirma que c'était pour mon bien et fut immédiatement mise sous les verrous pour le restant de ses jours.

Mon père déclara que je devais être élevée dans la religion catholique, de même pour tous ses enfants. Quand j'eus quatre ans, on me plaça dans un couvent, sous la protection du grand duc et de la grande duchesse de Toscane. Là, comme j'étais douée, on me fit tout de suite apprendre la musique, et à six ans, et peut-être plus encore à dix ans, je me consacrai à ce qui m'a toujours, depuis, paru extraordinaire. Je commençai le dessin à huit ans après avoir vu une jeune lady le pratiquer et j'adorai cela, plus encore que la musique. On me fit revenir à la maison et je fus prise en charge par une vieille lady célèbre - son portrait est aux offices. Je suivis beaucoup de cours, mais ce que je préférais, c'était la peinture. Cette dame comprit rapidement que j'apprenais très vite, plus qu'elle ne pouvait m'enseigner, et comme $\mathrm{M}$. Zofani était à Florence, mon père lui demanda de me donner des leçons. J'allais étudier aux Offices et au Palazzo Pitti et je copiai un grand nombre des plus belles peintures de ces musées. Grâce à [Joseph] Wright of Derby qui était venu passer quelques jours à Florence, m'avait repérée dans les salles et avait remarqué mon talent, je pus accéder au sommet de cet art. Mon père avait fort bon goût et de bonnes connaissances en arts et en sciences, ce qui contribua à la formation de mon esprit en tous domaines.

\section{Johann Heinrich Füssli, Dante et Virgile sur la glace du Cocyte}

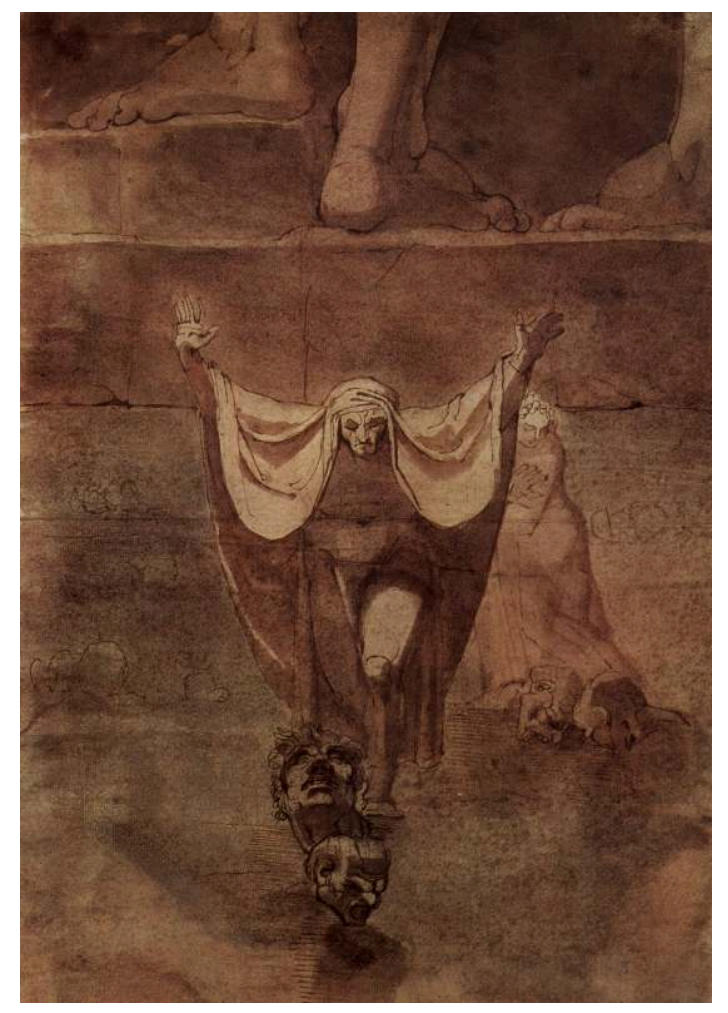

1774 , aquarelle, $39 \times 22,4 \mathrm{~cm}$, Zurich, Kunsthaus. 


\section{Johann Heinrich Füssli, Le Rêve du berger}

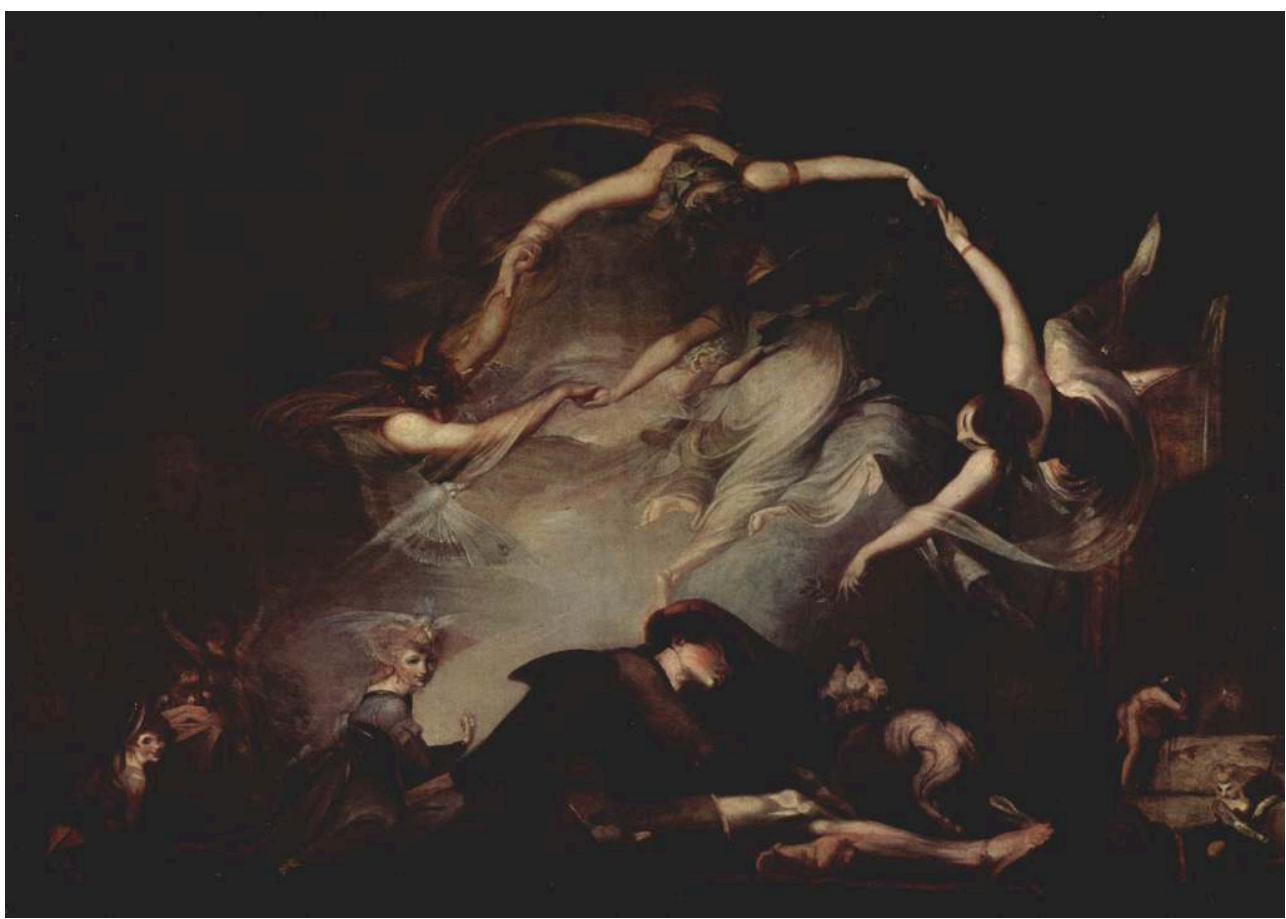

1793, huile sur toile, 154,5 × 215,5 cm, Londres, Tate Gallery.

\section{Johann Heinrich Füssli, Le Silence}

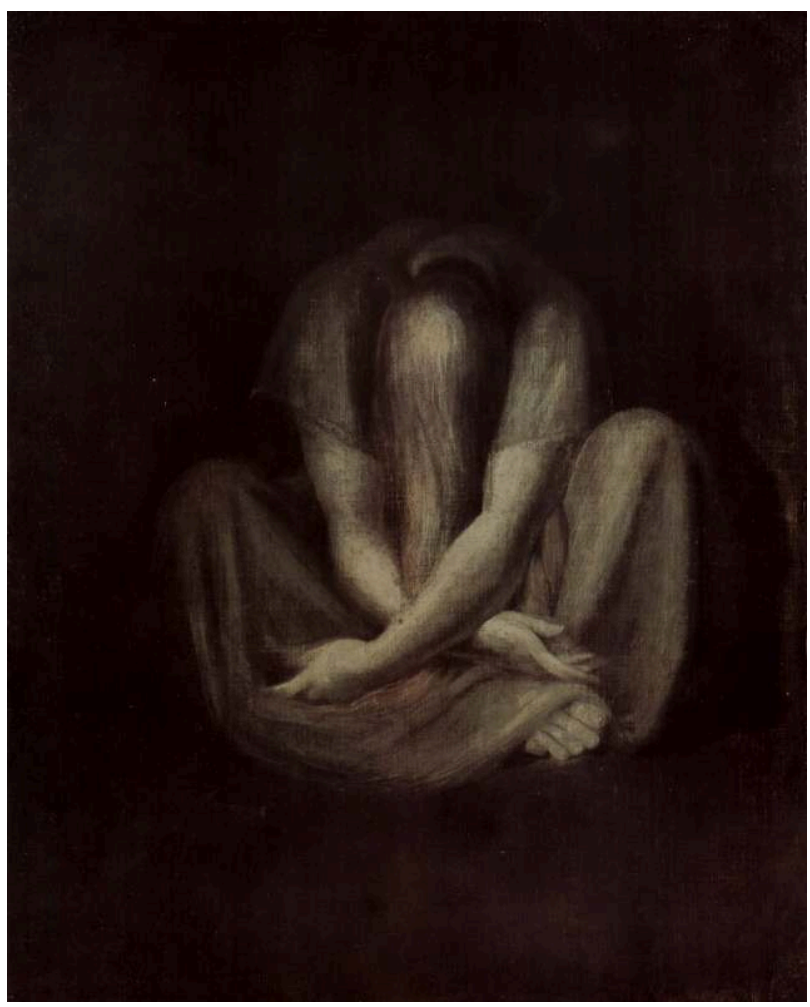

1799-1801, huile sur toile, $63,5 \times 51,5 \mathrm{~cm}$, Zurich, Kunsthaus. 
5 Il songeait à s'installer en Angleterre avec toute sa famille, mais comme il souhaitait que je visite Rome, Mrs Gore, la mère de Lady Cowper, m'y emmena et j'eus l'occasion de connaître intimement tous les plus grands artistes vivants: Battoni, Mengs, Maron et bien d'autres peintres anglais, Fuseli et ses extraordinaires Visions frappèrent mon imagination (fig. 1 à 3). Je ne fis pas d'études à proprement parler, mais durant une année et demie je consacrai tout mon temps à voir ce qui se faisait de mieux en matière de peinture et de sculpture, je réalisai des croquis, etc. À cette époque, je perdis mon père, et ma mère me fit revenir à Florence pour que je l'accompagne en Angleterre. Depuis toute petite, j'aspirais à entrer dans les ordres; je souhaitais donc retourner dans mon couvent, mais cette perspective rendait ma mère très malheureuse et je me laissai persuader d'aller avec elle. Je reçus des lettres de Lady Rivers qui évoquaient tous les gens les plus en vue du moment - Sir J. Reynolds, Cipriani, Bartolozzi, Angelika Kauffmann. Je fus mise en contact avec M. Cosway, sa proposition fut acceptée, les vœux de ma mère furent comblés et je me mariai, bien que n'étant pas majeure. Durant une année environ, je ne sortis pas dans le monde, jusqu'à ce que je me sente en phase avec la société que je devais fréquenter, les effets que produisaient sur moi les expositions, les goûts et le caractère du pays.

6 Le souhait de M. Cosway était que je continue de pratiquer les arts, ce que je fis. Les premières toiles que j'exposai consacrèrent d'emblée ma réputation - la nouveauté et mon jeune âge y contribuèrent, plus que mon talent. Le portrait de la duchesse du Devonshire, une femme ravissante, arbitre des élégances, réalisé à la façon de la Cynthia de Spencer, fit apparemment son effet, ainsi que d'autres tableaux à sujet historique tirés de Shakespeare, Virgile et Homère. Cela m'encouragea, mais pour autant je n'en conçus aucune fierté et poursuivis au gré de mon imagination. Si M.C. m'avait autorisée à me ranger parmi les peintres professionnels, j'aurais dû être une meilleure artiste mais, laissée à moi-même, je cessai peu à peu de progresser et perdis tout ce que j'avais appris durant mes jeunes années en Italie.

7 La pratique de la musique faisait de mes soirées des moments fort agréables. Lady Lyttelton, l'honorable Mrs Damer, comtesse d'Ailesbury, Lady Cecilia Johnston, marquise de Townsend, étaient de très proches amies, et ensemble nous allions rendre visite à Lady M. Duncan, à Miss Wilks et au général Paoli, le ministre des Affaires étrangères, à Lord Sands et M. Erskine, des étrangers raffinés, des hommes très talentueux, et bien d'autres tout aussi distingués, qui formaient une agréable compagnie avec qui passer nos soirées. On donna même de grands concerts dont on parla jusque dans un ouvrage sur la musique paru en Allemagne sous la houlette du grand professeur H.R.H., le prince de Galles, dont l'éloge est fait continûment.

Le climat ne me réussissait pas et malgré ces moments si heureux, j'avais toujours des problèmes de santé. M. C. eut la bonté de m'emmener visiter les Flandres et Paris. Il me proposa d'aller en Italie, mais tous les ans le voyage fut reporté.

9 Je n'eus qu'un enfant, une petite fille. La grossesse fut difficile et l'accouchement pire encore, au point de mettre ma vie en danger, et les médecins m'incitèrent à changer d'air. Lady Wright se rendait en Italie pour y faire soigner son fils; mon frère George Hadfield avait été gratifié de la médaille d'or et allait séjourner à l'Académie de Rome. M. Cosway m'acheta un attelage et tous ensemble, avec une domestique, nous prîmes la route de Rome. Mais ma santé fut si fragile que je ne pus aller jusqu'au terme du voyage. Dès que je me sentis un peu mieux, j'écrivis à M. C. que j'étais prête à revenir. Durant presque trois années, du printemps à l'automne, il me fit la promesse constante 
de me rejoindre à Rome. Mais il tomba subitement malade : je pris la route et voyageai sans m'arrêter, traversant les pays en guerre et affrontant moult dangers et, en plein mois de novembre, j'arrivai à la maison saine et sauve et eus le bonheur de retrouver M. C. en meilleure santé. J'engageai une jeune fille très bien pour s'occuper de toutes mes affaires. Mes amis eurent l'immense plaisir de me retrouver. Durant deux ans, j'eus la joie de voir grandir ma fille et de profiter de son éducation; elle fut prise par un mauvais mal de gorge et nous la perdîmes alors qu'elle n'avait que six ans; notre chagrin fut immense.

De nouveau, je me consacrai à la peinture. Je m'attelai à plusieurs fresques pour des églises. On parlait beaucoup de la galerie du Louvre, à cette époque. M. C. ne pouvait s'y rendre car les deux pays étaient en guerre, et du coup il m'y dépêcha. Je fis mon miel de toutes les œuvres et eus l'occasion de fréquenter de près la famille régnante. J'interrompis mon travail, mais ne pus rentrer dans mon pays, faute de passeport. L'archevêque de Lyon, Mgr Fesch, me proposa de me trouver une école pour jeunes femmes, et avec la permission de M. C., j'en pris la direction. Mais le changement de gouvernement mit fin à ce projet. Je me rendis à Milan : ma sœur, qui s'était mariée, habitait non loin. Un vieil ami à moi, Melzi, duc de Lodi, désireux d'établir en Italie un établissement semblable à celui de Lyon, acheta un couvent à Lodi et je m'y attelai avec beaucoup de succès. La paix revenue, je rentrai dans mon pays et y séjournai jusqu'à la mort de M.C. Aujourd'hui je suis ici [en Italie] - je m'attache à aider cette école à s'établir solidement, ce qui me vaut la réputation d'être la première femme en Italie ayant suivi la vocation qui fut toujours la mienne: m'occuper de bonnes œuvres en faveur des jeunes femmes. Mes mémoires seront peut-être aussi longs que ceux de M. C. sont brefs, mais ils contiendront une foule d'anecdotes intéressantes. Je ne sais jusqu'à quel point je peux aujourd'hui en dire plus : dites-moi si ce que je vous ai écrit ici est suffisant pour le moment. Ma situation aisée et heureuse pouvait susciter l'envie, la méchanceté et l'inimitié - je préfère ne pas en tenir compte, cela ne mérite pas qu'on y pense. Un jour, mes amis auront la preuve que je méritais leur amitié - et c'est au nombre de mes amis que je vous compte et vous aurai toujours en mon souvenir, comme votre obligée et bien affectionnée

Maria Cosway

Je vous prie de bien vouloir demander à Lady Cosway et Miss Gardner qu'elles aient la gentillesse de remarquer que je n'avais nullement l'intention de vous être importune, mais juste de vous faire part de mes intentions, vu que vous devez faire un choix dans les informations que je vous donne - et je vous prie également de bien vouloir m'envoyer des nouvelles du roi.

\section{ANNEXES}

Lire des extraits du Journal de Maria Cosway

Lire l'introduction à Maria Cosway écrite par Fanny Reboul 
Anne Plumptre (1760 - 1818) 


\title{
Introduction
}

\author{
Isabelle Baudino
}

1 Le goût d'Anne Plumptre pour les voyages constitue le véritable fil directeur de son œuvre littéraire originale. Dans ses romans, Antoinette (1796), The Rector's Son (1798), Something New, or, Adventures at Campbell House (1801) et The History of Myself and a Friend (1817), les hésitations amoureuses et les dilemmes moraux entraînent les héros dans des aventures et sous des cieux exotiques. En prolongement des récits de ses propres voyages en Europe continentale et en Irlande, elle publia, entre 1803 et 1814, les traductions des voyages en Afrique du Sud d'Henry Lichtenstein, de ceux de François Pouqueville dans l'Empire ottoman et de l'expédition de Georg Heinrich von Langsdorff autour du monde. Connue également pour ses traductions du récit de la peste de 1720 à Marseille par Jean-Baptiste Bertrand, de la correspondance de Friedrich von Matthisson, de la biographie et de pièces de théâtre d'August von Kotzebue, Anne Plumptre fut une femme de lettres audacieuse et talentueuse.

2 Née à Norwich dans une famille qui comptait plusieurs générations d'ecclésiastiques et d'intellectuels, elle reçut une excellente éducation. Sa mère, elle-même fille d'instituteur cultivée, et son père, membre du clergé anglican et recteur du Queen's College à Cambridge, lui offrirent, ainsi qu'à ses cinq sœurs, une ouverture culturelle et des enseignements exceptionnels pour l'époque (PLUMPTRE [1801] 1996, introduction, p. vii). Ce fut également à Norwich qu'Anne - accompagnée de sa sœur Annabella (1769-1838) - fit ses débuts littéraires, en 1790, dans le cercle réformiste rassemblé autour du pasteur unitarien William Enfield et du germaniste William Taylor. Les sœurs Plumptre se lièrent alors d'amitié avec une jeune femme de lettres, Amelia Alderson, qui partageait leur engagement politique (PLUMPTRE [1801] 1996, introduction, p. ix-X).

3 En 1802, Anne Plumptre partit en France en compagnie d'amis, dont peut-être Amelia Alderson et son époux, le peintre John Opie. Comme les nombreux Britanniques qui traversèrent la Manche à la faveur de la paix d'Amiens, elle était mue par une curiosité politique autant qu'artistique. Cela transparaît dans son Narrative of A Three Years' Residence in France, Principally in the Southern Departments, from the Year 1802 to 1805 où elle propose une analyse de l'action de Bonaparte et de sa réception par les Français. Revendiquant ce que nous appellerions aujourd'hui un travail de terrain, elle s'appuie sur une enquête menée pendant trois ans sur tout le territoire français (dont huit mois 
à Paris) pour dresser un portrait positif du dirigeant français. Soucieuse de rectifier les critiques britanniques à l'égard de Napoléon, elle rédige une défense très argumentée et ne dissimule pas son admiration, notamment dans les derniers chapitres de son récit. Paru en 1810, huit ans après la paix d'Amiens, et dans un contexte de tensions renouvelées entre la France et le Royaume-Uni, son panégyrique lui valut des attaques très virulentes.

Moins critiqués, ses commentaires artistiques n'en sont pas moins personnels. Sa connaissance des arts transparaît dans ses commentaires des œuvres exposées au Louvre. On y décèle aussi sa volonté de ne pas se cantonner dans un rôle de commentatrice. Elle remet en question le choix de certains sujets, ou leur traitement par les artistes, mais également les évaluations des critiques. Dans les musées parisiens, comme devant les paysages du sud de la France qui l'éblouissent, elle affiche une confiance en son goût et une autorité toutes mécénales.

\section{BIBLIOGRAPHIE}

PLUMPTRE (1801) 1996

Anne PluMPTRE, Something New, or, Adventures at Campbell House, Deborah McLeod (éd.),

Peterborough, Broadview Press, (1801) 1996.

PLUMPTRE 1810

Anne PLUMPTRE, A Narrative of A Three Years' Residence in France, Principally in the Southern Departments, from the Year 1802 to 1805: Including Some Authentic Particulars Respecting the Early Life of the French Emperor, and a General Inquiry into his Character 3 volumes, Londres, Mawman, Ridgeway, Clarke, crosby and Constable, 1810.

SHAFFER 2004

Elinor SHAFFER, “Plumptre, Anne (1760-1818)", Oxford Dictionary of National Biography, Oxford University Press, 2004. [En ligne] : consulté le 26 août 2011.

\section{ANNEXES}

Diaporama des œuvres observées par Anne Plumptre lors de son voyage en France, relaté dans son ouvrage Relation d'un séjour de trois ans en France : http://www.flickr.com//photos/73632227@N02/sets/72157629321265256/show/ Lire des extraits de la Relation d'un séjour de trois ans en France d'Anne Plumptre Liste complète des œuvres d'arts commentées par Anne Plumptre à travers ses textes édités dans Plumes et pinceaux 


\section{Anne Plumptre, Relation d'un séjour de trois ans en France, 1810}

A Narrative of a Three Years' Residence in France, Principally in the Southern Departments, from the Year 1802 to 1805: Including some Authentic Particulars Respecting the Early Life of the French Emperor, and a General Inquiry into his Character, Mawman et al. (éd.), Londres.

\section{Chapitre III}

Diverses entrées de Paris. L'hôtel d'Angleterre. Le musée du Louvre. Le musée des Monuments français. La Bibliothèque nationale

Il faut convenir que Paris ne se montre pas sous un jour flatteur au voyageur qui y entre en venant de Calais ; autant entrer dans Londres par Shoreditch ou Smithfield; les rues sont étroites et sales à l'excès, les maisons pauvres et sordides. Paris, comme Londres, ne doit pas être abordé par le nord mais par l'ouest pour être vu sous son meilleur aspect, car en passant par les Champs-Élysées ou en suivant la rive du fleuve par les hameaux de Chaillot et de Passy, certains des édifices qui se présentent à la vue sont parmi les plus beaux de la ville.

Nous avons pris pension, ainsi qu'on nous l'avait conseillé par erreur, chez M. Roch, à l'hôtel d'Angleterre, rue des Filles-Saint-Thomas, près du Palais-Royal. Mais je ne recommanderais cet hôtel à aucun de mes compatriotes, dans l'éventualité très souhaitable où des relations amicales se renoueraient entre la France et l'Angleterre. Je les engage au contraire à l'éviter à tout prix; l'hôtellerie elle-même est sinistre, sombre, malpropre, et dans un mauvais quartier de la ville; et si je doute que l'honnêteté des tenanciers d'hôtels garnis soit d'ordinaire l'aspect le plus reluisant que la capitale française ait à offrir, j'espère cependant que la profession compte peu de coquins aussi fieffés que M. Roche. Cet avertissement me paraît nécessaire, puisqu'il paye un bon prix les postillons pour attirer les étrangers dans son établissement, de sorte que ces gens ne manquent jamais de le recommander consciencieusement. 
Je ne détaillerai pas par le menu les nombreux objets de curiosité que Paris propose à l'attention des étrangers. Parmi les Anglais qui visitèrent la capitale en 1802, on en a publié tant de descriptions que tout lecteur anglais se trouve désormais amplement familiarisé avec elle ou en possède les moyens; du moins pour ce qui regarde les plus précieuses productions, tant de la nature que de l'art, dont elle est dépositaire, et les profondes connaissances scientifiques ou autres que ses savants et ses lettrés ont acquises. Un ouvrage en particulier, intitulé Paris as it was and as it is ${ }^{1}$, fait de tout cela une relation si complète, si érudite et si fiable que, si je m'étais surtout proposé en entreprenant celle-ci de donner une description de Paris, j'aurais jeté ma plume en voyant l'essentiel de ce que je pourrais dire beaucoup mieux exprimé ailleurs. Cependant, je n'omettrai pas tout à fait ce chapitre de mon séjour, d'abord parce que ce serait dissocier les autres parties de mon récit; et de plus, comme chaque visiteur d'un pays étranger est naturellement conduit, par ses propres goûts, habitudes et manières d'envisager les choses ainsi que les événements, à rechercher et considérer ce qui échappe à autrui, quelques remarques et réflexions rapides peuvent être hasardées sans encourir le risque de répéter tout bonnement ce que d'autres ont déjà dit.

4 Même en considérant la magnifique collection qui fait la meilleure part de ce que l'on pourrait nommer les « curiosités » de Paris, j'entends le musée du Louvre, j'ai constaté que des objets à mon avis très remarquables étaient passés sous silence par certains, malgré la minutie de leurs critiques de détail sur l'ensemble de la collection ou ses diverses pièces.

\section{1. [Anonyme], Diane}

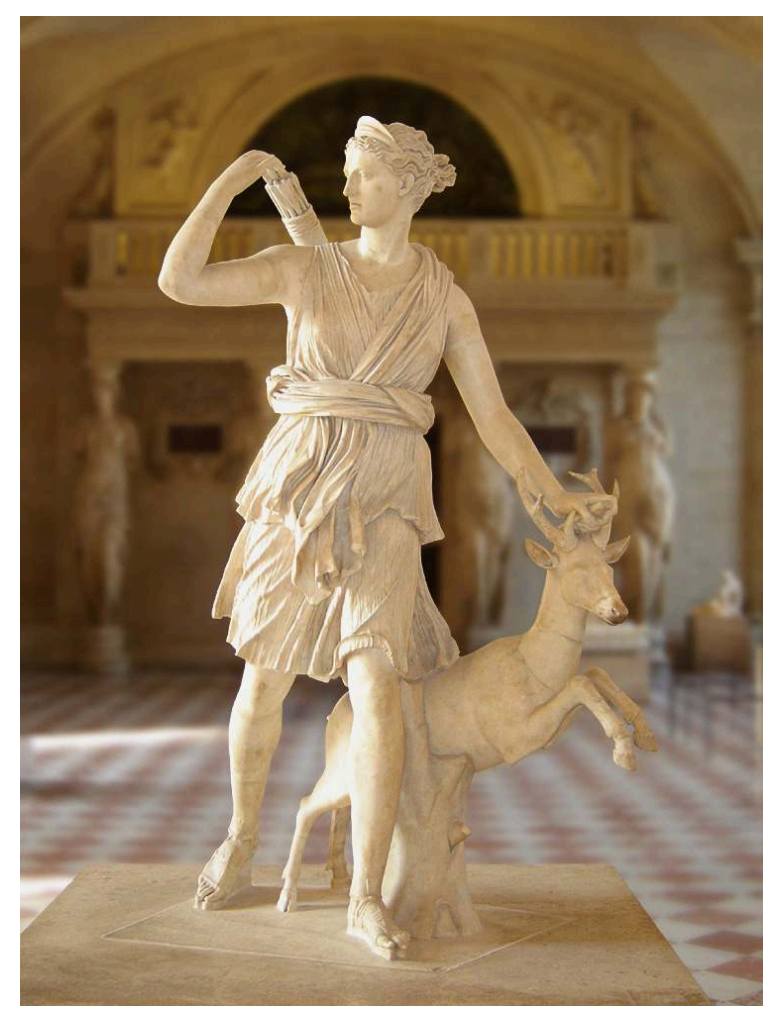

Paris, musée du Louvre. 


\section{2. [Anonyme], Apollon du Belvédère}

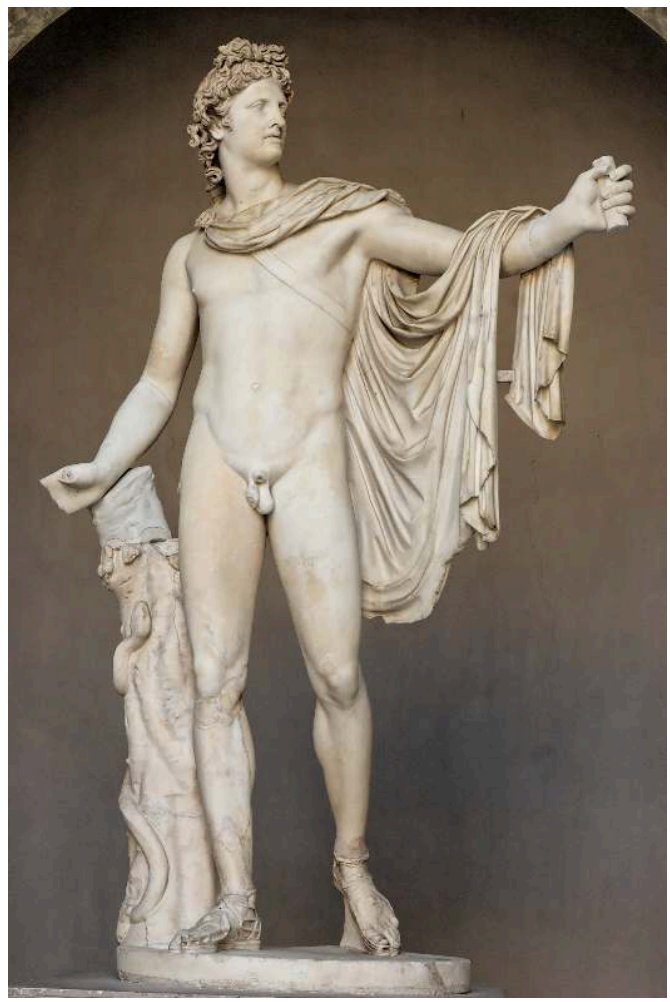

Copie romaine réalisée vers 130-140 après J.-C., marbre, 224 cm, cité du Vatican, musée Pio Clementino.

\section{3. [Anonyme], Laocoon}

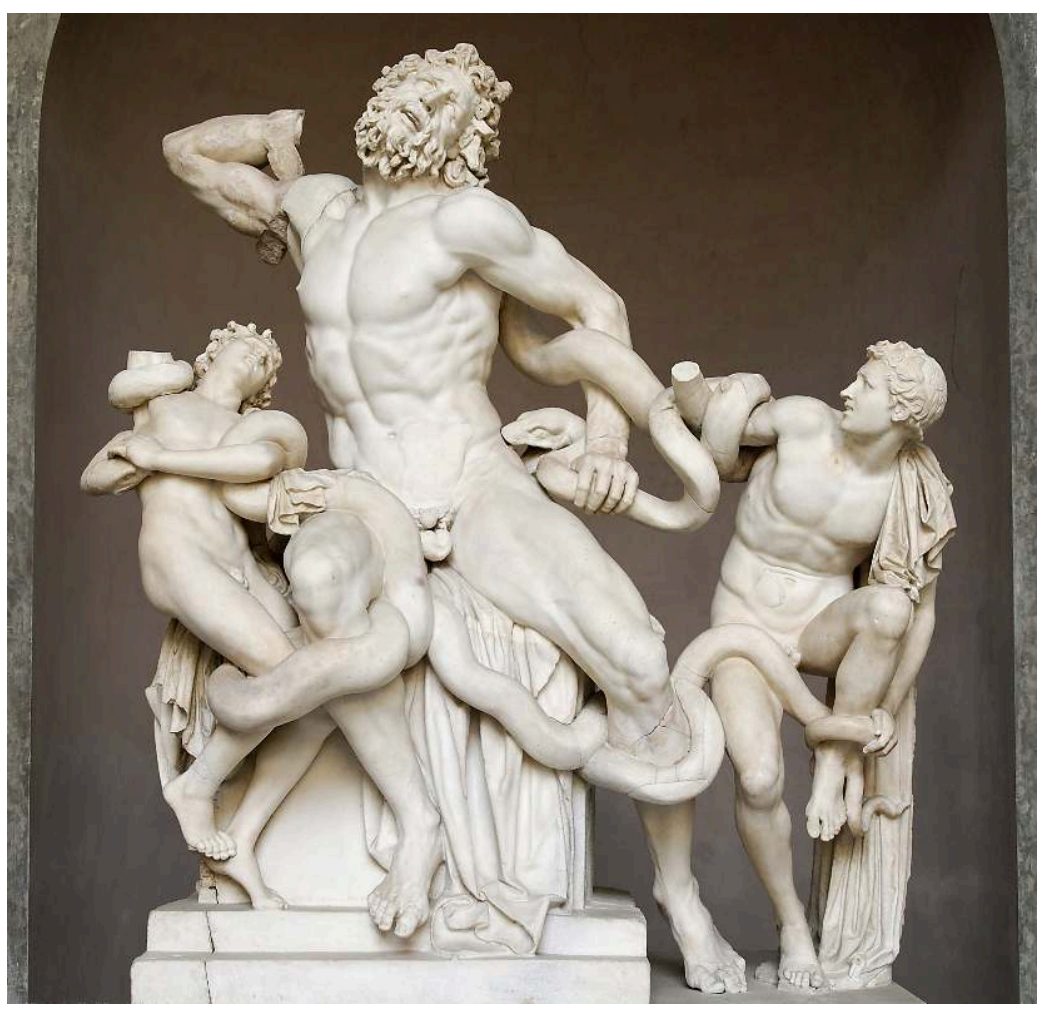

Ier siècle av. J.-C., marbre, 242 cm, cité du Vatican, musées du Vatican. 
Ainsi, la superbe Diane de la salle des Saisons n'a pas été particulièrement signalée, pour autant que je sache, si ce n'est dans l'ouvrage mentionné plus haut, et il s'agit pourtant de l'un des objets les plus dignes d'admiration que cette salle contienne (fig. 1). Elle n'est pas inférieure, ou de bien peu, à l'Apollon du Belvédère, et c'est le plus bel éloge que l'on puisse faire (fig. 2). Le Laocoon, quoique également admirable comme sculpture, n'offre pas à la contemplation le même degré de plaisir; en assistant au tourment de l'âme et du corps qu'endurent les êtres représentés là, exprimé d'une manière dont on a peine à croire qu'un marbre insensible ait pu s'y prêter, l'habileté de l'artiste nous frappe d'étonnement, mais d'un étonnement mêlé de détresse au spectacle de ces agonies (fig. 3) ; alors qu'en contemplant l'Apollon et la Diane, la seule beauté des figures nous inspire du plaisir, indépendamment de toute idée annexe touchant les singuliers talents que leur dessin et leur exécution supposent.

Si j'ai mentionné cet exemple parmi d'autres qui se présentaient à moi, c'est afin d'illustrer mon propos, à savoir que l'objet devant lequel tel spectateur passe à la hâte voit souvent tel autre s'y arrêter avec une dilection particulière; et que si chacun convient que cette collection, prise dans son ensemble, est incomparable, tous ne s'accordent pas sur les objets qu'ils ont choisi de distinguer. L'Apollon est si bien établi dans sa gloire qu'il est prisé de tout le monde, personne ne lui refuse le tribut d'admiration qu'il mérite ; alors que la Diane, dont les titres à la célébrité sont peutêtre équivalents, ne jouit pas d'une faveur aussi universelle et doit compter sur l'intérêt qu'elle peut susciter par ailleurs. Je ne puis rien dire de la Vénus Médicis, car elle n'était pas arrivée à Paris au moment de mon départ. Durant mon séjour, une nouvelle salle fut ouverte où parmi quantité d'œuvres de valeur se trouvaient quelques mosaïques d'une beauté sans égal. Pour le reste, à dire vrai, il faudrait demeurer fort longtemps dans les parages de cette collection et la fréquenter avec une attention suivie, avant de se faire une juste idée de l'éminente et même suréminente qualité de la multitude d'objets divers qu'elle contient. Ayant séjourné huit mois à Paris, je l'ai visitée à maintes reprises sans acquérir ne serait-ce que la moitié des connaissances souhaitables; je n'ai pu prendre de la variété de ses mérites une idée suffisamment précise à mon goût, et il me semble que je pourrais employer huit mois encore à parfaire autant que je le désire la compréhension qui leur est due. Au nombre des choses les plus frappantes et dont je n'ai pas trouvé mention, il y a dans la Grande Galerie de peintures un bronze de Mercure prêt à l'essor, un pied détaché du sol et l'autre n'y tenant plus que par la pointe, figure d'une légèreté si aérienne que l'on s'attend à tout moment à la voir s'envoler pour de bon. Dans une boutique, j'en ai vu une copie dont le propriétaire demandait une centaine de couronnes ou de demicouronnes, comme on dit, soit 125 livres. Elle était de très bonne facture. 


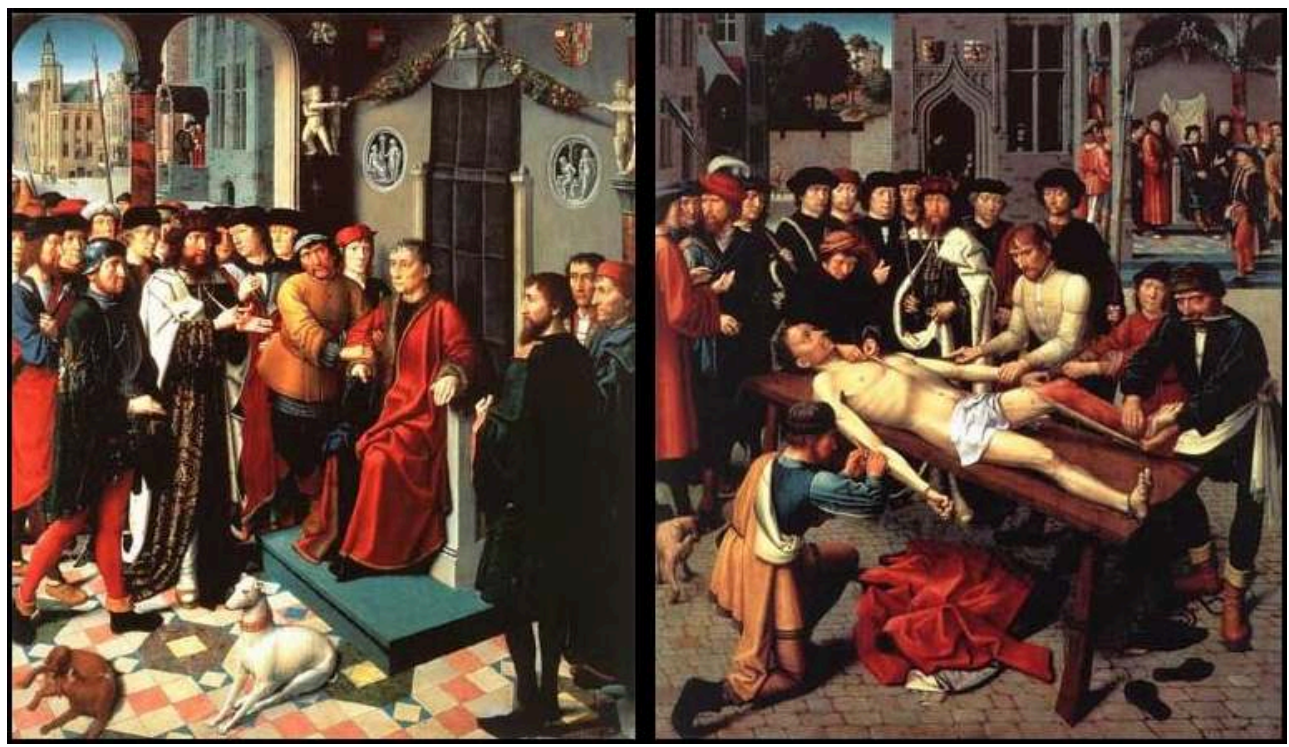

Diptyque : Le Jugement de Cambyse, l'arrestation ; Le Jugement de Cambyse, Le Supplice, 1498 (?), Bruges, Groeningemuseum.

7 Pourtant, parmi ces objets d'enchantement, la Grande Galerie possède une peinture, bien exécutée d'ailleurs, mais dont le sujet est à mon avis trop horrible pour qu'on l'expose publiquement devant toutes sortes de personnes, et de toutes qualités. Je veux parler de l'histoire bien connue du mauvais juge, écorché vif sur ordre de Cambyse, roi des Perses (fig. 4). Je ne peux exprimer l'impression que cette image m'a faite : parler d'horreur extrême, ce serait peu dire ; il est une espèce d'horreur qui ne manque pas de produire un effet salutaire à l'esprit; mais celle-ci vous déchire les nerfs; l'âme se révulse de dégoût à l'idée qu'un être humain ait pu ordonner et que d'autres aient exécuté une sentence si atrocement barbare. Si injuste que ce juge ait été, quelle que fût son iniquité, à moins d'avoir prononcé lui-même une peine de ce genre, rien ne saurait justifier pareil châtiment. Aujourd'hui encore, il m'est impossible d'évoquer cette image sans frissonner et sans me demander comment un peintre peut occuper son esprit d'un tel sujet, avec le soin et le temps que requiert le parfait achèvement de son ouvrage. L'impression que nous en retirons quant à son goût et à sa sensibilité n'est guère favorable : pour son goût, on le jugera mauvais sans craindre de se tromper, car aucun homme de goût n'aurait choisi d'exercer ses talents sur un sujet en tout point révoltant, et un tel choix ne donne pas une opinion plus favorable de son cœur. L'œuvre est attribuée à Antoine Cloissens, un peintre flamand ${ }^{2}$.

Décidément, je le répète, il me semble que pour des raisons morales un tel sujet ne devrait pas être exposé à la portée de tous les regards. Les personnes aux nerfs fragiles risquent d'être sérieusement atteintes dans leur sensibilité, et pour une autre sorte d'individus des conséquences plus graves sont à craindre. Immanquablement, l'être disposé à la cruauté sentira s'endurcir son cœur s'il s'accoutume à la représentation d'un geste d'une atrocité si poussée, même sur une toile muette. Rien n'est plus susceptible de corrompre le cœur, que de le familiariser avec des scènes dont il devrait se détourner avec horreur.

9 Il m'a toujours semblé que la plupart des cruautés commises durant la Révolution pouvaient s'expliquer par la tournure d'esprit que l'habitude des exécutions publiques 
a donnée aux Français sous l'Ancien Régime, en les accoutumant si bien à ces scènes d'horreur qu'elles ne soulevaient en eux aucune répugnance. Lorsque nous lisons une description du supplice de la roue et songeons que des personnes de tous rangs et de toutes conditions assistaient à ce genre de spectacles, que chacun s'y pressait de haut en bas, riches et pauvres, hommes, femmes et enfants, faut-il s'étonner que le peuple, endurci par ces scènes détestables, se soit rué à toute sorte d'excès lorsque les entraves qui le refrénaient eurent cédé? En regard de ceux qui pouvaient ordonner et administrer de telles peines, on est tenté de dire que Robespierre n'était pas un monstre. Quoiqu'il fitt tomber les têtes par centaines, sous sa dictature personne ne fut mis au chevalet ni rompu sur la roue ; ses victimes mourant sur le coup, leur souffrance physique était brève; et quant aux souffrances morales, si la perspective d'être guillotiné en un instant est une idée terrible sans doute, combien plus, infiniment, celle d'une mort lente et de tourments prolongés! La Révolution n'aurait-elle rien apporté d'autre à la France que l'abolition de ces scènes dégradantes et nocives pour le pays, le gain ne serait-il pas somme toute incontestable? Les lois divines qui autorisent ici-bas nos législateurs à retrancher le meurtrier de la surface de la Terre ne sauraient justifier le chevalet ni les tortures.

On peut dire, je le sais, que la torture n'était pas pratiquée sous Louis XVI. Cela est très vrai ; mais quoique les dispositions de Louis fussent humaines et douces, et que son administration corrigeât les abus qu'autorisait une législation vicieuse par nature, ces lois cependant ne laissaient pas d'exister et pouvaient redevenir sous une main moins clémente le fléau que le pays avait souvent connu par le passé. Rien, sinon leur abrogation complète, n'aurait pu réellement assurer le peuple qu'on ne les brandirait plus un jour ou l'autre à ses dépens; elles sont abolies désormais, et le châtiment des criminels s'en trouve adouci autant qu'il peut l'être, puisqu'une peine qui ne se ferait pas sentir ne mériterait plus son nom.

11 Passer sans lui accorder un regard devant le musée des Monuments français, au cidevant couvent des Petits-Augustins, serait chose impossible. Il mérite d'être décrit, en vérité, comme ces lieux

« habités par la seule innocence,

où règne, avec la paix, un éternel silence ${ }^{3}$ ».

Les héros et les dieux fabuleux du Louvre, même si nous leur accordons la suprême admiration que méritent les modèles parfaits de la statuaire, ne sauraient produire sur la sensibilité l'effet que nous éprouvons en contemplant ces monuments de la vertu et de la grandeur défuntes. Nous admirons les splendides proportions, l'exquise symétrie de l'Apollon et de la Diane, pourtant leurs personnes n'éveillent nul sentiment de sympathie dans nos cœurs; mais qui peut contempler sans un soupir le tombeau d'Héloïse et d'Abélard!

13 En visitant cet endroit, chacun concevra une admiration profonde pour la ténacité et la persévérance dont le grand Lenoir a fait preuve en imaginant, en réalisant le plan du musée et en sauvant ainsi de la destruction tant de précieux vestiges de l'ancien temps ; et le goût que leur agencement atteste n'est pas moins admirable. Je n'entreprendrai pas d'analyser l'histoire de cette institution, sa renommée a pris une telle ampleur que la chose serait superflue. Je n'ai pu pénétrer là sans une sorte de crainte sacrée, tant on dirait que nous y entourent en un même point de l'espace et du temps des êtres éloignés les uns des autres autant que de nous-mêmes par les lieux et les jours où ils vécurent. Cela est bien plus impressionnant que Westminster Abbey, dans la mesure où 
l'on n'eut ici d'autre objet que de préserver les morts vénérables et les ouvrages d'art qui leur rendent honneur; ainsi, rien ne vient rompre le cours des pensées qu'un tel assemblage nous inspire à dessein, mais dans Westminster Abbey d'autres objets et d'autres associations s'interposent et s'entremêlent à la musing melancholy qui touche tout esprit disposé à la contemplation de la fragilité des grandeurs humaines, dont l'idée semble prendre corps sous nos yeux.

Cependant, si nous considérons uniquement ces monuments comme des spécimens de sculpture et que, retournant au Louvre, nous les comparions aux représentants d'un art sans égal, l'esprit se sent frappé d'une morne stupeur en mesurant l'immense distance qui sépare les meilleurs ouvrages des époques tardives et ceux, fussent-ils les plus ordinaires, que des âges autrement lointains nous ont laissés. En comparant les productions de ces diverses périodes, il perçoit de la manière la plus vive ce que fut la régression des arts dans les sociétés civilisées lorsque les invasions barbares eurent recouvert et abattu l'Empire romain. Il nous semble bien peu naturel, à nous qui voyons toutes choses s'améliorer progressivement dans les arts et les sciences, que les frustes statues du XII ${ }^{\mathrm{e}}$ siècle soient venues si longtemps après l'Apollon du Belvédère.

Le bras de la Providence a retenu la France sur la pente d'une autre régression, en cette journée à jamais mémorable du 9 thermidor qui vit finir le règne de Robespierre. Eût-il triomphé alors, le destin de la France était scellé, et tout ce qui subsistait de bon dans le pays en fait de morale comme dans les arts et les sciences était jeté par-dessus bord. Le train des destructions précédentes n'eût été qu'un faible gage de celles qui devaient suivre, si un succès avait affermi ce jour-là son système dévastateur.

Quand on voit à quels excès fut portée la frénésie de destruction qu'il s'employa à exciter tant que dura son pouvoir, comment elle se propagea partout en France, se communiquant d'une personne à l'autre et de province à province aussi rapidement qu'une contagion, on s'étonne seulement que tant d'objets de valeur, et de toutes sortes, aient pu être sauvegardés. Chose surprenante, quand chaque jour de si terribles hécatombes étaient offertes en sacrifice sur les ruines de la noblesse et de la royauté défuntes, beaucoup d'objets qui semblaient destinés par nature à nourrir le bûcher funèbre furent épargnés des flammes. Quand les églises étaient vouées à la destruction, les ministres du culte chassés du pays, abreuvés d'humiliations, il semble extraordinaire que de précieuses bibliothèques aient été préservées en si grand nombre et que Paris les possède encore; rien de plus singulier: la démagogie choisissait d'exercer sa fureur sur des pierres inoffensives alors que les livres, qui sont les pires ennemis des démagogues parce qu'ils éclairent l'esprit, échappaient à leurs ravages.

Les collections de la Bibliothèque nationale sont dignes d'une nation comme la France, qui a longtemps soutenu un rang si distingué dans la science et la littérature; mais leur rangement actuel les dessert, et ceux qui se contentent de les traverser seront moins impressionnés par leur ampleur qu'elles ne le méritent en réalité. On dit que l'intention de Bonaparte était de retirer les livres du Louvre et de les disposer selon un nouveau plan. Ils sont à présent dispersés sur un trop grand espace; et tandis que la longue succession des salles dégage une impression de grandeur, le nombre des livres éparpillés de la sorte paraît moins considérable que s'ils se trouvaient rassemblés. Le Cabinet des médailles, gemmes antiques et autres curiosités, est d'un agrément inépuisable.

18 Évoquer en passant des lieux tels que le Louvre, le musée des Monuments français ou la Bibliothèque nationale, c'est risquer de paraître insensible à leurs mérites ou, portée 
par un sentiment de jalousie patriotique, à leur dénier sciemment l'admiration qui leur est due. Si je ne m'y suis pas attardée davantage, je dois le redire ici, c'est dans la seule crainte d'ennuyer le lecteur en lui répétant ce qu'il a déjà lu ailleurs plusieurs fois.

Les Français sont dignes de louanges pour la libéralité dont ils témoignent en laissant l'usage et l'agrément de leurs collections au public, et en particulier aux étrangers. Toutes sont ouvertes deux fois par semaine à quiconque se propose de les visiter, alors que les étrangers, les artistes et les lettrés peuvent y entrer tous les jours et ce, la chose mérite d'être notée, sans aucune dépense ; aucun homme de service, portier ou autre employé, n'est autorisé à recevoir la moindre gratification. Voilà qui est digne, vraiment, d'une nation libérale et éclairée. Qui veut voir et examiner les trésors de ces collections fera bien de choisir l'un des jours réservés; mais il est bon d'y venir quelquefois les jours publics, pour se mêler à la compagnie. Les salles sont alors remplies d'une foule de personnes de toutes conditions et de toute espèce, toutes observant l'ordre le plus exact, et offrant l'extraordinaire spectacle de l'ignorance la plus complète et de la connaissance la plus éclairée réunies dans une admiration commune, l'ignorant contemplant avec le même respect que l'homme de science et, apparemment, avec un égal plaisir, des œuvres dont la vraie valeur doit passer de bien loin sa compréhension; je doute que dans notre pays une foule aussi composite manifeste le même respect devant des œuvres comparables ou sache observer le même ordre et la même tenue que la populace parisienne. En vérité, je doute que John Bull puisse retirer le même agrément ou le même profit d'un libre accès à des collections de ce genre. Il préférerait probablement l'enseigne d'une bonne chope de bière, devant le seuil de quelque débit de boisson, aux toiles les plus achevées de Raphaël ou du Corrège, et estimerait que le marbre serait mieux employé au lestage d'un navire ou aux travaux de voirie qui faciliteraient le passage de la malle-poste.

\section{Chapitre XVII}

Saint-Cloud. Versailles. Le Petit Trianon. Adieu à Paris

Une excursion que nous avions projeté de faire aux environs de Paris durant une semaine ou une dizaine de jours se réduisit finalement à un dimanche à Saint-Cloud et un autre à Versailles. Le temps qui nous restait fut réservé à notre retour à Paris, où je n'étais pas revenue encore.

21 À Saint-Cloud, nous n'avons pu entrer dans le château, car il était plein d'ouvriers qui le préparaient à recevoir Bonaparte, et personne n'était autorisé à le visiter. Déception supplémentaire, nous étions mal informés des heures où sont actionnés les jeux d'eau, aussi sommes-nous arrivés un quart d'heure après qu'ils eurent cessé. Malgré ces déceptions, Saint-Cloud m'a charmée. Les jeux d'eau artificiels sont imposants, sans doute, mais les arbres penchés sur les coteaux qui montent de la Seine ont une beauté naturelle que ne peut surpasser aucun effort de l'art. Ils ont de quoi surprendre, car la nature est généralement bannie des jardins français. Les Anglais trouvent extraordinaire ce goût pour les allées, pour les parterres découpés en carrés, cercles, demi-cercles, parallélogrammes, triangles et autres figures géométriques de toute sorte, jointes aux jets d'eau, aux cascades artificielles que nous avons vues jaillir tant de fois autour de nous, choses si fréquentes en France. Certes, une longue avenue a un air de grandeur, quoiqu'elle s'écarte de la nature, et elle ajoute souvent à la beauté d'un 
grand parc, mais les petits carrés, cercles et demi-cercles sont incontestablement dénués de grandeur et de goût.

Quoique dans le parc de Saint-Cloud un tel souci de symétrie m'étonne et que les forêts laissées à la nature me semblent l'emporter de bien loin sur le formalisme de la plupart des jardins français, les Français estiment de leur côté que s'il est besoin de défendre Saint-Cloud, c'est que la régularité y laisse à désirer. Mais, disent-ils, l'irrégularité du sol ne permettait pas de mieux faire, et c'est pourquoi Le Nôtre, qui se chargea de l'agencer, a disposé chaque chose avec une habileté merveilleuse, de sorte que l'ordre le plus parfait semble régner partout; aussi voient-ils là le chef-d'œuvre de l'art des jardins. Cette justification me semble tout à fait superflue, mes compatriotes en conviendront. J'avoue que Saint-Cloud me paraitrait d'une beauté sans pareille si Le Nôtre n'y avait pas touché et que les soins de son embellissement aient répondu au goût moins régulier qui prévaut dans les jardins anglais.

Le château de Saint-Cloud se dresse sur le versant d'une grande colline, d'où la vue s'étend sur la campagne alentour et, plus loin, jusqu'à Paris. Un jour, à Paris, comme nous traversions le pont des Tuileries et croisions deux passants qui se saluaient, l'un demandant à l'autre où il allait d'un si bon pas, nous l'entendîmes répondre qu'il se hâtait vers les Tuileries pour voir monseigneur Bonaparte qui se rendait en visite officielle au Sénat. À Saint-Cloud, on nous déclara que nous ne pouvions visiter le château car on le préparait à recevoir M. de Bonaparte : c'en était fini du Citoyen consul ou du Citoyen général.

Le parc et les jardins de Saint-Cloud sont toujours ouverts au public le dimanche; la compagnie y était donc nombreuse et la plupart, s'adonnant à leur divertissement préféré, dansaient par petits groupes. Je ne vois rien, je l'avoue, de foncièrement immoral à danser le dimanche, mais comme il me semble que la convenance ou l'inconvenance de la chose dépend entièrement des coutumes du pays, j'ai toujours observé avec plaisir l'enjouement qui règne partout en France ce jour-là, et le trouve plus conforme à l'esprit qui préside au repos dominical que la morne et sombre manière dont nous l'employons en Angleterre. Au fond, passer l'après-midi du dimanche à danser est une occupation plus innocente, à n'en pas douter, que d'aller boire à la taverne ; ceux qui mènent d'ordinaire une existence dissipée, s'ils peuvent consacrer un jour par semaine à des réflexions plus sérieuses, à supposer qu'ils soient capables de réfléchir, eh bien tant mieux; pour eux, rompre chaque fin de semaine avec leurs plaisirs déréglés peut être bénéfique au corps comme à l'esprit; mais pour qui doit gagner sa maigre subsistance en travaillant durement pendant six jours, il n'est certes pas déraisonnable de se délasser le septième, et qu'ayant observé le matin ses devoirs religieux il lui soit permis d'achever sa journée par un plaisir innocent. J'ai souvent observé les danses dominicales des paysans français, car la joie qu'ils en retirent faisait toujours plaisir à voir; et je n'ai jamais constaté dans leur comportement rien qui passe les bornes de la plus stricte décence. L'enjouement qui régnait parmi eux n'était pas mon seul plaisir, c'en était un autre de les voir danser. Cela semble un talent si naturel aux Français, à tous les étages de la société, que parmi ces paysans sans instruction j'en ai vu danser qui, en Angleterre, auraient fait honte à plus d'un habitué de nos salles de bal. Je ne sais si le roastbeef et la porter alourdissent le corps et ankylosent les membres au point de nous empêcher d'accomplir aisément les évolutions requises, mais il est certain que les Français montrent une agilité et une légèreté de mouvement auxquelles les Anglais n'atteignent jamais. À l'entrée du parc 
de Saint-Cloud on trouve des restaurateurs, et la compagnie peut y dîner sous de très jolis berceaux de verdure.

Il est certain vieux gentleman dont le nom, assure-t-on en Angleterre, doit être épargné aux oreilles honnêtes, mais que les Français prononcent si couramment que toutes les oreilles ont dû l'entendre ici bien souvent. On sait que ce vieux gentleman est un ouvrier très habile, puisque rares sont les contrées qui n'en conservent quelque témoignage, matériel s'entend, car pour ses œuvres spirituelles il est à craindre qu'elles ne prévalent en tout pays. Au bord de la Seine, à Saint-Cloud, on peut voir une pierre de pont, et voici ce que la tradition rapporte à son sujet. L'architecte chargé de le construire trouvait que l'ouvrage n'avançait guère, et il avait rencontré tant de difficultés que sa tâche commençait à lui donner du souci; enfin, dans un moment d'irritation, il invoqua notre ouvrier, l'appelant à son aide et lui promettant pour récompense, s'il parvenait à finir le pont, la première chose qui viendrait à le traverser. Le vieux gentleman, toujours sur le pied de guerre, apparut à l'instant, accepta la proposition, et tous deux conclurent le marché en se serrant la main. Avec sa promptitude coutumière, il remplit son contrat en une nuit, car sachez qu'il travaille dans l'ombre et réclame son dû au matin; mais voici! Lorsqu'il vit le pont achevé, l'architecte y fit passer un chat que Sa Majesté infernale fut contrainte d'accepter selon leur accord, à sa très grande rage. C'est ce qui s'appelle tromper le $\mathrm{d}$...

Le château de Versailles est un empilement d'édifices plein de magnificence, sans conteste, et ses jardins de grand style manifestent la hauteur de vue du monarque qui les fit construire. Tout compte fait, pourtant, ces lieux m'ont donné moins de plaisir que Saint-Cloud; c'est trop d'apparat. Avant le règne de Louis XIV, Versailles n'était que l'un des pavillons de chasse des rois de France et, s'il conçut le dessein d'en faire un palais magnifique et le siège de son gouvernement, c'est que, semble-t-il, l'endroit n'offrant aucun avantage naturel, tout devait y être la création du roi. Le sol est sec et aride, la campagne alentour plate et découverte; pas une goutte d'eau, à moins qu'on ne l'achemine à force d'art et à grands frais. En un mot, aucune des conditions susceptibles d'inciter quelqu'un, selon les critères du sens commun, à dépenser les sommes énormes qui furent englouties ici.

Des avenues bordées d'arbres, où passent trois grandes routes menant à Versailles depuis Paris, Sceaux et Saint-Cloud, convergent vers la grande cour du château, anciennement nommée place Royale, aujourd'hui place d'Armes. De ce côté, la façade de l'édifice est très irrégulière et ne répond pas à ce que l'on attend du château de Versailles. Mais la façade principale donne sur le jardin, elle est d'une ampleur surprenante et respire la magnificence, quoique la trop grande distance qui éloigne les ailes du corps du bâtiment soit à mes yeux un défaut. Cependant, je dois convenir que l'allure de l'ensemble est superbe de grandeur. L'un des nombreux touristes qui l'ont visité en 1802 donne à la façade dix-huit cents pieds de longueur; son calcul doit compter un chiffre de trop; je dirais huit cents pieds, ce qui représente une longueur considérable.

L'entrée principale des appartements royaux s'ouvre sur un escalier extérieur tout de marbre, éclairé d'en haut par une voûte ; mais il est fermé à présent, car cette partie du bâtiment a accueilli pendant un certain temps les invalides de guerre. Aujourd'hui, les visiteurs accèdent au palais par une porte basse, au coin de la petite cour. 
enrichir les musées de Paris. Les appartements royaux demeurent dignes d'intérêt, bien que leur mobilier ait été déplacé et transféré au Tuileries, quand la cour fut contrainte de quitter Versailles pour Paris. Les plafonds peints par Le Brun ont été conservés; et malgré l'humidité et la négligence dont ils ont souffert par endroits, ils n'ont pas perdu leur beauté. Une vaste collection de tableaux, tous d'artistes français, occupe ces appartements, et elle contribue beaucoup à dissiper l'impression de vacuité qu'ils pourraient donner. Elle compte quelques œuvres de grande qualité, deux Van Loo en particulier ; parmi les plus saisissantes, un charmant paysage enneigé. On a proposé de faire du château de Versailles un grand musée dédié aux productions en tous genres de l'industrie et de l'art français ; mais j'ignore dans quelle mesure ce projet a été mis en œuvre. Dans ce cas, il était convenu que la façade donnant sur la ville, réordonnée, serait un monument de l'architecture française, et le plan prévu à cet effet est exposé dans l'une des salles. Son dessin ne manque ni de grandeur ni de beauté.

La grande galerie est superbe. Elle mesure deux cent trente pieds dans sa longueur, mesure anglaise, et quarante-cinq en largeur. Avec les salons de la Paix et de la Guerre à ses deux extrémités, elle occupe toute la longueur du corps de bâtiment qui regarde le jardin. Il y a dix-sept fenêtres d'un côté, le long de la galerie, et autant d'arcades de l'autre, avec d'immenses glaces dans l'intervalle. Les fenêtres, comme les arcades, sont séparées par des pilastres de marbre et le sol est recouvert de marbre incrusté. Le plafond est à compartiments, peints par Le Brun. Les peintures sont des représentations allégoriques de quelques-uns des plus mémorables exploits de Louis XIV.

31 La chapelle est entièrement en marbre, le plafond excepté, dont les compartiments, une nouvelle fois, sont peints par Le Brun. Celui du milieu représente le Père Tout-Puissant au milieu de sa Cour céleste ; celui du fond, au-dessus de l'autel, la résurrection; le plus proche, la descente du Saint-Esprit. On s'étonne qu'il soit permis dans les pays catholiques de peindre ces soi-disant représentations du Dieu éternel; ce que les protestants interdisent formellement, et jugent le comble de la profanation. Ces représentations n'ont rien d'exceptionnel; j'ai même vu exposer chez un marchand d'estampes la gravure d'un vieillard pourvu d'une longue barbe, au bas de laquelle on pouvait lire: "Le Père éternel». La chapelle mesure cent cinquante pieds de long, cinquante de large; la Révolution l'a épargnée, mais elle a quelque peu souffert de l'humidité et de l'incurie.

32 Le théâtre fut construit à l'occasion du mariage de Louis XVI, et son élégance égale sa splendeur; il a une telle profusion de dorures que son faste éclate même à la lumière du jour et, lorsqu'on l'illumine, il doit éblouir les yeux. Il servait de salle de bal autant que de théâtre.

L'homme qui nous faisait visiter les lieux nous a proposé, par faveur spéciale, de nous laisser voir un portrait en pied de Louis XVI, et un autre de la reine, avec la princesse et le dauphin, tous deux enfants. Sur le moment, je n'ai pas compris ce qui nous valait pareille faveur, à moins que notre petite troupe, composée en majorité d'Anglais, ne fût également concernée. Mais j'ai compris ensuite que cette faveur particulière était faite à tout le monde et qu'elle n'était qu'un moyen de tirer encore quelques sous de la compagnie. La pièce où se trouvaient les tableaux était fermée à clef, et nous y fûmes introduits avec force mystère et grande discrétion, afin que la comédie soit complète. Sur ce portrait, la reine m'a paru moins belle que les descriptions ne le laissaient attendre. Son visage présente un défaut notable, on est frappé par la hauteur du front. 
Certains de ses portraits y ont remédié par la suite, quand on eut adopté la mode de coiffer les cheveux plus bas sur le front, et le visage y gagne en beauté.

\section{Pierre Puget, Persée et Andromède}

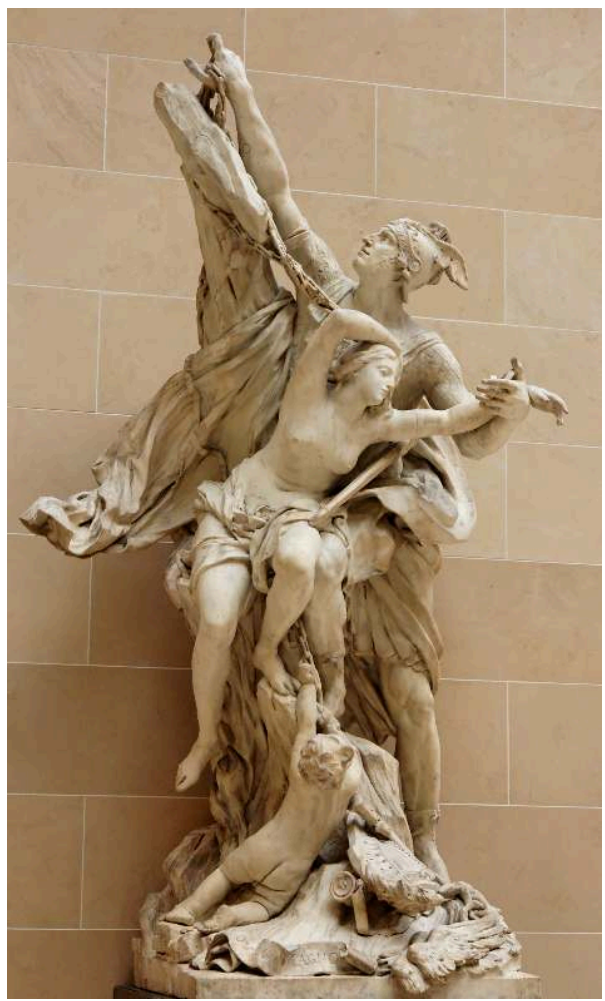

1684, marbre, 320 x 106 × 114 cm, Paris, musée du Louvre. 


\section{Pierre Puget, Milon de Crotone}

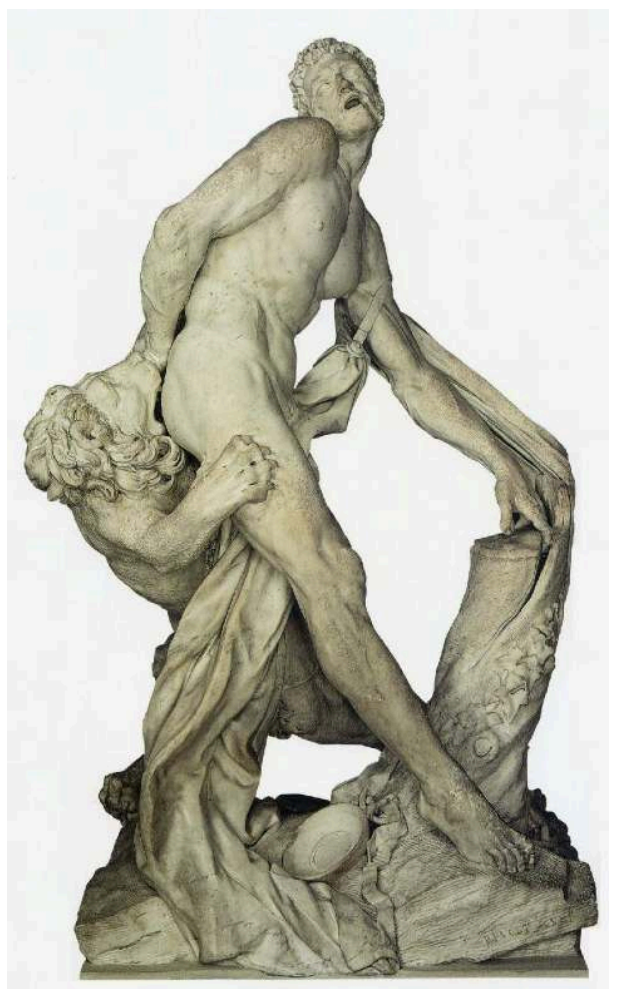

1683, marbre, 270 x 140 cm, Paris, musée du Louvre.

\section{Jean-Baptiste Tuby, Bassin d'Apollon}

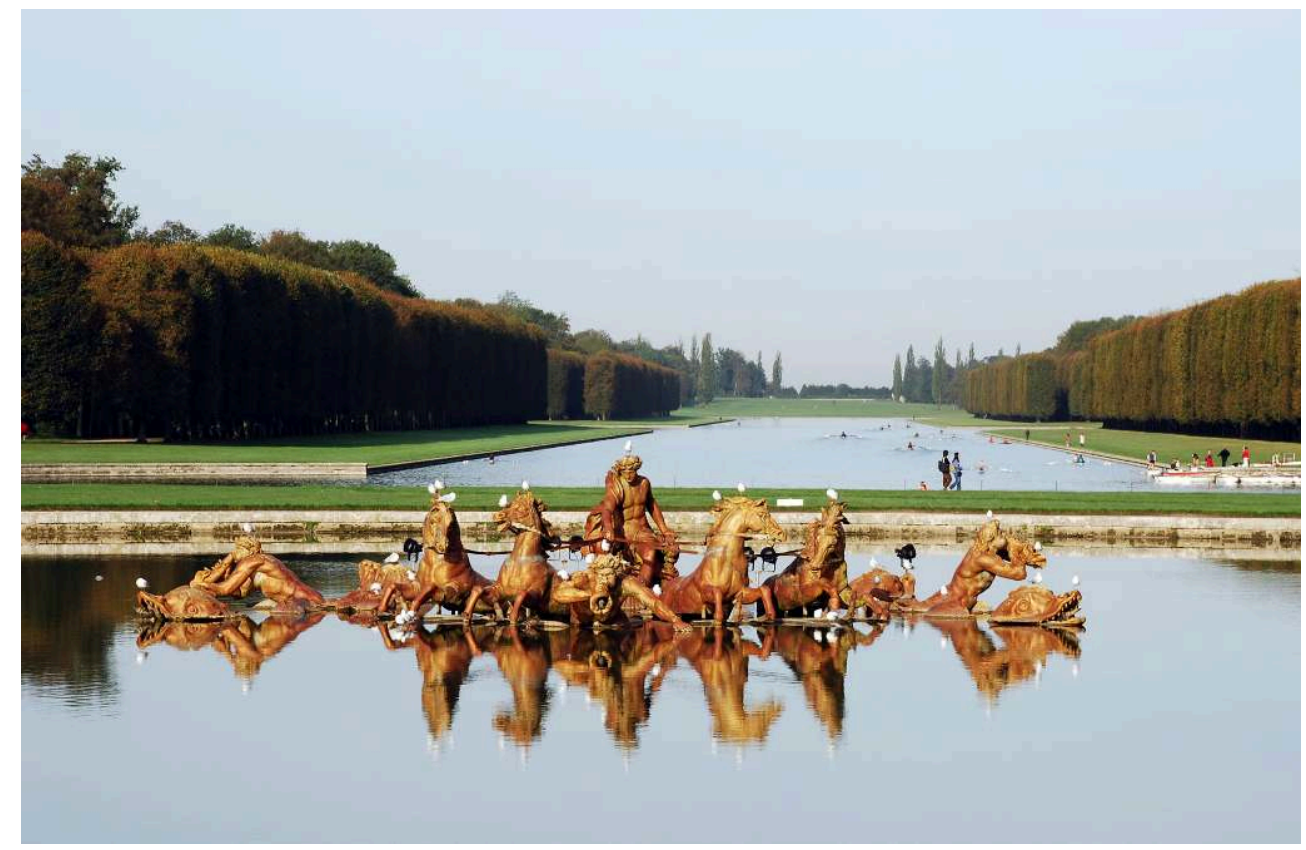

Versailles, jardins du château. 


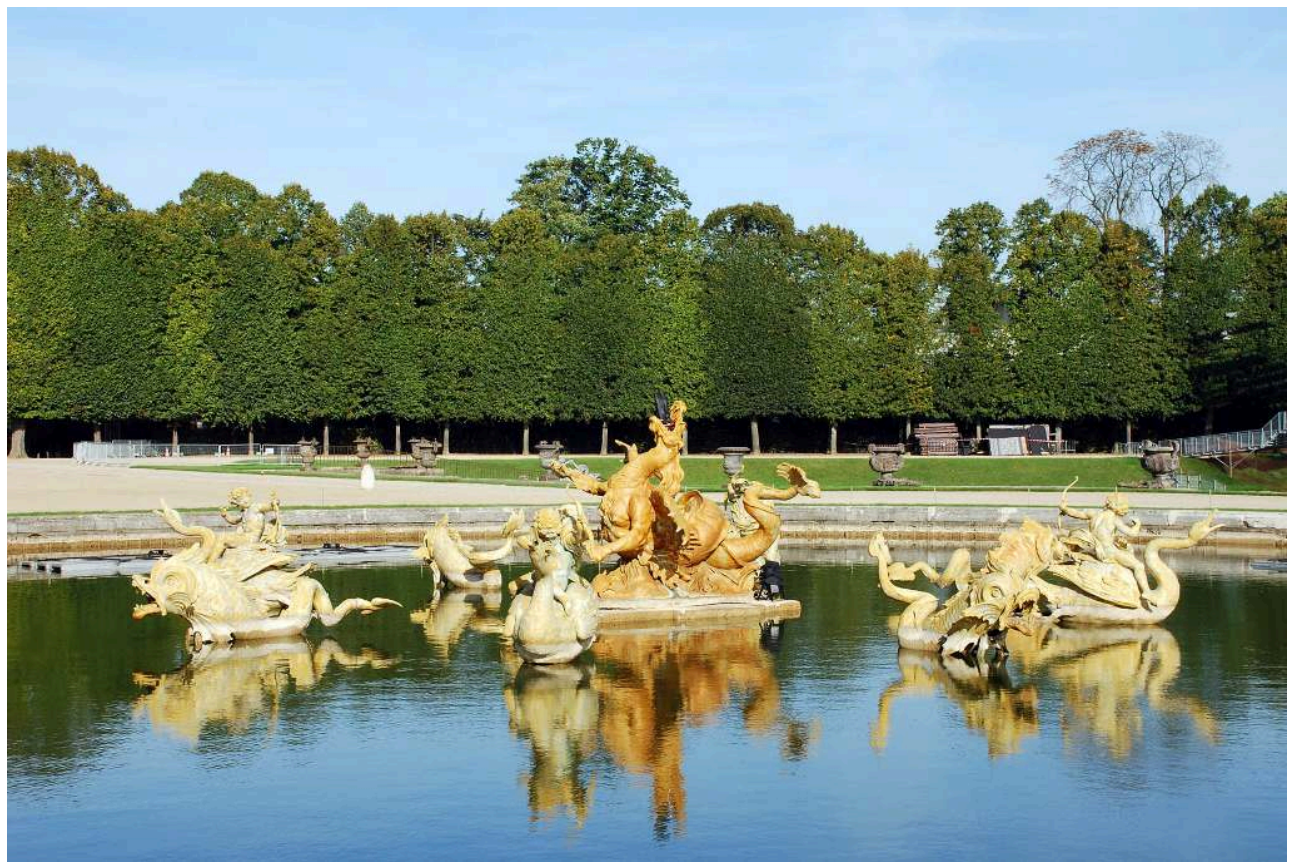

1682, Versailles, jardins du château.

En face du château, le parterre d'eau compte de nombreux bassins et jets d'eaux, ornés de statues de bronze représentant des nymphes, des rivières, des tritons et autres emblèmes aquatiques. La grande cascade se trouve à l'une des extrémités de ce parterre et une belle volée de marches descend de chaque côté vers ce que l'on appelle l'allée d'eau. Des rangées de statues se dressent de part et d'autre de cette allée, elles ont traversé la Révolution sans dommages. Viennent en tête les deux célèbres groupes de Persée et Andromède, et le Milon de Crotone de Puget (fig. 5 et 6). L'allée s'achève sur une vaste pièce d'eau, nommée le bassin d'Apollon, au milieu duquel un bronze représentant le dieu sur son char, entouré de tritons et de dauphins, fait jaillir de sa bouche un superbe jet d'eau (fig. 7). Celui du bassin de Neptune l'est tout autant, qui fuse sur la droite de l'allée d'eau (fig. 8).

Plus loin, on arrive enfin au Grand et au Petit Trianon. Les jardins de ce dernier sont supérieurs selon moi, malgré leur peu d'étendue, aux grands parterres qui environnent le château. Ils sont dessinés dans le goût anglais, mais se trouvent dans un bien triste état. La ferme de la reine, un groupe de petits bâtiments formant une ferme en miniature, n'est plus que ruines: les pelouses sont mal tenues, les arrivées d'eau obstruées, et l'on constate à chaque pas que ces lieux furent non seulement livrés, ici ou là, à la destruction pure et simple, mais laissés par ailleurs dans l'abandon le plus complet. La maison et les jardins sont loués à présent par un restaurateur, à charge pour lui d'assurer leur entretien, sans qu'il mette beaucoup de zèle à honorer son engagement. On a compté tous les arbres, et il en a la responsabilité. Comme nous étions un dimanche, c'était jour de danse au bal champêtre de la reine, un enclos de la taille d'une très grande salle, jonché de sable fin à l'intention des danseurs sous de charmants petits berceaux de verdure : illuminé et peuplé de monde, il doit être du plus bel effet. Les Français ne pardonneront jamais à Marie-Antoinette d'avoir fait couper plusieurs belles allées d'arbres pour aménager le jardin du Petit Trianon, qu'ils appellent un insipide jardin anglais. 


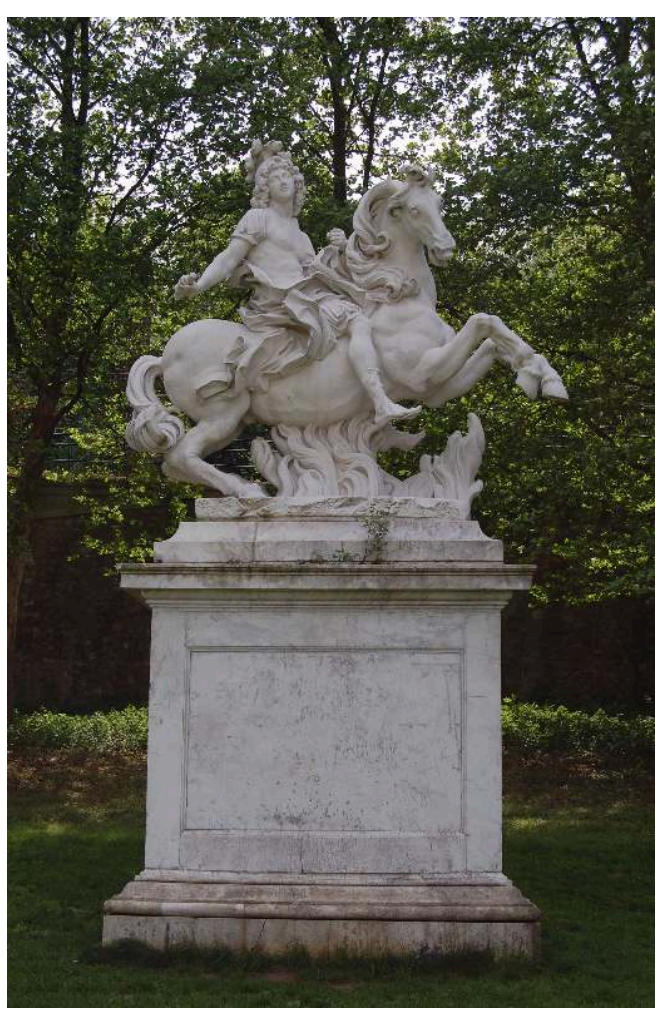

1688, marbre blanc, Versailles, jardins du château.

Au sud du grand parterre, dans les jardins du château et en contrebas de ce dernier, se trouve l'orangerie. L'édifice est spacieux et de belle allure, la collection d'orangers magnifique. L'un d'eux fut planté, dit-on, par François I ${ }^{\mathrm{er}}$, il a donc trois cents ans. Ces arbres, il est vrai, vivent fort longtemps. En Espagne, voilà six ans, dans les jardins de l'ancien palais de Séville, on pouvait en voir qui étaient vieux de quatre cents ans, paraît-il, et qui donnaient encore de très bons fruits. On descend à l'orangerie et au parterre attenant par deux splendides volées de marches de chaque côté du bâtiment. Au-delà du parterre s'étend un canal, la plus vaste pièce d'eau des jardins: on la nomme la pièce des Suisses. Au bout, se dresse une statue de Marcus Curtius s'apprêtant à lancer son cheval dans l'abîme, un superbe morceau de sculpture, œuvre du Bernin (fig. 9). Le même touriste qui donne dix-huit cents pieds de longueur au château nous assure qu'il s'agit en fait d'une statue équestre de Louis XIV ; mais la Révolution l'a débaptisée, dit-il, et renommée Quintus Curtius se sacrifiant à la patrie. Quel fut le sacrifice de Quintus Curtius à la patrie, l'histoire ne nous en dit rien; mais à propos de cette statue, il ne fut jamais question que de Marcus Curtius: les plus anciennes descriptions de Versailles la désignent sous ce nom, jamais sous celui de Louis XIV. Il suffit d'ailleurs de la considérer avec quelque attention pour s'épargner l'erreur de confondre un monarque français des temps modernes avec un héros de la Rome antique.

Avant la Révolution, Versailles possédait une ménagerie de premier choix; mais beaucoup d'animaux moururent après qu'on eut abandonné les lieux, et les survivants furent transférés au Jardin des plantes de Paris. Parmi les animaux empaillés qui sont conservés là, beaucoup vivaient au temps de Versailles, entre autres le rhinocéros. 

attend, sur la foi des récits qui circulent en Angleterre. À ce propos, la superbe invocation poétique de Mrs Wollstonecraft m'avait laissé une forte impression, lorsqu'elle nous parle des nocturnes orgies qui avaient lieu ici, dans son Histoire de la Révolution, et je m'attendais vraiment à trouver un monument lugubre de la grandeur déchue.

"Que Versailles est silencieux à présent!", nous dit-elle, «les pas solitaires qui gravissent le somptueux escalier s'attardent à chaque palier, pendant que les yeux parcourent ces lieux déserts et s'attendent à voir les vives figures du songe revenir à la vie. La lignée des Louis, pareille à la postérité des Banquos, passe avec une tristesse solennelle en dénonçant le néant des grandeurs humaines, elle disparaît dans les froides tapisseries qui recouvrent la nudité des vastes murs, tandis qu'une atmosphère obscure vient accroitre les ombres des figures gigantesques qui paraissent sombrer dans l'étreinte de la mort. Comme il s'avance avec précaution à travers les appartements sans fin, fermés pour moitié, le promeneur pensif projette des ombres furtives dans les longs miroirs qui lancent de tous côtés leurs vaines lueurs et engourdissent les nerfs sans atteindre le cœur. L'air est si glacial que l'on craint d'étouffer; et, de toute part, la destruction distille son humide langueur à travers les piliers. Le cœur oppressé cherche quelque soulagement dans les jardins ; mais là encore les mêmes images flottent au long des vastes allées à l'abandon : tout est figé dans une immobilité inquiétante; et si un ruisselet qui sinue sur la mousse amoncelée au bas de la cascade nous remémore les descriptions des grands jeux d'eau, ces tentatives dérisoires d'égaler la Nature ne peuvent nous arracher qu'un sourire languissant. »

Mais je n'ai rien trouvé à Versailles qui ressemble au silence et à la solitude; pas de murs dénudés, ni d'atmosphère humide et lourde, nul air glacial oppressant la poitrine. Au château comme dans les jardins, la foule se pressait en habits du dimanche, parlant, riant, dansant, bondissant et s'adonnant à toutes sortes de gambades, qui n'évoquent en rien les ombres des Louis ou des Banquos, et j'avais peine à croire que les mêmes scènes eussent inspiré quelques années plus tôt cette forte page. Dirais-je que je fus déçue, ou que j'aurais dû l'être? Peut-être n'en ai-je pas conçu précisément de la déception, mais je fus saisie, c'est certain, par le singulier contraste que faisaient ce que j'avais devant les yeux et ce que je m'attendais à voir. J'étais venue là, l'esprit tout occupé de la leçon morale où je m'arrêtais en pensée, songeant à l'effet que devait produire la solitude en ces lieux qui furent le théâtre d'une magnificence et d'un luxe démesurés, et disposée à de sévères réflexions sur la précarité des grandeurs humaines. Pourtant, s'il arrivait que le souvenir de ceux qui y vécurent et l'idée de leur fierté déchue s'imposent un moment à mon imagination, et qu'une impression de mélancolie commence à s'insinuer en moi, elle se dissipait sur-le-champ au spectacle, non des ombres des Louis s'avançant dans une solennelle tristesse, mais d'une gaieté et d'un enjouement partout manifestes.

41 La Bibliothèque royale, dont le bâtiment est séparé mais proche du palais, a été bien conservée et possède une riche collection. Sa curiosité la plus remarquable est un ouvrage sur vélin, superbement enluminé et qui représente le grand tournoi donné par Louis XIV, à l'imitation des joutes anciennes, sur la place du Carrousel, à Paris, pour célébrer la conclusion de la paix générale. Les dessins représentent les différents tableaux de la cérémonie. Les princes du sang, et la noblesse présente pour l'occasion, se montrèrent dans les costumes que portaient les diverses nations dans les tournois de 
l'ancien temps. L'endroit où ces festivités se déroulèrent a conservé depuis le nom de place du Carrousel. C'est là la seule copie que l'on ait faite de cette œuvre.

Il est tant d'achever ces remarques sur Paris et ses environs. Je ne décrirai pas les nombreux établissements publics, écoles, sociétés littéraires et scientifiques, instituts pour l'éducation des sourds-muets ou des aveugles, et autres sujets particulièrement dignes d'attention ; comme je l'ai dit, je veux éviter de mentionner ce qui a été souvent décrit ailleurs. Je crains seulement que l'on me reproche de m'être trop attardée encore sur Paris. Aussi, ayant pris soin de recommander de nouveau l'excellent ouvrage que j'ai déjà cité, Paris as it was and as it is, à ceux qui désirent s'informer davantage des lieux où brillent les arts et les sciences, il ne me reste plus qu'à prendre congé de la capitale française.

\section{ANNEXES}

Lire l'introduction à Anne Plumptre écrite par Isabelle Baudino

\section{NOTES}

1. (NdA) Francis Blagdon, Paris as it was and as it is, 2 vol., Londres, Baldwin, 1803.

2. (NdÉ) En fait l'œuvre est de Gérard David.

3. (NdT) Charles-Pierre Colardeau, « Lettre d'Héloïse à Abélard imitée de Pope » (1756). 
Julie Candeille (1767 - 1834) 


\title{
Introduction
}

\author{
Anne Lafont
}

1 Julie Candeille fut une enfant prodige, douée notamment pour la musique et la comédie, talents que son père exploita dès son plus jeune âge, en l'exhibant à la cour et en monnayant ses capacités extraordinairement précoces de cantatrice et de claveciniste. Elle fut ensuite une actrice remarquée de la Comédie-Française, interprétant notamment Mirza, personnage principal de L'Esclavage des nègres, l'heureux naufrage, pièce anti-esclavagiste écrite en 1788 par son amie Olympe de Gouges, en laquelle on reconnaît aujourd'hui une figure pionnière du féminisme. Engagée dans la première révolution des partisans de la Constituante, les Girondins, Julie Candeille fut inquiétée durant la Terreur et essuya finalement un revers de carrière qui la réorienta vers l'écriture, sous le Directoire. Elle s'employa alors à mener de front une carrière d'auteure et d'interprète - Catherine ou la Belle Fermière (1794) -, puis à écrire des romans historiques inspirés de femmes illustres - Bathilde reine des Francs (1814), Agnès de France ou le XII siècle (1821) -, suivant en cela une mode troubadour, que les peintres lyonnais de la seconde école de David avaient initiée. De même, sa sensibilité aux nouvelles lois autorisant le divorce lui inspira sans doute Lydie ou les Mariages manqués (1809), d'autant qu'elle avait elle-même divorcé à deux reprises d'un certain Laroche, médecin, et du spéculateur belge Simmons.

2 Cette œuvre et ce parcours singuliers laissent à penser que Julie Candeille participa de ce féminisme naissant qui vit des femmes de lettres envisager leur vie dans une émancipation relative vis-à-vis du mariage, dénonçant - sans y renoncer tout à fait cette institution imposée comme seul moyen de subsistance pour les femmes. Dans cette perspective, Julie Candeille contribua aussi au rééquilibrage, en termes de genre, de l'édifice patriotique, choisissant de mettre en scène des figures de femmes françaises exceptionnelles qui, grâce à la fiction, accédaient au statut d'héroïnes nationales (Bathilde et Agnès) et/ou de modèle moral (Louise ou la Réconciliation, 1808).

3 Ses textes sur l'art sont d'une nature particulière puisqu'il ne s'agit en aucun cas de critiques d'œuvres exposées au Salon, de traités théoriques ou encore d'histoire de l'art au sens d'un récit téléologique. Dans un souci de montrer la diversité des formes que prit l'écrit sur l'art à cette époque, y compris dans ses aspects les plus triviaux dimension attachée à l'art qui préoccupe évidemment aussi les femmes -, il nous a 
semblé opportun de présenter un ensemble de textes témoignant de son engagement dans la promotion de la renommée publique de Girodet et de l'aide qu'elle lui apporta dans sa recherche d'une clientèle lucrative. Autrement dit, comme l'a bien montré Heather Belnap Jensen ${ }^{1}$, Julie Candeille, bonne amie de Girodet dans la seconde partie de sa vie, fut aussi sa conseillère artistique, son porte-parole et son intermédiaire professionnelle. En ce sens, cette précieuse correspondance - publiée récemment mais malheureusement sans appareil critique - renseigne sur la professionnalisation de la médiation artistique au début $\mathrm{du} \mathrm{XIX}^{\mathrm{e}}$ siècle et place Julie Candeille dans un rôle précurseur d'experte et de communicatrice, rôles qui anticipent certainement le métier de journaliste, de critique ou d'historienne que poursuivront Marie d'Agoult ou Alida de Savignac.

\section{BIBLIOGRAPHIE}

LAFONT 2005

Anne Lafont, Girodet, Paris, Réunion des musées nationaux-Adam Biro, 2005.

LASSÈRE 2005

Madeleine Lassère, Le Portrait double. Julie Candeille et Girodet, Paris, L'harmattan, 2005.

LETZER et ADELSON 2000

Jacqueline Letzer et Robert Adelson, "Women Opera Composers face the Parisian comités de lecture. Where institutional barriers meet social barriers to performance", Studies on Voltaire and the Eighteenth Century, 2000, n 5, p. 355-369.

\section{ANNEXES}

Diaporama des tableaux de Girodet commentés par Julie Candeille dans sa correspondance avec le peintre :

http://www.flickr.com//photos/73632227@N02/sets/72157629321726178/show/

Lire des lettres de Julie Candeille à M. Girodet

Lire les Stances irrégulières. Vers improvisés sur le tableau d'Atala pour G[irodet] de Julie Candeille

Liste complète des œuvres d'arts commentées par Julie Candeille à travers ses textes édités dans Plumes et pinceaux

\section{NOTES}

1. Voir le volume d'essais Plumes et Pinceaux - Discours de femmes sur l'art en Europe (1750-1850), Paris, Presses du réel, 2012, p. 205. 


\section{Julie Candeille, Lettres à M. Girodet, $1808,1809,1810,1813$}

Montargis, musée Girodet, extraits choisis.

\section{6 rue Grange-Batelière, $1808 ; n^{\circ} 78$}

1 Mon ami, avez-vous, comme les marchands du passage Feydeau ou du Panorama, un prix pour le public et un prix particulier? Peignez-vous en grand ou en miniature? Voilà les questions que vous adresse par ma bouche le grand gros millionnaire que vous avez rencontré chez moi l'autre soir. Je pouvais me passer de vous pour y répondre. Cependant, comme il connait toute la Terre, peut-être vous convaincra-t-il de traiter avec lui. Il a, m'écrit-il, l'idée de fantaisie de cumuler sa face à celle de sa fille dans un tableau en pied... Je sais que pour une seule personne vous prenez 5000 francs. Est-ce 10 [...] pour deux personnes dans les mêmes cadres ? Veuillez me le dire au plus tôt. Et, du reste, faites cinq petits trous dans un fromage à la crème et vous aurez déjà atteint la ressemblance de la beauté que Monsieur le chambellan songe à confier à vos pinceaux. Et si son idée de fantaisie se fixe en votre faveur, n'oubliez pas de prendre vos sûretés ; car il est excessivement avare : ce qui va sans dire, puisqu'il est riche et bête.

2 Mon ami, je suis triste ce soir, ou du moins j'étais triste avant de vous écrire. Mon cœur n'est plus qu'un tombeau depuis la perte irréparable de ma très chère illusion.

Toute à vous, Girodet.

Julie Candeille

\section{$1809 ; n^{\circ} 21$}

$\mathrm{M}^{\text {me }}$ de l'Étang, femme aimable, grand amateur de tout ce qui est beau et très liée avec monseigneur de Sommariva, m’a témoigné le désir d'aller voir avec lui vos ouvrages. Monseigneur de Sommariva, maintenant à la campagne, en reviendra la semaine prochaine. Pourriez-vous le recevoir? Vous conviendrait-il de lui vendre l'Endymion? Pour quel prix en feriez-vous le sacrifice? Voilà ce que je vous prie de me faire savoir demain mardi dans la matinée. Non que je sois certaine de rien. Mais parce que demain 
dans la journée, je verrai $\mathrm{M}^{\mathrm{me}}$ de l'Étang et que je suis bien aise de pouvoir enfin répondre positivement à sa question qu'il m'a plus d'une fois adressée à ce sujet.

\section{$1810 ; n^{\circ} 64$}

5 Tous les yeux, mon ami, ne sont pas faits pour s'arrêter avec respect sur une aussi belle production qu'Atala (fig. 1).

\section{Anne-Louis Girodet, Atala [Les Funérailles d'Atala]}

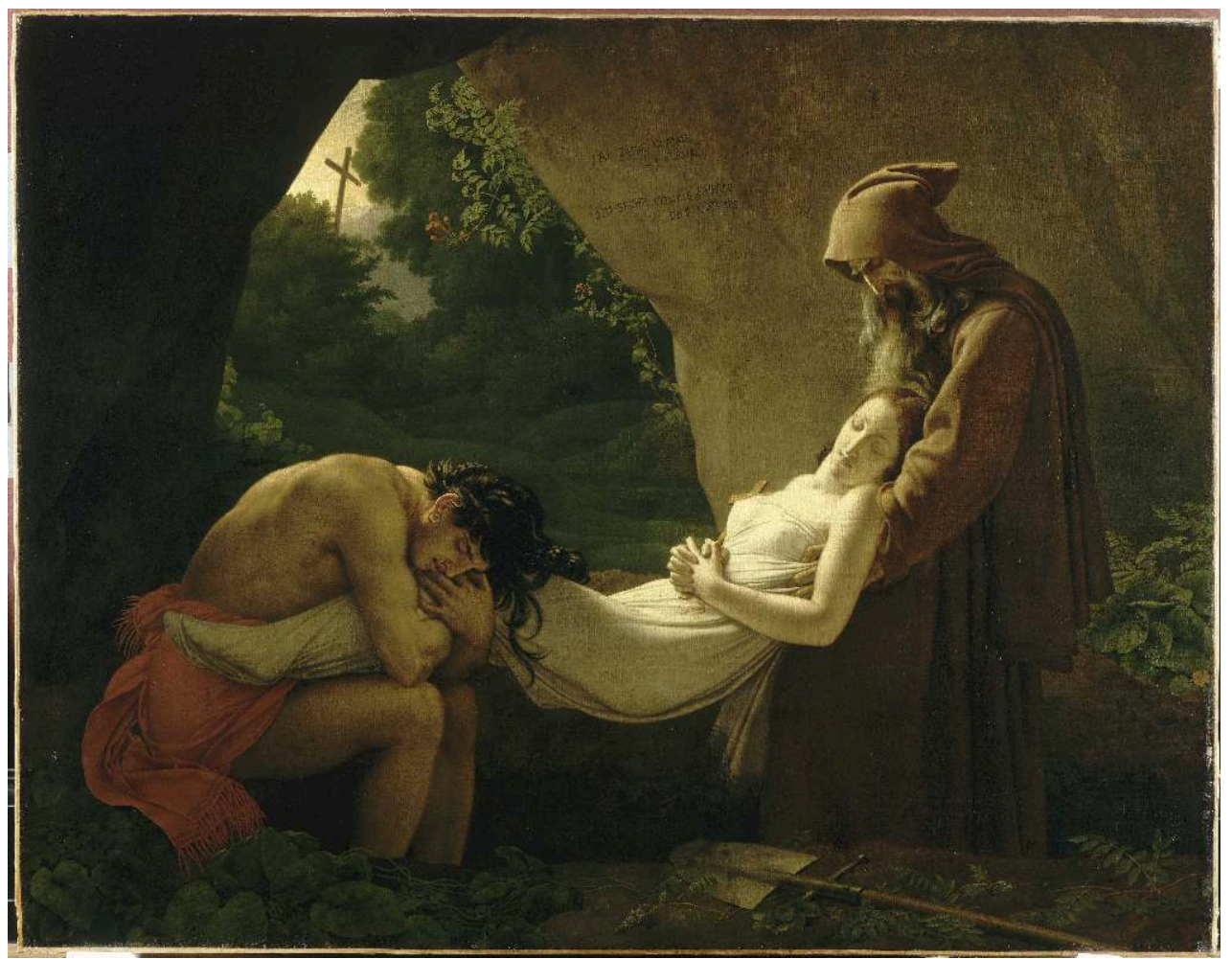

1808, huile sur toile, 207 x 267 cm, Paris, musée du Louvre.

Le cœur des envieux n'est dans le secret de ses beautés que pour tâcher de les traverser, et celui des bonnes gens qui les y ramène à leur insu ne crie pas tout à fait. Si tant que l'impatience de vos adversaires maladroits qui ne sentent pas qu'en cabotant contre un ouvrage de cet ordre-là, ils en donnent d'autant plus de fond à l'écho de sa renommée!... Atala, au surplus, pouvait se passer de leur secours. C'est le sens du Salon; le seul, soyez-en sûr, qui laissa après lui un sentiment profond du pouvoir de votre art. Il n'est cependant pas bien éclairé. La tête de Chactas, cette tête si expressive, perd beaucoup par le surcroît d'ombre qu'elle reçoit de l'angle où elle est placée : un homme qui vous rend justice en a fait l'observation. Votre grand tableau est le meilleur des quatre; mais je conçois ce que vous devez souffrir de le voir ainsi exposé en peignoir à l'ignorance publique. Quant à la concurrence de l'autre Atala, si vous la devez à mon indiscrétion, j'espère que vous m'en remercierez. Je n'ai jamais chargé de palette ; mais je crois qu'avec du blanc et du noir, on peut venir à bout de copier ce chef-d'œuvre. $\mathrm{M}^{\text {me }} \mathrm{Clau[...]} \mathrm{n'était} \mathrm{pas} \mathrm{des} \mathrm{nôtres.} \mathrm{Dans} \mathrm{quelques} \mathrm{jours} \mathrm{j'y} \mathrm{retournerai} \mathrm{avec} \mathrm{elle...} \mathrm{Mais}$ je renonce au métier d'espion dont je voulais m'aviser en votre faveur. C'est au contraire moi que chacun aurait l'air d'espionner. Que m'importe? Ne sommes-nous 
pas amis, une fois, et jusqu'au tombeau ? Si vous étiez capable de trahir un attachement si pur, vous n'auriez pas dans l'âme les premiers éléments de votre beau génie... Je compte donc sur vous. Je vous aime ; je vous honore; je vous embrasse avec tout mon cœur. - Au revoir.

\section{$1813 ; n^{\circ} 14$}

7 Mon ami, j'ai vu ce matin M.S[...] qui m'a donné l'espoir le plus fondé pour le prix destiné au Déluge (fig. 2.).

\section{Anne-Louis Girodet, Déluge [Scène de Déluge]}

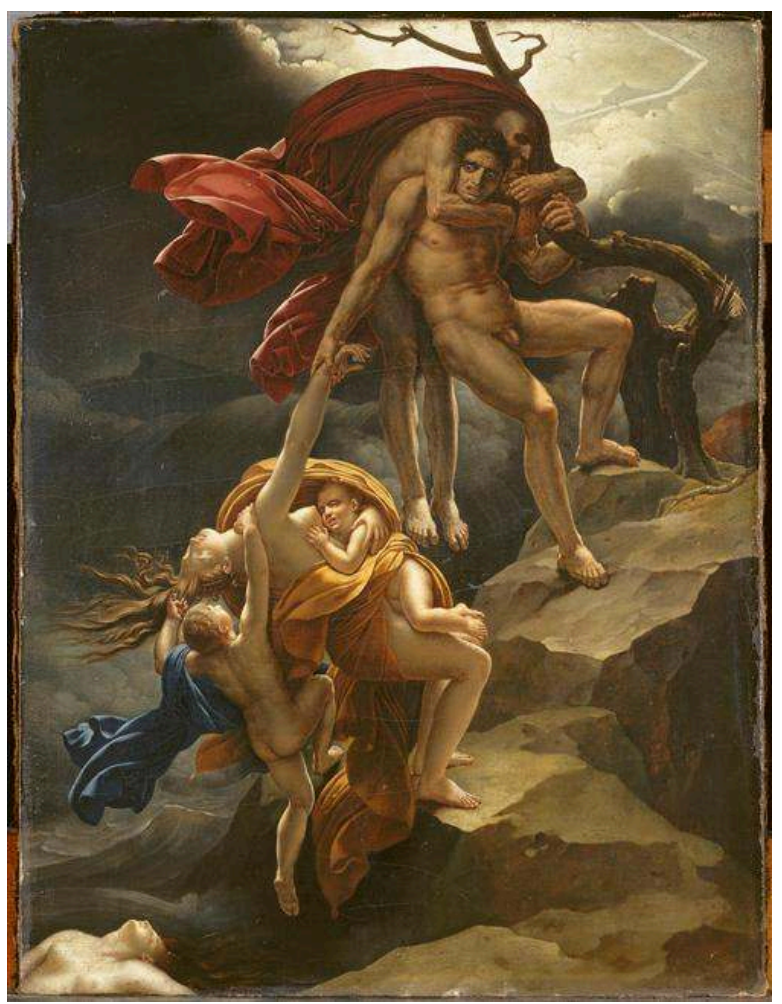

Salon de 1806, huile sur toile, 441 x 331 cm, Paris, musée du Louvre.

Demain j'en aurai des nouvelles plus positives par quelqu'un qui déjà m'en avait parlé. J'espère que vous avez songé à me communiquer vos demandes à ce sujet. Je vous invite à ne pas manquer ce soir $\mathrm{M}^{\mathrm{me}} \mathrm{Clau}[. .$.$] dont le mari et les amis peuvent faire nombre de$ voix. Vous viendrez quand vous en aurez le temps, demandez-moi pardon de votre si petit billet qui s'explique, au surplus, par l'absence d'un mot, et dont je ne vous ai grondé que pour vous engager à être un peu plus à ce que vous faites quand vous vous occupez un instant de votre amie. 


\section{ANNEXES}

Lire les Stances irrégulières. Vers improvisés sur le tableau d'Atala pour G[irodet] de Julie Candeille

Lire l'introduction à Julie Candeille écrite par Anne Lafont 


\section{Julie Candeille, Stances irrégulières. Vers improvisés sur le tableau d'Atala pour G[irodet]}

[s.d.] ; Montargis, musée Girodet, inv. Ms 967. 2. 3.

Anne-Louis Girodet, Atala [Les Funérailles d'Atala]

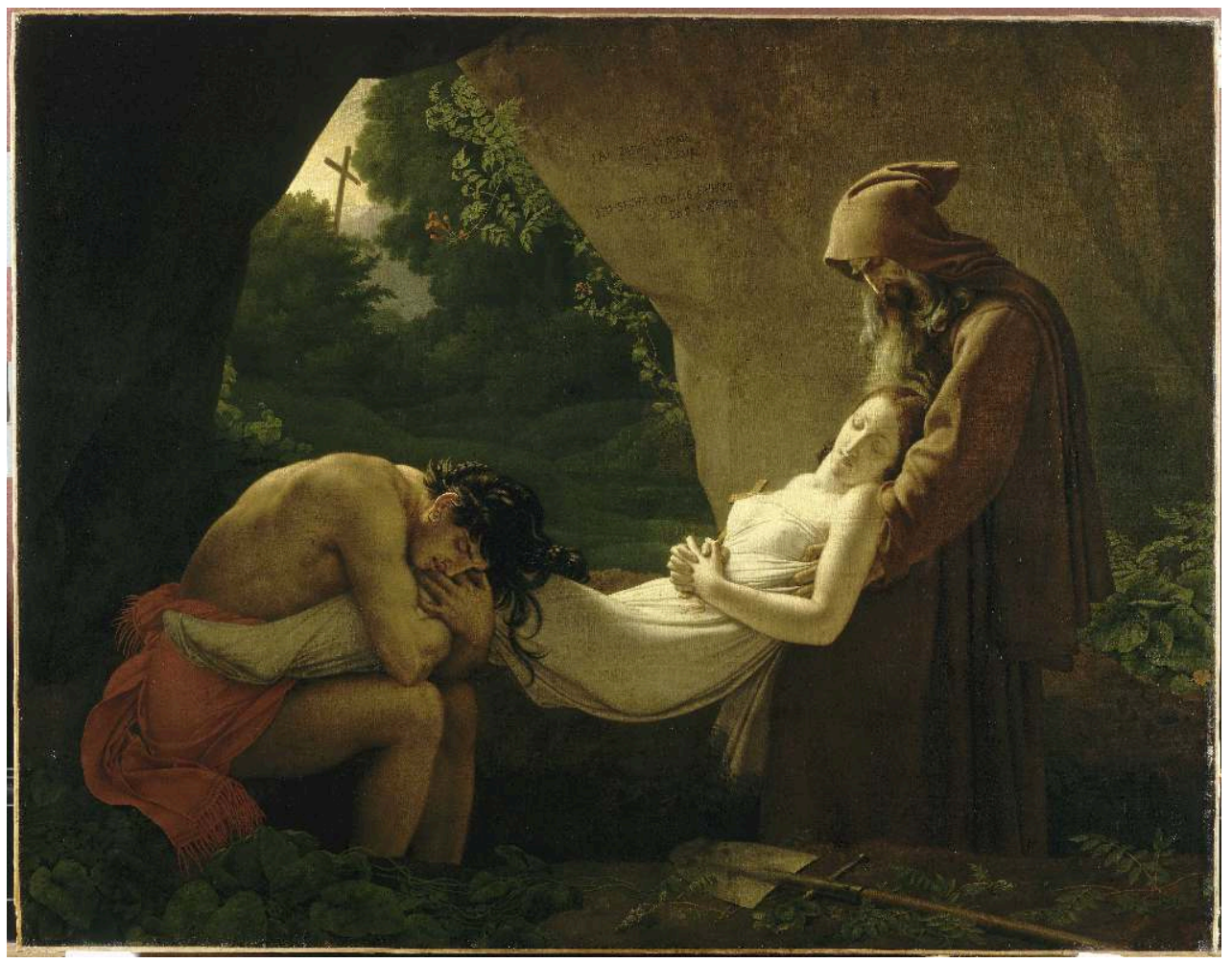

1808, huile sur toile, $207 \times 267$ cm, Paris, musée du Louvre.

Ô du talent effort suprême !

Le peintre, en ce touchant tableau 
A donné la vie au tombeau

Et du grave à la mort même.

[illisible] de perdre le jour

Avant d'avoir perdu tes charmes,

Belle Atala, revoir les larmes

Que sur ton sort verse l'amour.

L'amour contrarié, source féconde

De chefs-d'œuvre et de bienfaits,

Doit régner dans un nouveau monde

Et se nourrir par les regrets...

Des cieux la sagesse éternelle

Avec son ministre Dédale

S'exile en vain dans les déserts

Il parle... et toute erreur succombe ;

Il meurt... et du fond de sa tombe

Il instruit encore l'univers.

Objet d'études et d'envie,

Sur ce tableau peint du génie

Ainsi les siècles profiteront,

Les siècles le rajeuniront

Et le temps prépare sa gloire...

Pour la mienne, pour mon bonheur,

Que ne puis-je enfin de mon cœur

Sonner la trop douce mémoire

Et de l'ouvrage et de l'auteur !

\section{ANNEXES}

Lire des lettres de Julie Candeille à M. Girodet

Lire l'introduction à Julie Candeille écrite par Anne Lafont 
Germaine de Staël (1766 - 1817) 


\title{
Introduction
}

\author{
Anne Lafont
}

1 Germaine de Staël est certainement l'un des auteurs français les plus connus de la période qui va de l'Ancien Régime à la Restauration, tant par ses écrits romanesques, théoriques, poétiques, historiques que pour ses engagements politiques à une époque instable pour la France et l'Europe. Germaine de Staël doit aussi sa renommée à sa filiation et à son cercle amical composé de l'élite européenne d'alors: de son père Necker, ministre de Louis XVI, aux écrivains Benjamin Constant, René de Chateaubriand ou encore en Allemagne, Goethe et les frères Schlegel, sans oublier son amitié avec l'illustre figure féminine de ce premier $\mathrm{XIX}^{\mathrm{e}}$ siècle, Juliette Récamier. Germaine de Staël bénéficia d'une éducation et d'une instruction extrêmement soignées qui lui valurent en toutes circonstances une aptitude de jugement et de critique dont elle usa durant la Révolution française et l'Empire, même si cela lui coûta, de 1803 à 1815, l'interdiction napoléonienne de séjourner et de résider à Paris. Elle transforma cet exil involontaire et cette vie itinérante (Suisse, Allemagne, Russie, Italie, Angleterre...) en la source de travaux exemplaires, fondés sur l'observation et l'étude approfondies des mœurs et des cultures des populations européennes. Corinne ou l'Italie (1807), De l'Allemagne (1810), parmi d'autres, témoignent, selon des modalités narratives différentes (le premier ouvrage est un roman; le second est un essai), de ces travaux frayant avec ce que l'on appelle aujourd'hui les sciences humaines et sociales.

2 Les nombreuses recherches qu'ont suscitées les écrits fort divers de Germaine de Staël sur l'art renforcent l'idée que son œuvre est exceptionnelle et fondatrice, au point qu'elle transforma pour partie le discours sur l'art. Son influence se fait sentir, notamment mais pas seulement, dans les discours des femmes sur l'art, comme on le perçoit à la lecture chronologique de cette anthologie, qui voit les textes se renforcer théoriquement après les publications de l'égérie du groupe de Coppet: sur le plan conceptuel et concernant les références artistiques, mais aussi sur le plan du dispositif, rompant à la fois avec la mascarade propre à une forme de critique d'art et avec le prototype des vies d'artistes en vogue depuis Vasari et largement répandu depuis Félibien en passant par Dezallier d'Argenville jusqu'à Decamps. Dans les extraits qui suivent, Germaine de Staël présente, s'approprie et discute les concepts de l'esthétique allemande, pourtant encore timidement revendiquée dans les textes sur l'art signés par 
des auteurs français, à l'instar de Lessing, Winckelmann et Herder, puis ceux présentés dans la revue l'Athenaeum qui accueillit notamment les écrits d'August Wilhelm von Schlegel, compagnon de voyage de Germaine de Staël de 1803 à 1807 en Italie, en Suède et en Angleterre.

Les pensées sur l'art de Germaine de Staël présentent certainement un intérêt majeur dans cette anthologie. À plusieurs égards au moins : la dimension cosmopolite de son parcours intellectuel, qui se nourrit de l'art et des cultures littéraires européennes dans leur ensemble; l'affirmation d'une voix de femme auteure qui considère le difficile statut social des femmes artistes en 1800 et distingue les cultures politiques nationales dans leurs préjugés sexistes (dans Corinne, la société italienne et la société britannique gèrent différemment la renommée des artistes femmes) ; l'étendue et l'expertise de ses écrits sur l'art qui couvrent les peintures de la Renaissance italienne avec la même aisance que les arts contemporains tant français qu'allemands, ou encore l'architecture et l'urbanisme romains anciens. Germaine de Staël est assurément l'une des femmes d'exception dans ce champ encore indéfini des voix des femmes dans la littérature sur l'art.

\section{BIBLIOGRAPHIE}

BALAYÉ 1979

Simone Balayé, Me de Staël. Lumières et liberté, Paris, Klincksieck, 1979.

GIRARD 1988

Marie-Hélène Girard, «Corinne collectionneur, ou le musée imaginaire de $\mathrm{M}^{\text {me }}$ de Staël », Art et littérature. Actes du congrès de la Société française de littérature générale et comparée, (Aix-enProvence, 24-26 septembre 1986), Aix-en-Provence, université de Provence, 1988, p. 241-261. JENSEN 2007

Heather Belnap Jensen, "Divisionary Tactics. Art Criticism as Political Weapon in Germaine de Staël's Corinne, or Italy (1807)”, dans Waltraud Maierhofer, Gertrud Rösch et Caroline Bland (éd.), Women Against Napoleon. Historical and Fictional Responses, Francfort/New York, Campus Verlag, 2007, p. 161-186.

LOTTERIE 2004

Florence Lotterie, « $\mathrm{M}^{\text {me }}$ de Staël : la littérature comme "philosophie sensible" ", Romantisme. Revue du dix-neuvième siècle, 2004, $\mathrm{n}^{\circ}$ 124, p. 19-30.

PLANTÉ, POUZOULET et VAILLANT 2000

Christine Planté, Christine Pouzoulet et Alain Vaillant (dir.), Une mélodie intellectuelle, Corinne ou l'Italie de Germaine de Staël, actes des journées d'études, (12 et 17 février 2000, Lyon et Montpellier), Montpellier, université Paul Valéry, 2000. 


\section{ANNEXES}

Diaporama des œuvres commentées dans les romans de Germaine de Staël Corinne ou l'Italie et De l'Allemagne :

http://www.flickr.com//photos/73632227@N02/sets/72157629737052544/show/

Lire les extraits du roman de Germaine de Staël Corinne ou l'Italie

Lire les extraits du roman de Germaine de Staël De l'Allemagne

Liste complète des œuvres d'arts commentées par Germaine de Staël à travers ses textes édités dans Plumes et pinceaux 


\section{Germaine de Staël, Corinne ou l'Italie,} 1807

Édition établie, présentée et annotée par Simone Balayé, Paris, Gallimard, 1985, extraits choisis.

\section{« Rome »}

\section{Livre IV - chapitre III}

On passe, en allant à Saint-Pierre, sur le pont Saint-Ange, et Corinne et Lord Nelvil le traversèrent à pied. « C'est sur ce pont, dit Oswald, qu'en revenant du Capitole j'ai pour la première fois pensé longtemps à vous. [...] - Je ne sais si je me trompe, reprit Corinne, mais il me semble qu'on se devient plus cher l'un à l'autre, en admirant ensemble les monuments qui parlent à l'âme par une véritable grandeur. Les édifices de Rome ne sont ni froids, ni muets; le génie les a conçus, des événements mémorables les consacrent $;[. .]$.

2 En allant à Saint-Pierre, ils s'arrêtèrent devant le château Saint-Ange : "Voilà, dit Corinne, l'un des édifices dont l'extérieur a le plus d'originalité ; ce tombeau d'Adrien, changé en forteresse par les Goths, porte le double caractère de sa première et de sa seconde destination. Bâti pour la mort, une impénétrable enceinte l'environne, et cependant les vivants y ont ajouté quelque chose d'hostile par les fortifications extérieures qui contrastent avec le silence et la noble inutilité d'un monument funéraire. On voit sur le sommet un ange de bronze avec son épée nue, et dans l'intérieur sont pratiquées des prisons fort cruelles. Tous les événements de l'histoire de Rome depuis Adrien jusqu'à nos jours sont liés à ce monument. Bélisaire s'y défendit contre les Goths et, presque aussi barbare que ceux qui l'attaquaient, il lança contre ses ennemis les belles statues qui décoraient l'intérieur de l'édifice. Crescentius, Arnaud de Brescia, Nicolas Rienzi, ces amis de la liberté romains, qui ont pris si souvent les souvenirs pour des espérances, se sont défendus longtemps dans le tombeau d'un empereur. J'aime ces pierres qui s'unissent à tant de faits illustres. J'aime ce luxe du maître du monde, un magnifique tombeau. Il y a quelque chose de grand dans l'homme 
qui, possesseur de toutes les jouissances et de toutes les pompes terrestres, ne craint pas de s'occuper longtemps d'avance de sa mort. Des idées morales, des sentiments désintéressés remplissent l'âme, dès qu'elle sort de quelque manière des bornes de la vie. C'est d'ici, continua Corinne, que l'on devrait apercevoir Saint-Pierre, et c'est jusques ici que les colonnes qui le précèdent devaient s'étendre: tel était le superbe plan de Michel-Ange, il espérait du moins qu'on l'achèverait après lui; mais les hommes de notre temps ne pensent plus à la postérité. Quand une fois on a tourné l'enthousiasme en ridicule, on a tout défait, excepté l'argent et le pouvoir. - C'est vous qui ferez renaître ce sentiment, s'écria Lord Nelvil. Qui jamais éprouva le bonheur que je goûte? Rome montrée par vous, Rome interprétée par l'imagination et le génie; Rome, qui est un monde, animé par le sentiment, sans lequel le monde lui-même est un désert ${ }^{1}$. $[\ldots]$ »

3 Alors Saint-Pierre leur apparut, cet édifice, le plus grand que les hommes aient jamais élevé, car les pyramides d'Égypte elles-mêmes lui sont inférieures en hauteur. [...] Oswald sentit une émotion tout à fait extraordinaire en arrivant en face de Saint-Pierre. C'était la première fois que l'ouvrage des hommes produisait sur lui l'effet d'une merveille de la nature. C'est le seul travail de l'art, sur notre terre actuelle, qui ait le genre de grandeur qui caractérise les œuvres immédiates de la création. Corinne jouissait de l'étonnement d'Oswald. «J'ai choisi, lui dit-elle, un jour où le soleil est dans tout son éclat pour vous faire voir ce monument. Je vous réserve un plaisir plus intime, plus religieux, c'est de le contempler au clair de la lune; mais il fallait d'abord vous faire assister à la plus brillante des fêtes, le génie de l'homme décoré par la magnificence de la nature. »

4 La place de Saint-Pierre est entourée par des colonnes légères de loin, et massives de près. Le terrain, qui va toujours un peu en montant jusqu'au portique de l'église, ajoute encore à l'effet qu'elle produit. Un obélisque de quatre-vingts pieds de haut, qui paraît à peine élevé en présence de la coupole de Saint-Pierre, est au milieu de la place. La forme des obélisques elle seule a quelque chose qui plaît à l'imagination ; leur sommet se perd dans les airs, et semble porter jusqu'au ciel une grande pensée de l'homme. Ce monument, qui vint d'Égypte pour orner les bains de Caligula, et que Sixte-Quint a fait transporter ensuite au pied du temple de Saint-Pierre, ce contemporain de tant de siècles, qui n'ont pu rien contre lui, inspire un sentiment de respect ; l'homme se sent si passager, qu'il a toujours de l'émotion en présence de ce qui est immuable. À quelque distance des deux côtés de l'obélisque, s'élèvent deux fontaines dont l'eau jaillit perpétuellement et retombe avec abondance en cascade dans les airs. Ce murmure des ondes, qu'on a coutume d'entendre au milieu de la campagne, produit dans cette enceinte une sensation toute nouvelle; mais cette sensation est en harmonie avec celle que fait naître l'aspect d'un temple majestueux.

5 La peinture, la sculpture, imitant le plus souvent la figure humaine, ou quelque objet existant dans la nature, réveillent dans notre âme des idées parfaitement claires et positives ; mais un beau monument d'architecture n'a point, pour ainsi dire, de sens déterminé, et l'on est saisi, en le contemplant, par cette rêverie, sans calcul et sans but, qui mène si loin la pensée. Le bruit des eaux convient à toutes ces impressions vagues et profondes ; il est uniforme, comme l'édifice est régulier.

"L'éternel mouvement et l'éternel repos ${ }^{2}$ "

6 sont ainsi rapprochés l'un de l'autre. C'est dans ce lieu surtout que le temps est sans pouvoir ; car il ne tarit pas plus ces sources jaillissantes, qu'il n'ébranle ces immobiles 
pierres. Les eaux qui s'élancent en gerbes de ces fontaines sont si légères et si nuageuses, que, dans un beau jour, les rayons du soleil y produisent de petits arcs-enciel formés des plus belles couleurs. [...] [Oswald] s'avança dans le temple, et l'impression qu'il reçut sous ces voûtes immenses fut si profonde et si religieuse, que le sentiment même de l'amour ne suffisait plus pour remplir en entier son âme [...].

Corinne interrompit la rêverie d'Oswald, et lui dit : « Vous avez vu des églises gothiques en Angleterre et en Allemagne, vous avez dû remarquer qu'elles ont un caractère beaucoup plus sombre que cette église. Il y avait quelque chose de mystique dans le catholicisme des peuples septentrionaux. Le nôtre parle à l'imagination par les objets extérieurs. Michel-Ange a dit, en voyant la coupole du Panthéon : "Je la placerai dans les airs." Et en effet Saint-Pierre est un temple posé sur une église. Il y a quelque alliance des religions antiques et du christianisme dans l'effet que produit sur l'imagination l'intérieur de cet édifice [...]. Regardez, continua Corinne, ces statues placées sur les tombeaux, ces tableaux en mosaïque, patientes et fidèles copies des chefs-d'œuvre de nos grands maitres. Je n'examine jamais Saint-Pierre en détail, parce que je n'aime pas à y trouver ces beautés multipliées qui dérangent un peu l'impression de l'ensemble. Mais qu'est-ce donc qu'un monument où les chefs-d'œuvre de l'esprit humain eux-mêmes paraissent des ornements superflus! Ce temple est comme un monde à part. On y trouve un asile contre le froid et la chaleur. Il a ses saisons à lui, son printemps perpétuel que l'atmosphère $d u$ dehors n'altère jamais. Une église souterraine est bâtie sous le parvis de ce temple; les papes et plusieurs souverains des pays étrangers y sont ensevelis, Christine, après son abdication, les Stuart, depuis que leur dynastie est renversée. Rome depuis longtemps, est l'asile des exilés du monde, Rome elle-même n'est-elle pas détrônée ! son aspect console les rois dépouillés comme elle. [...]

«Placez-vous ici, dit Corinne à Lord Nelvil, près de l'autel au milieu de la coupole, vous percevrez à travers les grilles de fer l'église des morts qui est sous nos pieds, et en relevant les yeux vos regards atteindront à peine au sommet de la voûte. Ce dôme, en le considérant même d'en bas, fait éprouver un sentiment de terreur. On croit voir des abîmes suspendus sur sa tête. Tout ce qui est au-delà d'une certaine proportion cause à l'homme, à la créature bornée, un invincible effroi. Ce que nous connaissons est aussi inexplicable que l'inconnu; mais nous avons pour ainsi dire pratiqué notre obscurité habituelle, tandis que de nouveaux mystères nous épouvantent et mettent le trouble dans nos facultés. »

\section{« Les statues et les tableaux »}

\section{Livre VIII - chapitre II}

Pendant les jours qui suivirent la maladie d'Oswald, Corinne évita soigneusement ce qui pouvait ramener une explication entre eux. Elle voulait rendre la vie de son ami aussi douce qu'il était possible. [...]

Revenant donc à l'aimable adresse dont elle avait coutume de se servir pour empêcher Oswald de se livrer à ses inquiétudes passionnées, elle voulut intéresser de nouveau son esprit et son imagination par les merveilles des beaux-arts qu'il n'avait point encore vues, et retarder ainsi l'instant où le sort devait s'éclaircir et se décider. [...] 
11 Corinne, parmi ses innocentes ruses pour varier les amusements d'Oswald, avait encore réservé les statues et les tableaux. Un jour donc, lorsque Lord Nelvil fut rétabli, elle lui proposa d'aller voir ensemble ce que la sculpture et la peinture offraient à Rome de plus beau. "Il est honteux, lui dit-elle en souriant, que vous ne connaissiez ni nos statues, ni nos tableaux, et demain il faut commencer le tour des musées et des galeries. - Vous le voulez, répondit Lord Nelvil, j’y consens. [...]»

12 Ils allèrent d'abord au musée du Vatican, ce palais des statues où l'on voit la figure humaine divinisée par le paganisme, comme les sentiments de l'âme le sont maintenant par le christianisme. Corinne fit remarquer à Lord Nelvil ces salles silencieuses où sont rassemblées les images des dieux et des héros, où la plus parfaite beauté, dans un repos éternel, semble jouir d'elle-même. En contemplant ces traits et ces formes admirables, il se révèle je ne sais quel dessein de la divinité sur l'homme, exprimé par la noble figure dont elle a daigné lui faire don. L'âme s'élève par cette contemplation à des espérances pleines d'enthousiasme et de vertu ; car la beauté est une dans l'univers, et, sous quelque forme qu'elle se présente, elle excite toujours une émotion religieuse dans le cœur de l'homme. Quelle poésie que ces visages où la plus sublime expression est pour jamais fixée, où les plus grandes pensées sont revêtues d'une image si digne d'elles!

13 Quelquefois un sculpteur ancien ne faisait qu'une statue dans sa vie, elle était toute son histoire. Il la perfectionnait chaque jour : s'il aimait, s'il était aimé, s'il recevait par la nature ou par les beaux-arts une impression nouvelle, il embellissait les traits de son héros par ses souvenirs et par ses affections. Il savait ainsi traduire aux regards tous les sentiments de son âme. La douleur dans nos temps modernes, au milieu de notre état social si froid et si oppressif, est ce qu'il y a de plus noble dans l'homme; et, de nos jours, qui n'aurait pas souffert, n'aurait jamais senti ni pensé. Mais il y avait dans l'Antiquité quelque chose de plus noble que la douleur, c'était le calme héroïque, c'était le sentiment de sa force qui pouvait se développer au milieu d'institutions franches et libres. Les plus belles statues des Grecs n'ont presque jamais indiqué que le repos. Le Laocoon et la Niobé sont les seules qui peignent des douleurs violentes; mais c'est la vengeance du ciel qu'elles rappellent toutes les deux, et non les passions nées dans le cœur humain. L'être moral avait une organisation si saine chez les Anciens, l'air circulait si librement dans leur large poitrine, et l'ordre politique était si bien en harmonie avec les facultés, qu'il n'existait presque jamais, comme de notre temps, des âmes mal à l'aise : cet état fait découvrir beaucoup d'idées fines, mais ne fournit point aux arts, et particulièrement à la sculpture, les simples affections, les éléments primitifs des sentiments qui peuvent seuls s'exprimer par le marbre éternel.

14 À peine trouve-t-on dans leurs statues quelques traces de mélancolie. Une tête d'Apollon au palais Justiniani, une autre d'Alexandre mourant, sont les seules où les dispositions de l'âme rêveuse et souffrante soient indiquées, mais elles appartiennent l'une et l'autre, selon toute apparence, au temps où la Grèce était asservie. Dès lors, il n'y avait plus cette fierté, ni cette tranquillité d'âme qui ont produit chez les Anciens les chefs-d'œuvre de la sculpture et de la poésie composée dans le même esprit.

15 La pensée qui n'a plus d'aliments au-dehors se replie sur elle-même, analyse, travaille, creuse les sentiments intérieurs ; mais elle n'a plus cette force de création qui suppose et le bonheur, et la plénitude de forces que le bonheur seul peut donner. Les sarcophages même chez les Anciens ne rappellent que des idées guerrières ou riantes : dans la multitude de ceux qui se trouvent au musée du Vatican, on voit des batailles, 
des jeux représentés en bas-reliefs sur les tombeaux. Le souvenir de l'activité de la vie était le plus bel hommage que l'on crût devoir rendre aux morts. Rien n'affaiblissait, rien ne diminuait les forces. L'encouragement, l'émulation étaient le principe des beaux-arts comme de la politique ; il y avait place pour toutes les vertus, comme pour tous les talents. Le vulgaire se glorifiait de savoir admirer, et le culte du génie était servi par ceux-mêmes qui ne pouvaient point aspirer à ses couronnes.

La religion grecque n'était point, comme le christianisme, la consolation du malheur, la richesse de la misère, l'avenir des mourants; elle voulait la gloire, le triomphe; elle faisait pour ainsi dire l'apothéose de l'homme. Dans ce culte périssable, la beauté même était un dogme religieux. Si les artistes étaient appelés à peindre des passions basses ou féroces, ils en sauvaient la honte à la figure humaine, en y joignant, comme dans les faunes et les centaures, quelques traits des animaux; et, pour donner à la beauté son plus sublime caractère, ils unissaient tour à tour dans les statues des hommes et des femmes, dans la Minerve guerrière et dans l'Apollon musagète, les charmes des deux sexes, la force à la douceur, la douceur à la force ; mélange heureux de deux qualités opposées, sans lequel aucune des deux ne serait parfaite.

Corinne, en continuant ses observations, retint Oswald quelque temps devant des statues endormies qui sont placées sur des tombeaux, et montrent l'art de la sculpture sous le point de vue le plus agréable. Elle lui fit remarquer que toutes les fois que les statues sont censées représenter une action, le mouvement qui s'arrête produit une sorte d'étonnement quelquefois pénible. Mais les statues dans le sommeil, ou seulement dans l'attitude d'un repos complet, offrent une image de l'éternelle tranquillité, qui s'accorde merveilleusement avec l'effet général du Midi sur l'homme. Il semble que là les beaux-arts soient les paisibles spectateurs de la nature, et que le génie lui-même, qui agite l'âme dans le Nord, n'est, sous un beau ciel, qu'une harmonie de plus.

Oswald et Corinne passèrent dans la salle où sont rassemblées les images sculptées des animaux et des reptiles; et la statue de Tibère se trouve par hasard au milieu de cette cour. C'est sans projet qu'une telle réunion s'est faite. Ces marbres se sont d'eux-mêmes rangés autour de leur maitre. Une autre salle renferme les monuments tristes et sévères des Égyptiens, de ce peuple chez lequel les statues ressemblent plus aux momies qu'aux hommes, et qui par ses institutions silencieuses, roides et serviles, semble avoir, autant qu'il le pouvait, assimilé la vie à la mort. Les Égyptiens excellaient bien plus dans l'art d'imiter les animaux que les hommes, c'est l'empire de l'âme qui semble leur être inaccessible.

Viennent ensuite les portiques du musée, où l'on voit à chaque pas un nouveau chefd'œuvre. Des vases, des autels, des ornements de toute espèce entourent l'Apollon, le Laocoon, les Muses. C'est là qu'on apprend à sentir Homère et Sophocle : c'est là que se révèle à l'âme une connaissance de l'Antiquité, qui ne peut jamais s'acquérir ailleurs. C'est en vain que l'on se fie à la lecture de l'histoire pour comprendre l'esprit des peuples; ce que l'on voit excite en nous bien plus d'idées que ce qu'on lit, et les objets extérieurs causent une émotion forte, qui donne à l'étude du passé l'intérêt et la vie qu'on trouve dans l'observation des hommes et des faits contemporains.

$\mathrm{Au}$ milieu des superbes portiques, asile de tant de merveilles, il y a des fontaines qui coulent sans cesse et vous avertissent doucement des heures qui passaient de même, il y a deux mille ans, quand les artistes de ces chefs-d'œuvre existaient encore. Mais l'impression la plus mélancolique que l'on éprouve au musée du Vatican, c'est en contemplant les débris de statues que l'on y voit rassemblés; le torse d'Hercule, des 
têtes séparées du tronc, un pied de Jupiter, qui suppose une statue plus grande et plus parfaite que toutes celles que nous connaissons. On croit voir le champ de bataille où le temps a lutté contre le génie; et ces membres mutilés attestent sa victoire et nos pertes.

Après être sortie du Vatican, Corinne conduisit Oswald devant les colosses de Monte Cavallo, ces deux statues représentant, dit-on, Castor et Pollux. Chacun des deux héros dompte d'une seule main un cheval fougueux qui se cabre. Ces formes colossales, cette lutte de l'homme avec les animaux, donnent, comme tous les ouvrages des Anciens, une admirable idée de la puissance physique de la nature humaine. Mais cette puissance a quelque chose de noble qui ne se retrouve plus dans notre ordre social, où la plupart des exercices du corps sont abandonnés aux gens du peuple. Ce n'est point la force animale de la nature humaine, si l'on peut s'exprimer ainsi, qui se fait remarquer dans ces chefs-d'œuvre. Il semble qu'il y avait une union plus intime entre les qualités physiques et morales chez les Anciens qui vivaient sans cesse au milieu de la guerre, et d'une guerre presque d'homme à homme. La force du corps et la générosité de l'âme, la dignité des traits et la fierté du caractère, la hauteur de la statue et l'autorité du commandement étaient des idées inséparables, avant qu'une religion tout intellectuelle eût placé la puissance de l'homme dans son âme. La figure humaine, qui était aussi la figure des dieux, paraissait symbolique ; et le colosse nerveux de l'Hercule, et toutes les figures de ce genre de l'Antiquité, ne retracent point les vulgaires idées de la vie commune, mais la volonté toute puissante, la volonté divine, qui se montre sous l'emblème d'une force physique surnaturelle.

Corinne et Lord Nelvil terminèrent leur journée en allant voir l'atelier de Canova, le plus grand sculpteur moderne. Comme il était tard, ce fut aux flambeaux qu'ils se le firent montrer; et les statues gagnent beaucoup à cette manière d'être vues. Les Anciens en jugeaient ainsi, puisqu'ils les plaçaient souvent dans leurs thermes, où le jour ne pouvait pas pénétrer. À la lueur des flambeaux, l'ombre plus prononcée amortit la brillante uniformité du marbre, et les statues paraissent des figures pâles qui ont un caractère plus touchant et de grâce et de vie. Il y avait chez Canova une admirable statue destinée pour un tombeau : elle représentait le Génie de la douleur, appuyé sur un lion, emblème de la force. Corinne, en contemplant ce Génie, crut y trouver quelques ressemblances avec Oswald, et l'artiste lui-même en fut aussi frappé. Lord Nelvil se détourna pour ne point attirer l'attention en ce genre; mais il dit à voix basse à son amie : "Corinne, j'étais condamné à cette éternelle douleur quand je vous ai rencontrée; mais vous avez changé ma vie; et quelquefois l'espoir, et toujours un trouble mêlé de charmes, remplit ce cœur qui ne devait plus éprouver que des regrets. »

\section{Livre VIII - chapitre III}

Les chefs-d'œuvre de la peinture étaient alors réunis à Rome, et sa richesse, sous ce rapport, surpassait toutes celles du reste du monde. Un seul point de discussion pouvait exister sur l'effet que produisaient ces chefs-d'œuvre. La nature des sujets que les grands artistes d'Italie ont choisis se prête-t-elle à toute la variété, à toute l'originalité de passions et de caractères que la peinture peut exprimer? Oswald et Corinne différaient d'opinion à cet égard; mais cette différence, comme toutes celles qui existaient entre eux, tenait à la diversité des nations, des climats et des religions. 
Corinne affirmait que les sujets les plus favorables à la peinture étaient les sujets religieux. Elle disait que la sculpture était l'art du paganisme, comme la peinture était celui du christianisme, et que l'on retrouvait dans ces arts, comme dans la poésie, les qualités qui distinguent la littérature ancienne et moderne. Les tableaux de MichelAnge, ce peintre de la Bible, de Raphaël, ce peintre de l'Évangile, supposent autant de profondeur et de sensibilité qu'on en peut trouver dans Shakespeare et Racine. La sculpture ne saurait présenter aux regards qu'une existence énergique et simple, tandis que la peinture indique les mystères du recueillement et de la résignation, et fait parler l'âme immortelle à travers de passagères couleurs. Corinne soutenait aussi que les faits historiques, ou tirés des poèmes, étaient rarement pittoresques. Il faudrait souvent, pour comprendre de tels tableaux, que l'on eût conservé l'usage des peintres du vieux temps, d'écrire les paroles que doivent dire les personnages sur un ruban qui sort de leur bouche. Mais les sujets religieux sont à l'instant entendus par tout le monde, et l'attention n'est point détournée de l'art pour deviner ce qu'il représente.

\section{Raphaël, L'École d'Athènes}

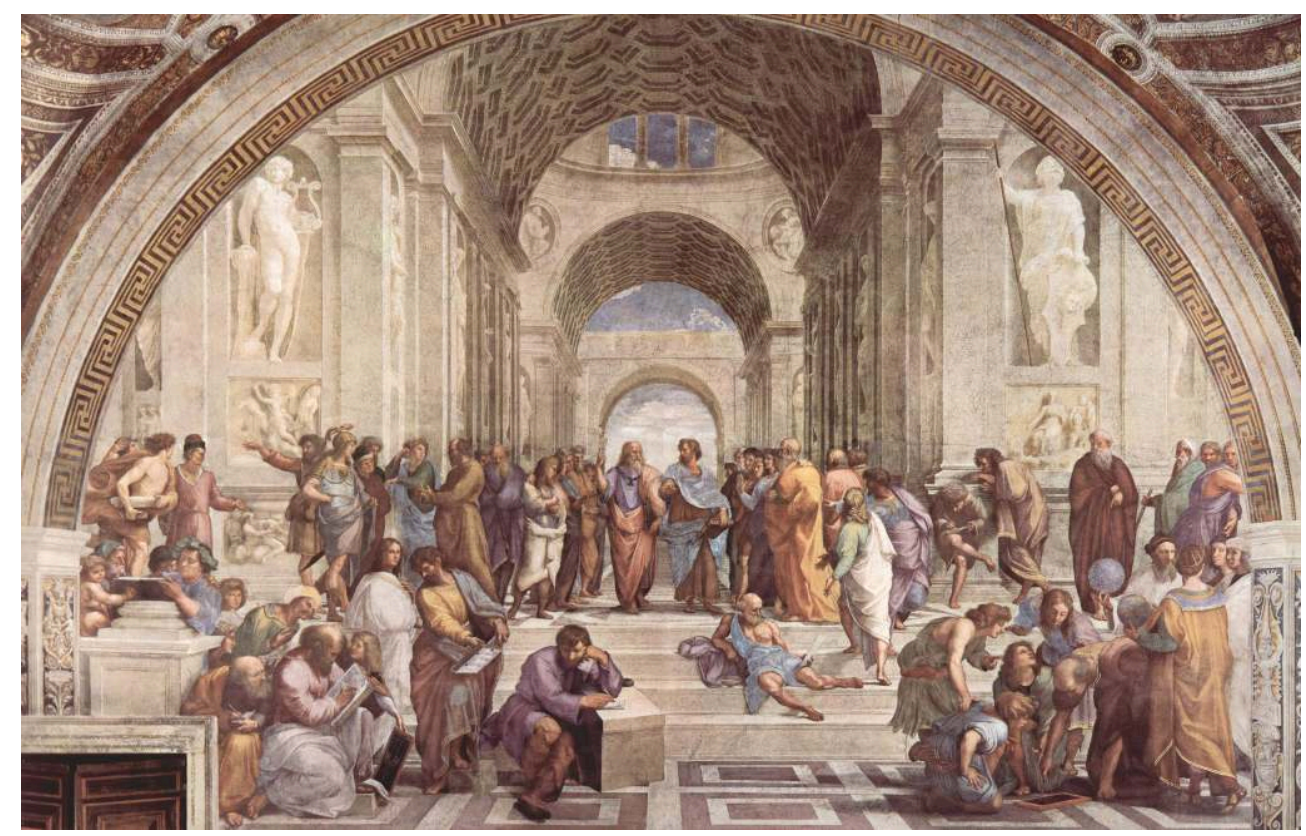

1510, fresque, base $700 \mathrm{~cm}$, cité du Vatican, musées du Vatican. 


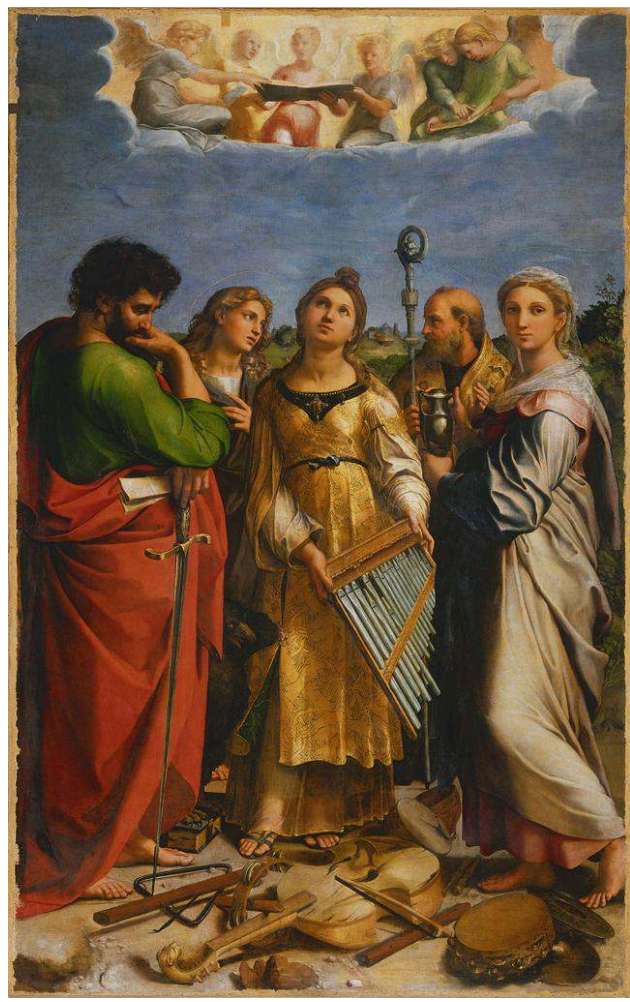

1514, huile sur bois transposé sur toile, 220 x 136 cm, Bologne, Pinacoteca Nazionale.

Corinne pensait que l'expression des peintres modernes, en général, était souvent théâtrale, qu'elle avait l'empreinte de leur siècle, où l'on ne connaissait plus, comme Andrea Mantegna, Pérugin et Léonard de Vinci, cette unité d'existence, ce naturel dans la manière d'être, qui tient encore du repos antique. Mais à ce repos est unie la profondeur de sentiments qui caractérise le christianisme. Elle admirait la composition sans artifice des tableaux de Raphaël, surtout dans sa première manière. Toutes les figures sont dirigées vers un objet principal, sans que l'artiste ait songé à les grouper en attitude, à travailler l'effet qu'elles peuvent produire. Corinne disait que cette bonne foi dans les arts d'imagination, comme dans tout le reste, est le caractère du génie, et que le calcul du succès est presque toujours destructeur de l'enthousiasme. Elle prétendait qu'il y avait de la rhétorique en peinture comme dans la poésie, et que tous ceux qui ne savaient pas caractériser cherchaient les ornements accessoires, réunissaient tout le prestige d'un sujet brillant aux costumes riches, aux attitudes remarquables; tandis qu'une simple vierge tenant son enfant dans ses bras, un vieillard attentif dans la messe de Bolsène, un homme appuyé sur son bâton dans l'école d'Athènes (fig. 1), sainte Cécile levant les yeux au ciel, produisaient, par l'expression seule du regard et de la physionomie, des impressions bien plus profondes (fig. 2). Ces beautés naturelles se découvrent chaque jour davantage; mais au contraire, dans les tableaux d'effet, le premier coup d'œil est toujours le plus frappant.

Corinne ajoutait à ces réflexions une observation qui les fortifiait encore ; c'est que les sentiments religieux des Grecs et des Romains, la disposition de leur âme en tout genre, ne pouvant être la nôtre, il nous est impossible de créer dans leur sens, d'inventer pour ainsi dire sur leur terrain. L'on peut les imiter à force d'étude ; mais comment le génie trouverait-il tout son essor dans un travail où la mémoire et l'érudition sont si 
nécessaires? Il n'en est pas de même des sujets qui appartiennent à notre propre histoire ou à notre propre religion. Les peintres peuvent en avoir eux-mêmes l'inspiration personnelle; ils sentent ce qu'ils peignent, ils peignent ce qu'ils ont vu. La vie leur sert pour imaginer la vie ; mais en se transportant dans l'Antiquité, il faut qu'ils inventent $d$ 'après les livres et les statues. Enfin Corinne trouvait que les tableaux pieux faisaient à l'âme un bien que rien ne pouvait remplacer, et qu'ils supposaient dans l'artiste un saint enthousiasme qui se confond avec le génie, le renouvelle, le ranime et peut seul le soutenir contre les dégoûts de la vie et les injustices des hommes.

Oswald recevait, sous quelques rapports, une impression différente. D'abord il était presque scandalisé de voir représenter en peinture, comme l'a fait Michel-Ange, la figure de la divinité même revêtue de traits mortels. Il croyait que la pensée n'osait lui donner des formes, et qu'on trouvait à peine au fond de son âme une idée assez intellectuelle, assez éthérée pour l'élever jusqu'à l'Être suprême; et quant aux sujets tirés de l'Écriture sainte, il lui semblait que l'expression et les images dans ce genre de tableaux laissaient beaucoup à désirer. Il croyait, avec Corinne, que la méditation religieuse est le sentiment le plus intime que l'homme puisse éprouver; et, sous ce rapport, il est celui qui fournit aux peintres les plus grands mystères de la physionomie et du regard ; mais la religion réprimant tous les mouvements du cœur qui ne naissent pas immédiatement d'elle, les figures des saints et des martyrs ne peuvent être très variées. Le sentiment de l'humilité, si noble devant le ciel, affaiblit l'énergie des passions terrestres et donne nécessairement de la monotonie à la plupart des sujets religieux. Quand Michel-Ange, avec son terrible talent, a voulu peindre ces sujets, il en a presque altéré l'esprit, en donnant à ses prophètes une expression redoutable et puissante qui en fait des Jupiter plutôt que des saints. Souvent aussi il se sert, comme Le Dante, des images du paganisme, et mêle la mythologie au christianisme. Une des circonstances les plus admirables de l'établissement du christianisme, c'est l'état vulgaire des apôtres qui l'ont prêché, l'asservissement et la misère du peuple juif, dépositaire pendant longtemps des promesses qui annonçaient le Christ. Ce contraste entre la petitesse des moyens et la grandeur du résultat est très beau moralement; mais en peinture, où les moyens seuls peuvent paraître, les sujets chrétiens doivent être moins éclatants que ceux tirés des temps héroïques et fabuleux. Parmi les arts, la musique seule peut être purement religieuse. La peinture ne saurait se contenter d'une expression aussi rêveuse et aussi vague que celle des sons. Il est vrai que l'heureuse combinaison des couleurs et du clair-obscur produit, si l'on peut s'exprimer ainsi, un effet musical dans la peinture ; mais, comme elle représente la vie, on lui demande l'expression des passions dans toute leur énergie et leur diversité. Sans doute il faut choisir parmi les faits historiques ceux qui sont assez connus pour qu'il ne faille point d'étude pour les comprendre; car l'effet produit par les tableaux doit être immédiat et rapide comme tous les plaisirs causés par les beaux-arts; mais quand les faits historiques sont aussi populaires que les sujets religieux, ils ont sur eux l'avantage de la variété des situations et des sentiments qu'ils retracent.

Lord Nelvil pensait aussi qu'on devait de préférence représenter en tableaux les scènes de tragédie ou les fictions poétiques les plus touchantes, afin que tous les plaisirs de l'imagination et de l'âme fussent réunis. Corinne combattit encore cette opinion, quelque séduisante qu'elle fût. Elle était convaincue que l'empiétement d'un art sur l'autre leur nuisait mutuellement. La sculpture perd les avantages qui lui sont particuliers, quand elle aspire aux groupes de la peinture ; la peinture, quand elle veut atteindre à l'expression dramatique. Les arts sont bornés dans leurs moyens, quoique 
sans bornes dans leurs effets. Le génie ne cherche point à combattre ce qui est dans l'essence des choses; sa supériorité consiste, au contraire, à la deviner. "Vous, mon cher Oswald, dit Corinne, vous n'aimez pas les arts en eux-mêmes, mais seulement à cause de leurs rapports avec le sentiment ou l'esprit. Vous n'êtes ému que par ce qui vous retrace les peines du cœur. La musique et la poésie conviennent à cette disposition; tandis que les arts qui parlent aux yeux, bien que leur signification soit idéale, ne plaisent et n'intéressent que lorsque notre âme est tranquille et notre imagination tout à fait libre. Il ne faut pas non plus, pour les goûter, la gaieté qu'inspire la société, mais la sérénité que fait naître un beau jour, un beau climat. Il faut sentir, dans ces arts qui représentent les objets extérieurs, l'harmonie universelle de la nature; et quand notre âme est troublée, nous n'avons plus en nous-mêmes cette harmonie, le malheur l'a détruite. - Je ne sais, répondit Oswald, si je ne cherche dans les beaux-arts que ce qui peut rappeler les souffrances de l'âme ; mais je sais bien au moins que je ne puis supporter d'y trouver la représentation des douleurs physiques. Ma plus forte objection, continua-t-il, contre les sujets chrétiens en peinture, c'est le sentiment pénible que fait éprouver l'image du sang, des blessures, des supplices, bien que le plus noble enthousiasme ait animé les victimes. Philoctète est peut-être le seul sujet tragique dans lequel les maux physiques puissent être admis. Mais de combien de circonstances poétiques ces maux cruels ne sont-ils pas entourés! Ce sont les flèches d'Hercule qui les ont causés. Le fils d'Esculape doit les guérir. Enfin cette blessure se confond presque avec le ressentiment moral qu'elle fait naitre dans celui qui en est atteint, et ne peut exciter aucune impression de dégoût.

\section{Raphaël, La Transfiguration}

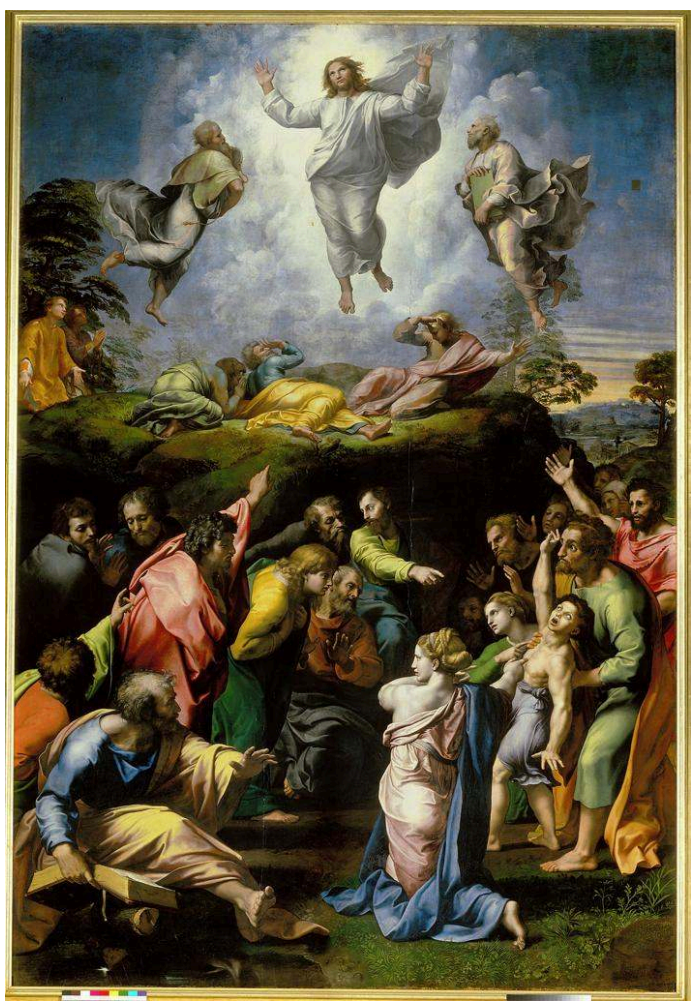

Vers 1517-1520, huile sur bois, 405 × 278 cm, cité du Vatican, musées du Vatican.

Mais la figure du possédé, dans le superbe tableau de la Transfiguration par Raphaël (fig. 3), est une image désagréable et qui n'a nullement la dignité des beaux-arts. Il faut 
qu'ils nous découvrent le charme de la douleur, comme la mélancolie de la prospérité ; c'est l'idéal de la destinée humaine qu'ils doivent représenter dans chaque circonstance particulière. Rien ne tourmente davantage l'imagination, que des plaies sanglantes ou des convulsions nerveuses. Il est impossible que dans de semblables tableaux l'on ne cherche et l'on ne craigne pas en même temps de trouver l'exactitude de l'imitation. L'art qui ne consisterait que dans cette imitation, quel plaisir nous donnerait-il ? Il est plus horrible ou moins beau que la nature même, dès l'instant qu'il aspire seulement à lui ressembler.

\section{Le Dominiquin, Communion de saint Jérôme}

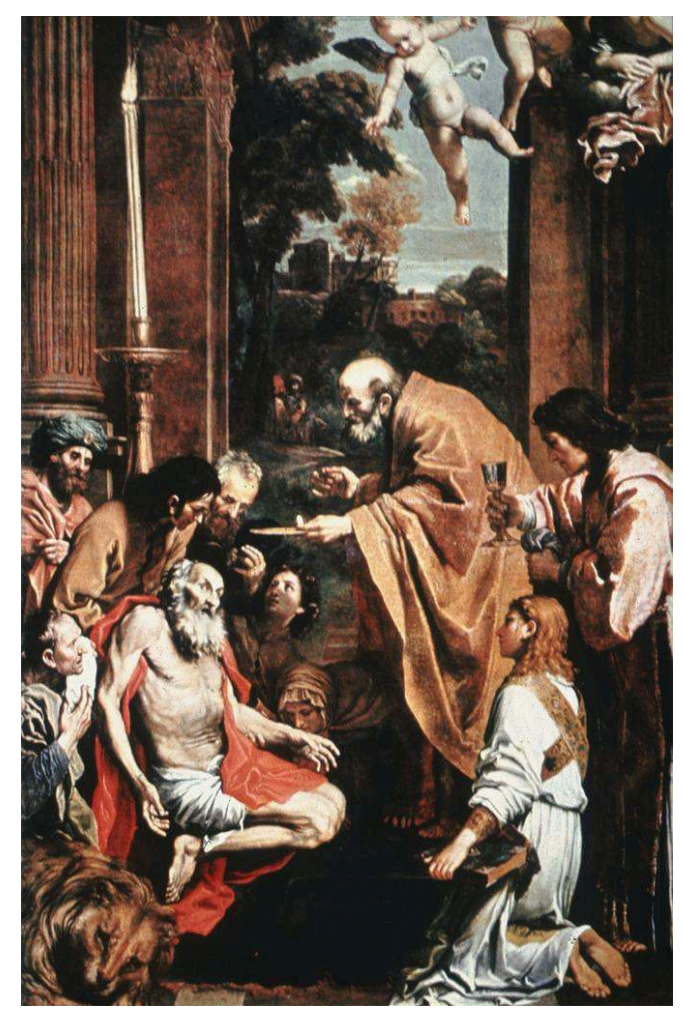

1614, huile sur toile, 419 × 256 cm, cité du Vatican, musées du Vatican.

« Vous avez raison, milord, dit Corinne, de désirer qu'on écarte des sujets chrétiens les images pénibles; elles n'y sont pas nécessaires. Mais avouez cependant que le génie, et le génie de l'âme, sait triompher de tout. Voyez cette communion de saint Jérôme par le Dominiquin (fig. 4). Le corps du vénérable mourant est livide et décharné : c'est la mort qui se soulève. Mais dans ce regard est la vie éternelle, et toutes les misères du monde ne sont là que pour disparaître devant le pur éclat d'un sentiment religieux. [...] »

\section{Livre VIII - chapitres III-IV}

«J'ai essayé ce que vous désirez, dans la galerie de tableaux que des artistes de mes amis m'ont composée, et dont j'ai moi-même esquissé quelques dessins. Vous y verrez les défauts et les avantages des sujets de peinture que vous aimez. Cette galerie est dans ma maison de campagne à Tivoli. Le temps est assez beau pour la voir, voulez-vous que nous y allions demain?» Et comme elle attendait qu'Oswald y consentît, il lui dit: 
«Mon amie, pouvez-vous douter de ma réponse? Ai-je un autre bonheur dans ce monde, une autre idée que vous ? Et ma vie, que j'ai trop affranchie peut-être de toute occupation, comme de tout intérêt, n'est-elle pas uniquement remplie par le bonheur de vous entendre et de vous voir?»

Ils partirent donc le lendemain pour Tivoli. [...]

\section{Jacques-Louis David, Les Licteurs rapportent à Brutus les corps de ses fils}

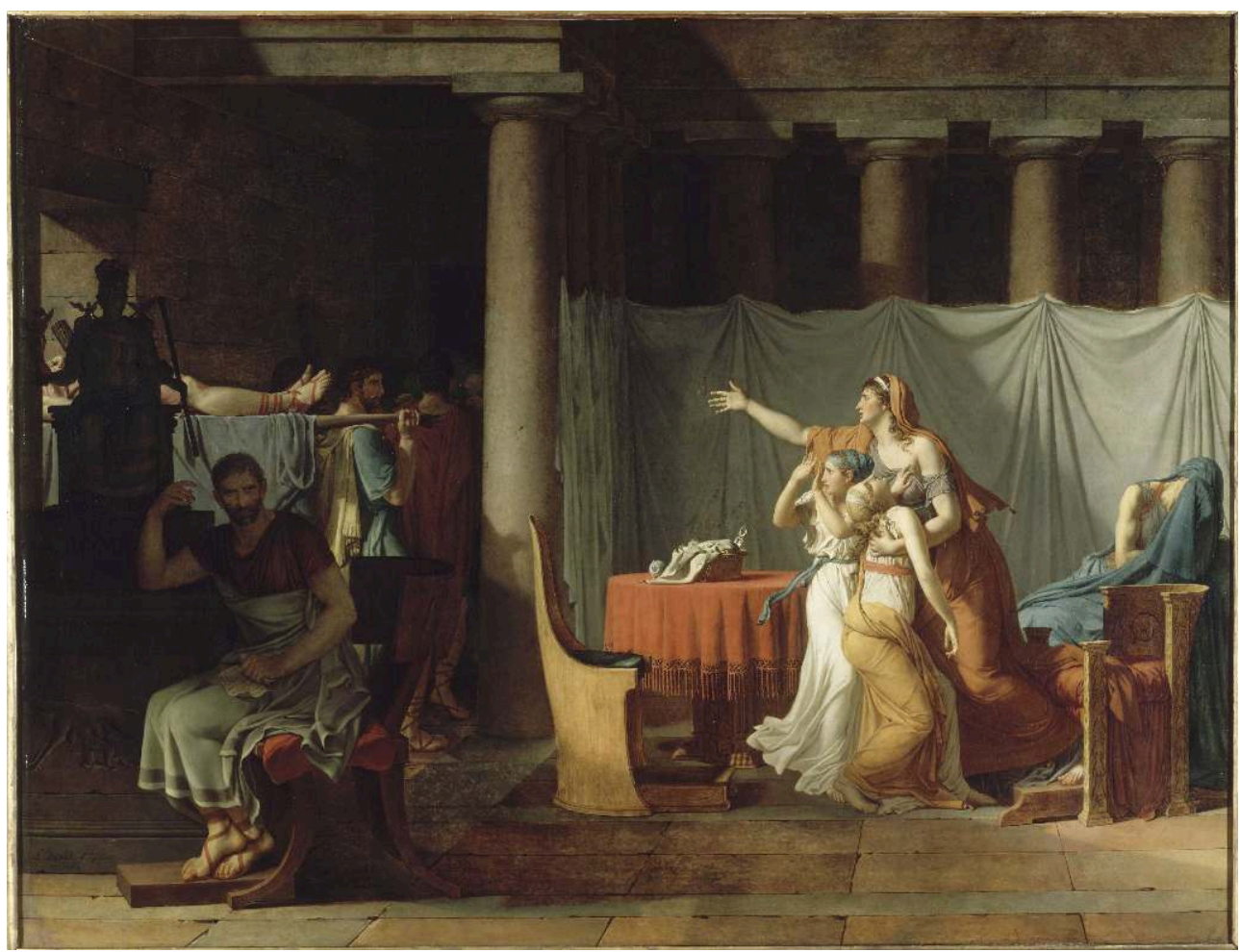

1789, huile sur toile, 323 × 422 cm, Paris, musée du Louvre.

31 Sa galerie était composée de tableaux [d'histoire], de tableaux sur des sujets poétiques et religieux, et de paysages. Il n'y en avait point qui fussent composés d'un très grand nombre de figures. Ce genre présente sans doute de grandes difficultés, mais il donne moins de plaisir. Les beautés qu'on y trouve sont trop confuses ou trop détaillées. L'unité d'intérêt, ce principe de vie dans les arts, comme dans tout, y est nécessairement morcelée. Le premier des tableaux historiques représentait Brutus dans une méditation profonde, assis au pied de la statue de Rome (fig. 5). Dans le fond, des esclaves portent ses deux fils sans vie, qu'il a lui-même condamnés à mort, et de l'autre côté du tableau la mère et les sœurs s'abandonnent au désespoir; les femmes sont heureusement dispensées du courage qui fait sacrifier les affections du cœur. La statue de Rome, placée près de Brutus, est une belle idée : c'est elle qui dit tout. Cependant comment pourrait-on savoir, sans une explication, que c'est Brutus l'ancien qui vient d'envoyer ses fils au supplice? Et néanmoins il est impossible de caractériser cet événement plus qu'il ne l'est dans ce tableau. L'on aperçoit dans l'éloignement Rome, simple encore, sans édifices, sans ornements, mais bien grande comme patrie, puisqu'elle inspire un tel sacrifice. "Sans doute, dit Corinne à Lord Nelvil, quand je vous ai nommé Brutus, toute votre âme s'est attachée à ce tableau ; mais vous auriez pu le voir, sans en deviner le sujet. Et cette incertitude, qui existe presque toujours dans 
les tableaux historiques, ne mêle-t-elle pas le tourment d'une énigme aux jouissances des beaux-arts qui doivent être si faciles et si claires?

6. Jean-Germain Drouais, Marius épargné par le Cimbre [Marius prisonnier à Minturnes]

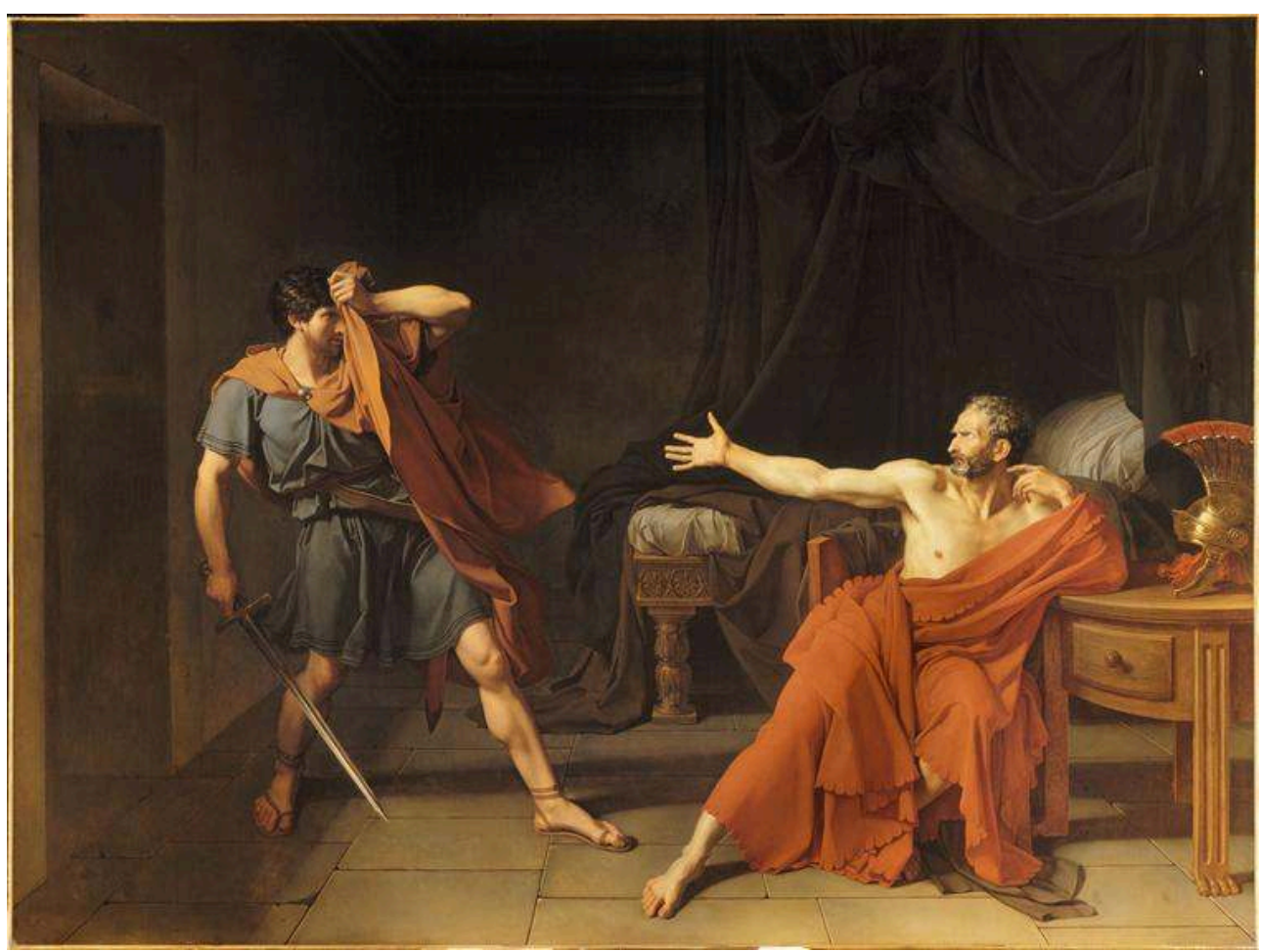

1786, huile sur toile, 271 x 365 cm, Paris, musée du Louvre. 


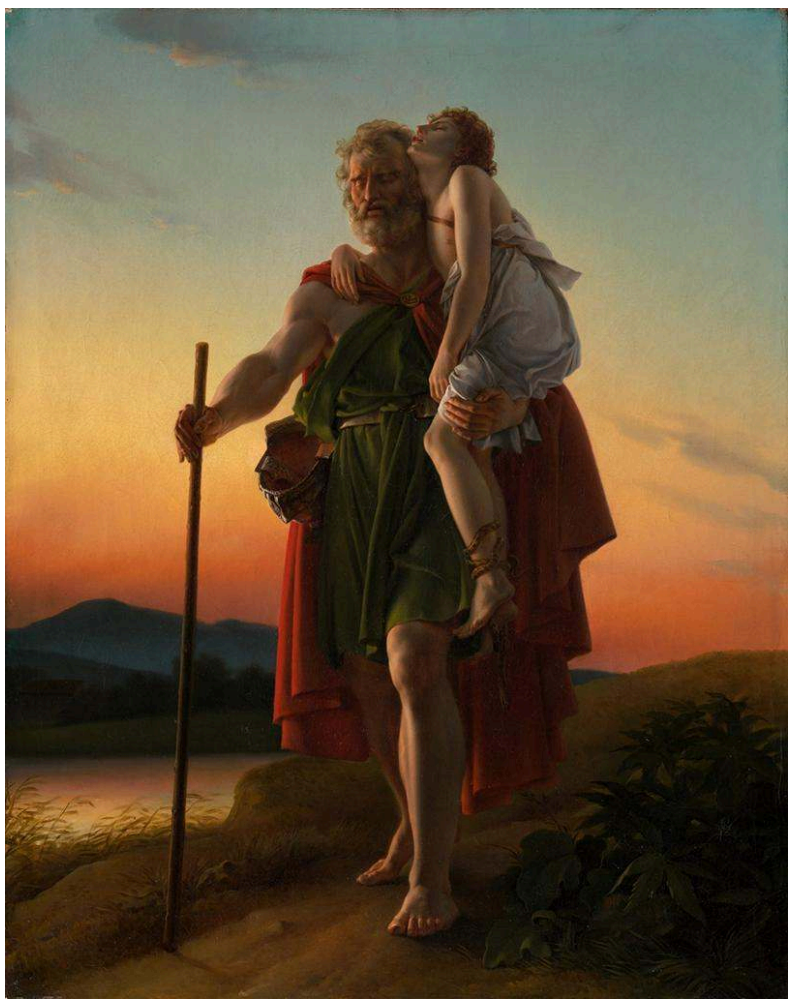

1797, huile sur toile, 91 x 74 cm, Los Angeles, J. Paul Getty Museum.

«J'ai choisi ce sujet, parce qu'il rappelle la plus terrible action que l'amour de la patrie ait inspirée. Le pendant de ce tableau, c'est Marius épargné par le Cimbre, qui ne peut se résoudre à tuer ce grand homme : la figure de Marius est imposante; le costume du Cimbre, l'expression de sa physionomie est très pittoresque (fig. 6). C'est la deuxième époque de Rome, lorsque les lois n'existaient plus, mais quand le génie exerçait encore un grand empire sur les circonstances. Vient ensuite celle où les talents et la gloire n'attiraient que le malheur et l'insulte. Le troisième tableau que voici représente Bélisaire portant sur ses épaules son jeune guide mort en demandant l'aumône pour lui (fig. 7). Bélisaire aveugle et mendiant est ainsi récompensé par son maître; et dans l'univers qu'il a conquis, il n'a plus d'autre emploi que de porter dans la tombe les tristes restes du pauvre enfant qui seul ne l'avait point abandonné. Cette figure de Bélisaire est admirable, et depuis les peintres anciens on n'en a guère fait d'aussi belles. L'imagination du peintre, comme celle d'un poète, a réuni tous les genres de malheur, et peut-être même y en a-t-il trop pour la pitié ; mais qui nous dit que c'est Bélisaire ? Ne faut-il pas être fidèle à l'histoire pour la rappeler; et quand on y est fidèle, est-elle assez pittoresque? Après ces tableaux qui représentent dans Brutus les vertus qui ressemblent au crime; dans Marius, la gloire, cause de malheurs; dans Bélisaire, les services payés par les persécutions les plus noires, enfin dans toutes les misères de la destinée humaine que les événements de l'histoire racontent chacun à sa manière, j'ai placé deux tableaux de l'ancienne école qui soulagent un peu l'âme oppressée en rappelant la religion qui a consolé l'univers asservi et déchiré, la religion qui donnait une vie au fond du cœur, quand tout au-dehors n'était qu'oppression et silence. Le premier est de l'Albane; il a peint le Christ enfant endormi sur la croix. Voyez quelle douceur, quel calme dans ce visage! Quelles idées pures il rappelle, comme il fait sentir 
que l'amour céleste n'a rien à craindre de la douleur ni de la mort. Titien est l'auteur du second tableau; c'est Jésus-Christ succombant sous le fardeau de la croix. Sa mère vient au-devant de lui. Elle se jette à genoux en l'apercevant. Admirable respect d'une mère pour les malheurs et les vertus divines de son fils! Quel regard que celui du Christ! Quelle divine résignation, et cependant quelle souffrance et quelle sympathie par cette souffrance avec le cœur de l'homme! Voilà sans doute le plus beau de mes tableaux. C'est celui vers lequel je reporte sans cesse mes regards, sans pouvoir jamais épuiser l'émotion qu'il me cause.

\section{Bénigne Gagnereaux, Clorinde mourante et Tancrède [Le Baptême de Clorinde par Tancrède]}

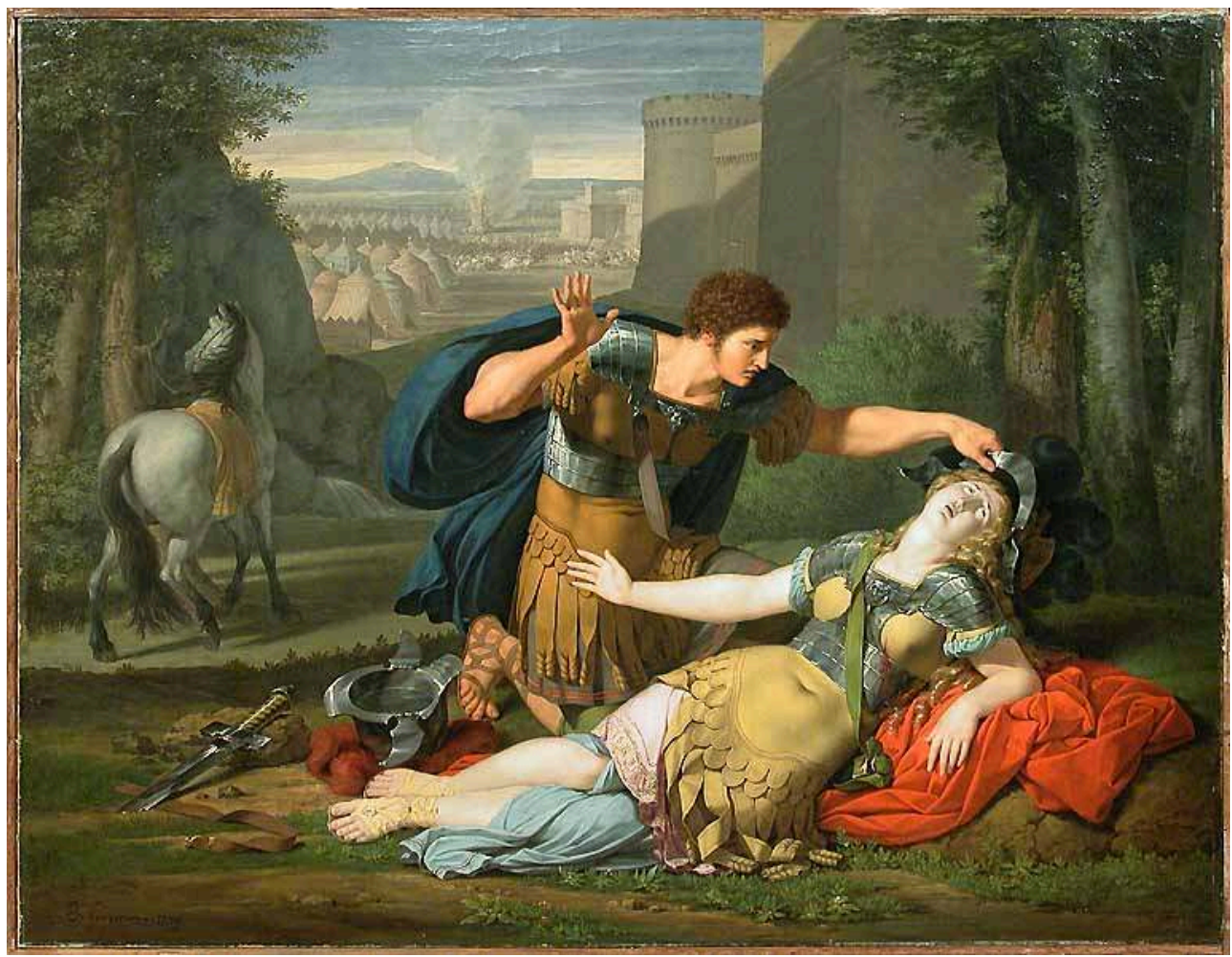

1789, huile sur toile, 76 × 98 cm, Paris, musée du Louvre.

Viennent ensuite, continua Corinne, les tableaux dramatiques tirés de quatre grands poètes. Jugez avec moi, milord, de l'effet qu'ils produisent. Le premier représente Énée dans les Champs-Élysées, lorsqu'il veut s'approcher de Didon. L'ombre indignée s'éloigne et s'applaudit de ne plus porter dans son sein le cœur qui battrait encore d'amour à l'aspect du coupable. La couleur vaporeuse des ombres, et la pâle nature qui les environne, font contraste avec l'air de vie d'Énée et de la Sibylle qui le conduit. Mais c'est un jeu de l'artiste que ce genre d'effet, et la description du poète est nécessairement bien supérieure à ce que l'on peut en peindre. J'en dirai autant du tableau que voici, Clorinde mourante et Tancrède (fig. 8). Le plus grand attendrissement qu'il puisse causer, c'est de rappeler les beaux vers du Tasse, lorsque Clorinde pardonne à son ennemi qui l'adore et vient de lui percer le sein. C'est nécessairement subordonner la peinture à la poésie, que de la consacrer à des sujets traités par les grands poètes; car il reste de leurs paroles une impression qui efface tout, et presque toujours les situations qu'ils ont choisies tirent leur plus grande force du développement des passions et de leur éloquence, tandis que la plupart des effets 
pittoresques naissent d'une beauté calme, d'une expression simple, d'une attitude noble, d'un moment de repos enfin digne d'être indéfiniment prolongé, sans que le regard s'en lasse jamais.

33 « Votre terrible Shakespeare, milord, continua Corinne, a fourni le sujet du troisième tableau dramatique. C'est Macbeth, l'invincible Macbeth, qui, prêt à combattre Macduff, dont il a fait périr la femme et les enfants, apprend que l'oracle des sorcières s'est accompli, que la forêt de Birnam parait s'avancer vers Dunsinane, et qu'il se bat avec un homme né depuis la mort de sa mère. Macbeth est vaincu par le sort, mais non par son adversaire. Il tient le glaive d'une main désespérée ; il sait qu'il va mourir, mais il veut essayer si la force humaine ne pourrait pas triompher du destin. Certainement il y a dans cette tête une belle expression de désordre et de fureur, de trouble et d'énergie; mais à combien de beautés du poète cependant ne faut-il pas renoncer? Peut-on peindre Macbeth précipité dans le crime par les prestiges de l'ambition qui s'offrent à lui sous la forme de la sorcellerie? Comment exprimer la terreur qu'il éprouve ? Cette terreur qui se concilie cependant avec une bravoure intrépide. Peut-on caractériser le genre de superstition qui l'opprime? Cette croyance sans dignité, cette fatalité de l'enfer qui pèse sur lui, son mépris de la vie, son horreur de la mort? Sans doute la physionomie de l'homme est le plus grand des mystères ; mais cette physionomie fixée dans un tableau ne peut guère exprimer que les profondeurs d'un sentiment unique. Les contrastes, les luttes, les événements enfin appartiennent à l'art dramatique. La peinture peut difficilement rendre ce qui est successif : le temps ni le mouvement n'existent pas pour elle.

\section{Pierre-Narcisse Guérin, Thésée protège son épouse [Phèdre et Hippolyte]}

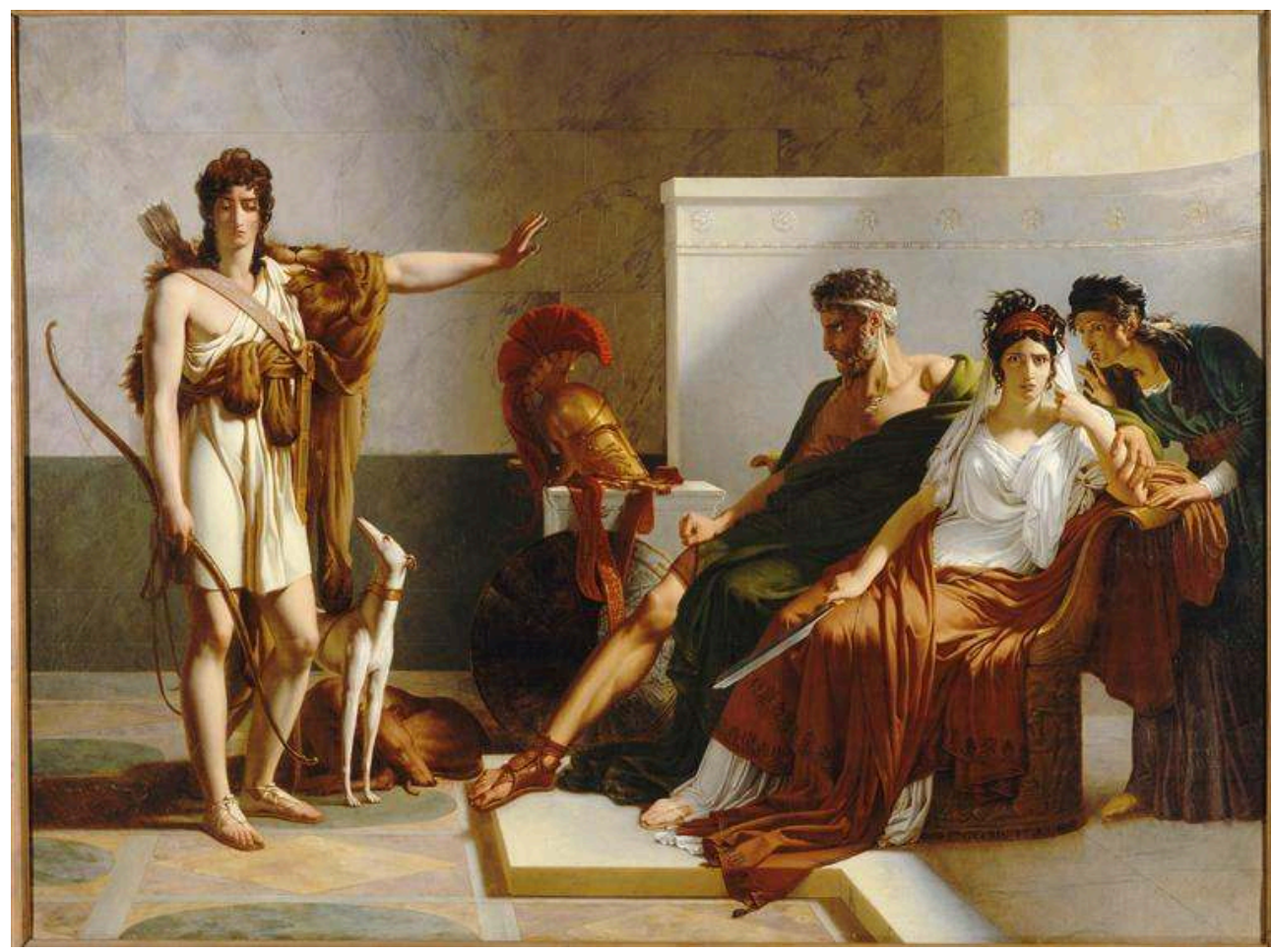

Vers 1802, huile sur toile, 257 × 335 cm, Paris, musée du Louvre.

«La Phèdre de Racine a fourni le sujet du quatrième tableau, dit Corinne, en le montrant à Lord Nelvil (fig. 9). Hippolyte, dans toute la beauté de la jeunesse et de l'innocence, 
repousse les accusations perfides de sa belle-mère ; le héros Thésée protège encore son épouse coupable, qu'il entoure de son bras vainqueur. Phèdre porte sur son visage un trouble qui glace l'effroi; et sa nourrice, sans remords, l'encourage dans son crime. Hippolyte, dans ce tableau, est peut-être plus beau que dans Racine même; il y ressemble davantage au Méléagre antique, parce que nul amour pour Aricie ne dérange l'impression de sa noble et sauvage vertu; mais est-il possible de supposer que Phèdre en présence d'Hippolyte pût soutenir son mensonge, qu'elle le vît innocent et persécuté, et ne tombât point à ses pieds ? Une femme offensée peut outrager ce qu'elle aime, en son absence, mais quand elle le voit, il n'y a plus dans son cœur que de l'amour. Le poète n'a jamais mis en scène Hippolyte avec Phèdre, depuis que Phèdre l'a calomnié ; le peintre devait les réunir pour rassembler, comme il l'a fait, toutes les beautés des contrastes; mais n'est-ce pas une preuve qu'il y a toujours une telle différence entre les sujets poétiques et les sujets pittoresques, qu'il vaut mieux que les poètes fassent des vers d'après les tableaux, que les peintres des tableaux d'après les poètes? L'imagination doit toujours précéder la pensée, l'histoire de l'esprit humain nous le prouve.»

Pendant que Corinne expliquait ainsi ses tableaux à Lord Nelvil, elle s'était arrêtée plusieurs fois, espérant qu'il lui parlerait ; mais son âme blessée ne se trahissait par aucun mot: seulement, chaque fois qu'elle exprimait une idée sensible, il soupirait et détournait la tête, afin qu'elle ne vît pas combien, dans sa disposition actuelle, il était facilement ému : Corinne, oppressée par ce silence, s'assit en couvrant son visage de ses mains; Lord Nelvil se promena quelque temps avec vivacité dans la chambre, puis il s'approcha de Corinne, et fut au moment de se plaindre et de se livrer à ce qu'il éprouvait; mais un mouvement de fierté tout à fait invincible dans son caractère réprima son attendrissement, et il retourna vers les tableaux, comme s'il attendait que Corinne achevât de les lui montrer: elle espérait beaucoup de l'effet du dernier de tous ; et faisant effort à son tour pour paraître calme, elle se leva et dit : «Milord, il me reste encore trois paysages à vous faire voir; deux font allusion à quelques idées intéressantes: je n'aime pas beaucoup les scènes champêtres, qui sont fades en peinture comme des idylles, quand elles ne font aucune allusion à la fable ou à l'histoire. Ce qui vaut le mieux, ce me semble, en ce genre, c'est la manière de Salvator Rosa, qui représente, comme vous le voyez dans ce tableau, un rocher, des torrents et des arbres, sans un seul être vivant, sans que seulement le vol d'un oiseau rappelle l'idée de la vie. L'absence de l'homme au milieu de la nature excite des réflexions profondes. Que serait cette terre ainsi délaissée ? CEuvre sans but, et cependant œuvre encore si belle, dont la mystérieuse impression ne s'adresserait qu'à la divinité.

« Enfin, voici les deux tableaux où, selon moi, l'histoire et la poésie sont heureusement unies au paysage. L'un représente le moment où Cincinnatus est invité par les consuls à quitter sa charrue pour commander les armées romaines. C'est tout le luxe du Midi que vous verrez dans ce paysage, son abondante végétation, son ciel brûlant, cet air riant de toute la nature qui se retrouve dans la physionomie même des plantes; et cet autre tableau qui fait contraste avec celui-ci, c'est le fils de Caïrbar endormi sur la tombe de son père. Il attend depuis trois jours et trois nuits le barde qui doit rendre des honneurs à la mémoire des morts. Ce barde est aperçu dans le lointain, descendant de la montagne ; l'ombre du père plane sur les nuages ; la campagne est couverte de frimas ; les arbres, quoique dépouillés, sont agités par les vents, et leurs branches mortes et leurs feuilles desséchées suivent encore la direction de l'orage. » 
Oswald jusqu'alors avait conservé du ressentiment contre ce qui s'était passé dans le jardin ; mais, à l'aspect de ce tableau, le tombeau de son père et les montagnes d'Écosse se retracèrent à sa pensée, et ses yeux se remplirent de larmes. Corinne prit sa harpe, et devant ce tableau elle se mit à chanter les romances écossaises dont les simples notes semblent accompagner le bruit du vent qui gémit dans les vallées. Elle chanta les adieux d'un guerrier en quittant sa patrie et sa maîtresse, et ce mot « jamais » (no more), un des plus harmonieux et des plus sensibles de la langue anglaise, Corinne le prononçait avec l'expression la plus touchante. Oswald ne résista point à l'émotion qui l'oppressait, et l'un et l'autre s'abandonnèrent sans contrainte à leurs larmes. «Ah! s'écria Lord Nelvil, cette patrie qui est la mienne ne dit-elle rien à ton cœur? Me suivrais-tu dans ces retraites peuplées par mes souvenirs? Serais-tu la digne compagne de ma vie, comme tu en es le charme et l'enchantement? - Je le crois, répondit Corinne, je le crois, puisque je vous aime. - Au nom de l'amour et de la pitié, ne me cachez plus rien, dit Oswald. - Vous le voyez, interrompit Corinne, j'y souscris. Ma promesse est donnée; je n'y mets qu'une condition, c'est que vous ne me demanderez pas de l'accomplir avant l'époque prochaine de nos solennités religieuses. Au moment où je vais décider de mon sort, l'appui du ciel ne m'est-il pas plus que jamais nécessaire? - Va, s'écria Lord Nelvil, si ce sort dépend de moi, Corinne, il n'est plus douteux. - Vous le croyez, reprit-elle, je n'ai pas la même confiance ; mais enfin, je vous en conjure, ayez pour ma faiblesse la condescendance que je désire. » Oswald soupira sans accorder ni refuser le délai demandé. "Partons maintenant, dit Corinne, et retournons à la ville. Comment vous rien taire dans cette solitude! Et si ce que je dois vous dire devait vous détacher de moi, faudrait-il que sitôt... Partons. Oswald, vous reviendrez ici, quoiqu'il arrive, mes cendres y reposeront. » Oswald attendri, troublé, obéit à Corinne. Il revint avec elle, et pendant la route ils ne se parlèrent presque pas. De temps en temps ils se regardaient avec une affection qui disait tout; mais néanmoins un sentiment de mélancolie régnait au fond de leur âme quand ils arrivèrent au milieu de Rome.

\section{ANNEXES}

Lire les extraits du roman de Germaine de Staël De l'Allemagne

Lire l'introduction à Germaine de Staël écrite par Anne Lafont

\section{NOTES}

1. Ces deux vers sont de Goethe, le poète de l'Allemagne, le philosophe, l'homme de lettres vivant, dont l'originalité et l'imagination sont les plus remarquables : „Eine Welt zwar bist du, o Rom ; doch ohne Liebe / wäre die Welt nicht die Welt, wäre denn Rom auch nicht Rom."

2. (NdÉ) Vers de M. de Fontanes. 


\section{Germaine de Staël, De l'Allemagne,}

\section{4}

Paris, Garnier-Flammarion, 1968, extraits choisis.

\section{« Lessing et Winckelmann »}

Parmi les écrits de Lessing, l'un des plus remarquables, c'est le Laocoon; il caractérise les sujets qui conviennent à la poésie et à la peinture avec autant de philosophie dans les principes que de sagacité dans les exemples. Toutefois l'homme qui fit une véritable révolution en Allemagne dans la manière de considérer les arts, et par les arts la littérature, c'est Winckelmann. Je parlerai de lui ailleurs sous le rapport de son influence sur les arts ; mais la beauté de son style est telle qu'il doit être mis au premier rang des écrivains allemands. 
1. [Anonyme], Apollon du Belvédère

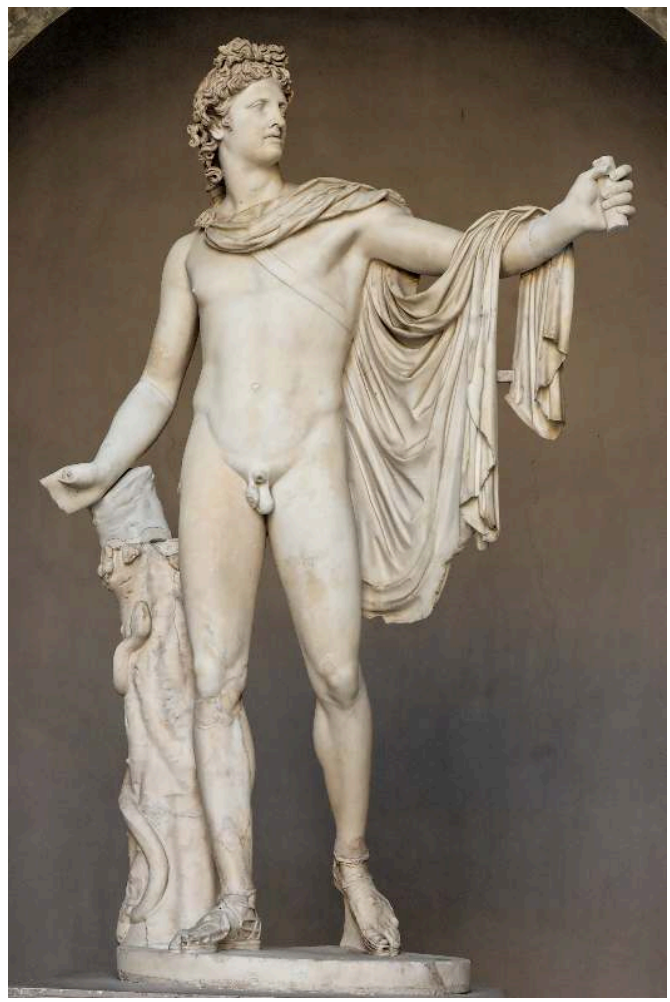

Copie romaine réalisée vers 130-140 après J. C., marbre, 224 cm, cité du Vatican, musée Pio Clementino.

\section{2. [Anonyme], Laocoon}

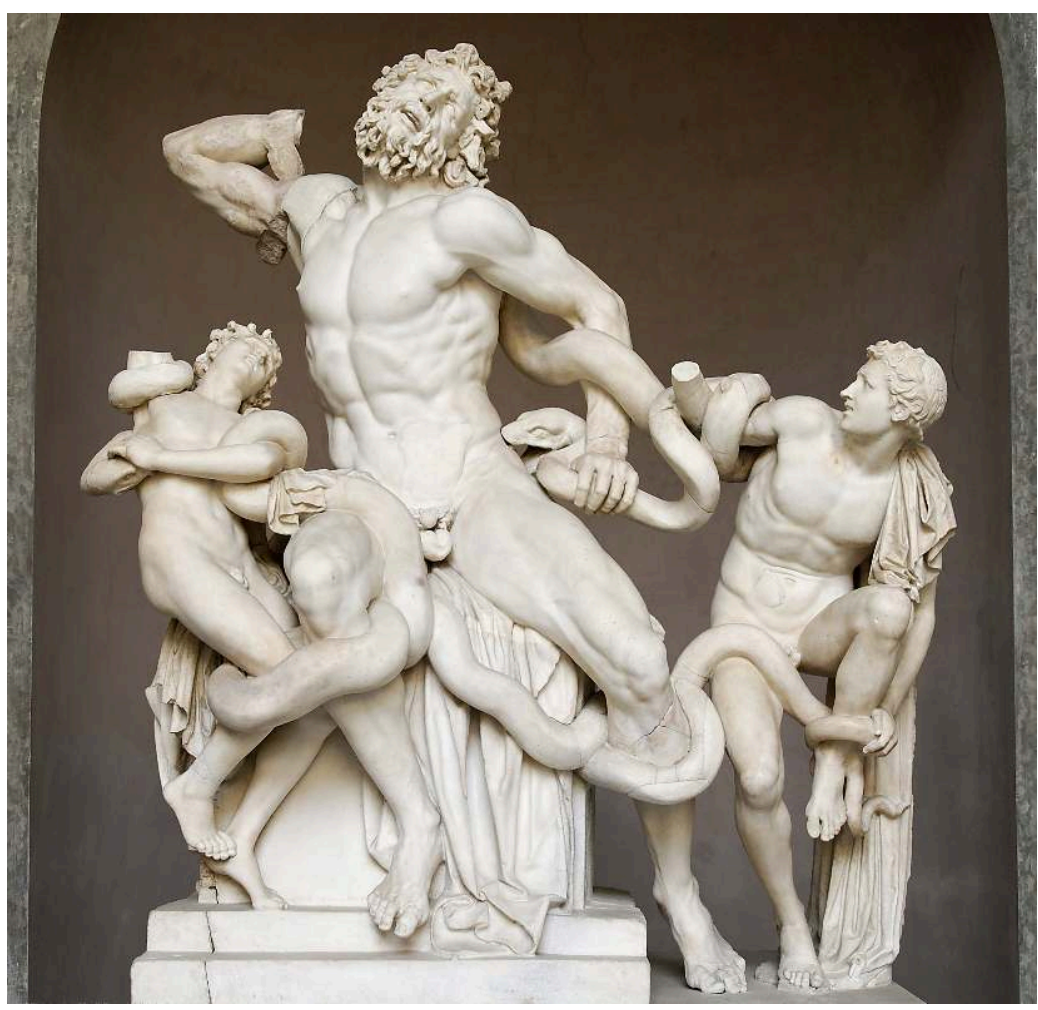

Ier siècle avant J.-C., marbre, 242 cm, cité du Vatican, musées du Vatican. 
2 Cet homme, qui n'avait d'abord connu l'Antiquité que par les livres, voulut aller considérer ses nobles restes; il se sentit attiré vers le Midi avec ardeur. On retrouve encore souvent dans les imaginations allemandes quelques traces de cet amour du soleil, de cette fatigue du Nord qui entraîna les peuples septentrionaux dans les contrées méridionales. Un beau ciel fait naître des sentiments semblables à l'amour de la patrie. Quand Winckelmann, après un long séjour en Italie, revint en Allemagne, l'aspect de la neige, des toits pointus qu'elle couvre, et des maisons enfumées le remplissait de tristesse. Il lui semblait qu'il ne pouvait plus goûter les arts, quand il ne respirait plus l'air qui les a fait naître. Quelle éloquence dans ce qu'il écrit sur l'Apollon du Belvédère, sur le Laocoon! (fig. 1 et 2) Son style est calme et majestueux comme l'objet qu'il considère. Il donne à l'art d'écrire l'imposante dignité des monuments, et sa description produit la même sensation que la statue. Nul avant lui n'avait réuni des observations exactes et profondes à une admiration si pleine de vie; c'est ainsi seulement qu'on peut comprendre les beaux-arts. Il faut que l'attention qu'ils excitent vienne de l'amour, et qu'on découvre dans les chefs-d'œuvre du talent, comme dans les traits d'un être chéri, mille charmes révélés par les sentiments qu'ils inspirent. [...]

Winckelmann a développé les vrais principes admis maintenant dans les arts sur l'idéal, sur cette nature perfectionnée dont le type est dans notre imagination, et non audehors de nous. L'application de ces principes à la littérature est singulièrement féconde.

4 La poétique de tous les arts est rassemblée sous un même point de vue dans les écrits de Winckelmann, et tous y ont gagné. On a mieux compris la poésie par la sculpture, la sculpture par la poésie, et l'on a été conduit par les arts des Grecs à leur philosophie. La métaphysique idéaliste, chez les Allemands comme chez les Grecs, a pour origine le culte de la beauté par excellence, que notre âme seule peut concevoir et reconnaître ; c'est un souvenir du ciel, notre ancienne patrie, que cette beauté merveilleuse; les chefs-d'œuvre de Phidias, les tragédies de Sophocle et la doctrine de Platon s'accordent pour nous en donner la même idée sous des formes différentes.

\section{« Des beaux-arts en Allemagne »}

Tome II - chapitre XXXII

p. 162-164.

Les Allemands en général conçoivent mieux l'art qu'ils ne le mettent en pratique : à peine ont-ils une impression, qu'ils en tirent une foule d'idées. Ils vantent beaucoup le mystère, mais c'est pour le révéler, et l'on ne peut montrer aucun genre d'originalité en Allemagne, sans que chacun vous explique comment cette originalité vous est venue ; c'est un grand inconvénient, surtout pour les arts, où tout est sensation; ils sont analysés avant d'être sentis, et l'on a beau dire après qu'il faut renoncer à l'analyse, l'on a goûté du fruit de l'arbre de la science, et l'innocence du talent est perdue.

6 Ce n'est pas assurément que je conseille, relativement aux arts, l'ignorance que je n'ai cessé de blâmer en littérature; mais il faut distinguer les études relatives à la pratique de l'art, de celles qui ont uniquement pour objet la théorie du talent ; celles-ci, poussées trop loin, étouffent l'invention ; l'on est troublé par le souvenir de tout ce qui a été dit sur chaque chef-d'œuvre ; on croit sentir entre soi et l'objet que l'on veut peindre une foule de traités sur la peinture et la sculpture, l'idéal et le réel, et l'artiste n'est plus seul 
avec la nature. Sans doute l'esprit de ces divers traités est toujours l'encouragement; mais à force d'encouragement on lasse le génie, comme à force de gêne on l'éteint ; et dans ce qui tient à l'imagination, il faut une si heureuse combinaison d'obstacles et de facilité, que des siècles peuvent s'écouler sans que l'on arrive à ce point juste qui fait éclore l'esprit humain dans toute sa force.

7 Avant l'époque de la réformation, les Allemands avaient une école de peinture qui ne dédaignait pas l'école italienne. Albrecht Dürer, Lucas Cranach, Holbein, ont, dans leur manière de peindre, des rapports avec les prédécesseurs de Raphaël, Pérugin, Andrea Mantegna, etc. Holbein se rapproche davantage de Léonard de Vinci; en général cependant, il y a plus de dureté dans l'école allemande que dans celle des Italiens, mais non moins d'expression et de recueillement dans les physionomies. Les peintres $d u$ $\mathrm{Xv}^{\mathrm{e}}$ siècle avaient peu de connaissance des moyens de l'art; mais une bonne foi et une modestie touchantes se faisaient remarquer dans leurs ouvrages; on n'y voit pas de prétentions à d'ambitieux effets, l'on n'y sent que cette émotion intime pour laquelle tous les hommes de talent cherchent un langage, afin de ne pas mourir sans avoir fait part de leur âme à leurs contemporains.

Dans ces tableaux du XIV et du $\mathrm{Xv}^{e}$ siècle, les plis des vêtements sont tout droits, les coiffures un peu raides, les attitudes très simples; mais il y a quelque chose dans l'expression des figures qu'on ne se lasse point de considérer. Les tableaux inspirés par la religion chrétienne produisent une impression semblable à celle de ces psaumes qui mêlent avec tant de charmes la poésie à la pitié.

9 La seconde et la plus belle époque de la peinture fut celle où les peintres conservèrent la vérité du Moyen Âge, en y joignant toute la splendeur de l'art : rien ne correspond chez les Allemands au siècle de Léon X. Vers la fin du XVII ${ }^{e}$ siècle et jusqu'au milieu du $\mathrm{xVIII}$, les beaux-arts tombèrent presque partout dans une singulière décadence ; le goût était dégénéré en affectation; Winckelmann alors exerça la plus grande influence non seulement sur son pays, mais sur le reste de toutes les imaginations artistes vers l'étude et l'admiration des monuments antiques : il s'entendait bien mieux en sculpture qu'en peinture; aussi porta-t-il les peintres à mettre dans leurs tableaux des statues coloriées, plutôt que de faire sentir en tout la nature vivante. Cependant la peinture perd la plus grande partie de son charme en se rapprochant de la sculpture ; l'illusion nécessaire à l'une est directement contraire aux formes immuables et prononcées de l'autre. Quand les peintres prennent exclusivement la beauté antique pour modèle, comme ils ne la connaissent que par des statues, il leur arrive ce qu'on reproche à la littérature classique des modernes, ce n'est point dans leur propre inspiration qu'ils puisent les effets de l'art.

10 Mengs, peintre allemand, s'est montré un penseur philosophe dans ses écrits sur son art : ami de Winckelmann, il partagea son admiration pour l'antique; mais néanmoins il a souvent évité les défauts qu'on peut reprocher aux peintres formés par les écrits de Winckelmann, et qui se bornent pour la plupart à copier les chefs-d'œuvre anciens. Mengs s'était aussi proposé pour modèle Le Corrège, celui de tous les peintres qui s'éloigne le plus dans ses tableaux du genre de la sculpture, et dont le clair-obscur rappelle les vagues et délicieuses impressions de la mélodie.

11 Les artistes allemands avaient presque tous adopté les opinions de Winckelmann, jusqu'au moment où la nouvelle école littéraire a étendu son influence aussi sur les beaux-arts. Goethe, dont nous retrouvons partout l'esprit universel, a montré dans ses ouvrages qu'il comprenait le vrai génie de la peinture bien mieux que Winckelmann; 
toutefois, convaincu comme lui que les sujets du christianisme ne sont pas favorables à l'art, il cherche à faire revivre l'enthousiasme pour la mythologie, et c'est une tentative dont le succès est impossible ; peut-être ne sommes-nous capables, en fait de beauxarts, ni d'être chrétiens ni d'être païens; mais si, dans un temps quelconque, l'imagination créatrice renaît chez les hommes, ce ne sera sûrement pas en imitant les Anciens qu'elle se fera sentir. [...]

On trouve en Allemagne un grand nombre de galeries de tableaux et de collections de dessins qui supposent l'amour des arts dans toutes les classes. Il y a chez les grands seigneurs et les hommes de lettres du premier rang de très belles copies des chefsd'œuvre de l'Antiquité ; la maison de Goethe est à cet égard fort remarquable ; il ne recherche pas seulement le plaisir que peut causer la vue des statues et des tableaux des grands maîtres, il croit que le génie et l'âme s'en ressentent. «J'en deviendrais meilleur, disait-il, si j'avais sous les yeux la tête du Jupiter olympien, que les Anciens ont tant admirée. » Plusieurs peintres distingués sont établis à Dresde; les chefsd'œuvre de la galerie y excitent le talent et l'émulation. Cette Vierge de Raphaël, que deux enfants contemplent, est à elle seule un trésor pour les arts : il y a dans cette figure une élévation et une pureté qui sont l'idéal de la religion et de la force intérieure de l'âme. La perfection des traits n'est dans ce tableau qu'un symbole; les longs vêtements, expression de la pudeur, reportent tout l'intérêt sur le visage, et la physionomie plus admirable encore que les traits, est comme la beauté suprême qui se manifeste à travers la beauté terrestre. Le Christ, que sa mère tient dans ses bras, est tout au plus âgé de deux ans ; mais le peintre a su merveilleusement exprimer la force puissante de l'être divin dans un visage à peine formé. Le regard des anges enfants qui sont placés au bas du tableau est délicieux ; il n'y a que l'innocence de cet âge qui ait encore du charme à côté de la céleste candeur ; leur étonnement, à l'aspect de la Vierge rayonnante, ne ressemble point à la surprise que les hommes pourraient éprouver ; ils ont l'air de l'adorer avec confiance, parce qu'ils reconnaissent en elle une habitante de ce ciel que naguère ils ont quitté. 


\section{Le Corrège, La Nuit [La Nuit sainte]}

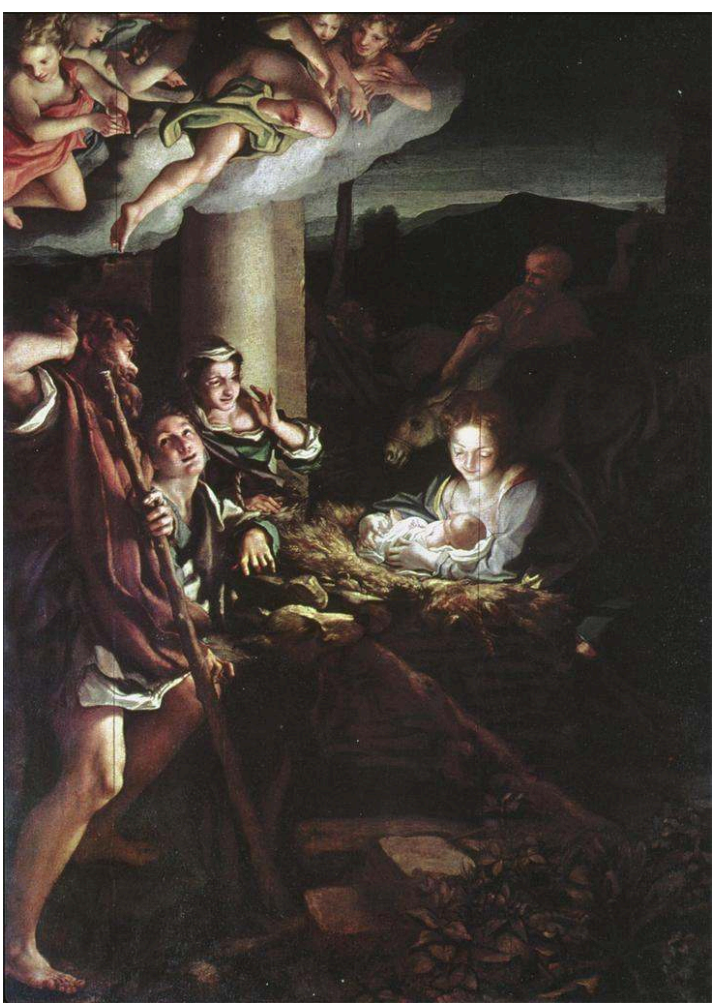

1529-1530, huile sur bois, 256,5 x 188 cm, Dresden, Gemäldegalerie.

13 La Nuit du Corrège est, après la Vierge de Raphaël, le plus beau chef-d'œuvre de la galerie de Dresde (fig. 3). On a représenté bien souvent l'adoration des bergers; mais comme la nouveauté du sujet n'est presque de rien dans le plaisir que cause la peinture, il suffit de la manière dont le tableau du Corrège est conçu pour l'admirer : c'est au milieu de la nuit que l'enfant sur les genoux de sa mère reçoit les hommages des pâtres étonnés. La lumière qui part de la sainte auréole dont sa tête est entourée a quelque chose de sublime; les personnages placés dans le fond du tableau, et loin de l'enfant divin, sont encore dans les ténèbres, et l'on dirait que cette obscurité est l'emblème de la vie humaine, avant que la révélation l'eût éclairée.

Parmi les divers tableaux des peintres modernes à Dresde, je me rappelle une tête du Dante qui avait un peu le caractère de la figure d'Ossian, dans le beau tableau de Gérard. Cette analogie est heureuse : le Dante et le fils de Fingal peuvent se donner la main à travers les siècles et les nuages. Un tableau de Hartmann représente la visite de Madeleine et de deux femmes nommées Marie au tombeau de Jésus-Christ ; l'ange leur apparaît pour leur annoncer qu'il est ressuscité; ce cercueil ouvert qui ne renferme plus de restes mortels, ces femmes d'une admirable beauté levant les yeux vers le ciel, pour y apercevoir celui qu'elles venaient chercher dans les ombres du sépulcre, forment un tableau pittoresque et dramatique tout à la fois.

15 Schick, autre artiste allemand, maintenant établi à Rome, y a composé un tableau qui représente le premier sacrifice de Noé, après le déluge ; la nature, rajeunie par les eaux, semble avoir acquis une fraîcheur nouvelle; les animaux ont l'air d'être familiarisés avec le patriarche et ses enfants, comme ayant échappé ensemble au déluge universel. La verdure, les fleurs et le ciel sont peints avec des couleurs vives et naturelles, qui retracent la sensation causée par les paysages de l'Orient. Plusieurs autres artistes 
s'essayent, de même que Schick, à suivre en peinture le nouveau système introduit, ou plutôt renouvelé dans la poétique littéraire ; mais les arts ont besoin de richesses, et les grandes fortunes sont dispersées dans les différentes villes de l'Allemagne. D'ailleurs, jusqu'à présent, le véritable progrès qu'on a fait en Allemagne, c'est de sentir et de copier les anciens maitres selon leur esprit: le génie original ne s'y est pas encore fortement prononcé.

\section{Thorwaldsen Bertel, Jason [Jason et le veau d'or]}

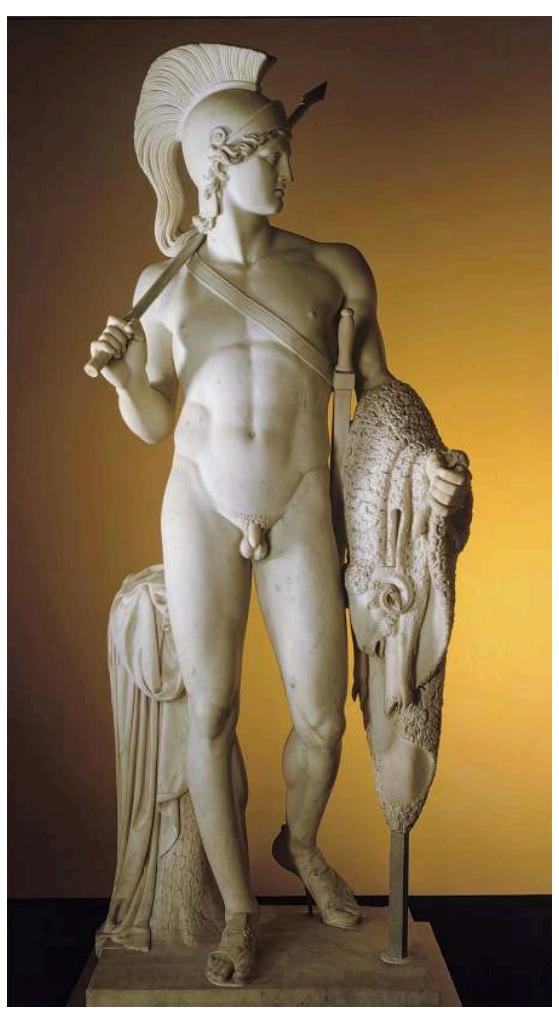

Modelé à Rome en 1802-1803, complété en marbre en 1828, 242 cm, Copenhague, musée Thorwaldsen.

La sculpture n'a pas été cultivée avec un grand succès chez les Allemands, d'abord parce qu'il leur manque le marbre, qui rend les chefs-d'œuvre immortels, et parce qu'ils n'ont guère le tact ni la grâce des attitudes et des gestes, que la gymnastique ou la danse peuvent seules rendre faciles; néanmoins un Danois, Thorwaldsen, élevé en Allemagne, rivalise maintenant à Rome avec Canova, et son Jason ressemble à celui que décrit [Pindare], comme le plus beau des hommes ; une toison est sur son bras gauche ; il tient une lance à la main, et le repos de la force caractérise le héros (fig. 4).

17 J'ai déjà dit que la sculpture en général perdait à ce que la danse fût entièrement négligée; le seul phénomène qu'il y ait dans cet art en Allemagne, c'est Ida [Brunn], jeune fille que son existence sociale exclut de la vie d'artiste ; elle a reçu de la nature et de sa mère un talent inconcevable pour représenter par de simples attitudes les tableaux les plus touchants, ou les plus belles statues; sa danse n'est qu'une suite de chefs-d'œuvre passagers, dont on voudrait fixer chacun pour toujours : il est vrai que la mère d'Ida a conçu dans son imagination tout ce que sa fille sait peindre aux regards. Les poésies de $\mathrm{M}^{\mathrm{me}}$ Brunn font découvrir dans l'art et la nature mille richesses nouvelles, que les regards distraits n'avaient point aperçues. J'ai vu la jeune Ida, encore 
enfant, représenter Althée prête à brûler le tison auquel est attachée la vie de son fils Méléagre ; elle exprimait, sans paroles, la douleur, les combats et la terrible résolution d'une mère; ses regards animés servaient sans doute à faire comprendre ce qui se passait dans son cœur; mais l'art de varier ses gestes, et de draper en artiste le manteau de pourpre dont elle était revêtue, produisait au moins autant d'effet que sa physionomie même ; souvent elle s'arrêtait longtemps dans la même attitude, et chaque fois un peintre n'aurait pu rien inventer de mieux que le tableau qu'elle improvisait ; un tel talent est unique. Cependant, je crois qu'on réussirait plutôt en Allemagne à la danse pantomime qu'à celle qui consiste uniquement, comme en France, dans la grâce et dans l'agilité du corps.

\section{ANNEXES}

Lire les extraits du roman de Germaine de Staël Corinne ou l'Italie

Lire l'introduction à Germaine de Staël écrite par Anne Lafont 
Helmina von Chézy (1783 - 1856) 


\title{
Introduction
}

\author{
David Blankenstein
}

1 À l'apogée de l'Empire, Helmina von Chézy publia les deux volumes de Leben und Kunst in Paris seit Napoleon I. (1805 et 1807). Bien que le recueil rende compte de sa vie et de celle de la société parisienne l'environnant, il ne s'agit pas d'un récit autobiographique, mais plutôt d'un état de ses observations professionnelles, journalistiques et poétiques. Ce recueil hétérogène comprenait des lettres, des descriptions de châteaux, de musées, de collections, de bibliothèques, d'œuvres artistiques et littéraires, mais aussi des portraits de personnages de la société parisienne, et des anecdotes relatant les événements culturels importants de l'époque, enfin, des traductions de trouvailles littéraires. L'ouvrage, publié par le Landes-Industrie-Comptoir Weimar de l'illustre, et très commerçant, éditeur Friedrich Justin Bertuch, poursuit un double objectif : nourrir l'imaginaire d'un large public allemand, avide de détails sur la vie scintillante de la métropole, et s'adresser au cercle érudit d'Outre-Rhin, qui déplorait - à l'instar de Goethe - la médiocrité des informations disponibles sur les arts et les sciences à Paris, et l'absence de recensement fiable des courants artistiques contemporains et des biens conservés dans les collections publiques et privées. Bien que ni artiste, ni universitaire - profil impensable pour une femme à cette époque -, Helmina von Chézy, élevée par sa mère et sa grand-mère, deux femmes de lettres affranchies des conventions d'alors, était consciente de sa légitimité à aborder le monde des arts. Grâce à ses relations avec les artistes, les mécènes, les scientifiques et les administrateurs culturels - français et allemands expatriés -, elle put en effet avoir un accès privilégié aux idées qui circulaient sur l'art, ses styles, son histoire, ainsi qu'aux lieux cachés au grand public.

Le chapitre sur la « nouvelle école française » reproduit dans cette anthologie témoigne de la préoccupation de l'auteure à faire connaître des éléments méconnus de la vie culturelle parisienne: Chézy comble ainsi les connaissances lacunaires sur l'art contemporain français en Allemagne en évoquant, certes, la génération davidienne, mais en introduisant aussi celle encore inconnue de leurs élèves comme Gérard, Gros, Ingres parmi d'autres. Le fait que l'auteure ne s'en tint pas aux visites annuelles aux Salons, mais qu'elle construisit un récit relativement systématique et cohérent à partir de fréquentations d'ateliers, de collections, d'échanges avec les artistes et les connaisseurs, dépasse les attentes de l'époque concernant les articles d'une 
correspondante à l'étranger. Ses références occasionnelles à l'histoire de l'art, ses comparaisons et ses analyses stylistiques, ses observations du milieu social de l'art et des conditions structurelles de la production artistique y sont argumentées librement, sans qu'elle se censure eu égard à sa condition de jeune femme. Cependant, cette condition est peut-être la raison même de la quasi-absence d'informations sur la réception de l'ouvrage en Allemagne, alors qu'il constitue le récit le plus complet de l'époque sur les arts à Paris en langue allemande.

\section{BIBLIOGRAPHIE}

BLANKENSTEIN et LOHMANN 2010

David Blankenstein et Malte Lohmann, «Helmina von Chézy », dans Michel Espagne et Bénédicte Savoy (dir.), Dictionnaire des historiens de l'art germaniques, Paris, éditions du CNRS, 2010, p. 35-42.

CHÉZY [1805-1807] 2009

Helmina von Chézy, Leben und Kunst in Paris seit Napoleon I., Bénédicte Savoy (éd.), Berlin, Akademie-Verlag, [1805-1807] 2009.

HUNDT 1997

Irina Hundt, „Geselligkeit im Kreise von Dorothea und Friedrich Schlegel in Paris in den Jahren 1802-1804“, dans Hartwig Schultz (éd.), Salons der Romantik. Beiträge eines Wiepersdorfer Kolloquiums $z u$ Theorie und Geschichte des Salons, Berlin/New York, W. de Gruyter, 1997, p. 83-133.

SOLOVIEFF 2005

Georges Solovieff, « Une irréductible : Helmina de Chézy (1783-1856) », dans Georges Solovieff (éd.), Cinq figures féminines méconnues du Romantisme allemand, Reims/Paris, Firmin/Didot, 2005, p. 233-299.

STRUCKMEYER et BLANKENSTEIN 2009

Nina Struckmeyer et David Blankenstein, « Saisir la vie, transférer des savoirs : Helmina de Chézy à Paris sous le Premier Empire », Histoire de l'art, 2009, nº 64, p. 95-102.

\section{ANNEXES}

Diaporama des œuvres commentées par Helmina von Chézy dans son ouvrage La Vie et les Arts à Paris depuis Napoléon I $I^{\text {er }}$ : http://www.flickr.com//photos/73632227@N02/sets/72157629752473822/

Lire les extraits du roman d'Helmina von Chézy La Vie et les Arts à Paris depuis Napoléon I er Liste complète des œuvres d'arts commentées par Helmina von Chézy à travers ses textes édités dans Plumes et pinceaux 


\section{Helmina von Chézy, La Vie et les Arts à Paris depuis Napoléon $I^{\text {er }}, 1804$}

Essai d'une vue d'ensemble de la nouvelle école française [Leben und Kunst in Paris seit Napoleon I. Versuch einer Übersicht der neuen französischen Schule], Berlin, Akademie-Verlag, 2009, extraits choisis.

Traduction : Évelyne Sinnassamy depuis l'allemand

\section{Chapitre XIII}

1 J'ai beau avoir séjourné cinq ans à Paris, ce centre des artistes de France, et avoir contemplé à maintes reprises les nouvelles productions artistiques, il ne m'a pas encore été possible de concevoir une vue d'ensemble complète de la richesse de cette école et de classer convenablement ses maitres et ses œuvres.

Beaucoup a été réalisé, beaucoup même pour les circonstances et l'époque, et pas mal pour l'art même. [...]

3 Si l'on mesure les nombreux efforts avec lesquels la jeunesse de France s'adonne à l'art et qu'on ajoute le nombre d'œuvres importantes que leurs maîtres ont déjà produites, on peut espérer que l'abondance et la beauté des produits de l'art en France égaleront celles que célébra l'Italie au $\mathrm{xv}^{\mathrm{e}}$ siècle. Que ne peut-on espérer de la France, dans cette époque si riche en merveilles, surtout si les victoires de Napoléon donnent bientôt la paix au monde et laissent au monarque couronné de lauriers le loisir d'être comme François $I^{\mathrm{er}}$ un père et un ami pour les artistes de notre temps !...

Un fait pourrait par la suite être un obstacle aux progrès de l'art en France: l'indifférence du grand monde à l'égard de tout ce qui le concerne. Alors que jadis un Raphaël comme d'autres grands maîtres d'Italie pouvait se réjouir de l'approbation, de l'amitié d'une cour brillante et des premières familles du pays, alors qu'il se voyait partout où son regard se tournait, reconnu, aimé, honoré, récompensé et, ce qui est plus encore, compris, les artistes français en revanche doivent se borner à travailler pour l'œil de leurs compagnons d'armes et ils voient leurs œuvres vantées, payées mais rarement appréciées à leur juste valeur! Pour un grand homme, que vaut le fade compliment qu'on lui présente dans des soirées comme sur un plateau, et qui est plus 
calculé pour l'amour-propre de l'hôte que pour la satisfaction de l'artiste ? et à côté, l'éloge souvent si peu intelligent, en grande partie exagéré, dans les journaux ? Que lui importe que toutes les femmes à la mode se fassent peindre par lui, si elles finissent pourtant ensuite par être plus satisfaites de leur miroir que de son tableau?

5 L'enthousiasme stimulant qui, il y a des siècles en Italie, enflamma d'amour pour un chef-d'œuvre divin tout un peuple, qui inspira aux poètes de beaux hymnes et fit bouillonner dans tous les cœurs la ferveur et la vénération envers l'artiste, cela pourrait lui élever l'âme et le soutenir vers de nouvelles ambitions.

6 À vrai dire, les artistes français ont d'autant plus de mérite qu'ils font vraiment tout pour l'art lui-même, et vu le peu d'encouragement qui leur est réservé de la part du public, les grands pas accomplis par l'art en France peuvent être considérés comme miraculeux.

7 Ce qui est infiniment important, c'est le contraste entre la dernière école à présent complètement disparue et la nouvelle qui doit sa floraison aux mérites de Vien et à l'excellence de David, Vincent, Regnault, Suvée.

8 Mais si méritoires que soient ces maîtres, si capables de conduire à la maturité le grand bouleversement qu'ils ont accompli, l'école française n'est pourtant pas encore une école caractéristique particulière, comme la vénitienne, la romaine, la florentine et même l'allemande "altdeutsch”, certes sans grâce ni perfection, mais singulière, dont on reconnait dans les œuvres le type, le principe fondamental. Le Français cherche toujours à adapter ses idées à un modèle, et il lui est impossible d'oublier ce qu'il a vu. Depuis la Révolution, la rage de l'Antique s'est emparée des jeunes élèves, de sorte que les rares compositions singulières qui paraissent çà et là sont des exceptions louables. «Style » est le plus grand mot que les jeunes peintres ont à la bouche et avec lequel ils ont tout dit. Ils s'admirent entre eux pour peu que leur œuvre rappelle une figure de vase étrusque ou un groupe antique. Des boucles de pierre dans un ordre antique, des casques richement ornés, de gracieuses sandales et cordelettes, des draperies jetées en plis raides et des nez antiques, font aux yeux du jeune homme le principal mérite de son tableau, car dans son aveuglement il tient le contour de l'Antique pour l'esprit de ce dernier.

9 Si l'artiste a alors atteint aussi dans cette forme une grande habileté et ne sait pas l'animer, nous avons gagné peu de chose au grand changement de style et nous sommes simplement tombés d'un extrême à l'autre. La nature seule doit guider l'artiste, qu'il cherche à découvrir ses trésors et qu'il épie ses nuances les plus subtiles, qu'il tente de les fixer, de les refléter; et qui voit son tableau partagera avec lui dans sa contemplation le ravissement qu'il a éprouvé en contemplant la nature.

10 On a cependant trop accablé de reproches cet extrême et on en est devenu injuste envers lui ; car il était hautement nécessaire afin d'arracher immédiatement avec force les artistes à l'esclavage de l'école précédente ; un esprit génial atteindra facilement la cible, et ceux qui collent trop à la forme et ne comprennent pas son essence feraient des caricatures dans un autre sens en voulant se former d'après Le Corrège, car on peut traiter les peintures de l'époque précédente d'applications caricaturales du principe du Corrège ; de même que les mauvaises peintures du temps présent sont des caricatures d'Apollon et de Niobé.

11 Cet aveuglement va si loin que j'entendis un bon dessinateur de l'école de David dire: «Raphaël n'aurait rien fait d'aussi parfait que la Diane (au musée Napoléon).» Certes, 
cette Diane est parée tout à la fois du comble de la grâce et de la beauté, et ses formes sont comme animées du souffle tiède de la vie, au point que l'œil abusé croit le marbre tiède et tendre comme la rose. Pourtant la Madone de Raphaël, par exemple celle del donatorio, peut bien rivaliser avec cette œuvre magnifique, en particulier du point de vue de l'âme, du charme, de l'élévation et de la douceur, comme de la beauté ravissante et de la virginité de la figure. On ne peut pas objecter les difficultés que le créateur de Diane a surmontées, puisqu'il l'a fixée comme en vol, dans sa hâte à partir, fougueuse et leste, et le regard déjà arrivé au but, si bien qu'il semble qu'elle va dans l'instant lever son pied délicat pour avancer. Alors qu'au contraire les madones sont représentées assises; Raphaël a en effet prouvé dans mille autres figures que de telles positions pouvaient être réalisées dans la peinture avec effet et charme.

12 Mais quel que soit le nombre d'erreurs que cette nouvelle manière a parfois causées, un résultat principal en est déjà tout de même visible, qui est vraiment étonnant en un temps si court : l'ambition dans l'art est ennoblie et la juste mesure est déjà atteinte par bien des artistes de mérite et découverte par plus d'un disciple prometteur.

Ce que l'école française a de meilleur dans cette manière, elle le doit à l'excellent David : il écarta et tourna en dérision le commun et le guindé dans la forme et la pose, et attira l'attention de ses élèves sur la sérénité gracieuse et la noble culture de l'Antiquité. Lui-même dans ses œuvres savait unir la pureté anatomique à la beauté et transmuter la forme ordinaire en culture antique en alliant l'austérité et la sérénité du style antique à l'âme et à la vivacité. [...]

14 Nulle part en Europe une école ne peut aussi facilement former les multiples branches de l'art qu'ici à Paris, en particulier depuis que la communication avec l'Italie est si facile. Pour celui qui cherche à former dans ses tableaux une belle nudité et des groupes idéaux, les riches trésors de l'Antiquité sont ouverts à l'étude. Celui qui veut représenter le Moyen Âge trouve dans les gravures sur cuivre de la bibliothèque impériale, dans les monuments des églises et des couvents, dans l'arsenal des anciennes armures et autres lieux tout ce qu'il peut désirer pour le costume et la décoration. Et si l'artiste veut représenter les époques glorieuses du temps moderne, il trouve ici les originaux vivants pour ses tableaux et peut aussi entendre de la bouche du soldat des traits qui l'enthousiasment et lui inspirent des images.

15 Mais c'est là pourtant que réside la plupart des difficultés ; en particulier s'il s'agit de louer l'Empereur et de le représenter dans sa gloire. Des figures mythologiques allégoriques sont insipides et communes, pour des religieuses l'intérêt manque aussi bien chez l'artiste que chez le public. Une telle entreprise ne réussit qu'aux rares artistes qui se contentent d'un simple récit et qui peuvent mettre dans ce récit le caractère qui le rend attirant et qui lui donne de la substance pour le penseur. À cette classe appartiennent le Bonaparte au pied du mont Cenis de David et le Bonaparte dans l'hôpital de Jaffa de Gros.

16 Vincent et David sont des élèves de Vien. Il leur fit étudier l'antique et dirigea leurs pas vers un but que lui-même n'a pas atteint. Vincent demeura sur une voie singulière, on peut facilement distinguer ses œuvres, elles sont pleines d'énergie et d'expression et restent dans l'axe entre la saine humanité et la forme noble. S'il n'a pas instauré un aussi pur principe de la forme pour l'école française que David, il n'est pas moins digne d'éloge et d'estime que ce dernier, car il fut pour beaucoup d'artistes à la fois maître, père et protecteur. Il n'accueillit jamais un jeune homme dans son école sans lui consacrer une attention paternelle et sans gagner sa confiance. Si son disciple était 
alors pauvre, habile, assidu, ou s'il montrait donc au moins un don et de la bonne volonté, Vincent devenait son bienfaiteur et persistait dans ses bienfaits jusqu'à ce que le jeune homme pût s'en passer. Avec cela se joint à son altruisme un tel tact que ses bienfaits n'éclatent au grand jour que si son objet les révèle. Souvent son noble cœur eut à soupirer de l'ingratitude, mais il ne se lassa pas pour autant de faire le bien, au contraire il se consola à de nouveaux actes de noblesse, en oubliant les ingrats. Sa générosité persévérante fit que presque tous ceux qui furent ingrats envers lui regrettèrent leur insensibilité. J'ai entendu son éloge le plus chaleureux de la bouche d'un tel jeune homme, et c'était assurément un éloge sans ambiguïté. À vrai dire il y a unanimité sur ce digne maître qui à tous égards a une si haute valeur aussi en tant qu'homme. Ô que tous ceux qui commencent leur carrière puissent être d'abord formés en tant qu'êtres humains et ensuite en tant qu'artistes, puisque de nobles sentiments en soi éveillent l'amour du beau et de l'action et que les circonstances de la vie réclament avant tout un cœur pur! La réputation d'un homme immoral apparaît comme une tache même sur la plus belle de ses œuvres, et il est impossible de ressentir la pure admiration que suscite un chef-d'œuvre si ce que nous savons de l'artiste lui est défavorable - le plaisir est détruit et ce sentiment contraire se transmet à la postérité, car l'histoire retient le souvenir et les traits de celui qui a agi pour l'art et la science, et le rend toujours méprisable en le rendant inoubliable.

17 La belle épouse défunte de Vincent était son élève : elle peignait avec âme et finesse, son coloris avait beaucoup de vérité, de grâce et quelque chose d'éclatant et de chaud, ce qui se trouve rarement dans les travaux de femme. Elle a formé quelques élèves méritoires. [...]

1. Vincent François André, Esquisse d'un tableau de bataille des Pyramides [La Bataille des Pyramides]

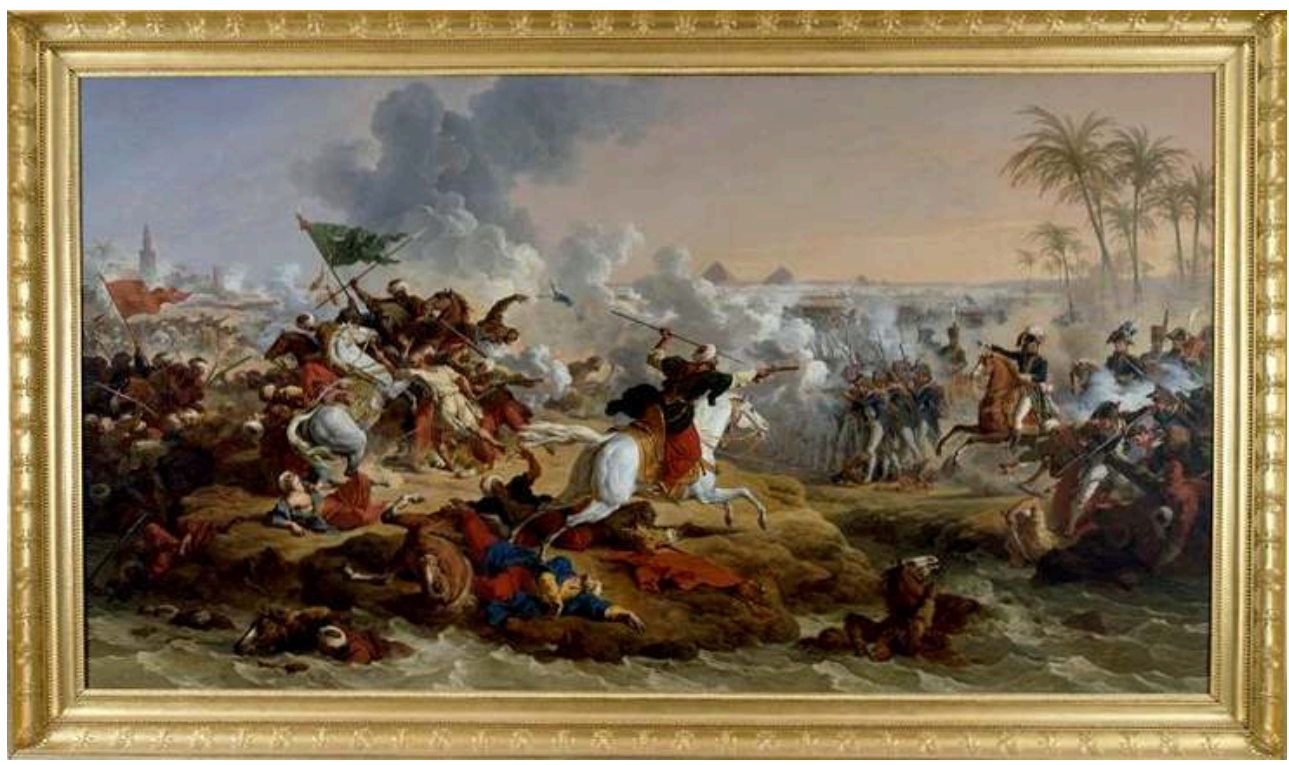

Vers 1800, huile sur toile, 80 × 125 cm, Paris, musée du Louvre.

On doit regretter que sa santé continuellement fragile empêche à présent cet excellent artiste de travailler, car les victoires de l'Empereur lui ont inspiré de nouvelles images. Il a esquissé il y a un an et demi un tableau de la bataille des Pyramides qu'il voulait réaliser sur un espace de vingt et un pieds, et dont les contours étaient déjà dessinés (fig. 1). Cette esquisse est pleine de flamme et très caractéristique. On voit la noble 
singularité et la pondération des guerriers français contre la sauvagerie et le feu aveugle des courageux musulmans; les positions et les regroupements de l'armée, le dessin des chevaux, le plan du champ de bataille, tout est excellent. Il m'a dit qu'il ne se sentait plus les forces de réaliser cette magnifique peinture en grand, et qu'il la peindrait sur un plan de sept pieds. Pourvu qu'il se rétablisse, pourtant! Il est facile de voir la différence entre l'époque ancienne de la France et son état actuel quand on considère seulement les objets qui furent autrefois traités par les artistes. L'époque était si pauvre en événements que Le Brun et les autres ont dû chercher refuge dans l'histoire romaine et grecque, alors qu'au contraire l'actuelle abondance de grandes actions et d'hommes remarquables trouve pour leur représentation à peine suffisamment de mains dans l'assez grand nombre d'artistes français habiles; c'est pour cela qu'il serait regrettable qu'un tableau aussi estimable d'une journée mémorable dût se perdre. Le disciple préféré de Vincent, c'est Meynier qui est entre autres connu pour sa Calypso. Cette composition respire l'esprit grec des idylles, simplement on lui souhaiterait plus de finesse. Les formes ne sont pas aussi marmoréennes qu'elles le sont d'habitude quand le peintre à force de tendre vers l'Antique tombe dans l'artificiel et le rude. Maintes attitudes naïves donnent au groupe des nymphes un charme surprenant. Les nymphes sont de véritables jeunes filles, pas des dames coquettes, pas non plus des prostituées, comme c'est si souvent le cas chez les peintres français. Le coloris est agréable et éclatant, sans toutefois pouvoir prétendre à la vraie carnation. Pour le paysage on souhaiterait plus de variété, mais le vert frais des bois est interrompu de façon charmante par les groupes clairsemés. La figure principale, Calypso en colère, est théatrale et peu féminine; Eucharis, qui implore en se blottissant, est réussie. Les études pour ce tableau se trouvent dans l'excellente collection de dessins de Neergard.

19 Vincent forma encore maints artistes de mérite, et maintes bonnes artistes dont les noms sont si connus que je n'ai pas besoin de les répéter; pourtant je ne veux pas me priver du plaisir de citer ici le peintre de Düsseldorf, Kolbe, qui dans l'art unit aussi les meilleures connaissances au talent et à l'habileté. [...] 
2. Jean-Baptiste Regnault, Jeunesse d'Achille [L'Éducation d'Achille par le centaure Chiron]

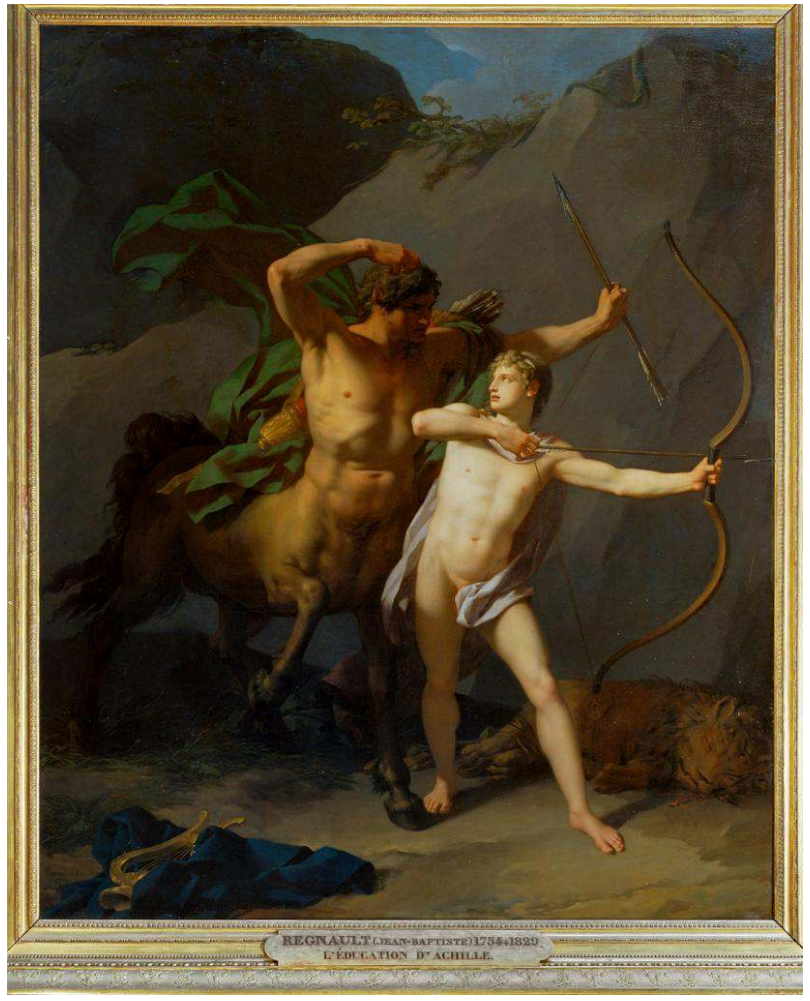

1782, huile sur toile, $261 \times 215$ cm, Paris, musée du Louvre.

20 Je ne m'attarderai pas sur Regnault : dans la première partie de mon ouvrage j'ai déjà cité ses plus belles toiles. La Jeunesse d'Achille est la plus appréciée de ses œuvres (fig. 2) ; il la fit en Italie et dit ensuite : «Ce n'est que là que j'ai pu la faire !» Il a formé d'excellents disciples. 
3. Anne-Louis Girodet, Endymion [Le Sommeil d'Endymion]

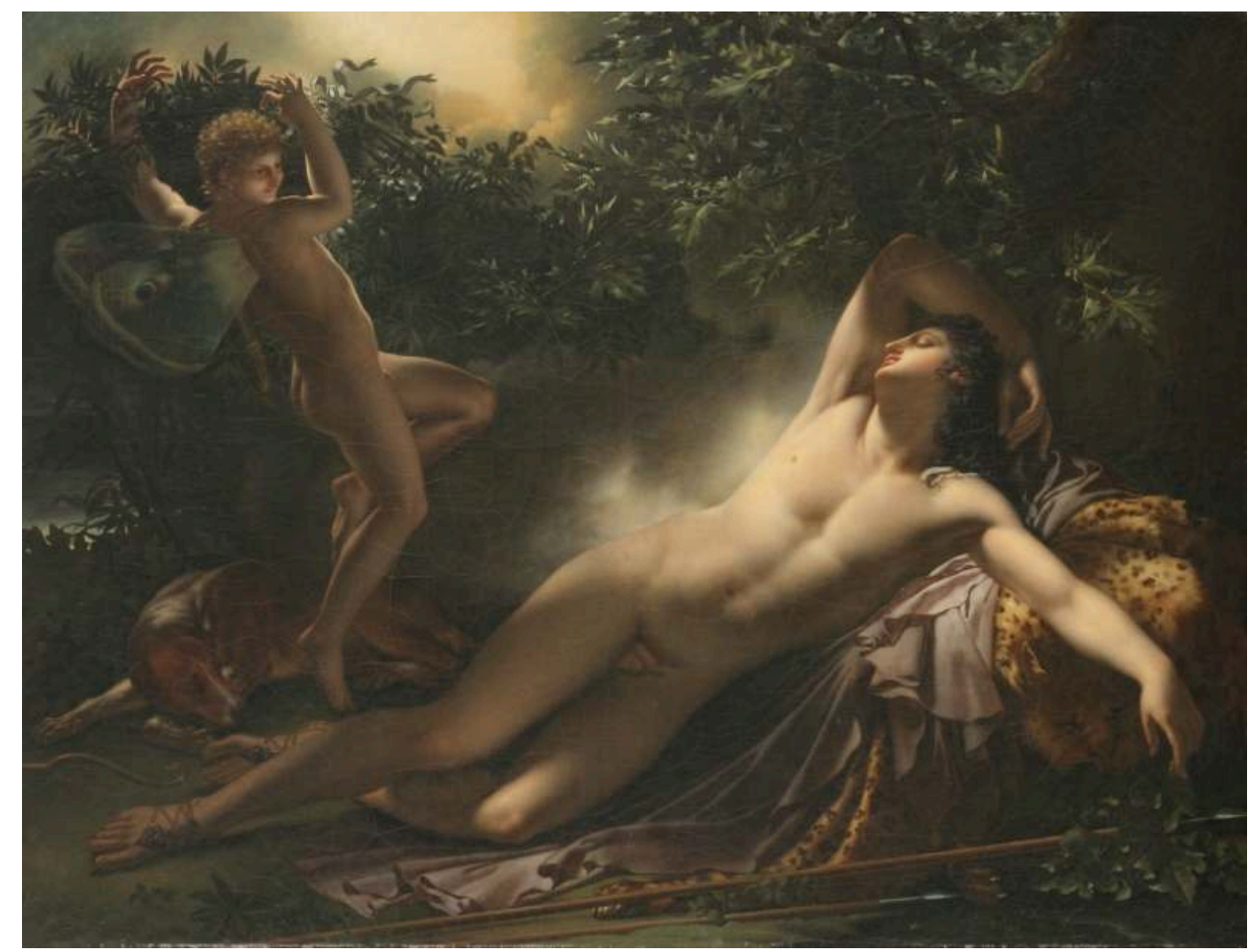

1791, huile sur toile, 198 × 261 cm, Paris, musée du Louvre.

Girodet est l'aîné des disciples de Regnault, c'est un homme aux dispositions les plus rares. Guérin a, comme lui, un caractère d'une profonde mélancolie; tous deux prennent une voie différente de la représentation. L'exaltation de Girodet est plus élevée et plus suave et plane dans les régions de la poésie ; Guérin s'en tient plus à la vie même. Comme une étoile lumineuse, plane dans le ciel de l'art de France le doux Endymion de Girodet dont la vue remplit l'âme de ravissement (fig. 3). Dans l'ivresse bienheureuse d'un somme, dans la sereine nuit d'été, le jeune homme est étendu comme dans le giron d'invisibles Charites. Tout est plein de charme et de vie dans le plus grand raffinement. Le rayon de Lune tombe en caresse sur la belle joue du dormeur et crée une douce magie dans le clair-obscur du buisson vaporeux qui l'entoure. L'âme est aussitôt transportée et entraînée dans ce poétique pays des dieux; avec quelle ardeur et quelle pureté Girodet a ressenti la beauté de la fable grecque et avec quelle maîtrise il l'a exprimée ! Aucun Grec n'aurait honte de cette œuvre, ou alors ce serait à cause de l'Amour qui écarte les branches et qui est superflu, et pas non plus représenté de façon assez naturelle, et qui dérange tout simplement. Girodet a dans ce tableau bien fait ressortir la magie de la lueur de la lune qui autrement était bannie presque uniquement dans le domaine du peintre de paysage, car elle est bien propice aux images mélancoliques dans lesquelles elle crée une douce harmonie. [...] 


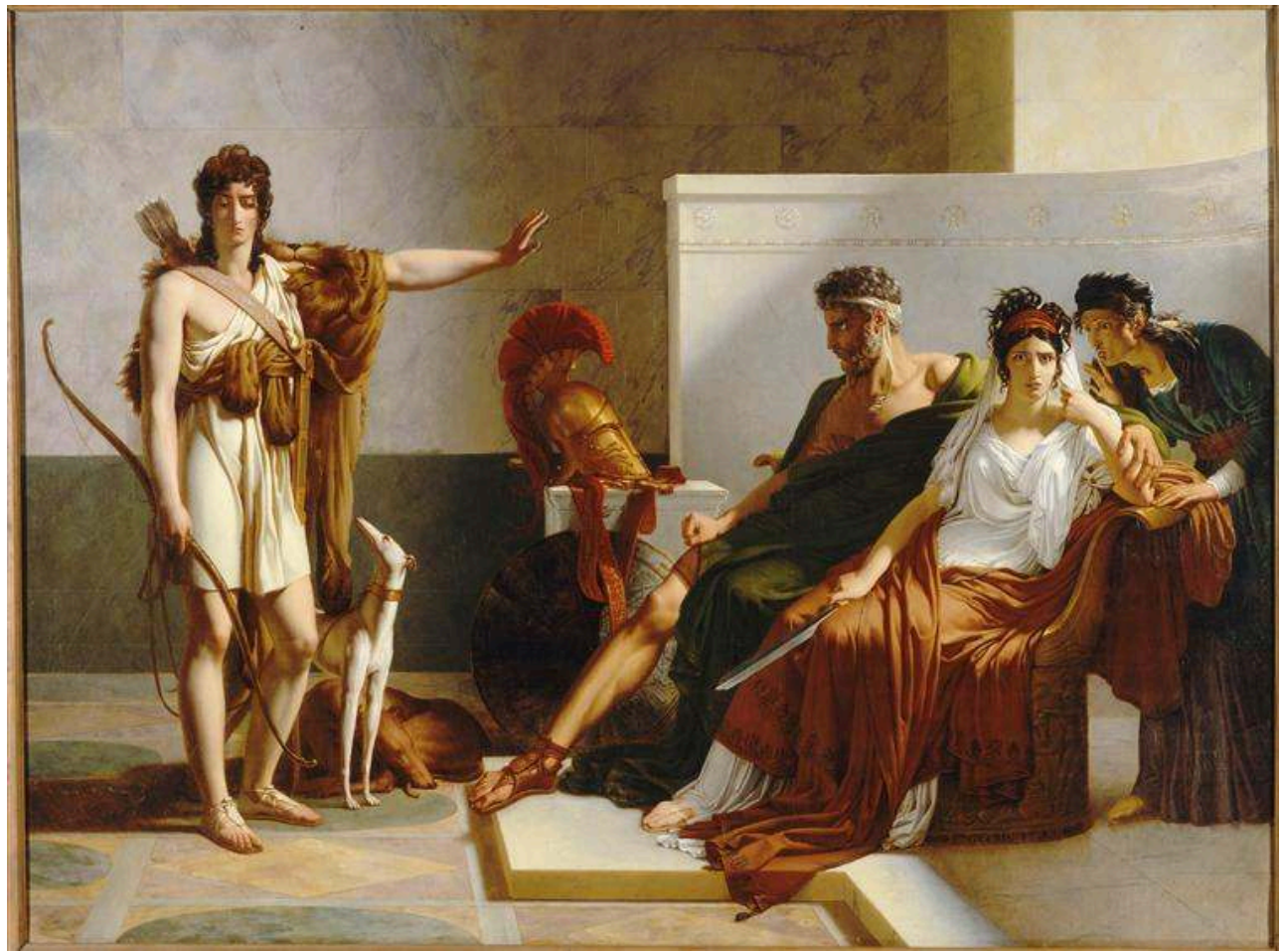

1802, huile sur toile, 257 × 335 cm, Paris, musée du Louvre.

Guérin est un jeune homme intéressant, voué de toute son âme à l'art, et souvent souffreteux, car il se consacre trop à son labeur. [...] Quand Guérin partit pour l'Italie, ce qui lui avait été accordé pour le prix remporté avec son Hippolyte (fig. 4), il expliqua avec modestie combien il se sentait bien en dessous des grands modèles de l'art pictural et combien il souhaitait ardemment découvrir en Italie le véritable esprit de l'art. Il est revenu depuis six mois. On l'emploie à des représentations des événements actuels. [...]

J'ai déjà parlé de David et j'aurais encore plus à dire à son sujet, si ses excellents tableaux célèbres et son école florissante ne constituaient pas son plus bel éloge. De jeunes artistes dans tous les domaines, dont quelques-uns comptent déjà parmi les maitres, sont issus de cette école qui est sans conteste devenue la première en Europe aussi bien grâce à l'esprit du maître que grâce aux circonstances favorables dans lesquelles on peut étudier l'art à Paris. [...]

Dans les portraits de David, on discerne l'esprit qui épie la beauté et les manifestations de l'âme, légères mais d'une profonde signification, dont son tableau comme un miroir fixe le regard. Il peint les enfants avec beaucoup de grâce, même les petits garçons sur le tableau des Sabines sont très beaux. Pour les images de belles femmes, il ne cherche absolument pas à produire une figure antique, mais il leur laisse la particularité qui fait le comble de la ressemblance d'un tableau. Bien que David n'ait pas de coloris brillant, quelques coloristes excellents sont pourtant issus de son école, tout à fait formés dans l'esprit vénitien, alors que l'on pourrait plutôt classer les œuvres de David dans l'école romaine, c'est ce qu'il a de commun avec Raphaël, de même que la grande pureté et finesse de la forme.

25 Le grand artiste déplore toujours la perte de ses chers disciples Drouais et Harriet qui trouvèrent tous deux une mort prématurée en Italie. On sait que Chaudet, Gauffier et 
Drouais magnifiquement doués partirent en même temps pour Rome et que Chaudet eut la douleur d'y perdre ses amis qui promettaient tant. La digne mère de Drouais conserve toujours le tableau qui a immortalisé son fils, Les Gracques, dont elle ne veut à aucun prix se défaire. Le musée Napoléon conserve un tableau de cet artiste, un sujet de concours : la femme adultère devant le Christ, dans lequel se manifeste une habileté infinie ; il fut achevé en quarante jours et est composé dans un esprit plein de dignité et d'émotion. Il est rare de réussir ces sujets de concours qui sont presque toujours composés avec une certaine anxiété, parce que les jurys exigent strictement l'exécution du thème. À propos des sujets de concours, je ne peux omettre le fait que David a eu part à la formation du jeune Tieck, le frère de notre poète, qui a remporté un prix à Paris et qui a laissé dans les cœurs de ses professeurs et de ses amis un souvenir plein de cordialité et d'estime. Le Florentin Lorenzo Bartolini, un artiste ardent et tout imprégné de l'esprit de l'Antiquité, est lui aussi issu de l'école de David. Son bas-relief Cléobis et Biton, qu'il a malheureusement détruit, est plein d'une beauté pure et touchante.

\section{Lorenzo Bartolini, Tête colossale de l'empereur Napoléon [Napoléon Ier]}

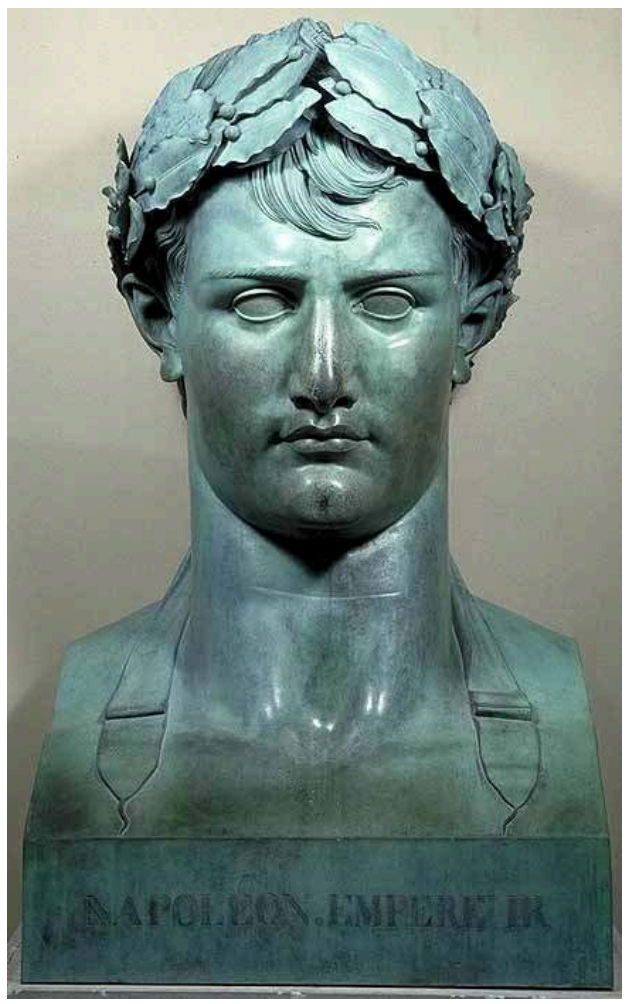

1805, bronze, 155 × 91 x76 cm, Paris, musée du Louvre.

C'est pour cette œuvre que le prix lui fut décerné, mais il ne lui fut pas remis parce qu'il était étranger. Sa tête colossale de l'empereur Napoléon était très belle et majestueuse, mais a été pour ainsi dire ratée lors de la fonte, la tête est devenue trop lourde, il semble qu'ici ils ne s'y connaissent toujours pas plus qu'au temps de Benvenuto Cellini pour couler l'airain (fig. 5). Du reste, l'Empereur n'a pas posé pour cette tête, il ne se résout généralement pas volontiers à poser. Même à David qui pour son tableau réclamait avec insistance plusieurs séances de pose, il demanda : « Ne pouvez-vous pas me peindre d'après l'idée ? Vous devriez bien le faire, car Scipion et les autres guerriers 
de jadis ne posent pas non plus pour vous. - C'est différent, répondit David, les contemporains de Scipion ne sont pas là qui pourraient exiger de moi le vrai Scipion, mais les gens d'aujourd'hui et de l'avenir vont exiger de moi Bonaparte. »

C'est Gérard qui serait désigné comme le premier et le meilleur disciple de David, s'il ne figurait pas déjà lui-même comme maître auprès de son maître. Ses œuvres se distinguent par une quête fervente du charme d'une belle nature, et il n'y a là-dedans aucune recherche d'un effet extraordinaire ou d'un ordre théâtral. Son dessin est si pur, sa couleur si gracieuse, éclatante et vraie, et il peut avec le temps y réussir aussi bien que les excellents Vénitiens y sont parvenus.

Dès sa prime jeunesse, l'étincelle du talent futur de Gérard apparut avec éclat. Son premier maître voulait seulement lui apprendre à dessiner, mais Gérard chercha à la dérobée à gagner pour lui du temps et de la couleur, et à quatorze ans peignit un tableau qui représentait une peste. Cette composition, qui ne sent pas la copie, respire un esprit noble et ardent et un sens de la beauté et des proportions antiques ${ }^{1}$. Avec une rapidité inconcevable, le jeune artiste poursuivit son chemin et arriva, sous la direction de David, mais plus encore grâce à sa propre inspiration, à un degré rarement atteint de perfection.

\section{François Gérard, Bélisaire [Bélisaire portant son guide piqué par un serpent]}

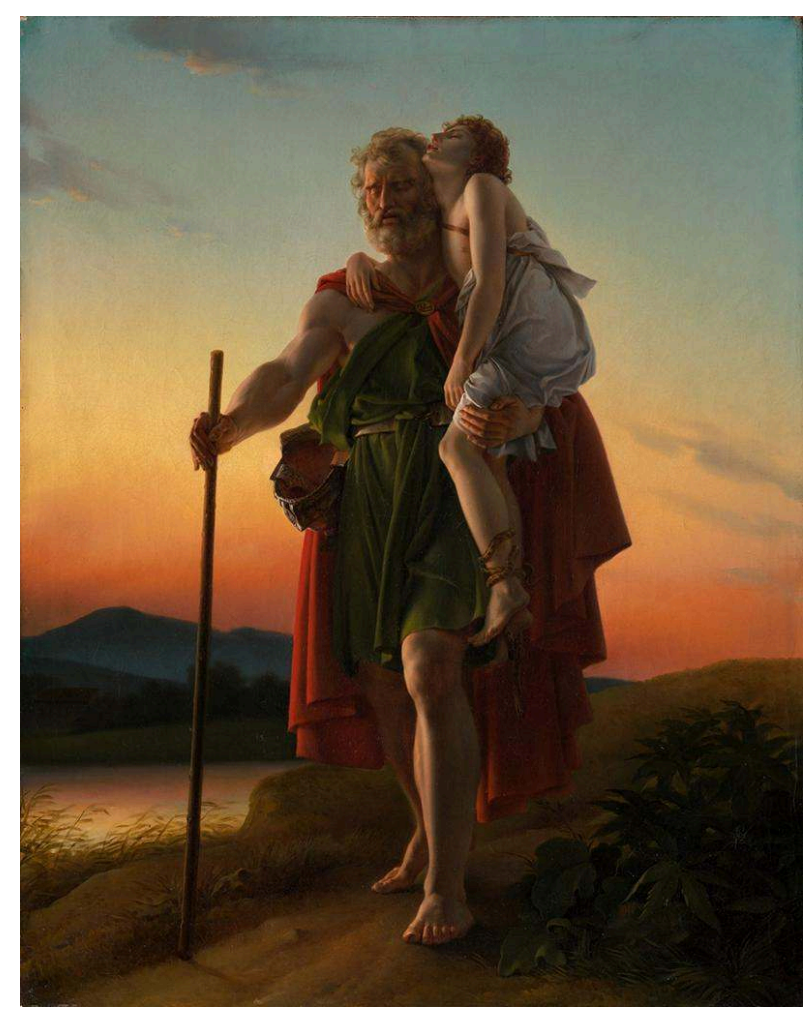

1797, huile sur toile, 91 × 74 cm, Los Angeles, J. Paul Getty Museum. 
7. François Gérard, Ossian [Ossian ou L'Apothéose des Héros français morts pour la patrie pendant la guerre de la Liberté]

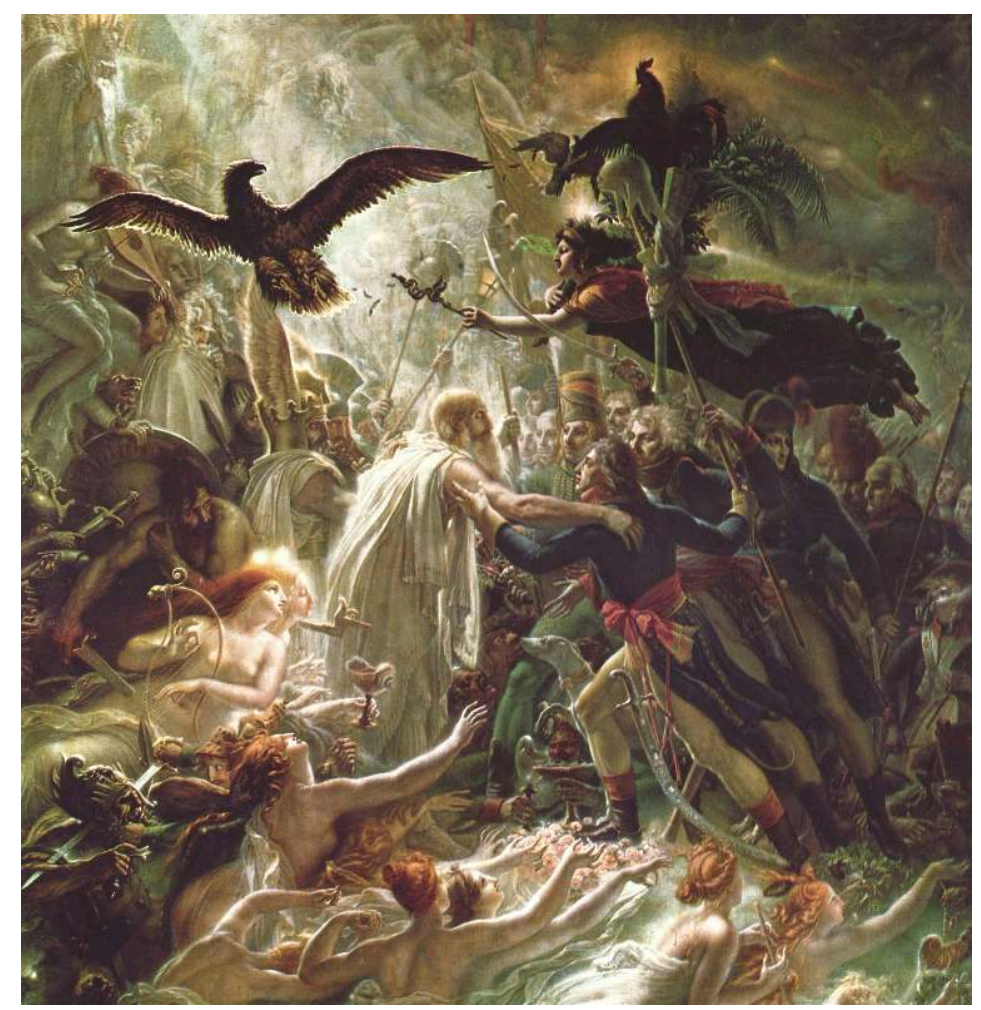

Commandé par Bonaparte en 1800, 192,5 x 184 cm, Rueil-Malmaison, musée national des châteaux de Malmaison et de Bois-Préaux. 


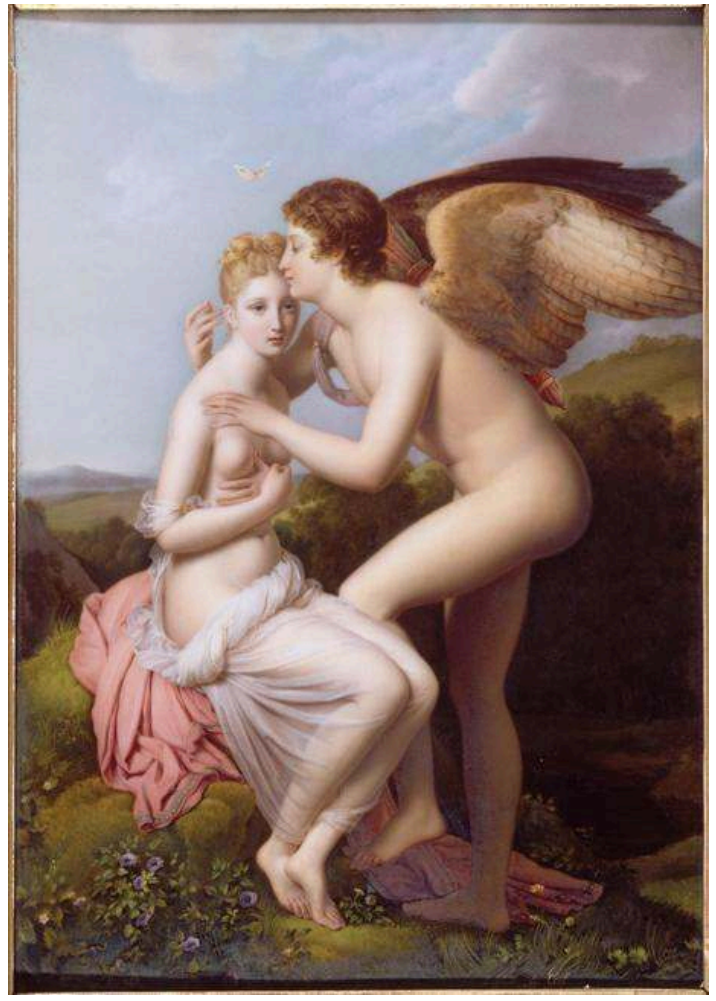

1797, huile sur toile, 186 × 132 cm, Paris, musée du Louvre.

29 On aurait tort de juger Gérard d'après quelques-unes de ses nombreuses œuvres, car ses toiles ne sont pas toutes de la même haute perfection ; en particulier pour les portraits, il est inégal à lui-même ; il en traite certains avec enthousiasme et amour, pendant qu'il en prend d'autres comme des poèmes de circonstances, et pour ainsi dire s'y repose. C'est ainsi qu'il arrive que certains de ses portraits ne soient pas dotés de l'attrait plein d'âme que Gérard imprime à ses œuvres; pourtant dans aucune d'elles on ne peut méconnaître sa griffe, c'est seulement que çà et là elle se montre plus ou moins vive et riche.

Nous ne possédons de lui que trois toiles historiques: Bélisaire (fig. 6), Ossian (fig. 7), Psyché (fig. 8) ; les futures mûrissent dans son atelier. [...] 
9. Léonard de Vinci, La Joconde

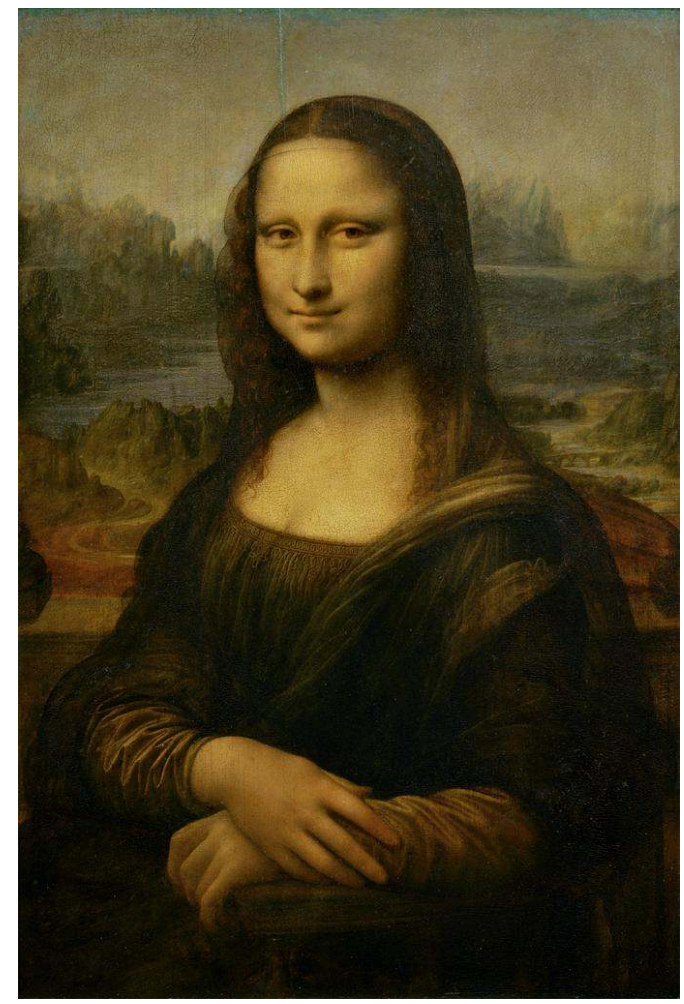

1503-1506, huile sur bois, 77 × 53 cm, Paris, musée du Louvre.

31 Il y a dix ans apparut au Salon le portrait de la demoiselle Brongniart, une jeune dame intéressante et digne d'estime qui est dotée de rares attraits intellectuels. Le tableau fit universellement sensation et sera un jour aussi précieux et célèbre que maintenant La Joconde de Léonard. Jamais depuis Gérard n'a achevé un tableau d'une telle plénitude et profondeur, et tendu là avec tant d'ardeur vers la perfection des anciens maîtres. Touché par le chaste attrait plein d'âme de son original, Gérard a dans ce tableau copié la nature dans ses nuances les plus fines et les plus légères, et a représenté le modèle comme un deuxième moi de ce dernier, si bien que la vérité et la perfection de son tableau doivent frapper même un spectateur froid et non exercé. Mais si cet avantage d'un chef-d'œuvre est propre au tableau de la demoiselle B., il n'en ravit pas moins le connaisseur en esthétique par son individualité noble et chaste, délicate et profonde. Raphaël peignit Marie et la représenta dans sa maternité humaine de façon merveilleusement émouvante en la magnifiant en même temps de la gloire divine ; Léonard de Vinci sut mettre dans son tableau de La Joconde tout l'attrait, toute la finesse et la profondeur d'une femme spirituelle, belle et ardente (fig. 9) ; Gérard ouvre une nouvelle manière de voir, il peint une figure ingénue et virginale, et y développe toute la richesse d'une belle âme et d'un cœur pur et profond. Une jeune fille de notre temps, mais une des apparitions les plus rares et les plus précieuses qui pourra à cette époque et en toutes circonstances garder sa valeur et se voir reconnue.

Ce tableau est un portrait en demi-grandeur. La gracieuse jeune fille est debout, sérieuse mais sereine, les bras naturellement croisés, ses boucles brunes sans autre ornement flottent autour d'elle dans un ordre agréable et sans prétention, sa robe blanche à collerette est tenue sur la poitrine par une émeraude sertie d'or. Ce vêtement dans sa simplicité peut s'adapter à toutes les époques. Dans tout le tableau respire la 
plus pure et la plus haute perfection, les bras et les mains sont vivants et formés à ravir.

$[\ldots]$

\section{Antoine-Jean Gros, La Bataille d'Aboukir}

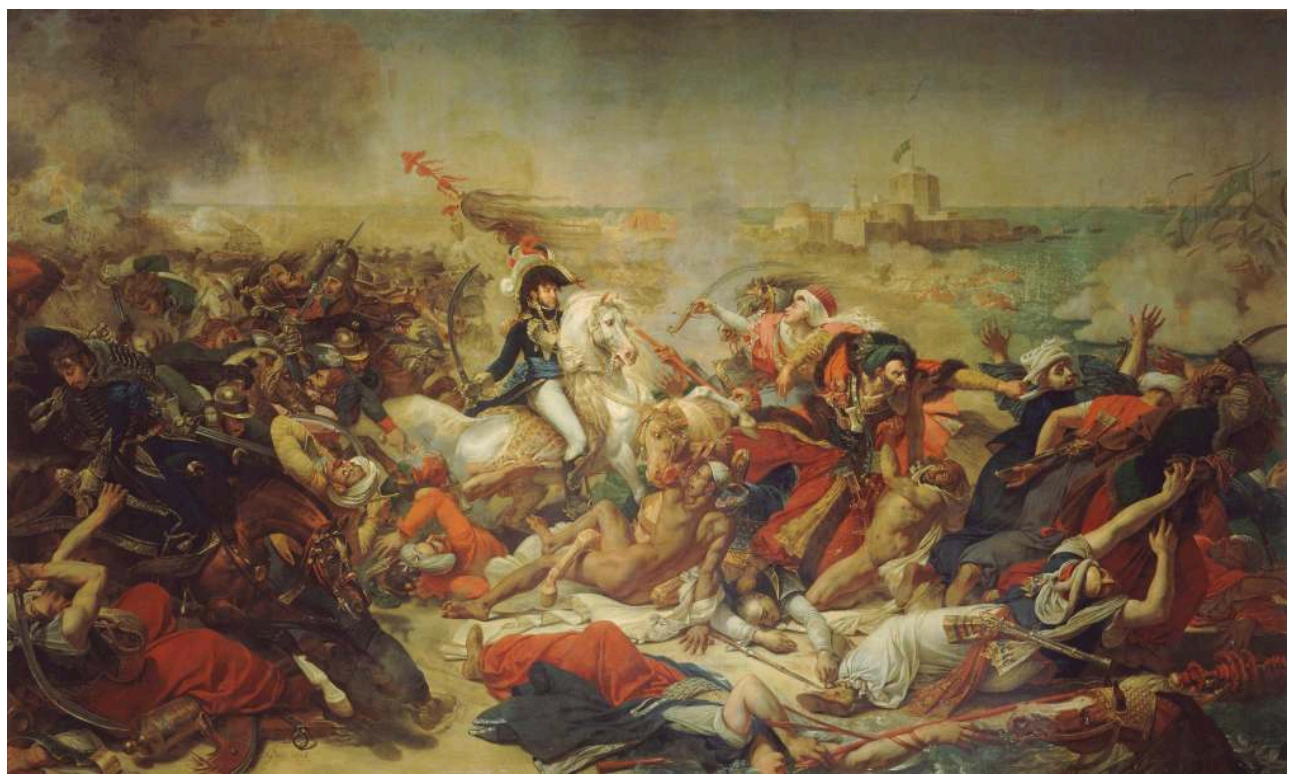

1806, huile sur toile, 578 × 968 cm, musée des châteaux de Versailles et de Trianon.

\section{Antoine-Jean Gros, Bonaparte dans l'hôpital de Jaffa [Bonaparte visitant les pestiférés...]}

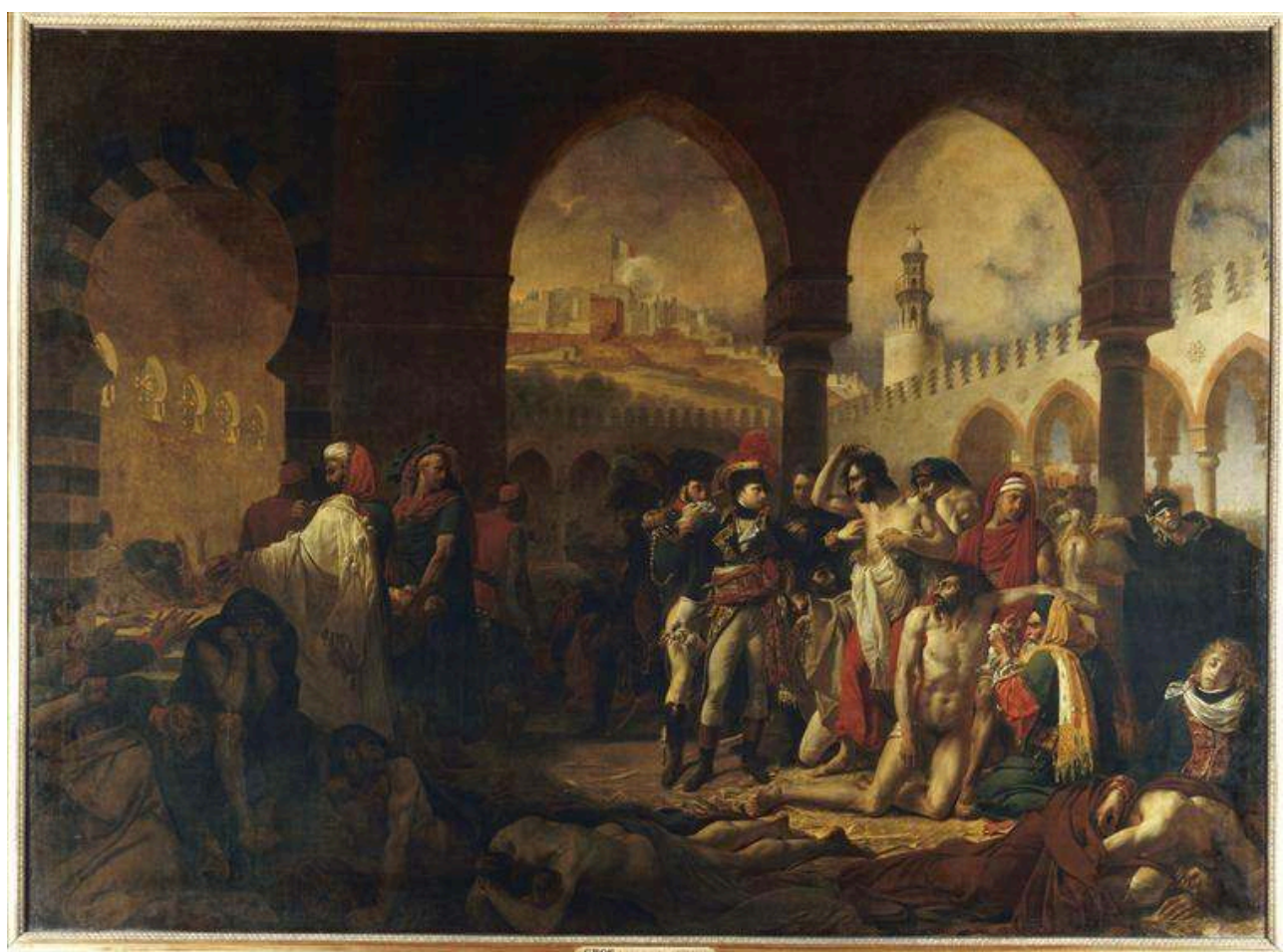

1804, huile sur toile, $73 \mathrm{~cm} \times 59$ cm, Paris, musée du Louvre.

À côté de Gérard apparait Gros qui s'est formé également à l'école de David et dont le chef-d'œuvre qu'il vient de terminer, La Bataille d'Aboukir, le place aux côtés des 
grands peintres (fig.10). Ce jeune homme génial, dont l'apparence est tout à fait modeste et simple, était encore il y a trois ans connu comme excellent coloriste grâce à quelques bons portraits, dont je découvris chez Lucien Bonaparte celui qui représentait l'Empereur en Premier consul et qui tout de suite me révéla une grande capacité. Quelques années plus tard, il entreprit Les Pestiférés de Jaffa (fig. 11), tableau que j'ai décrit dans la première partie de cet ouvrage et sur lequel mon opinion non seulement ne concorde pas avec celle d'autres artistes célèbres, mais a été aussi en même temps corrigée par ceux-ci. La précipitation avec laquelle M. Fiorillo qualifie cette toile, qu'il n'a jamais eue sous les yeux, de dégoûtante et horrible me navre d'autant plus que cet ouvrage diffusé partout d'un érudit si connu pourrait facilement être tenu pour plus compétent que celui d'une femme ignorante. Bien des peintres de premier plan au monde ont peint des pestes et peu ont, selon mon sentiment, traité leur sujet avec tant de vérité et de perfection.

Cette toile fit unanimement sensation, elle fut couronnée, le gouvernement l'acheta, et Gros reçut une nouvelle commande: La Bataille d'Aboukir. Il l'ébaucha tout feu tout flamme et garda l'esquisse sans changement. Il y a travaillé environ quatorze mois, études annexes comprises, comme des portraits, des croquis et autres.

Il représente l'action qui décida de la mémorable victoire que l'armée française sous le commandement de Bonaparte remporta alors sur le Pacha de la Romélie le 7 thermidor de l'an VII de la République. [...]

Après Gros, on peut citer le prometteur Hennequin qui a déjà livré diverses toiles dans lesquelles se montrent du talent, des idées mais aussi de grandes fautes. Son imagination est un peu débordante et revêt un caractère ténébreux. Il n'y a pas de clarté dans ses œuvres, mais il peut pourtant devenir un excellent peintre.

Depuis quelques années, Ingres, un «flamand » de l'école de David, s'est fait connaître par quelques toiles et dessins dans lesquels luit un rayon d'authentique talent, dans lesquels les fautes sont aussi grossières et visibles que quelques beautés extraordinaires qui y apparaissent. Ingres va partir pour l'Italie et il va peut-être oublier là-bas qu'il est né pour accomplir quelque chose de grand, et c'est justement pour cela qu'il atteindra un but élevé. Les erreurs d'Ingres viennent, à mon avis, d'une conscience trop nette de ses capacités et d'un désir démesuré de briller sur une voie nouvelle et insolite. Ses toiles sont bizarres et pas assez naturelles, on y voit trop clairement le recherché. Il a voulu dans la forme l'extraordinaire et le stylisé, et s'astreint trop dans la couleur à l'effet de détail, sur quoi il néglige l'harmonie générale et les lois de la perspective. Là où il réalise des beautés, apparaît un sens gracieux et idéal de la forme et de l'expression morale, et un excellent usage du costume. Ses étoffes et ses métaux sont d'une telle vérité et d'un effet si brillant que jamais aucun pinceau ne les a atteints, pas même chez les Vénitiens. Ainsi, par exemple, dans une de ses dernières œuvres, un portrait de l'Empereur, l'or ressort avec plus d'éclat que le cadre doré qui l'entoure et le costume est magnifiquement utilisé, la position noble, sans pourtant être banale, mais majestueuse et sublime. Toutefois, cet empereur-là est assis sur un riche trône dont le dossier s'arrondit autour de lui et apparaît comme une roue de paon, l'image a l'air d'être découpée et recollée dessus, mais les couleurs sont d'une beauté délicieuse. On voit qu'il a voulu peindre à la manière de Holbein ou de Van Eyck et que Napoléon devait être représenté ici dans le style et l'esprit du siècle de Charlemagne. Mais ce n'est pas cela, et on ne reconnaît jusqu'ici que l'effort vers cette manière dont on peut bien approuver l'idée. 


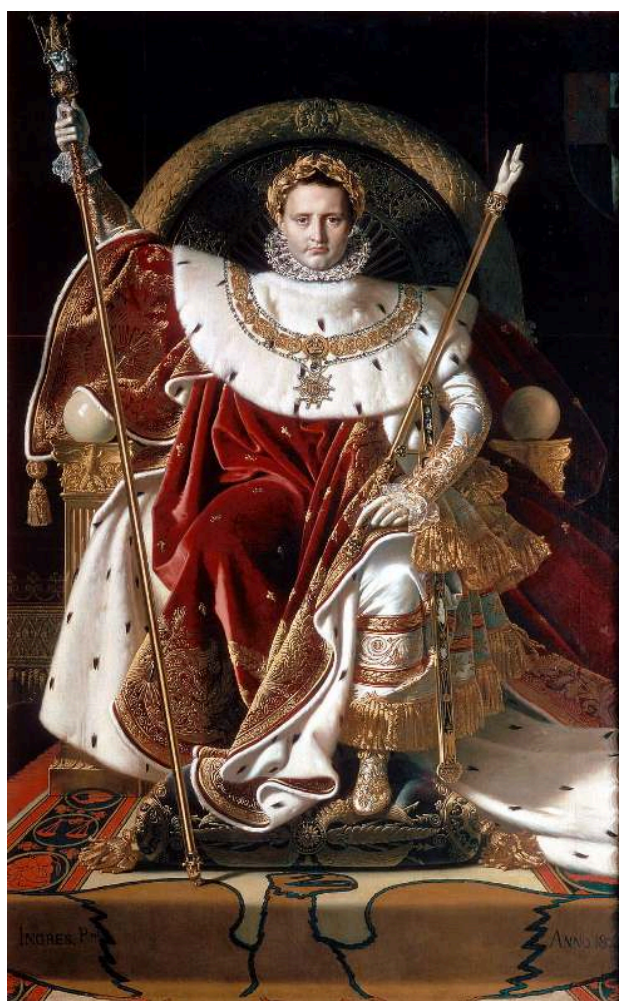

1806, huile sur toile, 260 × 163 cm, Paris, musée de l'Armée.

Le visage de l'Empereur est pâle, barbare et ténébreux, le peintre voulait le faire héroïque (fig. 12). Il est complètement en face ${ }^{2}$, une grande difficulté, à vrai dire, mais en rien pour cela plus excellente, d'autant plus qu'Ingres n'a pas encore assez étudié la chair pour opposer à cette difficulté l'habileté du génie. 
13. Jean-Auguste Dominique Ingres, Portrait de Napoléon en Premier consul

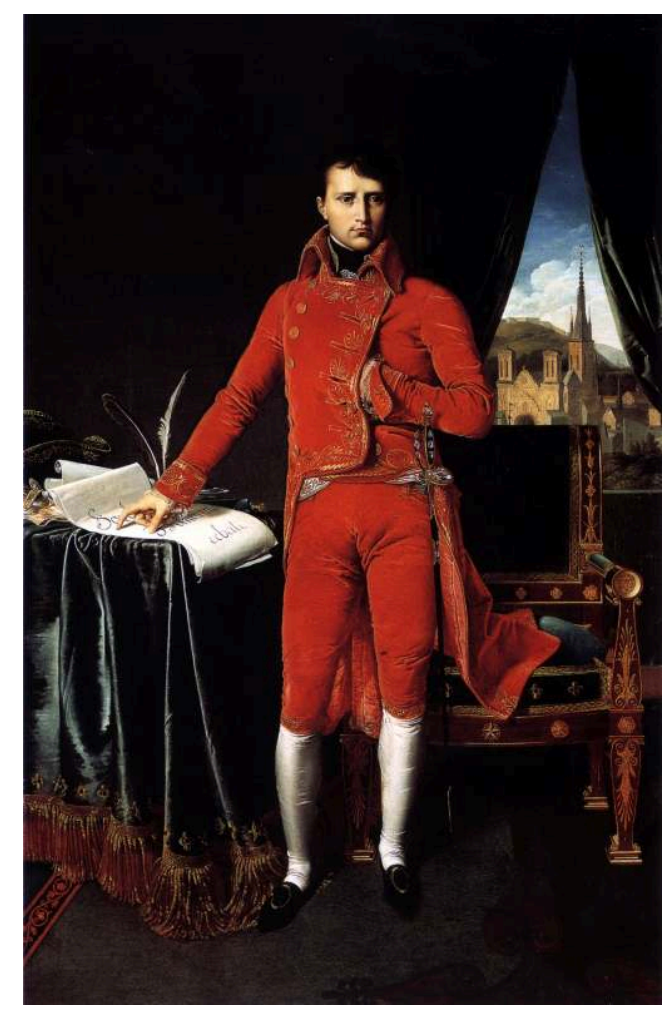

1804, huile sur toile, 227 x 147 cm, Liège, musée des Beaux-Arts.

39 Un autre tableau de l'Empereur qu'Ingres a peint il y a deux ans et qui était destiné à Gand a, pour ce qui est de la ressemblance et de la pose simple, plus de mérites que celui que nous venons de citer (fig. 13). Seuls les pieds sont mal dessinés, tout le reste est excellent. Le costume, velours rouge chamarré d'or, est joliment employé, les plis tombent dans un esprit raphaélique, la lumière est très belle, et le visage animé et plein d'une gravité sereine et douce, aux couleurs également très réussies. Je m'abstiens de parler des autres toiles de cet artiste prometteur qui, avec de si grands dons, doit seulement se méfier d'une maturité trop rapide.

Après lui apparaît Pierre Bergeret, un jeune homme aux rares connaissances et capacités dont le premier essai, Raphaël sur son lit de mort, a ravi les artistes et les connaisseurs. Ce disciple de David vient de province. Son père voulait à toute force l'empêcher de dessiner, mais lui, dès sa jeunesse, dessina en cachette et chercha à partir pour Paris. Là, il entra à l'école de Vincent qui s'intéressa beaucoup à lui et en prit particulièrement soin; la recherche du changement propre aux jeunes gens conduisit Bergeret dans l'atelier de David, mais il n'oublia jamais ce qu'il devait à Vincent. Il se forma avec zèle tout en devant travailler pour gagner son pain. Sous le poids du destin, il sut cependant conserver courage et habileté et ne négligea point, tout en exerçant l'habileté de sa main, de former son esprit. On le trouvait chaque jour dans les bibliothèques, étudiant l'histoire et les costumes, et qui le connaissait devait admirer le calme et la noble fierté, l'apparence convenable d'un jeune homme dont toute l'existence dépendait de son assiduité et qui dans cette situation ne gaspillait pas même un mot de flatterie envers des gens qui auraient pu lui être utiles.

41 Raphaël sur son lit de mort est une composition excellente, pleine d'esprit et d'étude, traitée avec sérieux et amour. La couleur est vraie, l'effet est harmonieux, le dessin pur 
et vigoureux, les groupes s'agencent et ressortent de façon excellente et le costume témoigne de beaucoup d'étude. Maîtres, élèves et connaisseurs ont rendu justice à ce tableau dans lequel il n'y a aucun charlatanisme mais un véritable mérite. [...]

42 Je pourrais encore nommer quelques disciples prometteurs de David et indiquer leurs œuvres, si mon sujet ne m'avait pas déjà conduite trop loin.

\section{Robert Lefebvre, Un portrait de l'Empereur grandeur nature [Napoléon en habits impériaux]}

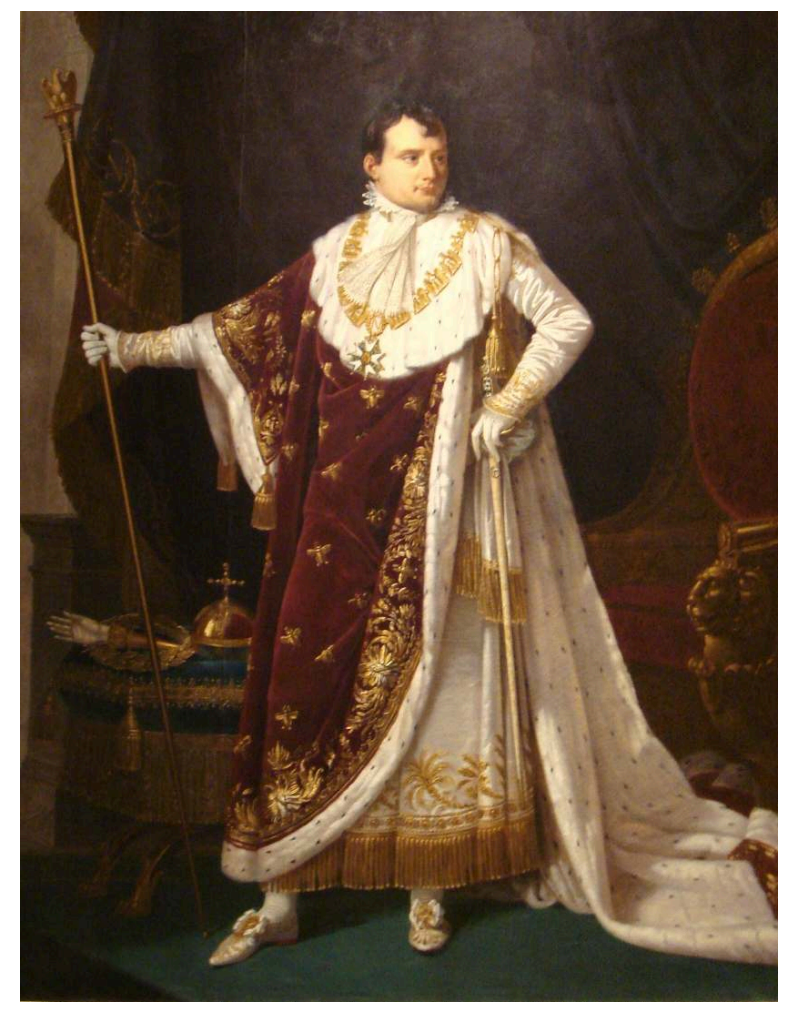

1807, Paris, musée de la Légion d'honneur.

Il est presque superflu de citer le fameux peintre de portraits, Robert Lefebvre (fig. 14). Sa dernière œuvre, un portrait de l'Empereur grandeur nature, en tenue de cérémonie, se levant de son trône, est ordonnée de façon très avisée et très belle, et pleine de grâce et de majesté. La couleur est un peu froide et sèche, mais ce défaut disparait devant les autres perfections et qualités de cet excellent portrait.

Il ne faut pas non plus oublier Riesener dans les rangs des bons peintres de portraits.

Le peintre de bataille Carle Vernet, fils du célèbre peintre de paysage, est également connu de tous, il est à présent extraordinairement occupé, car il ne manque pas à notre époque d'événements qui conviennent à son domaine.

Si incomplète que soit cette vue d'ensemble, je crois cependant n'avoir ignoré aucun des artistes les plus appréciés, et pouvoir maintenant passer à une autre classe.

J'ai ignoré les femmes, pas seulement parce que les noms de Chaudet, [Vigée-] Lebrun, Mongez, Benoist, Romany, Lorimier, $\mathrm{M}^{\text {me }}$ Kugler sont partout connus, mais aussi parce que je ne suis pas d'avis que les femmes puissent amener des progrès quelconques dans l'art, même si elles touchent souvent, comme le font aussi ces artistes de mérite, une des plus agréables cordes de l'art et animent leurs toiles de la magie du sentiment. 
serait cependant injuste de passer sous silence une qualité de l'artiste Chaudet qui est rare dans la peinture moderne et qu'elle possède au plus haut point : l'étude et le sens de l'enfance. La plupart de ses toiles sont des scènes enfantines représentées avec toute la grâce qui accompagne cet âge printanier. La touche de $\mathrm{M}^{\text {me }}$ Chaudet est légère et éclatante, les contours sont d'une pureté et d'un charme qu'on voit rarement.

15. Jeanne Élisabeth Chaudet, Portrait de la princesse Laetitia [Marie-Laetitia Murat portant le buste de Napoléon ler]

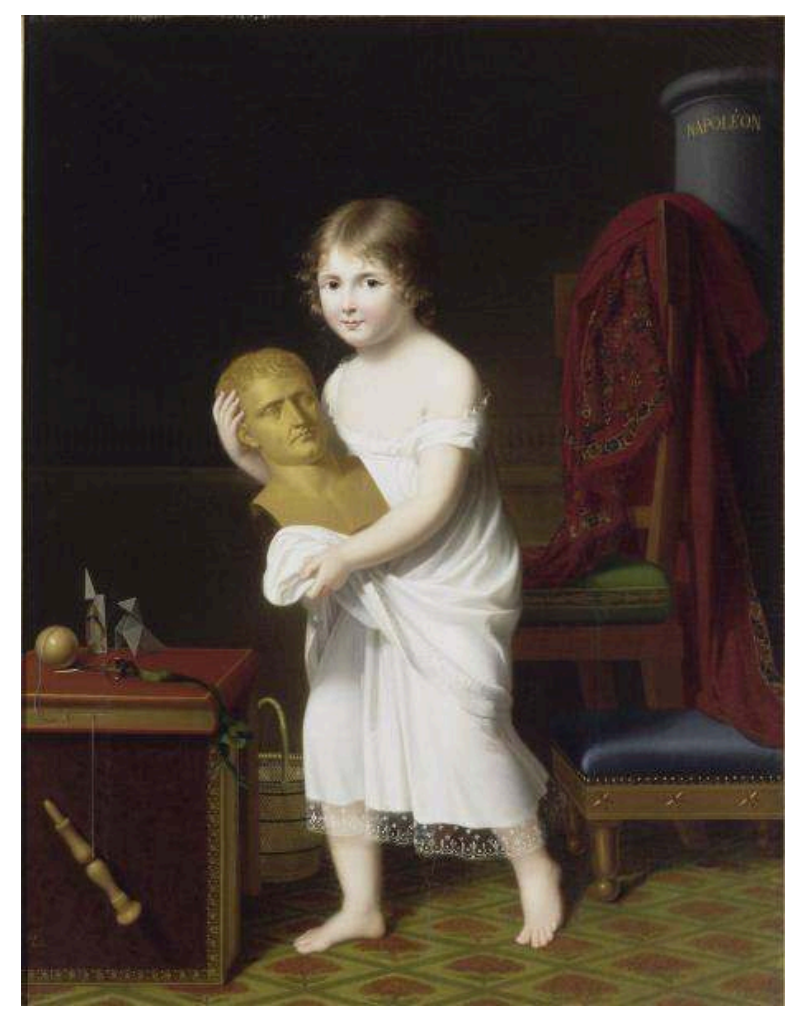

1806, huile sur toile, $125 \times 98$ cm, Ajaccio, musée Fesch [il existe une autre version conservée aumusée national du Château de Fontainebleau].

Un de ses derniers tableaux est celui de la princesse Laetitia, fille de la princesse Caroline, grande-duchesse de Berg, sœur de l'Empereur (fig. 15). Cette enfant épanouie a une allure où rivalisent la beauté, la santé et le charme. Parmi les innombrables enfants que je connais, je n'ai jamais vu une créature aussi magnifique. C'est à elle qu'on pourrait appliquer les quatre vers arabes qu'un orientaliste a découverts il y a peu sur la couverture d'un manuscrit :

«Jamais mon regard ne se posa sur un être aussi mignon que toi

Jamais une femme n'a mis au monde un aussi bel enfant

Tu es née absolument sans défaut

Comme si tu étais née de tes désirs. "

Le portrait de cette belle enfant est d'une ressemblance frappante, et plein de vivacité et de grâce. Elle est debout sur un tapis sombre, en vêtements blancs, le buste de son oncle naïvement serré dans ses petits bras qui, comme les petites jambes et les petits pieds, sont nus, car la légère robe en percale qui l'habille, bordée d'une large lisière, tombe à peine jusqu'aux chevilles. Les boucles blondes volent, spirituelles et gracieuses, autour du visage frais comme une rose de mai, et les grands yeux bleu clair nous jettent un regard si sage et si innocemment joyeux et aimable que l'on en est ravi. La pose est 
d'une ingénuité toute naïve, le décor est bien choisi, le tableau est plein de mérite artistique et tout à fait sans reproche.

51 Si nous examinons la miniature, des noms célèbres nous attendent tout de suite: Augustin, Isabey dont les œuvres excellentes plaisent unanimement et sont dotées des plus rares qualités. Après eux apparaît Guérin, l'artiste plein de mérite et de goût de Strasbourg, et puis Laurent qui s'est fait connaître par quelques charmantes inventions dans des groupes de miniatures et dont l'application et les connaissances sont dignes d'éloges. De même, on doit tout aussi peu oublier l'habile artiste qu'est Lagrenée.

De nombreuses dames à Paris peignent des miniatures avec une habileté extraordinaire, c'est le genre où elles réussissent le mieux. S'il est peu convenable de ranger des femmes de la bonne société parmi les artistes, je ne peux pourtant me priver du plaisir de citer la demoiselle de Launay, pleine de talent et digne d'estime, dont je connais quelques excellents portraits miniatures de la famille impériale.

\section{ANNEXES}

Lire l'introduction à Helmina von Chézy écrite par David Blankenstein

\section{NOTES}

1. Cette toile se trouve dans une petite collection, qui ne manque pas d'intérêt, du chanteur d'opéra-comique Ehenard [(NdT) en réalité Simon Chenard]. Le portrait de cet acteur par Gérard, une de ses œuvres les plus anciennes, appartient aussi à cette collection, de même qu'une esquisse de Guérin pour Hippolyte, entre autres.

2. (NdT) En français dans le texte. 
Marianne Colston (1792 ? - 1865) 


\title{
Introduction
}

\author{
Isabelle Baudino
}

1 Partiellement éclairée par la publication de son Journal of a Tour in France, Switzerland, and Italy, During the Years 1819, 20, and 21, la vie de Marianne Colston demeure assez obscure. Dans les archives comme dans la société britannique de son époque, Marianne Jenkins, fille unique de William Jenkins, originaire de Shepton Mallet, hameau du Somerset, accéda à la notoriété par son mariage avec Edward Francis Colston (1795-1847) le $1^{\mathrm{er}}$ novembre 1819. Fils aîné d'un propriétaire terrien, Colston avait dû recevoir l'éducation classique réservée aux héritiers et il devait nourrir le projet de se lancer dans un Grand Tour. On peut supposer que Marianne partageait son intérêt pour le voyage et qu'elle avait été associée aux préparatifs, puisque le jeune couple s'embarqua pour la France dès le lendemain de leur mariage.

Bien que dédié à une parente, le récit de ce périple de deux ans n'est pas rédigé par Marianne sous une forme épistolaire mais divisé en chapitres, correspondant aux étapes principales du voyage. Jeune femme apparemment cultivée, l'auteure avait sans doute été éduquée, comme de nombreuses filles de sa génération, selon les préceptes populaires de Maria Edgeworth, à laquelle elle rend hommage dans la préface de son Journal (COLSTON 1822, vol. 1, p. vii). Elle semble avoir lu les classiques de la littérature anglaise, auxquels elle fait référence, ainsi que des ouvrages d'histoire, d'archéologie et d'art. Son intérêt pour les arts se manifeste dans les commentaires très informés des œuvres qu'elle admire sur le continent et dans les cinquante dessins qu'elle exécuta pendant le voyage et qu'elle publia dans un volume séparé, adjoint aux deux tomes de son récit.

3 Au fil des pages de son Journal, sa prédilection pour le paysage s'affirme dans les descriptions qu'elle donne des contrées qu'elle traverse, dans les tableaux qu'elle remarque ainsi que dans les cinquante vues, toutes paysagères, dont elle illustre son récit. Elle ne se lasse pas d'apporter des détails sur les spécificités du relief, de la végétation et $\mathrm{du}$ climat $\mathrm{du}$ continent. Les comparaisons fréquentes avec les régions d'Angleterre font ressortir le pittoresque des pays qu'elle visite tandis que les références aux tableaux de Gaspard Dughet (Poussin) et de Claude Lorrain témoignent de l'artialisation de la nature. Sur les traces des amateurs d'art qui l'ont précédée, guidée par ses repères esthétiques, Marianne Colston éprouve le sublime lorsqu'une 
chute de neige précoce la surprend dans le Jura, ou lors de l'ascension des cols alpins (Colston 1822, vol. 1, p. 48 et 70). Enthousiasmée par la journée passée à la villa de Mécène à Tivoli, elle la qualifie de " plus belle excursion qu'il lui ait été donné de faire dans sa vie» (COLSTON 1822, vol. 1, p. 205). Elle éprouva sans doute en visitant ce site cette sensation - si recherchée par les Britanniques, notamment par l'utilisation de ces petits miroirs de poche, appelés aussi «miroirs de Claude » - d'arpenter un paysage représenté dans un tableau de Claude Lorrain.

4 Riche en émotions artistiques, son voyage fut émaillé de souvenirs heureux dont la naissance de sa fille aînée, Arabella Sarah, à Côme le 29 juillet 1820, un événement qu'elle évoque avec émotion dans son Journal (COLSTON 1822, vol. 1, p. 346). Trois autres enfants naquirent après le retour de la famille en Angleterre. En 1827, Edward Francis Colston hérita, à la mort de son père, du titre et de la propriété familiale de Filkins Hall dans l'Oxfordshire. En 1840, il racheta la propriété de New Park dans le Wiltshire ; la demeure, renommée Roundway Park, avait été conçue par l'architecte James Wyatt et le jardin aménagé par Humphrey Repton.

\section{BIBLIOGRAPHIE}

COLSTON 1822

Marianne colston, Journal of a Tour in France, Switzerland, and Italy, During the Years 1819, 20 , and 21. Illustrated by Fifty Lithographic Prints, from original Drawings, taken in Italy, the Alps, and the Pyrenees, Paris, Galignani, 1822.

PHELPS 1836

William PHELPS, The History and Antiquities of Somersetshire, Londres, Nichols, 1836, p. 470.

\section{ANNEXES}

Diaporama des œuvres commentées par Marianne Colston dans son Journal d'un voyage en France :

http://www.flickr.com//photos/73632227@N02/sets/72157629752933306/

Lire les extraits du Journal d'un voyage en France de Marianne Colston

Liste complète des œuvres d'arts commentées par Marianne Colston à travers ses textes édités dans Plumes et pinceaux 


\section{Marianne Colston, Journal d'un voyage en France, 1822}

[Journal of a Tour in France, Switzerland \& Italy, During the Years 1819, 20, 21], Paris, Galignani, extraits choisis.

Traduction: Jean Piétri depuis l'anglais

\section{Volume I, chapitre I}

p. $13-15$

1 Jeudi matin, en compagnie de M. B., nous avons visité la magnifique galerie du Louvre. Avec quelle splendeur l'architecture, la sculpture, la peinture, les marbres et les dorures concourent ici à l'enchantement du spectateur! Et comme ils agissent puissamment sur les natifs de nos froides contrées, où les beaux-arts exercent leurs pouvoirs pour ainsi dire de manière individuelle, isolée (non sans succès dans certains cas, il faut le reconnaître) mais avec moins d'effet, et sans produire l'irrésistible attrait de leurs beautés rassemblées. Nous ne pouvions séjourner longtemps à Paris, car nous devions rejoindre l'Italie avant que l'hiver ne s'installe, aussi nous a-t-il fallu parcourir le Louvre à la hâte, en une matinée; il était donc impossible de retirer rien de plus qu'une idée générale des peintures et des statues qu'il contient, et je dois me limiter pour l'heure à quelques remarques. L'exposition ayant ouvert ses portes, les toiles des artistes vivants, par une disposition très regrettable, nous cachaient la plupart des maîtres anciens. Au terme de cette rapide visite du Louvre, je dirais que l'art de peindre est florissant en France: plusieurs dames démontraient ici le crédit que méritent le génie et l'habileté de notre sexe en ce pays. Les œuvres de Vernet et de Granet sont toutes excellentes. Parmi celles que nous avons admirées surtout, se trouvait une vue du chœur de l'église des capucins à Rome, par Granet: la perspective et l'admirable emploi du clair-obscur produisent une telle illusion qu'après avoir contemplé cette scène un moment il est difficile de se croire devant une toile peinte. 
1. Jean-Honoré Fragonard, L'Adoubement de François ler [François ler armé chevalier par Bayard]

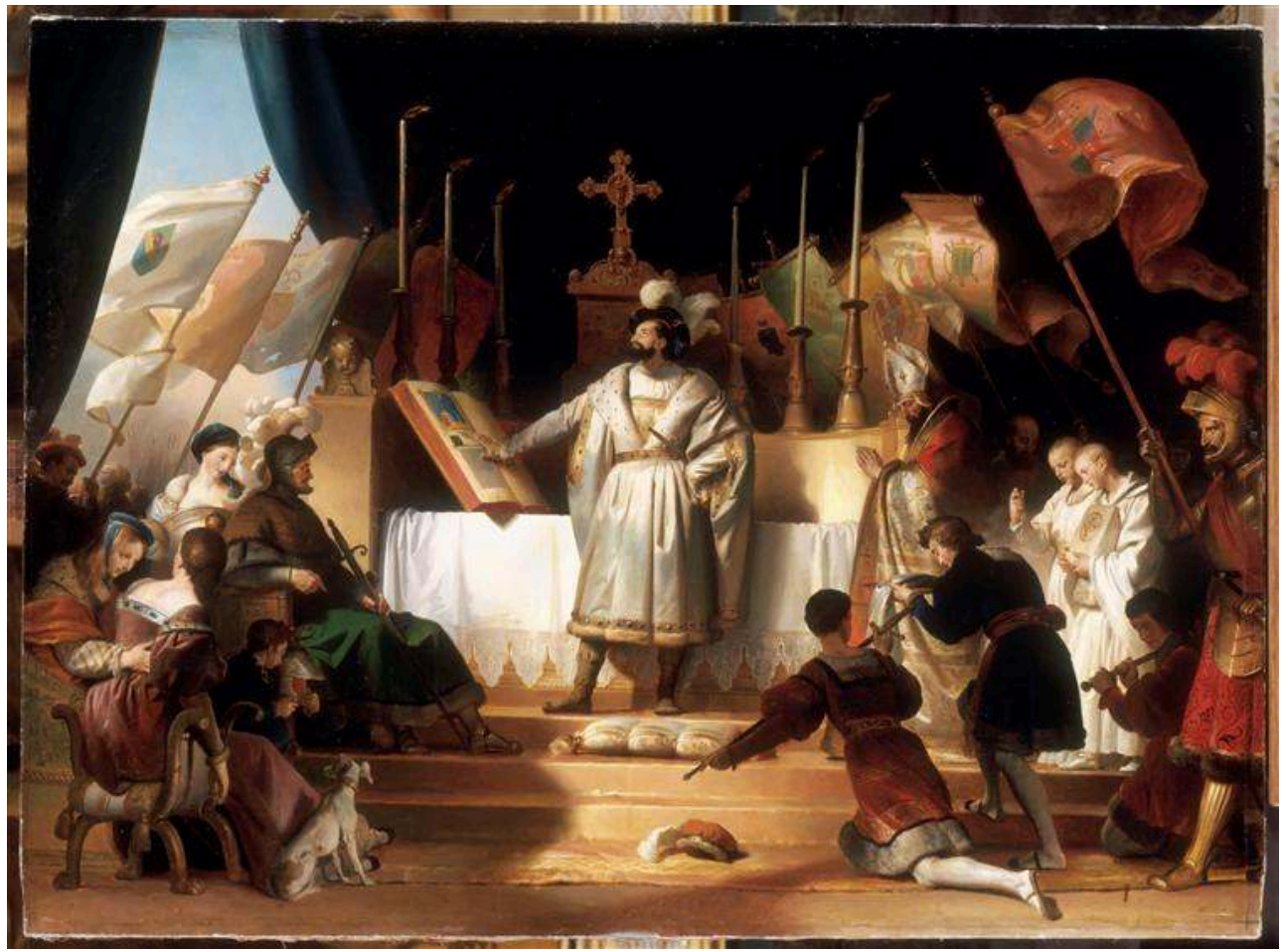

Salon de 1819, huile sur toile, 85,5 × 115,5 cm, Paris, musée du Louvre.

\section{François-Édouard Picot, Cupidon quittant Psyché [L'Amour et Psyché]}

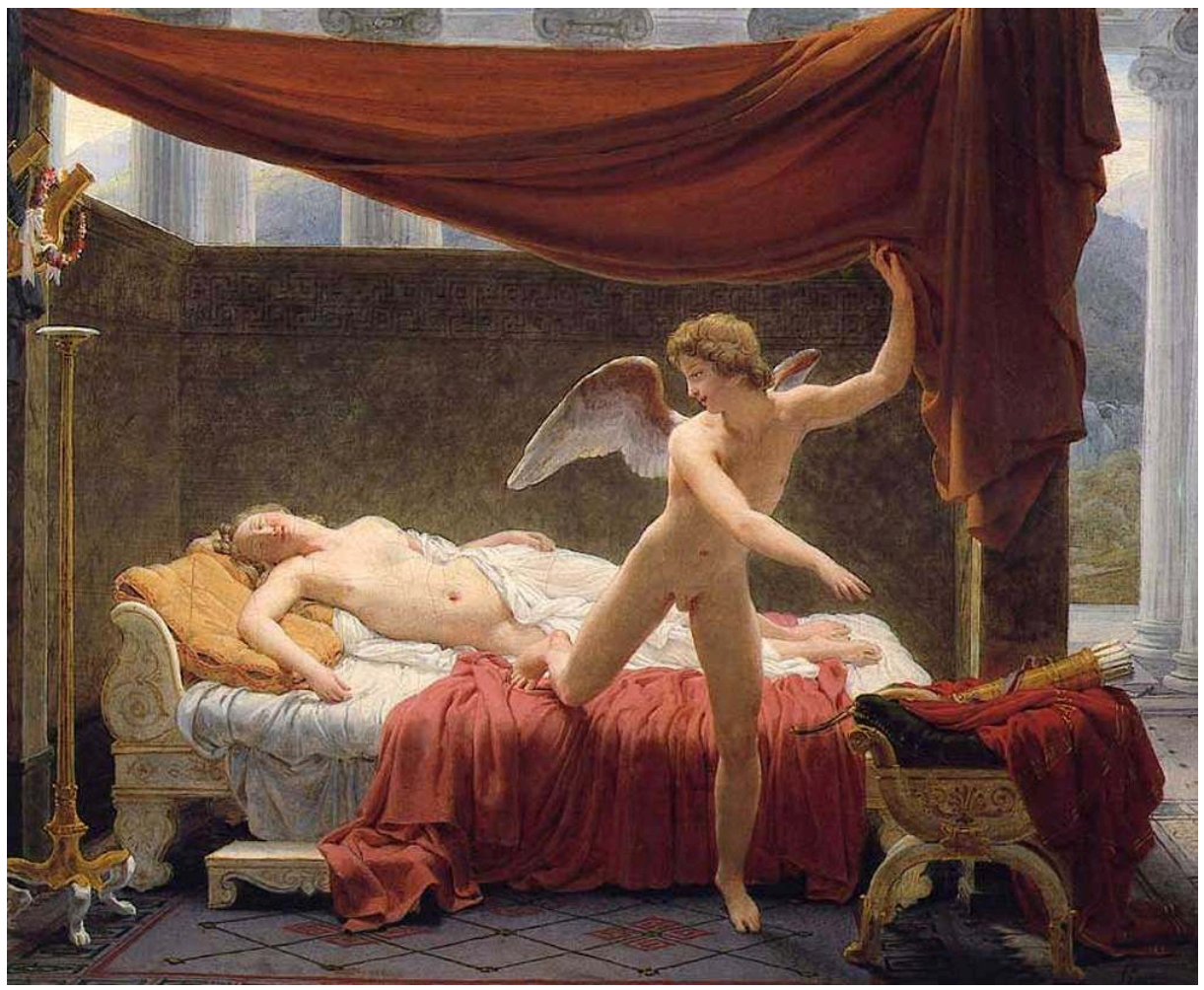

Salon de 1819, huile sur toile, 234 × 291,5 cm, Paris, musée du Louvre. 
Un Christ calmant la tempête, par Dubufe, une vue de l'église des Invalides, par Genillion, et un paysage, de Watelet, nous ont paru particulièrement réussis; ainsi que l'attaque d'un convoi français par l'armée espagnole, du général Lejeune; l'adoubement de François ${ }^{\text {er }}$, par Fragonard (fig. 1); des fleurs, peintes de manière inimitable, par Van Dael ; et Cupidon quittant Psyché, de Picot (fig. 2).

2 Mais m'étant acquittée de ces justes éloges, je dois à la vérité de dire qu'il y avait là beaucoup de barbouillages piteux, ne valant guère mieux que des peintures d'enseignes et peut-être inférieurs à celles des relais de Rouen, dont la plupart sont très joliment peintes. Plus d'une fois, M. B. se détourna avec dégoût en se plaignant de ce que ses yeux subissaient. Parvenus au bout de la galerie, nous eûmes la satisfaction de voir les œuvres des maitres anciens, puisque les peintures modernes ne les masquaient plus; après quelques minutes, lorsque nos yeux en eurent fini avec le coloris clinquant des modernes, lequel donne d'abord une sombre apparence aux œuvres du passé, ces dernières nous firent goûter les délices de leurs harmonieuses et chastes beautés qui, comme celles de la nature, s'accroissent sous nos yeux et nous enchantent davantage à mesure que nous les contemplons. Elles ont une vérité, une réalité, une simplicité, une force qui font le contentement de l'œil et, guidant notre esprit, donnent à nos idées le cours le plus aimable. Nous avons admiré une Sainte Famille de Raphaël : mais c'est en vain que je tenterais d'en parler avec plus de précision. Enfin, quittant le Louvre, notre faculté d'attention épuisée, nous avons déambulé tout le long de l'édifice qui rejoint le palais aux Tuileries, et s'étend sur près d'un quart de mile en longueur! Sa taille est surprenante et inspire au spectateur un sentiment de crainte et de respect. Le bâtiment des Tuileries est une lourde masse ; le mélange dénué de goût, irrégulier, d'ordres et de styles divers dans un même édifice nuit considérablement à sa beauté, et la façade du palais ressemble davantage à cinq maisons mises ensemble qu'à un seul grand édifice. $[\ldots]$

\section{Volume II, chapitre XXIII}

p. 236-241

3 En 1814, le Louvre contenait probablement la plus éclatante réunion de chefs-d'œuvre artistiques qui se fût jamais vue en une même collection. En l'an 1815, les armées alliées les restituèrent à leurs propriétaires légitimes, au grand regret de l'ensemble de la nation. Certains Français m'ont déclaré qu'ils auraient consenti à perdre plus de batailles, pourvu qu'ils eussent conservé ces trésors. Il est vrai, je crois pouvoir le dire, que ces peintures sont revenues de leur pérégrination en bien meilleur état qu'elles n'étaient parties; car elles avaient été nettoyées et restaurées avec le plus grand soin durant leur séjour à Paris.

Ce musée possède encore une très belle collection de peintures de maîtres anciens de France, d'Italie, des Flandres, etc., et le lieu illustre où elles sont placées les met on ne peut mieux en valeur. C'est un sujet que j'ai déjà abordé, mais la matière en est inépuisable; et je puis me flatter en quelque mesure d'avoir mûri mon jugement par l'expérience, ayant eu l'occasion de contempler des œuvres de qualité en si grand nombre ; aussi vais-je me risquer à noter quelques observations.

$5 \quad$ Les vues des ports de France, de Vernet, se présentent au visiteur dès l'entrée de cette magnifique galerie: elles sont exécutées dans un style magistral, et pour la plupart admirables de naturel et de vérité. Les marines de l'artiste ont de grandes similitudes 
avec celles de Claude le Lorrain, et ses représentations du clair de lune sur l'eau sont d'une beauté exquise ; mais ses paysages ne soutiennent pas aussi bien la comparaison, l'artiste que je viens de nommer demeurant sans égal dans ce domaine. Dans sa Vue de Bayonne, Vernet n'est pas d'une parfaite exactitude ; le pont sur l'Adour ne compte pas plus de dix-sept arches, quand l'artiste lui en donne trente, modification qui nuit à la simplicité du pont. Ce tableau démontre qu'aucune habileté dans le traitement du sujet ne saurait compenser le défaut d'un mauvais point de vue (du moins sans prendre la liberté d'être infidèle à la nature) et qu'aucune beauté d'arrière-plan, ou de second plan, ne peut suppléer l'absence d'un premier plan adapté au tableau : rien de pire que la longue rangée de maisons mise ici.

\section{Pierre-Paul Rubens, Le Débarquement de Marie de Médicis à Marseille, 1622-1625}

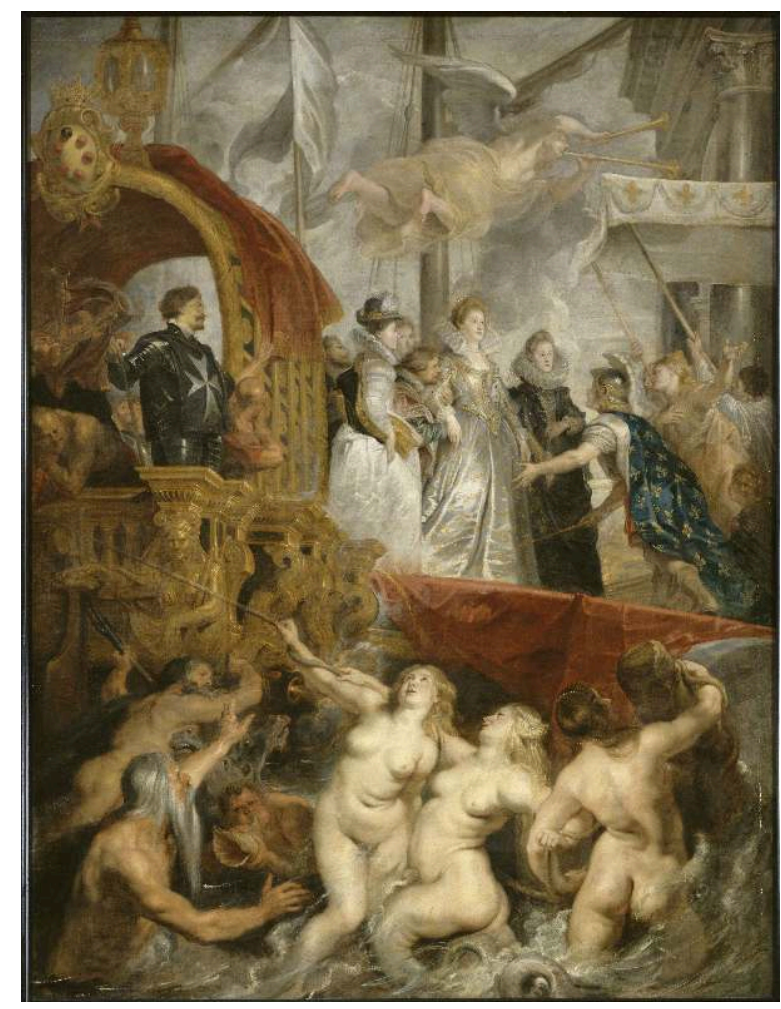

1622-1625, huile sur toile, 394 × 295 cm, Paris, musée du Louvre.

6 La suite de tableaux allégoriques où Rubens a représenté la régence de Marie de Médicis et les principaux événements de sa vie occupe un immense espace du musée (fig. 3). Le spectateur se prend à regretter que le peintre n'ait pas plutôt employé son talent à retracer les plus notables actions de son illustre époux ; mais d'après le dicton, un âne vivant vaut mieux qu'un lion mort; et il semble que, suivant ce principe, l'artiste ait préféré une Marie vivante au défunt Henri. Il installe fréquemment cette reine au milieu de nuages qui, à l'évidence, ne sauraient suffire à supporter le poids de sa personne; et elle apparaît si laide et acariâtre dans la plupart de ces tableaux, que j'ai repensé au mot piquant de la marquise de Verneuil : «Si le roi m'eût fait justice, j'aurais tenu la place de cette grasse banquière ${ }^{1}$. » 


\section{Raphaël, La Belle Jardinière}

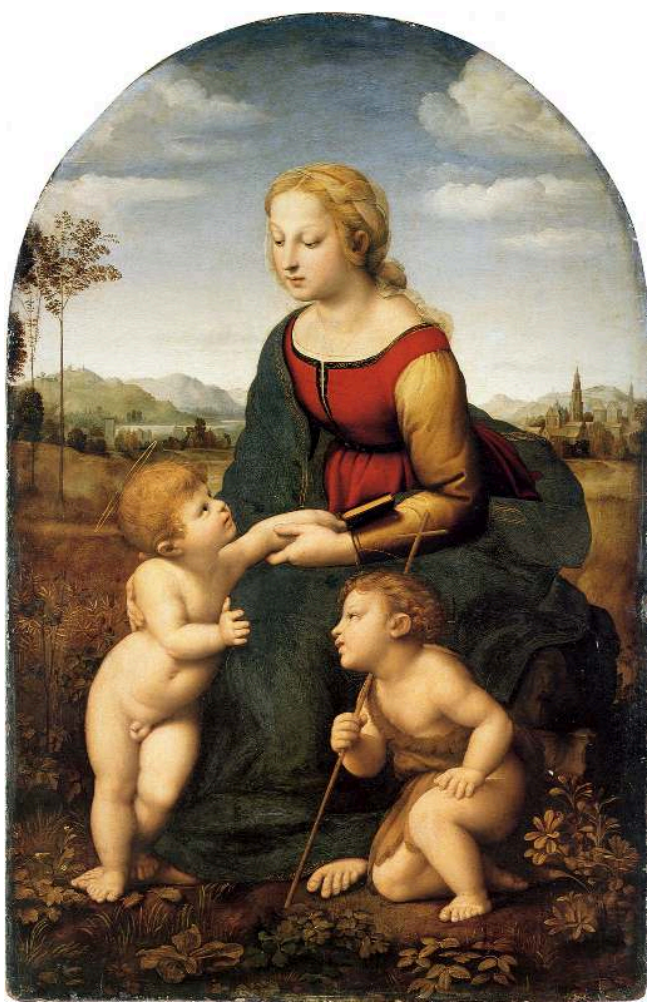

1507-1508, huile sur toile, 122 × 80 cm, Paris, musée du Louvre.

7 Dans cette collection, beaucoup de Lorrain d'un grand charme, qui se distinguent par la grâce inimitable propre aux compositions du peintre: on trouve plusieurs de ses splendides couchers de soleil, comme seule la nature italienne en déploie. Albane, avec ses troupes gracieuses de Cupidons qui semblent découpés et fixés sur leur arrière-plan vert sombre; Dominiquin, ses attitudes rayonnantes de beauté et d'intelligence, ses yeux noirs italiens auxquels lui seul, peut-être, a restitué leur splendeur entière; quelques bons Corrège; beaucoup d'œuvres admirables d'Andrea del Sarto, peintre possédant à un degré peu commun l'art de mélanger les couleurs ; mais pas un Raphaël qui puisse donner une idée convaincante des chefs-d'œuvre de ce grand maître; les rares œuvres que j'ai vues de lui ici sont des spécimens de sa première manière, pleine de rudesse avant que son génie n'ait saisi le grand style pictural. Je dois excepter $L a$ Belle Jardinière, une toile qui malgré les défauts dont je parle est d'une grande beauté (fig. 4). Plusieurs Raphaël mentionnés dans le catalogue du musée ont été déplacés, et je les ai cherchés en vain. Une Madeleine du Guide, dans sa manière la plus suave; et de nombreux Titien, mais parmi eux rien de ce que son pinceau a produit de meilleur.

De l'école française, après Vernet, viennent d'admirables réussites de Gaspar et Nicolas Poussin, également de Lesueur, de Philippe de Champaigne, de Le Brun, etc. Entre les œuvres de l'école flamande, d'excellentes scènes de troupeau par Paul Potter et Berchem; des églises, de Pieter Neefs; des portraits par Van Dyck; et beaucoup de Rembrandt, Teniers, Gérard Dou, etc.

9 Les salles de marbre du rez-de-chaussée du Louvre sont bien supérieures à celles du Vatican. Leurs murs sont incrustés pour la plupart de marbres divers qui montent jusqu'aux corniches; d'antiques piliers de serpentine et de roche verte soutiennent les hauts plafonds peints par Barthélemi, Meynier, Romanelli, Prud'hon, Lethière, etc., de 
scènes allégoriques variées; et beaucoup sont d'une grande beauté de dessin et de composition, bien qu'elles ne puissent supporter la comparaison avec les célèbres fresques qui ont donné aux murs romains la consécration d'une gloire immortelle.

De hauts candélabres, des vases finement sculptés, d'immenses bassins de porphyre se mêlent dans une magnifique perspective où apparaissent de nobles statues déployant les attitudes les plus imposantes, pleines de force ou de grâce : figures consacrées par le temps, que l'on dirait issues d'une race d'immortels. Certes taciturnes, mais représentant avec toute l'énergie possible les sentiments et les habitudes de l'humanité, en tout temps semblable à elle-même. Ma petite, livrée à ses gambades enfantines parmi leurs formes immobiles, ressemble à une image d'Ève à l'heure où elle s'éveilla pour la première fois à la lumière et à la vie, tout émerveillement et délices.

11 Les limites que je me suis imposées ne me permettront que quelques observations. La salle des Cariatides accueillait durant la régence de Catherine de Médicis les fêtes et les représentations théâtrales de la Cour; divertissements détestables, où sous le masque du plaisir se dissimulaient la fourberie et le carnage! Cette salle fut construite sur les dessins de Lescot ; la superbe sculpture et les ornements qui la décorent sont de Goujon et de Ponce. Les quatre cariatides qui supportent la tribune sont le chef-d'œuvre du ciseau de Goujon; plus haut, l'élégante figure de bronze en relief, par Benvenuto Cellini, illustre une statuaire qui demeure la plus imaginative d'Italie.

\section{Agasias d'Éphèse, Gladiateur au combat [Gladiateur au combat dit Gladiateur Borghèse]}

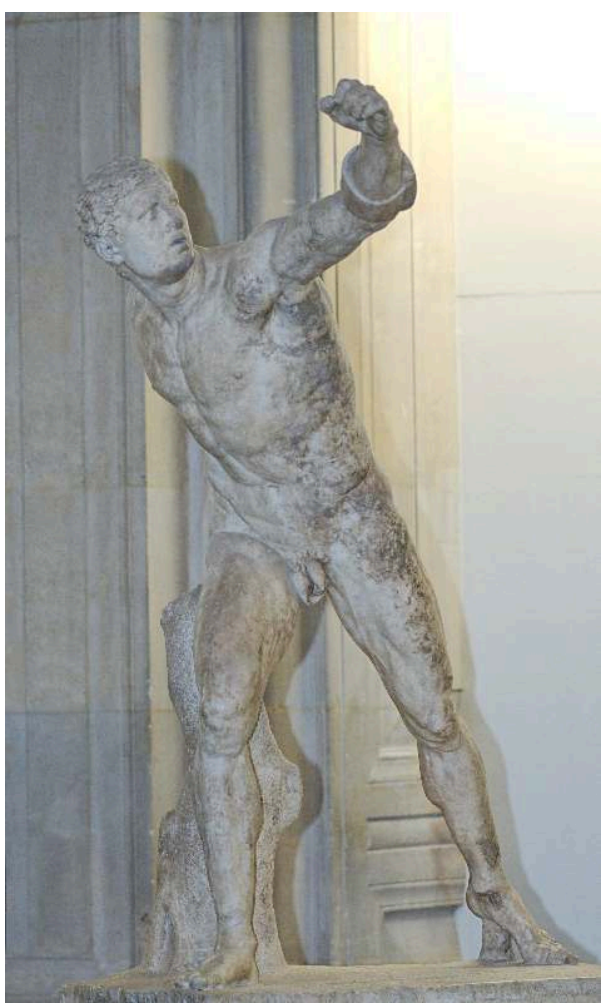

IIle-ler siècle avant J.C., sculpture, marbre, 199 cm, Paris, musée du Louvre.

Le Gladiateur au combat (dans la salle qui porte son nom) est une statue magnifique (fig. 5). De quelque côté qu'on l'observe, l'attitude conserve une grâce, une noblesse et une force égales. Le piédestal, qui est moderne, est embelli de figures en haut-relief d'excellente facture. 


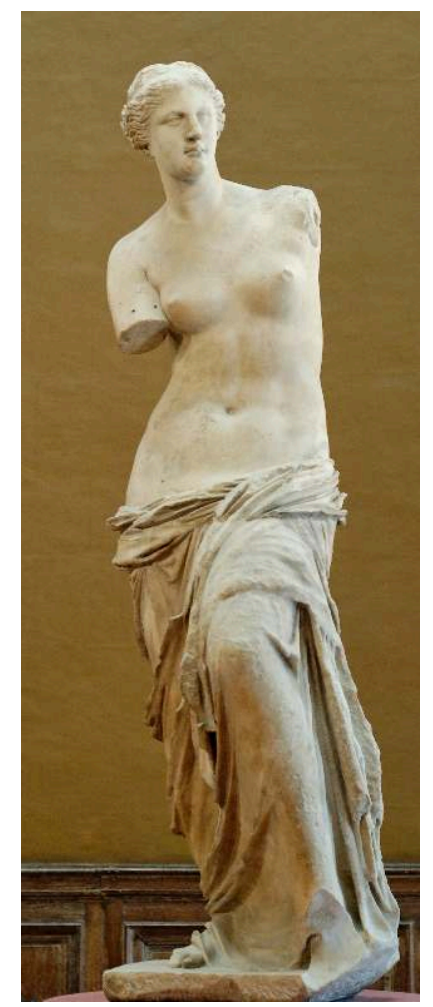

Env. ler siècle avant J.-C., sculpture, marbre, 202 cm, Paris, musée du Louvre.

13 Dans la même salle se trouve la statue de Vénus récemment exhumée, nommée Vénus Victrix, que l'on a découverte sur l'île de Milo voilà neuf mois environ (fig. 6). La tête est très belle; les traits réguliers et gracieux; les cheveux rejetés en arrière dégagent la figure de manière libre, avec aisance. La tournure de la tête, le cou, et la chute des épaules sont empreints d'une grâce particulière ; les bras sont perdus ; j'ai été surprise par la taille du corps, trop grand en proportion de la tête et du cou ; mais j'ai appris qu'au jugement des connaisseurs les proportions sont justes. La statue d'Antinoüsen Herculeest très belle; et celle du Faune dansant est pleine de grâce et de légèreté. La salle de Melpomène est ornée d'un superbe pavement de mosaïques, exécuté à Paris, par Belloni.

14 La salle de Diane et le cerf est la moins décorée ; l'attitude de la statue est saisissante et gracieuse, la draperie élégamment disposée. 

serpent]

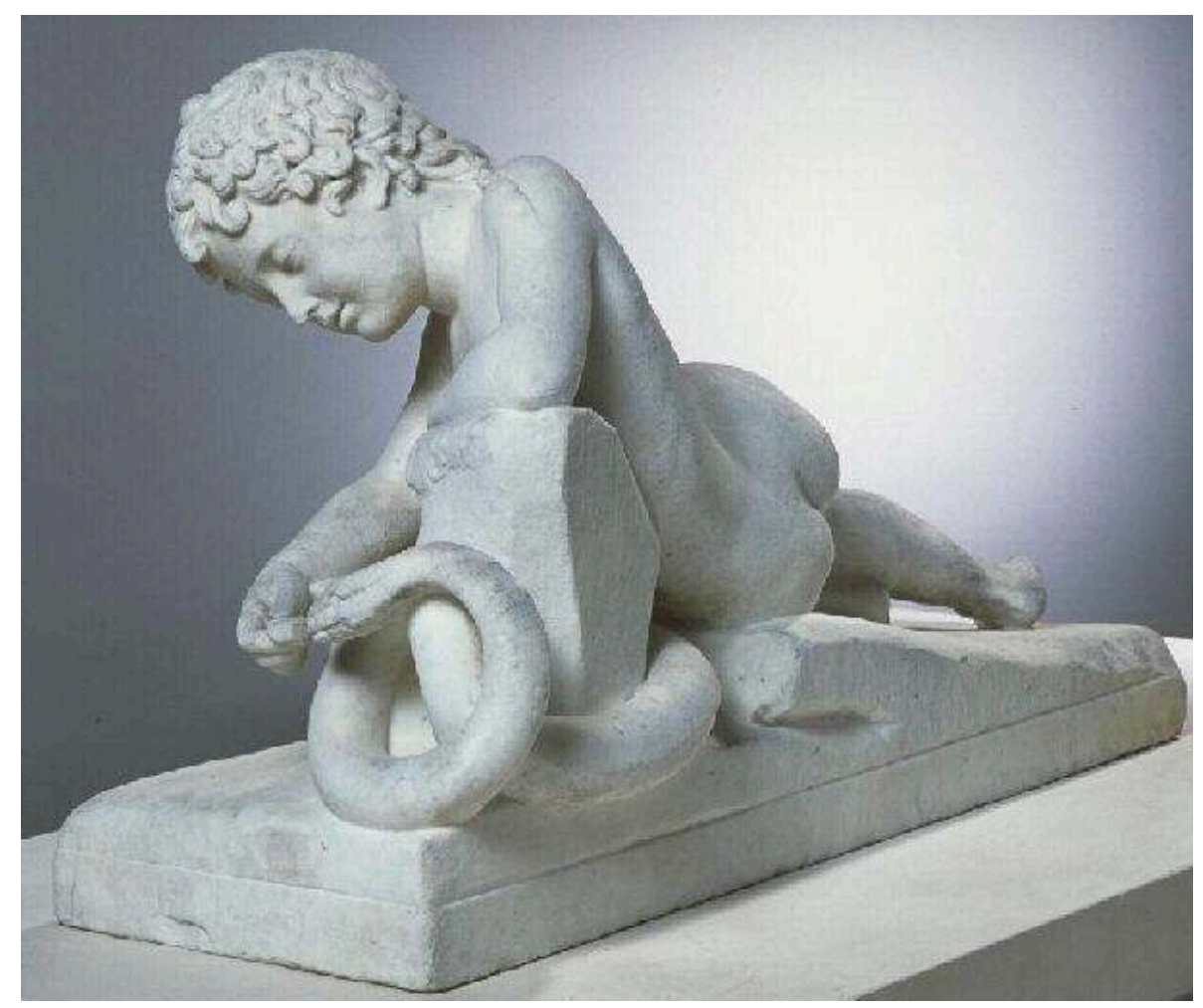

1822, marbre, 57 × 95 × 35 cm, Douai, hôtel de la sous-préfecture.

Une partie du Carré du Louvre sert à l'exposition des sculptures modernes. Parmi celles qui, ces dernières années, furent présentées au public, beaucoup étaient de simples moulages; mais il y avait là quelques belles statues; notamment une Minerve de Carlier ; une figure colossale, aux proportions très gracieuses ; un Enfant nourrissant un serpent, par Guillois (fig. 7); la Nymphe Écho et un Faune dérobant un fruit à une Bacchante endormie, tous deux par Lemoyne Saint-Paul ; c'étaient là d'intéressantes réalisations de l'art moderne.

La galerie d'Apollon fut construite sous Marie de Médicis, et Le Brun peignit les plafonds. À présent, comme d'autres salles du Louvre, elle est réservée aux expositions de peintures modernes: une disposition préférable, et de loin, à celle que j'avais constatée lors de ma première visite de Paris, quand ces dernières étaient placées dans la grande galerie, de sorte qu'elles masquaient les toiles anciennes. 


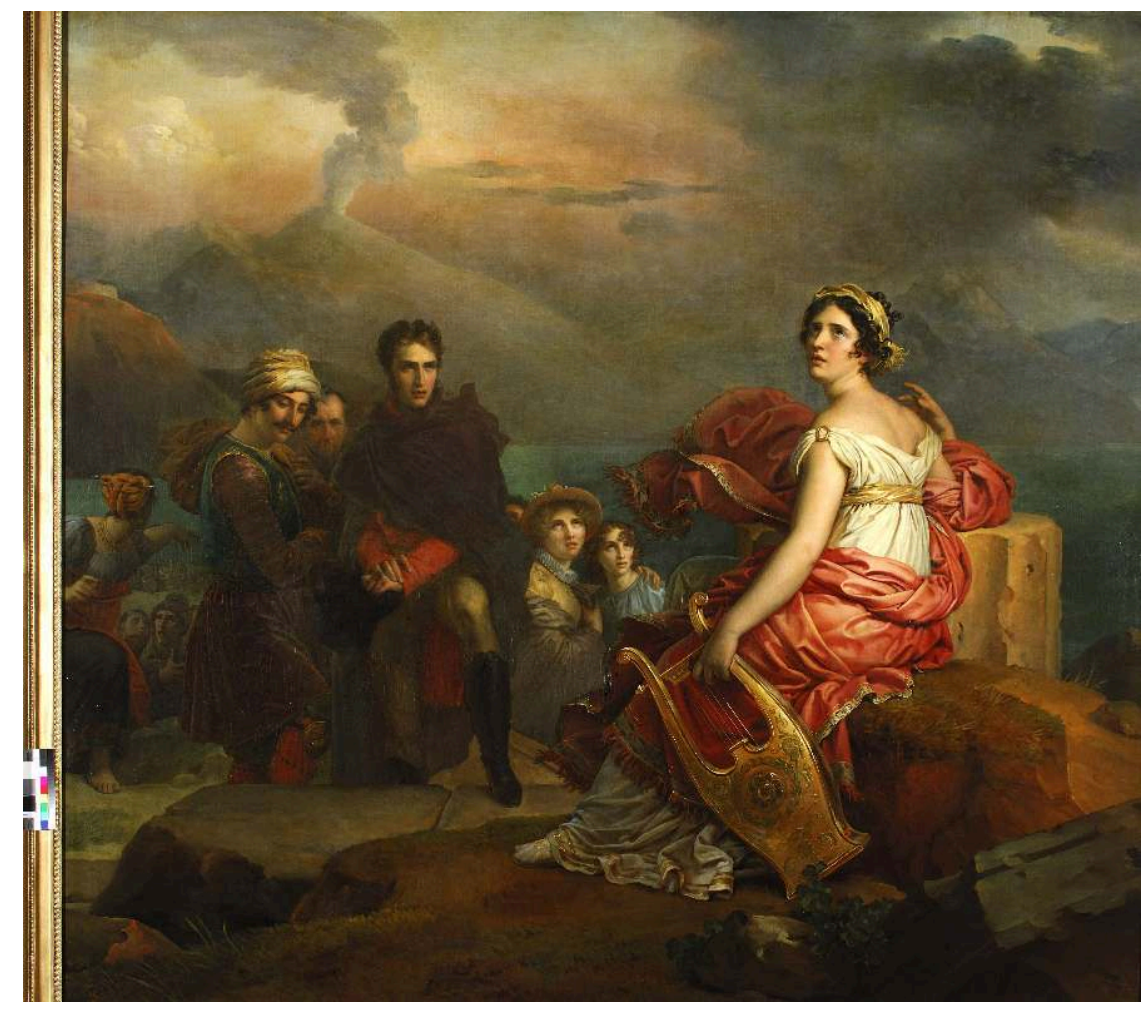

1819-1821, huile sur toile, 256,5 x 277 cm, Lyon, musée des Beaux-Arts.

17 Cette année, l'exposition des œuvres modernes manque d'éclat ; elle ne compte que très peu de toiles des principaux artistes vivants de l'école française, dont les travaux, je crois, sont trop demandés pour prendre place ici. Deux charmants paysages, par Bertin, sont les seules œuvres que l'on peut voir de ce maître; quelques Watelet, en petit nombre, sont également remarquables. L'unique toile d'Horace Vernet représente Joseph Vernet (le célèbre peintre des ports de France) dans une felouque, au cours d'une violente tempête, esquissant tranquillement cette scène où règnent l'horreur et le danger : la mer est quelque peu opaque, mais l'ensemble est exécuté avec art et dans un style qui rappelle Salvator Rosa. Un intérieur d'église, bien rendu par Granet; une Corinne de Gérard, très inspirée (fig. 8) ; David charmant et chassant l'esprit mauvais qui habite Saul, et un paysage, tous deux de Gros, se signalent par leur grande harmonie et la beauté de leur couleur, qualités qui font défaut à la plupart des meilleurs artistes français. Quelques bouquets de fleurs excellents, et parmi les toiles de petites dimensions, beaucoup sont de très bonne facture, en particulier un chasseur qui a blessé son chien à mort, par un peintre de Lyon. Il y a là également quelques paysages plaisants, par Bidault ; et Le Chasseur de l'Apennin, une toile intéressante de Forbin. 


\section{ANNEXES}

Lire l'introduction à Marianne Colston écrite par Isabelle Baudino

\section{NOTES}

1. (NdÉ) En français dans le texte. 
Félicité de Genlis (1746 - 1830) 


\title{
Introduction
}

\author{
Charlotte Foucher
}

$1 \quad$ Issue d'une famille noble de Bourgogne, Stéphanie-Félicité Du Crest épousa le comte de Genlis à l'âge de dix-sept ans, avant de devenir une femme de lettres et une musicienne accomplie. Son œuvre littéraire, riche de près de quatre-vingts volumes, compte surtout des traités d'éducation (Théâtre à l'usage des jeunes personnes, 1779-1780; Annales de la vertu, 1782; Adèle et Théodore ou Lettres sur l'éducation, 1782...) qui firent sa renommée d'auteure pédagogue. Dame d'honneur de la duchesse de Chartres, elle éduqua, selon des principes rousseauistes, les filles de la famille d'Orléans avec plusieurs autres enfants adoptés. En 1792, au moment de l'arrestation du roi à Varennes, elle quitta seule la France - son époux fut guillotiné l'année suivante - et voyagea en Suisse, en Allemagne et en Angleterre où elle poursuivit son activité romanesque et pédagogique, vivant des droits d'auteur de ses ouvrages. À son retour à Paris en 1800 , Bonaparte mit à sa disposition un appartement à la bibliothèque de l'Arsenal dans lequel elle tint un salon réputé.

2 Les dernières années de sa vie sont loin de marquer la fin de sa production littéraire, comme en témoigne le sixième tome de ses mémoires où elle aborda, à près de soixante-quatorze ans, la rédaction d'un Essai sur les arts : " [j]'ai beaucoup travaillé à Villers dans ce dernier été [...]. J’y ai [...] fait un Essai sur les arts [...] écrit dans un livre relié, orné de vignettes et de culs-de-lampe » (GENLIS 1825, p. 143). "Ce qu'il y a de particulier à cet ouvrage, c'est que je l'ai fait non seulement sans aucun brouillon, mais sans aucune rature, puisque je l'ai écrit sur un livre blanc relié ; je voudrais, pour répondre à la confiance de $\mathrm{M}$. de Sommariva, qu'il fût un chef-d'œuvre " (GENLIS 1825, p. 186). Les circonstances de la création et de la fortune de cet essai sont bien connues et furent relatées dans les Mémoires de la comtesse, qui racontent que le livre fut donné en 1820 à Alfred Lemaire, son élève orphelin à qui elle enseignait la musique, pour qu'il puisse l'échanger contre une harpe. Proposé dans un premier temps au marchand de musique Errard qui l'accepta volontiers, l'Essai sur les arts fut - sur les conseils de $\mathrm{M}^{\text {me }}$ de Choiseul qui pensait que la comtesse pouvait en tirer un bénéfice plus grand encore - finalement acheté par le comte de Sommariva, amateur d'art. C'est à ce moment précis, au début de l'année 1820, que Genlis décida de l'accompagner d'un 
volume supplémentaire et personnalisé, dédié aux peintures du cabinet de ce collectionneur éclairé.

3 La retranscription de ces deux volumes (conservés à la bibliothèque municipale de Nancy,), inédits jusqu'ici, permet d'exhumer une autre facette de la personnalité de la comtesse qui était encore trop peu connue, car, outre ses activités de pédagogue, d'auteure et de musicienne, elle écrivit sur l'art et la théorie de l'art. Son Essai est d'ailleurs un ouvrage d'une audace rare et Genlis s'y révèle la seule femme auteure de cette époque à écrire une histoire de l'art telle qu'on l'entend aujourd'hui. L'Essai sur les arts s'approprie le récit chronologique et inscrit donc la production artistique dans le temps - de l'Antiquité à la période contemporaine - mais aussi dans l'espace, selon un classement par écoles régionales incluant évidemment les écoles italienne, française, flamande et allemande, et sans omettre, ce qui est plus rare, les écoles anglaise et espagnole. Un échantillon précis des préférences artistiques de l'auteure se retrouve justement dans le cabinet du comte de Sommariva où cohabitent peinture italienne (Barberi, L'Albane, Titien, Véronèse, Le Guide...) et école française contemporaine (David, Girodet, Prud'hon, Gérard, Drolling...). Le choix du dialogue scénarisé entre Alcime et Lydanie, qui puise dans les schémas de la critique d'art du XvIII siècle mettant en scène des personnages populaires, permettait à la comtesse, de manière détournée, de continuer à défendre avec sincérité les artistes qu'elle aimait, tout en valorisant avec bienveillance la collection de celui qui venait d'acheter son Essai sur les arts. À l'opposé de ce catalogue divertissant, l'Essai sur les arts démontre que son opposition idéologique aux Encyclopédistes ne s'était pas atténuée en 1820. Soutenant avec conviction des partis pris tranchés, elle se positionna vigoureusement contre les Réflexions critiques sur la poésie et sur la peinture de l'abbé Du Bos, ouvrage de théorie esthétique qui faisait alors autorité, en reprochant entre autres à ce dernier de n'aborder la peinture et la musique qu'en « littérateur ».

\section{BIBLIOGRAPHIE}

BESSIRE et REID 2008

François Bessire et Martine Reid (dir.), $M^{m e}$ de Genlis. Littérature et éducation, Mont-Saint-Aignan, Publications des universités de Rouen et du Havre, 2008.

BROGLIE 1985

Gabriel de Broglie, $M^{m e}$ de Genlis, Paris, Librairie académique Perrin, 1985.

DE POORTERE 2004

Machteld De Poortere, Les Idées philosophiques et littéraires de $M^{m e}$ de Staël et de $M^{m e}$ de Genlis, New York, Peter Lang, 2004.

GENLIS 1825

Félicité de GENLIS, Mémoires inédits de $M^{m e}$ la comtesse de Genlis, sur le dix-huitième siècle et la Révolution française, depuis 1756 à nos jours, t. VI, Paris, Ladvocat, 1825, p. 143. 
LABORDE 1966

Alice M. Laborde, L'Euvre de $M^{m e}$ de Genlis, Paris, Éditions A.-G. Nizet, 1966.

MAZZOCUT-MIS 2010

Maddalena Mazzocut-Mis, Corpo e voce della passione. L'estetica di Jean-Baptiste Du Bos, Milan, Edizioni Universitarie di Lettere Economia Diritto, 2010.

\section{ANNEXES}

Diaporama des œuvres commentées par Félicité de Genlis dans L'Essai sur les arts et le Catalogue pittoresque du cabinet de tableaux de Monsieur le comte de Sommariva :

http://www.flickr.com//photos/73632227@N02/sets/72157629663375768/

Lire les extraits de l'Essai sur les arts de Félicité de Genlis

Lire les extraits du Catalogue pittoresque du cabinet de tableaux de Monsieur le comte de Sommariva de Félicité de Genlis

Liste complète des œuvres d'arts commentées par Félicité de Genlis à travers ses textes édités dans Plumes et pinceaux 


\section{Stéphanie-Félicité Du Crest, Essai sur les arts, vers 1825}

[s. d.], Nancy, bibliothèque municipale, Ms 765, extraits choisis.

\section{«Sur les beaux-arts - Avertissement »}

1 L'abbé Du Bos a fait un livre sur ce sujet, mais il n'a parlé de la musique et de la peinture qu'en littérateur, et ce n'est point assez. D'ailleurs, il était contemporain et admirateur passionné de Lully, il n'a connu ni la musique nouvelle, ni même Rameau qui, le premier, a fait un excellent traité d'harmonie, fondé sur une grande découverte', et qui, enfin, a commencé en France une révolution dans la musique. Ainsi, il se trouve beaucoup d'erreurs et surtout un nombre infini d'omissions dans la longue dissertation de l'abbé Du Bos sur la musique. Néanmoins, il a fait sur ce sujet des recherches curieuses et, lorsque j'en ai profité, je le cite. En outre, j'ai fait un grand nombre de lectures dont ce livre contient les traits les plus intéressants. J'ai tâché de lui donner le mérite si rare de la concision, mais j'ose croire qu'on y trouvera quelques idées neuves, et tout ce que la culture des arts, de longs voyages, l'étude de l'Antiquité, de mûres réflexions, pouvaient y rassembler de nouveau, de piquant et d'agréable.

\section{«De la peinture »}

p. 50-62

On a prodigieusement disserté et disputé, surtout depuis cent cinquante ans, pour soutenir ou pour nier la prééminence des anciens peintres sur les modernes ; l'abbé Du Bos, qui n'a consacré dans son ouvrage qu'un très petit nombre de pages [à la peinture], ne dit presque rien sur cette matière et se borne à faire sur ce sujet quelques citations. On n'avait découvert de son temps ni Herculanum ni Pompéi, ni une foule d'autres monuments antiques qui nous ont donné à cet égard beaucoup de nouvelles lumières.

3 Je vais d'abord apporter quelques anecdotes curieuses sur les tableaux de l'Antiquité, et je [me] hasarderai [à] donner mon opinion sur la peinture de cette époque ; ensuite, je 
tâcherai d'expliquer (ce qu'on n'a jamais fait) pourquoi les Anciens ont excellé dans les espèces de peintures qu'on appelle improprement des arabesques, et après cette dissertation, je terminerai cet article par la peinture moderne.

\section{Timomaque de Byzance, Médée tue ses enfant}

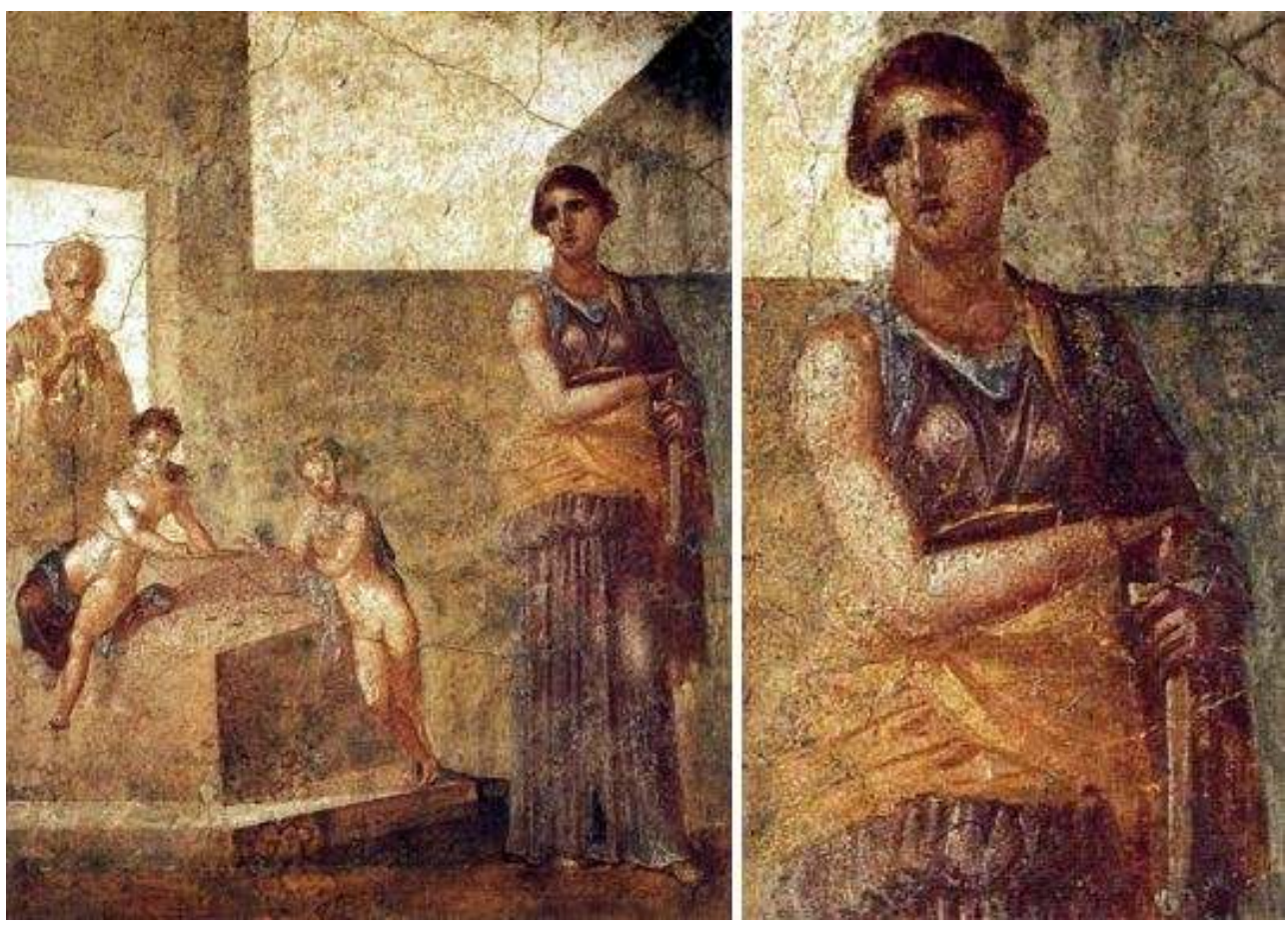

Entre 62 et 79 av. J.-C., fresque, 120 × 97 cm, Naples, Musée national archéologique.

4 La plupart des louanges que les auteurs anciens donnent aux tableaux dont ils parlent sont l'éloge de l'expression. C'est ainsi qu'Aurore vante la Médée de Timomaque, où Médée était représentée un poignard à la main et prête à immoler ses enfants endormis (fig. 1). On voyait, dit le poète, la rage, l'horreur et la compassion mêlées ensemble sur son visage, et à travers la fureur qui la dominait, on découvrait encore dans ses traits quelques traces de la tendresse maternelle.

Lucien décrit avec une vive admiration une grande composition qui représentait le mariage d'Alexandre et de Roxane et dans laquelle on voyait l'Amour jouant avec les armes d'Alexandre ${ }^{2}$. Ce beau tableau était de Zeuxis et porta bonheur au peintre : une jeune personne très riche, séduite par sa célébrité, l'épousa.

6 C'est dans Lucien que l'on trouve la description de ce tableau. 


\section{2. [Anonyme], Laocoon}

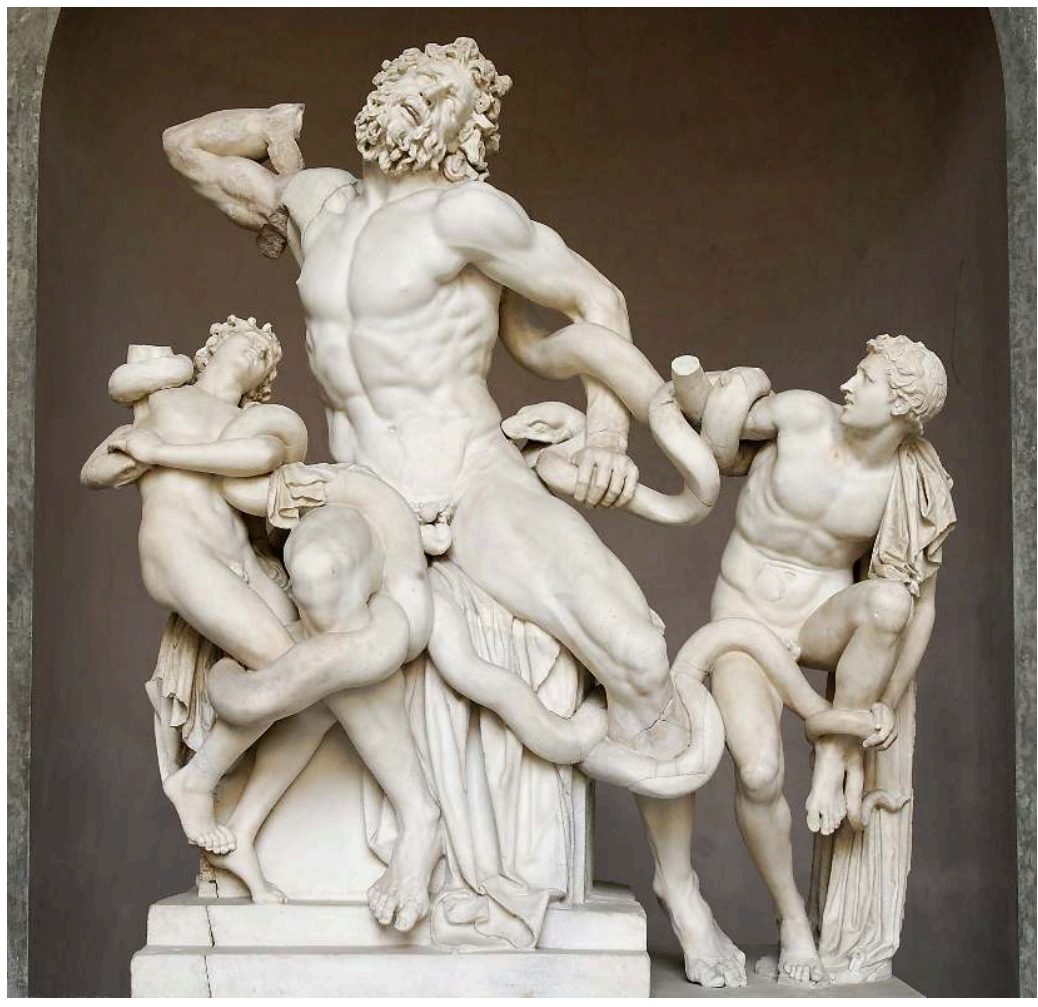

Ier siècle avant J.-C., marbre, 242 cm, cité du Vatican, musées du Vatican.

7 Un autre tableau aussi fameux que celui dont on vient de parler est celui qui représentait le sacrifice d'Iphigénie par le peintre nommé Timanthe, dans lequel l'artiste avait représenté Agamemnon se voilant le visage. MM. de Voltaire, Diderot, Marmontel et les autres se sont extasiés sur cette circonstance en disant que le peintre, sentant qu'il était impossible d'exprimer la douleur d'Agamemnon, avait pris le parti de mettre un voile sur sa tête. Tous ces beaux esprits qui n'avaient fait aucune étude de l'Antiquité et qui n'avaient aucune idée des arts ont répété à l'envi les uns des autres que cette idée du peintre grec était sublime et prouvait que l'artiste avait un génie prodigieux. Mais en supposant, ce qui n'est pas, que telle eût été son intention, il n'y aurait dans cette idée qu'un petit artifice spirituel et non du génie, car le génie, loin de chercher à éluder une grande difficulté, se plaît à la surmonter et il en triomphe. C'est ce qu'ont fait les grands artistes de l'Antiquité. Nulle douleur ne peut surpasser celle de Laocoon expirant avec ses enfants, étouffés par les serpents entortillés autour de leurs corps, et cependant le sculpteur n'a pas craint ce terrible sujet et il a su exprimer, et avec noblesse, ces affreuses douleurs physiques et morales (fig. 2).

J'ai dit que dans le tableau du Sacrifice d'Iphigénie, le peintre n'avait point eu l'idée que lui supposent Voltaire, Marmontel, etc. Et en effet, il ne représente Agamemnon se voilant le visage que pour se conformer à l'usage universellement établi qui ne permettait pas à un héros de montrer sa figure lorsqu'il éprouvait une vive souffrance ou lorsqu'il pleurait. C'est ainsi qu'Ulysse, chez Alkinoos, en écoutant le récit de ses propres aventures, se cache le visage, parce qu'il s'attendrit et qu'il sent qu'il va verser des larmes. C'est ainsi qu'EEdipe, conduit par Antigone, lorsqu'il touche à ses derniers moments, se couvre le visage avec un pan de sa robe. On pourrait citer mille exemples semblables ${ }^{3}$. C'est donc bien gratuitement que les encyclopédistes ont fait sur ce sujet 
comme sur mille autres tant de phrases portant à faux. Je ne puis ici passer sous silence un tableau fameux que personne n'a vu mais dont tout le monde loue avec enthousiasme l'idée, et uniquement à cause d'une inscription qui s'y trouve et qui néanmoins ne me paraît ni juste ni raisonnable, du moins telle qu'on la rapporte généralement: je veux parler des Bergers d'Arcadie de Poussin. C'est un paysage représentant le beau ciel de la Grèce et, dans un site charmant de l'Arcadie, une troupe de bergers dansant, tandis que deux ou trois réfléchissent tristement sur un tombeau qu'ils viennent d'apercevoir, et qui porte cette inscription :

«Et moi aussi j'ai vécu dans la délicieuse Arcadie !... »

«Et moi aussi » répond à l'action, à la dame qui exprime la joie et la gaieté, ce qui est tout à fait extravagant, car on n'a pu faire graver sur la tombe ces mots qui n'ont de sens que pour le moment actuel. Et si on retranche ces mots, l'épitaphe sera fort insipide.

10 Les Anciens ont souvent mêlé l'idée de la mort à celle des jeux; c'est eux qui ont représenté le vieil épicurien Anacréon sortant d'un festin et entrant dans un jardin en chantant et en chancelant, et, dans ce mouvement, laissant tomber sa couronne de roses $^{4}$ au pied d'un cyprès !... Cette idée vague et mélancolique offre un contraste frappant et ingénieux.

11 Il nous reste si peu de peintures des Anciens que l'on ne peut guère juger de leur talent en ce genre. Mais ils ont tellement excellé dans la sculpture et l'architecture que l'on ne peut pas croire que les peintres qui, parmi eux, ont joui d'une grande réputation, aient été des artistes médiocres. Ils n'ont peint qu'à fresque, mais le coloris de la fresque peut égaler la beauté de celui des peintures à l'huile, comme le prouve le superbe tableau de Raphaël appelé la Messe de Jules II, peint à fresque, et dont le coloris est admirable. On sait d'ailleurs que les Anciens faisaient tant de cas de cet art qu'ils payaient les tableaux des grands maitres un prix exorbitant.

12 Nous voyons, dit l'abbé Du Bos, dans les ouvrages de saint Augustin, qui mourut l'an quatre cent trente de l'ère chrétienne, que dès son temps, les théâtres commençaient à se fermer dans la plupart des villes de l'empire romain. L'inondation des barbares, qui se répandaient dans tout l'empire, était aux peuples des pays désolés le moyen de faire la dépense des spectacles. Cette dépense était immense : la représentation de trois tragédies de Sophocle coûta plus aux Athéniens que la guerre du Péloponnèse. On connaît les dépenses exorbitantes des Romains pour élever des théâtres, des amphithéâtres et des cirques, même dans les villes de provinces ; quelques-uns de ces bâtiments qui subsistent encore sont des monuments précieux d'une superbe architecture et la preuve de cette magnificence qui fut poussée jusqu'à la folie.

13 Les Romains eurent la même passion pour les spectacles. Macrobe dit qu'Ésope, célèbre comédien tragique et contemporain de Cicéron, laissa en mourant une succession de cinq millions qu'il avait amassés à jouer la comédie. Le comédien Roscius, ami de Cicéron $^{5}$, touchait des deniers publics neuf cents francs par jour, et cette somme était pour lui seul - il n'en partageait rien avec sa troupe. Macrobe dit encore que Jules César donna vingt mille écus ${ }^{6}$ à Laberius pour l'engager à jouer lui-même dans une pièce que ce poète avait composée.

14 Comme on l'a dit, les théâtres commençaient à se fermer du temps de saint Augustin ; néanmoins, ils n'étaient pas encore entièrement fermés près d'un siècle après; il est vraisemblable qu'ils ne le furent pour toujours que lorsque Rome eut été prise et ruinée par Totila ${ }^{7}$. Ce pillage de Rome fut plus cruel et plus terrible dans toutes ses 
circonstances que tous les précédents, puisqu'on vit après cet événement des dames patriciennes mendier à la porte de leurs propres maisons dont les barbares s'étaient rendus les maitres. Telle fut la véritable époque de l'anéantissement presque total des lettres et des arts: depuis longtemps les grands artistes, privés de récompenses et d'encouragement, avaient disparu, mais les arts eux-mêmes ne disparurent que dans ce temps.

\section{« Des arabesques »}

Les Anciens ont excellé dans ce genre, qui nous paraît très extravagant et qui ne l'était nullement pour eux. Les serpents, les sphinx, les chimères, les chevaux ailés et une infinité de monstres étaient pour les Grecs et pour les Romains des représentations religieuses. La mythologie est remplie d'êtres fabuleux et monstrueux, et comme les Grecs et les Romains mêlaient peu à peu à leur culte les cérémonies et des cultes des autres nations païennes, on joignit à leurs arabesques une grande quantité d'attributs et de figures tirés des hiéroglyphes égyptiens, qui ne sont eux-mêmes que des arabesques symboliques et mystérieuses. De là cet assemblage bizarre de monstres, d'armes, de flèches, de carquois, d'arcs, d'oiseaux, de plantes, parmi lesquelles se retrouve souvent le lotus, fameux par tant de fables indiennes et tant de fleurs représentant des métamorphoses ou des consécrations, tant de vases rappelant des traits mythologiques, comme par exemple celui dont Vénus fit don au beau Phaéton, celui qu'Amarius cassa, événement qui lui causa tant de douleur que les dieux par pitié le changèrent en marjolaine ${ }^{8}$, etc. On voit aussi dans ces arabesques un grand nombre de riches ornements et de draperies, qui sans doute représentent aussi des fables; les colliers d'or retracent la célèbre aventure et la trahison d'Ériphile, et les offrandes dont on ornait les statues des temples. Les draperies figurent les voiles qui jouent un si grand rôle dans la fable, ceux de la pudeur et celui de Pénélope qui se couvrit du sien pour toute réponse, lorsqu'Icarius son père lui demanda si elle aimait mieux suivre Ulysse qu'elle venait d'épouser que de rester avec lui ; le voile que la belle Harmonie reçut de Vénus, etc. Les perles étaient consacrées, ainsi que les roses, à la volupté. Les têtes de cerfs et d'autres animaux étaient des hommages de chasseurs rendus à Diane dans les bois qui étaient consacrés, ainsi que les hures de sangliers qui rappelaient aussi l'aventure de Méléagre. Comme toutes ces choses retraçaient des emblèmes et des faits miraculeux, les peintres ne s'attachaient qu'à donner de l'élégance à leur entrelacement, ils ne cherchaient jamais à y mettre de la vraisemblance, parce qu'ils voulaient que tout y parût merveilleux; c'est ainsi qu'ils ont peint des vases supportés par des fils de perles ou des guirlandes de fleurs, etc. Ils imaginèrent ce genre de peinture religieuse pour ne point placer toutes ces représentations dans les tableaux de figures, et c'est un bon goût dont on doit les louer.

D'après ces réflexions, ce genre est raisonnablement expliqué et il n'est pas étonnant que de grands artistes n'aient pas dédaigné ce genre de peinture consacré à la religion. On a trouvé de nos jours dans les fouilles de Pompéi des arabesques charmantes peintes sur les murs intérieurs d'une maison de campagne - on fait revivre les couleurs en jetant des seaux d'eau sur ces murailles. 

et de là ce nom est resté à toutes les compositions bizarres que l'on peut employer en ornement.

\section{«Des peintres modernes »}

p. 69-91

C'est à l'Italie que l'Europe doit la restauration de la peinture ; le Cimabue commença à la sortie de l'enfance où elle était tombée ${ }^{9}$; mais elle fit peu de progrès après lui, le Giotto qui vient longtemps après est le seul peintre célèbre de cette époque. La peinture ne prit un véritable éclat que sous le règne brillant de Léon $\mathrm{X}^{10}$, de la maison de Médicis, amateur éclairé des beaux-arts qu'il eut le temps de protéger avec succès, puisqu'il monta sur le trône pontifical à trente-sept ans ${ }^{11}$.

Les plus grands peintres italiens furent Michel-Ange, qui fut encore un sublime sculpteur et le plus grand architecte. On a peine à croire que le même homme ait fait Saint Michel terrassant le Diable, et tant d'autres tableaux, la statue admirable de Moïse descendant du mont Sinaï avec les tables de la Loi, et qu'il ait fait le plan et en grande partie l'église de Saint-Pierre de Rome et son incomparable et superbe coupole ${ }^{12}$.

\section{Raphaël, La Transfiguration}

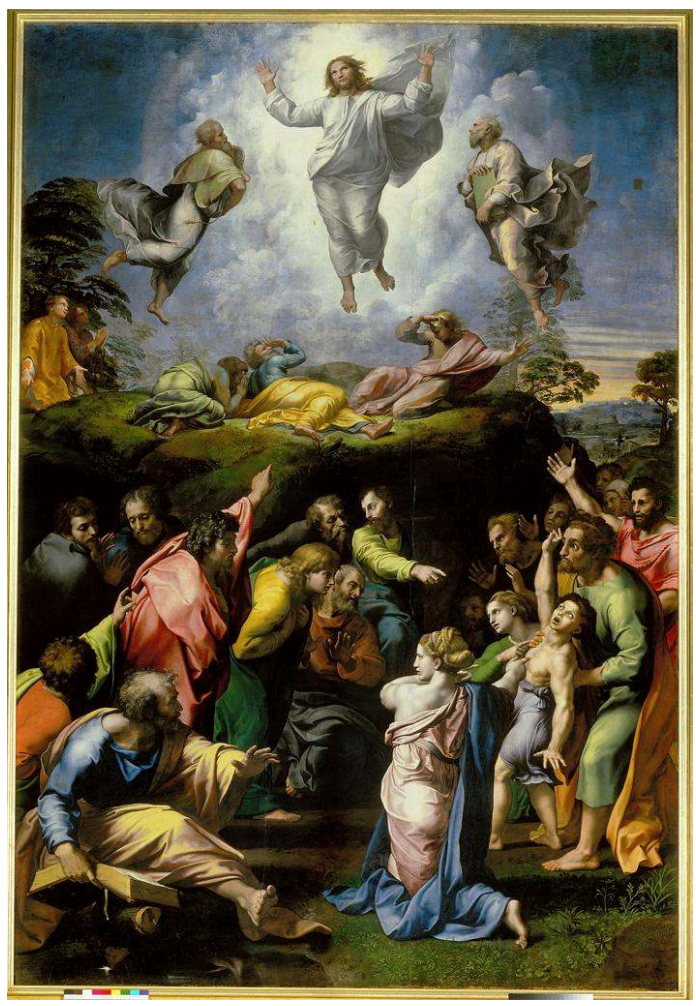

1516-1520, huile sur bois, 405 × 218 cm, cité du Vatican, musées du Vatican. 
4. Le Dominiquin, Communion de saint Jérôme

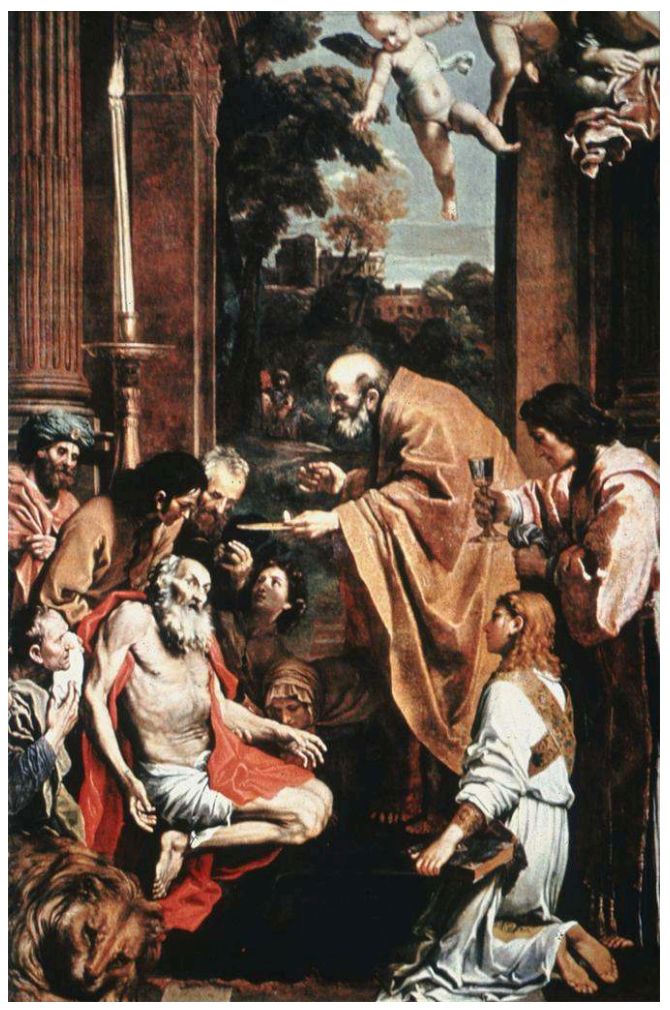

1614, huile sur toile, $419 \times 256$ cm, cité du Vatican, musées du Vatican.

21 Raphaël fut aussi peintre, sculpteur et architecte; son Jonas est une statue universellement admirée et l'on voit encore à Rome un beau palais bâti par lui. Aucun peintre n'a su donner à la Sainte Vierge un caractère plus noble, plus gracieux et plus divin, et une expression aussi pure et aussi touchante ; il fallait une sorte de révélation pour pouvoir représenter sur ces visages célestes le mélange - [il] doit s'y trouver - de noblesse royale et d'humilité, d'innocence, de candeur, de virginité, et d'amour maternel !... Le tableau de La Transfiguration de Raphaël est unanimement regardé comme le premier tableau de l'Europe (fig. 3). J'oserai pourtant hasarder une critique sur cet admirable ouvrage que je n'ai jamais entendu faire, mais qui me paraît sans réplique, parce qu'elle est de fait: le peintre a placé sur le devant du tableau, sur le premier plan, une figure de femme à genoux qui est certainement beaucoup trop grande, car si on la suppose debout, on voit qu'elle dépasse de la tête tous les autres personnages. Étant à Rome, je fis faire cette remarque à plusieurs grands artistes qui, tous, convinrent que j'avais raison. Après la mort de Raphaël, on rendit les plus grands honneurs à sa mémoire, on lui fit de magnifiques funérailles dont le plus glorieux ornement fut le tableau de La Transfiguration qu'on y porta en pompe. Ce tableau sans doute est d'une beauté supérieure, mais il n'est pas parfait et j'en connais deux qui le sont: Saint Pierre dans la prison pleurant son péché du Guide, et la Communion de saint Jérôme du Dominiquin (fig. 4). L'expression, le coloris, le dessin, la composition, tout est également parfait dans cette sublime peinture, dont il est bien surprenant que l'abbé $\mathrm{Du}$ Bos ne parle pas. Quelques personnes, par ignorance des usages anciens, ont fort mal à propos blâmé le peintre d'avoir fait recevoir le viatique à saint Jérôme dans l'église : disant qu'il n'est pas naturel qu'un moribond ne le reçoive pas dans son lit, et qu'à l'agonie il ait la force de se transporter à l'église ; cependant, on voit, dans toutes 
les vies des religieux, des ordres austères : les chartreux, les moines de Sept-Fons, ceux de la Trappe, tous ces religieux exaltés à l'heure de la mort qui se ranimaient miraculeusement lorsqu'on leur annonçait qu'ils n'avaient plus que quelques instants à vivre et qui, fortifiés soudainement par le ravissement de voir finir leur exil sur la Terre, tous, reprenant la force et le mouvement, sortaient aussitôt de leurs lits et se rendaient à l'église sans qu'il fût nécessaire de les y transporter, s'emparant ainsi de l'Éternité avant le moment fixé par la nature pour y entrer. Le Corrège ${ }^{13}$, contemporain de Raphaël, est aussi un admirable talent. Il découvrit lui-même son talent en voyant pour la première fois un tableau de Raphaël ; après l'avoir attentivement examiné, il vit qu'il connaissait aussi tous les artifices de l'art de peindre et il dit : « Et moi aussi je suis peintre. » Il était encore absolument inconnu.

\section{Le Corrège, La Vierge, l'Enfant Jésus, la Madeleine, saint Jérôme [Madone de saint Jérôme ou Le} Jour]

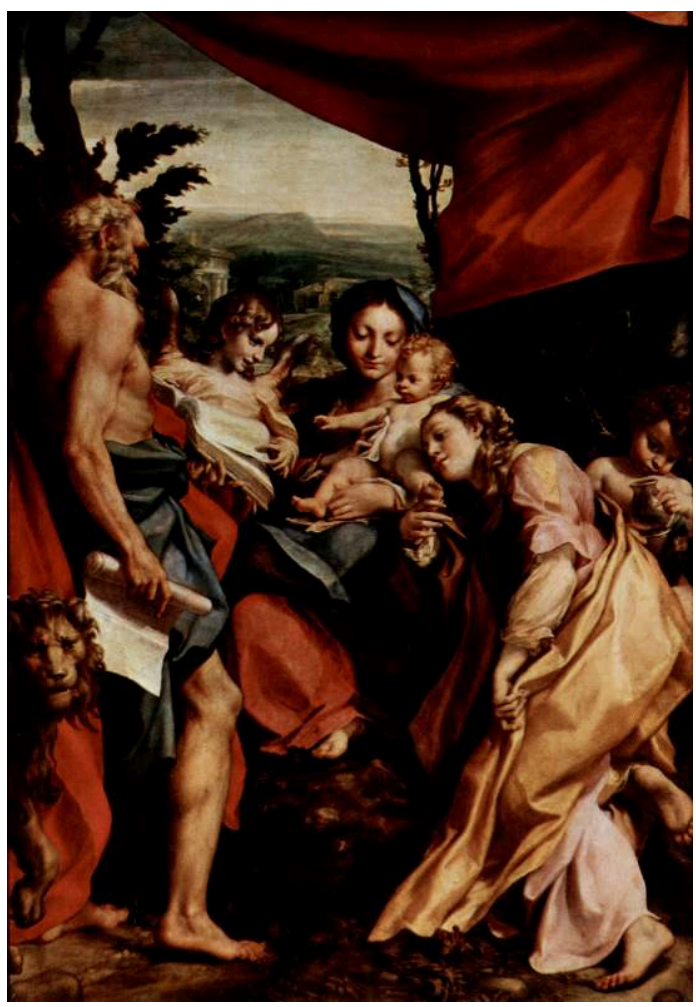

1525-1528, huile sur bois, 235 x $141 \mathrm{~cm}$, Parme, Galerie nationale. 


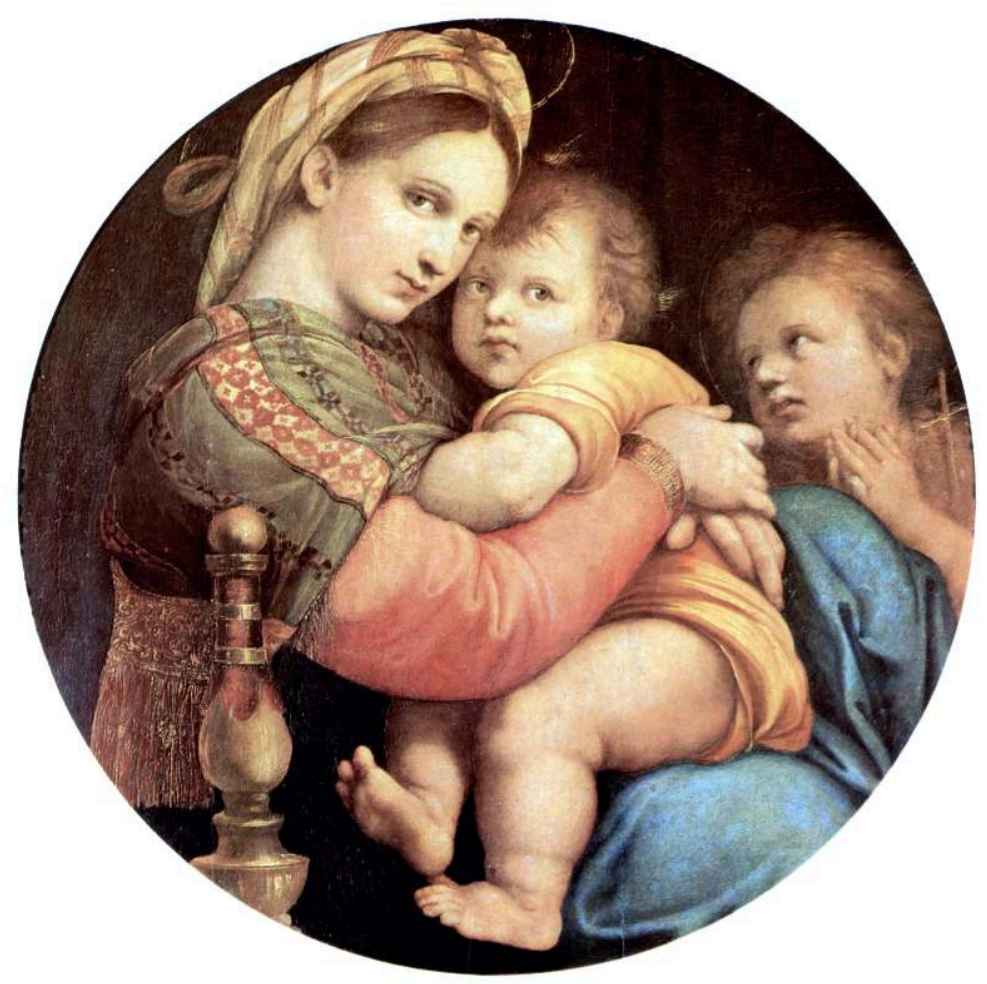

1513-1514, huile sur panneau, diamètre 71 cm, Florence, palais Pitti.

22 Le Corrège fut, dit-on, le premier qui osa dans les plafonds mettre des figures véritablement en l'air et qui plafonnent comme disent les peintres; jusqu'à lui, on avait peint ces figures comme si elles eussent dû tapisser des murailles. Le Corrège, ayant découvert cette règle d'optique, la mit en usage dans l'Assomption de la Vierge, qu'il peignit dans la coupole de la cathédrale de Parme, et dans l'Ascension de Jésus-Christ qu'il peignit dans la coupole de l'abbaye de Saint-Jean de la même ville. Son plus beau tableau représentant la Vierge, l'Enfant Jésus, la Madeleine, saint Jérôme, etc. (fig. 5). Le Palais-Royal ${ }^{14}$ possédait un chef-d'œuvre du Corrège représentant un amour adolescent, formant un arc. On ne sait ce que ce beau tableau est devenu. On voyait aussi dans le même palais deux chefs-d'œuvre de Raphaël, La Vierge et l'Enfant Jésus embrassant le petit saint Jean-Baptiste, tableau appelé La Vierge à la Sedia (à la chaise ${ }^{15}$ ) (fig. 6), et le tableau admirable représentant saint Jean dans le désert.

Raphaël fit une grande fortune ; Le Corrège vendit mal ses tableaux et mourut pauvre.

Le Guide s'est placé au rang de ces grands peintres; on lui reprocha d'avoir fait quelquefois les têtes de ses figures trop plates et un coloris trop gris, mais aucun de ces défauts ne se trouve dans son magnifique tableau de saint Pierre en prison pleurant son péché $^{16}$. Enfin Titien, Jules Romain, les Carrache, Daniel Volterra, le Dominiquin, Solimène, Pierre de Cortone, Léonard de Vinci, Paul et Alexandre Véronèse, l'Albane ${ }^{17}$, etc. furent des peintres immortels, ainsi que ceux qu'on a déjà nommés. J'avoue qu'il me semble que l'Albane est au-dessous de sa réputation; en général ses compositions me paraissent monotones et un peu fades. Il faudrait une grâce enchanteresse et beaucoup d'imagination pour être toujours supérieur en donnant un grand nombre d'ouvrages et en se bornant au seul genre gracieux; il est si difficile alors d'éviter 
l'insipidité ; la puérilité et même l'afféterie: si la simplicité n'est pas sublime, ou du moins attrayante, elle est ennuyeuse.

\section{Jacques-Louis David, Le Serment des Horaces}

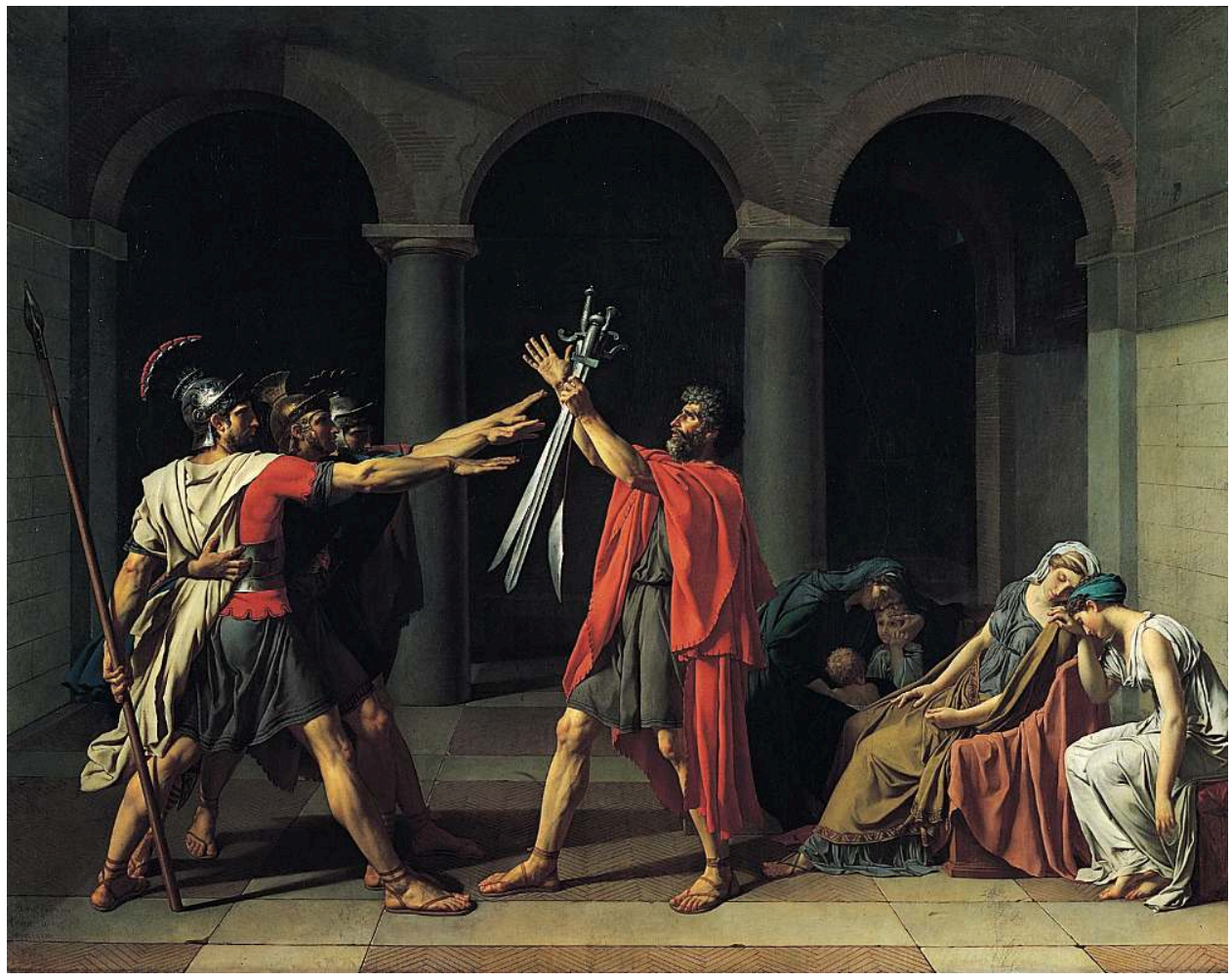

1784, huile sur toile, $330 \times 425$ cm, Paris, musée du Louvre.

\section{Jacques-Louis David, La Mort de Socrate}

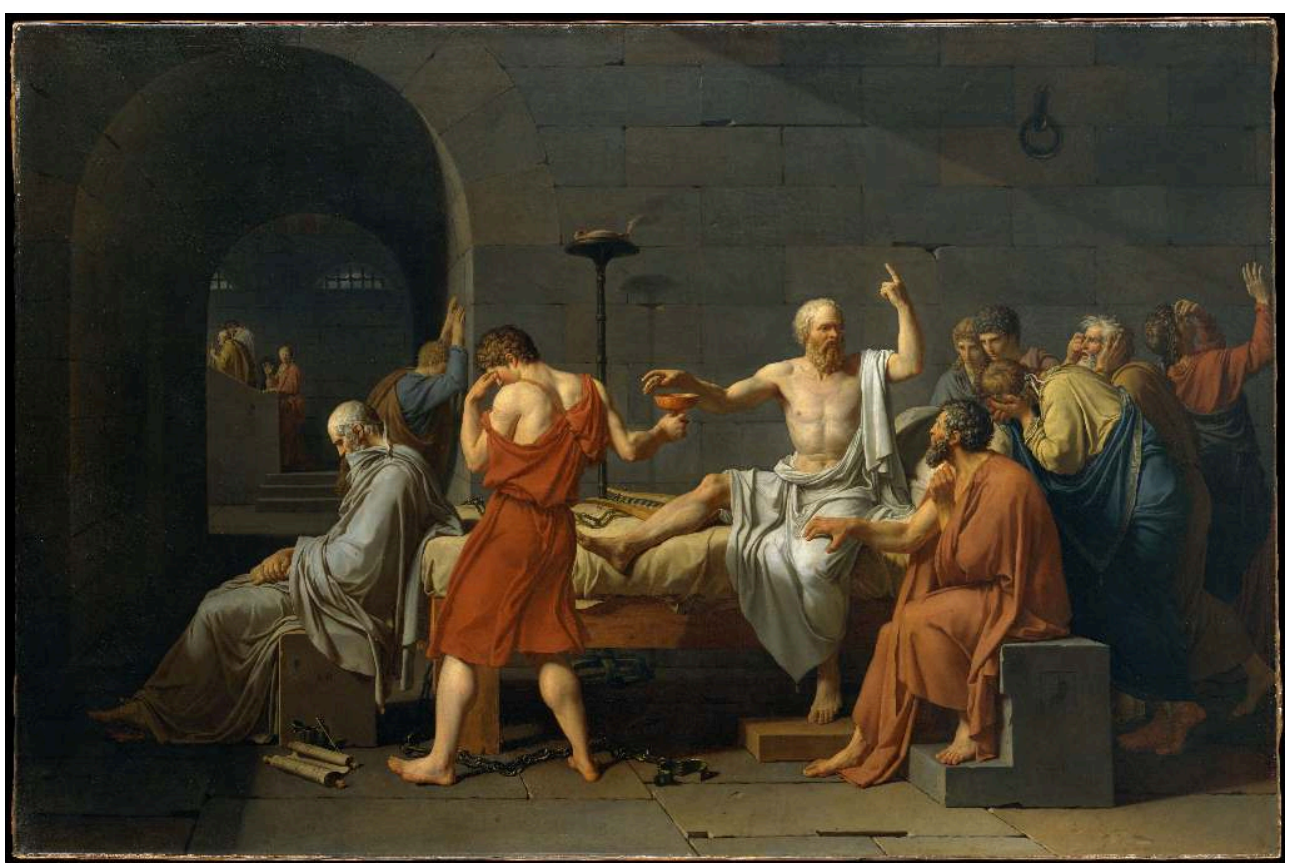

1789, huile sur toile, 323 × 422 cm, New York, The Metropolitan Museum of Art. 
Voici les plus beaux tableaux de ces grands maîtres qui enrichissaient la collection du Palais-Royal, outre ceux dont on a parlé : La Descente de Croix, figures demi-nature d'Annibal Carrache, tableau sans prix ; Notre Seigneur dans le Temple au milieu des docteurs de la Loi de Jules Romain; L'Apparition des anges à Abraham d'Alexandre Véronèse; L'Enfant Jésus endormi sur une croix du Guide; La Gardeuse de cassette, ou la Femme à la cassette de Titien ${ }^{18}$; Léda et le cygne de Paul Véronèse, etc. Les plus éminents peintres français sous Louis XIV ont été Poussin, Le Sueur ${ }^{19}$, Champaigne - nul peintre n'a fait mieux les divines figures de Christ et il est remarquable aussi par la beauté de ses fonds de tableaux ; Le Brun, Mignard ; pour le portrait : Rigaud ; pour la miniature en émail : Petitot (qui n'a point été égalé) ; pour les fleurs : Baptiste. Les peintres du XVIII siècle n'ont point surpassé ceux-là : Boucher, fort à la mode pendant quelque temps, gâta l'école française que releva Vien, peintre froid, mais qui avait du goût et qui fit de bons élèves; David appartient au siècle dernier ainsi qu'à celui-ci et d'autant plus que c'est dans ce siècle qu'il a fait ses plus beaux tableaux : Le Serment des Horaces (fig. 7) et la Mort de Socrate $e^{20}$ (fig. 8) ; Vernet a excellé dans les marines; et aujourd'hui, Horace Vernet soutient dignement ce nom si célèbre dans l'art de la peinture, et Girodet, Guérin ${ }^{21}$, Gérard, soutiennent avec éclat la gloire de l'école française, qui depuis cent ans l'emporte incontestablement sur l'école italienne.

Nous avons plusieurs paysagistes excellents. Pour la miniature, Isabey, Augustin et quelques autres montrent un talent supérieur ; Vandal, Redouté et Van Spaendonck en ont un très grand pour les fleurs, mais il serait à désirer que ce dernier mît plus d'esprit et de variété dans ses compositions; Madame la marquise de Grollier a atteint la perfection de ce genre par le fini, la fraîcheur de ses tableaux, et par les ingénieuses compositions qui les animent. Je ne dois pas oublier dans cette nomenclature l'aimable artiste qui a contribué aussi à la gloire de notre école, $\mathrm{M}^{\mathrm{me}}$ Vigée-Lebrun. Nulle femme dans ce siècle et dans le précédent n'a montré parmi nous un talent aussi distingué et aussi charmant. 
9. Jean-Baptiste Greuze, Petite fille pleurant son serin [Petite fille pleurant son oiseau mort ou L'Oiseau mort]

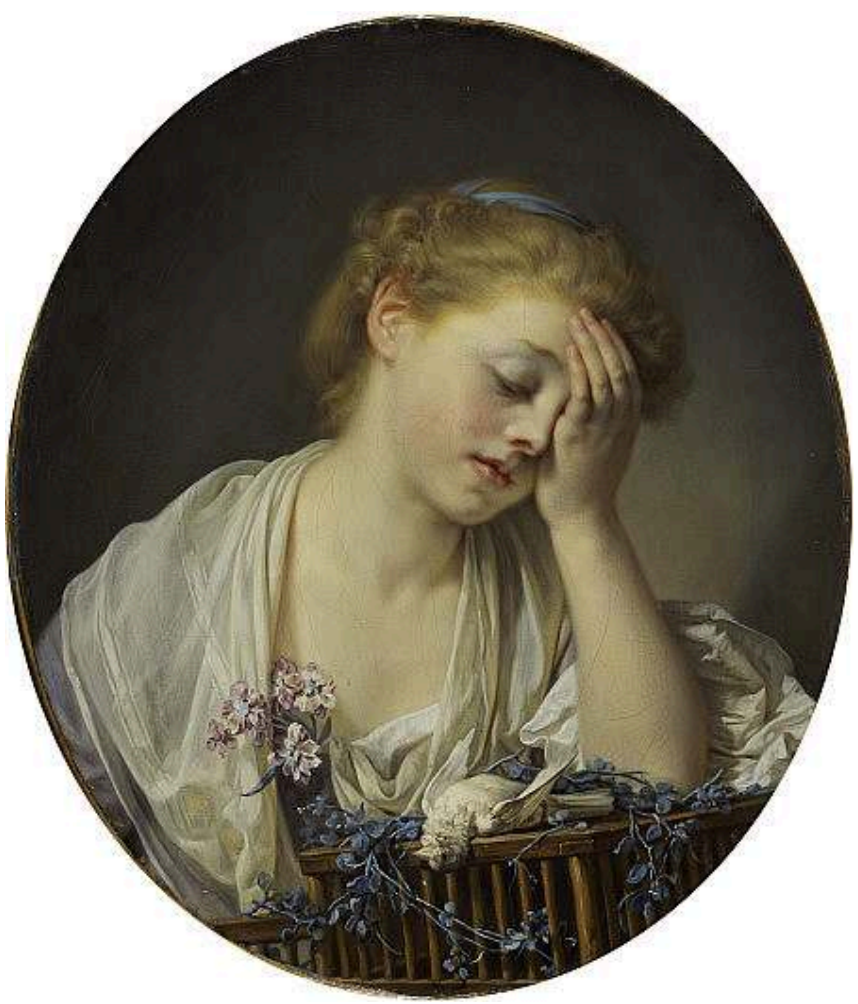

1765, huile sur toile, 52 × 45,6 cm, Édimbourg, National Galleries of Scotland.

10. Jean-Baptiste Greuze, La Noce de village [L'Accordée de village]

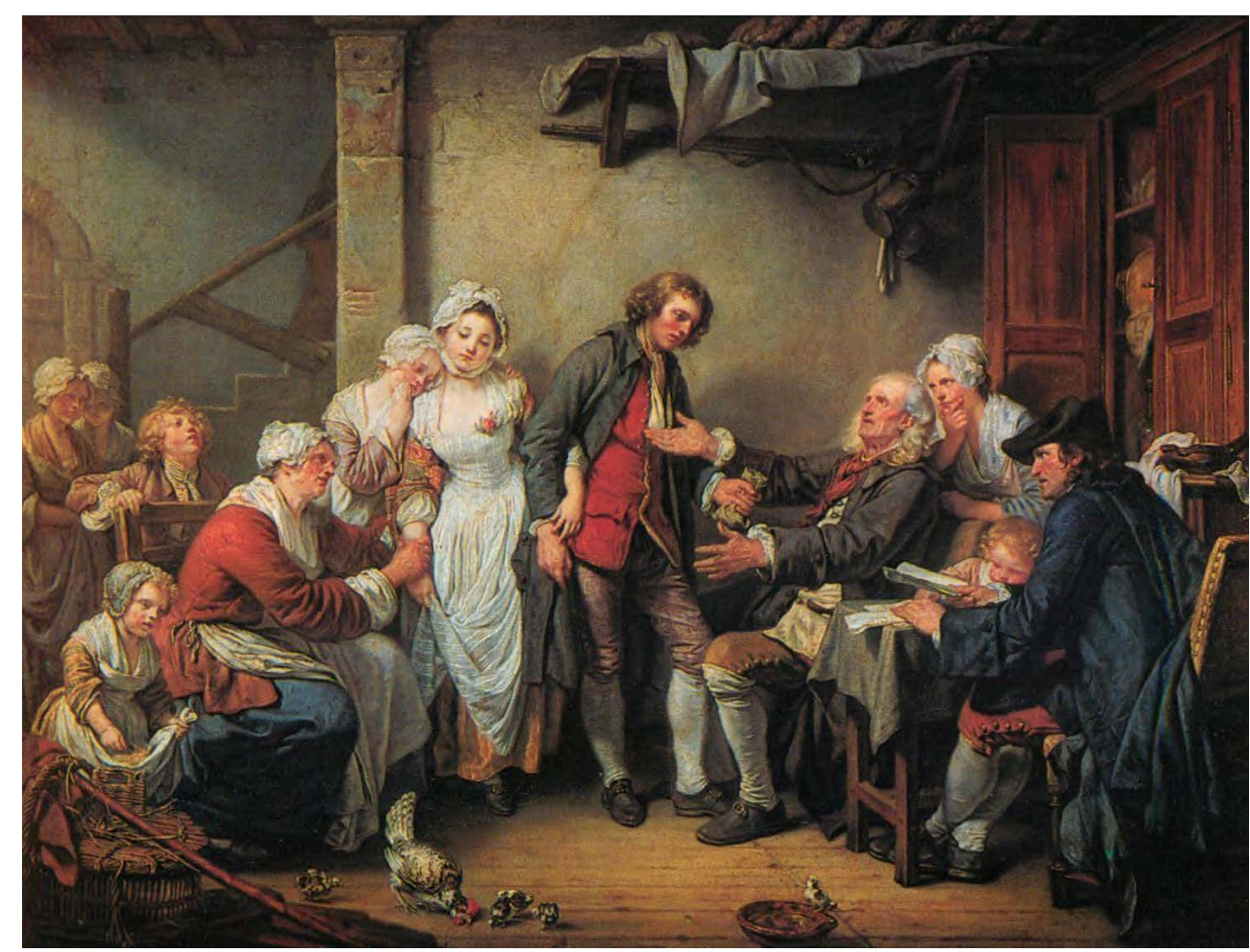

Salon de 1761, huile sur toile, $92 \times 117$ cm, Paris, musée du Louvre. 


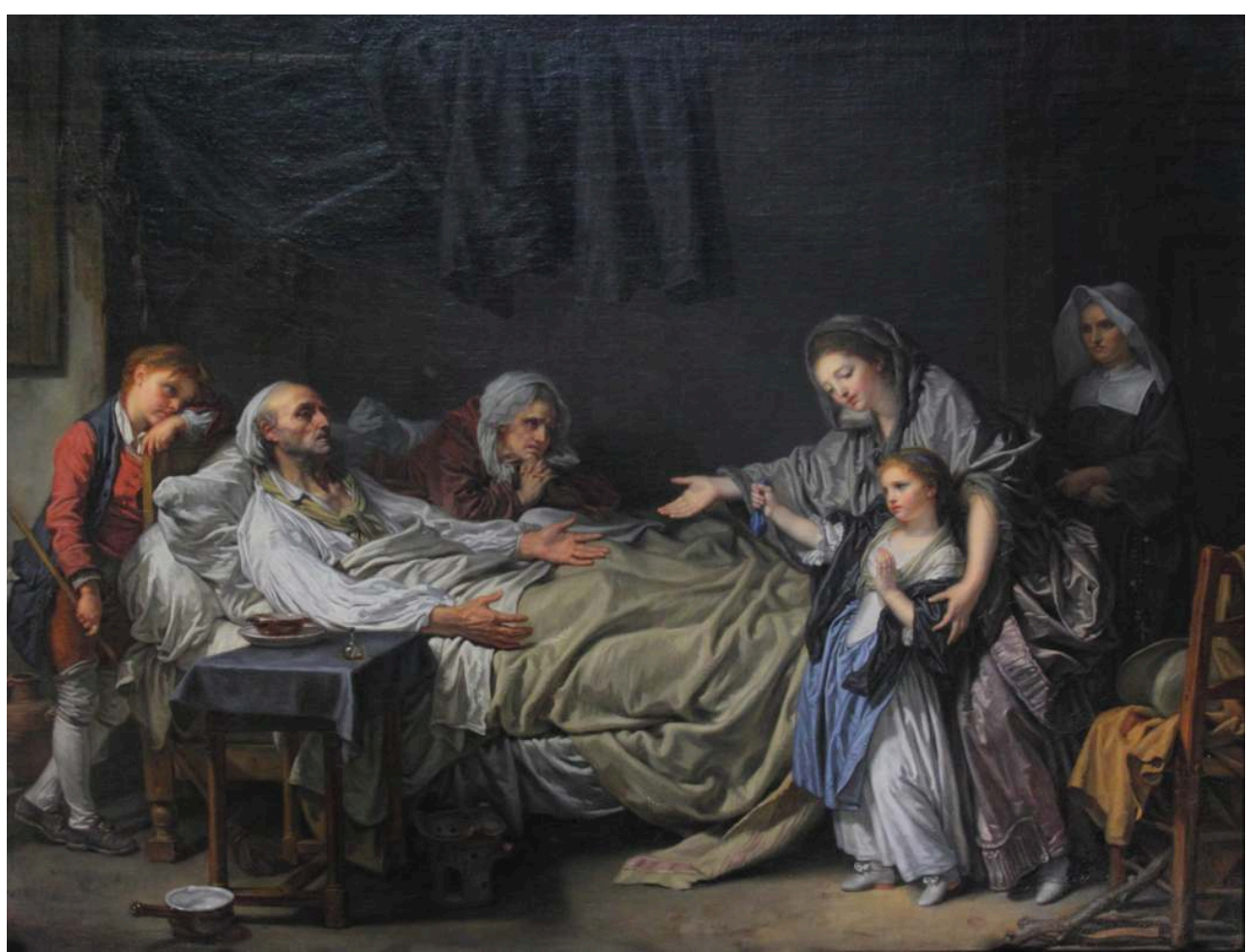

Vers 1772-1775, huile sur toile, 112 x 146 cm, Lyon, musée des Beaux-Arts.

En peintres de genre, nous n'en avons jamais eu d'aussi ingénieux et d'aussi spirituel que Greuze : La Petite Fille pleurant la mort de son serin (fig. 9) ; La Noce de village (fig. 10); La Dame de charité (fig. 11); La Malédiction du père de famille, etc. ne laisseront jamais périr son nom. C'est une idée de génie de n'avoir pas choisi le moment affreux de cette action terrible et d'avoir préféré l'instant où le malheureux père venant de donner sa malédiction se repent et tend les bras à son fils épouvanté qui voulait fuir et que retiennent sa mère et sa sœur, tandis qu'une autre sœur à genoux devant le père implore son pardon. Toute cette composition est d'une grande beauté.

Greuze est mort dans la misère et c'est une des taches du règne impérial. Je dois mettre au rang des plus grands paysagistes de nos jours mon élève feu Monsieur le duc de Montpensier, l'un des frères de Monsieur le duc de Chartres ${ }^{22}$. Ce jeune prince qui fut confié à sept ans, moins quelques mois, à mes soins montre dès son enfance des dispositions extraordinaires pour le dessin, et je ne négligeai rien pour les développer; ses progrès furent si rapides qu'à treize ans il copia à la gouache le Martyre de sainte Apolline du Guide (figures en demi-nature) et avec une telle perfection que M. David en fut étonné et jugea ce tableau digne d'être mis au Salon - mais comme je connais l'incrédulité du public sur les talents des princes, je ne le voulus pas. Ce jeune prince qui avait véritablement un goût passionné pour la peinture perfectionna tellement ce talent qu'il parvint à le rendre supérieur avant la fin de son éducation qui fut terminée à dix-huit ans. Depuis notre séparation, il se fixa au genre de paysages à l'huile, mais avec des figures, qui furent dans ses tableaux aussi belles que celles de Polembourg et de Poussin. Émigré en Amérique, il y passa tout son temps à aller chercher des sites inconnus et pittoresques; il passa mille fois des matinées entières, enfoncé dans des 
marais et dans des eaux croupissantes, restant là immobile dans la vase jusqu'aux genoux et souvent jusqu'aux hanches pour dessiner des vues qui lui plaisaient. Il porta ensuite à Londres des tableaux, des dessins et des ébauches d'un prix inestimable, mais ces études et ce travail périlleux détruisirent sans retour sa santé. La preuve de la supériorité de son talent, c'est qu'il se fit un superbe cabinet de tableaux sans en acheter un seul : il les troquait contre les siens sans donner de retour : il eut ainsi des Poussin, des Claude Lorrain, des Rubens, etc. et de toutes les écoles; ce prince si intéressant par ses talents, son esprit, ses vertus, eût mérité un meilleur sort !...

\section{Gérard Dou, La Femme hydropique [La Femme hydropique ou Docteur examinant les urines d'une} femme]

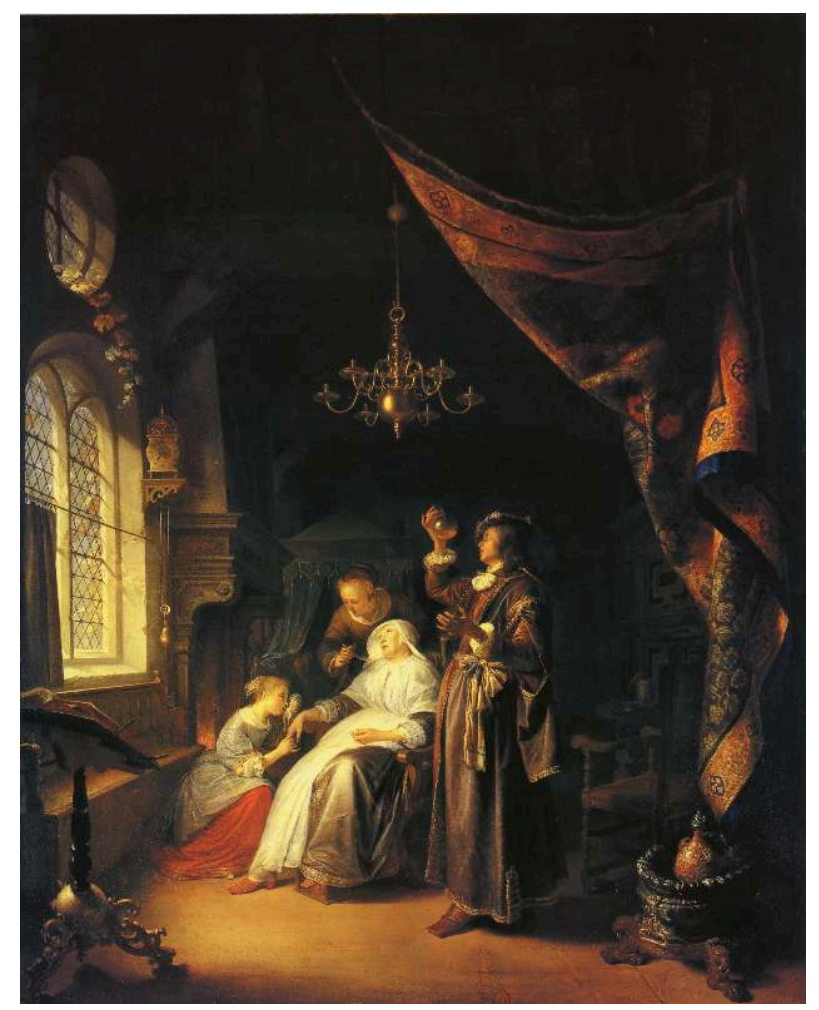

1663, huile sur bois, 83 x 67 cm, Paris, musée du Louvre. 


\section{Pierre-Paul Rubens, Jugement dernier [Le Grand Jugement dernier]}

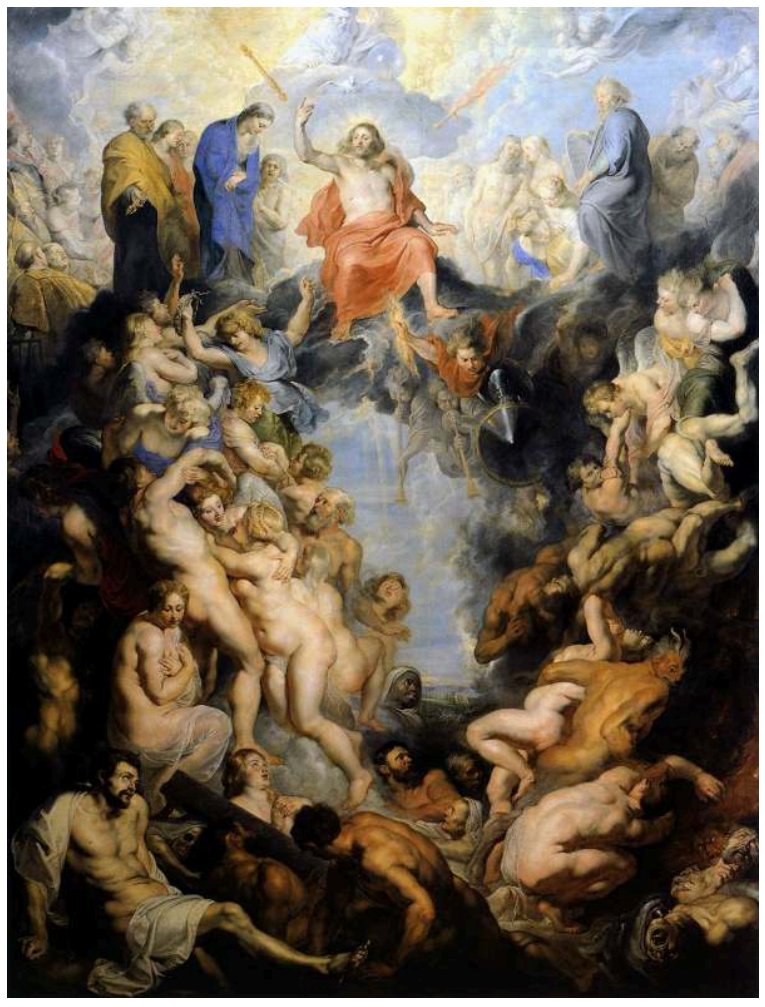

1615-1616, huile sur bois, 604 × 474 cm, Munich, Alte Pinakothek.

\section{Pierre-Paul Rubens, La Descente de Croix}

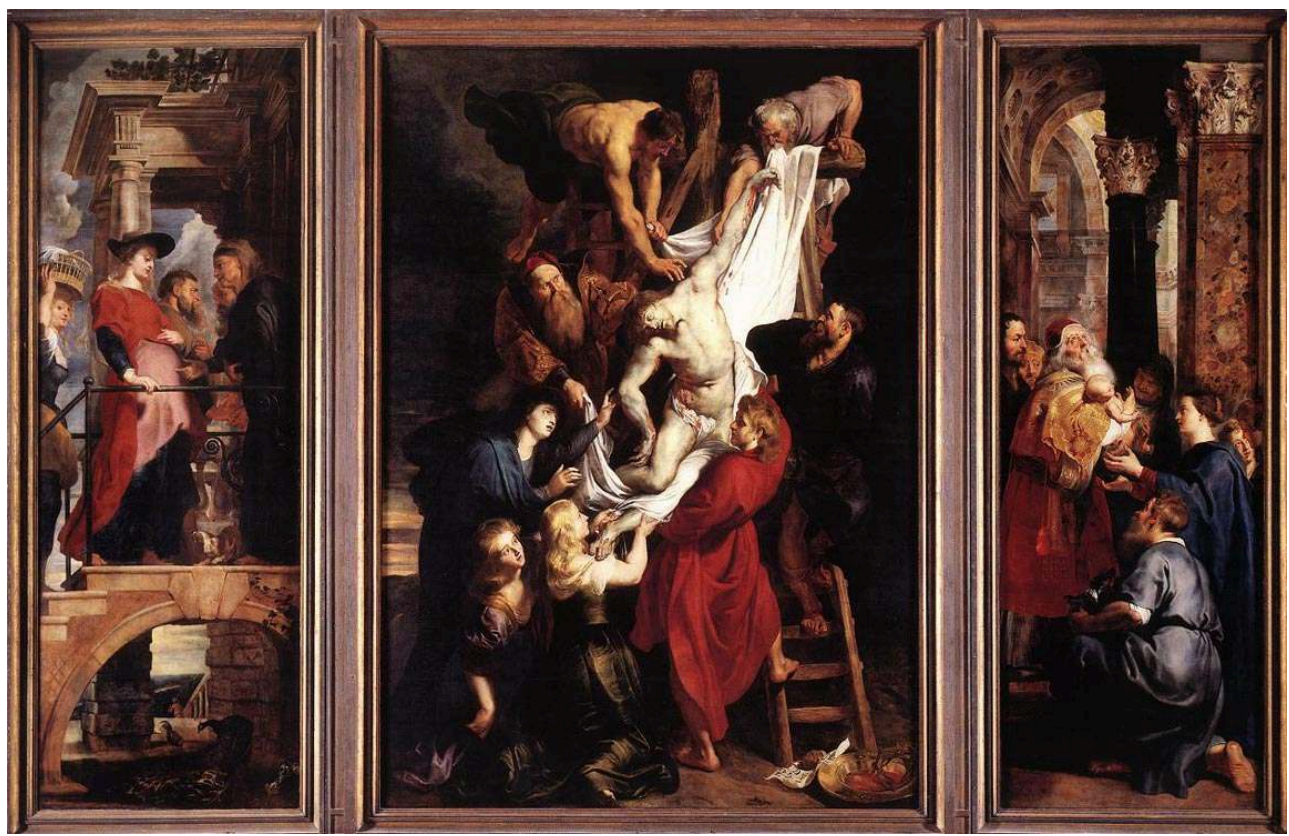

1611-1614, huile sur bois, triptyque, panneau central, 420 × $310 \mathrm{~cm}$, panneaux latéraux, $420 \times 150 \mathrm{~cm}$ chacun, Anvers, cathédrale Notre- Dame.

On sait que l'école flamande a produit une grande quantité de peintres de genre. Teniers, si facile à reconnaître par le ton gris et argenté de ses tableaux; Gérard Dou, 
admirable par le fini des détails : La Femme hydropique, de la collection de Turin, est son plus beau tableau (fig. 12) ; Metsu dont le tableau le plus vrai et le mieux peint est dans la galerie de Düsseldorf et représente une veille des rois ${ }^{23}$, etc. Mais les artistes qui ont véritablement illustré cette école sont Rubens, le premier de tous. Son Jugement dernier (fig. 13), tableau immense de la galerie de Düsseldorf, La Descente de croix d'Anvers (fig. 14).

\section{Pierre-Paul Rubens, L'Accouchement de Marie de Médicis [La Naissance de Louis XIII]}

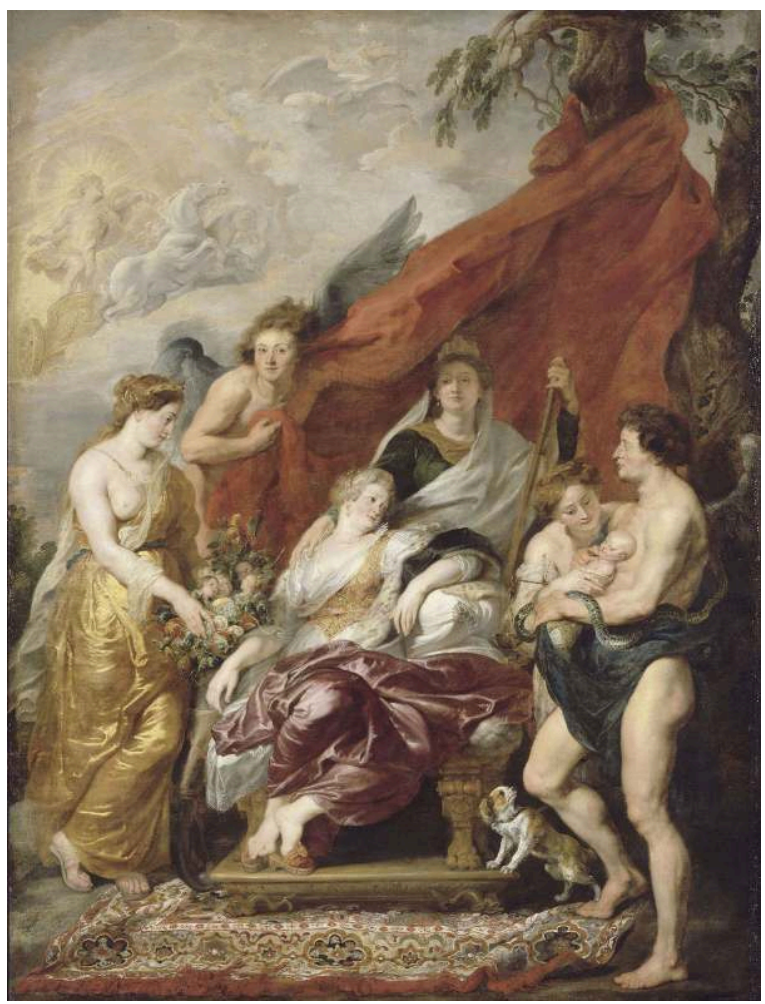

Vers 1622-1625, huile sur toile, 394 × 295 cm, Paris, musée du Louvre

La galerie du Luxembourg à Paris suffirait pour l'immortaliser. C'est là qu'on voit le fameux tableau représentant L'Accouchement de Marie de Médicis (fig. 15); on admire sur le visage de cette princesse deux expressions très distinctes: le reste des douleurs de l'enfantement et la joie maternelle que lui inspire la vue de son enfant. Rubens se distingue surtout par la beauté de la couleur et par l'expression. Il y a encore de lui à Florence au palais Pitti un tableau admirable, dont le sujet est l'entrée d'Henri IV à Paris. Il est composé avec un esprit infini : tous les détails en sont charmants, tous se rapportent à Henri IV et servent à sa gloire. Par exemple, dans un coin du tableau, le peintre a placé une jeune fille du peuple qui reconnaît avec ravissement son amant dans un jeune soldat de la suite de Henri ; tandis que ces deux amants se font des signes mutuels, une vieille femme, tante ou grand-mère de la jeune fille, la tire rudement en lui montrant le roi, et l'on croit entendre cette femme lui dire: « Eh, laisse là ton amourette et regarde notre bon roi ! »... Monseigneur Gérard, en traitant le même sujet, n'a pas eu une idée aussi heureuse lorsqu'il a représenté le duc de Bellegarde saluant d'un air d'intelligence la belle Gabrielle qui est à une fenêtre, ce qui jette une sorte de ridicule sur Henri IV. Le tableau de Rubens est de la plus grande dimension et d'une beauté supérieure, il est pour nous éminemment national - cependant les Français 
victorieux en Italie et qui en ont rapporté tant de dépouilles y laissèrent ce superbe tableau! J'ai toujours pensé que des ordres supérieurs les avaient empêchés de s'en emparer ; on ne se souciait pas de reproduire Henri le Grand entrant à Paris.

Après les peintres flamands dont on vient de parler, on peut citer encore Schalken, si célèbre par les effets produits par les lumières dans la nuit, quoique cependant à mon avis son ton de couleur dans ces effets soit trop rouge; Cuyp dont nous avons vu au Salon avant la Révolution Le Baptême de l'eunuque de la reine Candace. L'artiste a placé la scène en plein midi, dans un beau site, sans le secours d'aucune opposition d'ombre, cet effet hardi est superbe. Ce tableau paraissait être une fenêtre ouverte éclairant le Salon; on croyait sentir l'ardeur de ce soleil éblouissant. Ce tableau fut acheté dix-sept mille francs. Du temps de l'abbé Du Bos, Quellin était le dernier élève de l'école d'Anvers fondée par Rubens, école tout à fait tombée à cette époque.

\section{Joshua Sir Reynolds, Miss Sydons [Mrs Siddons en muse tragique]}

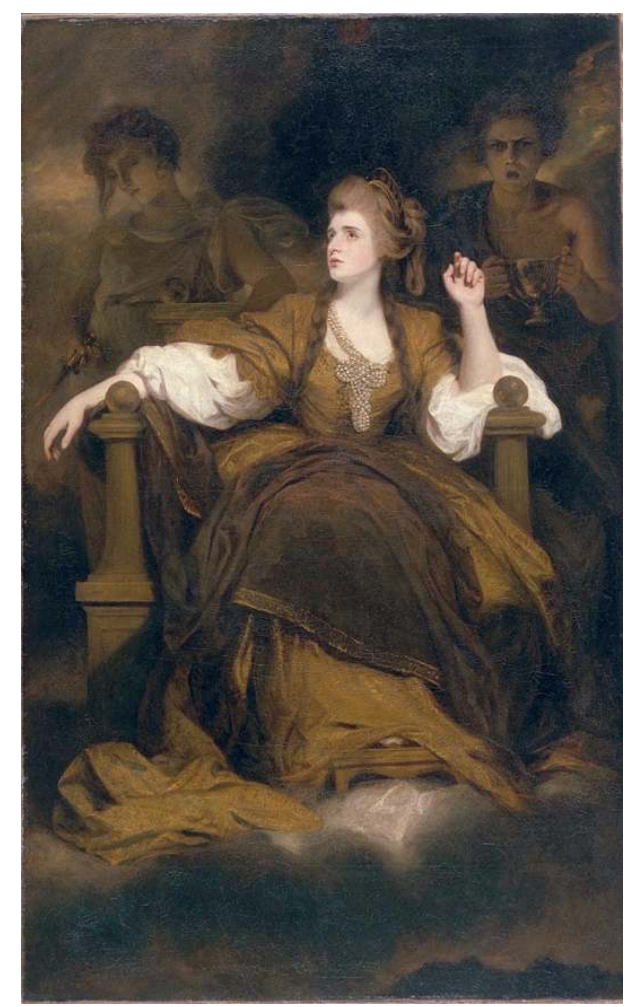

1784, huile sur toile, 236 x 146 cm, California, San Marino, Huntington Library and Art Gallery.

Il est sorti de l'école d'Espagne de très grands peintres, entre autres Murillo, celui de tous les peintres, sans exception, dont le pinceau inimitable est le plus moelleux, le plus suave et le plus séduisant. L'Angleterre a fourni un bien petit nombre de bons artistes, les meilleurs de nos jours sont West, mais qui pèche par le coloris, Angelika Kauffmann, dont les idées sont toujours ingénieuses. Voulant peindre La Dernière Pensée de Virgile, elle le représenta mourant dans les bras de sa muse éplorée, il tient d'une main des tablettes sur lesquelles il trace une ligne, et de l'autre main il tient sa lyre, dont toutes les cordes sont rompues, à l'exception d'une seule !... C'était elle encore qui, pour offrir dans deux tableaux l'expression de la vraie douleur et celle d'une douleur affectée, a représenté, dans l'un, Cléopâtre ornant fastueusement d'une guirlande de fleurs le tombeau d'Antoine, et dans l'autre, Andromaque dans l'attitude d'un profond 
accablement appuyée sur la tombe d'Hector. On a fait deux gravures charmantes de ces tableaux. Reynolds, peintre de portraits : le plus beau de tous est celui de la célèbre actrice miss Sydons (fig. 16) ; Romney, qui est aussi un excellent peintre de portrait. L'Allemagne a produit plusieurs grands peintres. Le plus justement célèbre est Mengs, né en Saxe, l'un de ses plus beaux ouvrages est à Rome, le plafond du cabinet des manuscrits au Vatican. Mengs a écrit d'excellentes choses sur son art, il serait à désirer que tous les peintres supérieurs en fissent autant.

De Piles, grand amateur de peinture sur la fin du règne de Louis XIV, a fait plusieurs ouvrages sur l'art de la peinture. Celui qui est intitulé La Balance des peintres, dans lequel il pèse et apprécie en les comparant leurs divers talents, est très estimé, quoique cependant sa balance ne soit pas toujours exacte ${ }^{24}$.

Monseigneur Le Mière, l'auteur tragique, a fait un poème en vers sur la peinture, qui contient de beaux vers. L'auteur comme poète a souvent de la verve, mais comme artiste, il ne dit que des lieux communs. Monseigneur Watelet a fait aussi un poème en vers sur la peinture, l'ouvrage à quelques égards n'est pas sans mérite, mais il est froid et peu instructif.

\section{« De la sculpture et de l'architecture »}

J'ai parlé avec détail de la sculpture antique et moderne, dans les Annales de la vertu; j'ajouterai ici seulement quelques traits sur ce sujet qui ne se trouvent point dans cet ouvrage.

Tous les auteurs du Iv ${ }^{\mathrm{e}}$ siècle disent qu'il y avait à Rome plus de statues que d'hommes vivants. Les plus belles statues de la Grèce qui ont tant d'éclat dans nos collections étaient de ce nombre, Rome les avait conquises en ravageant et subjuguant l'univers. Ainsi, dans l'Antiquité, le nombre des grands sculpteurs a été prodigieux. La plupart des sculpteurs romains, dit l'abbé Du Bos, faisaient leur apprentissage dans l'état d'esclaves; les marchands dont la profession était le négoce d'esclaves examinaient avec soin si parmi les enfants qu'ils élevaient pour les vendre il s'en trouvait qui fussent propres à devenir sculpteurs, et ceux qui annonçaient des dispositions pour cet art si en vogue alors recevaient l'éducation qui pouvait le mieux développer leur talent en ce genre. Un esclave devenant un bon artiste était un trésor pour son maître, soit que ce dernier voulût vendre les ouvrages en la personne de cet esclave, qui, assuré d'obtenir sa liberté après quelques années de travail, se livrait avec ardeur à l'étude : nous avons encore dans nos apprentissages des traces de cette espèce de servitude, car les apprentis s'engagent à travailler pendant un certain nombre d'années, non pour leur compte mais au profit de leur maître.

Il est triste, en principe, qu'un homme vende sa personne à un autre homme, mais c'est de fait ce que nous voyons arriver tous les jours; non seulement dans les apprentissages, mais dans les armées; les soldats s'engagent pour un grand nombre d'années, et leur désertion est punie de mort !... Pourquoi dans le système d'égalité exige-t-on des soldats une telle servitude, et pourquoi ne l'exige-t-on pas des officiers?

Mais revenons à la sculpture : l'abbé Du Bos prétend qu'il faut beaucoup moins de génie pour la sculpture que pour la peinture, et il fonde cette opinion sur des raisons pitoyables. Le sculpteur doit être plus grand dessinateur que le peintre, car ses figures 
doivent être parfaites dans tous les sens, puisqu'on peut tourner autour d'elles. Et quand il fait un bas-relief, il lui faut tout l'art du peintre (avec moins de ressources) pour grouper et faire ressortir ses figures. Le peintre avec son pinceau dispose à son gré de la lumière, il la suppose et la place où il veut; le sculpteur la reçoit de la seule nature et, pour la distribuer avantageusement, il a besoin d'une place qu'on lui refuse souvent; par exemple, l'Apollon du Belvédère avait perdu la moitié de sa beauté au Museum de Paris, parce qu'il était mal posé et mal éclairé. Les tableaux ont besoin sans doute d'un jour favorable, mais ils portent leurs ombres avec eux, et une statue vue de face peut en être totalement privée, du moins dans les parties dont les ombres surtout font le mieux valoir les beautés, telles que dans les têtes, l'enchâssement de l'œil, le nez et mille petits détails du visage, que les ombres seules dessinent et font sentir. Enfin, il semble qu'il y ait plus de mérite à faire une figure enchanteresse avec de la pierre ou du marbre, qu'avec l'artifice des couleurs, une fois inventé et connu. Si l'on n'avait jamais vu de statues, l'imagination ne se représenterait une figure faite en marbre blanc que sous les traits effrayants d'un fantôme ; quel art, quel génie il a fallu pour donner tant de grâces et de charme à ces figures privées de toute espèce de coloris !... Mais il faut, pour l'enchantement que peut causer une belle statue, que rien en elle ne rappelle l'idée de la couleur, qu'il faut oublier pour l'admirer. Un grand artiste moderne, Canova, met à ses statues des ornements d'or, et je crois qu'en cela il manque de goût. Il prétend que les Anciens ont jadis mis de ces ornements, ce qui ne serait pas une raison si la chose par elle-même ne vaut rien. D'ailleurs l'on a trouvé sur le cou et sur les bras de quelques statues antiques des traces qui marquent qu'elles ont porté jadis des colliers et des bracelets: mais comme elles étaient alors des objets de culte, il est vraisemblable que ces ornements étaient des offrandes de leurs adorateurs.

\section{Pierre Puget, Alessandro Sauli}

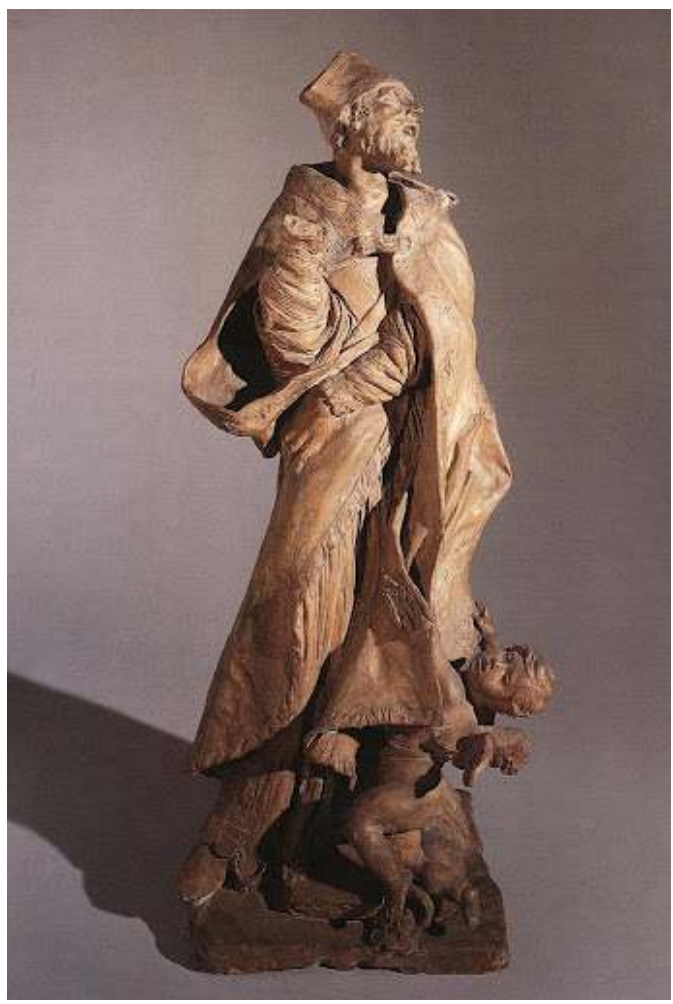

1663-1668, terre cuite, 70 cm, Cleveland, The Cleveland Art Museum of Art. 
Les Italiens, auxquels nous devons l'art de la sculpture, se sont servis longtemps de nos artistes. Puget, sculpteur de Marseille, fut choisi, de préférence à plusieurs sculpteurs italiens, pour faire deux des quatre statues dont on voulait orner les niches des pilastres qui portent le dôme de la magnifique église de Sainte-Marie-de-Carignan, à Gênes. Le Saint Sébastien et le Saint Alexandre Sauli sont de lui - cette dernière statue est d'une grande beauté et la première est sublime. Saint Sébastien mourut percé de flèches - il est représenté expirant et l'on voit sur son visage, de la manière la plus frappante, les deux expressions de la douleur physique et de la joie angélique d'avoir mérité la gloire du martyre (fig. 17). Cette admirable statue est un véritable chefd'œuvre. Quand les jésuites de Rome firent élever dans l'église de Jésus l'autel de SaintIgnace, ils mirent au concours deux groupes de cinq figures de marbre blanc qui devaient être placés aux côtés de ce superbe monument. Les plus habiles sculpteurs de l'Italie présentèrent chacun un modelé, des artistes français concoururent avec eux ; les modèles ayant été exposés, la voix publique décida que le modelé de Théodon et celui de Le Gros, tous deux Français, étaient sans comparaison les meilleurs ${ }^{25}$. Ils firent les deux groupes qui sont cités aujourd'hui parmi les chefs-d'œuvre de la Rome moderne. La balustrade de bronze qui renferme cet autel et qui est composée d'anges jouant dans des ceps de vigne mêlés d'épis de blé est encore l'ouvrage d'un sculpteur français. Les cinq meilleurs graveurs en taille-douce que l'on ait vus sous Louis XIV et sous Louis XV étaient français, il en est de même des graveurs sur métaux. L'orfèvrerie en grand et en petit, enfin tous les arts qui relèvent du dessin, ont toujours été en France plus parfaits que partout ailleurs ${ }^{26}$. Sous l'empereur Sévère, qui régnait plus de deux cents ans avant la première prise de Rome par Alaric, la sculpture et l'architecture antiques commencèrent à dégénérer ; les monuments qui nous restent des successeurs de Sévère font encore moins d'honneur à l'ancienne sculpture. Les médailles romaines frappées après le règne de Caracalla et celui de Macrin, son successeur qui ne lui survécut que deux ans, sont très inférieures à celles qui furent frappées sous les trente premiers empereurs; et sous Gallien qui régnait cinquante ans après Caracalla, elles n'étaient plus qu'une vilaine monnaie. 
18. Antonio Canova, Madeleine [Madeleine pénitente]

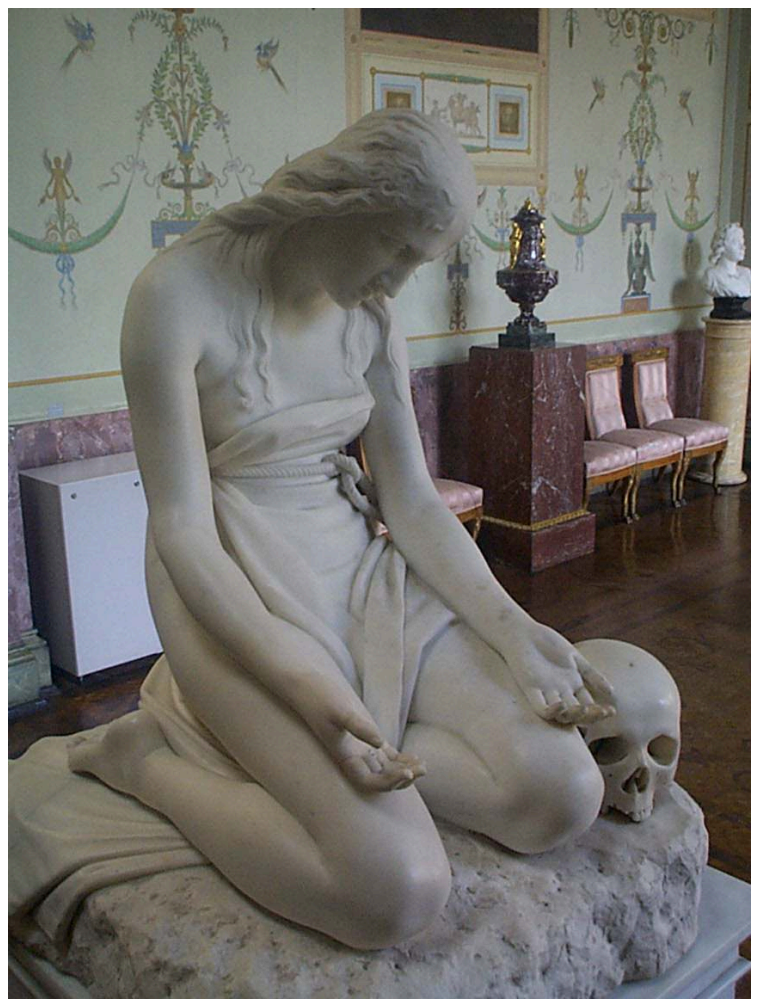

1809, sculpture, marbre, $95 \times 70 \times 77$ cm, Saint-Pétersbourg, musée de l'Ermitage.

41 L'art de la sculpture s'est soutenu avec gloire en France depuis Louis XIV et jusqu'à nos jours. On peut compter parmi les grands sculpteurs Pigalle, Houdon, Coustou, Julien, Allegrain, monseigneur du Paty, etc. Le plus célèbre sculpteur de l'Italie dans ce moment est Canova. On voit à Paris chez monseigneur de Sommariva une Madeleine de ce grand artiste, cette statue est admirable (fig. 18).

L'architecture, ainsi que je l'ai dit dans d'autres ouvrages, paraît être un art épuisé et cela doit être, puisqu'il n'est pas puisé dans la nature. L'architecture grecque ne produira jamais rien de plus beau que le Panthéon de Rome et le Colisée, rien de plus imposant que l'église de Saint-Pierre et la colonnade du Louvre et, dans le genre gothique, rien de plus hardi et d'un aspect plus vénérable que les anciennes cathédrales de France, d'Espagne et d'Angleterre. Il ne reste à l'architecture que d'inventer de belles décorations de fontaines. Nous n'en avons qu'un petit nombre de remarquables en Europe et l'on pourrait encore en surpasser l'élégance. On pourrait aussi composer et élever des arcs de triomphe plus ingénieux et plus majestueux que ceux que nous connaissons. Enfin, il est encore un genre de monuments qui pourrait exercer l'imagination des artistes, ce serait les bains publics : les ornements en seraient neufs et variés, puisqu'on pourrait y employer naturellement l'imitation des coquillages, des perles, des coraux, des madrépores, des joncs, des roseaux, des plantes marines, des dauphins, etc. Ainsi, ces espèces de compositions pourraient offrir des décorations neuves, riches et brillantes. Et il faut convenir que depuis soixante ans, l'architecture est, de tous les arts, celui dans lequel on a montré le moins de talent et d'imagination, surtout en France. 
Fini le 6 février 1820 cet ouvrage, entièrement inédit et composé, écrit, dessiné et peint par moi, et dont je n'ai gardé ni brouillon, ni copie.

Félicité Du Crest, comtesse de Genlis

\section{ANNEXES}

Lire les extraits du Catalogue pittoresque du cabinet de tableaux de Monsieur le comte de Sommariva de Félicité de Genlis

Lire l'introduction à Félicité de Genlis écrite par Charlotte Foucher

\section{NOTES}

1. Les principes de la basse fondamentale.

2. M.de Voltaire a pillé cette idée dans le chant de La Henriade qui commence par ce vers : «Sur les bords fortunés de l'antique Italie, il dit que l'Amour jouait avec les armes de Henri et qu'il riait en tenant dans ses débiles mains ce fer, l'appui du trône et l'effroi des humains. » Observons en passant que l'épithète débile convient à la vieillesse et non à l'enfance, et que d'ailleurs l'épée de Henri IV n'était l'effroi que des séditieux.

3. Les mêmes écrivains ont loué avec emphase un mauvais tableau que l'on peut voir encore dans le château de Chantilly. Il représente l'Histoire arrachant quelques pages de la vie du Grand Condé (les pages qui contiennent le récit de sa rébellion). Cette allégorie est grossièrement fausse, car c'est l'Histoire elle-même qui nous en a transmis le détail. Inflexible, exacte et sévère, l'Histoire rapporte avec impartialité et le bien et le mal. D'ailleurs le tableau dont il est ici question est détestable à tous égards.

4. On sait que dans les repas consacrés aux muses et à la gaieté, les Anciens se couronnaient de roses.

5. Qui le défendit dans un procès.

6. Toutes ces sommes en monnaie de France, suivant l'évaluation des savants.

7. En 546.

8. Les coupes d'Hébé, de Ganymède, de Bacchus, etc.

9. Le Cimabue naquit en 1240 .

10. Et un peu avant sous celui de Jules II, Michel-Ange illustra ce règne et plusieurs autres artistes contribuèrent à sa gloire.

11. Dans le $x v^{\mathrm{e}}$ siècle.

12. C'est lui qui eut l'idée sublime d'éclairer cette immense église le jour du vendredi saint, seulement par une croix lumineuse suspendue au plafond.

13. Nom qui lui vient de Corregio, lieu où il naquit.

14. À Paris. Le tableau fameux appelé la Nuit du Corrège représentant la Nativité, et toute la lumière portée sur l'Enfant Jésus, est à Dresde.

15. Un tableau semblable se trouvait à Florence, mais celui du $\mathrm{P}$ [alais] $\mathrm{R}$ [oyal], infiniment plus agréable, a toujours été regardé par tous les connaisseurs comme l'original. 
16. J'ai entendu dire à feu $M$. Greuze que le peintre qui a fait les plus beaux yeux dans les têtes de femmes et d'anges fut Le Guide ; et que celui qui a fait les plus beaux bras de femmes fut Pierre de Cortone.

17. Caravage, Calabrèse et Carle Maratte.

18. Une Danaé du même.

19. Il y avait au Palais-Royal un ravissant tableau de Le Sueur demi-nature, et représentant Alexandre prenant la médecine que lui présente Philippe, son médecin, en lui donnant la lettre qui l'accusa du dessein de l'empoisonner.

20. Dans ce dernier, les figures sont demi-nature; il est fâcheux que le peintre n'y ait pas placé le jeune et beau Apollodore, disciple favori de Socrate. Une jeune et charmante figure eût formé un agréable contraste avec la sévérité des autres têtes.

21. Voici à mon avis les chefs-d'œuvre de ces trois maîtres : Phèdre et Hippolyte de Guérin, Bélisaire de Gérard, et Galatée presque entièrement animée de Girodet, le plus ingénieux et le plus spirituel de tous nos peintres dans ses compositions.

22. Aujourd'hui duc d'Orléans.

23. Vandreveff dont les plus beaux tableaux et en grand nombre sont dans la galerie de Düsseldorf.

24. Nous avons de Dufrenoy un poème sur la peinture qui a eu de la réputation.

25. On voit encore à Rome un très beau morceau de sculpture de Le Gros, c'est la statue de saint Stanislas, représenté mort dans son cercueil ; sa figure est en marbre blanc et son habit de religieux en marbre noir.

26. Ce fut encore un de nos sculpteurs (Roubillac) qui enrichit l'Angleterre de ses plus beaux morceaux de sculpture. Entre autres de l'admirable statue du grand Newton qui se trouve à l'université de Cambridge. 


\section{Stéphanie-Félicité Du Crest,}

\section{Catalogue pittoresque du cabinet de tableaux de Monsieur le comte de Sommariva, 1820}

Nancy, bibliothèque municipale, Ms 766, p. 3-14, extraits choisis.

\section{« Discours préliminaire sur la magnificence »}

1 La magnificence, de quelque genre qu'elle puisse être, est toujours bienfaisante, quand elle ne fait pas faire de dettes. La magnificence, alors même qu'on peut la critiquer, est toujours une utile compensation de l'avarice. Le magnifique expie par ses folies mêmes l'égoïsme et la bassesse de l'avare.

Les gens qui, avec d'immenses richesses, manquent absolument de goût et d'instruction (ce qui peut se rencontrer), ne peuvent faire la distinction de la grande dépense et d'une noble magnificence. Durval devient tout à coup possesseur de deux cent mille livres de rentes; quel usage fera-t-il de cette grande fortune? Il ne veut ni thésauriser ni faire des dettes, excellente disposition. Que fera-t-il donc de son argent ? Achètera-til une bibliothèque? Il n'a lu dans toute sa vie que des pamphlets et des feuilles quotidiennes, ce qui n'a jamais donné le goût de la lecture ; la musique l'ennuie, il ne donnera pas de concerts ; quant à la peinture, il ne s'y connaît pas, et il n'aime que les caricatures; enfin il s'endort à la Comédie-Française et à l'opéra. Après une rapide réflexion, son parti est pris : il louera une loge à l'année aux Variétés, il aura un excellent cuisinier, il garnira ses caves des meilleurs vins de Bourgogne, de Sillery, du Languedoc, il fera venir à tout prix tout ce que l'Espagne, le Portugal et l'Italie offrent de plus parfait de ce genre, et il chargera tous les vaisseaux prêts à partir pour les îles de lui en rapporter une ample provision de liqueurs et de café. D'ailleurs, on trouvera toujours au mois d'avril, à ses dîners, des fraises et des petits pois, et durant l'année entière tous les monstres de la mer. Enfin, il a fait l'acquisition du plus vaste hôtel qu'il a pu trouver, il n'a pas eu besoin de réflexion pour en décorer l'intérieur; il a sur-lechamp donné l'ordre d'en dorer tous les lambris, tous les meubles, et même tous les 
balcons des fenêtres; et les étoffes les plus surchargées de clinquants et de dorures en formeront les ameublements et les tapis. Lorsqu'on voudra se faire une juste idée de l'extrême ductilité de l'or, il faudra aller visiter cette maison, car on y verra partout l'or étendu sur d'immenses surfaces ou serpentant en filets innombrables dans les franges et dans les broderies des tapisseries, des draperies et des rideaux. Trente chevaux dans son écurie et des voitures resplendissantes compléteront cette magnificence ; gardonsnous de la critiquer, car, en vérité, Durval ne pouvait rien faire de mieux.

3 Nous devons la même indulgence à cette veuve si riche qui se croit si magnifique! Clarinda est l'héroïne des marchandes de modes, des bijoutiers, des brodeurs, etc. Elle a les plus beaux diamants de Paris et avec ses superbes diadèmes de perles et de pierreries, elle se croit l'égale d'une reine ou d'une impératrice. Quoiqu'elle ait une extrême vanité et que son bonheur et ses seules passions soient d'être remarquée, de briller et d'effacer toutes les autres femmes, elle n'est envieuse d'aucune, quand elle est dans sa grande parure ; alors, la jeunesse, l'esprit, les talents, les grâces, la beauté ne lui causent nul ombrage, elle est persuadée que pour triompher de tous ces avantages et pour en anéantir la séduction frivole, il suffit de se présenter avec un beau châle de cachemire et avec une robe élégante garnie des fleurs fabriquées chez Batton.

4 Selnange fait un usage tout différent de ses richesses. Il n'a aucun goût pour les arts et pour les lettres; il n'aime ni la société, ni la bonne chère, il est ignorant, sobre et sauvage. Cependant, il a de l'amour-propre, il a été frappé de l'empressement des étrangers à aller voir les cabinets célèbres des amateurs, dans toutes les grandes villes ; il s'est décidé à former un cabinet, mais manquant de connaissances et de goût pour les belles choses, il a pris le parti de faire à grands frais une collection de choses rares. Il suffit dans ce genre d'avoir la certitude que la chose dont on veut faire l'acquisition vient de fort loin, ou qu'elle est d'un gothique ou d'une antiquité rare et qu'on ne peut se la procurer que très difficilement; d'ailleurs qu'elle soit belle ou laide, peu importe. Voilà donc Selnange rangé dans la classe des curieux. C'est un état, car on suppose presque toujours et fort gratuitement qu'un curieux est une espèce de savant. Le cabinet de Selnange est rempli d'arcs et de flèches et d'ustensiles de sauvages, d'ouvrages des sérails de Constantinople et d'Ispahan, de chats bleus et violets, de porcelaines de la Chine, de vases de porcelaine craquelée, que Selnange contemple avec délice, en songeant que cela est si laid, qu'il y a environ cinquante ans qu'on n'en fait plus, et qu'on n'en fera jamais. Il présente avec une complaisance particulière une mauvaise petite montre, grosse comme une noisette, qu'il a achetée cent louis, parce qu'elle porte le nom de myrmecide, le premier qui se soit avisé de faire des montres de cette petitesse. Selnange fait voir aussi aux amateurs distingués une vieille tabatière de corne de rhinocéros et une coupe de serpentine ornée de vilaines petites pierreries ternes et grossièrement montées qu'il croit avoir appartenu au grand Moghol. Il est en relation intime, non avec des artistes, mais avec tous les brocanteurs de Paris, qui s'entendent parfaitement pour lui vendre au poids de l'or toutes ces raretés qu'ils ont à bas prix et que souvent ils font fabriquer par des ouvriers des faubourgs.

5 Valmin, qui se pique de prendre toujours le premier toutes les modes nouvelles, a aussi la prétention de passer pour l'homme le plus magnifique de Paris; mais il n'y fait pas tant de façons: il est persuadé que la magnificence consiste uniquement dans la prodigalité et dans l'achat le plus précipité de toutes les nouveautés anglaises et françaises. Aussi, quand il paraît dans la boutique du Petit Dunkerque, tous les garçons aussitôt sont en l'air, et on lui montre toujours mystérieusement cinq ou six colifichets 
d'un prix extravagant, qui viennent, lui dit-on, d'arriver à l'instant de Londres et que personne encore n'a pu voir. Valmin s'empresse de faire ces précieuses emplettes, il se hâte de les emporter pour les faire voir, il remonte d'un air triomphant dans son cabriolet dont il va crever le cheval après avoir renversé deux ou trois passants, le tout pour faire quelques autres courses de cette importance. Valmin fait d'assez bonnes plaisanteries sur la passion de Selnange pour les choses gothiques et Selnange se moque du goût de Valmin pour les nouveautés, et en cela, ils n'ont tort ni l'un ni l'autre. Il est vrai que, dans le monde, il faut être bien sot ou bien aveugle pour faire une moquerie sans aucun fondement, les injustices en ce genre sont inexcusables, car les sujets ne manquent pas, il suffit de savoir regarder. Il est une noble et véritable magnificence, qui ne peut être le partage que des esprits délicats et cultivés, et des âmes élevées; formée par l'instruction unie au goût le plus pur, elle devient une vertu quand la raison et la grandeur des sentiments la dirigent et la fortifient.

6 Telle est la magnificence de Solmis. Protecteur éclairé des arts, il les sert ou les encourage par des bienfaits, il les récompense par son suffrage, et c'est un droit glorieux qui n'appartient qu'au mérite personnel et que ne donneront jamais le rang et les richesses sans les talents et les lumières.

7 Solmis s'est formé un cabinet de tableaux qui est justement admiré des véritables amateurs. Pour ses achats, il ne s'en rapporte pas à ces connaisseurs mercenaires sans goût et sans génie qui font un métier de l'art de juger les tableaux et dont toutes les connaissances en ce genre, mêlées de beaucoup de mauvaise foi et de charlatanerie, sont uniquement le fruit de l'habitude et de la routine. Solmis sait parfaitement que ces gens-là vantent avec exagération les tableaux qu'ils proposent et que toujours ils dénigrent avec injustice tous les autres. Solmis est en état de juger par lui-même et lorsqu'il désire un conseil, il n'a garde de s'adresser à ceux qui peuvent en donner de suspects et d'intéressés.

8 Solmis est loin de mépriser l'école flamande de peinture; et même indépendamment des ouvrages admirables de Rubens et de Van Dyck, qui honoreraient les écoles italiennes, il sait reconnaître le mérite des paysagistes hollandais et flamands et celui des peintres de genre de cette école, dont il apprécie le fini, la couleur et la vérité ; mais il préfère des sujets nobles aux scènes qui ne représentent que des tavernes, des corps de garde, des tabagies, des vendeuses de poisson et des cuisines. C'est ainsi qu'il aime mieux voir jouer une tragédie de Corneille, de Racine ou de Voltaire, représentée par les bons acteurs, ou une pièce de Molière, que le plus beau mélodrame ou la meilleure farce des Variétés, car il est des choses qu'on ne peut voir avec plaisir qu'en passant ; il en est d'autres qu'on ne se lasse point de revoir en peinture - l'estime et l'admiration qu'on accorde exclusivement aux grandes compositions héroïques et nobles ne sont point un préjugé : il ne faut que de l'habitude et de la patience, et le simple talent de l'observation, pour peindre avec naturel et avec exactitude les petites scènes vulgaires de la vie commune et bourgeoise, mais il faut du génie pour peindre des actions extraordinaires et de grands personnages et pour leur donner des attitudes et une expression qui ne soient ni faibles, ni forcées et pour savoir allier avec la correction du dessin et avec l'expression la plus énergique et la plus douloureuse la beauté des formes et celle des traits.

9 Ainsi la belle collection de tableaux de Solmis est noble et pure comme son goût. Tous les arts sont frères, et il est presque impossible d'en aimer un passionnément sans trouver un grand charme à tous les autres. Le véritable amateur de tableaux l'est aussi 
de la sculpture et de tous les genres de gravures. L'idée parfaite de la justesse des proportions lui donne les mêmes connaissances en architecture. Celui qui, dans les tableaux, peut juger du mérite de la composition dramatique et de la vérité de l'expression des passions diverses en verra avec plaisir la description dans les ouvrages de littérature, et il en sera naturellement un bon juge. Quand on a l'imagination remplie de la poésie des tableaux de Poussin, de Rubens, de l'Albane, de Raphaël, d'Angelika Kauffmann ${ }^{1}$, de Girodet, on doit aimer les poèmes et les beaux vers. Celui qui possède un tact si fin, un sentiment si délicat, pourrait-il être insensible au charme de la musique ? Non, la sensibilité vive et profonde pour tous les genres d'harmonie doit se trouver dans l'être organisé pour aimer les beaux-arts. Tel est Solmis : et ce portrait, auquel on pourrait ajouter encore des traits plus touchants, n'est point une fiction.

\section{Dialogue entre Alcime et Lydanie}

La scène est dans le cabinet de tableaux de Monsieur le comte de Sommariva.

Alcime

10 Cette première pièce est la salle à manger. Eh bien, madame, le hasard vous sert aussi bien que s'il n'était pas aveugle ! Ce tableau célèbre que vous aviez tant d'envie de voir est le premier qui s'offre à vos yeux...

1. Anne-Louis Girodet, Pygmalion et Galatée

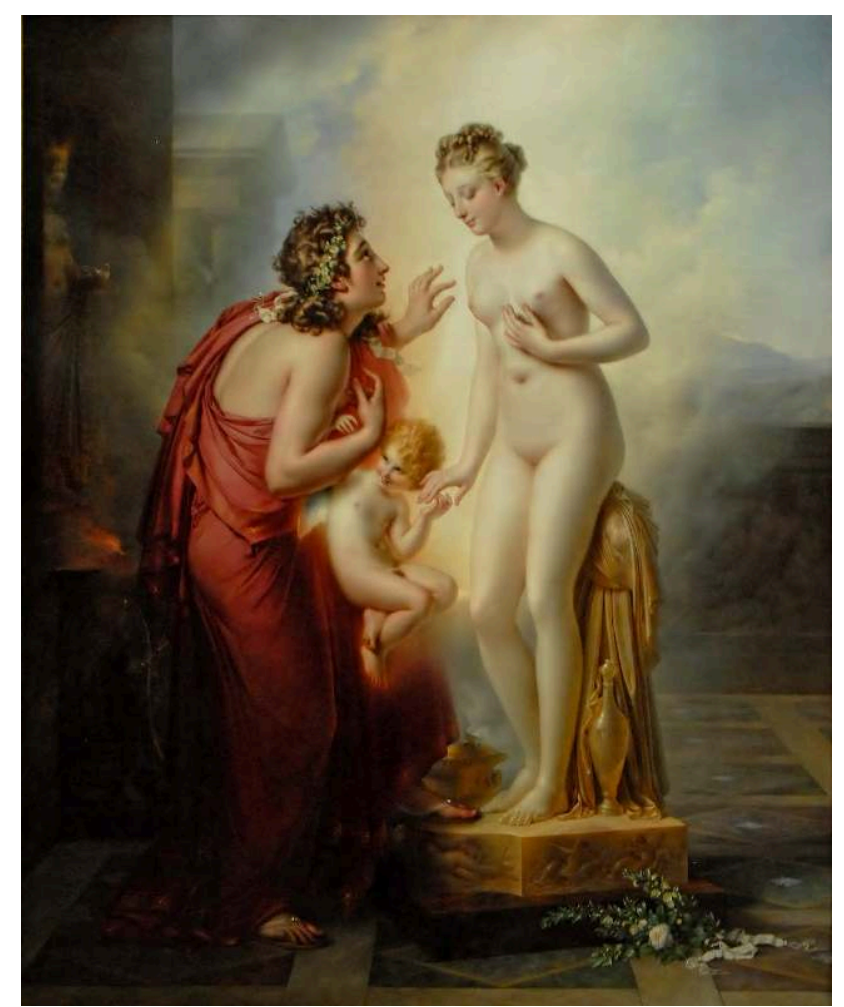

Salon de 1819, huile sur toile, 253 × 202 cm, Paris, musée du Louvre.

Lydanie

11 La Galatée de Girodet (fig. 1) !...

Alcime 

point encore le mouvement et la vie, mais ce reste de marbre qui n'est pas entièrement transformé l'est cependant assez pour ne pas nuire à l'harmonie du coloris. Il y a dans cette combinaison un art et un bon goût que l'on ne saurait trop admirer.

$$
\text { Lydanie }
$$

15 Ce que j'admire le plus, c'est l'expression si pure de cette figure ravissante! Elle n'exprime que le doux instinct d'une heureuse existence, et celui de la pudeur et de la timidité. La délicatesse de cette idée honore l'esprit et l'âme de l'artiste, elle était digne d'une femme ; Angélique Kauffmann ou $\mathrm{M}^{\mathrm{me}}$ Lebrun l'aurait eue.

Alcime

En rendant justice à l'admirable figure de Galatée, on a été d'une excessive sévérité pour celle de Pygmalion...

$$
\text { Lydanie }
$$
L'envie seule a pu dire que cette figure est mauvaise, elle est bien posée, bien dessinée, et elle est charmante...

Alcime

On voudrait que l'expression en fût plus passionnée...

Lydanie

Ce serait un défaut, car alors Pygmalion serait plus intéressant que Galatée, et c'est Galatée qui est et doit être la figure principale. L'artiste a donné à Pygmalion une expression très naturelle, celle de l'étonnement et de la curiosité, qui dans ce moment et à la vue d'un tel prodige doivent suspendre, ou pour mieux dire absorber tout autre sentiment et jusqu'à l'amour même.

Alcime

En effet, l'amour est là, suspendu entre l'un et l'autre, et avec les idées que vous venez de développer, cette allégorie est sublime. Mais permettez-moi de vous faire une objection; vous dites, madame, que tout l'intérêt doit porter sur la figure essentiellement principale, cependant cette règle est sans cesse démentie au théâtre ; l'unité d'intérêt n'y est prescrite que pour l'action et non pour les personnages : on s'y intéresse autant à Rodrigue qu'à Chimène...

Lydanie

Sans doute, parce que dans plusieurs scènes et plusieurs actes, tous les sentiments et tous les caractères peuvent être successivement développés. Il n'en est pas ainsi de la peinture qui ne peut représenter d'une action qu'un seul point unique et fixe. Tous les arts se tiennent, et néanmoins quand on en a cultivé plusieurs, on sait qu'il n'en est aucun que l'on puisse comparer exactement et sous tous les rapports à un autre : pas même la sculpture et la gravure à la peinture.

Alcime 
22 Assurément. Par exemple, combien ce beau tableau perdra dans la gravure, puisqu'on n'y pourra représenter ce reste de marbre si essentiel au sujet et si habilement peint par l'artiste.

\section{Lydanie}

23 Tous les gens de lettres du siècle dernier ont disserté sur les arts, ils en ont parlé sans aucune connaissance, et souvent ridiculement, parce qu'ils ne cultivaient que la littérature et qu'ils rapportaient uniquement à ses règles et à ses idées toutes celles des autres arts.

\section{Alcime}

Je ne me lasse point de contempler Galatée! Le dessin de toute sa personne est parfait, le coloris suave et brillant, le visage enchanteur ! Cependant j'y trouve un léger défaut...

$$
\text { Lydanie }
$$

Lequel?

Alcime

26 L'œil du grand côté est un peu trop petit et un peu trop rond, et les sourcils et les paupières ne sont pas tout à fait assez marqués.

$$
\text { Lydanie }
$$

27 Galatée statue n'avait point de paupières.

\section{Alcime}

L'amour en l'animant a dû lui donner tous les charmes qui lui manquaient. Je suis sûr que si sa bouche s'ouvrait, elle nous montrerait des dents admirables. Mais il faut nous arracher à cette délicieuse contemplation; nous avons tant d'autres tableaux à voir !

$$
\text { Lydanie }
$$

De qui est celui-ci? 


\section{Jacques-Louis David, Psyché [L'Amour et Psyché]}

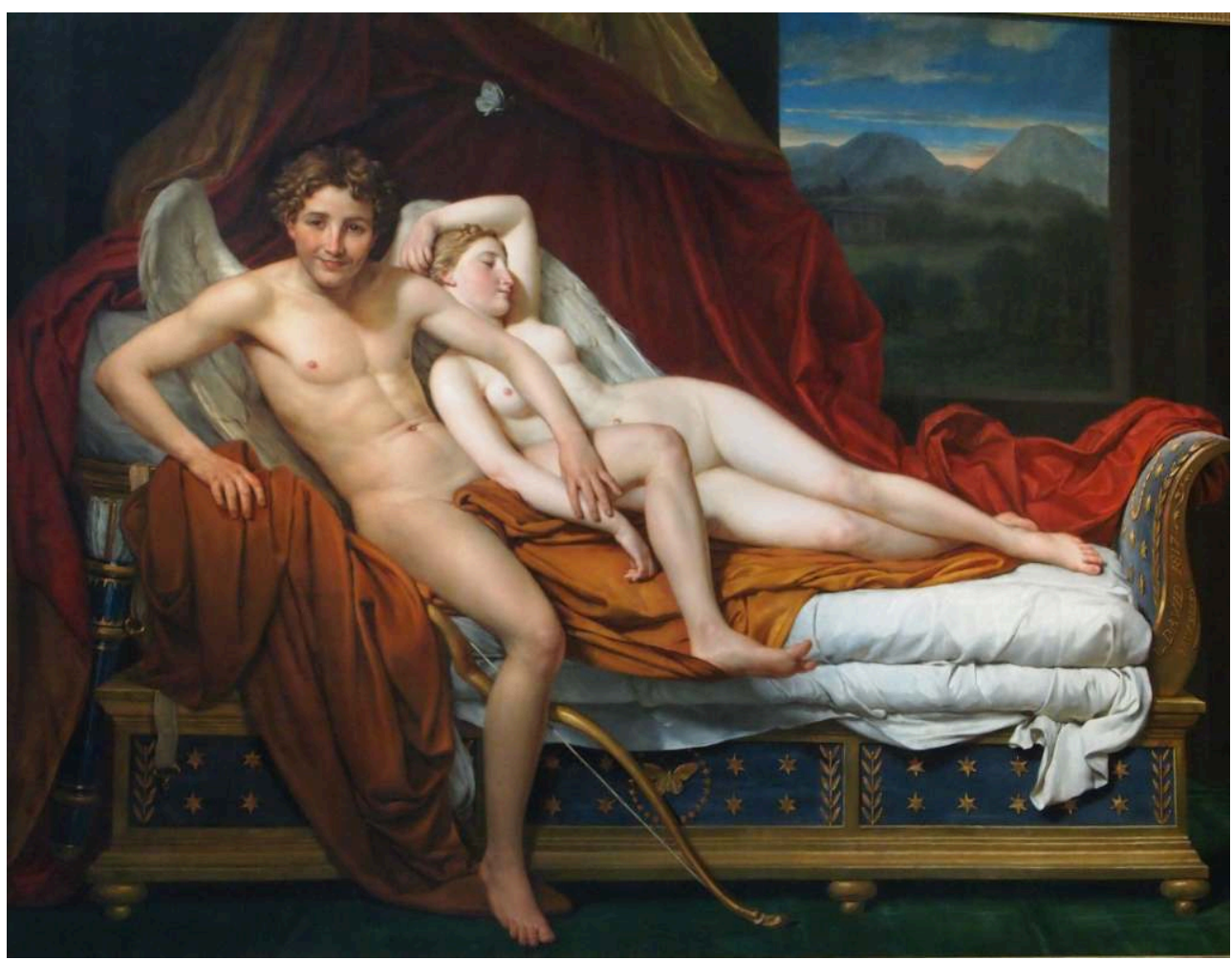

1817, huile sur toile, $184 \times 241 \mathrm{~cm}$, Cleveland, The Cleveland Museum of Art.

Alcime il est d'une grande beauté ; mais la Psyché est bien peu jolie, et quel Amour !...

Alcime

C'est la Psyché de David (fig. 2).

Lydanie

Je sais que les connaisseurs admirent ce tableau, et je sens qu'en effet comme peinture

C'est l'Amour physique que l'artiste a voulu peindre...

Lydanie

Celui-là ne mérite ni d'être décrit ni d'être peint; et d'ailleurs, pourrait-il s'attacher à Psyché, dont le nom signifie âme! C'est un contresens. Oh! quel Amour! Et par bonheur, qu'il est ignoble et laid !...

Alcime

Oui, j'en conviendrai, ce tableau peint si parfaitement est sans doute très beau.

« Dans l'art de peindre, ainsi qu'Apelle

David peut servir de modèle

Et ne redoute aucun rival. »

Mais ce tableau d'ailleurs est tout à fait moral :

«Et toute mère de famille

Pourrait avec fruit chaque jour

Le faire admirer à sa fille

Pour la dégoûter de l'amour. »

Lydanie

Voyons les autres tableaux. 
Alcime

$$
\text { cathédrale? }
$$

Alcime

39 chose qui devrait se trouver dans toutes les collections de ce genre. Ce tableau, qui est
un chef-d'œuvre de perspective, représente la cathédrale de Milan, il est de Migliara... Lydanie intérieur de cette vaste église.

\section{Alcime}

42 Allons.

43

Alcime

Nous voici dans la pièce qui est immédiatement avant le Salon.

Lydanie, jetant les yeux sur le portrait de Monsieur le comte de Sommariva.

Ah !... L'on nous a dit que M. de Sommariva n'est point ici, et le voilà !...

Alcime

Oui, il ne lui manque que la parole.

Lydanie

Ce qui est fort à regretter pour lui et ce qui ne le serait pas pour tant d'autres !

Alcime

Et même, comme le dit un poète italien, la parole ne lui manque même pas, si l'on en croit ses yeux...

Lydanie

Je n'ai point vu de portrait aussi parfaitement ressemblant.

Alcime

Aussi est-il d'un excellent peintre, de Prud'hon...

Lydanie

Et ce grand tableau de Drolling?

Alcime

C'est La Mort d'Abel.

Lydanie

Il est beau. Les deux figures sont admirables! Que celle d'Abel est touchante! Le peintre a répandu sur ses traits, et même sur ses formes si jeunes et si délicates, tout l'intérêt 
que doit inspirer la première victime de l'envie et de la méchanceté humaine : et l'on voit dans la taille et dans l'attitude de Caïn toute la férocité du premier meurtrier et du premier fratricide.

\section{Alcime}

Voyez, madame, à côté de cette belle et terrible composition, deux charmants tableaux, une Vierge de Carlo Cignani et un cheval arabe d'Horace Vernet. En voici encore un précieux, c'est une Résurrection de notre Seigneur, de Cima Conegliano.

Lydanie pièce : ainsi, allons dans le salon...

Alcime

64 Je vous suis... (Ils passent dans le salon.) Remarquez, madame, que ces deux panneaux sont des glaces sans tain...

Lydanie

Ah! Cela est charmant !... cette jolie idée réunit cette pièce-ci à celle que nous venons de quitter, en lui donnant l'apparence d'une belle galerie, et fait jouir la vue de l'ensemble de tous ces superbes tableaux réunis !...

\section{Alcime}

Remarquez d'abord ce petit Albane, et au-dessus Saint Joseph embrassant l'Enfant Jésus, de Daniele Crespi, une Sainte Famille de del Sarto, une autre Sainte Famille du Titien de 
l'année 1526. Une tête d'enfant de Rembrandt, un philosophe de Cairo, une Vierge ou une sainte d'un peintre qui a fait tant de têtes gracieuses, Carle Dolci...

Lydanie

Oui, et je me rappelle d'avoir vu de cet artiste une Vierge charmante dans la galerie de Düsseldorf.

\section{François Gérard, Bélisaire [Bélisaire portant son guide piqué par un serpent]}

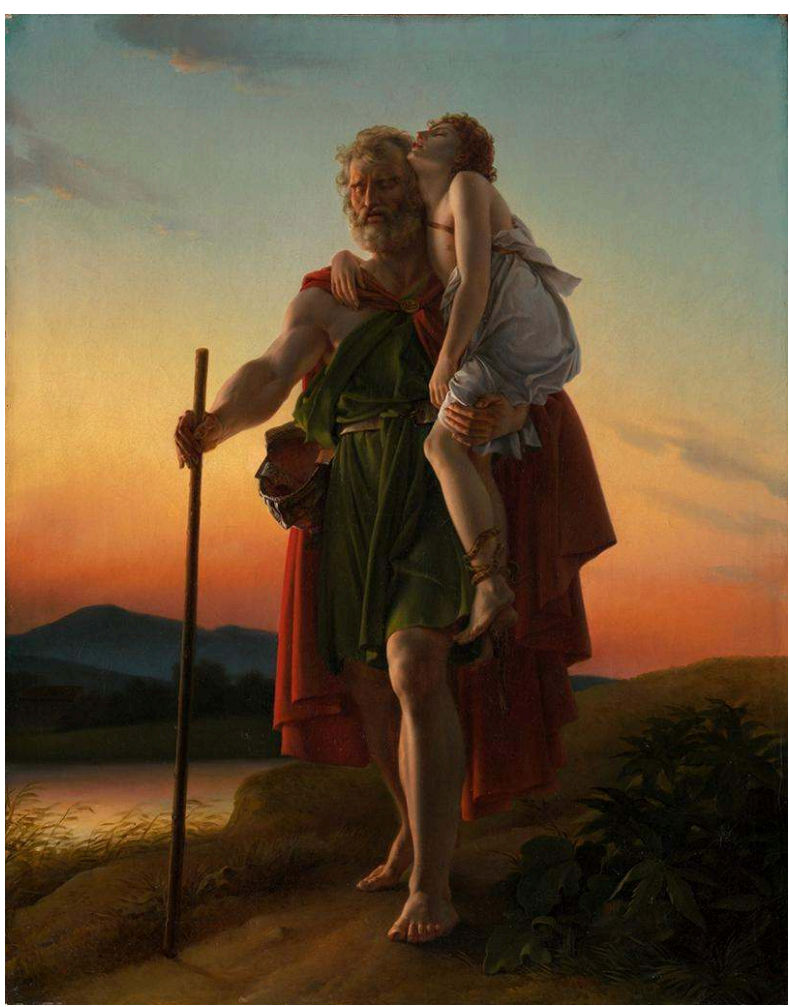

1797, huile sur toile, 91 x 74 cm, Los Angeles, J. Paul Getty Museum.

Alcime

Voici en petit le Bélisaire de Gérard (fig. 3).

Lydanie

Ce beau tableau de Gérard est véritablement admirable par le dessin, le coloris et l'expression, mais je n'en aime pas l'idée...

Alcime

Pourquoi?

Lydanie

71 Parce qu'elle n'est que triste.

Alcime

72 L'artiste a voulu représenter le dernier degré du malheur...

Lydanie

Sa composition n'atteint nullement ce but...

Alcime 
Comment ?... Le jeune guide de l'infortuné vieillard est piqué par un serpent, Bélisaire l'a chargé sur ses épaules, l'enfant est évanoui, et Bélisaire qui a continué de marcher est arrivé jusqu'au bord d'un précipice et il y va tomber... C'est bien là, le dernier degré du malheur...

Lydanie

Non, car Bélisaire est aveugle. Dans cet état, il n'a nul besoin de courage : il ne souffre point, il ignore son péril, il va devenir victime de la fatalité sans avoir connu son infortune, sans avoir eu le mérite de la résignation et de la fermeté. Cette mort obscure et sans gloire est mal inventée pour un grand homme.

Alcime

Dans la composition de quelque ouvrage qui puisse être, l'artiste ou le poète a toujours un grand mérite lorsqu'il parvient à exciter une violente émotion. Et certainement le danger de Bélisaire fait frémir...

Lydanie

On frémit aussi à quelques situations des plus mauvais mélodrames. Le peintre devait concevoir que le malheur extrême d'un grand homme doit toujours être uni à l'héroïsme, qu'une compassion vulgaire est un tribut indigne de lui et que la noble pitié qu'il peut inspirer doit toujours se confondre avec l'admiration. Cette composition ne serait bonne que si elle était historique, elle ne l'est pas, et, comme invention, elle manque de génie. Mais il y en a beaucoup, dans l'exécution et dans l'expression des figures. Celle de Bélisaire est admirable et l'enfant est aussi touchant qu'il peut l'être. Enfin je reprocherai encore à ce tableau un grand défaut dans l'action qu'il représente : le manque absolu de vraisemblance...

Alcime

En quoi donc?

Lydanie

Il n'est pas naturel que Bélisaire, ne pouvant plus ni être guidé par l'enfant, ni obtenir de lui une seule réponse, ait continué à marcher. Quel est son dessein ? Où peut-il espérer d'arriver? En pleine campagne et dans des lieux où se trouvent des précipices? En chargeant l'enfant sur ses épaules, il a su qu'il était blessé par un serpent. Comment ignore-t-il que ce serpent est entortillé autour de sa jambe et comment ne s'est-il pas arrêté pour tâcher avec son bâton de l'en délivrer? D'ailleurs, dans tous les cas, il devait cesser de marcher; et je le trouverais plus touchant assis sur un rocher à quelques pas du précipice tenant dans ses bras son jeune guide expirant et implorant pour lui la protection du ciel...

Alcime

Vous êtes bien sévère, et vous ne serez pas étonnée qu'on s'en plaigne !

Lydanie

81

Mon plus doux plaisir est d'admirer, mais je suis sincère, je crois avoir le sentiment du vrai et du beau, et je dis sans flatterie et sans exagération ce que je pense. Il me semble aussi qu'en tout genre, le goût se corromprait si les grandes beautés d'un ouvrage empêchaient d'en voir les défauts.

Alcime 

autorités.

Lydanie

L'admiration n'est un hommage que lorsqu'elle est éclairée. Il n'est permis qu'à l'amour d'en avoir une aveugle, elle est ainsi de si bonne foi !...

\section{Alcime}

84 et ne saurait se tromper ; il allume son flambeau au feu sacré dérobé par Prométhée et la flamme divine d'un tel feu ne produit point d'incertaines clartés! Enfin, rien n'est illusoire dans l'union céleste des âmes.

Lydanie

Vous raisonnez toujours en poète...

Alcime

Surtout en amant passionné, quoique toujours malheureux !...

Lydanie

87 avertis. Pourquoi m'avez-vous parlé de l'amour, et pour le calomnier !...

Lydanie

En effet, j'ai été bien injuste en disant qu'il est aveugle !...

Alcime

Revenons à Bélisaire.

Alcime

Cela vous est bien aisé à dire... Je ne vous écouterai plus qu'avec distraction, je vous en $z$ cette opinion aux autres femmes.

Lydanie

Beaucoup trop ne l'ont pas...

Alcime

Ce qui n'est en elles que de la crédulité serait en vous de l'injustice.

Lydanie

Nous ne sommes venus ici que pour voir ces beaux tableaux...

Alcime

Oui, vous, madame...

Lydanie

Ainsi, reprenons notre entretien... Nous parlions de Bélisaire. Vous avez été en Angleterre?

Alcime

Oui, mais bien peu de temps...

Lydanie

Avez-vous vu à Chiswick, près de Londres, le château du duc de Devonshire?

Alcime

Non... 
Lydanie

Eh bien, c'est là que se trouve le Bélisaire de Van Dyck, l'un des plus célèbres tableaux de ce grand maître. Il représente Bélisaire aveugle conduit par une enfant et demandant l'aumône, tandis qu'un soldat qui a servi sous ses ordres et qui, reconnaissant son illustre et malheureux général, le contemple avec un profond sentiment d'attendrissement et d'indignation contre ses barbares ennemis. Voilà une belle scène et une sublime conception.

Alcime

Marmontel s'en est emparé pour la placer dans son Bélisaire, et c'est assurément ce qu'il y a de mieux dans cet ouvrage. Il aurait dû dire dans une préface ou dans une note qu'il devait cette idée à Van Dyck.

\section{Lydanie}

101 Les philosophes du dernier siècle n'étaient pas si scrupuleux, ils pillaient sans pudeur et ne citaient jamais et, comme on était fort ignorant dans ce siècle des Lumières parce qu'on en était venu à ne plus lire que leurs ouvrages, les gens du monde ne s'apercevaient pas de ces brigandages littéraires.

Alcime

102 Cet usage si commode peut aux yeux de tant de personnes tenir lieu de talents !...

Lydanie

103 Aussi les chefs de la philosophie moderne l'ont-ils légué à leurs disciples, mais nous causons ici comme chez moi. Songeons donc que nous sommes ici dans l'un des plus beaux temples des arts, et ne nous occupons que de ce qu'il contient...

Alcime

Cela est impossible avec vous...

$$
\text { Lydanie }
$$

Je ne veux plus vous écouter.

Alcime

Et moins encore me comprendre...

Lydanie

Vous qui avez naturellement tout l'agrément de l'à propos, croyez-vous qu'il y en ait beaucoup dans tout ce que vous dites depuis un quart d'heure?

Alcime

Vous me flattez pour me gronder et pour me faire taire, mais il faut vous obéir. Allons ! je vais reprendre tout mon agrément d'à propos. Voici, madame, une Sainte Famille de Simone de Pesaro. Voici un vieillard du Caravage... Remarquez, je vous prie, en passant, cette belle table d'Italie.

Lydanie

Quel usage charmant on sait faire en Italie de ces belles productions de la nature qu'on $\mathrm{y}$ appelle pierres dures, et comment cet art, cultivé depuis si longtemps, surtout à Florence, et qui a produit la superbe chapelle, l'un des plus beaux ornements de cette délicieuse ville, comment cet art est-il inconnu en France? Il serait facile d'en faire venir les matériaux et la France même en fournirait plusieurs.

Alcime 
110 Conçoit-on au mieux que, dans ce siècle mémorable, où le génie des arts établit de si grandes communications entre l'Italie et la France, Colbert, qui forma des manufactures de glaces qui firent tomber celles de Venise, n'ait pas imaginé d'en établir une de mosaïque, afin d'éterniser les chefs-d'œuvre de Le Sueur, de Poussin et des tableaux qui représentaient les victoires de Louis XIV?

Lydanie

Il est étonnant que même depuis on n'ait pas eu cette idée.

Alcime

112 L'art de graver des camées en creux et en relief sur des pierres fines n'est point encore naturalisé en France, et il est porté en Italie à un point de perfection qui non seulement égale, mais souvent surpasse l'antique...

Lydanie

Il est d'autant plus surprenant que nous ayons négligé ce bel art, que nous en faisons grand cas et que nous possédons en ce genre des collections admirables.

Alcime

114 Oui, et entre autres celle du Palais-Royal, aujourd'hui dispersée dans toute l'Europe.

Lydanie

115 On peut juger par les gravures qui en restent de la beauté de cette collection, qui était également riche en antiques et en pierres gravées pour les artistes modernes les plus habiles : Coldoré et Pickler...

Alcime

116 La plus belle des antiques de ce cabinet était celle qui portait les profils des trois sœurs de Caligula ; l'artiste avait, à droite, placé sur les joues de ces profils une douce et légère teinte de couleur de rose qui s'était trouvée naturellement sur la pierre. La plus belle gravure moderne de ce même cabinet était une tête de Henri le Grand, d'un fini précieux et d'une ressemblance parfaite, gravée sur un superbe rubis.

Lydanie

Reprenons notre examen...

Alcime

Levez les yeux pour admirer cette Présentation de notre seigneur au Temple, par Le Pérugin...

Lydanie

119 Et là, une Nativité de Paul Véronèse.

Alcime

120 Voici deux sujets mythologiques, l'un d'Annibal Carrache, l'autre de Van Dyck. Un jeune garçon de Giorgione; une tête d'homme de Moroni ; une Sainte Famille de Bartolomeo ; une sainte tenant un agneau de Dolci.

Lydanie

Ce tableau de l'Albane représente, je crois, Hercule entre le vice et la vertu.

Alcime

Il me semble que la figure d'Hercule n'est ni assez grande ni assez noble...

Lydanie 
Celle du vice devrait avoir quelque chose de plus insinuant; Hercule n'aura nul mérite à lui résister, mais la figure de la vertu représentée sous les traits de Minerve, déesse de la Sagesse, est majestueuse et belle. Les Anciens ont excellé dans les allégories, néanmoins je n'ai jamais aimé celle-ci, parce qu'elle en détruit une autre plus ingénieuse : Hercule représentant la force est lui-même l'emblème de la vertu dans l'Antiquité. Ainsi, toute autre figure, surtout à côté de la sienne, ne peut représenter la vertu.

\section{Alcime}

Il est vrai que les sculpteurs antiques ont toujours offert la vertu sous les traits d'Hercule appuyé sur son invincible massue, et cette idée est belle parce qu'elle est juste. La vertu sur la Terre n'est autre chose qu'une force suprême bien dirigée et toujours armée, car elle a tout à combattre.

$$
\text { Lydanie }
$$

Nous avons encore plusieurs tableaux à voir dans ce salon...

Alcime

Oui, voilà un concert de Paul Véronèse et une Charité romaine du Guide...

$$
\text { Lydanie }
$$

Ah! Que le vieillard est beau...

Alcime

Comme son attitude et sa physionomie expriment avec vérité la reconnaissance et l'espèce de pudeur et de respect que doit inspirer un tel acte de piété filiale !...

Lydanie

Ce tableau est admirable! Quelle chasteté, quelle modestie, quelle douceur se peignent sur tous les traits de la jeune femme!

\section{Alcime}

Et quelle simplicité dans son maintien!

$$
\text { Lydanie }
$$

Oui, l'on voit qu'elle croit faire une action aussi simple que si elle était commune...

\section{Alcime}

Ne pensez-vous pas que, dans ce sujet, une mère serait plus touchante qu'un père? Il serait si attendrissant de penser que cette fille qui donne son lait à sa mère reçût d'elle dans son enfance cet aliment si pur !...

$$
\text { Lydanie }
$$

En donnant à la fille un devoir plus pressant et plus sacré, on diminuerait le mérite de son action, qui avec un père est presque un bienfait, et qui avec une mère ne serait en quelque sorte que l'indispensable paiement d'une dette, et quelle dette !... D'ailleurs, il faut l'avouer, la vieillesse n'est véritablement vénérable aux yeux que sous les traits d'un homme : un vieillard peut être beau, et d'une manière frappante, mais il n'y a point de belle vieille. Nos cheveux blancs n'inspirent point le respect. L'expérience d'un être faible qui n'a pu jouer un grand rôle n'a rien d'imposant. Il semble que la grâce doive être un attribut de la faiblesse. Nous cessons d'être femmes et d'intéresser lorsque nous la perdons. Quand le temps dessèche un chêne, on dit qu'il se couronne, quand il commence à décolorer une rose, on dit qu'elle est flétrie. La force laisse au 
moins de nobles vestiges, qui peuvent encore la rappeler et exciter l'admiration. La faiblesse, à laquelle l'âge seulement a donné son dernier degré, ne peut tout au plus inspirer que la pitié. Nous ne pouvons inspirer dans la vieillesse que le respect moral, fondé sur le souvenir d'une vie utile, bienfaisante et pure. Il faut connaître une vieille femme pour la révérer. Son seul aspect n'y dispose point ; ainsi les peintres ont raison de préférer aux têtes de vieilles des têtes de vieillards...

Alcime

134 À votre âge, il ne faut pas une grande impartialité pour parler ainsi des vieilles femmes, et pour moi, je crois, en vous regardant, qu'il y a quelquefois dans la jeunesse des grâces si piquantes et des charmes si touchants qu'il est impossible que le temps puisse entièrement les ravir.

$$
\text { Lydanie }
$$

135 Dans trente ans, cependant, mon visage ne vaudra certainement pas celui de ce beau vieillard...

\section{Alcime}

Quelle folie !... Dans trente ans, vous n'[en] aurez pas cinquante-cinq !...

Lydanie

Laissons là ma jeunesse et parlons de ce vieillard, de ce tableau qui m'en rappelle un sur le même sujet, qui lui est tout à fait inférieur, mais qui offre une idée ingénieuse et touchante...

\section{Alcime}

Une Charité romaine?

Lydanie

139 Oui, et le peintre avait imaginé de rehausser l'action de la jeune femme en plaçant dans le tableau son enfant au maillot, qui semble par ses cris réclamer l'allaitement que lui destinait la nature ; la jeune femme le regarde en pleurant...

\section{Alcime}

Où donc se trouve ce tableau?

Lydanie

141 Je l'ai vu à Rome au palais Spada, mais comme l'exécution en est fort médiocre, il n'a point de réputation.

\section{Alcime}

142 Je suis surpris que ce trait touchant de la Charité romaine n'ait jamais été mis au théâtre...

$$
\text { Lydanie }
$$

On a fait sur ce sujet une tragédie...

\section{Alcime}

\section{Une tragédie française?}

Lydanie

Non, la pièce est anglaise, et de Murphy, un auteur moderne. Elle a eu beaucoup de succès, et contient de beaux détails et des scènes fort touchantes.

Alcime 
Nous n'avons plus à voir dans ce salon qu'une belle statue de Canova...

Lydanie

La voilà... C'est un chasseur. Quelle grâce, quelle légèreté !... Croyez-vous que les Anciens aient surpassé les modernes dans l'art de la sculpture?

Alcime

Non, certainement. Il ne manque à nos chefs-d'œuvre en ce genre que l'antiquité ; quel enthousiasme ils exciteraient si on les croyait faits du temps de Périclès !...

$$
\text { Lydanie }
$$

On peut dire seulement que les sculpteurs modernes n'ont point exécuté de morceaux aussi considérables que les Anciens, soit pour le nombre des figures, soit pour la force d'expression exigée par le sujet.

\section{Alcime}

En effet, quel sujet que celui de Laocoon enlacé avec ses enfants dans les liens venimeux formés par d'horribles serpents et expirant avec les êtres qui lui sont les plus chers !...

$$
\text { Lydanie }
$$

Et la famille de Niobé, et Dircé attachée par les cruels enfants de sa rivale à la queue d'un taureau indompté ! Ce morceau de sculpture, le plus grand que l'on connaisse, est d'un seul bloc de marbre. Mais, à propos de chef-d'œuvre, où donc est ici la célèbre Madeleine de Canova?

Alcime

Dans un cabinet où je vais vous conduire.

$$
\text { Lydanie }
$$

Allons...

Alcime

Un moment...

Lydanie

Pourquoi?

Alcime

Il faut auparavant que vous me promettiez de ne point vous faire carmélite en sortant de ce cabinet...

Lydanie

Comment, carmélite ?...

Alcime

Vous êtes veuve, vous êtes libre et...

Lydanie

Et qui pourrait m'engager à prendre une telle résolution ?...

Alcime

Je vous connais, vous en seriez capable...

Lydanie

Et c'est ce cabinet qui...

Alcime 
Oui, qui vous inspirera cette idée.

Lydanie

Je dois aussi vous demander de ne point vous faire chartreux?

Alcime

Que vous importe?

Lydanie

Soyez tranquille pour moi. Allons, entrons dans ce redoutable et mystérieux cabinet.

Ils y entrent.

Alcime

Nous y voilà. Eh bien?

Lydanie

La voilà donc, cette belle Madeleine! Qu'elle est touchante ! Et quel bon goût de l'avoir placée solitairement dans cette petite pièce si modestement meublée !...

Alcime

Oui, combien lui sied cette tenture unie et brune qui tapisse les murs et le plafond!

Lydanie

Pas un pouce de dorure, pas un seul ornement ! Quelle élégance dans cette simplicité !...

Alcime

71 Seulement une glace, sans cadre doré, et placée derrière la statue, pour la faire voir d'un seul coup d'œil, sous tous les aspects...

Lydanie

Quelle tête admirable ! Asseyons-nous pour la contempler tout à notre aise.

Alcime

Ce n'est pas tout. Il y a encore ici une autre pénitente !...

Lydanie

Ah! un tableau qui représente aussi une Madeleine !

Alcime

Celle de Canova est un chef-d'œuvre de sculpture et l'autre, de Pordenone, en est un de peinture.

Lydanie,

\section{Regardant le tableau.}

Ah! Quelle figure ravissante et parfaite !... quelle expression sublime et qu'elle dit de choses !...

\section{Alcime}

Et quelle simplicité, quel charme dans l'attitude, quelle grâce dans le costume !...

Lydanie

Comme elle se repent!

Alcime

Il y a je ne sais quoi de vague dans son regard qui fait connaitre qu'elle ne pense qu'au passé... 
Lydanie

181

Cependant la douceur et l'espèce de calme répandus sur sa physionomie semblent exprimer qu'elle jouit déjà des consolations de l'expiation de ses égarements...

Alcime

Ses premiers remords ne sont plus que des regrets...

Lydanie

Et surtout de l'étonnement de ses fautes passées - elle ne peut plus les concevoir.

Alcime

Il est vrai que l'expression de son visage dit tout cela.

Lydanie

Paix, donc, elle parle...

Alcime

J'écoute...

Lydanie

Quoi, vous ne l'entendez pas?

Alcime

Servez-lui d'interprète... que dit-elle?

Lydanie

Que ne dit-elle pas !... En se rappelant les vaines illusions qui la séduisirent, elle n'en comprend plus le prestige! Elle voit que presque toutes les erreurs qu'elle appela des passions n'étaient que les égarements causés par l'orgueil le plus frivole! Et combien elle reconnaît la folie de ceux qu'elle peut attribuer à la sensibilité !... Ah! Cette âme immortelle formée pour aimer éternellement, pour adorer la perfection souveraine et suprême, abjure et profane son auguste destination, lorsqu'elle s'attache avec ardeur à des créatures imparfaites et à des objets périssables !... Avant d'arriver dans ce désert, elle a souffert des peines mille fois plus cruelles que les rigueurs de la plus austère pénitence. Elle a passionnément aimé, ainsi elle a connu tous les tourments du cœur : les craintes, les inquiétudes déchirantes, les chagrins amers causés par la jalousie, l'inconstance humaine et l'ingratitude. Elle sait apprécier la douceur du calme et de la tranquillité, et le bonheur de retrouver la paix en recouvrant la raison et l'innocence.

Alcime

Mais cette effrayante solitude?

Lydanie

Dieu pour elle en remplit l'immensité.

Alcime

Mais le souvenir des enchantements du monde...

Lydanie

N'est plus pour elle qu'un songe pénible. Elle ne voit plus sur la Terre que le vice dans toute sa difformité, sous quelque forme spécieuse qu'il puisse prendre, et la vertu dans tout son éclat enchanteur.

Alcime

Si belle, et si jeune !... 
Lydanie

195

196 Madeleines...

Lydanie

197 pendant quelques heures, se convertirait si elle avait le goût des arts et de l'âme.

Alcime

A cet égard, madame, vous pensez comme Aristote qu'il est « des tableaux aussi capables de faire rentrer en eux-mêmes des hommes vicieux que les préceptes de morale donnés par les philosophes ».

Lydanie

199 J'ai lu dans les Réflexions sur la peinture et la poésie, de l'abbé Du Bos, que saint Grégoire de Nazianze rapporte l'histoire d'une courtisane qui, dans un lieu où elle n'était pas venue pour faire des réflexions sérieuses, rentra tout à coup en elle-même, jetant les yeux par hasard sur le portrait de Polémon, philosophe fameux, par un changement subit de mœurs et de vie.

Cédrénus raconte, dit le même auteur, qu'un tableau du Jugement dernier contribua beaucoup à la conversion d'un roi des Bulgares.

Alcime

201 Pour vous, madame, vous n'avez pas besoin de ces salutaires impressions, mais vous devriez me ramener tous les jours dans ce cabinet et y passer chaque fois trois ou quatre heures avec moi pour m'expliquer les pensées des Madeleines, ce qui me ferait certainement un très grand bien.

Lydanie

202 En attendant, achevons de parcourir cette intéressante maison.

203 Ils sortent du cabinet.

Alcime

Quand nous aurons examiné cette pièce, nous n'en aurons plus qu'une à voir.

$$
\text { Lydanie }
$$

Voilà encore une charmante statue de Canova. C'est une muse...

Alcime

Et l'un des plus beaux morceaux de ce grand maître.

Lydanie

Quelle jolie petite naïade en marbre, de Chaudet !...

Alcime

Arrêtons-nous devant ce beau tableau de Carlo Cignani...

Lydanie

Il représente Psyché avec sa lampe regardant l'Amour endormi...

Alcime 
C'est un bien beau tableau.

$$
\text { Lydanie }
$$

211 Assurément. Il est dommage que l'Amour ne soit pas plus joli...

Alcime

212 Vous êtes difficile en amour, mais vous en avez le droit, et je n'en suis point effrayé.

$$
\text { Lydanie }
$$

213 Partout des dessus-de-porte précieux.

Alcime

214 Celui-ci est d'Angélique Kauffmann, et l'autre de Robert.

$$
\text { Lydanie }
$$

215 Voyons ces grands tableaux.

\section{Alcime}

216 Celui-ci de Granger, un de nos excellents peintres, représente, je crois, Apollon et Cyparisse mourant ${ }^{2}$ - cette dernière figure est admirable.

$$
\text { Lydanie }
$$

217 Je trouve qu'Apollon n'a pas l'air assez affligé...

\section{Alcime}

218 L'expression de la douleur convient-elle aux dieux?

$$
\text { Lydanie }
$$

219 Oui, puisque la mythologie leur donne tous les sentiments et toutes les passions des hommes.

Alcime

220 Il est vrai que les dieux de la fable avec une puissance surnaturelle et suprême ont, en même temps, toutes les faiblesses de l'humanité.

$$
\text { Lydanie }
$$

221 Ainsi nous devons savoir gré aux poètes qui les ont inventés de ne les avoir pas faits plus méchants.

\section{Alcime}

Voici un tableau fameux d'un peintre que vous aimez particulièrement...

$$
\text { Lydanie }
$$

Ah ! de Guérin...

$$
\text { Alcime }
$$

Oui, Céphale endormi enlevé par l'Aurore.

$$
\text { Lydanie }
$$

Que Céphale est charmant !...

Alcime

226 L'Aurore vous plait moins, j'en suis sûr ?...

Lydanie

Ah ! Qui pourrait donner de la grâce et du charme à une femme qui enlève un homme !...

Alcime 
Voici un autre enlèvement qui vous plaira peut-être mieux... C'est, de Boisfrémont, Vénus enlevant le petit Ascagne.

Lydanie

La Vénus est régulièrement belle, et cependant elle n'a rien de séduisant, et j'en sais la raison...

Alcime

Eh bien?

Lydanie

C'est qu'elle n'a pas la ceinture des Grâces.

Alcime

Elle en a une pourtant. Voyez ce large ruban bleu autour de sa taille et dont les pans si longs voltigent au gré des zéphyrs...

Lydanie

Si c'était la ceinture des Grâces, ce serait aussi celle de la pudeur...

Alcime

Et elle ne l'est pas. Je conviens que l'artiste aurait pu, et aurait dû former de ces pans égarés et flottants une draperie modeste - votre remarque a autant de justesse que de délicatesse.

\section{Lydanie}

Mais l'enfant est d'une beauté enchanteresse... Vous qui faites des vers avec tant de facilité, vous devriez faire un impromptu sur cette ravissante petite figure.

Alcime

Vous le voulez $? .$.

Lydanie

Je vous en conjure.

Alcime

Écoutez donc avec indulgence :

« Tout est divin dans cet enfant.

Que son sommeil est doux, quel calme ravissant!

Quelle fraîcheur et quelle grâce !...

Quel est donc cet attrait, ce charme qui surpasse

Celui même de la beauté ?

C'est le charme touchant de la naïveté,

De la candeur, de l'innocence,

De l'aimable sérénité,

Enfin celui de l'espérance

Qu'inspire à tous les cœurs l'intéressante enfance. »

Lydanie

Je vous remercie mille fois de cet impromptu. La pureté de ces idées lui donne un prix infini à mes yeux. 
Alcime Un amateur italien ordinaire se serait cru obligé de n'y admettre que des chefs-d'œuvre des anciennes écoles d'Italie; mais le véritable ami des beaux-arts n'exclut dans ses choix aucun pays. La patrie n'est pour lui qu'où elle doit être, c'est-à-dire dans les intérêts sociaux et politiques, et quand il s'agit d'apprécier les talents, la contrée, pour lui, n'y fait rien. Admirateur éclairé de tout ce qui est beau et bon, il se regarde comme le concitoyen de tous les hommes qui se distinguent avec grandeur, il se naturalise partout où il voit le génie. Enfin, il n'attend pas que le temps en ait consacré les productions, il aime à devancer le jugement de la postérité - c'est s'associer à la gloire de ceux dont elle immortalisera les noms; et certainement elle mettra l'école française actuelle de peinture au rang des écoles anciennes les plus justement célèbres.

Lydanie

259 Tout ceci me confirme dans l'idée que j'ai toujours eue qu'un goût véritablement pur suppose une infinité de qualités précieuses...

\section{Alcime}

260 Ah ! sans doute c'est un don du ciel, et quand il est perfectionné par l'étude et qu'il s'est enrichi de connaissances positives et réelles, cet heureux instinct d'un esprit délicat et d'une belle âme devient la lumière la plus éclatante et la plus sûre, et l'on peut dire avec vérité qu'en toutes choses le véritable bon goût n'est jamais frivole.

Lydanie

Oui, tous les résultats en sont si beaux!

Alcime

Et quand ils ne sont pas aussi brillants qu'ils le sont ici, ils ont toujours quelque utilité. 
Lydanie

Souvent même une importante utilité, c'est le goût qui, dans la société, a établi les règles les plus raisonnables et les idées les plus délicates, sur les bienséances, la politesse et la décence.

\section{Alcime}

Rien n'est plus vrai, car sans le goût, il n'y a point de véritable civilisation.

Lydanie

Sans le goût, que deviendrait la littérature?

Alcime

Ce qu'elle est aujourd'hui, tombant en décadence...

Lydanie

267 Le goût peut seul préserver les écrivains de l'enflure, de l'emphase, du galimatias, de l'affectation...

Alcime

Oui, le bon goût surtout prescrit le naturel...

Lydanie

269

Et en même temps il sert à le régler, il l'empêche de dégénérer en niaiseries ou en grossièretés...

Alcime

270 Entraîné par la conversation, j'ai oublié de vous dire une chose qui va vous charmer...

Lydanie

Quoi donc?

Alcime

272 Vous avez admiré ces charmantes miniatures en émail qui offrent de si élégantes copies de ces beaux tableaux, ce que vous avez appelé avec raison un magnifique catalogue...

$$
\text { Lydanie }
$$

273 Eh bien?

Alcime

274 Eh bien, il existe encore un autre catalogue de ces mêmes tableaux et beaucoup plus magnifique.

$$
\text { Lydanie }
$$

275 Est-il possible!

\section{Alcime}

276 Jugez-en : toute cette collection a été gravée en creux et en relief en Italie, sur des pierres fines, et par les plus habiles artistes en ce genre ${ }^{3}$.

$$
\text { Lydanie }
$$

277 On peut dire sans exagération que l'ingénieux possesseur de ce cabinet a su employer tous les arts pour multiplier et pour immortaliser cette collection...

Alcime

Oui, tous les arts, en effet, car outre tout cela, il fait graver au trait ces tableaux pour les placer dans un livre qui en sera le vrai catalogue. 
Lydanie

279 Je voudrais que toutes les miniatures et toutes les pierres gravées formant les copies des tableaux et complétant une triple collection de si belles choses fussent, avec le catalogue, réunies dans une pièce qui leur serait consacrée, et qui ne serait pas la moins intéressante de cette maison.

\section{Alcime}

C'est sûrement ce qu'on fera. J'attends vos ordres pour vous conduire dans la dernière pièce.

$$
\text { Lydanie }
$$

Ici, ce qu'on voit fait oublier ce qui reste à voir... Mais allons, je vous suis.

Ils sortent et entrent dans le dernier cabinet.

\section{Alcime}

Regardez d'abord ce grand et charmant tableau, qui est à mon avis le plus beau de Prud'hon...

$$
\text { Lydanie }
$$

Quelle ravissante figure! C'est l'Amour?

$$
\text { Alcime }
$$

Point du tout. C'est Zéphyr se balançant dans les airs en agitant des branches d'arbres.

$$
\text { Lydanie }
$$

Il est beau, comme on voudrait que ce fût l'Amour quand l'imagination ose se le représenter...

\section{Alcime}

287 Les jeux de l'Amour ne sont pas si innocents! Désoler un cœur sensible et passionné, le forcer d'aimer sans espérance, empêcher que l'indifférence et les rigueurs ne le guérissent, tels sont les jeux cruels de l'Amour !...

$$
\text { Lydanie }
$$

Et vous m'accusiez de le calomnier !...

Alcime

Me trouvez-vous donc injuste? Un seul mot de vous pourrait me le prouver...

$$
\text { Lydanie }
$$

C'est un mot qu'il est toujours inutile de prononcer; favorable ou non, il se devine si bien !...

\section{Alcime}

Je ne sais deviner que ce qui me désespère...

$$
\text { Lydanie }
$$

292 Nous parlerons de cette rare modestie dans un autre moment, il est tard, achevons de voir ce cabinet!

\section{Alcime}

Vous rompez toujours l'entretien au moment même où je voudrais le prolonger !...

Lydanie

Il est si nécessaire de vous rappeler à l'ordre ! Vous seriez un bien mauvais député !... 
Alcime

295

296

298

299 royale, l'éclat et le charme de la jeunesse, l'intérêt touchant de la maternité uni à celui de l'innocence virginale, la grâce de l'enfance jointe à l'empreinte de la divinité.

Lydanie

Il serait à désirer que les peintres connussent davantage l'Écriture sainte. Ils y trouveraient une foule de nouveaux sujets de tableaux, par exemple dans les amours si purs de Moïse et de Séphora: Ruth voulant suivre Noémie et lui disant: "votre Dieu sera mon Dieu, votre peuple sera mon peuple ${ }^{4} »$, etc.

Alcime 
La vie des saints doit sans doute aussi contenir un grand nombre de faits dont l'art de peindre pourrait s'enrichir...

\section{Lydanie}

310 Assurément. Sainte Dorothée recevant d'un ange un bouquet de roses; sainte Thècle, livrée aux bêtes et dans l'arène où les tigres et les lions ne se rassemblèrent autour d'elle que pour lui baiser les pieds, premier martyre d'une femme qui, au lieu d'être un supplice, fut un éclatant triomphe ; saint Numidique, condamné à être brûlé vif, sauvé par la piété de sa fille qui, voulant recueillir les ossements du martyr, le trouva dans les débris du bûcher et seulement évanoui, et l'emporta sur ses épaules; saint Genès, comédien, qui se convertit tout à coup sur le théâtre en recevant par dérision le baptême pour se moquer des cérémonies chrétiennes; sainte Panacée, âgée de quinze ans, à genoux, priant Dieu et prête à recevoir de sa méchante belle-mère le fatal coup de quenouille qui lui coûte la vie; saint Télémaque se jetant au milieu des gladiateurs pour les séparer, action qui le fit massacrer par le peuple, mais qui fit aussi abolir ces jeux barbares...

\section{Alcime}

En vérité, madame, vous avez une édifiante érudition...

$$
\text { Lydanie }
$$

Et je ne suis pas au bout, ma mémoire me rappelle encore plusieurs traits, mais en voilà bien assez pour une conversation...

\section{Alcime}

Non, non, de grâce, continuez...

Lydanie

Eh bien, je citerai encore!

Saint Luce, père du désert, dans sa grotte faisant des paniers et des corbeilles, pour les vendre au profit des pauvres. Saint Coprès cultivant devant sa grotte de petits jardins afin d'en vendre les fruits et les légumes au profit des pauvres. Saint Dorothé bâtissant avec des pierres, qu'il allait chercher au loin, de petits hospices pour servir de refuge aux voyageurs égarés dans le désert. Sainte Madeleine du désert, drapée seulement avec ses longs cheveux, rencontrant saint Zozime et se mettant à genoux pour implorer sa bénédiction, tandis que le saint, détournant un peu la tête pour éviter de la regarder, jette son manteau sur les épaules de la belle pénitente. Sainte Sophronie mourante dans le désert et écrivant sur l'écorce d'un arbre les actes de sa vie. La même Sophronie étendue morte à la porte de sa grotte, et tous les oiseaux du désert tenant dans leur bec des rameaux d'olivier et des fleurs qu'ils jetaient sur son corps. Le superbe et farouche Totila dans l'humble cellule de saint Benoît, abaissant devant lui toute sa fierté sauvage et le consultant sur sa destinée. L'impératrice d'Allemagne sainte Élisabeth, entourée d'enfants des pauvres auxquels elle enseigne elle-même à lire.

\section{Alcime}

Il est certain que tous ces traits formeraient de beaux sujets de tableaux et dans tous les genres, et surtout le premier que vous avez cité, sainte Dorothée recevant d'un ange un bouquet de roses, et la Madeleine du désert, donneraient les sujets de deux tableaux ravissants.

Lydanie 
317

318

Alcime Voici la seconde armoire qui renferme une tête de Christ, de Titien...

Lydanie

Alcime

$$
\text { Lydanie }
$$

Alcime enthousiasme...

$$
\text { Lydanie }
$$

Où sont-ils donc?

Alcime

Dans ces deux petites armoires.

Lydanie

Hâtons-nous de les ouvrir...

Alcime

Voici d'abord une Madeleine du Corrège...

Lydanie épuisée... qu'il faut contempler cette tête sacrée !...

Alcime

Il est impossible de la regarder sans une profonde émotion !...

Lydanie visage divin!

Alcime

Quels yeux! Et quel regard !...

Lydanie deux Madeleines.

\section{Alcime}

Il vous reste à voir encore deux chefs-d'œuvre dignes d'exciter tout votre

Je serais en extase devant elle si mon admiration pour les Madeleines n'était pas

uelle inimitable perfection de peinture, de vérité et d'expression! C'est à genoux

Toutes les douleurs humaines et toute la majesté de l'Évangile sont rassemblées sur ce

Il pénètre jusqu'au fond de l'âme !... Quelle expression ! Jamais la peinture n'atteignit à ce degré de sublimité ! Ce n'est point un tableau, c'est un portrait qui inspire le désir de se prosterner! Il ne peut être bien placé dans cette collection que dans le cabinet des

Lydanie 
Oui, sa place est naturellement marquée dans ce réduit solitaire qui semble être destiné à la prière et à la méditation, et là, sa vue seule expliquerait la conversion des deux pénitentes.

\section{Alcime}

Il me vient une idée...

$$
\text { Lydanie }
$$

\section{Quoi donc?}

Alcime

336 Nous avons passé en revue et jugé tous les tableaux de cette collection : savez-vous que si l'on écrivait notre conversation, ce serait un fort joli catalogue de ce beau cabinet..

Lydanie

Un fort joli catalogue : vous êtes modeste !...

Alcime

Je ne pense point à la part que j'ai pu y avoir, je ne me rappelle que ce que vous avez dit. Vous êtes trop polie pour me déclarer que j'ai mal répondu. Ainsi, vous voyez qu'entre nous deux il est décidé que notre dialogue a été charmant. Si vous y consentez, je me charge de l'écrire très fidèlement de mémoire. Et nous l'appellerons catalogue pittoresque...

\section{Lydanie}

Catalogue ! Le possesseur de ce cabinet en a déjà de si beaux !...

Alcime

Oui, mais non en ce genre. Le nôtre sera littéraire, il n'en a point de tel, nul autre n'en possède, ainsi ce sera du moins une chose absolument unique... Et alors, ce que vous disiez, que tous les beaux-arts concourraient à former des catalogues de cette collection, sera exactement vrai, puisqu'il y en aura un littéraire.

$$
\text { Lydanie }
$$

Eh bien, il manquerait encore un catalogue : celui de la musique...

\section{Alcime}

Cela est vrai ! Mais il ne serait pas impossible d'en faire un musical.

$$
\text { Lydanie }
$$

Comment?

Alcime

Lydanie

J'entends. Six ou huit vers, non pour chaque tableau, mais pour chaque sujet différent, et qui seraient mis en musique par quelques beaux compositeurs.

Alcime

Cela serait charmant, mais en attendant, j'écrirai notre catalogue pittoresque.

Lydanie

347 J'espère que vous en retrancherez toutes les folies que vous m'avez adressées ?...

Alcime 


\section{ANNEXES}

Lire les extraits de l'Essai sur les arts de Félicité de Genlis

Lire l'introduction à Félicité de Genlis écrite par Charlotte Foucher

\section{NOTES}

1. Ce fut elle qui fit ce tableau fameux qu'on appelle La Dernière Pensée de Virgile, ce qu'elle a exprimé en représentant Virgile mourant dans les bras de sa muse éplorée, tenant d'une main un stylo d'or avec lequel il trace une ligne et de l'autre sa lyre dont toutes les cordes sont rompues à l'exception d'une seule!

2. Ou le jeune Hyacinthe.

3. (NdA) La bibliothèque de l'INHA a récemment acquis un exemple de ces reproductions miniatures, non en émail mais sous la forme d'intailles qui sont dues aux graveurs Giovanni Beltrami et Giacomo Pichler (Ms 808 [1-2]).

4. Les cérémonies religieuses, entre autres celle de l'offrande de la gerbe sacrée dont les apprêts champêtres formaient un spectacle si riant et si solennel! 
Marie-Camille de G. (? - ?) 


\title{
Introduction
}

\author{
Amandine Gorse
}

1 Les événements qui agitèrent les premiers mois de la Monarchie de Juillet créèrent un contexte favorable à l'émergence d'une presse féministe, permettant aux premières journalistes militant en faveur des droits de la femme de trouver dans les colonnes de certains périodiques un lieu de débat où faire valoir leurs points de vue. Ainsi fut publiée, à partir de 1832 et sous la houlette d'un groupe de femmes déterminées à faire respecter leur liberté, La Tribune des femmes, connue auparavant sous le titre de La Femme libre (MALLET 1980, p. 203-212 et BITOUN 2007). Émancipées de la tutelle masculine, ces femmes firent le choix d'utiliser des pseudonymes ou de ne signer que de leur prénom, évitant ainsi toute subordination à un patronyme masculin. Parmi elles se trouvait la journaliste Marie-Camille de G., dont on connaît peu de chose (HARRISON, GAIGER et WOOD 1998, p. 155). On sait qu'elle prit part à la rédaction de la Tribune des femmes aux côtés de Claire Démar, Marie-Reine Guindorf, Désirée Véret et Suzanne Voilquin, jeunes femmes issues des couches populaires et mues par la doctrine saintsimoniste (ADLER 1979 et RIOT-SARCEY 2002, p. 27-38). Ce magazine éphémère, si l'on considère la durée de vie moyenne d'un périodique, parut de 1832 à 1834, date à laquelle il fut contraint à la faillite par les mesures répressives du nouveau gouvernement.

2 Dans sa critique du Salon de 1834 - le seul écrit qu'on lui connaisse -, Marie-Camille de G. exhortait les artistes à véhiculer les valeurs du saint-simonisme, en particulier l'idée de cohésion sociale (MCWILLIAM 2007, p. 93). Prônant l'égalité entre tous, elle souhaitait voir disparaître la menace d'un système monarchique corrompu et incapable de répondre aux besoins de la population. C'est pourquoi elle choisit de témoigner des drames internes d'une société en proie aux doutes et à la crise en célébrant sur un ton passionné l'expression, le mouvement et la musicalité de la couleur. Elle exalta le pouvoir de la peinture à faire de la misère humaine un sujet du Beau, à la manière de l'art romantique. Marie-Camille de G. élabora alors son texte comme un manifeste politique - le vocabulaire utilisé donne au texte la tonalité d'une harangue -, dans le but d'inscrire les arts dans la doctrine saint-simonienne. Elle convia les artistes à se rassembler dans une morale commune et à créer une œuvre utile à l'Homme. Sous couvert d'une critique de Salon, Marie-Camille de G. livra des commentaires sur la mise 
en place de la monarchie constitutionnelle et développa sa propre vision du saintsimonisme. Elle défendit le prolétariat face à un gouvernement qu'elle ne cautionnait pas.

\section{BIBLIOGRAPHIE}

ADLER 1979

Laure Adler, À l'aube du féminisme, les premières journalistes : 1830-1850, Paris, Payot, 1979.

BITOUN 2007

Carole Bitoun, La Révolte au féminin : portraits de femmes exemplaires, Paris, Hugo \& Cie, 2007.

HARRISON, GAIGER et WOOD 1998

Charles Harrison, Jason Gaiger et Paul Wood, Art in theory, 1815-1900: an anthology of changing ideas, Malden, Wiley-Blackwell, 1998.

MALLET 1980

Sylvie Mallet, «Tribune des Femmes : une éducation pour l'indépendance économique », Romantisme, $1980, \mathrm{n}^{\circ} 28$, p. 203-211.

MCWILLIAM 2007

Neil McWilliam, Rêves de bonheur : l'art social et la gauche française (1830-1850), Dijon, Les Presses du réel, 2007.

RIOT-SARCEY 2002

Michèle Riot-Sarcey, Histoire du féminisme, Paris, La Découverte, 2002.

\section{ANNEXES}

Diaporama des œuvres commentées par Marie-Camille de G. dans son article « Beauxarts - Salon de 1834 » paru dans la Tribune des femmes : http://www.flickr.com//photos/73632227@N02/sets/72157629753656958/

Lire l'article « Beaux-arts - Salon de 1834 » de Marie-Camille de G. publié dans la Tribune des femmes

Liste complète des œuvres d'arts commentées par Marie-Camille de G. à travers ses textes édités dans Plumes et pinceaux 


\section{Marie-Camille de G., Tribune des femmes, 1834}

[extraits choisis]

$\mathrm{n}^{\mathrm{o}} 10$, avril 1834, p. 158-164.

\section{« Beaux-arts - Salon de 1834 »}

1 L'artiste doit émouvoir. Cette puissance, il ne la possède véritablement que lorsqu'il est nourri par une pensée générale, une pensée religieuse, douce nourrice qui lui verse généreusement dans l'âme cet enthousiasme qui fait du poète un prophète, avec lequel Orphée donnait du sentiment à la pierre, avec lequel les peintres du Vatican arrachaient les convictions à ceux qui regardaient leurs tableaux. L'histoire des beauxarts peut se diviser en époques de pensée et époques de forme. Sous l'influence d'une pensée religieuse, la forme est comme les sentiments d'une âme ardente, naïve et sublime, désordonnée et naturelle, simple et biblique; voyez le langage patriarcal d'Homère et la franche allure des poésies du Moyen Âge. Mais lorsque cette source de miel est tarie, que l'incrédulité vient s'asseoir sur l'autel et glacer sur les lèvres du prêtre ses paroles brûlantes, alors à la préoccupation de la pensée succède la préoccupation de la forme qui devient sévère, régulière, classique. Lorsque Aristophane fait descendre les dieux de l'olympe sur le théâtre, qu'il les couvre d'oripeaux et les jette aux risées de la populace, alors viennent les rhéteurs. Lorsque le $\mathrm{XVI}^{\mathrm{e}}$ siècle, ce siècle de disputes entre les moines, les rois, le pape et l'avenir trouble le silence mystique du cloître et l'église, lorsque la divine colombe, s'effarouchant dans son nid d'ogives, prend son vol et remonte au ciel dans les bras de son père, alors les arts sortent du temple, froids comme un corps que la vie a déserté; on proclame la Renaissance, c'est-à-dire le triomphe de la forme sur la pensée. Ainsi les arts vivent de la même vie que l'humanité ; ils rayonnent d'enthousiasme quand elle est religieuse, ils manquent d'inspiration quand elle est incrédule.

2 De même que l'humanité se fatigue de marcher sur un sentier aride que ne fleurit aucun sentiment de bonheur, de n'avoir aucune pensée sur laquelle elle puisse reposer son âme brisée, de même les arts, lorsque l'époque classique a fait ses évolutions, qu'elle a eu son siècle d'Auguste ou son siècle de Louis XIV, qu'elle a dit son dernier mot 
dans un Virgile ou un Racine, que le mérite ne consiste plus qu'en des imitations et des pastiches, alors les arts s'efforcent de revenir à une forme d'originalité et de vie, on brise les règles de la rhétorique, on fait de la liberté, de l'art, du romantisme. Bientôt viennent des hommes intermédiaires, des éclectiques dans les arts comme dans la politique, comme dans la philosophie; et des hommes marchant à une forme d'avenir. Cette époque est la nôtre; en littérature, M. Casimir Delavigne est en face de M. Victor Hugo ; en peinture, M. P. Delaroche est en face de M. Ingres. Espérons qu'en sculpture, la question ne tardera pas à se dessiner mieux.

3 Une pensée nouvelle n'anime pas encore ces novateurs; ce n'est qu'un travail de forme, mais c'est une préparation nécessaire pour comprendre la parole de Dieu qui va parler par la bouche de son élu.

4 Ces premières idées vont nous servir à comprendre l'exposition et le mouvement des esprits. Pourquoi la foule, artistes et amateurs, tourbillonnent-ils autour de deux tableaux, celui de M.P. Delaroche et celui de M. Ingres ? C'est que tout le problème actuel de l'art se trouve renfermé dans le talent mixte de M.P. Delaroche, et le génie original de M. Ingres.

\section{Paul Delaroche, Jeanne Grey [L'Exécution de Jeanne Grey]}

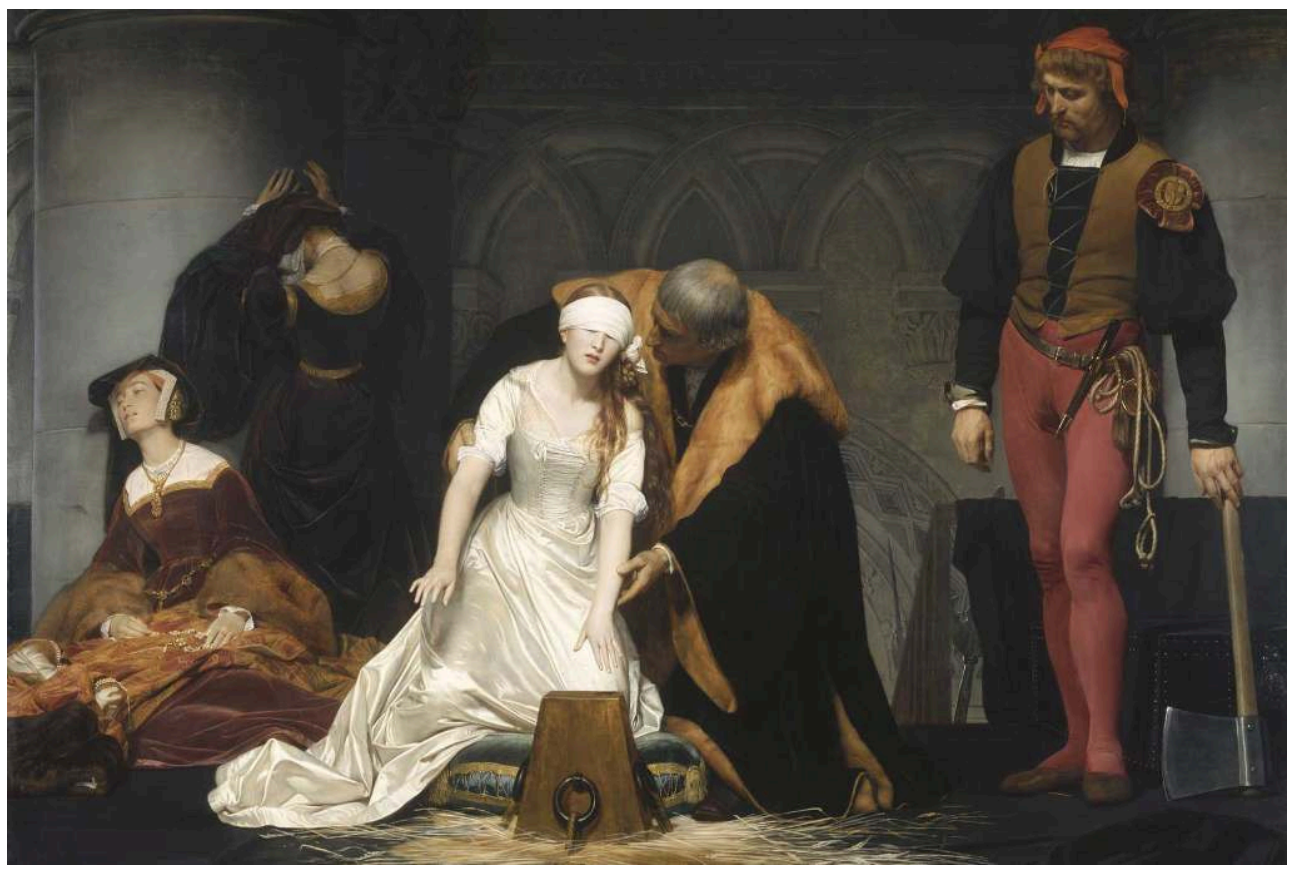

1834, huile sur toile, $180 \times 155 \mathrm{~cm}$, Londres, The National Gallery.

Le sujet du tableau de M. P. Delaroche est Jeanne Grey au moment où le bourreau va lui trancher la tête par ordre de la reine Marie (fig. 1). Pauvre jeune fille! Tu vas mourir pour avoir fait un rêve, tu as voulu te parer des ornements royaux, tu as voulu voir tes beaux yeux rayonner sous une couronne de diamants, mais Marie t'a fait descendre du trône au fond de la tour de Londres, au lieu d'une couronne brillante, elle t'a donné un bandeau qui te ferme les yeux, au lieu de coussins dorés pour reposer ta tête, elle te donne un billot. Oh ! Tu as bien souffert, tu as longtemps versé des larmes sur un passé fleuri, maintenant on voit qu'il te tarde d'être dépouillée d'une vie qui te pèse! Ta pensée heurte l'avenir... Tu fais bien, Jeanne, car l'immortalité est au bout de la hache du bourreau! En face de Jeanne est le bourreau, c'est une noble tête ; sous les plis de 
son front, il cache de la douleur. Il semble se dire à lui-même : pourquoi a-t-elle quitté son berceau parfumé de fleurs et de caresses ? Pourquoi dix-sept ans sont-ils venus l'un après l'autre lui apporter tant de grâces ? Pourquoi l'ont-ils parée de tant de beauté ? Pour qu'elle vînt épouser ma hache ! À côté de Jeanne est le gardien de la tour, dont la tête manque d'expression; derrière, les deux suivantes de la princesse s'évanouissent. La couleur de ce tableau est d'une vérité frappante, le dessin est régulier, les poses naturelles, mais on voit avec peine que l'artiste était trop préoccupé des détails, le tapis est soigneusement tendu, les plis de la robe de Jeanne tombent régulièrement, rien ne manque, pas un clou. M. Delaroche prend une position donnée, s'en pénètre bien et l'exprime avec exactitude, mais il manque d'originalité. Ce n'est qu'un homme de grand talent.

\section{Jean Auguste Dominique Ingres, Le Martyre de saint Symphorien}

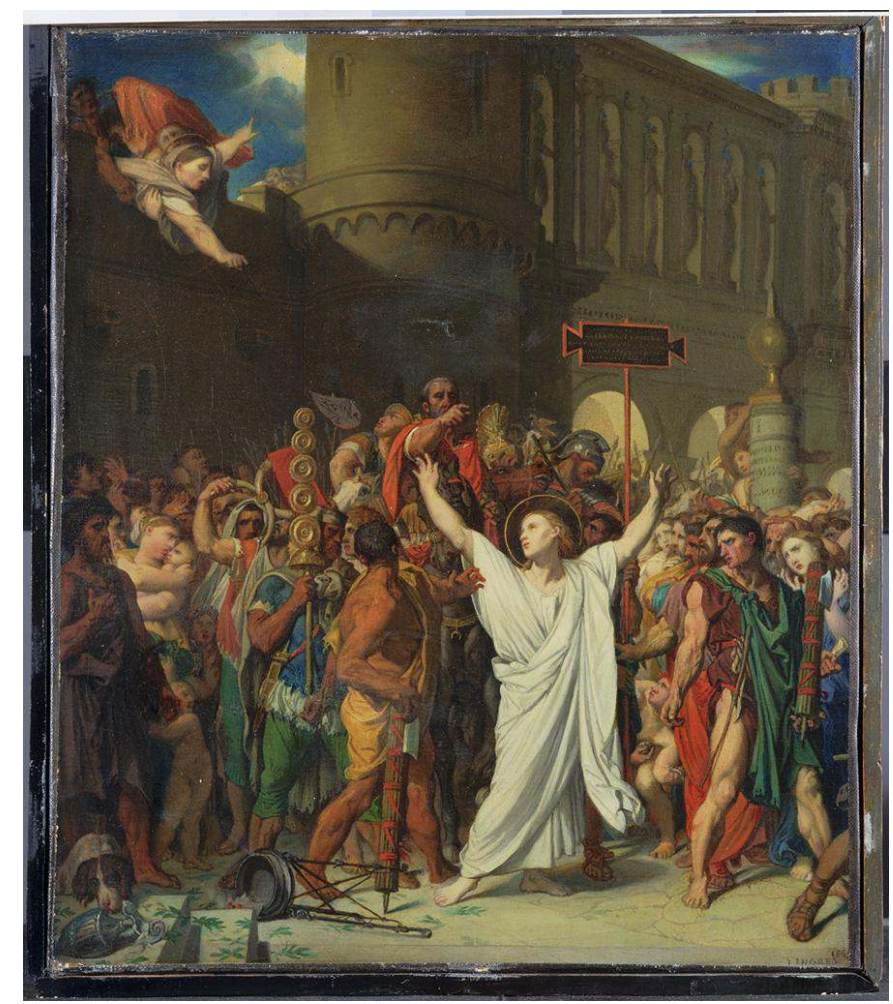

1834, huile sur toile, 405 × 337 cm, Autun, cathédrale Saint-Lazare

Que ceux qui ne conçoivent pas encore l'unité dans la variété s'approchent du tableau de M. Ingres (fig. 2). Saint Symphorien a souffert dans les cachots la soif, la faim et toutes les tortures. Sa chair a bien pu saigner, elle a pu s'ébranler et tomber en lambeaux sous les coups du licteur, mais son âme est restée inébranlable! Il marche au supplice comme un romain vainqueur marcherait au triomphe; il triomphe lui aussi, car tous les tourments sont venus se briser contre sa foi. Au milieu de son enthousiasme de martyr, un sentiment douloureux lui tombe dans le cœur... Sa mère! Il l'abandonne sur la Terre! Il lui jette un dernier regard, mais un regard où l'on voit son cœur suivre la lumière de ses yeux. Elle! Oh qu'elle est grande! Elle voit celui qu'elle a porté dans ses entrailles, celui pour lequel elle s'est fondue en soins et en caresses, marcher à la mort. Eh bien! Cette mère ne faiblit pas, car Dieu s'est révélé à elle, car elle a senti que la tombe n'est pas une fosse de boue, mais un bain où l'âme se 
dégage de ce qu'elle a d'impur pour planer plus radieuse et plus belle dans les champs d'une nouvelle existence! La mère et le fils semblent deux âmes prêtes à prendre ensemble leur vol vers l'éternité. Oh! Merci, M. Ingres, d'avoir fait cette tête de mère, c'est une belle réponse donnée à ceux qui pensent encore que la femme n'a reçu un cœur que pour des sentiments de faiblesse. Si Dieu les a douées de plus de sensibilité que les hommes, il ne leur a pas donné moins de dévouement et de grandeur. Derrière saint Symphorien est le proconsul, dont la figure, impassible et froide comme le texte de la loi, contraste singulièrement avec l'exaltation du martyr. Autour de l'action principale, M. Ingres en a groupé d'autres qui la développent et la complètent. Nous regrettons qu'au milieu de cette foule qui se presse, l'artiste n'ait pas semé quelques têtes qui pressentent le christianisme; avec cette expression qu'il sait donner aux figures religieuses, elles auraient produit un bel effet. Des défauts de couleur, de l'exagération dans le dessin, une oreille de femme mal placée, des jambes et des bras dénaturés sont de trop petites taches pour qu'on puisse s'y arrêter, ayant tant de belles choses à admirer. M. Ingres est un homme de génie.

7 D'après les distinctions que nous avons faites d'artistes éclectiques et d'artistes originaux, nous placerons après M.P. Delaroche, M. Delacroix et M. Vernet; après M. Ingres, MM. Granet, Decamps et Scheffer aîné.

\section{Eugène Delacroix, Bataille de Nancy}

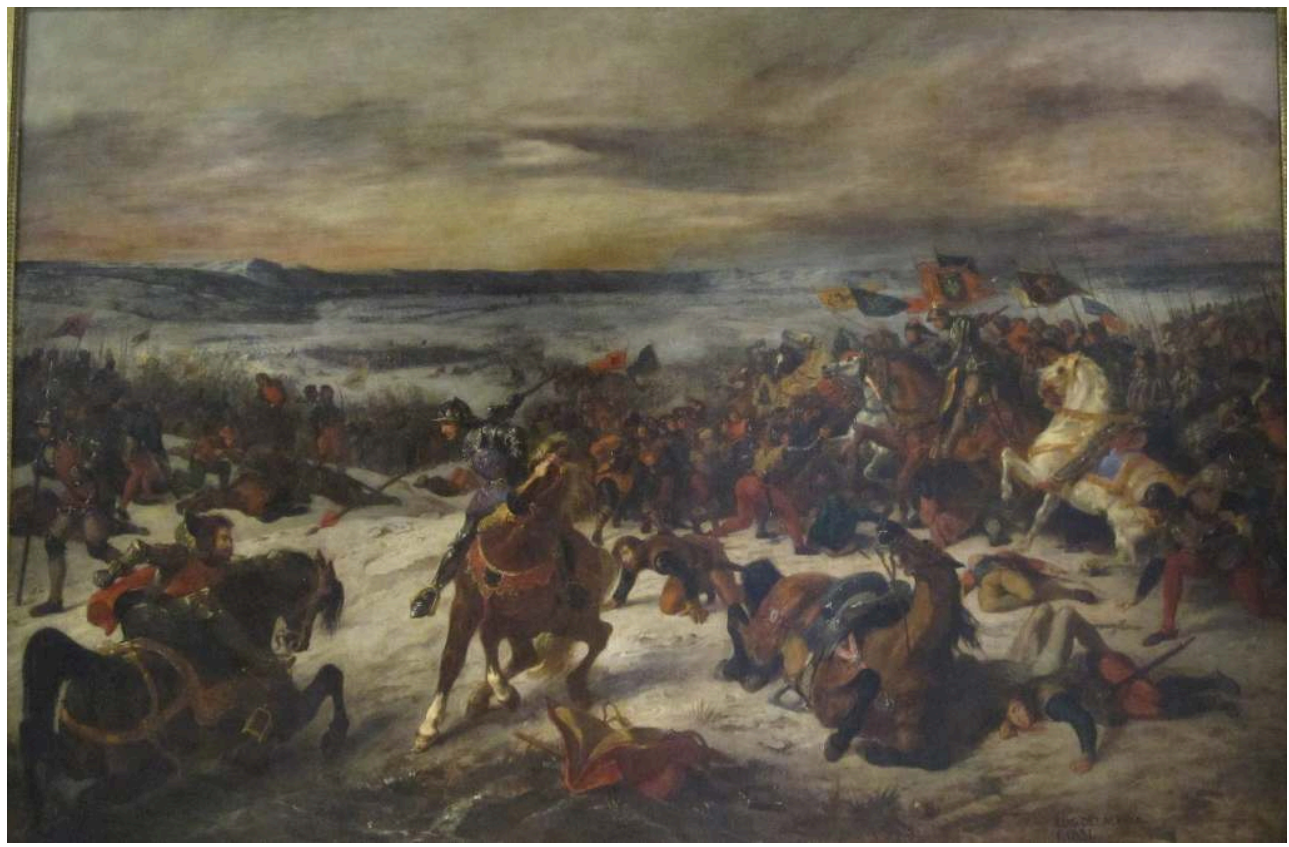

1831, huile sur toile, 237 × 350 cm, Nancy, musée des Beaux-Arts. 
4. Eugène Delacroix, Femmes d'Alger dans leur appartement

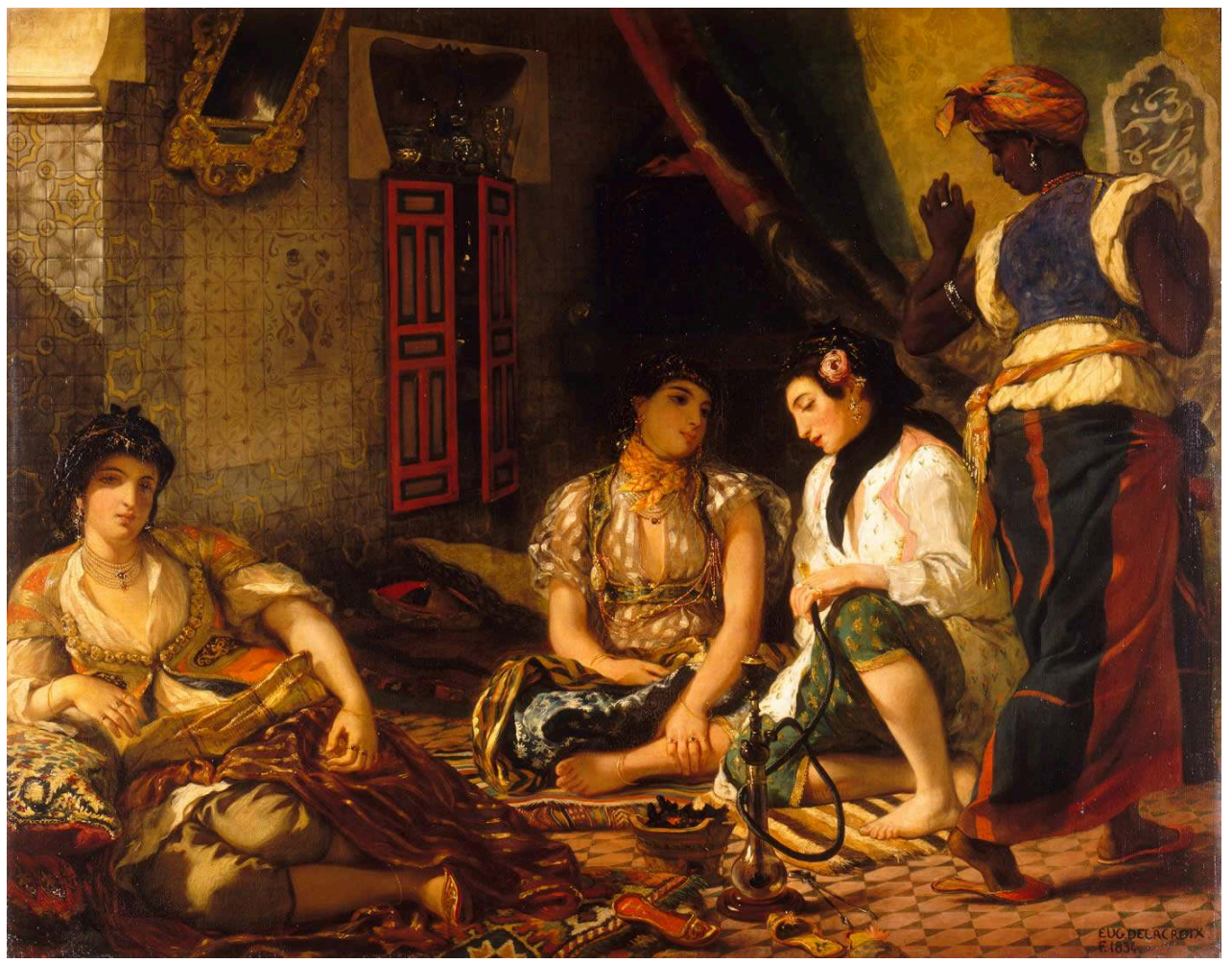

1834, huile sur toile, 180 × 229 cm, Paris, musée du Louvre.

8 M. Delacroix a donné plusieurs tableaux, les deux plus remarquables sont : La Bataille de Nancy (fig. 3), où fut tué le duc de Bourgogne, Charles le Téméraire, et Femmes d'Alger dans leur appartement (fig. 4).

L'ensemble de La Bataille de Nancy ne produit pas un bel effet, quelques détails méritent d'attirer l'attention, le désordre est trop régulier, il y a trop de clarté dans les rangs. Sur le premier plan du tableau, l'on voit un combat singulier : Charles, dont le cheval s'est embourbé dans un étang et fait de pénibles efforts pour en sortir, est attaqué dans ce moment par un chevalier lorrain qui le blesse d'un coup de lance; le duc, désarçonné, est vigoureusement peint, la fureur semble découler de ses cheveux hérissés et de ses grands yeux rouges de sang.

10 Les Femmes d'Alger sont nonchalamment assises sur des tapis, au milieu de nuages de parfums. L'artiste a bien exprimé leur ennui du désœuvrement et des voluptés; les pauvres filles sont insouciantes, elles ne savent ni agir ni penser ; elles s'abandonnent à un farniente qui les fatigue. 
5. Horace Vernet, L'Entrée du duc d'Orléans au Palais-Royal [Le Duc d'Orléans quitte le Palais Royal pour se rendre à l'hôtel de ville, 31 juillet 1830]

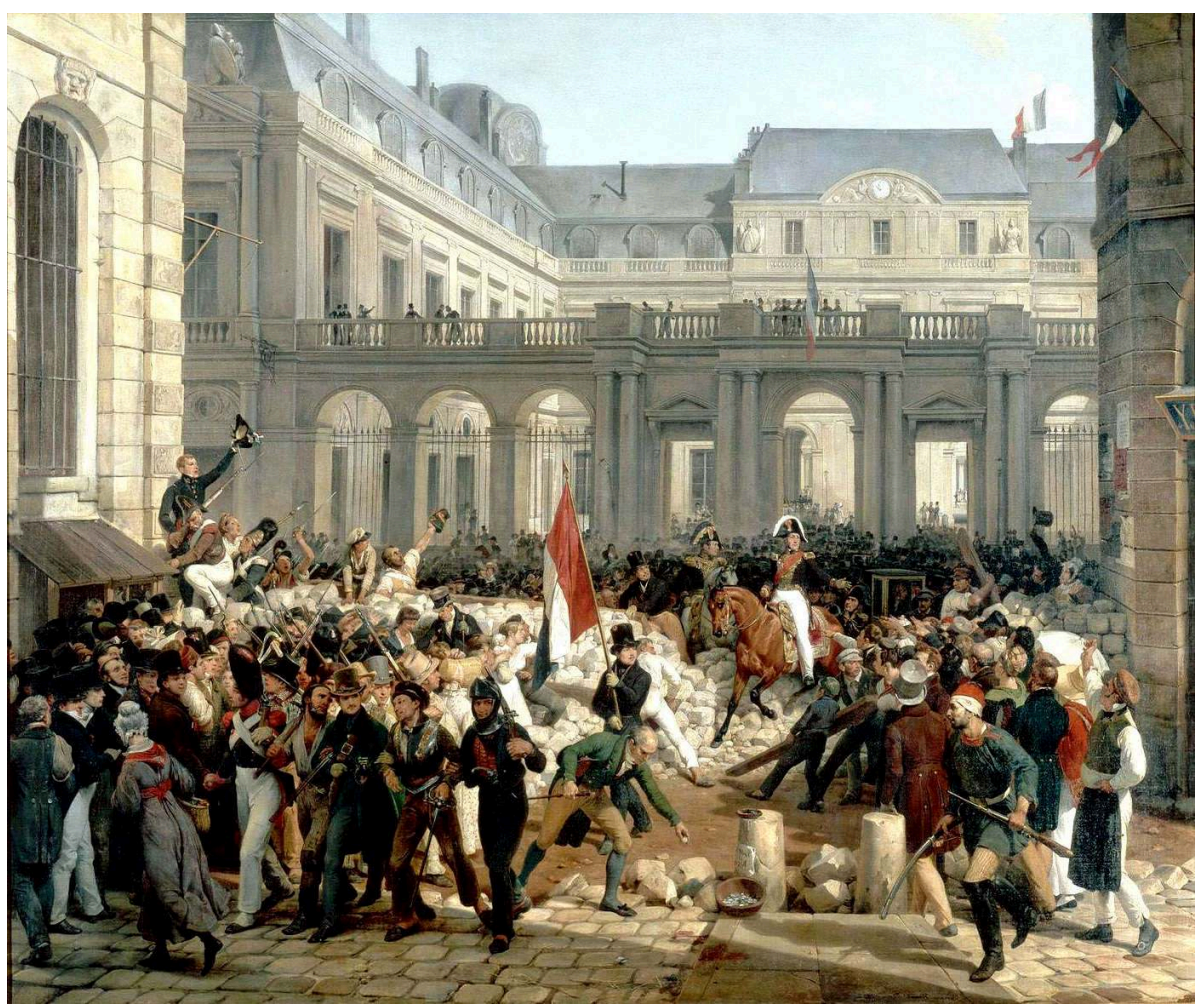

1833, huile sur toile, 228 × 258 cm, Versailles, musée national des châteaux de Versailles et de Trianon.

11 M. H. Vernet a peint L'Entrée du duc d'Orléans au Palais-Royal ; au milieu du tableau, trois héros de Juillet lisent une proclamation, leurs physionomies sont pleines de caractère (fig. 5). Si l'on ne connaissait les bonnes opinions de M. Vernet, on pourrait croire qu'il a voulu caricaturer son principal héros. 
6. Horace Vernet, Une scène d'Arabes dans leur camp [Chefs arabes en conseil ou Le Négociateur]

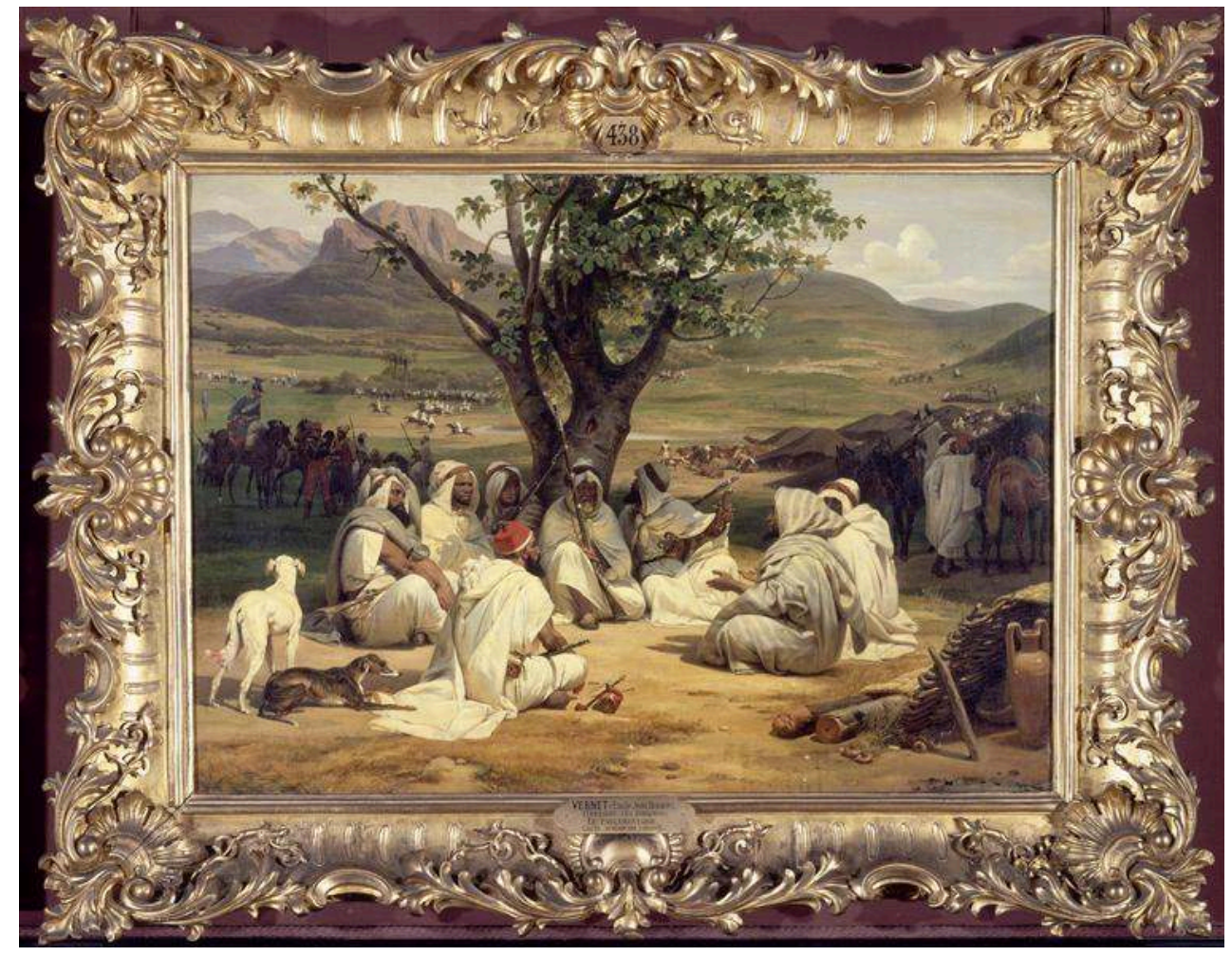

1834, huile sur toile, 98 ×52 cm, Chantilly, musée Condé.

12 Un second tableau du même auteur représente une scène d'Arabes dans leur camp, écoutant une histoire (fig. 6). Les figures des personnages expriment bien cette avidité effrénée des Arabes pour les histoires; toute leur existence semble suspendue aux lèvres de celui qui raconte. Une jeune fille qui avait fait un pas pour s'éloigner s'arrête, enchaînée par la curiosité. Ce tableau est plein de talent.

13 M. Granet a fait un beau tableau de la mort de Poussin, de cet homme de Dieu, plein de modestie et de conscience, qui rougissait quand on le comparait aux grands artistes qu'il admirait, qui refusait toujours une portion de la somme qu'on voulait lui donner d'une de ses œuvres. Dans tout, ce tableau respire une poésie naïve, couleurs et personnages, tout y est d'un naturel et d'une facilité remarquables. M. Demidoff en a donné 12000 francs sans marchander. 
7. Alexandre Gabriel Decamps, La Bataille que Marius gagna sur les Cimbres en Provence [Marius défait les Cimbres]

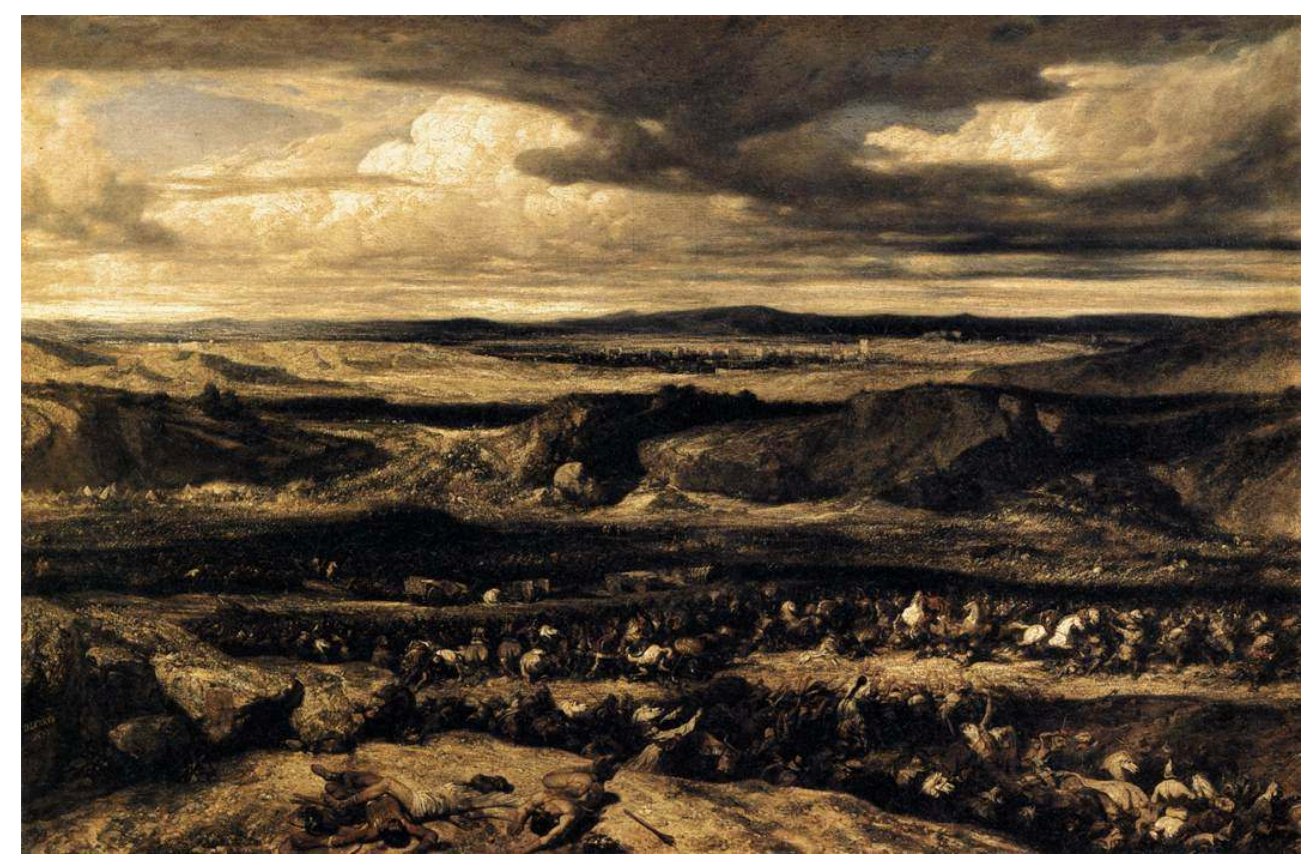

1834, huile sur toile, $130 \times 195$ cm, Paris, musée du Louvre.

14 M. Decamps a peint La Bataille que Marius gagna sur les Cimbres en Provence (fig. 7). On voit un déploiement de forces prodigieux, des milliers d'hommes vous apparaissent comme des nuages de moucherons dans certains jours d'été. Cependant quelques actions distinctes facilitent la compréhension du tableau. Un corps de garde sur la route de Smyrne à Magnésie est remarquable par le ton naturel qui y règne et la couleur si originale de M. Decamps. 
8. Ary Scheffer, L'Eberhad, comte de Wurtemberg, dit Le Larmoyeur [Le Larmoyeur]

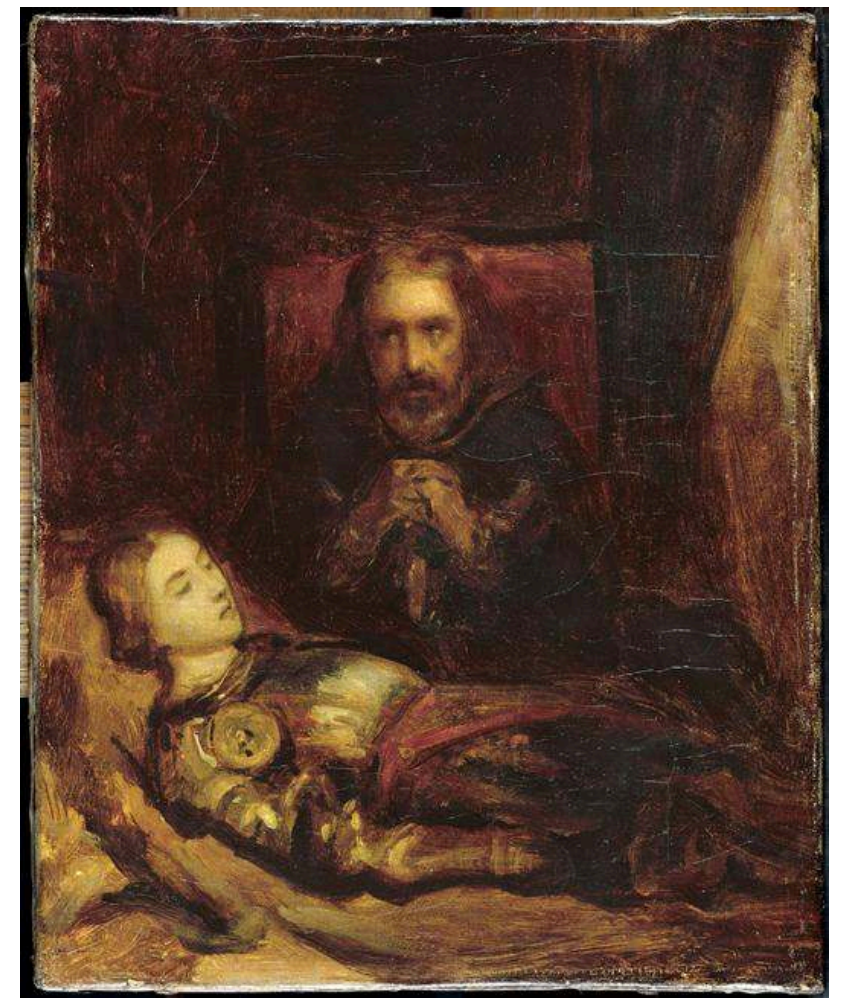

1834, huile sur toile, 26,5 × 21,5 cm, Dijon, musée Magnin.

15 C'est une ballade de Schiller qui a fourni à M. Scheffer le sujet de son tableau, L'Eberhad, comte de Wurtemberg, dit Le Larmoyeur (fig. 8).

16 «Et tandis que nous, dans le camp, célébrons notre victoire, que fait notre vieux comte ? Seul dans sa tente, devant le corps mort de son fils, il pleure.» («Ballade»)

Le cadavre du fils est peint avec une vérité qui fait impression; la tête du vieillard est belle de douleur.

18 Il y a une multitude d'autres tableaux qui méritent d'attirer au musée la foule des amateurs. En nommant MM. Schnetz, Guérin, Heim, Fleury, etc., on n'a pas de peine à persuader.

19 La peinture de genre est en général bien faite.

20 MM. Isabey et Gusin ont donné d'excellentes marines.

21 MM. E. Bertin, Watelet, Régnier soutiennent leur réputation dans le paysage.

22 Le nombre des portraits est prodigieux. On remarque celui d'un apôtre saint-simonien qui lance vers le ciel un regard d'inspiré.

23 En sortant du musée, il vous vient une pensée triste. Des batailles, des naufrages, des échafauds, des paysages, des portraits, des milliers de tableaux, et si peu de pensées d'avenir. Des efforts inouïs de dessin et de couleur, une dépense prodigieuse de talent pour ne peindre que des scènes usées et stériles.

24 Les peintres représentent la femme de toutes les façons, ils en font une fleur dont ils parent tous les bouquetiers dans les boudoirs; ils l'enivrent de parfums et de galants propos; dans les fêtes, vous la prendriez pour une prêtresse avec les riches vêtements dont ils la parent; dans les intérieurs de maison, ils la couchent voluptueusement sur 
un divan, le front couronné de rêves ; ici, comme une plante caressée du soleil, ils la font s'épanouir sous l'haleine de son amant, là, sans ménager sa pudeur, ils dévastent son beau corps pour la traîner au bourreau. Hélas! Messieurs, grâce de parfums et de parures, d'étreintes passionnées et d'échafauds; mais donnez à la femme une place digne d'elle! On a reproduit Ève cueillant le fruit défendu. Que l'auteur s'approche du tableau d'un de nos amis, Jules Laure, que nous remercions de s'être fait l'artiste des pensées d'une grande femme. Il verra Lélia agenouillée près du cadavre de Sténio ; tout un monde de douleurs pèse sur ce front de jeune femme; de cruelles déceptions ont apâli cette belle tête! Peut-être pensera-t-il que depuis assez longtemps les filles d'Ève se déchirent les entrailles et le cœur pour les fils d'Adam ; que depuis assez longtemps elles arrosent de pleurs les chemins de la Terre pour qu'enfin un nouvel Éden découvre pour elles son horizon de bonheur! Artistes! Si vous aimez la femme, si quelquefois sa beauté a versé dans vos âmes une poésie douce, si elle a donné à votre pinceau assez de délicatesse et d'inspiration pour fixer sur la toile vos rêves et vos joies, montrez-la grandissant en liberté! D'abord écrasée sous des boucliers, marchant comme le prolétaire étouffé sous le poids de ses chaînes, son corps, ses pensées, ses désirs, toute son existence, brisés dans la main de son tyran; puis, commençant à regarder son maitre en face et transformant progressivement son esclavage en une tutelle qu'elle veut rompre aussi ! Car Dieu, [ma] bonne, a soufflé dans son âme l'amour de la liberté ; elle veut être libre, la femme! Mais libre pour adoucir les maux de l'humanité, comme la sainte colombe qui descendit du ciel. Libre! Pour arracher la guerre du cœur de l'homme et le conduire dans les voies de Dieu, dans des voies de paix et de bonheur. Libre! Pour épouser comme le savant l'univers, avec son intelligence, et l'attirer dans un même réseau d'amour. Libre! Pour servir de lien entre les peuples comme entre les individus. Elle veut un piédestal dans le temple, pour jeter au monde les paroles religieuses qui grandissent les cœurs et montrent à la pensée le sentier de l'avenir !

Le prolétaire n'est entré dans les tableaux du Salon que les armes à la main, souillé de sang et de boue, jetant la rage de sa bouche et la cruauté de ses yeux. Artistes! Si vous avez frappé dans la main du fils du peuple, si vous avez senti tout ce qu'il y a de force et de grandeur sous sa grossièreté et son ignorance, montrez à nu ses plaies saignantes pour que ceux qui possèdent dans leurs mains les moyens d'adoucir ces souffrances s'attendrissent! Si vous aimez le drame, peignez ces scènes affreuses qui se jouent tous les jours sous vos yeux, peignez un malheureux père malade sur un grabat dévoré par l'agonie et la misère, ses nombreux enfants qui lui demandent du pain avec des cris et des pleurs, sa fille dont le travail ne peut suffire aux besoins de son père et de ses frères... Puis... Plus loin... Le riche lui montrant l'or nécessaire pour soulager son père et sauver ses jours... Mais à une condition infâme! Faites ainsi pleurer, gémir, crier, désespérer votre toile, qu'on y voie tout ce monde d'angoisses, de tortures, de déchirements que la civilisation voile d'un sourire menteur! Qu'on y entende les cris terribles de la faim et les sanglots de la prostitution! Que vos tableaux soient un miroir qui réfléchit toutes les douleurs du pauvre et les concentrent en un foyer qui fonde le fer, qui emboîte le cœur du riche et l'enserre si étroitement que tout battement soit étouffé. À Anvers on voile un Christ de Rubens, parce que sa vue produit une secousse électrique qui fait mal: qu'ainsi devant vos œuvres, les privilégiés s'effraient d'être heureux, quand des milliers d'autres agonisent de misère !

Si vous êtes enthousiastes, faites place, élargissez vos toiles pour que l'humanité puisse y jouer son drame gigantesque, marcher dans les airs, dans les eaux, dans les entrailles de la Terre, faire sur les mers des glissades de mille lieues, charger sur ses épaules les 
montagnes et les forêts pour en faire des pyramides ou des temples, prendre le monde dans ses mains, le briser, le piller, le concasser, le transformer, toujours pour obéir à la loi du progrès, cette loi puissante de Dieu qui l'appelle éternellement et lui fait traverser de nouveaux mondes d'idées, de besoins, d'inventions et la fait marcher! Marcher où ?... Vers le temple des vraies joies que nous n'apercevons encore que dans un horizon idéal, mais dont un jour nous verrons les colonnes se dresser et les éternelles tours traverser les airs.

27 Artistes! Vous pouvez vous créer une grande mission!

Marie-Camille de G.

\section{ANNEXES}

Lire l'introduction à Marie-Camille de G. écrite par Amandine Gorse 
Marceline Desbordes-Valmore (1786 - 1859) 


\title{
Introduction
}

\author{
Christine Planté
}

1 Née à Douai en 1786 dans une famille d'artisans bientôt ruinée, Marceline Desbordes a une jeunesse marquée par la Révolution, les ruptures familiales et l'expérience de la pauvreté. Entrée au théâtre à dix ans, partageant avec sa mère une vie errante qui la mène jusqu'aux Antilles en 1802, elle est actrice jusqu'en 1823, et épouse le comédien Prosper Valmore à Bruxelles en 1817. Son premier livre, Élégies, Marie et Romances, est publié en 1819, suivi de huit recueils poétiques entre 1820 et 1860 , ainsi que de plusieurs romans, dont L'Atelier d'un peintre (1833). L'originalité de ses textes lui vaut une reconnaissance non négligeable dès la période romantique. Saluée de son vivant par Lamartine, Balzac, Sainte-Beuve, Hugo, elle est une des rares femmes poètes inscrites dans la tradition poétique française.

Des liens familiaux lui donnent une familiarité avec le monde de la peinture. Son oncle, Constant Desbordes (1761-1828, peintre de portraits principalement, à qui on doit aussi une Scène de vaccine [Douai, musée de la Chartreuse] exposée au Salon de 1822 pour laquelle sa nièce a posé comme modèle), n'a pas fait une carrière spectaculaire, faute d'ambition, mais il a suscité l'estime de ses contemporains et parmi ses élèves on trouve Paul Delaroche, Gustave Drouineau et Michel Drolling. Marceline Desbordes a pu fréquenter son atelier lors de ses séjours parisiens, d'abord en 1805-1806, quand elle jouait à l'Opéra-Comique, Constant Desbordes étant alors installé dans l'ancien couvent des Capucines où ont travaillé notamment Girodet, Gros et Ingres ; puis en 1819-1820, alors qu'il avait déménagé à la Childeberte, lieu important de la vie artistique romantique. C'est là que Marceline Desbordes-Valmore fait la connaissance de l'écrivain Hyacinthe de Latouche, qui devient son amant. Son fils Hippolyte a été élève de Delaroche, puis de Delacroix, de 1840 à 1844 - sans néanmoins devenir peintre. Sa fille aînée Hyacinthe, dite Ondine, a pris, adolescente, des cours de dessin auprès de $\mathrm{M}^{\mathrm{me}}$ Hortense Haudebourt-Lescot.

Marceline Desbordes-Valmore n'a pas laissé de critique d'art (non plus que de critique littéraire en tant que telle) et semblait souscrire au préjugé qui refuse aux femmes l'autorité critique et esthétique. Mais dans ses écrits en prose, elle met en scène des figures d'artistes et une réflexion sur la création nourries de son expérience personnelle. Louis Aragon, qui republia son roman L'Atelier d'un peintre (1833) en 
feuilleton dans les Lettres françaises fin 1949, y voyait « un grand roman de la peinture » où «il est question comme nulle part ailleurs de la beauté qui sort des mains humaines ».

4 Les deux textes proposés ici (le premier : un extrait de L'Atelier d'un peintre, le second: un poème sans doute contemporain du Salon de 1847 auquel il fait allusion) font entendre, au-delà d'une soumission apparente aux préjugés sexistes du temps, un point de vue très personnel. Ils présentent deux lieux fondamentaux de l'expérience picturale, l'atelier et le Salon, symétriquement situés : l'un, privé, en amont; l'autre, public, en aval de l'œuvre. La narratrice pose sur l'art un regard décalé, à la fois par force (par son manque de culture) et par choix (par la discrète affirmation de critères autres). La reprise des stéréotypes d'une féminité sensible et ignorante permet de déplacer l'évocation vers la relation subjective (du peintre, et aussi des spectateurs) au tableau, et d'interroger les hiérarchies admises.

5 L'Atelier d'un peintre, dont l'action se situe sous le premier Empire, montre une communauté utopique et hiérarchisée de jeunes hommes tout dévoués à l'idéal du Beau, respectueux de l'autorité du maître au sein d'une sorte de famille élective. La jeune Ondine (double fictif de la romancière à qui elle a donné le surnom de sa fille aînée) n'y est admise que dans une position marginale. Cantonnée dans un rôle quasi domestique, assumant des goûts naïfs et entachés de prosaïsme, elle fait entendre dans le dialogue avec son oncle M. Léonard (transposition de Constant Desbordes) une réflexion timidement critique sur les grandes questions de la représentation, et sur la hiérarchie des artistes et des œuvres (George Sand, une vingtaine d'années plus tard, utilisera elle aussi la forme du dialogue familier pour développer une critique littéraire vivante, non dogmatique). La fin du chapitre montre pourtant Ondine nourrissant des ambitions de peintre, encouragée par le succès de sa contemporaine Hortense Lescot (sur lequel insiste la voix narrative, au prix de distorsions chronologiques, puisque certains tableaux cités n'ont en fait été exposés que plus tard, sous la Restauration).

Le poème, qui n'a pas été publié du vivant de Marceline Desbordes-Valmore, présente sur le manuscrit des hésitations non tranchées (non reproduites ici) et ne figure pas dans le recueil posthume des Poésies inédites de 1860. Il évoque une femme errant dans la foule du Salon de 1847 et qui se définit elle-même comme un " esprit sans culture ", aux «sens imparfaits». En proie à la nostalgie d'une nature qu'elle dit ne retrouver nulle part dans les tableaux qui l'entourent, elle est saisie par la rencontre d'un Christ dont elle ne nomme pas l'auteur (vraisemblablement le Christ en croix de Delacroix, aujourd'hui au Walters Art Museum de Baltimore). Le poème ne livre aucune description méthodique, il insiste avec exaltation sur la leçon mystique et politique du tableau, et sur l'expérience de la souffrance vécue par l'artiste, qui seule peut porter cette vision que les mots ne sauraient "rendre». L'émotion passe par une double identification implicite de la poète au Christ et au peintre, et le dernier vers peut s'entendre comme une paraphrase de l'Évangile (Madeleine est pardonnée car elle a beaucoup aimé, Luc, VII, 47). Insistant sur l'emploi de couleurs « introuvables » et sur le traitement de la lumière, Desbordes-Valmore rejoint les notations de Paul Mantz et de Théophile Gautier dans leurs comptes rendus, qu'elle n'avait sans doute pas lus (Gautier rapproche, pour la couleur, ce Christ des derniers tableaux de Prud'hon, autre peintre admiré par Desbordes-Valmore). 


\section{BIBLIOGRAPHIE}

AMBRIÈRE 1987

Francis Ambrière, Le Siècle des Valmore, Paris, Le Seuil, 1987, 2 vol.

ARAGON 1954

Louis Aragon, «L'Atelier d'un peintre. Marceline Desbordes-Valmore romancière ", dans La Lumière de Stendhal, Paris, Denoël, 1954, p. 215-229.

BANN 2007

Stephen Bann, "The Studio as Scene of Emulation: Marceline Desbordes-Valmore's L'Atelier d'un peintre", French Studies: A Quarterly Review, January 2007, Volume 61, Number 1, p. 26-35.

DESBORDES-VALMORE (1833) 1992

Marceline Desbordes-Valmore, L'Atelier d'un peintre, Paris, Charpentier, 1833 ; rééd. Lille, Miroirs éditions, 1992.

PLANTÉ 1998

Christine Planté, « L'Atelier d'un peintre de Marceline Desbordes-Valmore, le roman d'une poète », George Sand Studies, 1998, vol. XVII, nº 1 \& 2, p. 43-54.

\section{ANNEXES}

Diaporama des tableaux commentés par Marceline Desbordes-Valmore dans les passages choisis de L'Atelier d'un peintre :

http://www.flickr.com//photos/73632227@N02/sets/72157629875128218/

Lire les extraits de l'Atelier d'un peintre de Marceline Desbordes-Valmore

Lire le poème « Un Christ au Salon de 1847 » de Marceline Desbordes-Valmore

Liste complète des œuvres d'arts commentées par Marceline Desbordes-Valmore à

travers ses textes édités dans Plumes et pinceaux 


\section{Marceline Desbordes-Valmore, L'Atelier d'un peintre, 1833}

L'Atelier d'un peintre : scènes de la vie privée, Paris, Charpentier, tome I, chapitre II, extraits choisis.

\section{1 《Le couvent des Capucines »}

2 M. Léonard, de son côté, allait, disait-il, au Louvre boire de la peinture - en effet sa seule et chère ambroisie. De tous les monuments de Paris, il n'en connaissait bien qu'un seul, le Salon de peinture. Il le savait par cœur, comme sa chambre : il y fût allé les yeux fermés sans faire un faux pas; il eût mis la main à coup sûr dans l'obscurité la plus profonde sur quelque tableau que ce fût, de Raphaël ou de Rubens, et l'eût baisé.

Dans cette immense population qui se presse et s'agite, il n'avait de liens qu'avec une nation distincte de toutes les autres, celle des peintres ; et il continuait depuis vingt ans à recevoir dans son atelier plus d'élèves qu'il n'en pouvait contenir. Comme un Anglais qui passe reconnaît un Anglais dans une ville étrangère, comme un malheureux qui a des larmes sous le front devine dans la foule celui qui pleure souvent dans l'âme, M. Léonard, artiste-né, jeté au monde pour adorer la nature et la peindre, sentait en quelque sorte dans la rue les hommes imprégnés du parfum de la peinture, et tous ceux qui en vivent ou qui en meurent.

"Voilà un peintre, disait-il à sa nièce.

5 - Vous le connaissez, mon oncle?

6 - Non, mais vous allez voir.»

7 Il saluait alors d'un air grave, bienveillant et original, qui frappait à son tour le passant. On s'abordait; l'entretien s'engageait dans cette langue à part de toutes les langues parlées de nos jours; et il était rare que de telles rencontres n'augmentassent pas ce qu'il appelait sa famille, sa sublime, son humble famille !

8 L'atelier, nu d'ornements et de meubles superflus, ne s'agrandissait pas à mesure qu'on l'encombrait de cartons, de plâtres, de chevalets et de mannequins. La muraille un peu humide, ravivée tous les deux ou trois ans d'une couche épaisse de couleur grise, nuancée çà et là par la fraîcheur régnante de l'atmosphère, montrait pour tout luxe le portrait de Raphaël, celui de la mère de M. Léonard, où quelques traits de la jeune 
Ondine se révélaient sous l'immense bonnet flamand de sa grand-mère; et puis des mains modèles, les pieds ailés du Mercure, des bras d'enfant moulés sur nature, une tête de mort et un cadre de papillons.

9 Cet espace de vingt pieds carrés, oublié, debout encore sous la destruction du vieux cloître des Capucines, tombant sous les marteaux actifs d'un riche propriétaire, servait de ruche ou de Vatican à quelques brûlants éphémères, nés de cette flamme qui avait immortalisé et tué Raphaël.

10 Et la jeune Flamande, amoureuse de cette propreté luisante qui régnait au foyer de sa mère, accoutumée en naissant à l'ordre silencieux et calme d'un ménage du Nord, troublée d'abord au milieu de toutes ces abeilles confuses, s'en était doucement fait reine, et préparait sans bruit à toutes une place pour broyer et composer leur miel. Les ingrates, contrariées dans leur désordre, criaient à la tyrannie ; Ondine faisait la sourde oreille et régnait, rangeuse et modeste. [...]

11 Mais bien des abus glissaient sous [1]a vigilance [de $\mathrm{M}^{\text {lle }}$ Élisabeth, chargée du ménage]; un châle à peine déployé six fois depuis la noce de la sœur d'Ondine, châle bleu, tramé de soufre et de blanc, qui ne laissait dans l'esprit de la jeune fille aucune place à l'admiration pour les cachemires qui tapissent de leurs riches rosaces les magasins de la rue Vivienne; ce beau châle, qui rompait seul l'uniformité de la teinte grise de son horizon, figurait depuis six mois sur un mannequin habillé à la juive, pour un tableau de la bénédiction de Jacob; et son tablier de mousseline à fleurs sombres était tourné en turban sur la tête de l'Antinoüs, dont on allait faire un Grec moderne.

Ondine avait déclaré plusieurs fois l'impérieuse intention d'en secouer la poussière; mais les élèves, M. Léonard lui-même, poussaient des cris, et le tissu frêle et bleu continuait d'être mangé aux vers. C'était le seul incident qui attristât un peu les yeux sereins de la jeune artiste, quand ils tournaient autour de cet obscur musée comme autour de son univers.

13 L'atelier, jusqu'à nouvel ordre, était dans un long corridor de l'ancien couvent des Capucines, labyrinthe où ceux qui l'habitaient encore finissaient par se perdre quelquefois, comme les étrangers qui venaient les y chercher. On ne se retrouvait souvent qu'en s'appelant à voix haute, parmi les murs écroulés ou pendants de ce vieux monastère.

Quelques cellules étaient demeurées intactes, mais elles s'entouraient par degrés de tant de débris et de poutres chancelantes, il tombait à chaque heure de si hauts murs, avec un fracas si sourd et si menaçant, que sans la sécurité profonde de $\mathrm{M}$. Léonard, qui ne s'arrêtait jamais de peindre durant ces craquements destructifs, sa nièce eût pris la fuite avec épouvante. Souvent elle le regardait, indécise ; mais voyant l'immobile sangfroid qui l'enchaînait à sa place, elle dessinait à la sienne, sans y penser plus que lui. Il y a tant de sécurité dans la confiance que nous inspirent nos parents! ils savent tout ; ils étaient au monde avant nous!

15 Tant que Girodet peindra au-dessus de nos têtes, disait M. Léonard, comme répondant au regard inquiet de sa nièce, de quoi voulez-vous que je m'alarme? je ne ferai pas un pas avant lui pour chercher un atelier. Vous ne savez pas comme c'est effroyable de chercher un atelier! Transporter un monde d'objets, ma boîte à couleur pleine d'huile, mon cadre aux papillons, bouleverser toute une existence, on s'imagine que c'est la moindre chose au premier coup d'œil; mais voyez Girodet, s'il bouge? et très 
certainement je ne me séparerai d'un tel voisinage qu'à la dernière extrémité, au dernier cri de détresse. conseille, ma chère amie, de respirer cet air-ci de toutes vos forces et avec orgueil, puisqu'il le respire; il y roule une foule de petits tableaux qu'il ne tient qu'à vous d'exécuter pour le Salon. Mais en considération de votre âge, je ne vous en demande qu'un : c'est bien raisonnable de ma part. Grand Dieu! Si j'avais le temps de faire autre chose que le portrait ! Peintre de portraits! Il en pleut. Il est vrai que Van Dyck occupe une certaine hauteur dans les arts avec les siens, car il y a là, dit-il en regardant le portrait de Van Dyck lui-même, je ne sais quelle science harmonieuse qui contente l'ignorant et l'artiste qui sait. Le modelé des formes y passe et tourne comme dans l'air et le jour. Cette tête flotte au milieu du vide, ce vide, remarquez bien, qui n'est pas creux comme une boîte, et noir comme une étoffe tendue. Vous, petite, quel est le peintre qui vous dit quelque chose à l'oreille? Ne cherchez pas trop, afin de ne dire que votre pensée.

18 - Prud'hon! mon oncle...

19 - Rien que cela? dit M. Léonard avec un sourire approbateur, je vous en fais mon compliment : pour une pauvre petite Flamande, simple comme bonjour, vous n'avez pas l'instinct très vulgaire ; et peut-on savoir pourquoi vous l'aimez?

20 - Ah !... parce que je l'aime, mon oncle; parce que ses tableaux ravissent mes yeux, et qu'il me semble que quelque chose de triste parle au fond. Je ne me connais pas au reste.

21 - Enfin, vous l'aimez d'instinct, cela veut dire que vous l'aimerez toujours : tant mieux pour vous. Vous m'avez pourtant fait frémir quelquefois, quand je vous posais en face de tel ou tel chef-d'œuvre, dans le désir de vous récompenser d'un œil ou d'une oreille passablement obtenue; quand j'attendais un cri d'admiration qui m'eût rendu le plus heureux des hommes comme votre maître et comme votre oncle, vous me disiez la chose la plus écrasante, la plus bourgeoise, la plus inattendue ; une de ces choses qui cassent bras et jambes, et vous en avez beaucoup apporté de province dans vos petites poches; car vous portiez des poches, ma chère amie.

22 - Mon oncle!

23 - Ou bien c'était un silence vide et effrayant, pour quelqu'un qui guettait votre avenir dans un regard et dans vos premières impressions. Pauvre Ondine ! que vous m'en avez dit de cruelles!

24 - Oh ! mon oncle, je ne disais pas tout ce que je pensais ; mais souvent, si j’avais osé !...

25 - Oui, par soumission, et pour être une bonne fille, vous m'auriez fait des compliments ; comme un petit garçon qu'on m'amena un jour pour sonder ses dispositions sur la peinture, et à qui sans doute on avait recommandé d'être bien honnête : on le guettait aussi, le pauvre innocent, comme le lait sur le feu. "Monsieur, me dit-il enfin, pour dire quelque chose, en regardant je ne sais plus quoi, est-ce un homme, ça, ou un cheval ? C'est un homme, mon petit ami. - Ah ! c'est bien fait !"

26 «Et vous étiez de cette force... mais enfin, votre bandeau ne me paraît plus si épais; et je ne jurerais pas que Girodet, bien qu'à travers le plafond, n'y soit pour quelque chose. Quand de tels fronts secouent leur auréole, il en tombe des étincelles. Tendez votre 
tablier, mon enfant; les femmes ne seront jamais que des glaneuses; mais leurs bras faibles ont de la grâce et on leur pardonne, parce qu'ils ont l'air de prier. Songez bien... Vous m'écoutez toujours, n'est-ce pas?

- Toujours, mon oncle, dit Ondine en relevant la tête avec le sentiment de l'attention et du respect.

- Au reste, vous avez bien raison de m'écouter ; car c'est dans votre intérêt que je parle quelquefois un peu trop longtemps. Songez à la scène du déluge, à cet admirable fragment de la colère de Dieu, bien que vous trouviez l'homme trop laid pour avoir épousé de son consentement cette belle créature qui se noie, l'idée d'une folle enfant, pour laquelle on devrait vous mettre en pénitence; un jeune garçon ne l'eût jamais eue : mais vous autres demoiselles, vous ne rêvez que mariage d'inclination, même du temps du déluge.

29 - Non, mon oncle! mon Dieu, non ! c'est qu'il a une expression affreuse !

30 - Ne voulez-vous pas qu'il sente craquer l'arbre qui le soutient sur l'abîme, et qu'il fasse un sourire? Qu'il emporte son père, dont le poids est énorme, comme celui de tous les vieillards, et qu'il soit agréable, placide et rose comme Énée, qui enlève tranquillement son père aussi, lui, comme s'il n'enlevait rien? Ce qui m'a toujours un peu étonné dans un chef-d'œuvre. Mais ce qui s'explique du moins par l'assistance d'une grande déesse, qu'on ne voit pas, et qui a beaucoup aimé le père d'Énée.

31 - Oh! je ne l'aime pas, mon oncle; il ne s'inquiète pas plus de sa femme dans le feu que l'autre de sa femme dans l'eau.

32 - Diable, mademoiselle! Vous voulez de la galanterie jusque dans les scènes d'inondation!

33 - Mais, mon oncle, sa femme !

34 - C'est bon ! on va bien penser à une femme, quand on porte son père et qu'on a devant soi une immense étendue d'affliction et de scènes sublimes qu'on ne reverra plus. Quant à moi, ce qui m'eût le plus occupé, je crois, après ma mère, observa-t-il en s'inclinant avec respect du côté du portrait de femme habillée à la flamande, c'eût été de courir à ma palette pour arrêter, autant que possible, quelques-uns des effets d'une scène si grande et si peu redite. Sur cet homme, sous cet homme, les teintes sont molles et ternes et ne précisent ni jour, ni nuit, ni pluie, ni soleil, ni rien : elles rappellent ce vœu d'un paysan las d'une atmosphère étouffante, qui s'écriait: "Ah! pour un temps pareil, j'aimerais mieux qu'il n'en fit pas !" - Il n'en fait plus : la terreur qui nage dans cette scène est bien faite pour crisper l'homme qui en conçoit et en supporte toute l'horreur. Girodet a donc très bien fait de laisser cette pauvre et belle femme s'arranger comme elle peut avec le petit enfant qui s'attache à ses beaux cheveux mouillés, comme au câble de salut; et l'autre qui veut téter encore, sans se douter que ce n'est plus la peine et que l'on va mourir !

35 - Mais d'où vient, mon oncle, hasarda timidement l'écolière, que cette triste mère n'a pas un trait ému ni souffrant, tandis que l'enfant l'a saisie avec tant de violence par sa chevelure renversée? Mes cheveux me font mal en regardant! Le calme de cette mère me surprend. 
1. Anne-Louis Girodet, Déluge [Scène de Déluge]

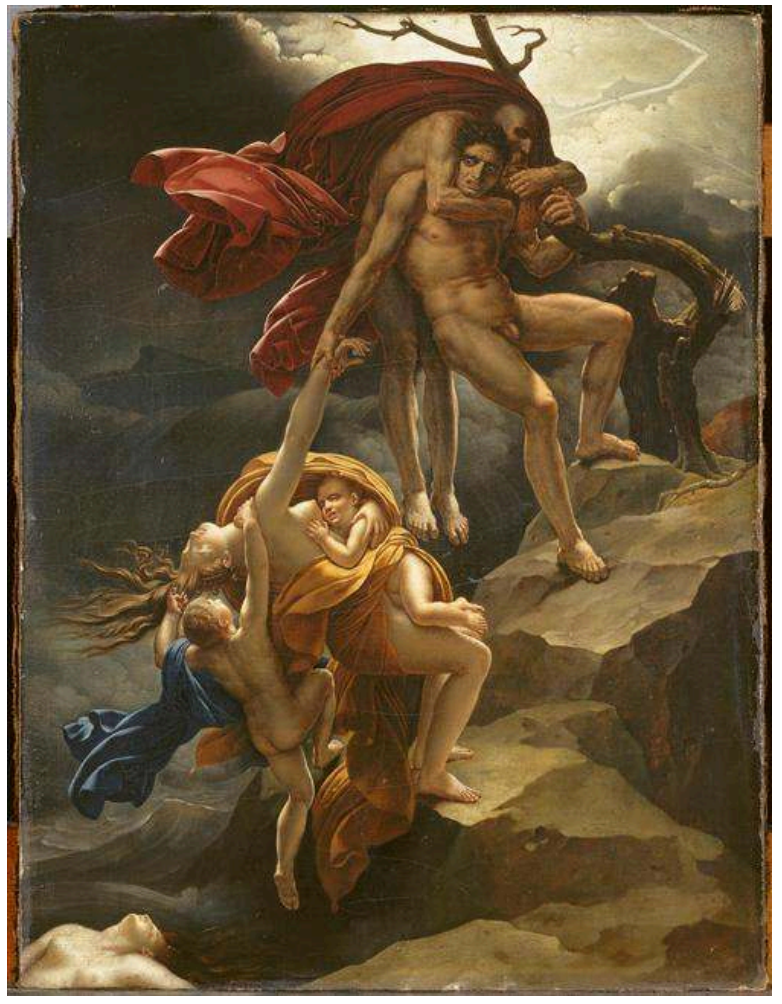

Salon de 1806, huile sur toile, 441 x 331 cm, Paris, musée du Louvre.

\section{Anne-Louis Girodet, Atala [Les Funérailles d'Atala]}

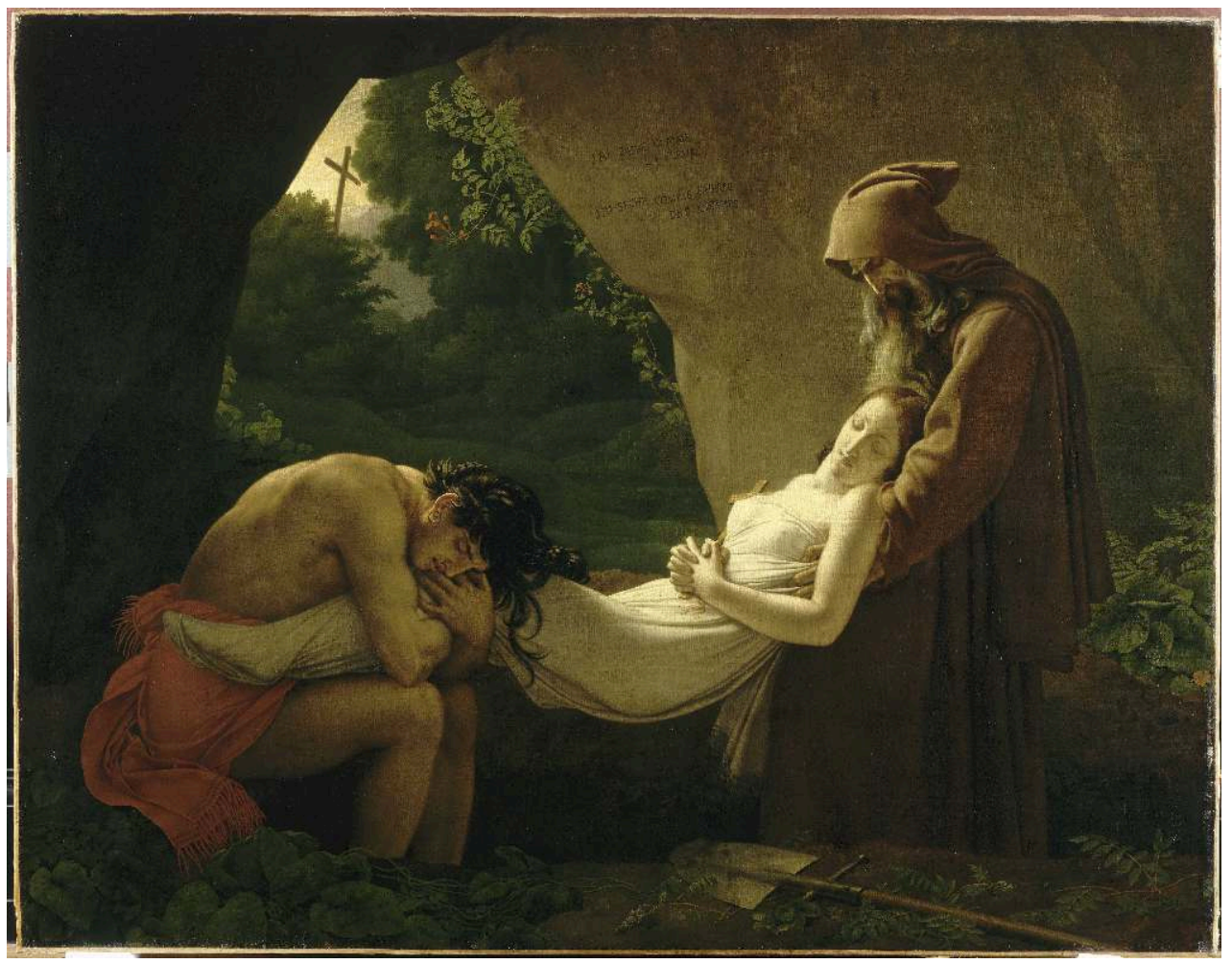

1808, huile sur toile, 207 × 267 cm, Paris, musée du Louvre. 

douillette, qui pousseriez des cris si l'on touchait vos tresses pour s'en faire un cordage. En second lieu, c'est qu'elle est morte, et déjà peut-être dans le ciel, où l'on ne souffre plus du tout: je le croirais d'autant mieux qu'il n'y a plus rien de terrestre dans ses formes - et l'on sait que la mort ennoblit la laideur. Jugez de la beauté ! la beauté jeune et dans sa fleur, comme celle de cette mère. Quelle chasteté sur ce sein nu !... Raphaël n'a pas été plus pudique, avec ses vêtements pleins de mystère, que Girodet sans voiles. Quoi qu'il en soit, ce coin de Déluge (fig. 1), et Atala (fig. 2), autre scène immortelle de la mort, ont été créés là-haut; et je n'entends pas, le soir, les pas du maître qui médite et travaille à la lampe, sans un frisson d'espoir et de respect. Ne donneriez-vous pas tout au monde pour le rencontrer?

Oui, vous! et vous avez juste l'air de me répondre: "Mon oncle, cela m'est égal." Quelle singulière personne! Un caillou lisse, au bord de l'eau, un feston de lilas qui s'échappe des murailles du boulevard, un mouton qui passe dans la rue, vous font tressaillir; et la vue d'un grand homme vous laisse droite comme une flèche; pas la moindre émotion ; c'est pour vous une chose simple. [...]

nuée d'élèves qui entrèrent presque tous à la fois donna bientôt un autre cours aux idées de M. Léonard. La sérénité ne tardait jamais à reparaître sur son front, quand il avait autour de lui tous ces jeunes amants de la peinture ; il semblait qu'il n'eût jamais eu lui-même d'autre maîtresse. [...]

À cette humble école, les riches ne payaient pas plus que les pauvres ; c'est-à-dire qu'ils ne payaient pas du tout. Par cela même, il y régnait un ton de concorde et d'égalité qui se tournait en respect pour le maitre, auquel ils ne voyaient qu'une belle passion, la gloire! Toutes ces jeunes têtes en brûlaient comme la sienne ; et dans ce coin obscur du monde, on ne respirait que l'amitié, le désintéressement et l'enthousiasme !

41 «Enfin, voilà!» s'écria tout à coup l'écolier Rodolphe, au milieu d'une méditation générale, en respirant jusqu'au cœur, comme quelqu'un qui sort d'un péril.

Cette exclamation fit retourner tout le monde vers lui ; on se groupa autour de son travail. La tête du Grec moderne était finie. Ondine aussi cria: «Enfin!» pour son écharpe, qui était reproduite au naturel et qu'elle allait reployer avec soin. L'admiration devenait unanime et bruyante, quand M. Léonard vint jeter l'huile ou l'eau sur ce brillant feu de paille. [...]

43 Ce silencieux empire du plus indulgent des hommes portait quelquefois chez ses disciples le découragement jusqu'aux larmes. Par le regard sans chaleur qu'il détournait avec un peu de chagrin du travail qui lui était soumis, on se sentait atteint et convaincu de médiocrité ; idée amère pour ceux qui s'accoutument au voisinage et à la contemplation des chefs-d'œuvre : à force de les admirer, on se familiarise avec eux ; on n'échappe pas toujours à l'espérance d'en créer au moins un. Quel est l'innocent barbouilleur qui n'a pas dit une fois dans sa vie : « Voyons donc si Raphaël est tout à fait mort!»

L'agreste Ondine elle-même, au fond du sommeil apparent où son maitre la croyait plongée, avait aussi ses émotions ambitieuses. Dès qu'elle était seule au chevalet, les chaînes de son intelligence tombaient, son indolence s'éveillait, ses yeux osaient s'ouvrir tout grands ; elle n'avait plus peur, elle croyait peindre pour l'avenir, et pour l'avenir reconnaissant! 
«Je ne le dirai pas à mon oncle, pensait-elle : il rirait ! C'est pourtant bien sérieux, la vie, quand on pense où elle doit nous conduire, ou le ciel, ou... quoi donc !... » [...]

Elle se rappelait avec quelque confusion qu'en arrivant de sa province du Nord elle avait égayé son oncle et ses amis par son inexpérience des arts, un jour, qu'en entrant au Salon de peinture, si brillant, si tumultueux durant l'exposition, et si nouveau pour ses regards éblouis, elle avait perdu la respiration, se demandant tout bas si elle entrait au Paradis. C'était alors que revenait de Rome une femme citée naguère pour la grâce et la légèreté de sa danse ; quand tout Paris, le Paris qui danse, qui vit de musique, de fêtes et d'idoles, quand tout ce Paris-là se précipitait chaque soir autour des poses légères et des pas innovés par elle dans cette carrière presque aérienne, où elle voltigeait, dit-on, élégante et fluide comme l'enfant divin de Prud'hon.

\section{Hortense Haudebourt-Lescot, Le Baisement des pieds à Rome [Le Baisement des pieds de la statue de Saint-Pierre dans la Basilique Saint-Pierre de Rome]}

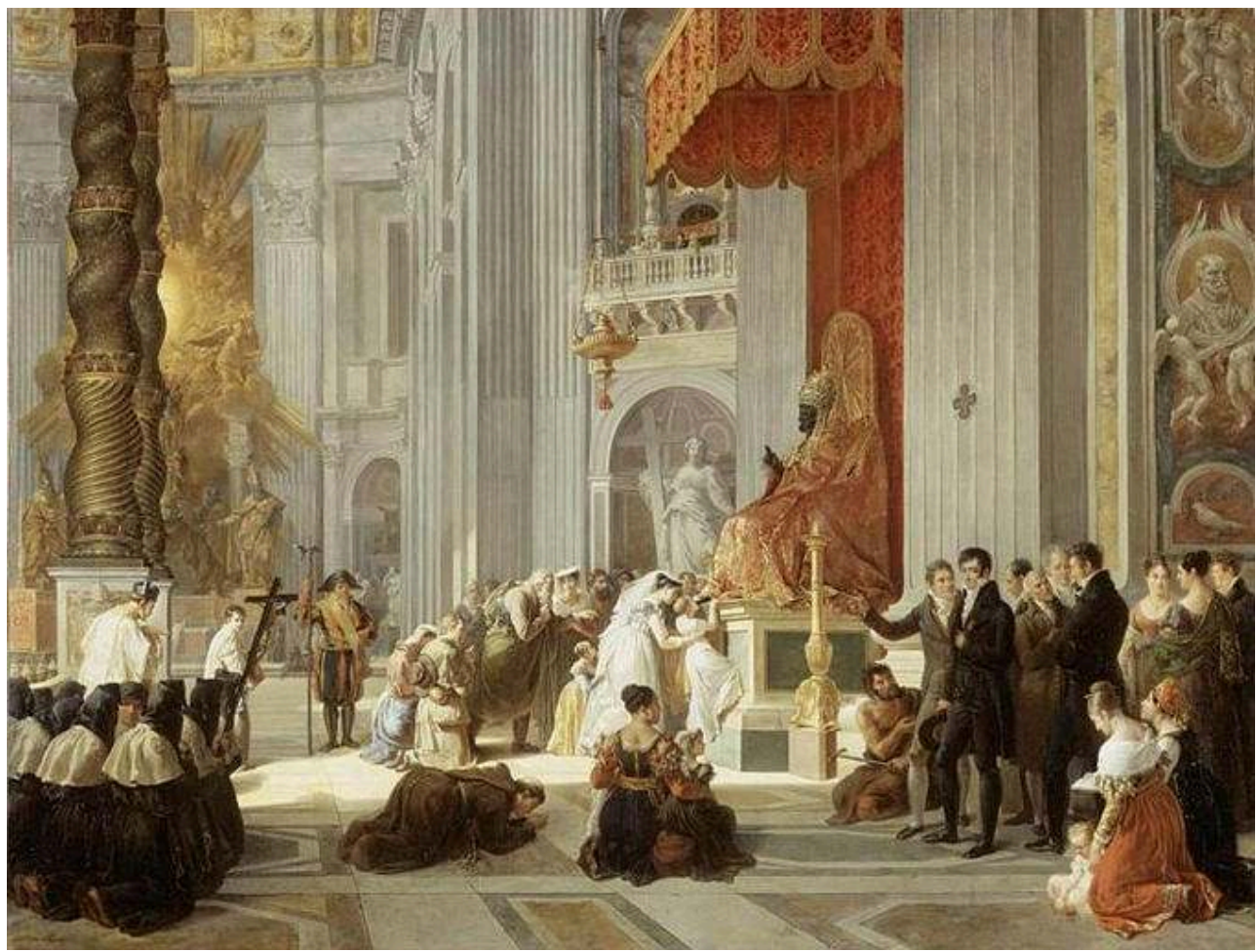

1812, huile sur toile, 148 x 196 cm, Fontainebleau, musée national du château. 
4. Hortense Haudebourt-Lescot, Le Condamné à mort [Un condamné exhorté par un moine capucin au moment de partir au supplice]

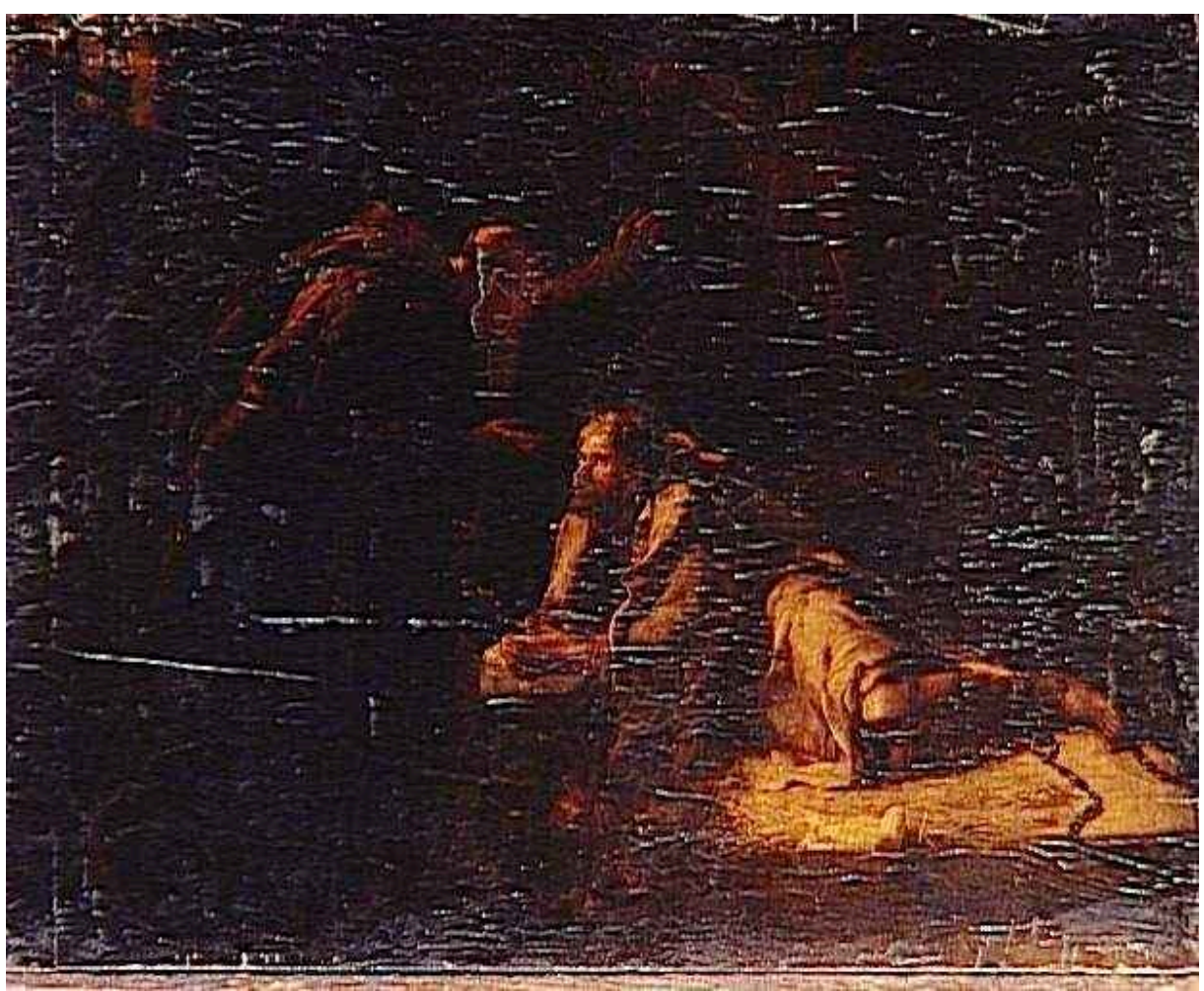

Salon de 1819, huile sur toile, 55 × 69 cm, Paris, musée du Louvre.

5. Hortense Haudebourt-Lescot, Le Meunier et son fils [Le Meunier, son fils et l'âne]

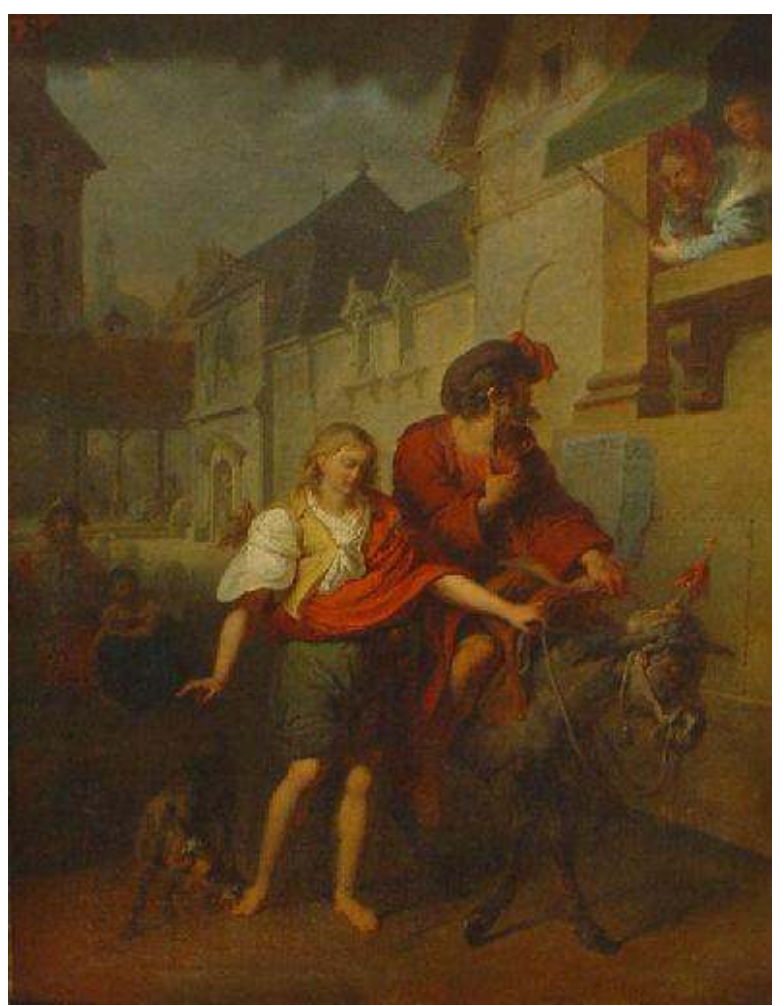

Huile sur toile, 41 × 32,5 cm, Château-Thierry, musée Jean de La Fontaine. 
47 Déjà, quand la petite Flamande aux lèvres rouges, entr'ouvertes d'ignorance et de curiosité, entra tremblante dans le sanctuaire majestueux des arts, on ne se demandait plus : "Avez-vous vu danser $\mathrm{M}^{\text {lle }}$ Lescot ? » mais : "Avez-vous vu les tableaux de $\mathrm{M}^{\text {lle }}$ Lescot? » Le Baisement des pieds à Rome (fig. 3), Le Condamné à mort (fig. 4), la spirituelle traduction du Meunier et son fils (fig. 5), et puis enfin, La Prière pendant l'orage de $\mathrm{M}^{\text {lle }}$ Lescot? Et ce nom ailé, plein de grâce et de gloire, bruissait partout aux oreilles timides et attentives d'Ondine, tandis que la foule tourbillonnant toujours l'emportait à demi étouffée devant ces tableaux qui intéressaient tant d'yeux et tant d'âmes, et venaient d'inscrire un nom de femme parmi les lauréats de l'école française.

Ce souvenir brillant passait quelquefois devant elle; il la faisait frissonner et sourire quand, retirée comme elle était alors derrière un immense paravent qui lui servait de cabinet d'étude, elle cherchait déjà dans le passé quelque espoir pour appuyer son vague avenir.

\section{ANNEXES}

Lire le poème « Un Christ au Salon de 1847 » de Marceline Desbordes-Valmore

Lire l'introduction à Marceline Desbordes-Valmore écrite par Christine Planté 


\section{Marceline Desbordes-Valmore, «Un Christ »}

(poème posthume), dans CEuvres poétiques de Marceline DesbordesValmore, éd. Marc Bertrand, Presses universitaires de Grenoble, 1973, 2 vol. , t. II, p. 642-643.

\section{Un Christ au Salon de 1847}

Delacroix Eugène, Un Christ [Christ en croix]

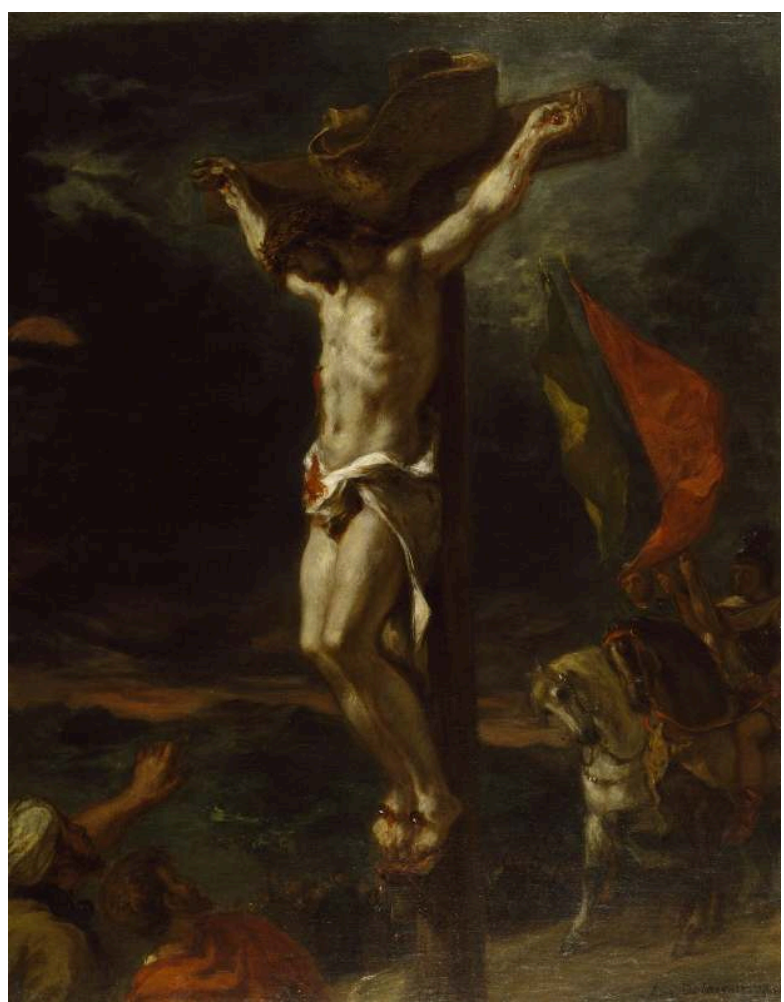

1846, Salon de 1847, huile sur toile, 80 × 64,2 cm, Baltimore, The Walters Art Museum. 
C'était le jour du peuple à visiter son Louvre,

$\mathrm{Et}$, roi silencieux, sous la porte qui s'ouvre,

Le peuple, comme un fleuve errant en liberté, Allait porter son vote à l'immortalité.

3 Et moi, prise au courant de cette foule aimée, Marchant avec effort dans son flot enfermée, J'ouvrais mes yeux sans voile aux mordantes clartés Qui des lambris vivants sortaient de tous côtés. Mais le cœur palpitant comme un cœur d'alouette Attirée au miroir où se heurte sa tête, J'avançais toute lasse et les yeux larmoyants, Laissant glisser mes pieds sur les parquets fuyants, Comme un rêve. Enlacée au bras d'une compagne : "Où donc l'air pur, disais-je, et l'ombre, et la campagne, Et la fleur véritable et qui se cueille, et l'eau Dont le semblant scintille au fond de ce tableau, Mais qui ne coule pas! » Ta voix fraîche, ô Nature, Appelait loin de l'art mon esprit sans culture, Et vous, pardonnez-moi, chefs-d 'œuvre confondus, Pour mes sens imparfaits vous étiez tous perdus.

4 Mais là-bas, séparé des marbres, des dorures, Des riantes beautés qu'enchaînent leurs bordures, Et d'enfants qu'on eût dits prêts à courir vers nous, Qui donc force la foule à plier les genoux ?

Quel sombre attirement, quelle chaste lumière, A secouru de loin ma brûlante paupière? Quelle halte pieuse à travers les bruits forts A suspendu la foule et ses houleux efforts? Un Christ! Une croix haute en silence gardée Par deux hommes rêveurs, deux soldats de Judée, Veilleurs insoucieux des meurtres d'alentour, Demandant à la nuit : Quand donc fera-t-il jour ?

5 Il fait jour! Il fait jour ! D'une croix éclairée, La lumière descend dans cette nuit sacrée ; Mais, pour vos yeux de chair et malgré son retour, ô veilleurs de la mort, il ne fera plus jour.

6 La lune sur la Terre avançant son visage De rayons effrayés perce le noir feuillage Comme un esprit vivant qui juge cette mort, Et le peuple qui tue et les rois sans remord.

$7 \quad \mathrm{Au}$ fond du lourd sommeil, la moquerie éteinte Partout d'un saint effroi laisse couler la teinte Et l'âme en pleurs est libre enfin de se plonger Dans ce repos terrible et doux à partager. Car de vos flancs ouverts, ô vrai roi qu'on ignore, ô Dieu vrai ! le pardon saigne et s'échappe encore ; 
Il saigne, oracle amer des maux qui vont couler Sur les ingrats que seul vous veniez consoler !

Qui donc a retracé ce triomphe sans armes,

Cet oracle muet qui crie avec des larmes?

Pour peindre ainsi son Dieu de tristesse expiré

$\mathrm{Au}$ fond d'un cœur mortel qu'il faut avoir pleuré !

Qui donc a retrouvé ces couleurs introuvables,

Ces ténèbres qu'on voit, ces pardons ineffables,

Ce silence étendu dans l'air terrifié,

Ce lamentable adieu du cher crucifié !

Cette nuit qu'on entend sangloter sous ces voiles,

Et l'orbe qui rougit dans un ciel sans étoiles,

Et l'herbe qui se penche en tremblant sous les pieds,

Les doux pieds de Jésus, les pieds froids et cloués.

9 Qui n'a pas vu cela ne saurait le comprendre ;

Qui l'a vu s'en abreuve et ne peut pas vous rendre,

ô Christ ! ô pieds meurtris ! ô visage incliné !

Ô grandeur ! ô Dieu mort qui pour nous étiez né !

10 J'y penserai toujours. Toujours, morte ou blessée,

J'aurai sur cette croix ma mémoire enlacée.

Dieu d'amour, si l'amour sauve tout de l'enfer,

Bénissez votre peintre, il a beaucoup souffert.

\section{ANNEXES}

Lire les extraits de l'Atelier d'un peintre de Marceline Desbordes-Valmore

Lire l'introduction à Marceline Desbordes-Valmore écrite par Christine Planté 
Élisabeth Vigée-Lebrun (1755 - 1842) 


\title{
Introduction
}

\author{
Charlotte Foucher
}

À quatre-vingts ans, Élisabeth Vigée-Lebrun, s'appuyant sur des notes prises tout au long de sa vie et avec l'aide de sa nièce Eugénie Tripier-Lefranc, également peintre, et de Louis Aimé Martin, éditeur de la correspondance de Bernardin de Saint-Pierre et ami de l'artiste, entama la rédaction de ses Souvenirs, qu'elle publia en trois volumes entre 1835 et 1837. Ce texte autobiographique, en plus d'être une source directe sur l'art et l'époque, de l'Ancien Régime à la Restauration, est l'un des premiers discours sur l'art écrit par une femme artiste. Exilée volontaire dès 1789 pour échapper aux menaces révolutionnaires qui pesaient sur elle en tant que portraitiste officielle de Marie-Antoinette, Élisabeth Vigée-Lebrun poursuivit une vie nomade dans toute l'Europe, profitant de l'hospitalité de ses amis aristocrates. "Son émigration est, comme l'écrivit Henri Rossi, une émigration joyeuse, perçue plutôt comme un voyage d'agrément et d'éducation artistique » (ROSsI 2003, p. 157). Avant de rejoindre l'Autriche et la Russie, elle commença son périple par l'Italie, voyageant de Turin à Rome, en passant par Parme, Florence et Venise où elle se confronta directement aux monuments, musées, églises et galeries qui constituaient la richesse de l'art italien. Elle vécut plusieurs années dans «un cadre de vie nouveau» et s'intégra à «un environnement humain fait, parfois, de retrouvailles, et bien sûr, de nouvelles sympathies liées avec ceux qui l'accueill[aient] ou que le hasard met[tait] simplement sur sa route" (BOUDARD 2003, p. 251). Au travers de la reconstitution de ce voyage initiatique où elle profita des invitations touristiques de ses hôtes, elle énuméra avec émotion et choisit de voir en priorité, en connaisseuse avisée, les œuvres des maîtres anciens qu'elle admirait, tels Rubens, Raphaël, Van Dyck ou encore Michel-Ange. Plus qu'un simple témoignage touristique, esthétique et artistique, ce récit révèle la volonté d'une peintre, consciente de son talent et de son rang, de s'insérer dans une lignée prestigieuse d'artistes, et plus particulièrement de portraitistes. Élisabeth Vigée-Lebrun aimait d'ailleurs répéter qu'en 1789, à Rome, «on [1]'appel[ait] $\mathrm{M}^{\text {me }}$ Van Dyck, $\mathrm{M}^{\mathrm{me}}$ Rubens » (cuzIN 1989, p. 12). Mais cette quête de légitimation ne se fondait pas uniquement sur ses connaissances historico-artistiques, elle s'exprimait aussi par un solide et ostensible savoir-faire technique, deux atouts qui consolidaient l'image d'une artiste complète, en pleine possession de ses moyens intellectuels et pratiques. De ce 
point de vue, ses Conseils pour la peinture du portrait, qui concluent le second volume de ses Souvenirs et constituent le premier manuel de peinture écrit par une femme artiste, montrent une conscience aiguë des enjeux identitaires et matriciels de sa carrière exceptionnelle. Ce petit texte fut aussi l'occasion pour elle de faire part des expériences grâce auxquelles elle avait pu atteindre ces niveaux de production et de clientèle. Elle conseillait notamment l'observation attentive et précise des détails anatomiques des visages, rappelant alors les principes prônés dans les traités physiologiques et physiognomoniques de l'époque.

\section{BIBLIOGRAPHIE}

BOUDARD 2003

Jacqueline Boudard, «L'exil de $\mathrm{M}^{\text {me }}$ Vigée-Lebrun en Italie (1789-1792) », dans Voyage et Révolution. Viaggi di uomini e di idee al tempo della Rivoluzione, Genève, Slatkine, 2003, t. II, p. 2249-2269.

CUZIN 1989

Jean-Pierre Cuzin, « Vigée-Lebrun, un peintre », dans Mémoires d’une portraitiste, Paris, éditions Scala, 1989, p. 7-17.

HAROCHE-BOUZINAC 2006

Geneviève Haroche-Bouzinac, « Entre correspondance et autobiographie. Élisabeth VigéeLebrun », dans Brigitte Diaz et Jürgen Siess (dir.), L'Épistolaire au féminin : correspondances de femmes, $\mathrm{XVIII}^{e}-\mathrm{XX} \mathrm{X}^{e}$ siècle, Caen, Presses universitaires de Caen, 2006, p. 51-64.

ROSSI 2003

Henri Rossi, « La Cour de Vienne dans les Souvenirs de $\mathrm{M}^{\text {me }}$ Vigée-Lebrun », Mémorialistes de l'exil : émigrer, écrire, survivre, Paris, L'Harmattan, 2003, p. 153-172.

SHERIFF 1996

Mary D. Sheriff, The Exceptional Woman. Élisabeth Vigée-Lebrun and the Cultural Politics of Art, Chicago, University of Chicago Press, 1996.

\section{ANNEXES}

Diaporama des œuvres d'arts commentées par Élisabeth Vigée-Lebrun dans ses Souvenirs :

http://www.flickr.com//photos/73632227@N02/sets/72157629964921934/

Lire les extraits des Souvenirs d'Élisabeth Vigée-Lebrun

Lire les Conseils pour la peinture du portrait d'Élisabeth Vigée-Lebrun 
Liste complète des œuvres d'arts commentées par Élisabeth Vigée-Lebrun à travers ses textes édités dans Plumes et pinceaux 


\section{Élisabeth Vigée-Lebrun, Souvenirs,} 1869

[Paris, Charpentier], Édition féministe de Claudine Herrmann, Paris, Des femmes Antoinette Fouque, 2005, tome I, p. 150-262, extraits choisis.

\section{Turin}

Pressée de continuer ma route vers Rome, je ne voulus voir personne à Turin. Je me contentai de visiter la ville et de faire quelques excursions dans les sites remarquables qui l'environnent. La ville est fort belle; toutes les rues sont parfaitement alignées et les maisons bâties régulièrement. Elle est dominée par une montagne appelée la Superga, lieu de sépulture, destiné aux rois de Sardaigne. 
1. Gérard Dou, La Femme hydropique [La Femme hydropique ou Docteur examinant les urines d'une femme]

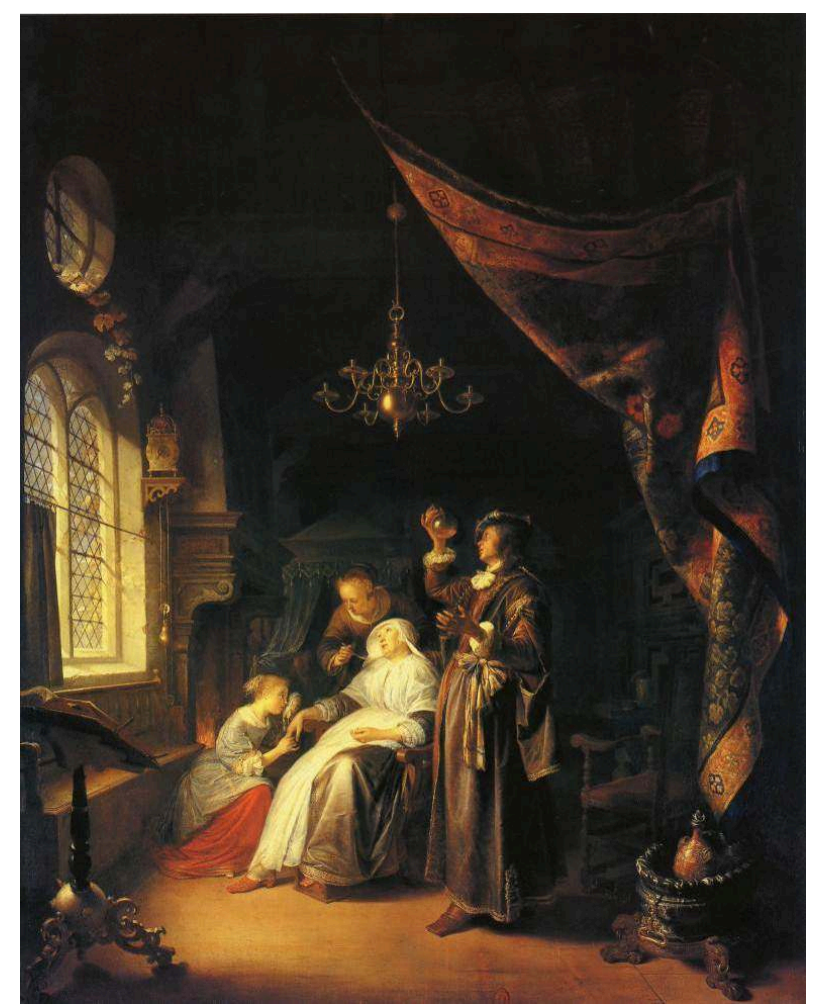

1663, huile sur bois, 83 × 67 cm, Paris, musée du Louvre.

Porporati me conduisit d'abord au Musée royal, où j'admirai une collection de superbes tableaux des diverses écoles, entre autres celui de La Femme hydropique de Gérard Dou, qu'on voit maintenant au musée du Louvre et qu'on peut appeler un chef-d'œuvre dans son genre (fig. 1). Je vis encore plusieurs tableaux admirables de Van Dyck, parmi lesquels je dois citer celui qui représente une famille de bourgmestres, dont les figures sont d'un pied et demi de hauteur. Il est certain que Van Dyck a pris plaisir à faire ce tableau si remarquable ; car, non seulement les têtes et les mains, mais les draperies, les moindres accessoires, tout est fini et tout est parfait, tant pour le coloris que pour l'exécution. Van Dyck, au reste, tenait la plus grande place dans ce musée du roi, où j'ai trouvé peu de tableaux des maîtres d'Italie. [...]

\section{Parme}

3 Je quittai mes aimables hôtes pour aller à Parme. À peine étais-je arrivée dans cette dernière ville que je reçus la visite du comte de Flavigny, qui y séjournait alors comme ministre de Louis XVI. [...] M. de Flavigny me fit voir tout ce que Parme offrait de remarquable. Après avoir été contempler le magnifique tableau du Corrège La Crèche ou La Nativité, que nous avons eu au musée du Louvre, je visitai les églises, dont les ouvrages de ce grand peintre sont aussi le plus admirable ornement. Je ne pus voir tant de tableaux divins sans croire à l'inspiration que l'artiste chrétien puise dans sa croyance : la fable a sans doute de charmantes fictions ; mais la poésie du christianisme me semble bien plus belle. 
Je montai tout au haut de l'église Saint-Jean ; là, je m'établis dans le cintre pour admirer de près une coupole où Le Corrège a peint plusieurs anges dans une gloire, entourés de nuages légers. Ces anges sont réellement célestes ; leurs physionomies, toutes variées, ont un charme impossible à décrire. Mais, ce qui m'a le plus surprise, c'est que les figures sont d'un fini tel qu'en les regardant de près, on croit voir un tableau de chevalet sans que cela nuise en rien à l'effet de cette coupole, vue du bas de l'église.

On peut admirer aussi dans l'église Saint-Antoine, en entrant à gauche, une autre figure de ce grand peintre, la plus gracieuse que je connaisse, et d'une couleur inimitable.

6 J'ai remarqué dans la bibliothèque de Parme un buste antique d'Adrien, très bien conservé, quoiqu'il ait été doré. Un petit Hercule en bronze d'un travail fort précieux, un petit Bacchus charmant, beaucoup de médaillons antiques, etc., mais Le Corrège !... Le Corrège est la grande gloire de Parme. [...]

\section{Bologne}

7 Après avoir traversé les montagnes qui ont quelque chose d'effrayant, car le chemin est très étroit, très escarpé et bordé de précipices, ce qui m'engagea à en faire une partie à pied, [ma fille, la gouvernante et moi] arrivâmes fatiguées à Bologne. [...] Je me rendis aussitôt à l'église de Sainte-Agnès, où se trouve placé le tableau du martyre de cette sainte, peint par Le Dominiquin. La jeunesse, la candeur est si bien exprimée sur le beau visage de sainte Agnès, celui du bourreau qui la frappe d'un poignard forme un si cruel contraste avec cette nature toute divine, que la vue de cet admirable tableau me saisit d'une pieuse admiration.

8 Je m'étais agenouillée devant le chef-d'œuvre, et les sons de l'orgue me faisaient entendre l'ouverture d'Iphigénie parfaitement bien exécutée. Le rapprochement involontaire que je fis entre la jeune victime des païens et la jeune victime chrétienne, le souvenir du temps si calme et si heureux où j'avais entendu cette même musique, et la triste pensée des maux qui pesaient alors sur ma malheureuse patrie, tout oppressa mon cœur au point que je me mis à pleurer amèrement et à prier Dieu pour la France. Heureusement j'étais seule dans l'église, et je pus y rester longtemps, livrée aux émotions si vives qui s'étaient emparées de mon âme.

En sortant, j'allai visiter plusieurs des palais qui renferment les chefs-d'œuvre des grands maîtres de l'école de Bologne, plus féconde qu'aucune autre école italienne. Il faudrait des volumes pour décrire les beautés dont Le Guide, Le Guerchin, les Carrache, Le Dominiquin, ont orné ces pompeuses habitations. Dans l'un de ces palais, le custode me suivait, s'obstinant à me nommer l'auteur de chaque tableau. Il m'impatientait beaucoup, et je lui dis doucement qu'il prenait une peine inutile; que je connaissais tous ces maîtres. Il se contenta de continuer à m'accompagner; mais comme il m'entendait m'extasier devant les plus beaux ouvrages en nommant le peintre, il me quitta pour aller dire à mon domestique : "Qui donc est cette dame? J'ai conduit de bien grandes princesses, mais je n'en ai jamais vu qui s'y connaisse aussi bien qu'elle. »

Le palais Caprara renferme, dans sa première galerie, des trophées militaires indiens et turcs, dont plusieurs sont la dépouille de généraux vaincus par la famille Caprara. Le portrait du plus célèbre guerrier de ce nom est au bout de la galerie qui, je crois, est unique dans son genre. 
11 On voit, dans la seconde galerie, une tête de prophète et la Sibylle de Cumes du Guerchin, dans son meilleur temps; une Ascensiondu Dominiquin, quelques têtes de Carlo Dolce et de Titien ; une Sainte Famille du Carrache, et deux petits tableaux ronds de l'Albane d'une grande finesse.

12 Le palais Bonfigliola possède un beau saint Jérôme de l'Espagnolet, une Sibylle du Guide, appuyée sur sa main tenant un papyrus; ainsi que plusieurs autres chefsd'œuvre.

\section{Le Guide, Saint Pierre et saint Paul causant ensemble}

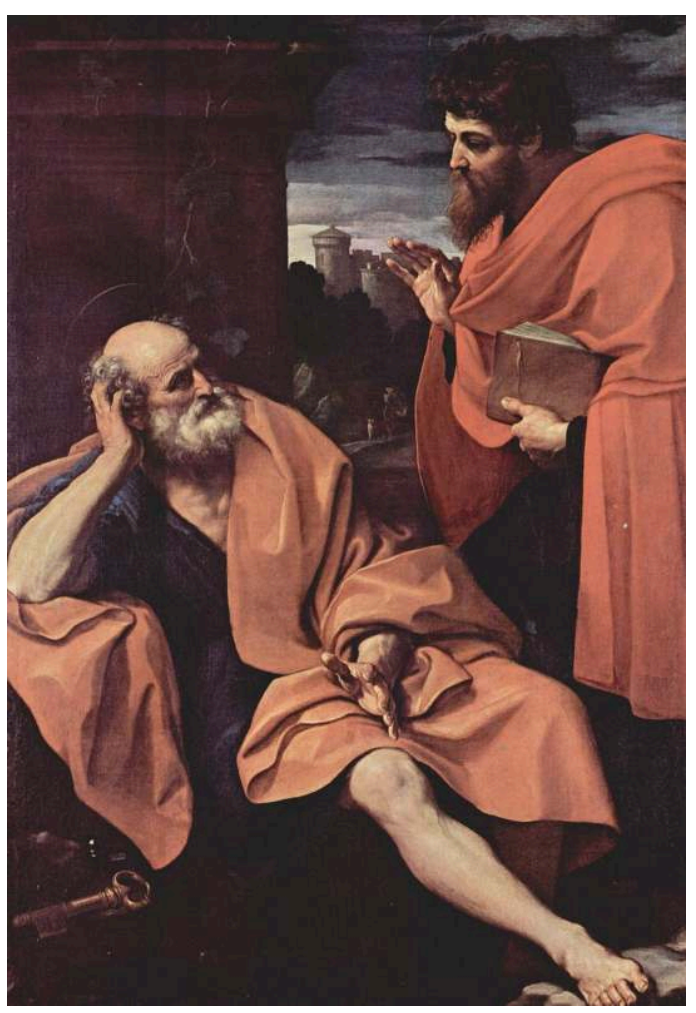

1605, huile sur toile, $197 \times 140$ cm, Milan, pinacothèque de Brera.

13 On voit au palais Zampieri Henri IV et Gabrielle par Rubens; dans la salle d'Annibal Carrache, la Déposition du Christ, effet de nuit, superbe tableau; le portrait de Louis Carrache peint par lui-même ; un plafond du Guerchin représentant Hercule qui étouffe Antée ; et le Départ d'Agar, beau tableau, plein d'expression. C'est dans ce palais que se trouve le chef-d'œuvre du Guide, Saint Pierre et saint Paul causant ensemble (fig. 2). Ce tableau réunit toutes les perfections; les moindres détails y sont d'une telle vérité que ces deux figures font illusion au point qu'on croit les entendre parler. C'est bien certainement ce que Le Guide a fait de plus beau. [...]

\section{Florence}

Je me consolai d'abandonner tant de chefs-d'œuvre par l'idée de tous ceux que j'allais trouver à Florence. [...] J'allai voir avant tout la célèbre galerie que les Médicis ont enrichie avec tant de magnificence. En entrant par le vestibule, on perçoit d'abord une quantité de tombeaux antiques; et, contre la porte, se trouve placée la fameuse statue 
du Gladiateur. De ce vestibule, on entre dans la galerie qui renferme tant de superbes statues. La Vénus de Médicis, Les Deux Lutteurs, Le Remouleur, Un jeune faune, Le Satyre et le Bacchus de Jean de Bologne, et la belle scène de La Niobé. Ces principales figures ornent la salle de la tribune, qui est aussi décorée par plusieurs beaux tableaux dont trois sont de Raphaël, un d'Andrea del Sarto, et d'autres de divers grands maîtres. Dans une seconde salle, on voit en sculpture Euphrosine couchée, Alexandre mourant ; en peinture, une Vénus de Titien, un très beau Vanderveft, de superbes paysages de Salvator Rosa, et cent autres chefs-d'œuvre que je ne cite point ; car il faudrait un volume pour entrer dans quelques détails sur toutes les richesses que j'eus le bonheur d'admirer dans ce lieu de délices pour un artiste.

\section{Raphaël, Vision d'Ézéchiel}

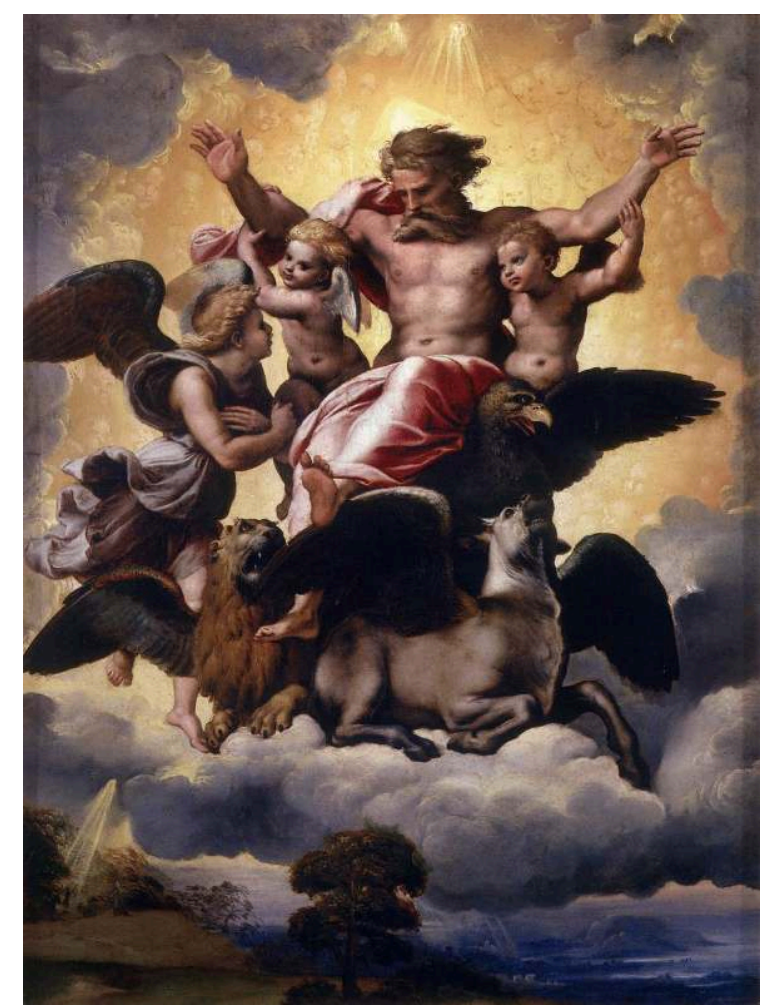

1518, huile sur bois, 40, 7 × 29, 5 cm, Florence, palais Pitti.

15 J'allai le lendemain au palais Pitti où, dans la première salle, je distinguai surtout $L a$ Charité, peinte par Le Guide, le Portrait d'un philosophe par Rembrandt, un tableau à la fois très fin et très vigoureux de Carlo Dolce, une Sainte Famille de Louis Carrache, et $L a$ Vision d'Ezéchiel, admirable petit tableau de Raphaël (fig. 3). J'y remarquai aussi le portrait d'une femme habillée en satin cramoisi, peint par Titien avec autant de vigueur que de vérité. 
4. Raphaël, Madonna della seggiola [Vierge à la chaise]

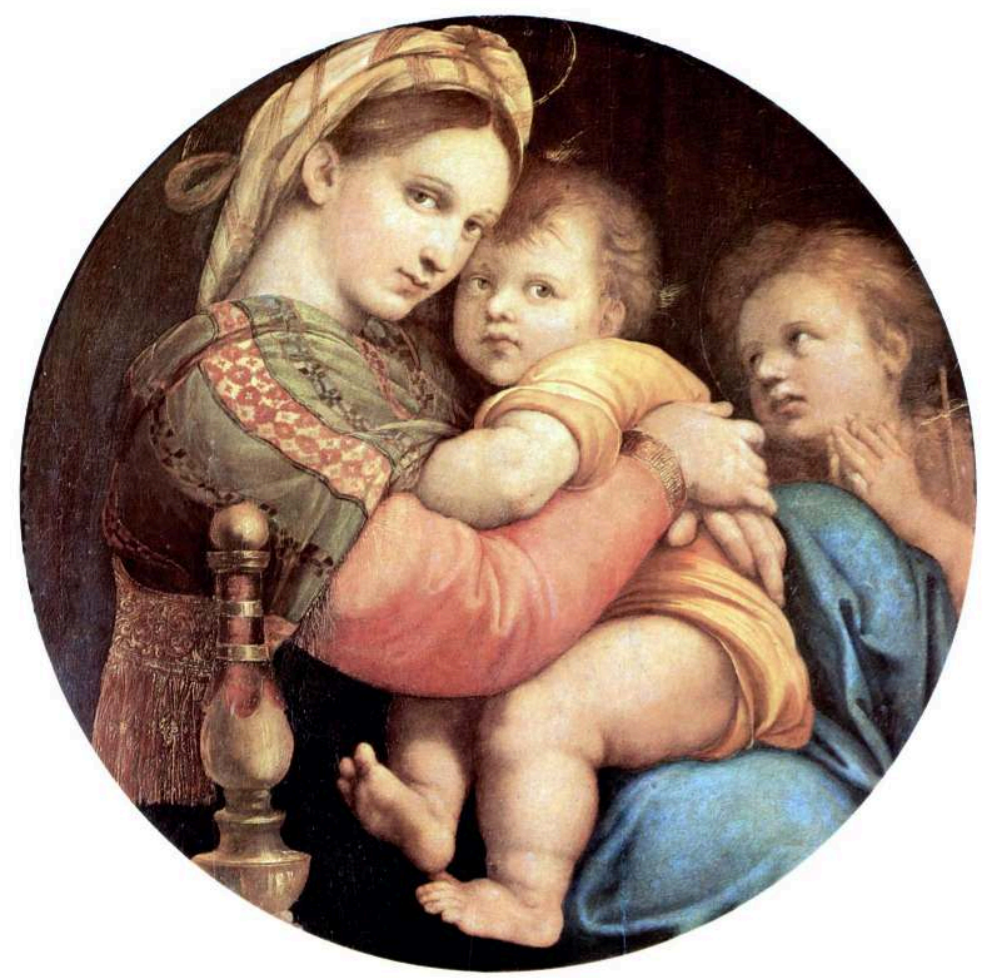

1513-1514, huile sur panneau, $71 \mathrm{~cm}$, Florence, palais Pitti.

5. Raphaël, Léon X [Le Pape Léon X avec les cardinaux Giulio de Médicis et Luigi de Rossi]

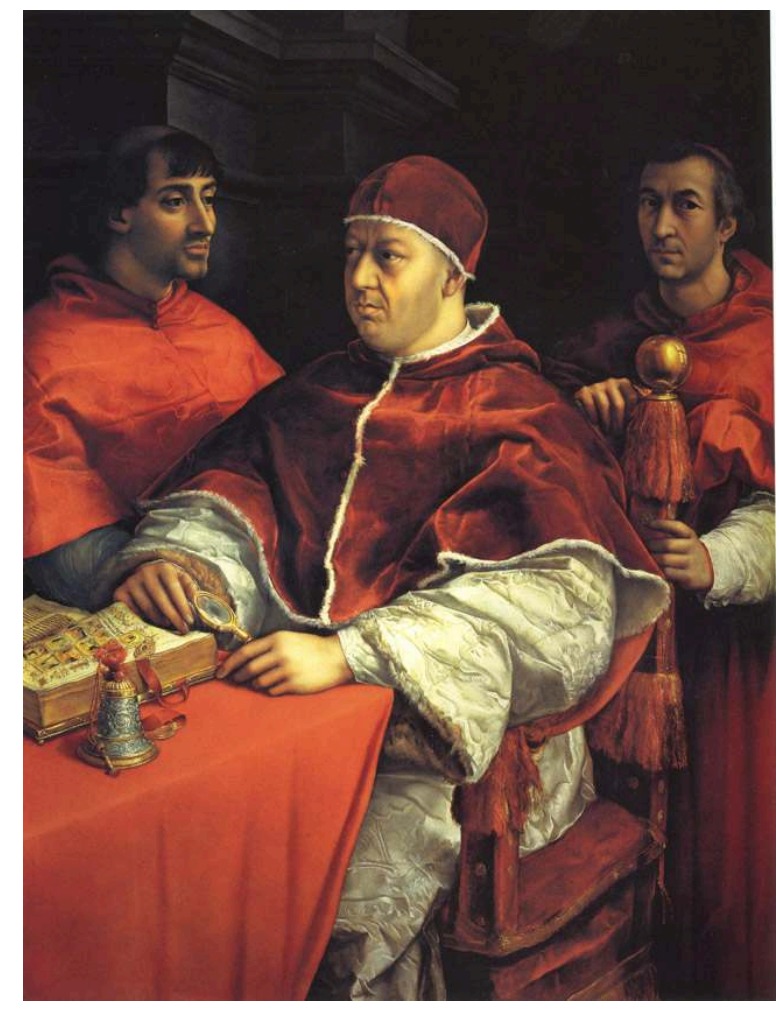

Vers 1518, huile sur panneau, 154 x 119 cm, Florence, galerie des Offices. 
La seconde salle renferme quatre beaux tableaux du vieux Palme; et de Rubens, un grand tableau allégorique, une Sainte Famille, ainsi que son tableau des Philosophes, qui est superbe ; le portrait d'un cardinal, peint par Van Dyck, dont la belle couleur et la grande vérité sont remarquables. C'est aussi dans cette salle que l'on voit la Madonna della seggiola (fig. 4), Léon X (fig. 5) et Jules II, par Raphaël, trois chefs-d'œuvre, si dignes de leur haute renommée.

\section{Andrea del Sarto, La Vierge, Jésus et saint Jérôme [peut-être La Sainte Famille]}

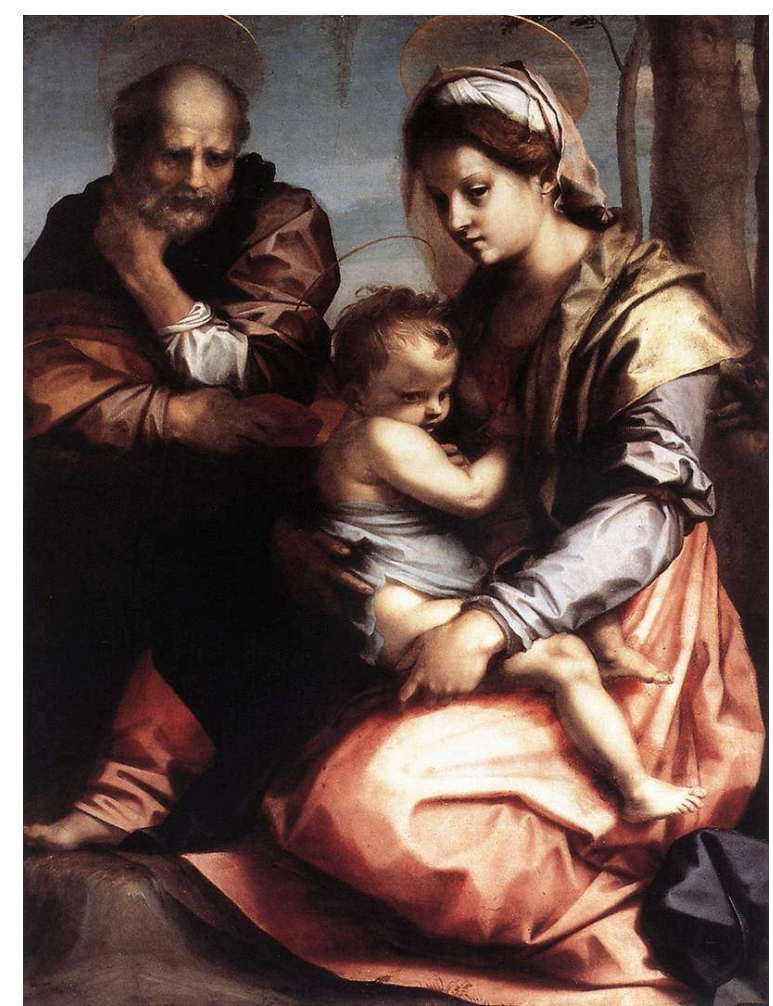

Huile sur bois, $130 \times 98$ cm, Florence, palais Pitti. 
7. Le Titien, Paul III

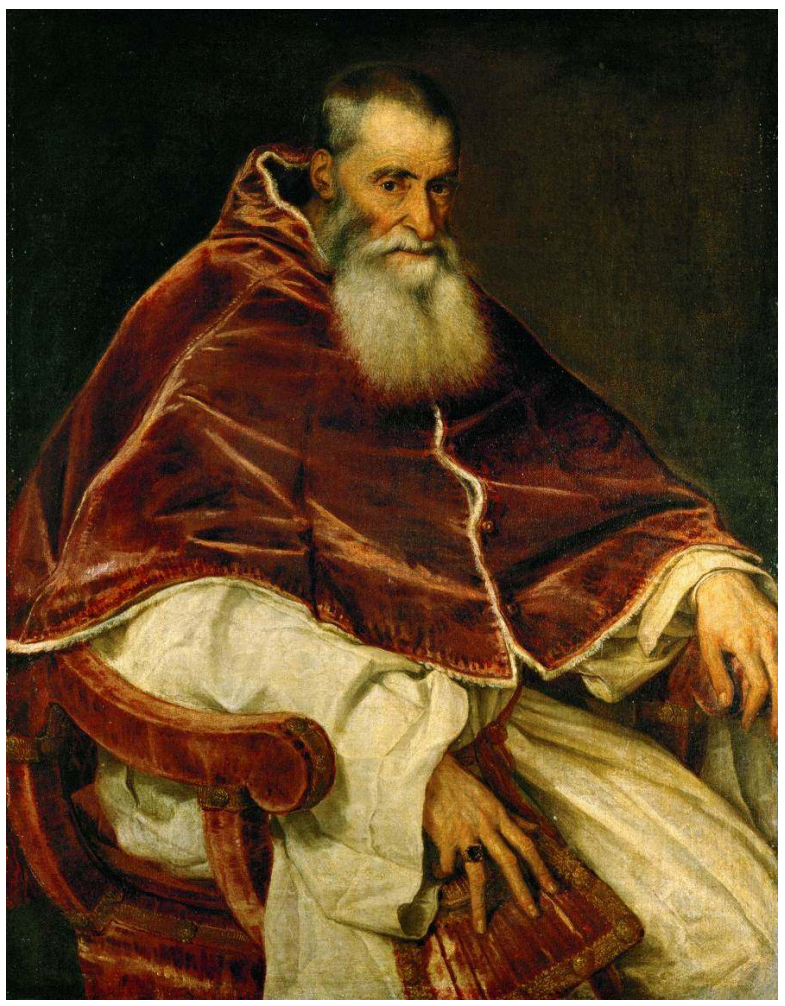

[existent trois versions : huile sur toile, $98 \times 79 \mathrm{~cm}$, Saint-Pétersbourg, musée de l'Ermitage ; 1543, huile sur toile, $107 \times 83 \mathrm{~cm}$, Naples, Museo nazionale ; vers 1549, huile sur toile, $89 \times 78 \mathrm{~cm}$, Vienne Kunsthistorisches Museum].

\section{Pierre-Paul Rubens, Fête de village [peut-être Ronde de paysans dite La Ronde]}

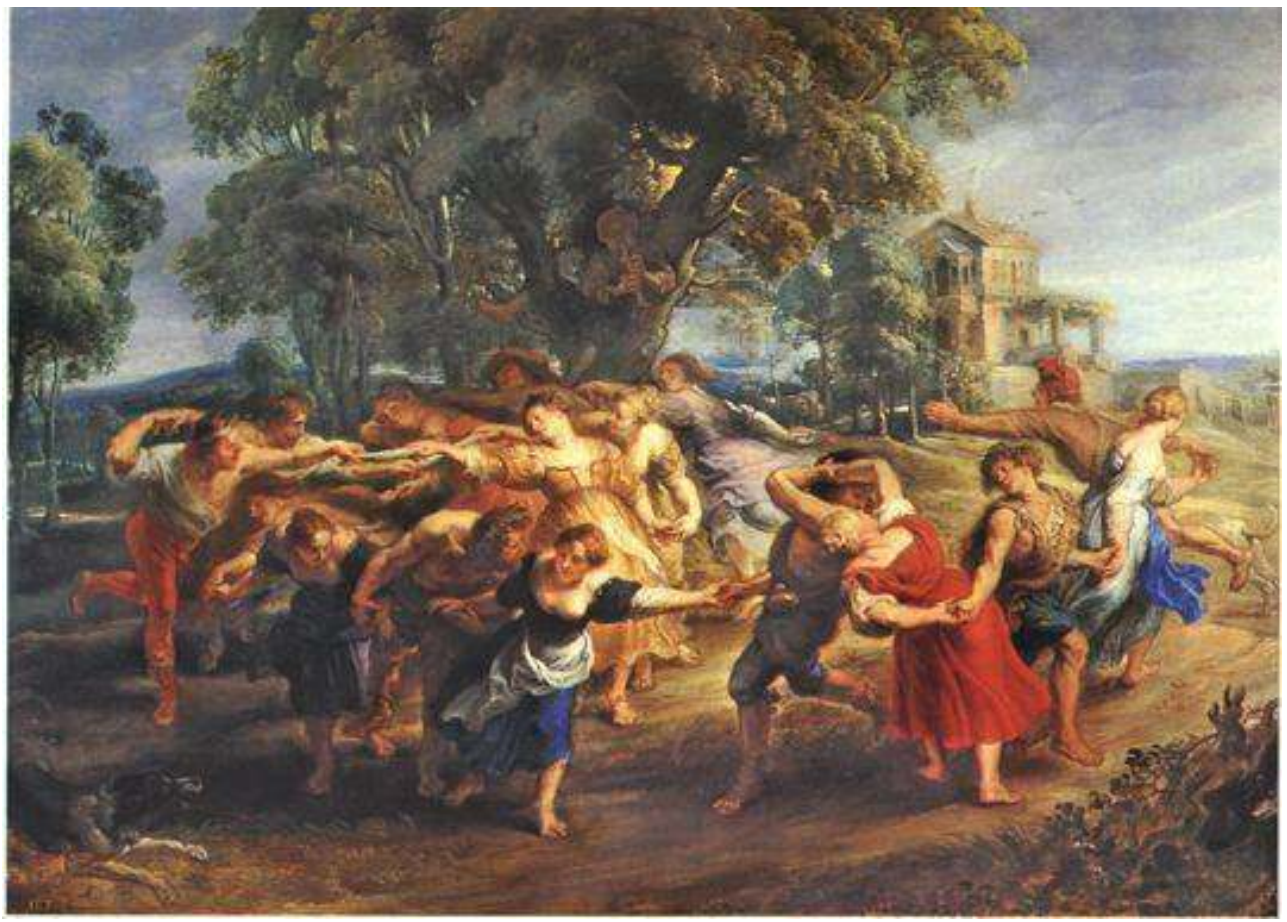

Vers 1640, huile sur toile, $73 \times 106$ cm, Madrid, musée du Prado. 
17 On trouve dans la troisième salle un grand et beau tableau d'Andrea del Sarto représentant la Vierge, Jésus et saint Jérôme (fig. 6); Paul III (fig. 7), de Titien, admirable de vérité ; un tableau allégorique, deux paysages, et la fameuse fête du village, par Rubens (fig. 8) ; enfin, une Sainte Famille assise sur des ruines, magnifique tableau de Raphaël.

18 Dans le jardin du palais Pitti, au-dessus d'un bassin qui a vingt pieds de diamètre, on voit une statue colossale de Neptune, et trois Fleuves qui versent de l'eau en abondance ; toutes ces figures, d'une très belle composition, sont de Jean de Bologne.

\section{Lorenzo Ghiberti, Portes du baptistère [Les Portes du Paradis]}

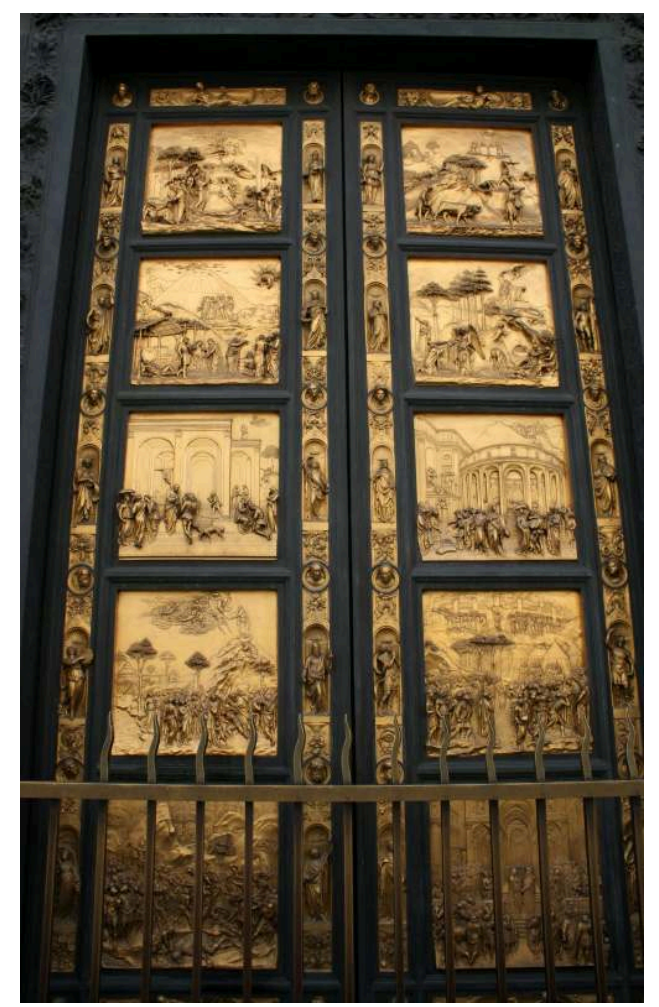

1429-1452, porte en bronze doré, Florence, cathédrale.

Dès que je pus m'arracher à la jouissance de parcourir la galerie des Médicis et le palais Pitti, j'allai voir les autres beautés que renferme Florence. D’abord, les portes du baptistère de Ghiberti, dont les sujets, en dix compartiments, sont d'une composition admirable. Ces sujets sont pris dans l'Ancien et le Nouveau Testament. Le relief des figures, le style des draperies, les accessoires, les arbres, les fabriques, tout est d'une exécution si parfaite qu'on pourrait en faire des tableaux, car il n'y manque que la couleur ; aussi Michel-Ange les nommait-il les portes du Paradis (fig. 9).

À l'église de Saint-Laurent, je m'arrêtai longtemps dans la chapelle des Médicis, dont plusieurs tombeaux ont été exécutés d'après les dessins de Michel-Ange. On ne peut rien voir de plus beau que ces tombeaux. Quelques-uns sont en granit oriental, d'autres en granit égyptien. Dans des niches en marbre noir, on a placé des statues en bronze doré. C'est dans l'église Santa Croce que se trouve le mausolée de Michel-Ange. Là, il faut se prosterner. 


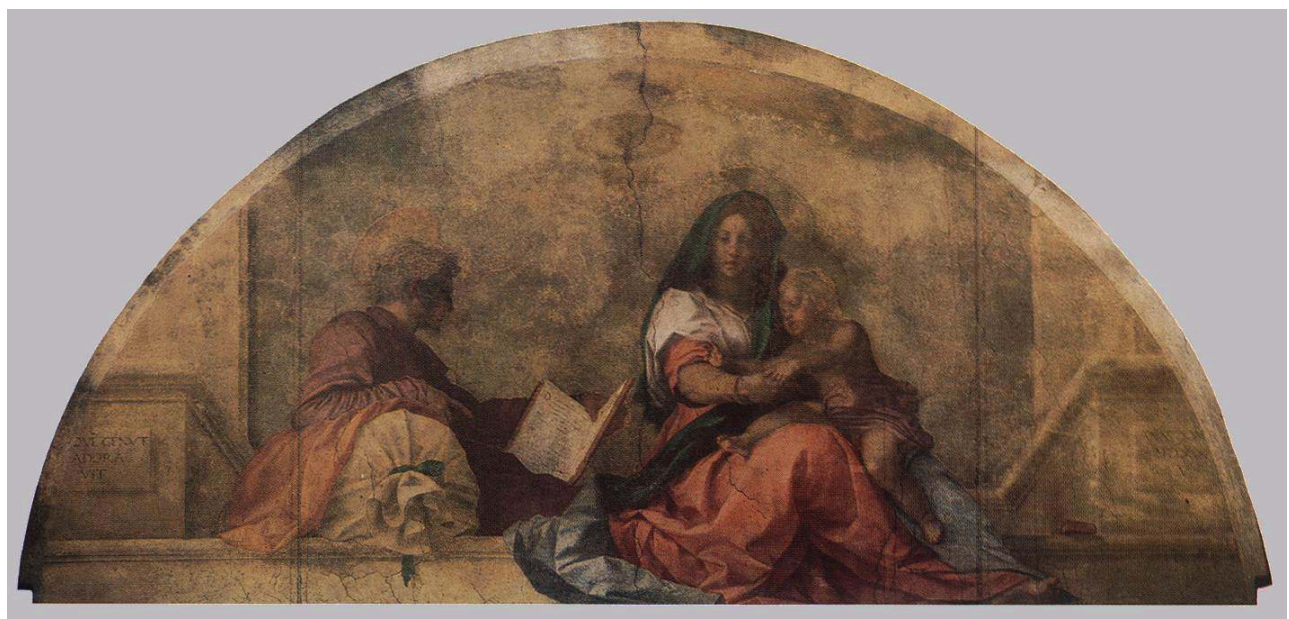

1525, fresque, 191 x 403 cm, Florence, église SS Annunziata.

21 Je suis montée au cloître de l'Annonciale, peint par Andrea del Sarto (fig. 10). Ses diverses compositions sont d'un style simple, qui convient au sujet, et qui tient même de l'antique. Les figures pleines d'expression et de vérité sont d'une excellente couleur. Il est bien malheureux que l'on n'ait pas soigné ces chefs-d'œuvre, qui auraient suffi à la réputation de ce grand peintre. La Vierge, nommée la Madone del Sacco, est divine. On la prendrait pour une Vierge de Raphaël.

On sent bien que je ne pouvais quitter Florence sans aller au palais Altoviti pour voir le beau portrait que Raphaël a fait de lui-même. Ce portrait a été mis sous verre afin de le conserver, et cette précaution a fait noircir les ombres, mais tous les clairs de la chair sont restés purs et d'une belle couleur. Les traits du visage sont régulièrement beaux, les yeux sont charmants, et le regard est bien celui d'un observateur.

23 Je ne négligeai pas de visiter la bibliothèque des Médicis, qui possède les manuscrits les plus rares. Il s'y trouve d'anciens missels dont les marges à gauche sont peintes dans la perfection; les sujets, ainsi, sont rendus en miniature avec des couleurs et un fini admirables. 


\section{Kaufmann Angelika, Autoportrait}

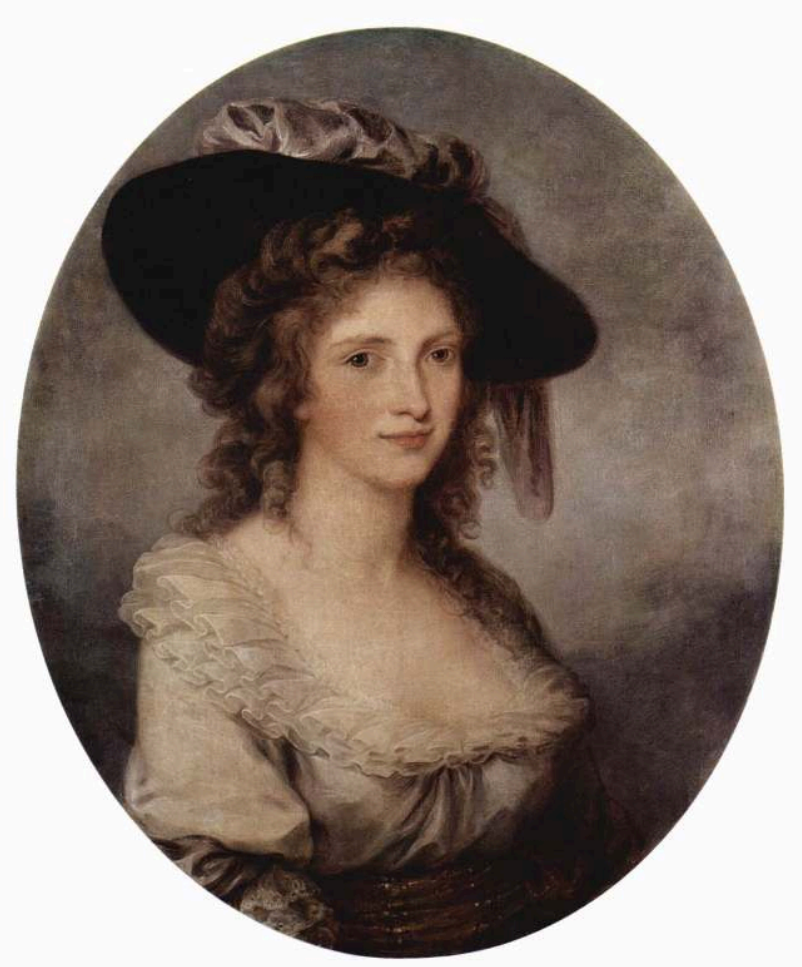

Entre 1780 et 1785, huile sur toile, 76,5 x 63 cm, Saint-Pétersbourg, musée de l'Ermitage. qui avaient eu le bonheur de séjourner ici. Vous savez combien je désirais visiter à mon tour cette belle patrie des arts. Je puis dire que j'avais pour Rome la maladie du pays. $[\ldots]$

\section{Rome}

J'ai monté [...] l'escalier qui conduit à la chapelle Sixtine, pour admirer la voûte peinte à fresque par Michel-Ange et le tableau représentant le Jugement dernier. Malgré toutes les critiques qu'on a faites de ce tableau, il m'a semblé un chef-d'œuvre du premier ordre, pour l'expression et la hardiesse des raccourcis. Il y a vraiment du sublime dans la composition et dans l'exécution. Quant au désordre qui y règne, il est, selon moi, complètement justifié par le sujet.

Le lendemain, je suis allée voir le Muséum. Il est bien vrai qu'on ne peut rien comparer sous le rapport des formes, du style et de l'exécution, à tant de chefs-d'œuvre antiques. 
C'est aux Grecs surtout qu'il appartenait de réunir, dans une aussi haute perfection, l'élégance des formes à la vérité. En voyant leurs ouvrages, on ne peut douter qu'ils n'aient eu de bien admirables modèles, et que les hommes et les femmes de la Grèce n'aient réalisé jadis ce que nous appelons le beau idéal. Je n'ai fait encore que parcourir le Muséum, mais l'Apollon, le Gladiateur mourant, le groupe du Laocoon, ces beaux autels, ces magnifiques candélabres, toutes ces beautés enfin qui me sont apparues, m'ont déjà laissé des souvenirs ineffaçables. [...]

29 Je sors du Vatican ; c'est là surtout que le divin maître a démontré toute la subtilité de son art. Les copies que l'on a faites des chefs-d'œuvre de Raphäl sont loin d'en donner une juste idée; il faut les voir face à face pour admirer le dessin, l'expression, la composition de chaque sujet: jusques aux draperies, tout y est parfait. J'ai même remarqué que, dans la plus grande partie de ces belles pages, la couleur avait la vérité de Titien.

\section{Raphaël, L'Incendie du Borgo}

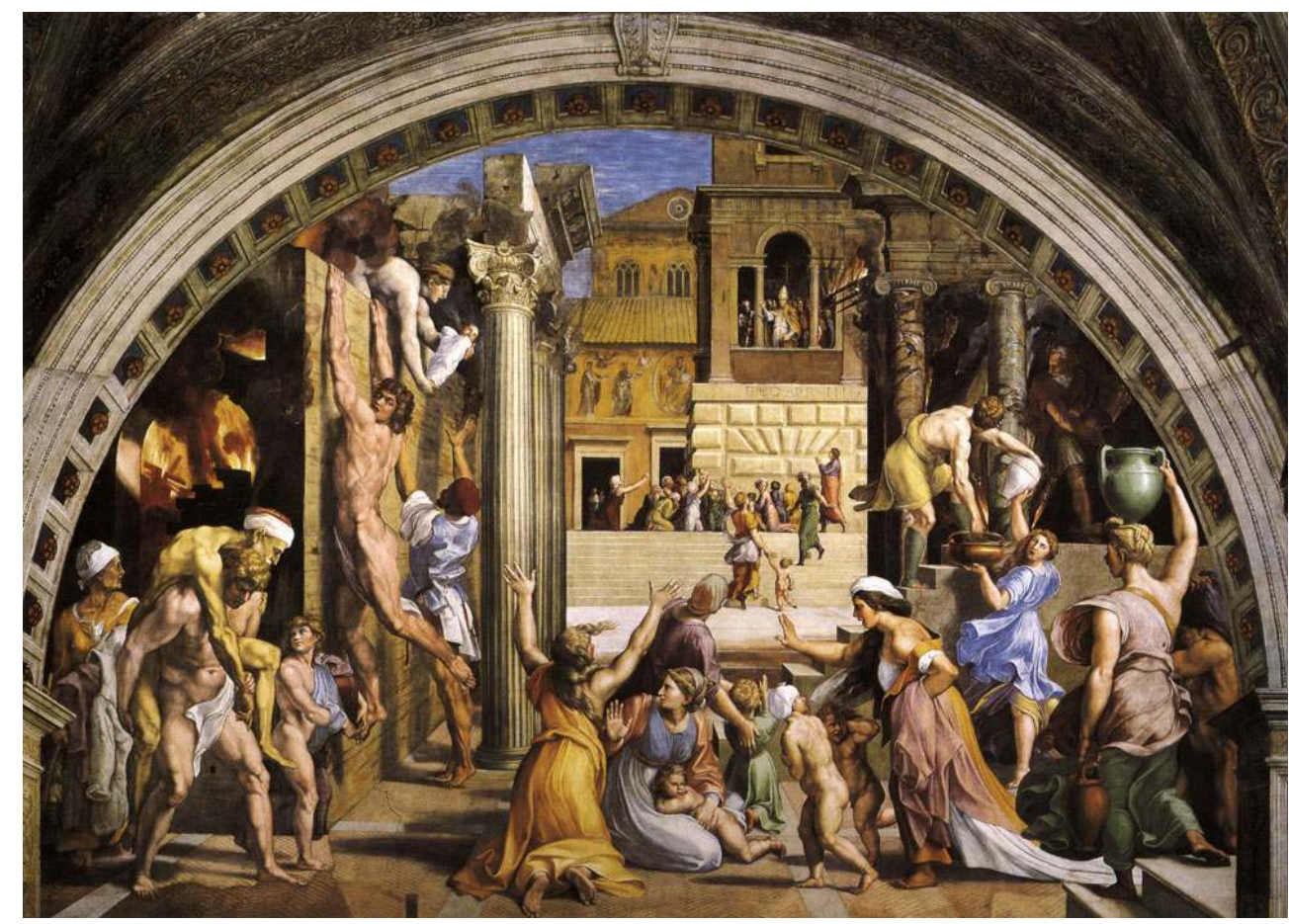

1514-1517, fresque, base 770 cm, cité du Vatican, musées du Vatican.

30 La galerie, les salles, et même ce corridor du Vatican où j'ai vu dans le fond la belle Cléopâtre mourante, tout cela est unique dans le monde. Combien ne s'étonne-t-on pas de la vérité des compositions de Raphaël en voyant cette École d'Athènes, ordonnée avec tant de sagesse, puis l'Incendie du Borgo, composé dans un genre si différent (fig. 12)? Mais ce qui surprend le plus, c'est que celui qui est mort si jeune ait laissé tant de chefsd'œuvre. Cela prouve avec évidence que la fécondité est un attribut inhérent au génie. [...]

31 Le palais Justinien renfermait alors une immense quantité de chefs-d'œuvre qui, depuis, ont tous été vendus. J'y admirai L'Ombre de Samuel, un des plus beaux tableaux de Gérard de la Notte ; c'est un effet de nuit du genre habituel de ce maître ; plusieurs 
statues antiques, entre autres la fameuse Minerve, devant laquelle on a longtemps brûlé l'encens, ce qu'on reconnaît en voyant le bas de cette statue qui est très enfumé.

Les palais Farnèse, Doria, Barbarini, étaient pleins aussi d'objets d'art que je ne me lassai pas d'aller revoir. Dans le dernier, qui est situé sur le mont Quirinal et dont la cour renfermait alors un obélisque égyptien, la voûte du grand salon est peinte par Pierre de Cortone ; dans d'autres salles, on trouvait La Mort de Germanicus, de Poussin ; une Magdeleine et un Enfant endormi, du Guide, et plusieurs beaux portraits de ce peintre. En sculpture, un magnifique buste d'Adrien, le Faune qui dort, et beaucoup d'autres statues et bas-reliefs antiques.

Le palais Colonna est cité comme le plus beau de Rome ; toutefois, il est loin d'offrir le même intérêt que le palais Borghèse. Celui-ci est si riche en tableaux des grands maitres et en statues, qu'il peut, ainsi que la villa du même nom, passer pour un musée royal. C'est là que j'ai vu les plus beaux tableaux de Claude Lorrain.

\section{Michel-Ange, Mausolée de Jules /I}

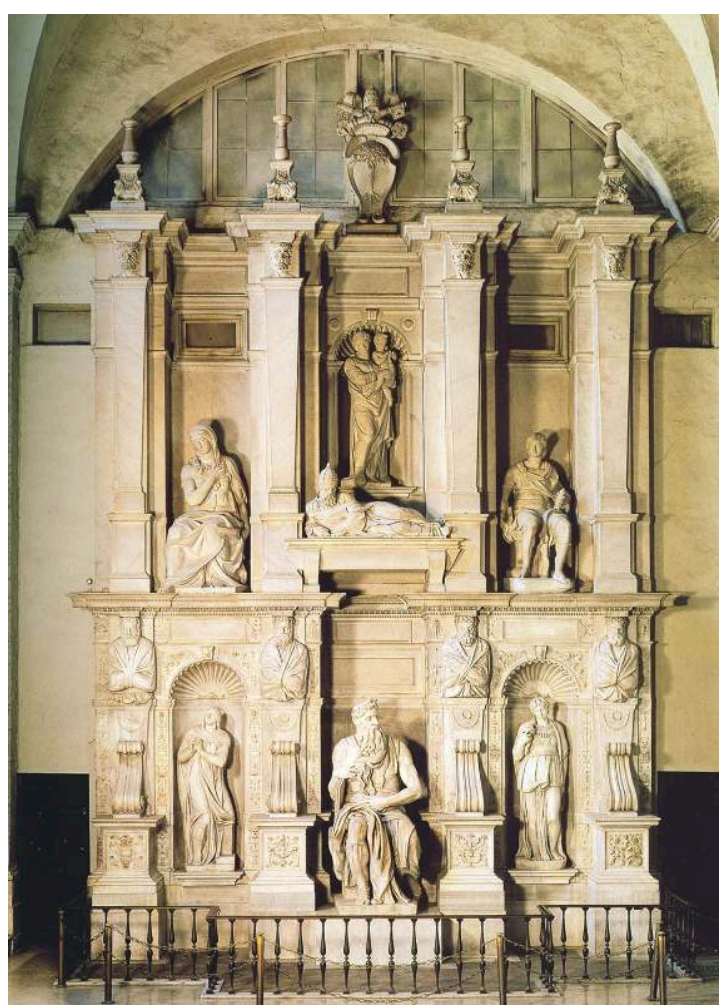

1505-1535, sculpture, marbre, Rome, Saint-Pierre-aux-liens.

34 Si l'on s'en croyait, on passerait sa vie à Rome dans les palais et dans les églises. Les églises renferment des trésors en peinture, en mausolées admirables. En ce genre, les richesses qui ornent Saint-Pierre sont assez connues ; pourtant je veux dire un mot du mausolée de Ganganelli par Canova, qui est une bien belle chose. C'est à Saint-Pierreaux-Liens que se trouve celui de Jules II par Michel-Ange (fig. 13). À Saint-Laurent-horsles-murs, on voit des tombeaux antiques : l'un d'eux représente un mariage, et l'autre une vendange. L'église de Saint-Jean-de-Latran, qui est ornée de colonnes, renferme aussi plusieurs tombeaux du même genre, dont l'un est en porphyre et d'une immense dimension ; le cloître, qui joint la sacristie, est rempli d'inscriptions antiques écrites en 
diverses langues. C'est à Saint-Jean-de-Latran que le peuple monte à genoux les vingthuit degrés qui précèdent le portail.

La plus belle des églises sous le rapport de l'architecture est celle de Saint-Paul-horsles-murs, dont l'intérieur, de chaque côté, est orné de colonnes. On ne peut douter que Saint-Paul n'ait été un temple, et c'est dans ce style que j'aurais désiré Saint-Pierre.

\section{Le Bernin, Sainte Thérèse [L'Extase de sainte Thérèse]}

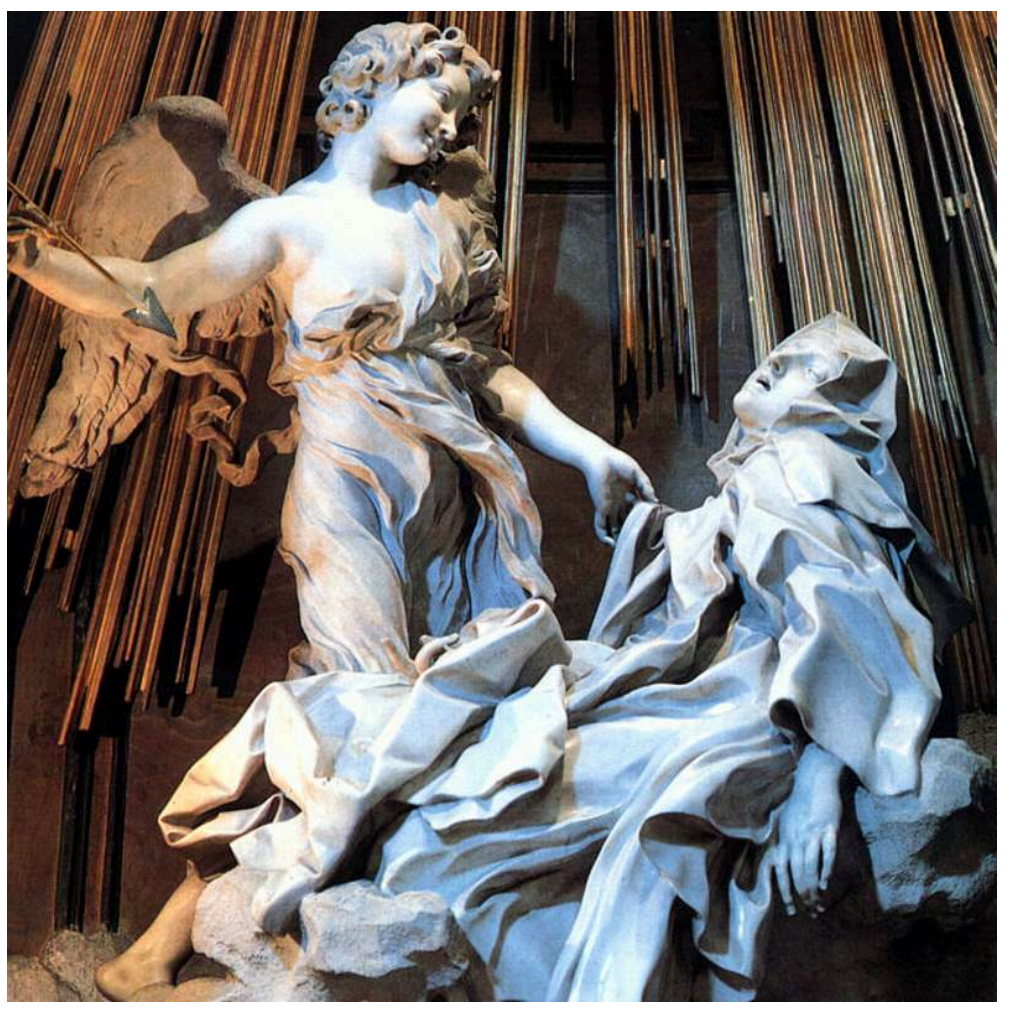

1647-1651, sculpture, marbre, 350 cm, Rome, église Sainte-Marie-de-la-Victoire

À Saint-André-de-la-Valle, la coupole et les quatre évangélistes sont peints par le Dominiquin. C'est à la Trinité-du-Mont que se trouve la célèbre Descente de Croix de Daniel de Volterra. Ce tableau, aussi admirable par la composition que par l'expression, est un des chefs-d'œuvre les plus remarquables de Rome. Je l'ai vu en très mauvais état ; mais on m'assure qu'aujourd'hui il est parfaitement restauré. Je ne sais s'il faut dire que l'on voit, dans l'église de la Victoire de Sainte-Marie, la fameuse Sainte Thérèse du Bernin, dont l'expression scandaleuse ne peut se décrire (fig. 14); mais c'est à San Pietro in Montorio qu'on pouvait admirer alors la Transfiguration de Raphaël. [...]

\section{Sienne}

37 Le lendemain, je fis quelques courses dans la ville, qui est très belle et très bien située, sur une hauteur. On y voit des palais et des maisons gothiques; entre autres la maison de sainte Catherine et celle de je ne sais quel saint. L'hôtel de ville renferme des peintures antiques; les augustins, une fort belle bibliothèque et la superbe église bâtie par Vanvitelli, où se trouvent des tableaux de Romanelli, de Carle Maratte et de Pierre Pérugin ; mais ce qu'on peut admirer avant tout, c'est la cathédrale. Cette belle église 
est gothique, extrêmement vaste, et revêtue de marbre en dedans et en dehors. Sa voûte est couleur d'azur, parsemée d'étoiles d'or ; les vitres du haut sont toutes peintes, et le pavé même est remarquable en ce que les sujets de l'Ancien Testament y sont retracés. Elle est ornée par douze statues en marbre, représentant les douze apôtres, par de belles fresques, par des tableaux de Preti le Calabrais, de Pierre Pérugin, etc., et plusieurs de ses chapelles ont été décorées par Le Bernin. [...]

\section{Mantoue}

Je voulus aller à Mantoue, qui méritait bien une visite, et comme patrie de Virgile, et comme sœur aînée du Capitole, car on prétend qu'elle a été bâtie par les Étrusques ou Toscans, trois cents ans avant la fondation de Rome. Cette ville, située au milieu d'un lac formé par le Mincio, est grande et belle. Sa magnifique cathédrale est de Jules Romain qui, comme on sait, était à la fois peintre, architecte et sculpteur. Jules Romain et le Primatice ont enrichi Mantoue de chefs-d'œuvre en tout genre. Toutes les salles du palais ducal sont ornées par ces deux grands peintres et par Gonzalès. Ce palais est immense et l'un des plus riches que l'on puisse voir sous le rapport des arts.

On fait voir à Mantoue la maison de Jules Romain; elle est située en face du palais Gonzalès, qui est construit aussi sur les dessins de ce célèbre maître. Il y a à Mantoue une Académie des beaux-arts et un musée de statues. L'église Saint-André renferme plusieurs beaux monuments et la bibliothèque, de nombreux manuscrits. Le palais du Té est aussi très remarquable par les peintures à fresque de Jules Romain et du Primatice. Ces fresques représentent des sujets héroïques et l'histoire de Psyché.

40 Jules Romain est mort à Mantoue en 1546 ; mais son nom vit encore avec toute sa gloire dans cette ville, où il a laissé un plus grand nombre de chefs-d'œuvre que partout ailleurs. [...]

\section{Venise}

Quoi qu'il en soit, mon ami me conduisit d'abord au palais pour y voir les chefs-d'œuvre que Venise possède, et qui sont en grand nombre. 
15. Le Tintoret, Le Crucifiement

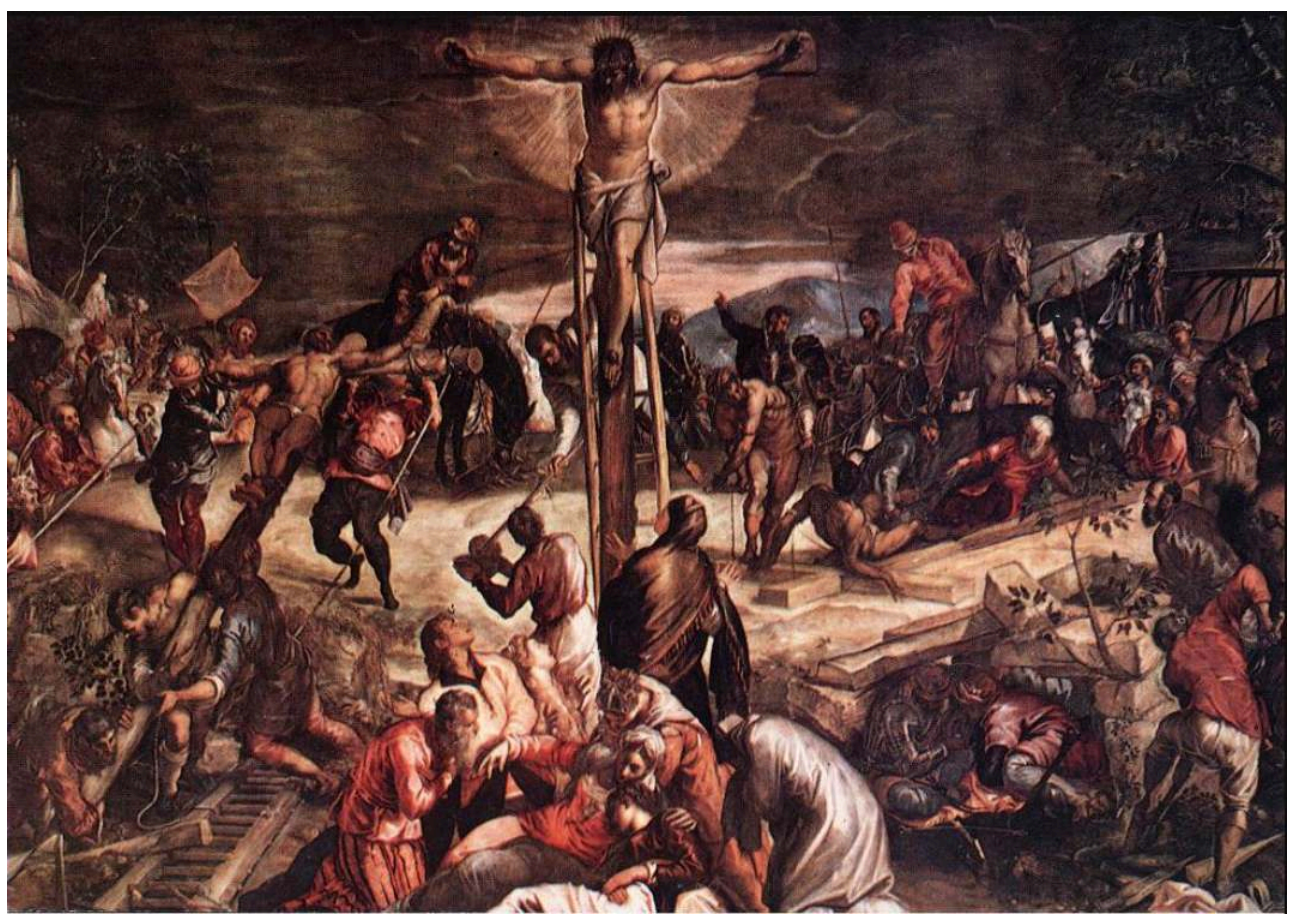

1565, huile sur toile, 536 × 1224 cm, Venise, Scuola di San Rocco.

Dans la plus grande salle des bâtiments de la confrérie, on s'arrête avec délice devant les belles pages à fresques peintes par le Tintoret. Le Crucifiement surtout est admirable, et ce n'est qu'à Venise qu'on peut apprécier ce grand peintre, qui réunit dans ses belles compositions le dessin, la couleur et l'expression (fig. 15). Il faut aussi remarquer, dans la première salle, La Fuite en Égypte : le paysage en est superbe.

Nous visitâmes ensuite les églises, qui sont remplies des plus beaux ouvrages du Tintoret, de Paul Véronèse, des Bassano et de Titien. C'est dans l'église de Saint-Jean-etSaint-Paul qu'on voit le Martyre de saint Pierre, composé de trois figures et de deux anges ; toutes ces figures sont pleines d'expression et le paysage est ravissant. L'église Saint-Marc, dont le lion est le symbole, est du style gothique. Les arcs de la façade sont soutenus par une quantité de colonnes en marbre et en porphyre ; les chevaux dorés, si fameux, ajoutent à ces ornements ; mais ces chevaux, quoique antiques, sont bien loin d'être parfaits. Quant à l'intérieur de l'église, il est impossible de détailler toutes les richesses qu'il renferme en tout genre; ces voûtes d'or, ces parois de jaspe, de porphyre, d'albâtre, de vert antique, ces tableaux, ces bas-reliefs, font de Saint-Marc un véritable trésor.

M. Denon me mena aussi chez un ancien sénateur; nous vîmes là une belle Danaé du Corrège, sujet que ce peintre a répété plusieurs fois, et douze portraits au pastel de la Rosalba, qui sont admirables pour la couleur et la vérité. Ces portraits, étant ceux de la famille du sénateur, n'ont jamais été déplacés, et ils sont conservés à tel point qu'ils ont encore toute leur fraîcheur. Un seul suffirait pour rendre un peintre célèbre. [...] 


\section{Vicence}

Je m'arrêtai à Vicence, qui date sa fondation de 380 ans av. J.-C. Ses beaux palais, parmi lesquels on remarque celui des comtes Chieracati, ont pour la plupart été bâtis par Palladio, et sont d'une élégance remarquable. La rotonde du marquis de Capra mérite aussi d'être citée. Elle est située sur une éminence, et Palladio en a fait un temple, aux quatre côtés duquel se trouvent quatre péristyles, ayant chacun six colonnes qui soutiennent un fronton. Au milieu est une salle ronde, entourée d'une galerie qui joint ces péristyles, dont les quatre points de vue sont admirablement diversifiés.

À la Madone del Monte, on plane sur de belles campagnes, enrichies des plus beaux arbres. Dans l'intérieur de cette église, on voit un magnifique tableau de Paul Véronèse ; il est d'une si belle couleur, et peint avec une telle vérité, que les figures se détachent du fond. À Sainte-Corone, le Baptême de Jésus, par Jean Bellin, est parfait pour le dessin.

Le théâtre de Vicence est du style antique. C'est le chef-d'œuvre de Palladio, qui l'a construit d'après les proportions et sur les dessins de Vitruve.

La traversée de la Brenta offre l'aspect le plus agréable. D'un côté, ses bords sont ornés d'une multitude de palais du style de Palladio, qui font l'effet de temples, et dont les formes grandioses se répètent dans les eaux.

48 Je suis allée dîner dans l'un de ces palais, chez le marquis ***; l'escalier même était d'un style qui me charma. Le propriétaire de cette belle habitation me fit une galanterie à laquelle j'étais loin de m'attendre : il me reçut dans une galerie où se trouvait posée, sur une table, une très grande quantité de gravures ; une seule était placée sens dessus dessous sur toutes les autres : la curiosité me porta bien vite à la retourner, et je vis mon portrait que l'on venait de graver d'après celui que j'avais donné à Florence.

On voit encore à Vicence la maison de Palladio, qui est un modèle d'élégance et de simplicité.

\section{Padoue}

Padoue est aussi située sur les bords de la Brenta. Cette ville est bien ancienne, s'il faut en croire les habitants, qui prétendent qu'elle a été bâtie par Anténor le Troyen. Le palais de justice ou l'hôtel de ville est une des plus belles fabriques de l'Europe. Le salon a cent pas de long sur quarante de large ; il est couvert de plomb et il est sans autre soutien que la muraille; on y voit les douze signes du zodiaque; dans une niche, on y remarque une Vierge qui a beaucoup de simplicité et de naturel.

51 On trouve aux Augustins des fresques de Montigni dont les figures et tous les accessoires sont de la plus grande finesse. L'église Saint-Antoine, qui est de style gothique, renferme un nombre infini de tombeaux, de bas-reliefs, et tant de marbre travaillé qu'elle en est fatigante à voir ; mais les fresques que Giotto a peintes dans cette église sont très bien composées; l'attitude simple et l'expression des figures se rapprochent du style des Anciens. La couleur est souvent celle de Titien, sans pourtant en avoir la perfection. En sortant du cloître, on remarque plusieurs tombeaux très anciens, dont les figures sont pleines de simplicité; la statue équestre d'Erasme de Narni, général vénitien, est aussi digne d'attention. 
Dans l'église de Saint-Jean-Baptiste, on admire Les Évangélistes dans le désert, un des plus beaux tableaux du Guide ; à la cathédrale, dans la sacristie, une Vierge de Titien, qui est bien conservée; à Saint-Jean, plusieurs fresques de Titien, représentant divers miracles, y attirent le regard. Les têtes, pleines d'expression, sont d'une belle couleur, et la touche, le ton du paysage et du ciel, sont admirables. Une autre fresque gothique est aussi très remarquable par la vérité des têtes et par l'attitude des personnages.

\section{Vérone}

53 Je passai toute une semaine à Vérone; c'est une grande ville, dont les rues sont spacieuses et bien alignées; les maisons sont fort belles. J'allai voir d'abord les restes de l'amphithéâtre, qui a été bâti sous le règne d'Adrien, et que les Gaulois ont détruit ; puis le dôme de l'église, qui est fort belle, et dans laquelle se trouve un tombeau antique, dont les ornements sont du plus fin travail. Comme, en Italie, les églises sont ouvertes toute la journée, je fis une tournée dans celles de Vérone. J'entrai dans celle de SaintGeorges, où le maître-autel est décoré d'un beau tableau de Paul Véronèse et d'un autre tableau de ce peintre, placé à droite en arrivant. J'y vis aussi une Vierge et deux évêques, de Chieralino, ainsi qu'un groupe d'anges; mais ce que je remarquai surtout du même maitre est un tableau de trois figures qui représente un concert; non seulement ce tableau est peint avec le plus grand soin, mais les figures sont encore pleines de grâce et de naïveté.

54 L'église de Sainte-Amastrasie est tout à fait de style gothique, avec des colonnes d'une belle proportion, qui produisent un grand effet; toutefois, je lui préfère l'église de Saint-Zemon. Celle-ci est très vaste, et le jour, qui l'éclaire seulement par en haut, lui donne un aspect mystérieux et mélancolique. Je me trouvais seule dans ce temple silencieux, et je me plus à me livrer aux idées religieuses et douces qui s'emparaient de mon âme. [...]

\section{Milan}

55 Je fus reçue à Milan de la manière la plus flatteuse ; le soir même de mon arrivée, les jeunes gens des premières familles de la ville vinrent me donner une sérénade sous mes fenêtres. Je me contentais d'écouter cette musique avec grand plaisir, ne soupçonnant pas le moins du monde que je fusse l'objet de cette galanterie italienne, quand mon hôtesse monta pour me le dire et m'assurer de l'extrême désir que l'on avait de me garder dans la ville au moins pendant quelque temps. Afin de témoigner ma reconnaissance d'un pareil accueil, je crus devoir m'établir pour plusieurs jours à Milan, où d'ailleurs je désirais voir les tableaux des grands maîtres et beaucoup d'autres choses curieuses. 
16. Léonard de Vinci, La Cène

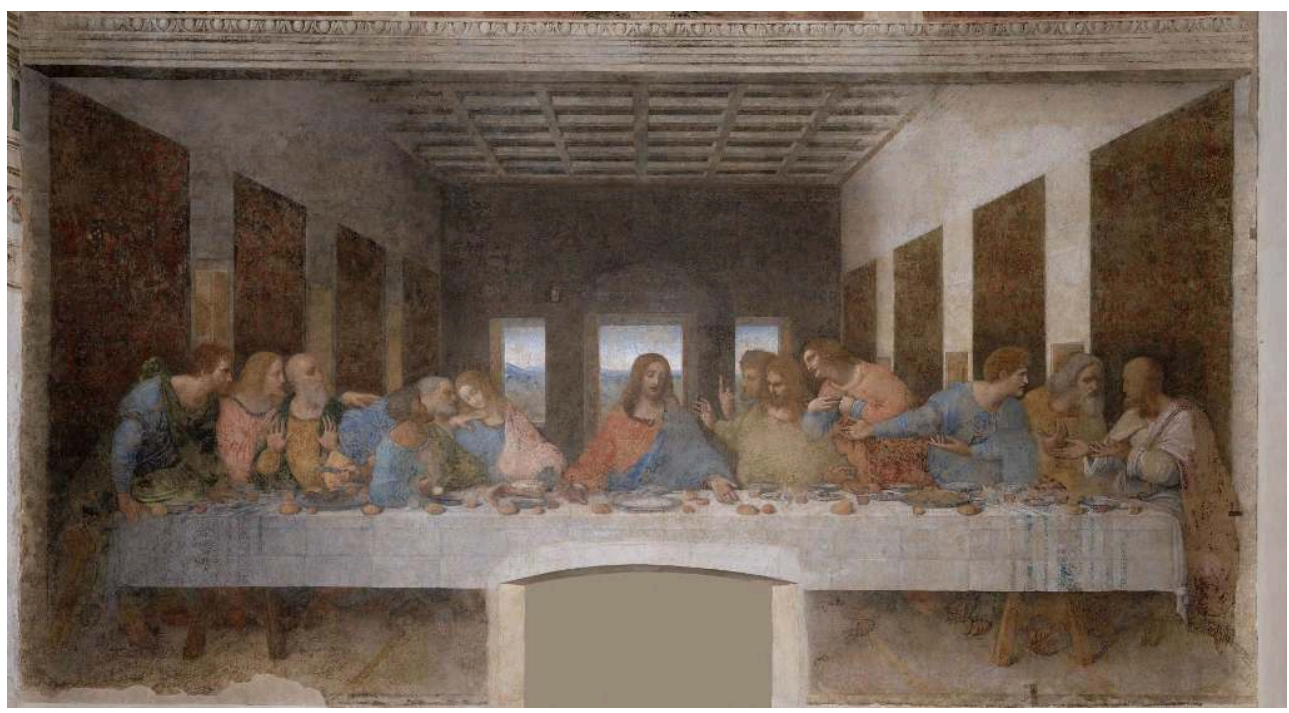

1494-1498, peinture murale à la tempera, Milan, église Santa Maria delle Grazie.

Je visitai d'abord le réfectoire de l'église des Grazie, où se trouve la fameuse Cène, peinte sur mur par Léonard de Vinci (fig. 16). C'est un des chefs-d'œuvre de l'école italienne ; mais en admirant ce Christ, si noblement représenté, tous ces personnages, peints avec tant de vérité et de caractère, je gémissais de voir un aussi superbe tableau altéré à ce point ; il a d'abord été couvert de plâtre, puis repeint dans plusieurs parties. Toutefois on pouvait juger de ce qu'avait été cette belle composition avant ces désastres puisque, vue d'un peu loin, elle produisait encore un effet admirable. Depuis, j'ai su que ce chefd'œuvre avait été bien autrement dégradé. On m'a dit que les soldats s'amusaient à tirer des coups de fusils à balles dans la Cène de Léonard de Vinci! Maudits soient ces barbares!

Je m'empressai, comme on peut le croire, d'aller voir les cartons de l'École d'Athènes, tracés par Raphaël, et je les contemplai longtemps avec délice. Puis je trouvai aussi à la bibliothèque Ambroisine une collection de dessins très précieux; car plusieurs sont de Raphaël, de Léonard de Vinci et d'autres grands maîtres. Ces dessins ne sont pas terminés, mais tout y est indiqué avec autant d'esprit que de sentiment ! Plus finis, ils auraient perdu de leur piquante originalité. On voit dans cette bibliothèque Ambroisine une grande quantité de médailles antiques, les plus intéressants manuscrits et des trésors en pierres rares et en marbres précieux.

\section{ANNEXES}

Lire les Conseils pour la peinture du portrait d'Élisabeth Vigée-Lebrun

Lire l'introduction à Élisabeth Vigée-Lebrun écrite par Charlotte Foucher 


\section{Élisabeth Vigée-Lebrun, Conseils pour la peinture du portrait, 1869}

[Paris, Charpentier], La Rochelle, Rumeur des âges, 1997, extraits choisis.

\section{Ce qu'on doit observer avant de commencer un portrait}

1 Il faut toujours être prête une demi-heure avant que le modèle arrive, afin de se recueillir : c'est une chose nécessaire pour plusieurs raisons.

2 1) Il ne faut pas se faire attendre ; 2) Il faut que la palette soit préparée ; 3) Faire en sorte de ne pas être tracassée par du monde et des détails d'affaires.

\section{Règle nécessaire}

3 Il faut placer son modèle assis, plus haut que soi; il faut que les femmes soient commodément ; qu'elles aient de quoi s'appuyer, et un tabouret sous les pieds.

4 Il faut, le plus possible, s'éloigner de son modèle, c'est le vrai moyen de bien saisir le juste ensemble des traits et l'aplomb des lignes, tant pour la tournure du corps que pour ses habitudes qu'il est nécessaire d'observer, même pour la ressemblance totale ; ne reconnaît-on pas les personnes par derrière, même sans apercevoir leur visage?

5 Pour faire le portrait d'un homme, surtout s'il est jeune, il faut le faire tenir un instant debout avant de commencer, pour tracer plus juste les signes généraux et extérieurs. Si on traçait le personnage assis, le corps n'aurait pas d'élégance et la tête paraîtrait trop rapprochée des épaules. Pour les hommes surtout, cette observation est nécessaire, les voyant plus souvent debout qu'assis.

6 Il faut ne pas placer la tête trop haut dans la toile, cela grandit trop le modèle, et trop bas cela le rapetisse : on doit placer la figure de manière qu'il y ait plus d'espace du côté où est tourné le corps. 
7 Il faut avoir derrière soi une glace, placée de manière à apercevoir son modèle et son portrait, pour pouvoir le consulter très souvent; c'est le meilleur guide, il explique nettement les défauts.

8 Avant de commencer, causez avec votre modèle; essayez plusieurs attitudes, et choisissez non seulement la plus agréable, mais celle qui convient à son âge et à son caractère, ce qui peut ajouter à la ressemblance; faites de même pour sa tête : placez-la de face ou de trois quarts, cela ajoute plus ou moins à la vérité des traits, surtout pour le public; le miroir peut aussi décider à ce sujet.

9 Il faut tâcher de faire la tête, le masque surtout, dans trois ou quatre séances d'une heure et demie chaque, deux heures au plus; car le modèle s'ennuie, s'impatiente (ce qu'il faut éviter), son visage change visiblement; c'est pourquoi il faut le faire reposer et le distraire le plus possible. Tout cela est d'expérience avec les femmes; il faut les flatter, leur dire qu'elles sont belles, qu'elles ont le teint frais, etc. Cela les met en belle humeur et les fait tenir avec plus de plaisir. Le contraire les changerait visiblement. Il faut aussi leur dire qu'elles posent à merveille; elles se trouvent engagées par là à se bien tenir. Il faut bien leur recommander de ne point amener de sociétés, car toutes veulent donner leur avis et font tout gâter. Quant aux artistes et aux gens de goût, on peut les consulter. Ne vous rebutez pas si quelques personnes ne trouvent aucune ressemblance à vos portraits; il y a grand nombre de gens qui ne savent point voir.

10 Tant que vous travaillez à la tête d'une femme, si elle est vêtue de blanc, mettez sur elle une draperie de couleur absente, c'est-à-dire grise ou verdâtre, afin de ne pas distraire les rayons visuels et qu'ils puissent se reposer seulement sur la tête du modèle : si cependant vous la peignez en blanc, laissez-en un peu pour la tête, qui doit en être reflétée.

11 Que le fond, derrière le modèle, soit en général d'un ton doux et uni, ni trop clair, ni trop foncé ; si c'est un fond de ciel, c'est autre chose : mettez du bleuâtre derrière la tête.

12 Pour peindre la tête au pastel ou à l'huile, il faut établir les masses de vigueur, les demiteintes, ensuite, les clairs. Il faut empâter les lumières et les rendre toujours dorées ; entre les lumières et les demi-teintes, il y a un ton mixte qu'il ne faut pas omettre, il participe du violâtre, du verdâtre, du bleuâtre. Voyez Van Dyck. Les demi-teintes doivent être de ton rompu et moins empâtées que les lumières, que la lumière de la tête indique fortement ses os et ses parties musculeuses qui cèdent aux premières.

Immédiatement après cette première lumière se trouve le ton de chair décidé selon le teint de la personne; il se perd avec les tons mixtes et fugaces des demi-teintes.

Les ombres doivent être vigoureuses et transparentes à la fois, c'est-à-dire point empâtées, mais d'un ton mûr, accompagné de touches fermes et sanguines dans les cavités telles que l'orbite de l'œil, l'enfoncement des narines, et dans les parties ombrées et internes de l'oreille, etc. Les couleurs des joues, si elles sont naturelles, doivent tenir de la pêche dans la partie fuyante, et de la rose dorée dans la saillante, et se perdre insensiblement avec les lumières occasionnées par la saillie des os et qui sont d'un ton doré. Où les lumières doivent toujours être, et se dégrader insensiblement, c'est à l'os du front, à celui de la joue autour du nez, au haut de la lèvre supérieure, dans le coin de la lèvre inférieure, et sur le haut du menton. Il faut observer que la lumière doit diminuer à mesure et que la partie la plus saillante, et la plus éclairée par conséquent, doit toujours être la plus lumineuse. Les lumières scintillantes, fines et 
générales d'une tête sont dans la prunelle, ou dans le blanc de l'œil, selon la position de l'œil et de la tête ; ces deux lumières cèdent aux autres de beaucoup et sont d'un ton moins doré, au milieu de la paupière supérieure, au milieu de la paupière inférieure, ou du moins sur une partie, c'est selon comme la tête est éclairée ; ensuite sur le milieu du nez, sur le cartilage, sur la lèvre inférieure : plus le nez de la personne est fin, plus la lumière doit être fine. Il ne faut jamais empâter les prunelles, pour qu'elles soient vraies et transparentes; il faut, le plus possible, les bien détailler, prendre garde de leur faire un regard équivoque, et surtout les faire rondes. Il faut observer que quelques personnes les ont plus petites ou plus grandes, mais toujours parfaitement rondes; le haut du cercle de la prunelle est toujours intercepté par la paupière supérieure; mais à l'œil en colère, la prunelle se voit entièrement. Quand l'œil sourit, la prunelle est interceptée par la paupière inférieure qui la recouvre. Le blanc de l'œil doit être d'un ton vierge et pur dans l'ombre, et la demi-teinte, quoique perdant son vrai ton de même que tous les objets, ne doit jamais être grise ni d'un ton sale. L'œil doit refléter quelquefois la lumière du nez et participer un peu de l'orifice. Les cils dans la partie ombrée se détachent en clair, c'est pourquoi il faut peindre ces tons avec de l'outremer, dans la partie claire en ombre. L'orbite de l'œil est bien à observer, elle est plus vigoureuse ou plus ou moins claire, selon sa forme. Elle est composée d'ombres, de clairs, de demi-teintes et de reflets du nez. Le sourcil doit être préparé d'un ton chaud et l'on doit sentir la chair dessous les petites échappées des poils, qui doivent être faits finement et avec légèreté.

Le battu, l'enchâssement de l'œil est toujours d'un ton fin (plus ou moins, selon la délicatesse et la blancheur de la peau), bleuâtre, violâtre. Il faut bien prendre garde de trop pousser ces tons, cela rendrait l'œil pleureur. C'est pourquoi il faut quelquefois les rompre par des dorés, mais avec ménagement.

16 Il faut bien observer la partie du front; elle est nécessaire à la ressemblance et donne en partie le caractère de la physionomie. Pour les fronts dont l'os a une saillie carrée, tels que Raphaël, Rubens, et Van Dyck, comme on peut le voir dans leurs portraits, la lumière s'indique fortement sur leurs saillies. La première est en haut du front, peu de distance après les cheveux. Elle s'interrompt un peu et vient s'asseoir près du sourcil, ce qui fait céder le ton de la tempe, où se décrit souvent la veine bleue, surtout aux peaux délicates. Après cette lumière est un ton de chair entier qui se dégrade vers le milieu ; la lumière se rappelle faiblement, sur cette même forme d'os du petit côté, par une demi-teinte, et se marie doucement par des demi-teintes qui vont gagner l'ombre qui dessine encore cette même forme de l'os frontal. Après cette ombre, il existe un reflet plus ou moins doré, selon la couleur des cheveux. Dessous le sourcil, le ton se prépare un peu plus chaud: les poils du sourcil multipliés font le même effet que des boucles de cheveux qui retomberaient sur un front éclairé. L'ombre en est chaude. Voyez les têtes de Greuze et observez bien l'habitude des cheveux du modèle que vous peignez, cela ajoute à la ressemblance et la vérité. Il faut bien observer les passages des cheveux qui se verront avec la chair, afin de les rendre aussi vrais que possible ; qu'il n'y ait jamais de dureté et que les cheveux se mêlent bien avec la chair, tant par le contour que par la couleur; afin que cela n'ait point l'air d'une perruque, ce qui arriverait immanquablement si l'on ne faisait pas ce que je viens d'expliquer.

Les cheveux doivent se dessiner par masse et très peu l'emporter ; le mieux serait de les faire par glacis, la toile produisant des transports dans l'ombre et dans le ton entier. Les clairs des cheveux ne s'établissent que sur les parties saillantes de la tête; les boucles 
des cheveux reçoivent la lumière au milieu et sont légèrement interceptées par quelques légères échappées de cheveux qui viennent en ôter l'uniformité. Il faut toujours que les bords des cheveux, comme le métal, participent du ton du fond, ce qui aide à faire tourner les parties fuyantes de la tête.

L'oreille est très nécessaire à bien étudier et à bien mettre à sa place, entendu qu'elle attache le col à la tête; il faut le plus possible la faire d'une belle forme. Étudiez l'antique ou la belle nature. On peut observer, par exemple, que généralement la nation allemande, et surtout la nation autrichienne, les a attachées plus haut qu'elles ne devraient l'être dans la proportion exacte, de même que l'emmanchement de son col est différent de celui des autres individus appartenant à d'autres pays. Il est large, gros, et prend très haut derrière l'oreille ; cette nation a le mastoïde très fort. Si l'on peint donc une Allemande, on doit conserver ce trait caractéristique de sa nation, qui se trouve aussi dans l'ossement large de son front et dans ses joues assez ordinairement plates et étroites. Il faut le plus possible faire en entier l'oreille et bien étudier ses cartilages, quitte à mettre par-dessus des cheveux. Ce qui détermine ses formes doit être d'une couleur chaude et transparente, excepté le trou du milieu qui est toujours vigoureux. Son ton de chair, même dans la lumière, doit céder en général à la lumière de la joue, qui est plus saillante. L'ombre portée de l'oreille sur le col doit être très chaude, le jour passant au travers ; la mâchoire doit se décrire par un ton coloré fin et par de légères demi-teintes, pour obtenir la saillie qu'elle doit avoir sur le col; si c'est une tête de femme, les restes du bas de la mâchoire se décrivent par des tons plus chauds que pour un homme, à cause des tons de la barbe, qui abasourdit les tons naturellement chauds de la chair. Le ton du col est en général d'un ton très fin, et cède beaucoup au ton sanguin du visage. Il est essentiel de bien observer l'aplomb des clavicules, relativement à la position de la tête, ainsi que leur lumière; la poitrine se colore toujours un peu plus près vers le milieu de l'attache des clavicules; en général les parties osseuses telles que le coude, la rotule, le talon, l'extrémité du doigt, doivent toujours être les plus fortes en couleur.

Si l'on doit peindre une gorge, éclairez-la de façon qu'elle reçoive bien la lumière ; les plus belles gorges sont celles dont la lumière n'est point interceptée, jusqu'au bouton qui se colore peu à peu jusqu'à l'extrémité ; les demi-teintes qui font tourner le sein doivent être du ton le plus fin et le plus frais ; l'ombre qui dérive de la saillie de la gorge doit être chaude et transparente.

Il y a la même dégradation de lumière sur tout le corps que celle ci-dessus expliquée pour la tête ; si la figure est assise, la lumière alors se rappellera très vivement sur les cuisses et dégradera jusqu'au talon.

\section{ANNEXES}

Lire les extraits des Souvenirs d'Élisabeth Vigée-Lebrun

Lire l'introduction à Élisabeth Vigée-Lebrun écrite par Charlotte Foucher 
Alida de Savignac (1790 - 1847) 


\title{
Introduction
}

\author{
Amandine Gorse
}

1 On connaît peu de chose sur la vie de cette institutrice protégée par $\mathrm{M}^{\mathrm{me}}$ Armande Roland. Dernière fille d'une vieille famille d'aristocrates déchus, Adélaïde Esther Charles d'Abillon de Savignac (1790-1847) refusa avec obstination les codes sociaux de son époque (LEJEUNE-RESNICK 1983). Restée célibataire, elle décida d'entamer une carrière d'institutrice pour subvenir seule à ses besoins et choisir librement son métier, au grand dam des valeurs de sa famille. Elle attacha un soin particulier à élaborer une pédagogie adaptée à l'enfant et rédigea dès 1823 de nombreux ouvrages éducatifs, des contes et des nouvelles. Ainsi parurent La Comtesse de Melcy ou le Mariage de convenance en 1823, une Économie domestique en 1828, des Contes bleus et une Galerie pittoresque (s.d.). Elle collabora à plusieurs périodiques dont Le Bon Génie. Journal des enfants (1824-1829) et fut en charge du bulletin littéraire dans Le Journal des femmes, ou gymnase littéraire (1832-1837).

2 C'est grâce à cette expérience qu'elle put intégrer l'équipe de journalistes féminines animée par Jeanne-Justine Fouqueau de Pussy (1786-1863), rédactrice en chef du Journal des demoiselles. Le mensuel avait été fondé en 1833 par Alfred Thiéry et était adressé aux jeunes filles de 14 à 18 ans issues de milieux aisés (LÉGER 1988 et BESSON-MOREL 1998, t. I, p. 55, note 3). La démarche pédagogique d'Alida de Savignac se voulait efficace puisque chacun de ses comptes rendus devait aborder toutes les notions qui permettaient de juger correctement une œuvre d'art, comme la composition, le coloris, l'expression ou encore l'harmonie des figures. Elle ne manquait pas de rappeler les thèmes iconographiques tout en exprimant un avis subjectif, parfois sévère, mais toujours lié au milieu mondain dans lequel évoluaient ses lectrices. Il est à noter qu'Alida de Savignac s'exprimait rarement en tant que femme: elle préférait employer "votre sexe" au lieu de "notre sexe» comme on peut le lire chez d'autres femmes journalistes.

3 Les textes d'Alida de Savignac, qui peuvent paraître ingénus au premier abord, sont donc conçus pour un public spécifique qu'elle connaît bien. Elle prônait une éducation fondée sur la lecture et sur l'expérience : « la lecture est la branche la plus importante de l'éducation des filles, [...] il faut donc qu'une femme lise beaucoup »; cependant, «que l'on ne croit pas qu'une jeune demoiselle puisse recevoir une instruction 
complète d'un cours de littérature ancienne : il faut marcher avec son siècle pour que ses idées, ses hardiesses, ses folies (et chaque temps a les siennes) ne vous prennent pas au dépourvu... » (cité par MARCoIN 2006, p. 350). Forte de son expérience, elle offrait à ses lectrices des valeurs issues d'un romantisme modéré (CROUZET 1996, p.13) qui répondait justement aux souhaits d'un public bourgeois dont les préoccupations restaient fidèles aux convenances et au bon goût.

\section{BIBLIOGRAPHIE}

BESSON-MOREL 1998

Anne Besson-Morel, La Presse enfantine sous la monarchie de Juillet, thèse de doctorat, université Paris IV-Sorbonne, 1998.

CROUZET 1996

Michel Crouzet (éd.), Stendhal, Paris, Presses de l'université de Paris-Sorbonne, 1996.

LÉGER 1988

Christine Léger, Le Journal des demoiselles et l'éducation des filles au XIX ${ }^{e}$ siècle, thèse de doctorat, université Paris VII, 1988.

LEJEUNE-RESNICK 1983

Évelyne Lejeune-Resnick, Les Femmes écrivains sous la Monarchie de Juillet (société et littérature), thèse de doctorat, université Paris IV-Sorbonne, 1983.

MARCOIN 2006

Francis Marcoin, Librairie de jeunesse et littérature industrielle au XIX siècle, Paris, H. Champion, 2006.

\section{ANNEXES}

Diaporama des de tableaux exposés à l'occasion des Salons de 1837, 1844 et 1846, et commentés par Alida de Savignac pour le Journal des demoiselles :

http://www.flickr.com//photos/73632227@N02/sets/72157628747383973/

Lire des articles d'Alida de Savignac sur le Salon de 1837 parus dans le Journal des demoiselles

Lire des articles d'Alida de Savignac sur le Salon de 1844 parus dans le Journal des demoiselles

Lire des articles d'Alida de Savignac sur le Salon de 1846 parus dans le Journal des demoiselles 
Liste complète des œuvres d'arts commentées par Alida de Savignac à travers ses textes édités dans Plumes et pinceaux 


\section{Alida de Savignac, Journal des demoiselles, 1837}

Articles « Beaux-arts - Salon de 1837 », extraits choisis.

\section{« Premier article » (mars 1837)}

Journal des demoiselles, $\mathrm{n}^{\circ} 3,5^{\mathrm{e}}$ année, p. 90-93.

1 Cette année, comme de coutume, les peintres ont fourni plus de dix-huit cents tableaux à l'exposition; viennent ensuite les sculpteurs, architectes, graveurs, lithographes, dont les statues, les plans, les estampes, occupent un peu moins de deux cents places; le public en a bientôt fini avec leurs productions, il n'y a pas pourtant de quoi l'accuser d'injustice : commençons par les sculpteurs. Si l'on témoigne peu d'empressement pour leurs ouvrages, à qui la faute? Ces messieurs n'ont rien exposé cette année qui soit capable de réchauffer leurs grandes salles basses si froides qu'elles semblent être le palais de la grippe. J'ai remarqué un Talma qui, m'a dit la notice, étudie un rôle: j'ignore quel rôle il pourra jouer dans un pareil costume ; mais il est si léger qu'on se sent enrhumé rien qu'à le regarder.

Quant aux graveurs et aux lithographes, ce sont assurément des artistes forts estimables ; mais leurs copies, si belles qu'elles soient, ne peuvent lutter d'intérêt avec les originaux. Si l'on nous disait: "Dans cette pièce est le grand homme que vous désirez connaître, et dans cette autre, son portrait peint par le plus grand peintre du monde ", nous irions tous vers l'homme, de préférence à l'image. Ainsi l'on fait des gravures quand on peut voir les tableaux. D'ailleurs, les gravures ont une exposition permanente sur les quais, sur les boulevards, tandis que l'on n'a que deux mois chaque année pour connaître les ouvrages de nos artistes vivants. Cela dit, suivons la foule dont le torrent nous porte aux salles de peintures.

Beaucoup de batailles et de tableaux d'histoire, peu de paysages, presque point de portraits, telle se présente l'exposition au premier coup d'œil. Éblouie d'abord par la multitude des divinités, apôtres, saints martyrs, guerriers de toutes les nations et de toutes les armes qui planent sur ma tête et qui, les yeux attachés sur moi, semblent 
défier ma critique ; plus incommodée encore par la foule vivante, tantôt roulant comme le flot qui surmonte un obstacle, ou bien s'arrêtant comme un roc pour, l'instant d'après, tourbillonner ainsi que les feuilles sèches dont se joue le vent d'automne, j'ai cru qu'il me serait impossible de vous parler du Salon dans le numéro de mars. Je me suis enfin aguerrie, j'ai cherché et trouvé des tableaux de premier ordre, rencontrant, chemin faisant, d'assez tristes médiocrités, et je vais vous parler sérieusement du premier des arts d'imitation; car, tout en désirant vous voir conserver les qualités et les vertus qui appartiennent vraiment à votre sexe, je déteste d'entendre attribuer aux femmes des talents ou un jugement mesquin.

\section{Delaroche : Sainte Cécile}

La Sainte Cécile de M. Delaroche n'a rien de celle de Raphaël: ceci n'est point une épigramme, c'est un fait que je rapporte (fig. 1).

\section{Paul Delaroche, Sainte Cécile et les anges}

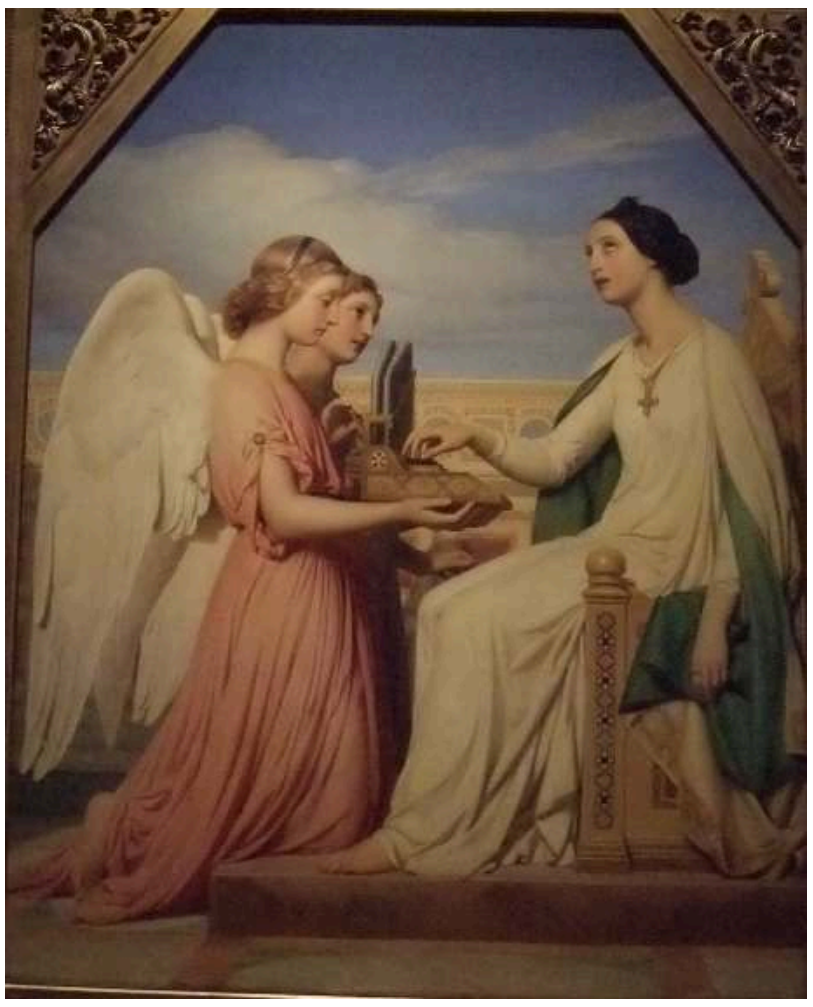

1836, huile sur toile, $202 \times 162 \mathrm{~cm}$, Londres, Victoria \& Albert Museum.

La Sainte Cécile du premier peintre du monde est une forte jeune fille, belle de fraîcheur et d'enthousiasme, ses chairs sont fermes, sa poitrine vaste, elle chante de tout son cœur la gloire de Dieu! Elle est si heureuse de chanter que lorsqu'elle chante elle est heureuse de vivre, et l'on conçoit que les accents de sa voix pure et pleine, montant jusqu'aux cieux, portent son allégresse aux anges joyeux de l'écouter. La Sainte Cécile de M. Delaroche a la blancheur d'un beau cygne; son chant, comme celui de cet oiseau, s'exhale avec sa vie, son âme va remonter au ciel et son corps frêle, et pour ainsi dire diaphane, ne rendra que peu de cendre à la terre; deux anges assistent et écoutent la sainte, deux beaux anges dont les douces figures, les traits réguliers font rêver... Ce ne 
sont pas des chérubins roses et bouffis; $\mathrm{M}$. Delaroche a placé près de sa Sainte Cécile les anges de la mélancolie et des saintes douleurs. Eh bien! Malgré toute cette poésie, ce n'est point une pensée du ciel qui m'est venue devant ce tableau. J'ai cru assister aux derniers moments de $\mathrm{M}^{\text {me }}$ Malibran ; le souvenir de cette grande cantatrice enlevée à la fleur de l'âge m'a longtemps suivie. Si nous considérons maintenant ce tableau sous le rapport de l'exécution matérielle, il faut signaler un coloris vrai, des chairs d'une grande finesse de ton, l'ensemble qui est d'un effet suave et doux parfaitement en harmonie avec l'expression des figures. Pourquoi faut-il que le premier peintre de notre époque recherche avec tant de persistance l'idéal de la maigreur?! Les artistes qui ne donnent jamais tort au succès vont décharner leurs personnages à qui mieux mieux, et chaque exposition nous offrira à l'avenir un cours complet d'ostéologie.

\section{Delaroche : Le Comte Strafford marchant au supplice}

5 La renommée de ce tableau a de beaucoup devancé l'exposition (fig. 2).

\section{Paul Delaroche, Lord Strafford marchant au supplice}

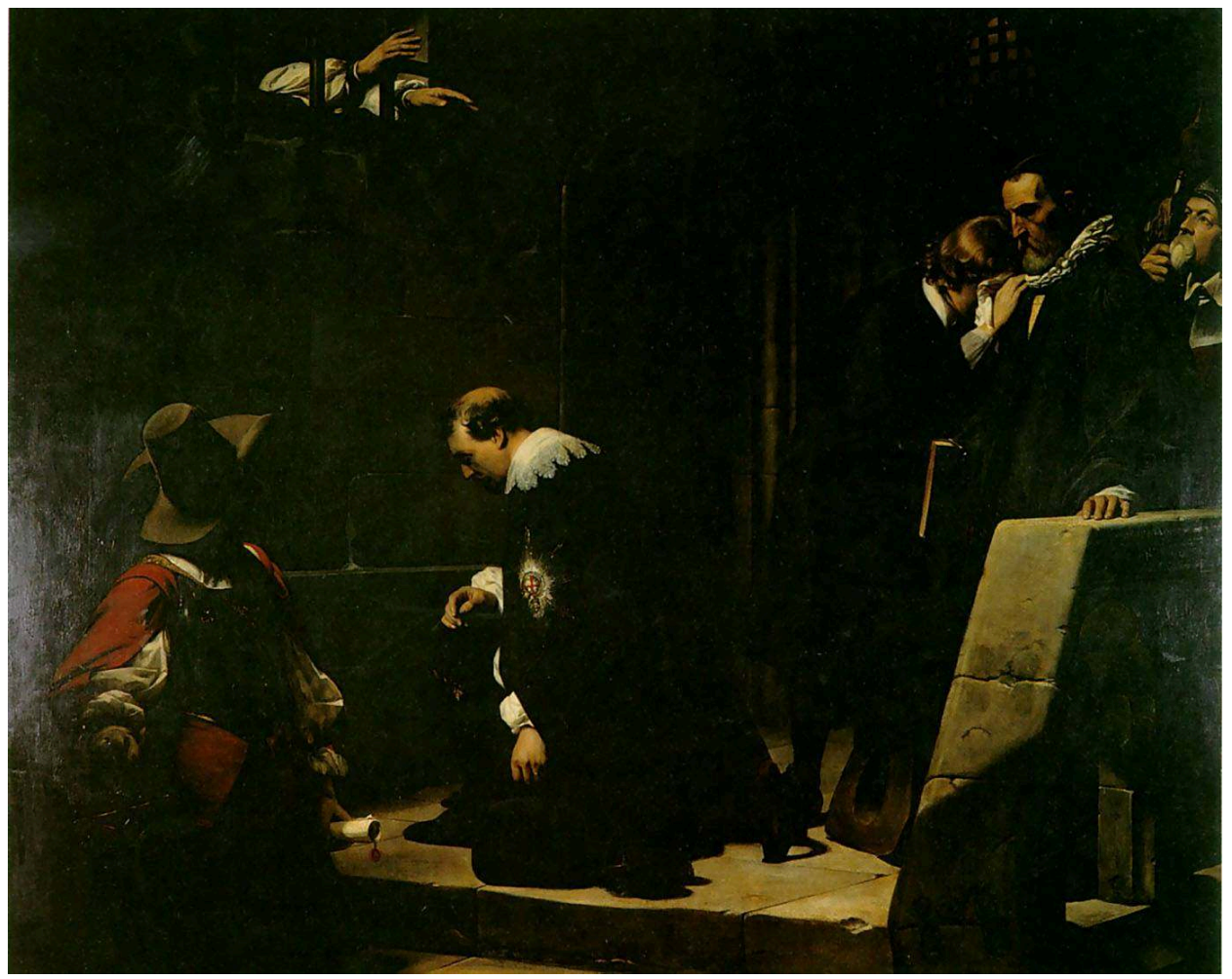

1837, huile sur toile, coll. part.

Cependant, je le confesse, il n'a pas répondu à mon attente : d'abord, quoique je plaigne toutes les victimes des discordes civiles, le sujet devait manquer son effet sur moi qui ne peux considérer Lord Strafford comme un martyr de sa fidélité à son maître. Avant d'être élevé à la dignité de comte, Wentworth, siégeant au parlement à côté d'Élior, d'Hampden, de Saint-John, était, comme eux, un des chauds défenseurs des privilèges des Communes. Le premier jour où il entra dans la chambre, en qualité de ministre du roi, il dit d'un ton railleur à ses anciens amis: "Vous voyez, messieurs, je vous ai quittés. - Et nous, milord, répondit hardiment Saint-John, nous ne vous quitterons plus tant que cette tête sera sur vos épaules. » 
6

Le gant ainsi jeté, Wentworth, confiant en ses grands talents, entreprit la lutte par ambition, peut-être la soutint-il par conviction; mais il la poussa à l'extrême par nécessité, succomba, et par sa mort ouvrit l'abîme qui devait engloutir Charles $\mathrm{I}^{\mathrm{er}}$ et la dynastie des Stuarts. Dans les discordes civiles, on joue sa vie pour le triomphe d'une idée, et la mort sur l'échafaud est aussi glorieuse au vaincu que celle reçue sur le champ de bataille. M. Delaroche n'a point manqué de conserver à son personnage principal cette impassibilité qui était dans les convenances historiques de son sujet; voilà donc une figure dénuée d'expression. Le greffier et les soldats du Parlement qui conduisent le comte au supplice sont froids, austères, silencieux; la Révolution n'en est point encore arrivée à ce point de délire où elle outragea ses victimes. Au moment de descendre l'escalier de la tour, Strafford s'arrête devant le cachot où est enfermé Land, archevêque de Cantorbéry, victime comme lui du triomphe des parlementaires; le comte s'agenouille et demande au prélat sa bénédiction. La tête de Land eût pu être belle et expressive, M. Delaroche a préféré ne nous montrer que deux bras couverts de larges manches d'un surplis blanc; ces bras, passant à travers une lucarne grillée, ouverte sur un mur noirci par le temps, produisent l'effet le plus bizarre et, j'ose le dire, le moins heureux.

En supposant que cette disposition des lieux soit d'une vérité scrupuleuse, l'artiste ne pouvait il pas y manquer pour nous montrer la figure de l'archevêque ? Je doute qu'on lui eût reproché cette licence poétique. Tandis que les mains du prélat bénissent le comte, le jeune Wentworth se couvre le visage comme si la hache du bourreau était prête à tomber sur la tête de son père. Encore une expression dramatique escamotée ; il semble que ce soit une gageure. Il n'y a donc sur cette toile qu'une seule expression pour six figures que l'on voit; et seulement trois couleurs pour tout le tableau : le brun verdâtre des murs, le noir des vêtements des principaux personnages, et les panaches et les écharpes rouges des soldats, encore cette couleur éclatante est-elle employée là contrairement à la vérité, puisque l'orange était la couleur du parlement.

\section{Delaroche : Charles Ier insulté par les soldats de Cromwell}

Ici, je ne reprocherai pas à M. Delaroche d'avoir éludé les expressions dramatiques : toutes les figures sont découvertes, celle du roi, vue de face, porte bien la résignation d'un homme de cœur, mais ce n'est pas assez à mon gré (fig. 3). 
3. Paul Delaroche, Charles Ier insulté par les soldats de Cromwell

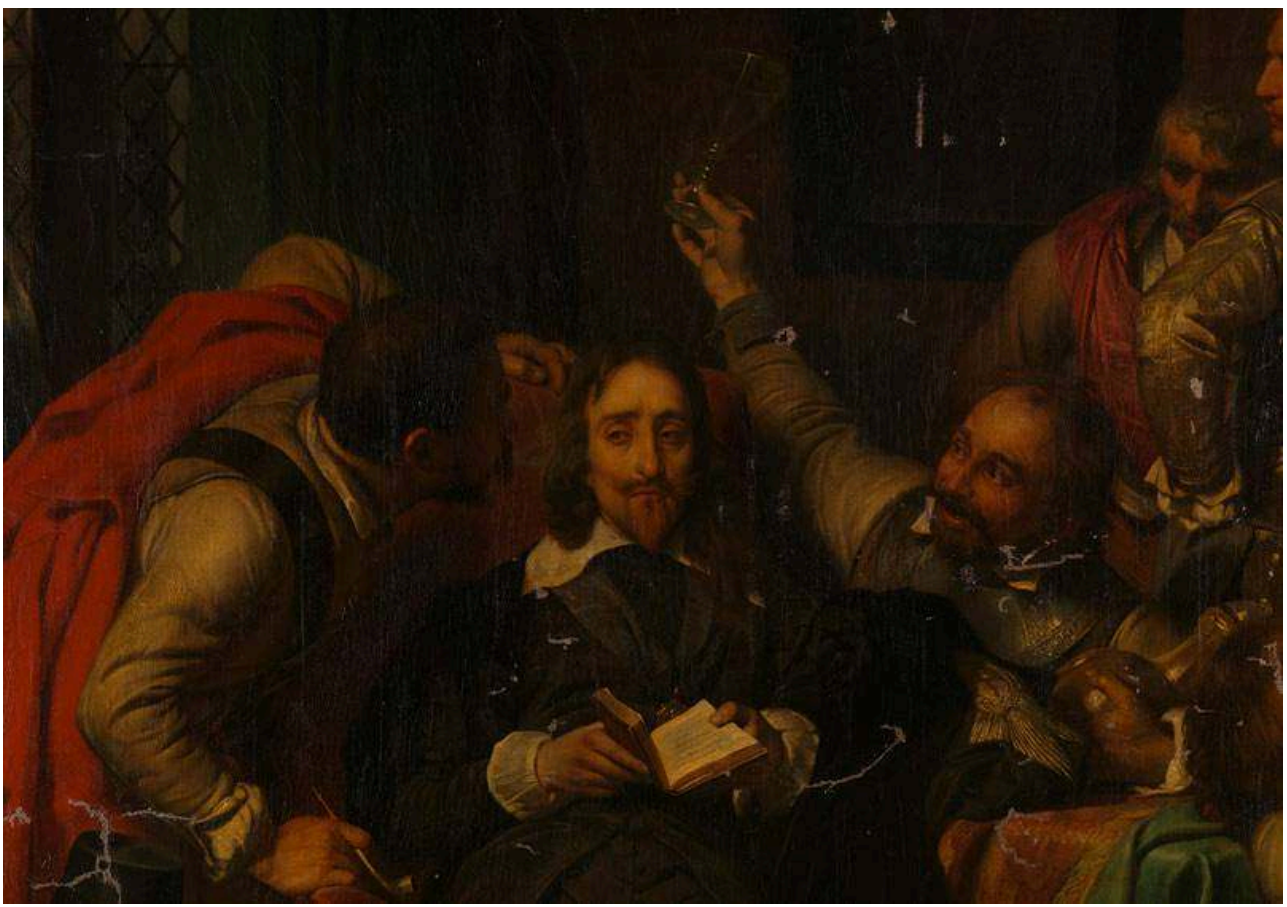

1836, huile sur toile, $300 \times 400 \mathrm{~cm}$, Londres, National Gallery.

Les soldats ivres qui insultent Charles $\mathrm{I}^{\mathrm{er}}$ ont du mouvement et une animation admirable ; puis ce grotesque de la démence ou de l'ivresse, dont frémissent plusieurs soldats puritains ou têtes-rondes (expression par laquelle on désignait les partisans de Cromwell), qui entourent une vaste cheminée, et témoignent par leurs regards chagrins et leurs mines austères, non de leur respect pour le roi, non de leur compassion pour une illustre victime, mais de leur mépris pour des passe-temps qu'ils oseraient presque nommer frivoles. Un vieux serviteur contemple seul cette scène avec un profond désespoir ; toutes ces figures sont belles, bien posées ; l'air et le jour circulent dans cette chambre splendide métamorphosée en corps-de-garde; enfin, rien ne manque de ce qui constitue un bon tableau.

\section{« Deuxième article » (avril 1837)}

Journal des demoiselles, $\mathrm{n}^{\circ} 4,5^{\mathrm{e}}$ année,

p. 121-124.

\section{Winterhalter : Le Décaméron}

Après des sujets aussi graves traités par M. Delaroche, les yeux se reposent avec plaisir sur la délicieuse peinture de $\mathrm{M}$. Winterhalter. La scène se passe dans une ville près de Florence, six femmes et trois hommes assis sur le gazon, à l'ombre de grands arbres, se délassent, pendant la grande chaleur du jour, en contant des histoires; l'une de ces femmes, posée sur un fût de colonne brisé, récite des vers, les autres écoutent. Mon Dieu ! Que ces femmes sont belles! Qu'il y a de grâce et de coquetterie dans leur laisseraller; que le désordre de leurs ajustements a d'élégance et de charme! Combien les hommes admis à cette intimité ont l'air braves, intelligents! Ce sont de vrais nobles de 
la cité florentine, le berceau de la renaissance des arts, dans ce temps où les hommes étaient habitués à porter la main au glaive à chaque instant du jour; nobles contre manants, guelfes contre gibelins, il fallait guerroyer sans cesse ; cependant ce n'est pas la guerre qui, en ce moment, préoccupe ces cavaliers : le soleil a de si chauds rayons, l'air est si doux, si pur, autour d'eux et de leurs ravissantes compagnes, qu'ils oublient tout pour ne songer qu'à en jouir. Depuis les Moissonneurs de l'infortuné Léopold Robert, aucun tableau ne m'avait causé l'espèce d'enchantement que j'ai éprouvé devant le Décaméron de M. Winterhalter.

\section{Alexandre Hesse : Henri IV rapporté au Louvre}

10 M. Hesse qui, l'an passé avait, à mon sens, les honneurs du Salon, expose aujourd'hui un tableau fort estimable, sans doute, de la mort de Henri IV (fig. 4);

\section{Alexandre Hesse, Henri IV rapporté au Louvre [Le Corps d'Henri IV exposé au Louvre]}

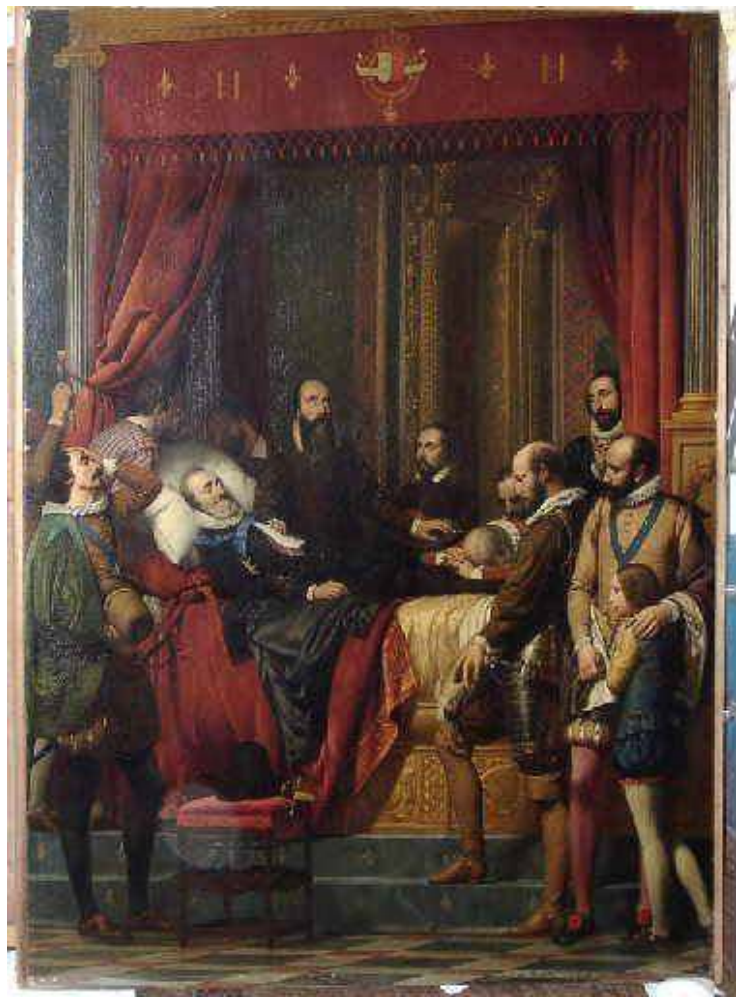

1837, huile sur toile, $172 \times 135$ cm, Pau, musée national du château de Pau.

mais c'est là une de ces compositions qui semblent patronnées de toute éternité pour être au service de tous les artistes à court d'invention; ces pourpoints noirs, ces cordons bleus, ce lit à courtines de velours rouge, les serviteurs pleurant, un page à genou, un vieux soldat terrifié, tous ces détails sont tellement connus, que du plus loin que l'on en aperçoive un seul, on s'écrie : Henri IV est mort! Sans porter la plus légère attention à la peinture. 


\section{Ary Scheffer : Le Christ consolateur}

11 Notre Seigneur vient, selon sa divine promesse, consoler les affligés, délivrer les esclaves (fig. 5).

\section{Ary Scheffer, Le Christ consolateur}

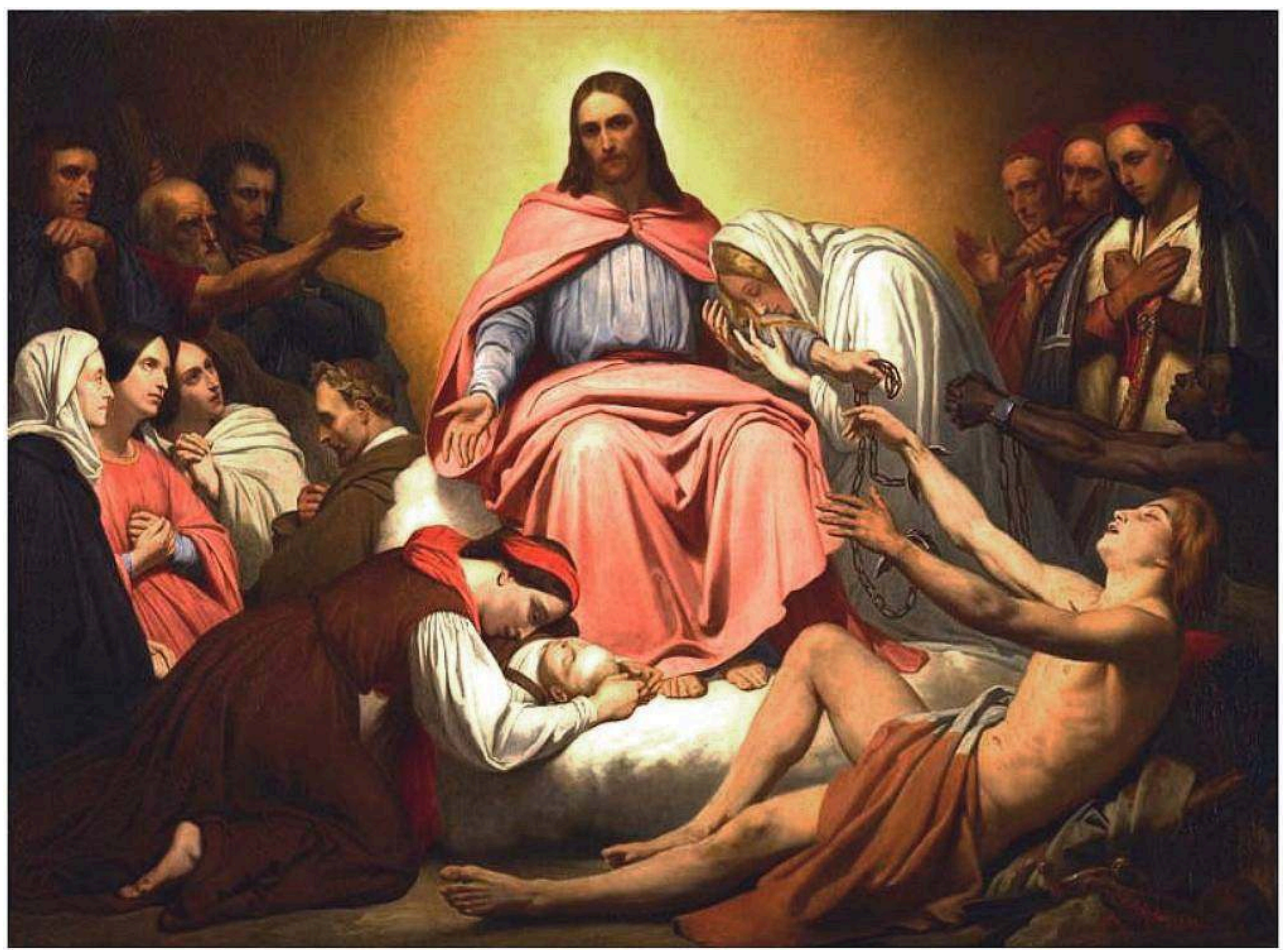

1837, huile sur toile, 184 × 248 cm, Amsterdam, Historisch Museum.

La pose du Christ est pleine de simplicité et de noblesse, sur sa figure rayonne une compassion toute divine ; à sa droite, sont les affligés ; à sa gauche, sont les esclaves, au premier rang desquels on voit la Madeleine qui, délivrée des entraves du péché, couvre de larmes la main de son rédempteur. Jésus a tendu son bras vers ceux dont il a brisé les fers, il tourne sa face du côté des mères, des filles, des épouses, des hommes de toutes conditions qui lui crient avec larmes : « Seigneur, ayez pitié de nous!»

\section{Ary Scheffer : La Bataille de Tolbiac}

Cette grande page, destinée au musée de Versailles, fait aussi grand honneur à M. Scheffer (fig. 6). 


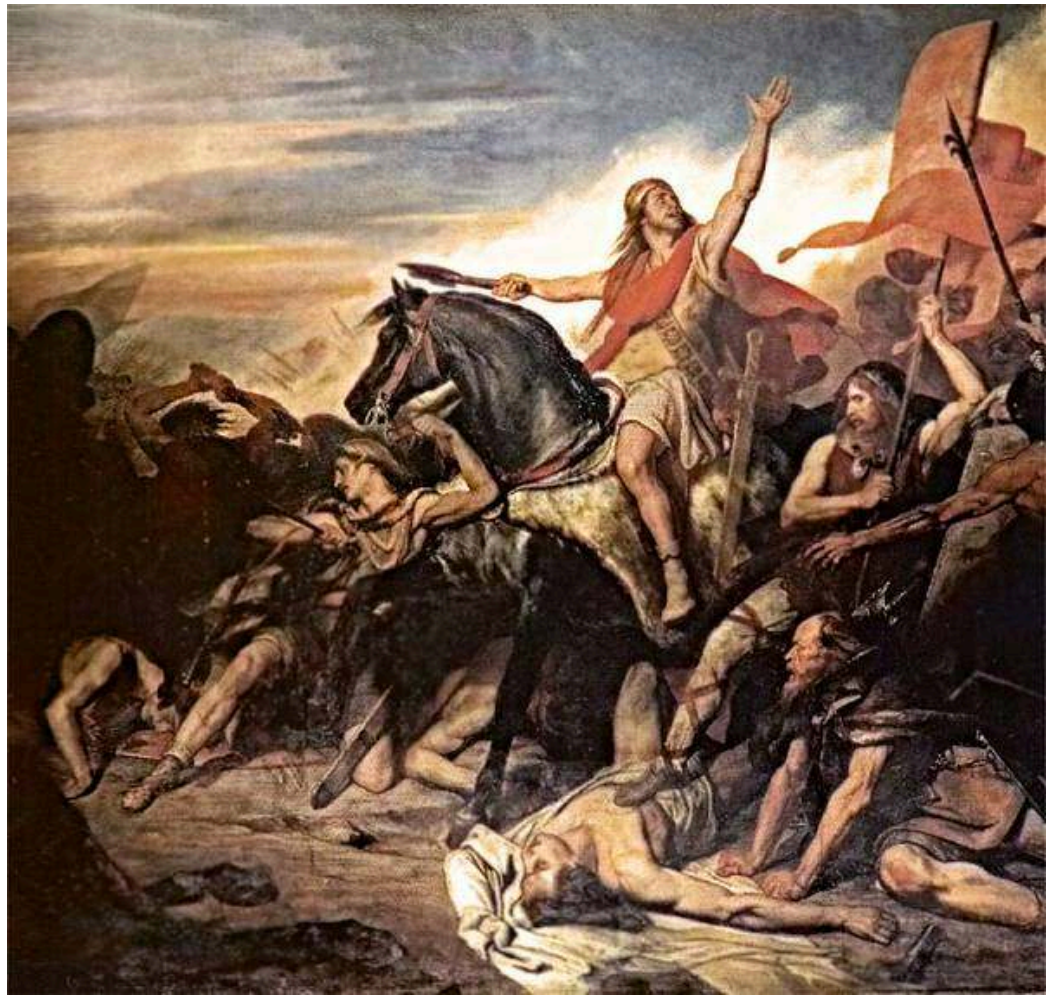

1836, huile sur toile, $415 \times 465 \mathrm{~cm}$, Versailles, musée national des châteaux de Versailles et de Trianon.

La tête de Clovis est belle, les yeux tournés vers le ciel, il fait le vœu d'adorer le Dieu de Clotilde, si ce Dieu est assez puissant pour lui donner la victoire.

M. Ary Scheffer a encore au salon deux charmants tableaux, la Prière de Rachel : ce sujet est tiré d'Ahasvérus de M. Edgar Quinet. Rachel est à genoux, elle prie et des anges répètent sa prière. Puis, La Plainte de la jeune fille, d'après une ballade de Schiller. Je ne vous dirai rien de ce gracieux tableau, mesdemoiselles, vous en recevrez la gravure dans le prochain numéro de votre journal.

\section{Henri Scheffer : La Bataille de Cassel}

C'est une idée très originale de nous montrer Philippe IV vu de dos, la tête hermétiquement enfermée dans un casque qui lui descend jusque sur les épaules (fig. 7); 


\section{Henry Scheffer, La Bataille de Cassel}

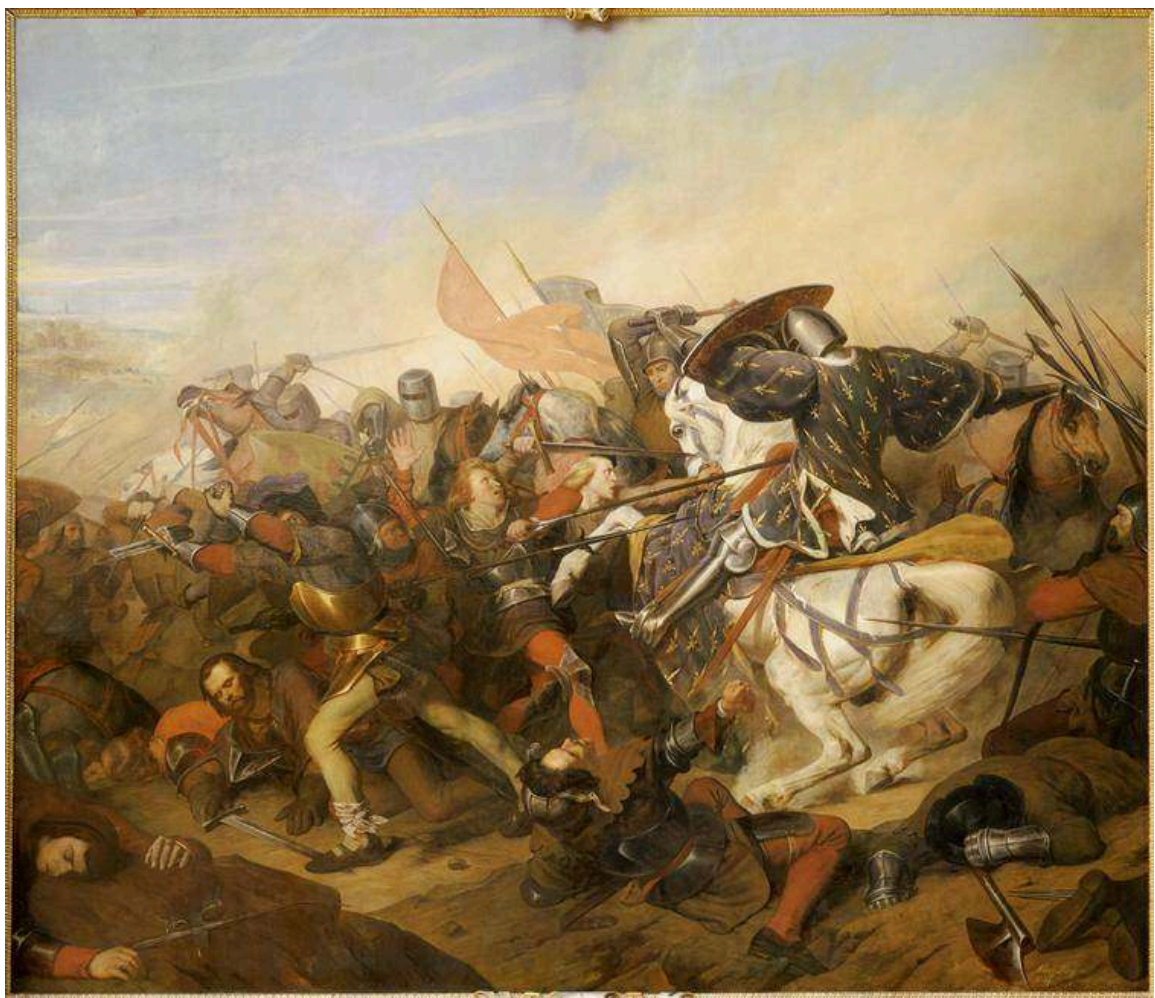

1837, huile sur toile, 465 × $543 \mathrm{~cm}$, Versailles, musée national des châteaux de Versailles et de Trianon.

le reste de l'armure est aussi complet; de sorte que pas un trait, pas une ligne de chair, ne se laissent soupçonner. Fort heureusement que la notice est là pour nous assurer que dans cette boîte de fer poli, recouverte d'une casaque fleurdelisée, est un prince grand par son courage et sa constance dans l'adversité. Soit! On se trouve toujours mieux de croire que de douter; mais cela ne m'empêchera pas de répéter que M. Scheffer a choisi une singulière manière de me faire connaître le compétiteur d'Édouard III.

\section{M. court : Mariage de la reine des Belges}

Je cherchais les tableaux de $\mathrm{M}^{\mathrm{me}}$ Brune; car j'aime le talent de cette dame et je ne remets pas au lendemain le plaisir de voir ses œuvres (fig. 8). 
8. Joseph-Désiré Court, Mariage de la reine des Belges [Mariage de Léopold ler, roi des Belges, et de Louise d'Orléans le 9 août 1832]

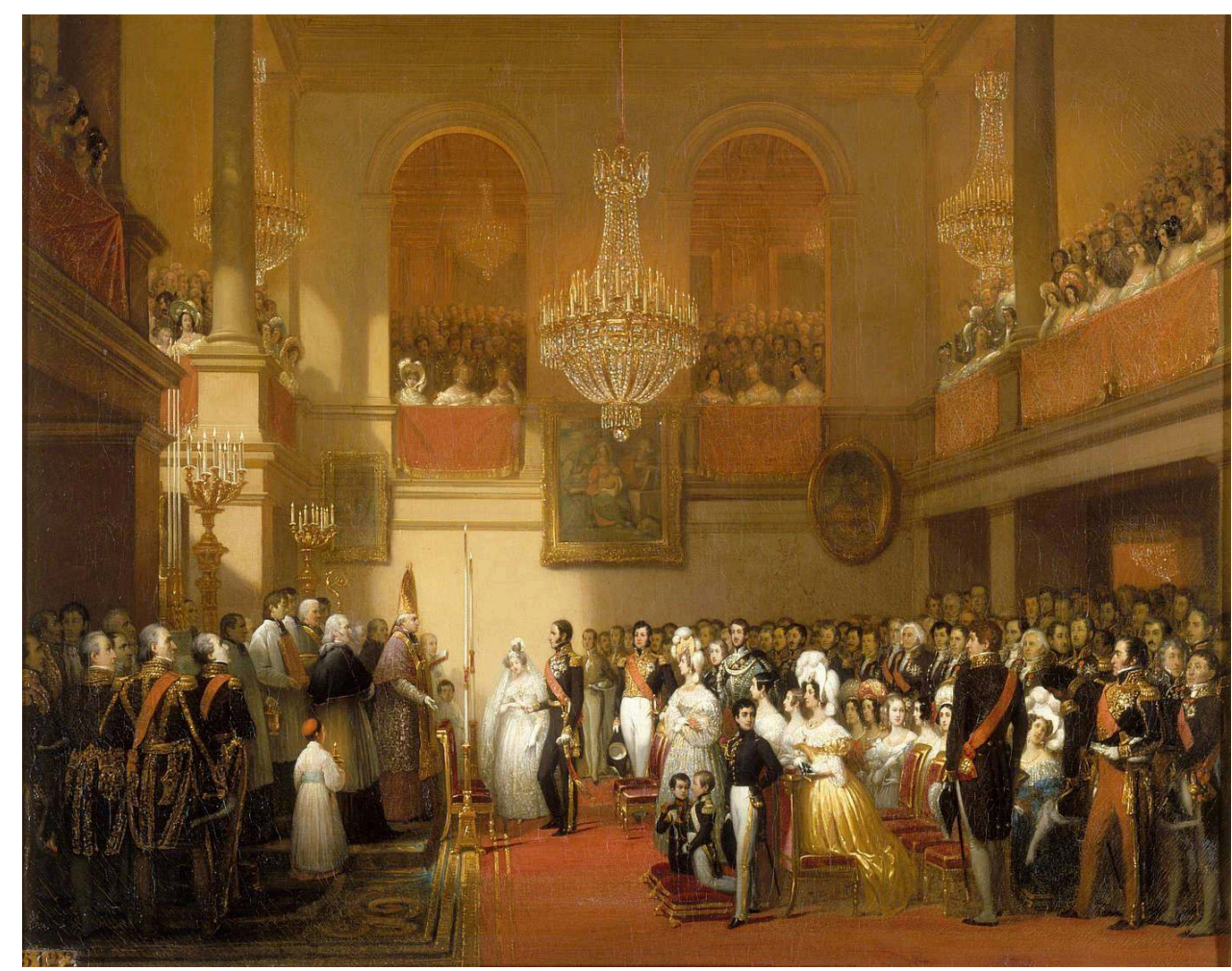

1837, huile sur toile, 90 x 116 cm, Compiègne, musée national du château de Compiègne.

Un artiste, auquel je m'informe où je pourrais trouver au moins l'un des trois tableaux qu'elle a au Salon, me dit : "Marchez encore. » Bientôt la foule nous sépare. J'avance lentement, regardant à droite; mes yeux tombent sur une multitude de figures: du rose, du blanc, du bleu, du noir, des moustaches, des ordres, des pantalons garance, des épaulettes d'officiers généraux, des images de modes découpées, et voulant représenter des femmes parées assises dans des tribunes; des lustres suspendus au plafond, deux grands cierges devant un autel : tout cela était la chapelle du château de Compiègne, lors de la célébration du mariage du roi des Belges avec notre charmante princesse Louise. Bon Dieu! Que le talent des artistes a de singuliers caprices! Et à combien de malheurs inattendus les princes sont exposés!

\section{Rouget : Mariage de l'empereur Napoléon et de Marie-Louise}

16 Je me détourne de la noce du roi des Belges pour heurter contre une autre (fig. 9). 
9. Georges Rouget, Mariage de l'empereur Napoléon et de Marie-Louise [Mariage religieux de Napoléon ler et de Marie-Louise dans le salon carré du Louvre, le 2 avril 1810]

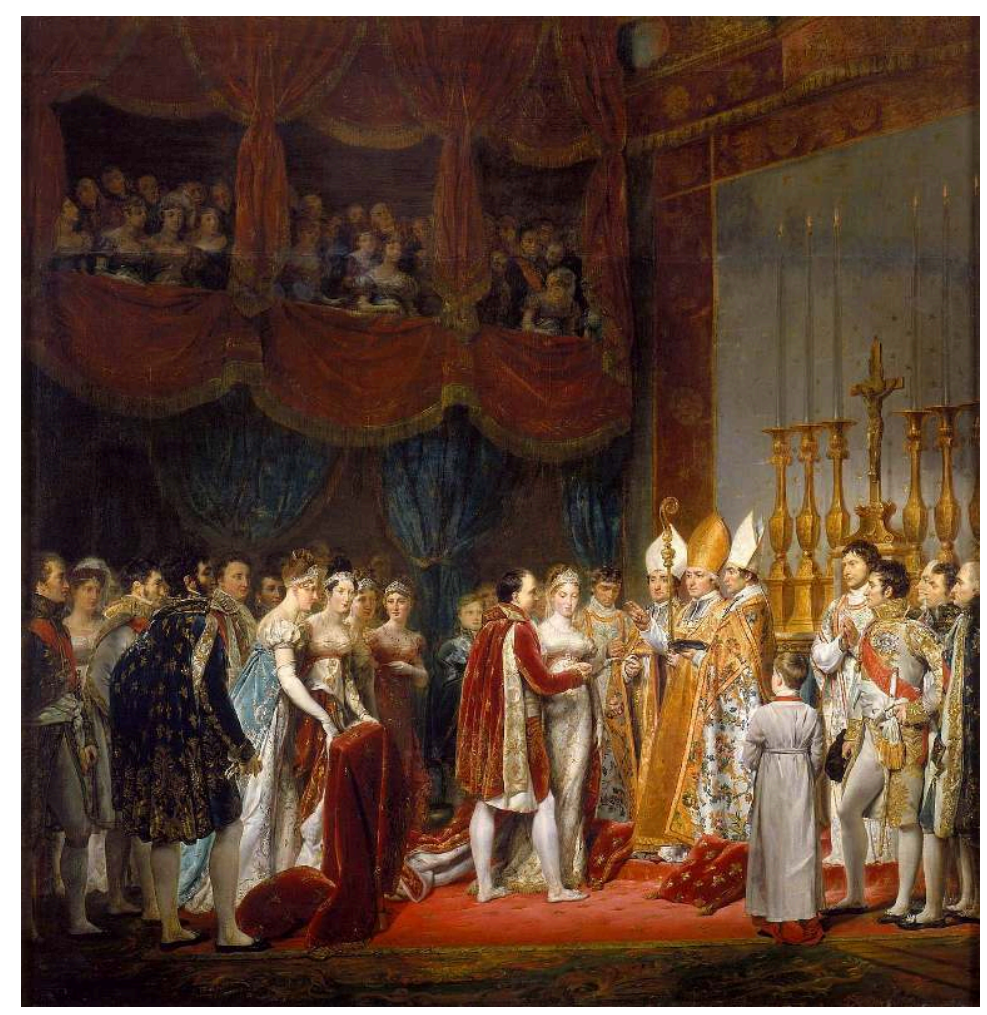

1837, huile sur toile, 185 x $182 \mathrm{~cm}$, Versailles, musée national des châteaux de Versailles et de Trianon.

Cette fois, c'est l'empereur Napoléon qui se marie. Le nom de l'artiste, M. Rouget, semble être une mauvaise plaisanterie en regard du coloris de ses figures et de la nuance qu'il a choisie de prédilection pour ses ajustements. Au reste, M. Rouget ne s'est point mis en frais d'invention : les tribunes, le groupe des princesses, celui de l'autel, veulent contrefaire le tableau du sacre, mais ne lui ressemblent pas.

\section{Mauvoisin : Le 9 thermidor}

Encore du bleu de ciel et des couleurs éclatantes. Mais doucement, ceci n'est point une noce : nous sommes au sein de la terrible Convention. Robespierre voulait arriver à la toute-puissance par l'oppression des représentants du peuple : il voulait recommencer Cromwell, mais il n'était pas assez fort pour accomplir un tel dessein. Le représentant Tallien soulève contre lui la majorité de l'assemblée, et le futur dictateur périt sur l'échafaud. Telle est la scène qu'a représentée $M$. Mauvoisin : scène remplie de tumulte, où les passions les plus violentes sont en jeu. Malheureusement, l'artiste a suivi trop scrupuleusement la mode de ce temps-là, en vêtissant ses députés d'habits de couleur claire, ce qui, joint aux têtes poudrées et aux écharpes tricolores, forme un papillotage de ton peu en harmonie avec la gravité du sujet.

\section{$M^{m e}$ Brune : Le Vœu}

Enfin, je trouvai Le Vœu, charmant tableau de $\mathrm{M}^{\text {me }}$ Brune (fig. 10). 


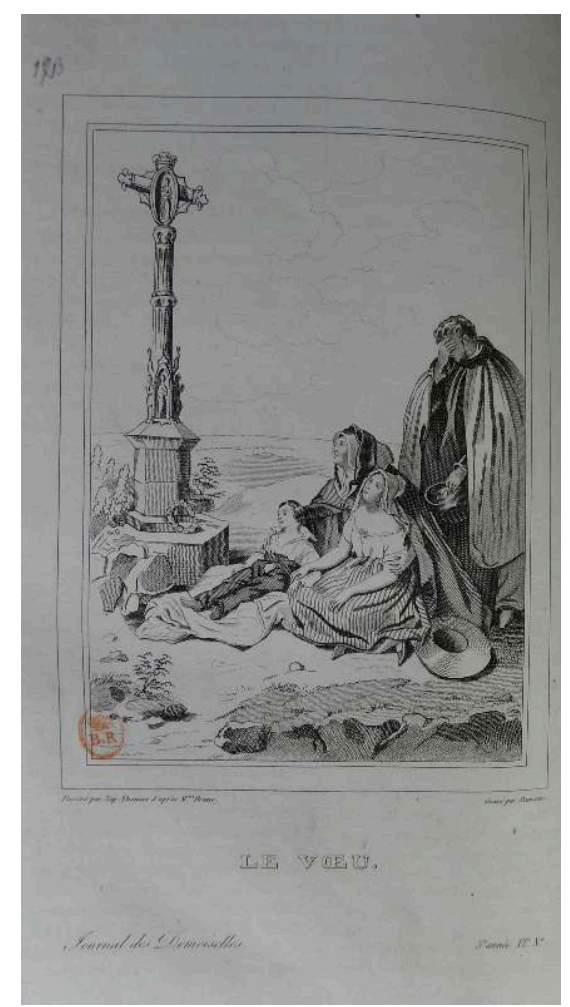

1837, reproduction dans le Journal des demoiselles. Original : huile sur toile, $130 \times 97 \mathrm{~cm}$, Troyes, musée d'Art, d'Archéologie et de Sciences naturelles.

Une famille de paysans dépose devant une croix un enfant malade. Ce sujet, traité à deux reprises, et d'une manière admirable, par M. Schnetz, ne pouvait être abordé que par un talent aussi ferme que celui de $\mathrm{M}^{\mathrm{me}}$ Brune. Pour l'entreprendre, il fallait être sûre de ne pas se préoccuper des compositions d'un maître, et se sentir la force de ne point les faire regretter. $\mathrm{M}^{\text {me }}$ Brune a parfaitement réussi à surmonter ces difficultés. Les quatre figures dont se compose son tableau sont disposées avec cette simplicité et ce naturel qui sont la perfection de l'art; elles ont bien le caractère villageois et sont belles de cette beauté qui se peut allier avec des privations de tous les instants et la fatigue des rudes travaux de la campagne. $\mathrm{M}^{\text {me }}$ Brune a permis, mesdemoiselles, que votre journal vous donnât la gravure de ce touchant tableau.

\section{Chassériau : Ruth et Booz}

19 La pauvre Ruth vient glaner dans le champ du riche Booz, afin d'avoir de quoi nourrir Noëmi, la mère de son mari. Noëmi veut dire belle; M. Chassériau n'a pas cru devoir étendre à la bru les anciennes qualités de la belle-mère. Cela seul a suffi pour me désenchanter de ce tableau, je viens de le dire, je le répéterai sans cesse, dans les arts comme dans toutes les autres productions du génie de l'homme : la vérité et la beauté sont des qualités indispensables. 


\section{$M^{m e}$ de Hérain : La Foi et l'Espérance remontant au ciel} nous jeter tant elles partent courroucées l'une et l'autre ; la foi surtout a un faux air de fanatisme que je ne pardonne pas à $\mathrm{M}^{\text {me }}$ de Hérain de lui avoir donné ; le groupe de $\mathrm{La}$ Charité, resté à terre au milieu des enfants qu'elle allaite, est beaucoup mieux; malheureusement, il rappelle trop le bas-relief de la Madeleine. En dépit des critiques que je me permets de lui adresser, $\mathrm{M}^{\text {me }}$ de Hérain est une artiste du premier ordre qui s'élève dans ses compositions au-dessus de ce que les femmes tentent ordinairement, et consacre ses pinceaux, toujours honorables, à des sujets de piété.

\section{« Troisième et dernier article » (mai 1837)}

Journal des demoiselles, $n^{\circ} 7,5^{\mathrm{e}}$ année, p. 154-157.

\section{Bendemann de Berlin : Jérémie pleurant sur les ruines de Jérusalem}

21

En envoyant les ouvrages de ses meilleurs artistes concourir avec les œuvres de nos peintres, l'Allemagne rend un éclatant hommage à notre école ainsi qu'au goût éclairé de nos amateurs.M. Bendemann, peintre du prince royal de Prusse, obtient plus d'éloges au Louvre que n'en recueillit, il y a quelques années, M. Barloff, pensionnaire de l'empereur de Russie, pour son tableau de la destruction de Pompéi. Jérémie pleurant sur les ruines de Jérusalem est une grande composition, parfaitement exécutée : le prophète, assis sur les débris d'un palais, pleure la destinée qu'il a inutilement prédite à la malheureuse Sion. Du lieu qu'il occupe, Jérémie domine tout le tableau; sa pose pleine de dignité et de sentiment, les flots de sa barbe argentée, la belle draperie de couleur sombre dont il s'enveloppe, tout concourt à attirer les yeux sur lui et à les y tenir attachés. Cependant, au pied de cette grande figure il se passe de ces scènes de douleur telles qu'en fournit le lendemain d'un jour de carnage et de destruction : à droite, deux femmes emportent un mourant qu'elles ont retiré d'entre les décombres ; un peu plus en avant, un jeune homme, assis sur un fragment de colonne, est plongé dans un morne accablement, tandis qu'un enfant cherche à la distraire en lui passant la main sous le menton. La figure de cet insoucieux enfant est charmante; elle fait diversion pour un moment à la contemplation de ces mères pleurant sur leurs petits égorgés dans leurs bras et à la pitié qu'inspirent ces femmes cherchant les corps de leurs maris, et ces jeunes filles voilant leurs visages flétris par la douleur. Toutes ces figures sont belles, expressives et bien posées. Quelques connaisseurs prétendent que le tableau de M. Bendemann est le plus beau de l'exposition, je suis trop patriote pour en convenir, je critiquerai même cet ouvrage tant admiré ; il manque de profondeur, tous les groupes sont alignés devant le public avec une symétrie qui répand une certaine froideur sur ce sujet si pathétique. 


\section{Henri Lehmann : Le Mariage de Tobie}

22 Malgré les exagérations de la couleur et les bizarreries de certaines parties du dessin, je préfère beaucoup La Fille de Jephté du même artiste au Mariage de Tobie. Les figures de ce dernier tableau sont disposées sur une seule ligne comme celles d'un bas-relief: commençons par la gauche. D'abord un ange raide, le corps grossièrement taillé dans un bloc de pierre blanche, puis le jeune Tobie ayant seulement un sayon autour des reins, et saluant comme l'un des trois innocents; Raguel est au milieu, seul il est vêtu dans ce tableau, il l'est même complètement et richement ; Sarah l'est aussi légèrement que son fiancé, et paraît très contente de se marier; elle regarde en dessous Tobie auquel elle abandonne sa main ; à ses côtés est sa mère, grosse cariatide faisant pendant avec l'ange. Comme la première condition de la peinture est d'imiter la nature, en la supposant toujours aussi belle que possible, et que des yeux démesurément grands, fendus comme avec un sabre, des chairs si fermes qu'elles ne font pas un seul pli, des doigts ridiculement effilés, terminés par des ongles aussi pointus que des griffes de chat, ne sont pas dans la nature, comme aussi le sujet biblique doit conserver sa majestueuse et naïve simplicité et qu'il y a autant d'affectation dans l'attitude et dans l'expression dans la Sarah de M. Lehmann que s'il avait fait poser une danseuse de l'opéra, je réprouve son tableau, sans m'inquiéter s'il s'y trouve quelques parties témoignant du talent de cet artiste.

\section{Clément Boulanger : La Procession de la gargouille}

23 Tous les ans, on promenait dans Rouen la châsse de saint Romain, et ce saint avait le privilège de délivrer un prisonnier (fig. 11). 


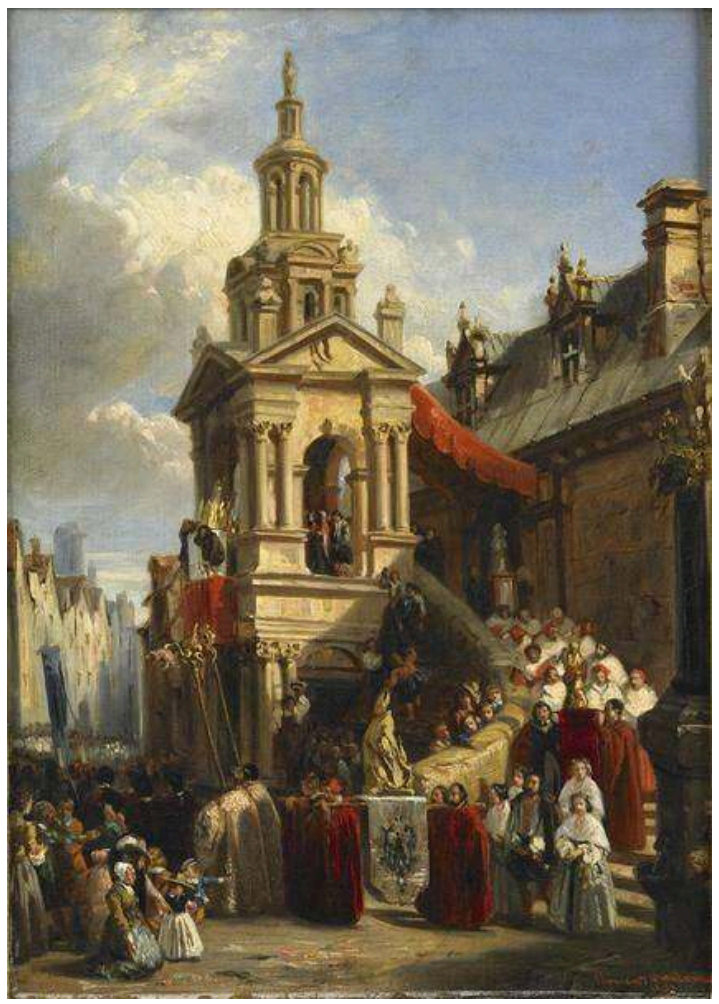

1837, huile sur toile, 320 × 227 cm, Toulouse, musée des Augustins.

Voilà la procession qui passe ; la tête serpente déjà dans les rues étroites et tortueuses de la ville que la queue est encore tout en haut de la tour de l'église de Saint-Romain : les confréries avec leurs bannières, le clergé avec ses belles chapes de velours cramoisi ; les jeunes filles tenant les guirlandes de fleurs qui remplacent les fers du condamné ; le peuple endimanché qui se presse pour voir la fête ; le joyeux tumulte qui règne dans cette scène, l'éclat prestigieux des couleurs, l'éclat du jour, font de l'œuvre de M. Clément Boulanger un tableau très séduisant, mais d'un voisinage redoutable pour ses pauvres voisins dont il fait paraître les toiles noires ou grises.

Voici l'origine de cette procession. L'an 626, sous Clotaire II, saint Romain, issu de la race des rois de France, était évêque de Rouen. Selon la légende, il y avait aux environs de cette ville un dragon qui dévorait les hommes et les bêtes. Saint Romain alla, dit-on, le jour de l'Ascension, dans les prisons d'où il retira un prisonnier convaincu de vol et de parricide, le conduisit devant le dragon et, ayant fait dessus le signe de la croix, commanda au prisonnier de le lui amener, ce qu'il fit sans éprouver de résistance, et conduisit le dragon sur la place publique où il fut brûlé. Le roi donna ensuite pouvoir à l'église de Rouen de délivrer tous les ans un criminel. Cet usage a duré jusqu'à la Révolution. Il n'est point parlé de ce fait dans la vie de saint Romain, mais " gargouille " est un vieux mot qui signifie une fête populaire dans laquelle on voyait des animaux étrangers. 


\section{Alfred Johannot : La Veuve de François de Guise et ses enfants à la cour de Charles IX} vint avec ses enfants demander justice au roi en son palais du Louvre. Les Parisiens, déjà mécontents de la cour, reçurent les Guise avec des transports qui troublèrent Catherine de Médicis, et moi je serais tentée d'accuser M. Johannot d'être aussi guisard que le populaire de la grande ville, car dans son tableau, la beauté, le sang, la vie, sont pour cette famille de Lorraine; le roi, sa mère et leurs courtisans ont des figures de l'autre monde. La notice, il est vrai, nous apprend que leur pâleur est causée par les vivats adressés aux Guise ; mais on ne voit pas le peuple, on n'entend pas ses cris de joie et, devant un tableau, on ne peut tenir compte de ce qui se passe derrière la toile. Anne d'Este est à genoux, devant elle est son fils aîné, Henri, qui fut plus tard surnommé le balafré: la figure de cet enfant est charmante, sa mine hautaine et mutine à la fois annonce bien ce qu'il sera un jour ; le futur cardinal de Lorraine et le duc de Mayenne, moins précoces dans leur hardiesse contre les Valois, se cachent timidement sous les voiles de leur mère.

\section{Brascassat : Paysages}

Plusieurs des paysagistes distingués manquent cette année, et les artistes les plus habitués aux succès du Salon semblent avoir pris à tâche de s'effacer pour laisser briller M. Brascassat, dont les superbes tableaux attirent la foule. Une lutte entre deux taureaux joint un effet dramatique à la plus riche exécution: on ne sait ce qu'on doit admirer davantage de l'éclat du ciel, de la légèreté des nuages ou de la perfection des lignes du paysage flamand, lieu de la scène. J'ai encore à vous citer un repos d'animaux dans une prairie, éclairée par un beau et chaud soleil : un troupeau rumine couché sur l'herbe, une seule vache broute encore, et il semble que l'on entend le bruit causé par le mouvement de ses mâchoires.

\section{André Giroux : Vue prise des Alpes françaises}

Il est rare que des paysagistes entreprennent des pages de la dimension du tableau de M. Giroux. Le site choisi par l'artiste est nommé Le Bout-du-Monde. En effet, il serait bien aisé d'oublier l'univers entier, le Louvre, ses tableaux, ses brillantes réunions du samedi, le musée de Versailles et les fêtes que l'on y prépare, si l'on fixait sa demeure sur les bords de ce torrent qui, roulant le long des flancs des Alpes françaises, creuse le ravin d'Alleva. Une troupe de daims, seuls habitants de cet âpre séjour, descend pour se désaltérer dans l'eau écumeuse; ils marchent paisibles, sans se douter que des chasseurs ont gravi des sentiers qui semblent inaccessibles aux pieds de l'homme et pourtant, tapis derrière une roche, ils guettent leur proie : tandis que l'un arme son fusil, l'autre comprime avec ses deux mains les aboiements indiscrets de son chien.

Ce paysage est d'un très bel effet; M. Giroux a bien surmonté les difficultés qu'il présente. De chaque côté, de hautes murailles de verdure ; dans le fond, se développe la cime neigeuse du Gleisin. L'artiste s'est heureusement tiré de cette opposition d'un vert sombre à la blancheur éclatante du glacier. Je n'oserais pas, sans avoir vu ce site, et dans les mêmes conditions de jour et de saison que celles reproduites par M. André 
Giroux, lui reprocher un coloris froid et monotone ; je me contente d'admirer ce que je comprends, sans crainte d'être démentie, en assurant que le paysage de M. Giroux est un tableau très remarquable.

\section{Portraits}

Les artistes murmurent fort contre les costumes adoptés en Europe. Il est vrai que, depuis bien des siècles, les vêtements non seulement cachent les formes, mais encore les dénaturent. Nous voyons la mode, dans ses caprices, amoindrir une partie du corps humain tandis qu'elle en enveloppe une autre de façon ridicule. Les larges épaules, qui donnent si bon air aujourd'hui, ont été longtemps le trait distinctif des femmes du peuple ; pour être bien faite alors, il fallait n'avoir pas le dos plus large que la main; il fallait pouvoir faire toucher sans peine ses deux coudes par-derrière. Essayez cela, à présent! Les femmes qui ne sont plus jeunes ont porté des ceintures sous les aisselles, et nos jeunes filles attachent les leurs sur les hanches, se serrent les flancs sans mesure, détruisent l'harmonie des proportions naturelles et gênent souvent les fonctions des organes digestifs. Si ce n'était cette aberration, c'en serait une autre. Lorsque les hommes portaient des souliers à la poulaine, des justaucorps rembourrés, d'énormes perruques blondes ou un échafaudage de cheveux poudrés, certes ils ne respectaient pas mieux les lois de la création que ne le font aujourd'hui nos dandys et nos élégantes. Pourtant les peintres reproduisaient avec talent ces monstruosités; il est vrai que les couleurs leur restaient. Longtemps les couleurs éclatantes furent recherchées; maintenant, le bon goût semble ne vouloir admettre en peinture que le blanc et le noir. M. Dubuffe, le Michel-Ange des images de mode, a signalé ce changement; il s'est exercé dans tous les effets possibles du noir, depuis le noir verni des souliers du roi, jusqu'à l'admirable blonde de $\mathrm{M}^{\text {me }}$ Lehon; pour la reine des Belges, elle est d'un blanc pur. M. Dubuffe a même repoussé de ce portrait l'écharpe bleu de ciel dont son prédécesseur, M. Kinson, faisait un si brillant usage. Tout est dit sur le talent de M. Dubuffe, le succès toujours croissant de ses tableaux est une preuve du prodigieux amour des femmes de Paris pour la toilette ; c'est le portrait de leur robe qu'il leur faut, leur visage vient après, c'est le moins important.

\section{Louis Boulanger}

Tout le monde veut voir le portrait de M. de Balzac, ce spirituel auteur d'Eugénie Grandet et du Médecin de campagne (fig. 12). 
12. Louis Boulanger, Portrait de M. de Balzac

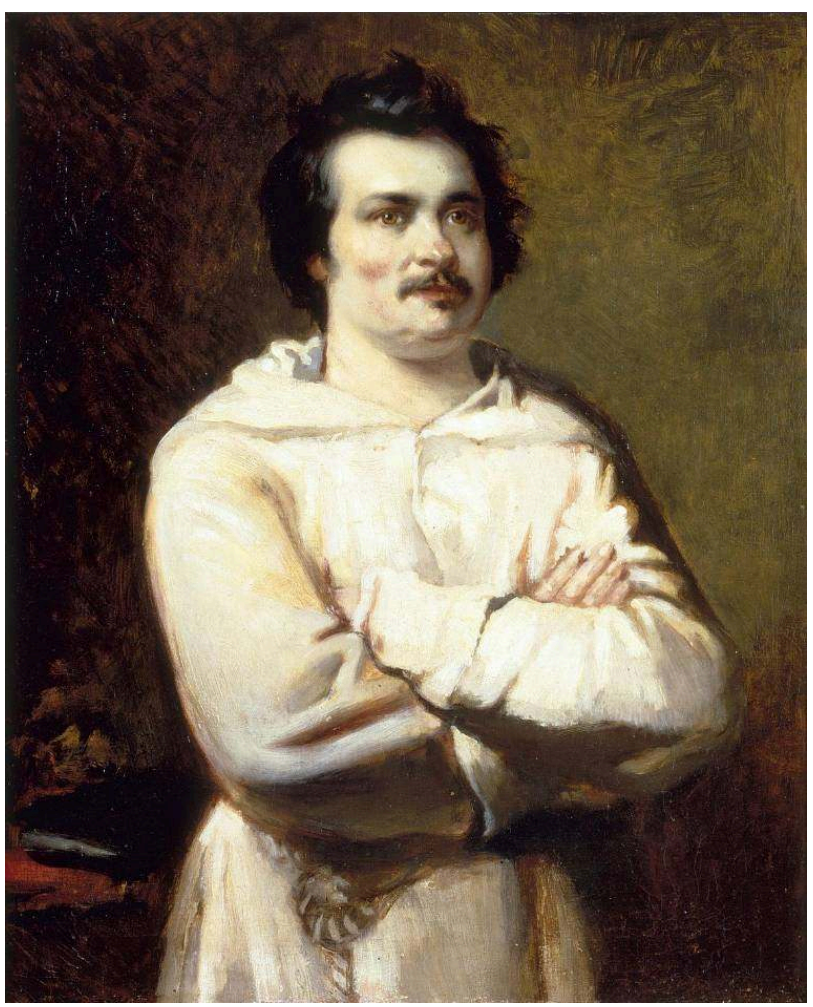

1837, huile sur toile, 610 x 500 cm, Tours, musée des Beaux-Arts.

La face rebondie que l'artiste a donnée à son modèle est faite pour tranquilliser les admirateurs du beau talent de M. de Balzac. Rien, dans le portrait, n'annonce le flambeau qui se consume en éclairant; on ne peut pas dire de lui que la lame use le fourreau, ni employer aucune de ces métaphores qui servent à excuser la maigreur des gens de lettres. L'énorme ampleur d'une robe de bénédictin suffit à peine à recevoir la rotondité de sa personne. Si M. Boulanger a été copiste fidèle, il est bien malheureux qu'il ne se soit pas fait un peu d'illusion; s'il a outré ce qu'il voyait, comme je le suppose, il est coupable, on doit respecter le génie !

\section{Miniatures}

31 Le nombre des portraits en miniature et à l'aquarelle diminue chaque année. Le nom de M. Isabey répand encore quelque éclat sur ce genre que des femmes soutiennent avec lui. $\mathrm{M}^{\mathrm{me}}$ de Mirbel n'a point de cadre cette année, heureusement, $\mathrm{M}^{\mathrm{me}}$ Watteville a envoyé au Louvre plusieurs portraits. $\mathrm{M}^{\text {lle }}$ Clothilde Gérard, qui s'était fait remarquer l'an passé par un très beau portrait à l'huile, a exposé deux pastels, genre dans lequel elle a acquis une grande réputation, ce qui ne m'a pas empêchée de regretter de ne point voir quelque grand ouvrage signé de son nom.

\section{$M^{\text {lle }}$ Deharme}

32 Cette jeune demoiselle poursuit sa brillante carrière, ses portraits joignent à une ressemblance parfaite une grande pureté de dessin et un faire tout à fait gracieux ; aussi $\mathrm{M}^{\text {lle }}$ Deharme est-elle un de nos meilleurs professeurs. Son éducation distinguée et son 
excellent ton la font rechercher par les mères de familles et les institutrices jalouses de ne mettre que de bons exemples sous les yeux de leurs élèves.

$\mathrm{M}^{\text {lle Isaure Bigot }}$

33 Je dois maintenant signaler un début. $\mathrm{M}^{\text {lle }}$ Isaure Bigot, dont le nom figure parmi les rédactrices du Journal des demoiselles, cultive les arts en même temps que la littérature. Une étude de Judith, grande miniature admise à l'exposition, place notre jeune émule au rang des dames artistes. Sa miniature m'a semblé d'un ton un peu chaud. Mais la tête est belle, et l'expression d'un pieux enthousiasme que lui a donnée $\mathrm{M}^{\text {lle }}$ Bigot convient parfaitement à l'héroïne juive.

$M^{m e}$ Alida de Savignac

\section{ANNEXES}

Lire des articles d'Alida de Savignac sur le Salon de 1844 parus dans le Journal des demoiselles

Lire des articles d'Alida de Savignac sur le Salon de 1846 parus dans le Journal des demoiselles

Lire l'introduction à Alida de Savignac écrite par Amandine Gorse 


\section{Alida de Savignac, Journal des demoiselles, 1844}

Articles « Beaux-Arts - Salon de 1844 », extraits choisis.

\section{«Premier article » (avril 1844)}

Journal des demoiselles, $\mathrm{n}^{\circ} 4,12^{\mathrm{e}}$ année, $3^{\mathrm{e}}$ série,

p. 122-124.

1 Depuis un mois, mes demoiselles, les journaux et les conversations retentissent des reproches adressés aux maîtres de l'art de ce qu'ils n'exposent pas leurs tableaux au Louvre. Je répéterai d'autant moins ces plaintes, que j'y trouve une sorte d'injustice. La plupart des artistes en renom sont occupés de travaux dans nos monuments publics: on ne peut peindre à la fois sur la toile dans son atelier et sur les murs des palais ou des églises; d'ailleurs c'est le fait des expositions annuelles d'amener sans cesse des noms nouveaux. Commençons donc notre revue, et faisons-la posément, puisque cette année nous avons du temps devant nous.

\section{Couder et Biard}

2 Ce sont deux traits de l'histoire moderne qui s'emparent tout d'abord de l'attention en entrant dans le grand Salon (fig. 1). 


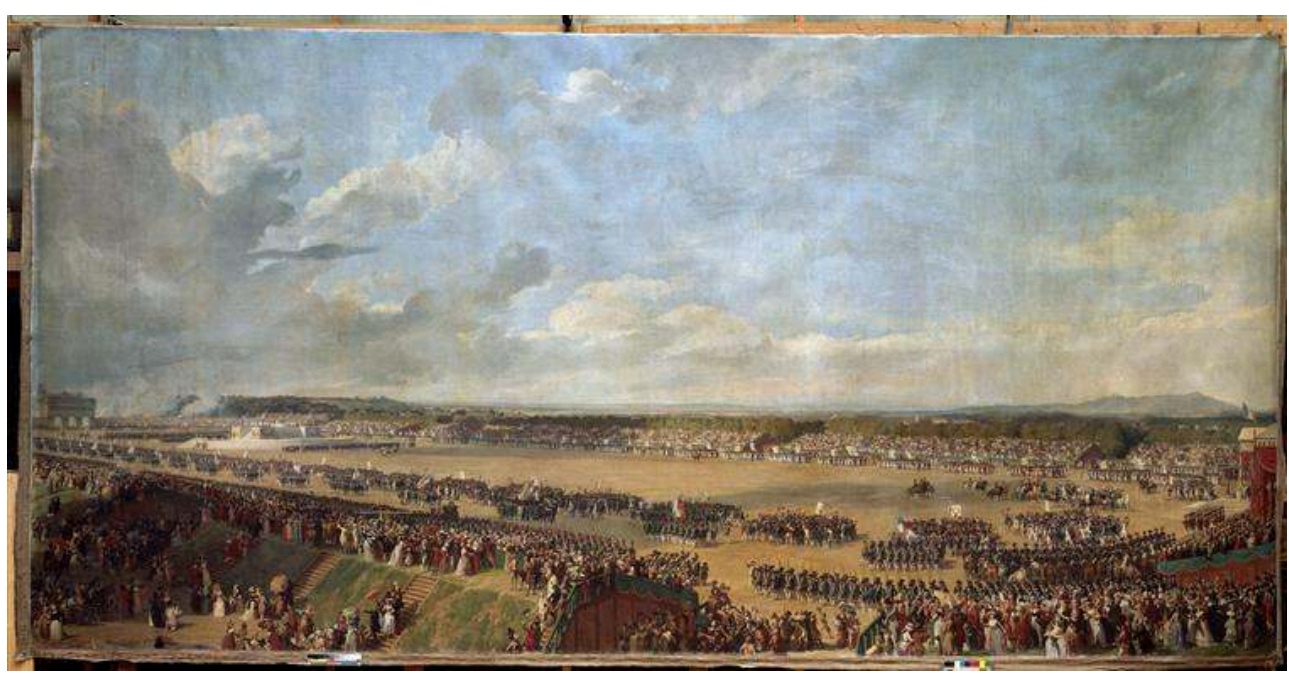

Vers 1838, huile sur toile, 451 x 847 cm, Versailles, musée national des châteaux de Versailles et de Trianon.

À droite, la Fédération de 1790, par M. Couder ; à gauche, le Bivouac de la garde nationale en 1832, par M. Biard : l'alpha et l'oméga de la Révolution française! Dans le premier de ces tableaux, M.Couder a daguerréotypé, on peut dire, une des pages des nombreux mémoires du temps. La toile a plus de trente pieds de long; un ciel immense et nuageux, comme il l'était en effet à ce premier anniversaire de la prise de la Bastille, et des figures de huit à neuf pouces de haut, se la partagent.

Sur la vaste étendue du Champ de Mars, les députations des quatre-vingt-six départements manœuvrent, leurs drapeaux en tête. Toute la population de Paris est là aussi avec les mœurs, les costumes, les passions de l'époque. Elle est accourue se grouper sur ces gradins, témoins prodigieux du zèle patriotique des habitants de la capitale du royaume de France: quiconque voulait la liberté y avait apporté une pelletée de terre, et l'ouvrage, qui aurait demandé des mois entiers à des brigades de terrassiers, s'était accompli en quelques jours! Ce tableau présente un ensemble imposant, une multitude de détails rendus avec finesse, talent, et beaucoup de vérité ; mais aucun intérêt, rien qui fasse pressentir l'exposition du plus grand drame qui se soit joué sur la scène du monde! L'action principale, celle du serment du roi Louis XVI, qui jure de maintenir la nouvelle constitution, est reléguée dans la bordure du cadre, de sorte que ce n'est qu'avec peine qu'on parvient à la découvrir (fig. 2). 


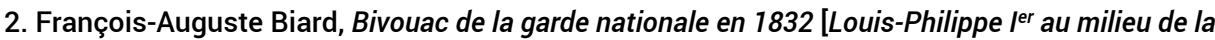
Garde nationale]

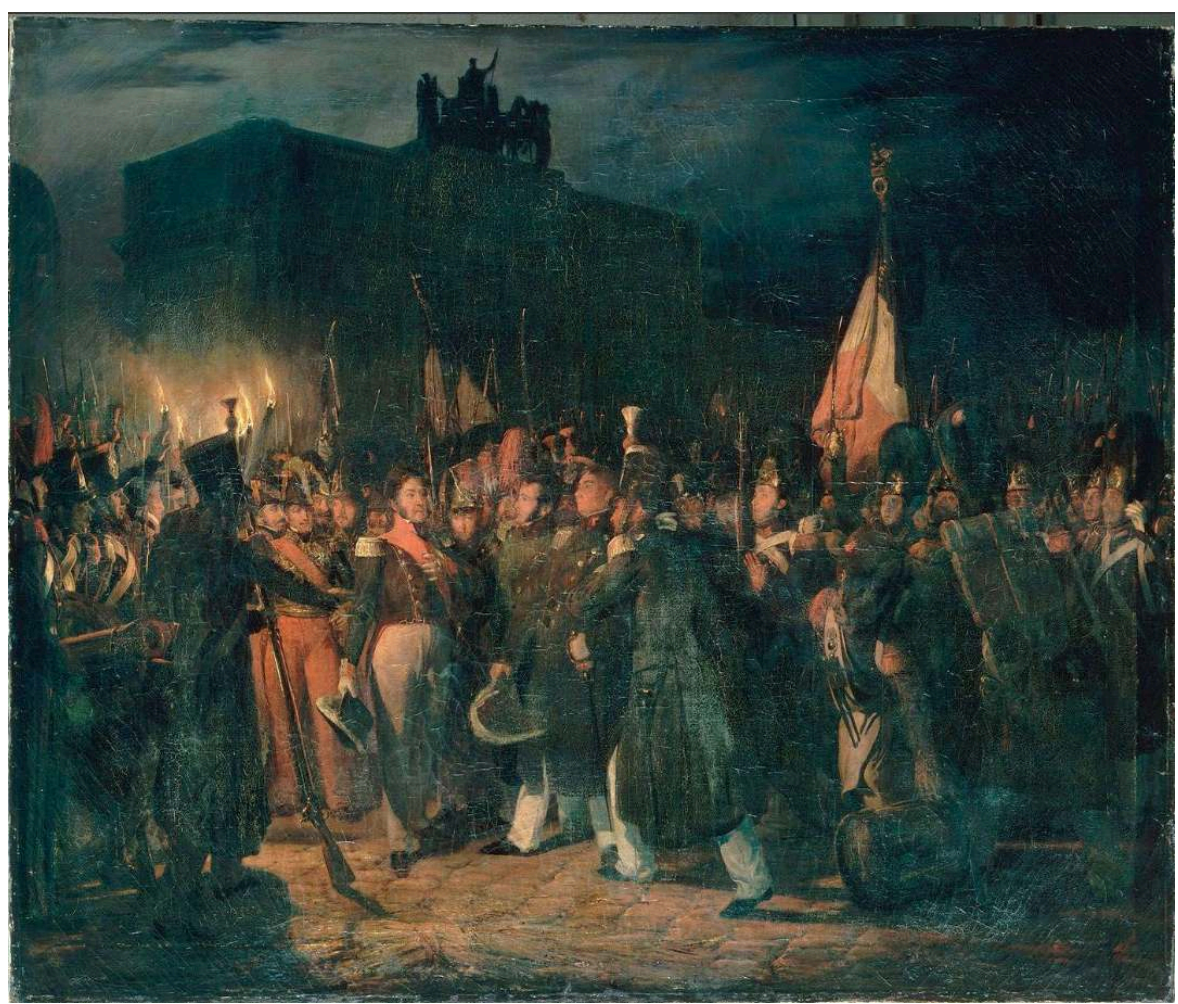

1836, huile sur toile, $78 \times 100$ cm, Versailles, musée national des châteaux de Versailles et de Trianon.

Quarante ans et plus se sont passés entre le tableau de M. Couder et celui de M. Biard. La constitution a été jurée, rejurée, faite, défaite, refaite... Nous sommes au mois de juin 1832 ; le roi Louis-Philippe dit aux gardes nationaux rassemblés en armes sur la place du Carrousel que grâce à leur dévouement et à leur courage, nous tenons enfin cette liberté tant poursuivie, tant désirée! Dieu veuille que nous soyons assez sages pour ne pas le démentir! M. Biard est un artiste dont personne ne conteste le talent ; il y a dans ce tableau un bel effet de nuit éclairée par la lune et par les torches que porte l'escorte du roi ; mais je reprocherai à M. Biard les figures de ces gardes nationaux qui viennent de sauver la patrie. Ne serait-il pas mieux de faire passer sur leur visage les nobles et beaux sentiments qui leur ont fait prendre les armes au péril de leur vie, sitôt que l'ordre a été menacé ?

\section{Beaume : Éducation de la Vierge}

5 La Vierge et sainte Anne ont des têtes d'une beauté suave, des poses remplies de grâce. Mais je trouve un peu de recherche et de manière dans le dessin et le coloris de ce groupe.

\section{Beaume : Enfants surpris par la marée}

Le tableau des Enfants surpris par la marée offre plus de vérité : il est mieux senti (fig. 3). 
3. Joseph Beaume, Enfants surpris par la marée

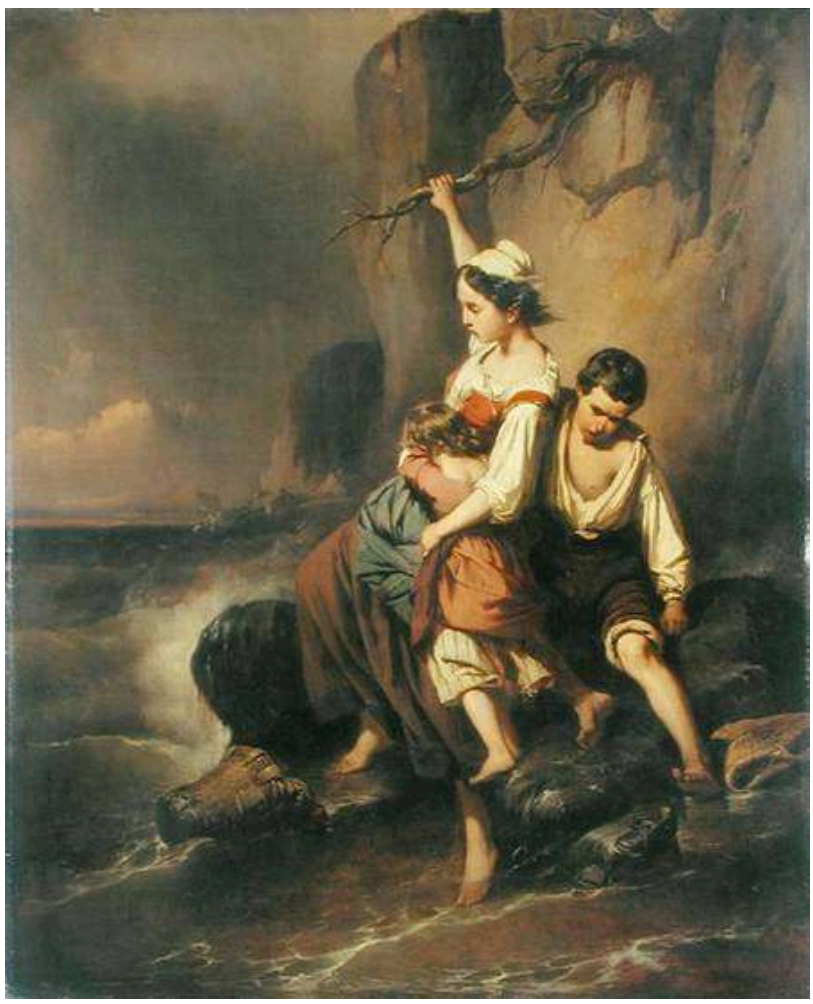

1844

Cette scène est de l'effet le plus dramatique. La jeune fille qui se cramponne d'une main au roc, en tenant sa petite sœur de l'autre, a une belle pose ; elle glisse, ses forces vont l'abandonner, aucun secours n'est en vue... On a la chair de poule, et pourtant on s'éloigne avec peine, comme si, en restant, on devait assister à la délivrance de ces pauvres enfants.

\section{Alophe : Charité, vertu du riche ; Résignation, vertu du pauvre}

7 Nos artistes ont trop d'esprit, ou du moins ils courent trop après l'esprit. Une femme charitable secourt les pauvres. Depuis Murillo, qui a fait un chef-d'œuvre d'Élisabeth, reine de Hongrie, recevant les mendiants, jusqu'à $\mathrm{M}$. Schnetz, vingt peintres ont traité ce sujet avec talent, vingt autres peuvent y réussir encore s'ils sont inspirés par lui. M. Alophe aurait été du nombre s'il ne s'était pas embarrassé dans la recherche d'une pensée morale et philosophique : la Charité est la vertu du riche. C'est très clair sur le papier ; sur la toile, il est moins aisé de l'exprimer. Ainsi, la femme qui, dans ce tableau, personnifie la richesse, a de longs vêtements de deuil et un air profondément triste que je ne m'explique pas, à moins qu'il ne serve à mieux faire ressortir la physionomie placide des pauvres résignés. Je demanderai encore compte à $\mathrm{M}$. Alophe de la manière dont la femme riche fait tomber une pièce d'argent du bout de ses doigts, comme l'aurore sème des gouttes de rosée; de plus, afin que nous jugions mieux de sa munificence, le pauvre a la paume de la main tournée de façon à ce que les vingt sous (car c'est là tout l'effort du riche !...) tombent à terre. 
8 Après les critiques de détail, je dois faire des éloges plus sérieux. Les lignes de la tête du vieillard sont belles; il y a le sentiment du vrai dans le coloris, la lumière est bien départie, la touche large est exempte de ces mignardises qui déshonorent tant de toiles.

\section{Horace Vernet : Un traîneau russe}

\section{4. Émile Jean Horace Vernet, Un traîneau russe [De retour du marché]}

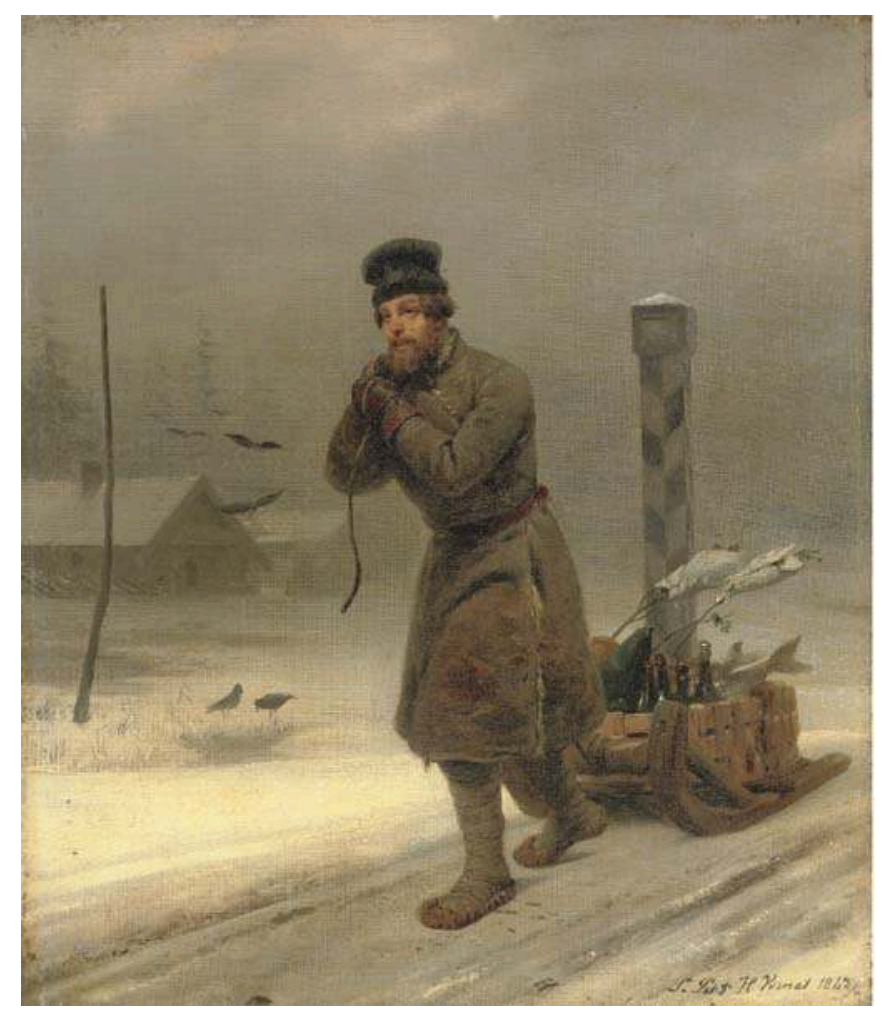

1843, huile sur toile, 36 × 31 cm, coll. part.

Et qu'on y voyage agréablement en traîneau! Le ciel gris semble toucher la terre et la neige s'étend uniformément depuis le premier plan jusqu'aux limites de l'horizon. Trois chevaux, l'œil sanglant, la crinière hérissée, se cabrent sous le fouet du paysan qui les conduit ; peut-être pressentent-ils un précipice, ou répugnent-ils à fouler un cadavre enseveli sous la neige... Des corbeaux qui s'abattent comme s'ils sentaient leur proie donnent assez de vraisemblance à cette supposition; mais qui sait s'ils ne se préparent pas encore pour eux un horrible festin... L'ouragan tourbillonne, les chevaux n'avancent pas, le traîneau va se briser, le malheureux voyageur baisse la tête pour ne pas voir des dangers qu'il ne peut combattre...

10 C'est superbe, mais c'est effrayant, et bien capable de dégoûter du voyage en traîneau sur la terre classique de ce genre de voiture.

\section{« Deuxième article » (mai 1844)}




\section{Couture : Amour de l'or}

Encore de l'esprit qui serait perdu sans la notice (fig. 5).

5. Thomas Couture, Amour de l'or [La Soif de l'or ou L'Amour de l'or]

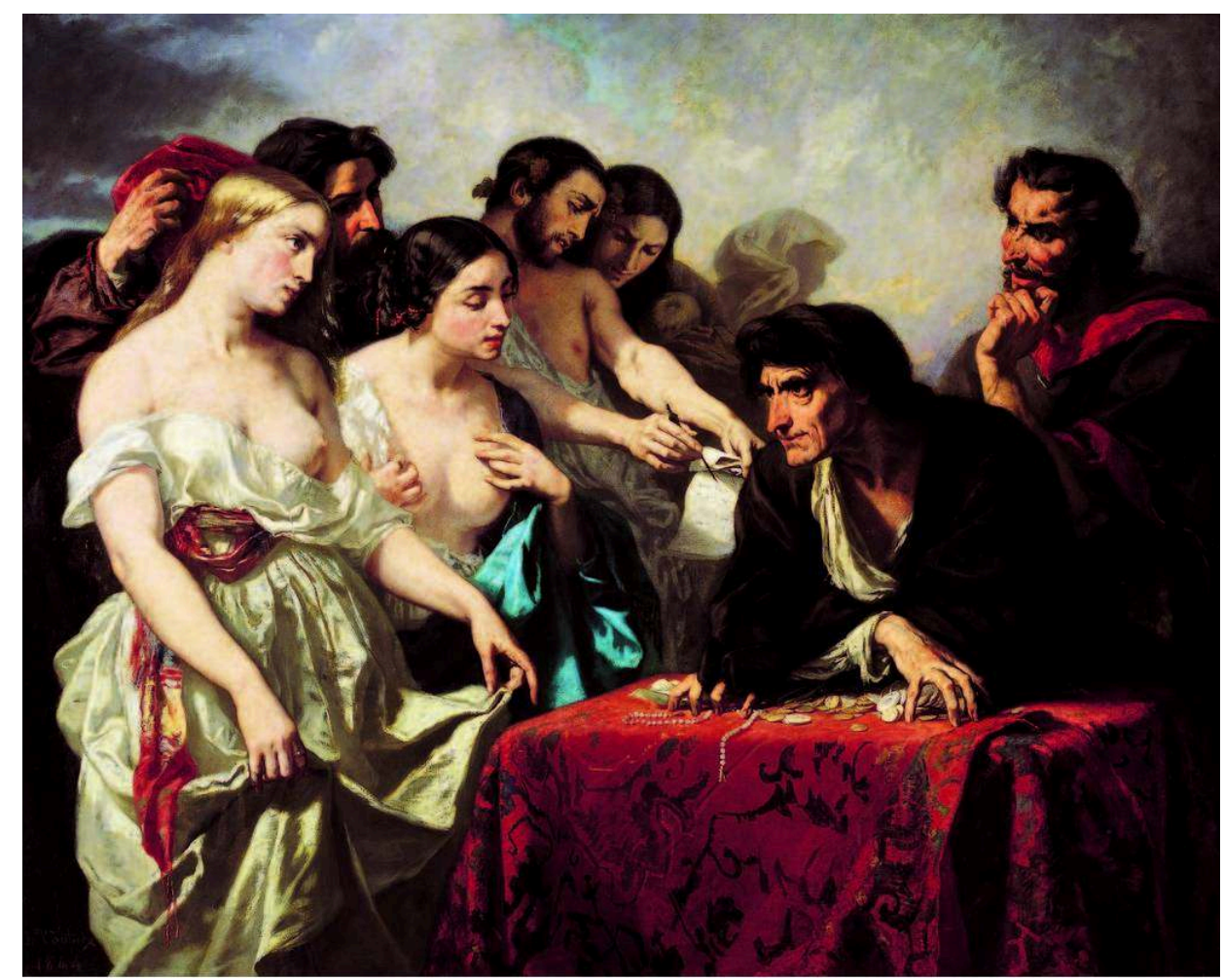

1844, huile sur toile, 154 × 188 cm, Toulouse, musée des Augustins

Certes, je vois très bien que cette vieille femme (on m'a dit depuis que c'était un vieil homme), qui rassemble de l'or, beaucoup d'or sous ses doigts crochus, est l'avarice en cornette de travers; mais ces deux belles jeunes créatures, passablement décolletées, cet écrivain qui se sourit à lui-même, ces artistes, ce tribun en toge, que font-ils là? S'ils aiment l'or aussi, ils devraient être furieux, car la vieille prend tout et ne leur donne rien.

Comment, me dira-t-on, voulez-vous qu'un artiste se préoccupe sans cesse du sujet qu'il traite s'il n'est ni poète ni historien? Mon Dieu! Je suis prête à accorder aux arts plastiques la permission de se borner à la reproduction de la nature sans faire appel au genre épique. Mais alors, que l'artiste se montre sublime, comme M. Saint-Jean, en nous servant des fraises sur une feuille de chou, qu'à l'exemple de Brascassat et de Paul Potter, il groupe des vaches et des brebis dans une prairie ou, si l'homme est son modèle de prédilection, qu'il peigne des portraits, des études, sans autre condition de succès que la vie, le sang, la chair, reproduits sur la toile, animée par un habile pinceau. Mais qu'il ne croie pas faire de l'art et de la poésie en formant une réunion incohérente de figures que l'on pourrait aussi bien intituler Une scène de Charenton que L'Amour de l'or. 


\section{Murat : Lamentations de Jérémie}

M. Murat est un artiste pensionnaire de l'Académie de France à Rome. On retrouve dans son beau tableau les études sévères du lauréat consciencieux et les heureuses inspirations du ciel d'Italie, de la terre classique des beaux-arts.

Les prophéties de Jérémie sont accomplies, Jérusalem n'est plus qu'un monceau de ruines; les vieillards assis sur les colonnes brisées du temple pleurent en silence les malheurs de la cité sainte; près d'eux les filles de Sion s'abandonnent à un désespoir plus expansif. Elles sont bien belles, ces vierges affligées! Leurs longues chevelures noires ruissellent sur des torses d'un galbe irréprochable. L'une d'elles, assise à terre, un coude appuyé sur son genou, est admirablement éclairée. Il y a là de la poésie comme on peut en faire en peinture. Je ferai le même éloge de la femme qui est debout et porte ses mains sur sa tête en signe de détresse. Mais je m'arrête... Il faudrait les décrire toutes si je voulais vous indiquer celles qui sont d'une beauté remarquable.

\section{Nicolas Gosse : Louis XI aux pieds de saint François de Paule}

Voilà un bon tableau de chevalet, où l'intérêt du sujet ajoute au mérite de l'exécution (fig. 6).

6. Nicolas Gosse, Louis XI aux pieds de saint François de Paule

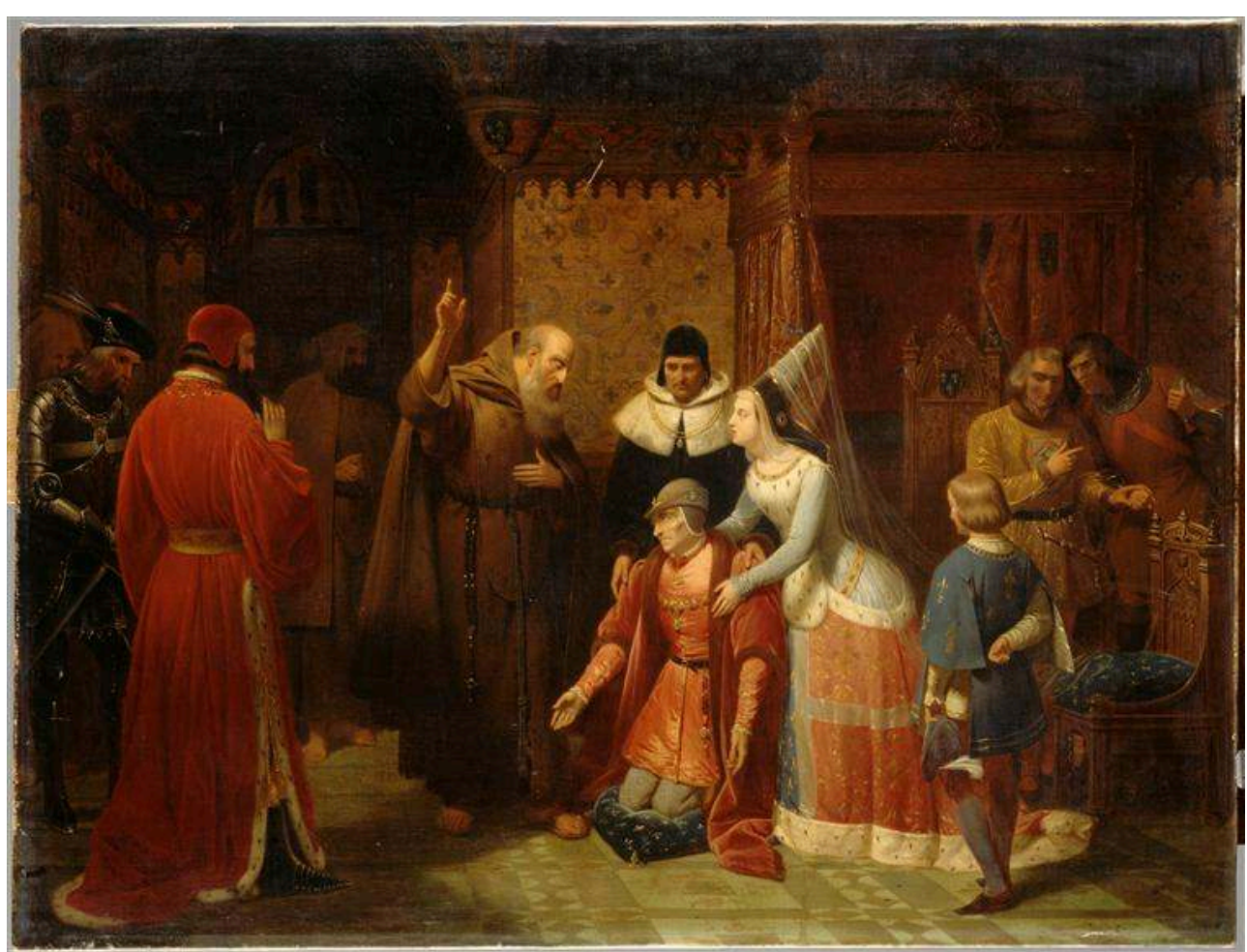

1844, huile sur toile, 64 × 86 cm, Paris, musée du Louvre.

Vers la fin de sa vie, Louis XI, tremblant devant le compte qu'il avait à rendre à Dieu d'une vie si peu chrétienne, pensa que les mérites de saint François de Paule pourraient obtenir du ciel qu'il retardât au moins l'heure du Jugement. 
narque cruel et despote, mais pourtant croyant, se prosterne aux pieds du saint dont toute la vie fut consacrée au soulagement des misères de l'humanité; il veut que le bien, fait par François de Paule, serve de compensation à ses crimes politiques, à lui, Louis XI. Tous les hommes sont, pour le saint, des frères, des fils, des pères... Le roi, qui a été mauvais fils, frère cruel, père indifférent, maître impitoyable, a, comme vous le voyez, plus d'un marché à lui offrir... Le saint exhorte le roi à travailler lui-même à sa réconciliation avec Dieu. Auprès du moribond agenouillé sont les seuls êtres qu'il aime, parce qu'il reconnaît pour lui leur utilité : ce sont $\mathrm{M}^{\mathrm{me}}$ de Beaujeu, sa fille, dont la main habile doit affermir la couronne sur la tête débile du jeune Charles; Coictier, le médecin, et le prévôt Tristan, exécuteur des hautes œuvres. Toutes ces figures ont le caractère que leur assigne l'histoire, sans pour cela sortir des voies de la nature.

C'est ainsi qu'il faut traiter le genre épisodique, conquête nouvelle, et qui ferait beaucoup d'honneur à l'école française si elle nous offrait souvent des tableaux du mérite de celui de M. Gosse.

\section{Bordier du Bignon : Bal donné à I'hôtel de ville de Paris, à l'occasion du mariage du roi de Westphalie}

En 1809, je crois, Jérôme Bonaparte, frère de l'empereur Napoléon, épousa la fille du roi de Wurtemberg, noble et vertueuse princesse, qui mérita par la suite de partager l'immortalité de la famille à laquelle elle s'alliait. La Ville de Paris se mit en frais pour célébrer la victoire de Wagram et fêter ces noces illustres. Le vieil hôtel de ville, paré qu'il était d'or et de lauriers, n'était pas le superbe monument d'aujourd'hui ; mais Napoléon foulait les dalles de son pied puissant, et les rois tributaires se pressaient à sa suite. De tout cela il n'y a que trente-cinq ans ; l'artiste assistait à ce bal, triste avantage qui est partagé par beaucoup de ceux qui regardent son tableau. Eh bien! Je ne crois pas que nos marins découvrent jamais de pays inconnus où les mœurs, les attitudes, les costumes, leur semblent plus étranges que ne le sont à nos yeux ceux représentés dans ce tableau. On ouvre le bal ; le roi de Westphalie, vêtu de satin blanc brodé d'or, s'élance pour un avant-deux. Quel pas de zéphyr! Et la mariée, et les reines de Naples, de Hollande ! C'est à passer une journée devant ces portraits dont les noms rappellent de si grandes choses et dont les tournures sont si bizarres!

Quant au mérite du tableau, il est tout dans l'exactitude des souvenirs de l'artiste ; car il est rare que les peintures où le jour est remplacé par les mille lumières des lustres présentent des effets vraiment dignes de l'art.

\section{Alexandre Colin}

Quatre petits tableaux représentant les quatre saisons de l'année, personnifiées dans des scènes plus ou moins pastorales. Au printemps, des enfants et des jeunes filles cueillent des fleurs, énormément de fleurs, plus même qu'il n'en faudrait pour l'effet et l'ordonnance du tableau : les buissons de roses et les prés émaillés ne font jamais très bien sur la toile. En été, un chevalier parle d'amour à une simple pastourelle; il y a longtemps que ce groupe a vu le jour pour la première fois. En hiver, le châtelain et la châtelaine distribuent des secours à des pauvres bien déguenillés. En automne, une chasse, sans doute, mais je n'ai pas trouvé le quatrième tableau. Ces peintures sont de 
celles que la lithographie se hâte de reproduire. Je crois même que celles-ci, coloriées, iront remplacer sur les murs des chambres d'auberge, l'oracle de la marguerite :

"Point ne viendra", répond la blanche fleur.

Or, le beau page était caché près d'elle ;

Il s'écria : "L'oracle est un menteur' !"

\section{Alfred Dedreux : Cheval abandonné sur un champ de bataille}

Ce tableau, très apprécié des amateurs, attire aussi les regards de la foule. Malgré soi on s'attendrit sur la misère de ce noble animal, traînant péniblement un reste d'existence. Il y a beaucoup de vérité et de poésie en même temps dans la figure de ce cheval blessé ; du serviteur délaissé on se reporte au maître... Il est mort, lui, et son corps dépouillé gît là quelque part, à peine couvert d'un peu de terre, tandis qu'une famille, une épouse, des enfants, attendent qu'une lettre vienne soulager leur poitrine du poids affreux qui l'oppresse.

C'est un beau tableau que celui de M. Dedreux, mais je n'aimerais pas à rester longtemps seule avec lui, quoique l'unique personnage soit un animal.

\section{Félix Philippoteaux : Avant-poste arabe ; Le Rapt ; La Razzia}

Des trois tableaux que je vous indique, celui qui représente un avant-poste arabe est sans contredit le meilleur sous le rapport de l'art: les figures sont bien traitées, les effets de nuit parfaitement rendus; mais La Razzia et surtout Le Rapt sont infiniment plus dramatiques (fig. 7).

\section{Henri Félix Emmanuel Philippoteaux, Le Rapt}

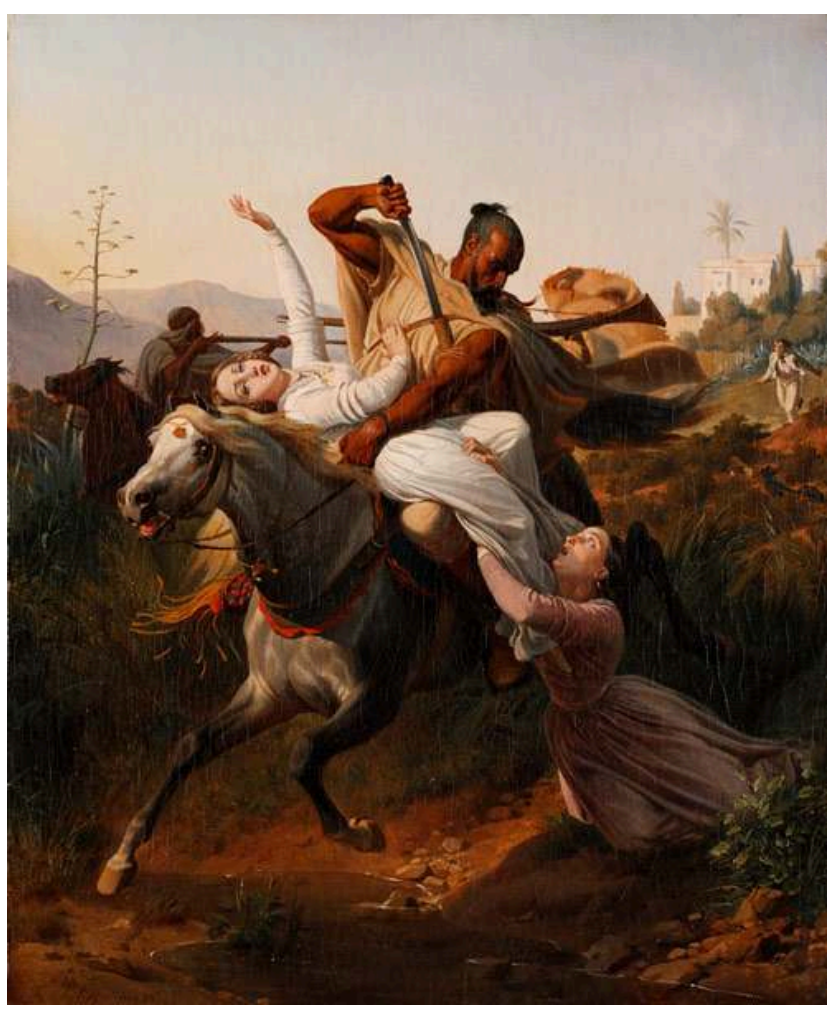

1844, huile sur toile, $46,5 \times 38 \mathrm{~cm}$, coll. part. 
Des Arabes se sont introduits dans l'enclos d'un colon; l'un d'eux s'est emparé d'une jeune fille qu'il a jetée en travers sur son cheval; la mère s'attache à son enfant et cherche à la retenir en poussant des cris que l'on croit entendre ; mais bientôt elle se taira... Le ravisseur tire son redoutable yatagan. On voit, il est vrai, accourir dans le lointain, le père armé seulement d'un bâton... Il est mort s'il approche... Mais il n'approchera pas... Déjà il est couché en joue par l'un de ces Bédouins dont le coup d'œil est si sûr.

Ces scènes de violences et de meurtre attirent de terribles représailles. Un corps de l'armée française entoure une tribu ;j'espère que c'est celle à laquelle appartenaient les coupables. La résistance est impossible, la fuite périlleuse: un Arabe tombe de son cheval, frappé au cœur par une balle, tandis que sa femme, qui le suivait, montée ainsi que ses enfants sur un chameau, porte ses mains à son front dans un mouvement sublime de douleur et d'effroi. Oh ! La guerre! La guerre est une affreuse chose !... Elle fait mal à voir même en peinture.

\section{$\mathrm{M}^{\text {me }}$ Mathilde Lagache : Le Chapelet}

Je ne vous détaillerai pas ce tableau, mesdemoiselles; la gravure qui est dans votre journal vous en offre une copie. Il y a dans l'ensemble de cette composition une pensée triste et consolante à la fois. À voir la figure si distinguée de cette jeune veuve, on devine qu'elle a connu des jours meilleurs, et l'on comprend qu'elle trouve dans la religion la résignation qui lui fait supporter les mauvais jours. Ce tableau est d'une simplicité vraie, d'une grâce naïve qui font beaucoup d'honneur au talent de $\mathrm{M}^{\mathrm{me}}$ Mathilde Lagache.

$M^{m e}$ Alida de Savignac

\section{ANNEXES}

Lire des articles d'Alida de Savignac sur le Salon de 1837 parus dans le Journal des demoiselles

Lire des articles d'Alida de Savignac sur le Salon de 1846 parus dans le Journal des demoiselles

Lire l'introduction à Alida de Savignac écrite par Amandine Gorse

\section{NOTES}

1. M. Revoil, « La Blanche Marguerite. Romance ». 


\section{Alida de Savignac, Journal des demoiselles, 1846}

Articles « Beaux-Arts - Salon de 1846 », extraits choisis.

\section{«Premier article » (avril 1846)}

Journal des demoiselles, $\mathrm{n}^{\circ} 4$, avril 1846, $14^{\mathrm{e}}$ année, $3^{\mathrm{e}}$ série,

\section{p. 120-122.}

1 Le Salon ou, pour parler plus correctement, les salons et galeries du Louvre, contiennent, en 1846, dix-huit cent trente-trois tableaux à l'huile, deux cent soixantequatorze miniatures, aquarelles, pastels, dessins; cent soixante et onze gravures, lithographies, dessins d'architecture ; enfin, cinq trente-quatre morceaux de sculpture, dus aux pinceau, crayon, burin ou ciseau de douze cent trente-deux artistes, pour la plupart jeunes, remplis d'ardeur et d'ambition, ayant travaillé avec zèle, avec conscience, avec dévouement, pour arriver qui à posséder la gloire, qui la fortune, qui, et malheureusement ce sera le plus grand nombre, à végéter dans l'obscurité... Dieu leur donne la résignation pour supporter leur cruel désappointement. Après cette statistique, nous allons entrer en matière et si vous le voulez bien, mesdemoiselles, commencer notre revue annuelle.

\section{Horace Vernet : La Bataille d'Isly}

2 Cette grande page, dont le développement ne peut cependant être comparé à celui de La Smala, est aussi destinée à orner une des salles des musées de Versailles, consacrée aux exploits de notre armée d'Afrique (fig. 1). 


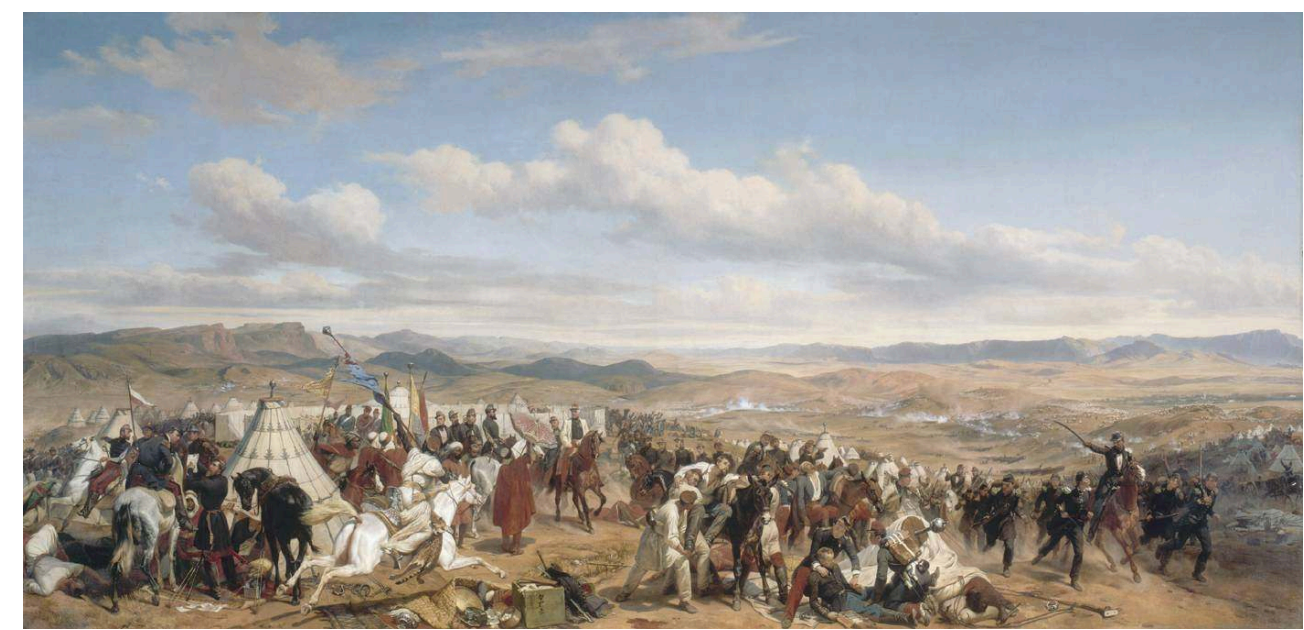

1846, huile sur toile, 514 x 1040 cm, Versailles, musée national des châteaux de Versailles et de Trianon.

L'action est terminée ; le maréchal Bugeaud est en possession du camp des Marocains et le colonel Jussuf lui présente le fameux parasol, trophée de notre victoire ; au fond est la tente que vous aviez vue aux Tuileries; à gauche du spectateur est un groupe de cavaleries, dont les chevaux sont superbes; à droite, un capitaine et des soldats d'infanterie s'élancent dans un ravin, en courant avec cette verve, ce mouvement que M. Vernet, seul, sait donner à ses personnages. Sur le premier plan, des blessés que l'on relève pour les porter à l'ambulance et, tout à fait contre la bordure du cadre, les provisions assez chétives du fils de l'empereur de Maroc: une pipe, une boîte à thé renversée, un pain de sucre et quelques oranges. Si ce tableau n'a qu'un médiocre intérêt dramatique, il est précieux à cause du grand nombre de portraits qui s'y trouvent et de la beauté de son exécution.

\section{Ary Scheffer : Sainte Monique et Saint Augustin ; L'Enfant charitable ; Marguerite et Faust ; Le Christ et les Saintes Femmes}

Il y a au Salon beaucoup de tableaux dont les sujets sont tirés des Livres saints ; mais on compte les tableaux religieux. 


\section{Ary Scheffer, Sainte Monique et Saint Augustin [Saint Augustin et sa mère Sainte Monique]}

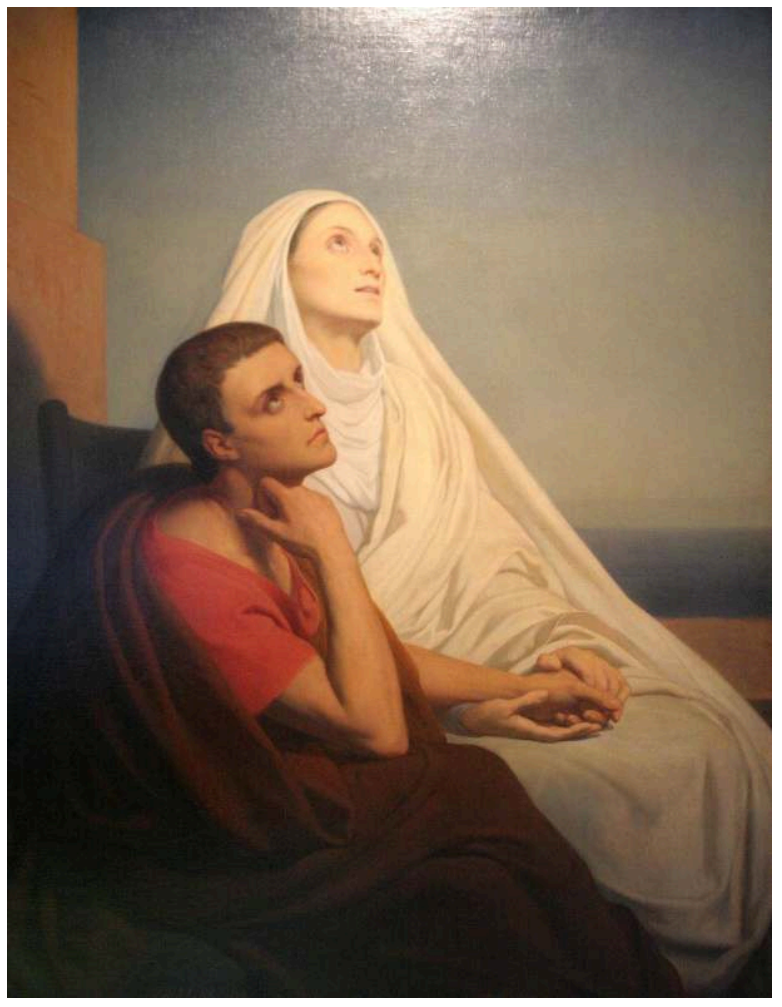

1846, huile sur toile, $147 \times 114$ cm, Paris, musée du Louvre.

\section{Ary Scheffer, L'Enfant charitable}

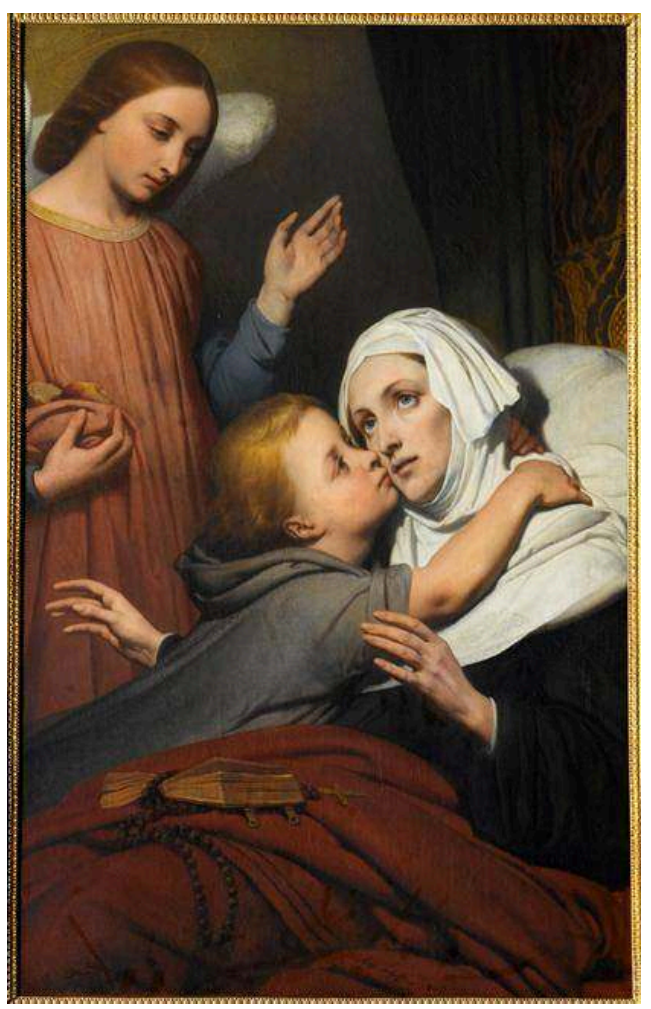

1840, huile sur toile, $118 \times 74$ cm, Nantes, musée des Beaux-Arts. 
4. Ary Scheffer, Marguerite et Faust au jardin

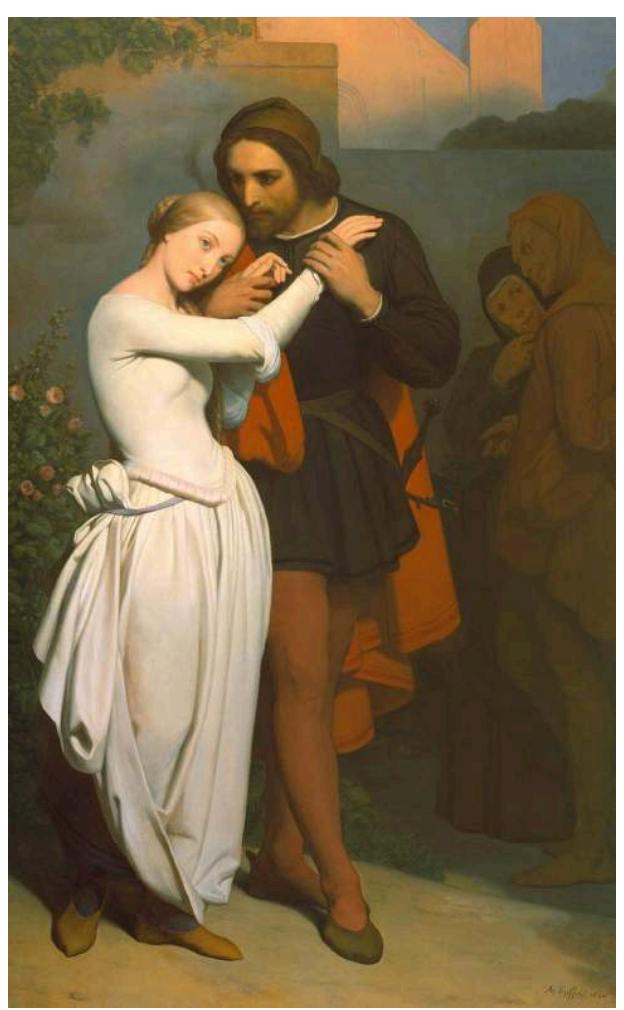

1846, huile sur toile, $218 \times 135 \mathrm{~cm}$, coll. part.

5. Ary Scheffer, Le Christ et les Saintes Femmes

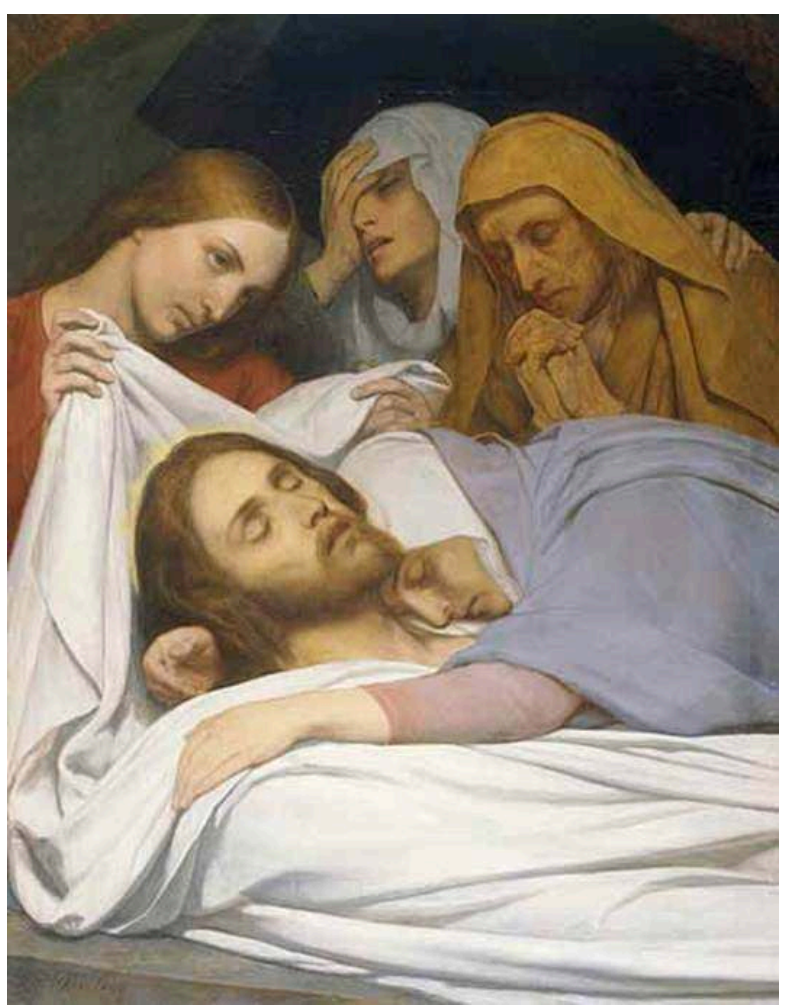

1846, huile sur bois, 108,8 x 86 cm, Manchester, Art Gallery. 
En tête de ceux-ci, il faut placer la Sainte Monique de M. Ary Scheffer (fig. 2) ; c'est un chef-d'œuvre de sentiment, rien que cela. Vous connaissez, mesdemoiselles, cet entretien que saint Augustin rapporte dans ses Confessions, où la mère et le fils, assis près d'une fenêtre, à Ostie, cherchaient à pénétrer quelles étaient ces joies promises aux élus, ces joies que l'œil ne peut voir, que l'esprit ne saurait imaginer... Tout à coup, sainte Monique, ravie, en extase, éprouve cette félicité de l'âme détachée de la terre et qui monte vers son Créateur. Il faut renoncer à vous donner, par un froid récit, une idée de ce merveilleux tableau ; on se sent saisi d'une émotion profonde et respectueuse, en présence de cette sainte à laquelle Dieu daigne se manifester, et nous le voyons, à n'en pas douter, dans son regard; nous en entendons les preuves dans ce soupir qui s'échappe de sa poitrine. De faire et de couleur, il n'en est plus question, pour moi du moins. Ce bel ouvrage appartient à Sa Majesté la reine. Qu'on est heureux d'être sur le plus beau trône du monde, pour acquérir de semblables tableaux et avoir tant de moyens divers d'exprimer à l'artiste son admiration !

Le sujet de L'Enfant charitable est tiré d'une ballade de Goethe, le poète qui, avec Dante, inspire les tableaux profanes de M. Scheffer (fig. 3). Ce cher petit enfant a donné son déjeuner à un vieux pauvre qui lui semblait bien malheureux; or, le pauvre était un ange et, en retour de son aumône, il confie à l'enfant le pouvoir de guérir les malades avec un baiser. Dans le tableau, l'enfant se jette entre les bras de sa grand-mère et lui rend la santé par ses caresses ; l'ange est derrière, portant dans le pan de sa robe rose la poire et le pain qu'il paye par ce miracle. Il y a dans ce tableau toute la naïveté et toute la grâce de la légende; l'enfant surtout est charmant. Les deux tableaux de Faust au jardin (fig. 4) et de Marguerite sortant du tombeau et apparaissant à son séducteur continuent la série des beaux tableaux par lesquels M. Scheffer popularise chez nous Faust, ce drame de Goethe.

\section{Marie-Louise Desnos : Interrogatoire et Condamnation de la princesse} de Lamballe, 1792 ; Le Journal du soir ou l'Appel des condamnés, 1793

5 Ces deux tableaux ont un prodigieux succès et font le plus grand honneur au talent facile et correct de $\mathrm{M}^{\mathrm{me}}$ Desnos ; les groupes sont parfaitement ordonnés et les lumières bien distribuées.

\section{$\mathrm{M}^{\text {me }}$ Brune : La Fille de Jephté}

6 La fille de Jephté, entourée de ses compagnes et prête à marcher au sacrifice, pleure sa jeunesse. Cette réunion de jolies têtes forme un tableau remarquable où l'on retrouve le pinceau ferme et gracieux de $\mathrm{M}^{\text {lle }}$ Aimée Pagès.

\section{Decamps : Souvenir de la Turquie d'Asie ; École turque}

Les tableaux de M. Decamps sont toujours un événement au Louvre (fig. 6). 


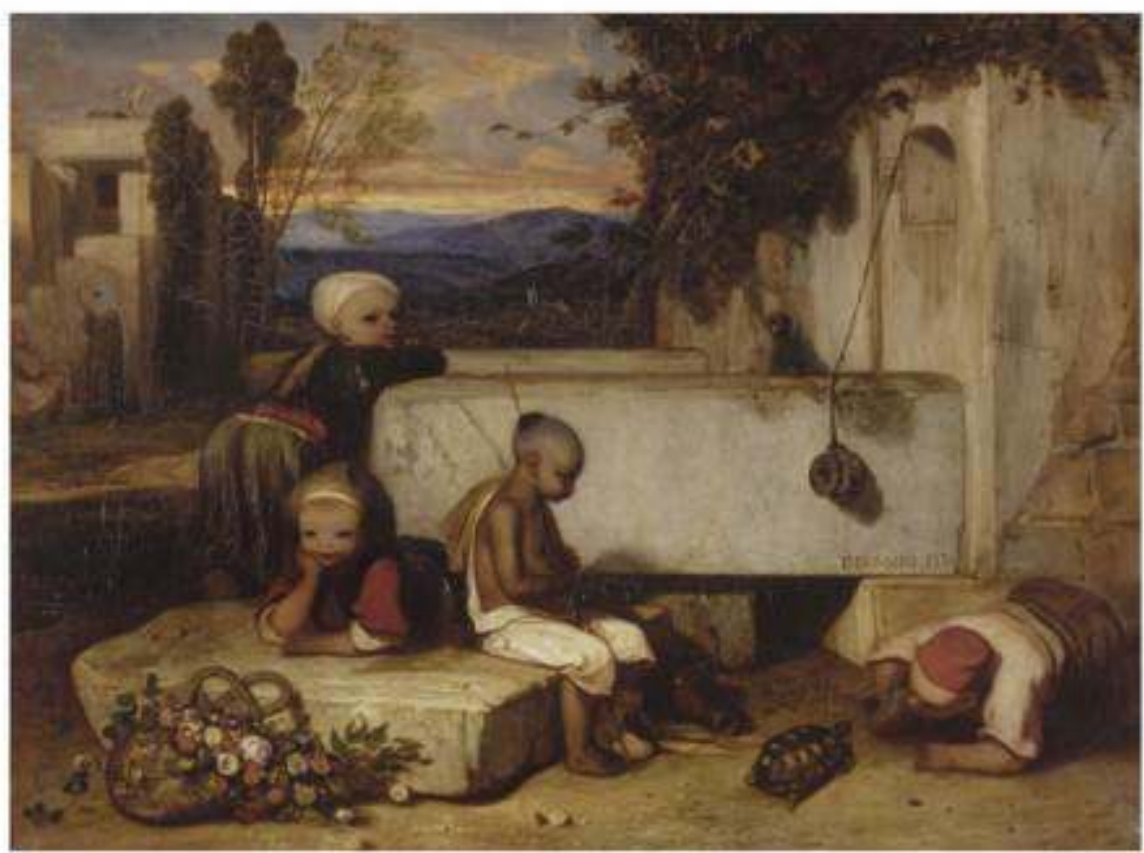

1836, huile sur toile, $72,5 \times 91$ cm, Chantilly, musée Condé.

Les amateurs de peinture propre et lisse, les enthousiastes de trompe-l'œil restent étonnés devant ces toiles et se révoltent contre le plaisir qui les envahit en dépit d'euxmêmes; mais les véritables artistes, les connaisseurs, les ignorants mêmes à qui Dieu a donné le véritable sentiment des arts, en raffolent. Si vous êtes capables d'apprécier les mérites de délicieux gamins noirs et crasseux, à peine couverts des guenilles les plus pittoresques, arrêtez-vous devant les tableaux de M. Decamps.

\section{Winterhalter : Salon du château de Windsor}

8 Ce talent, qui promettait de si gracieuses fantaisies, s'est mis au régime de la peinture officielle ; il attache des têtes historiques sur des mannequins très bien parés. 
7. Franz-Xavier Winterhalter, Salon du château de Windsor [Réception de Louis-Philippe, roi de France, au château de Windsor le 8 octobre 1844]

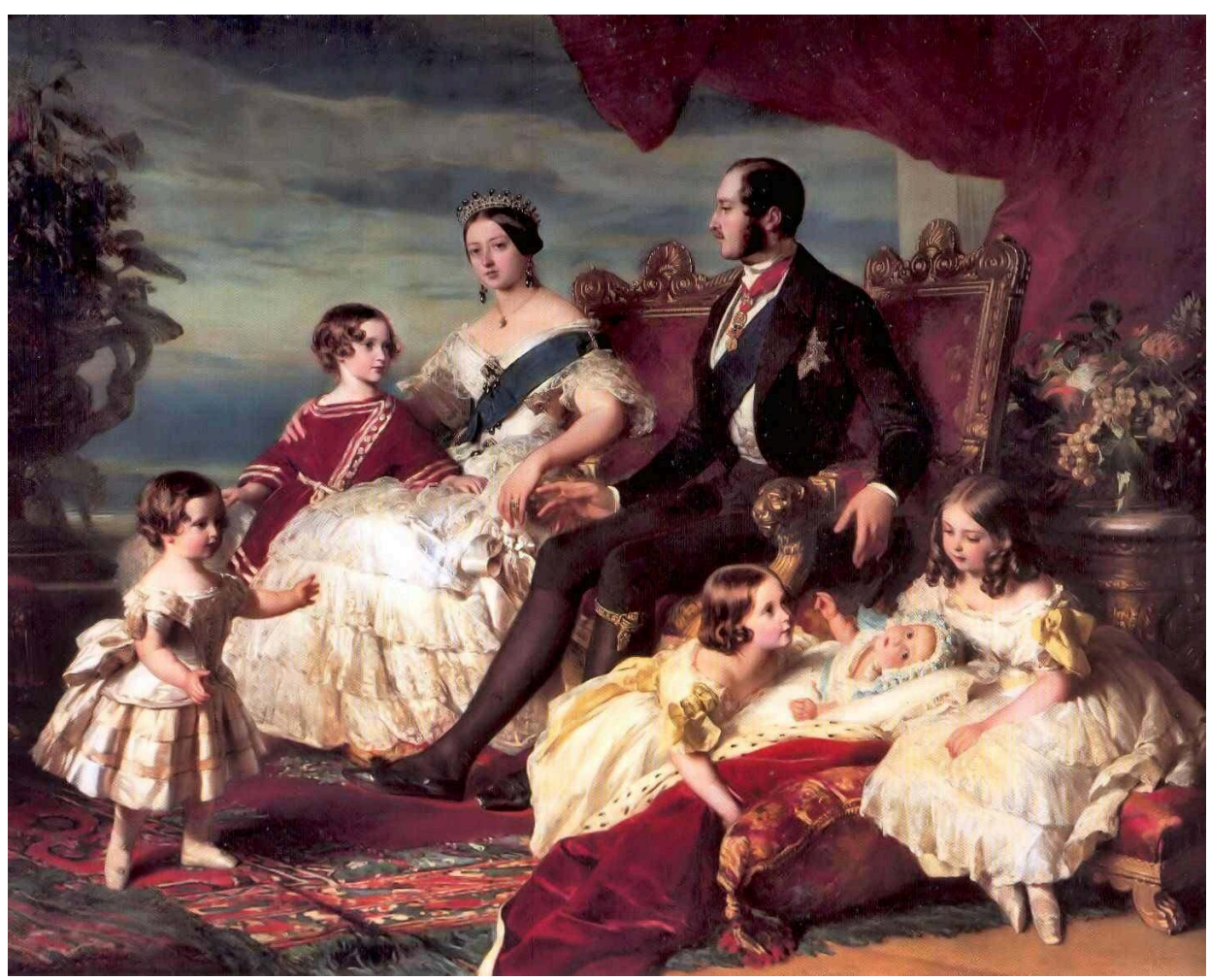

1844-1845, huile sur toile, 345 × 480 cm, Versailles, musée national des châteaux de Versailles et de Trianon.

Il faut convenir encore que tout est fort propre et fort confortable dans ce salon de Windsor, où la reine d'Angleterre présente, le 8 octobre 1844, quatre beaux enfants au roi Louis-Philippe (fig. 7). Du reste, ces royales scènes de famille sont multipliées au Louvre cette année. M. Winterhalter a une réunion de famille dans la galerie Victoria, au château d'Eu, lors du voyage de la jeune reine d'Angleterre, le 8 septembre 1845. La foule, curieuse de savoir comment on passe la soirée quand on est rois et reines, se presse devant ces cadres. Taillez vos crayons, artistes, préparez vos toiles; l'an 1846 vous promet bien d'autres merveilles à retracer !

\section{Labouchère : Luther, Melanchton, Pomeranus et Cruciger traduisant la Bible}


8. Pierre-Antoine Labouchère, Luther, Melanchton, Pomeranus et Cruciger traduisant la Bible

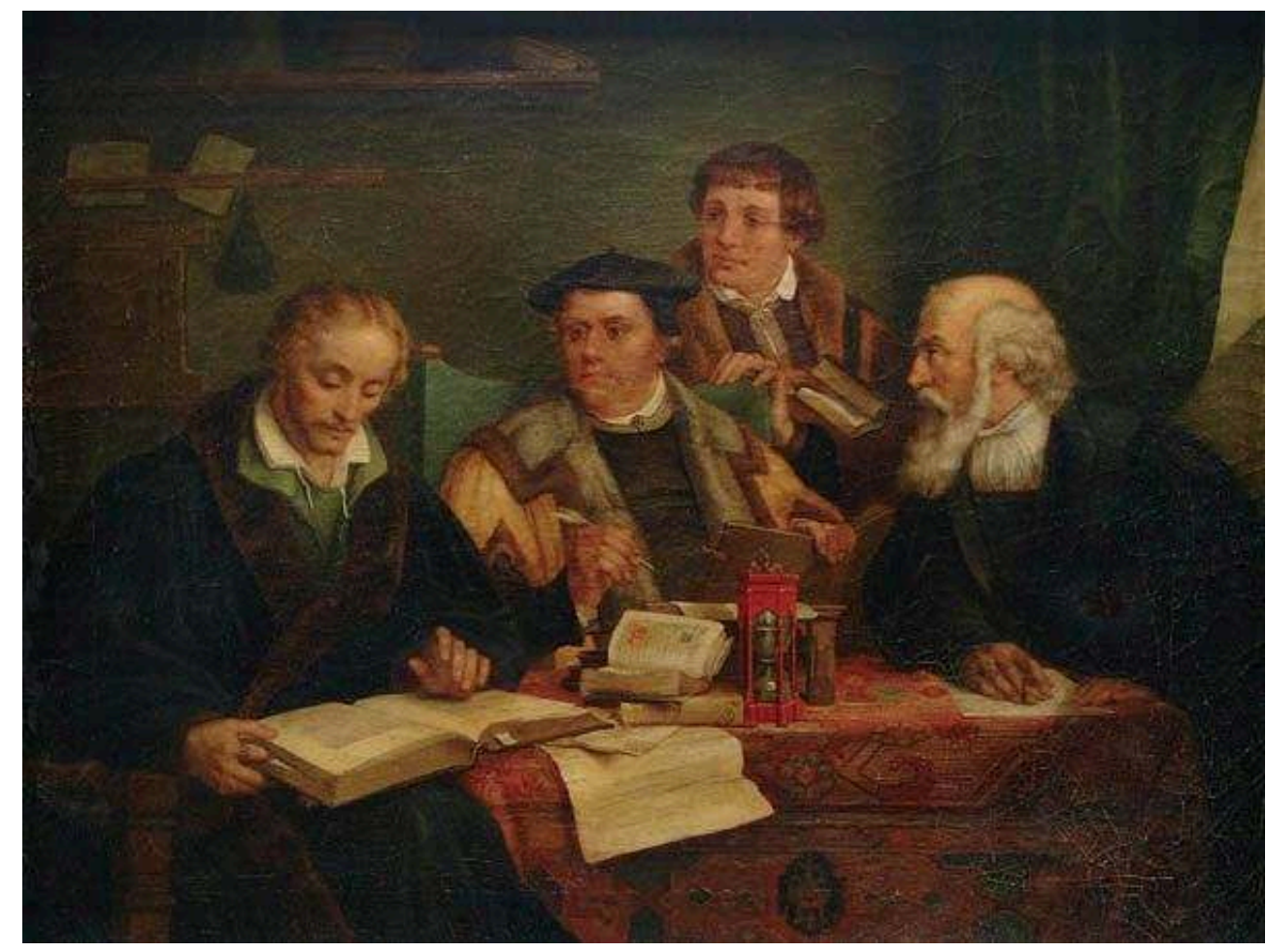

1846

9 Ce cadre rassemble ces quatre personnages historiques travaillant à la traduction de la Bible, l'un des plus beaux monuments de la littérature allemande (fig. 8). Ces portraits sont dessinés d'une main ferme, et vigoureusement peints : ce sont bien là les hommes de ce $\mathrm{XVI}^{\mathrm{e}}$ siècle qui tenaient au Moyen Âge par la vigueur et au nôtre par l'intelligence, siècle marqué par la hardiesse et la grandeur de ses entreprises.

\section{Norblin : Les Trois Parques, tableau peint à la cire}

10 Ce sujet est archiclassique, mais le vrai talent sait tout rajeunir. Ainsi la sage ordonnance de ce groupe, les poses nobles des trois Parques, la fermeté du dessin tout à fait antique et qui rappelle les plus admirables fresques, attirent et retiennent les amateurs devant ce beau tableau.

\section{Eugène Delacroix : Marguerite à l'église ; Le Sac du château de Front-de-Bœuf ; Les Adieux de Roméo et de Juliette}


9. Eugène Delacroix, Marguerite à l'église

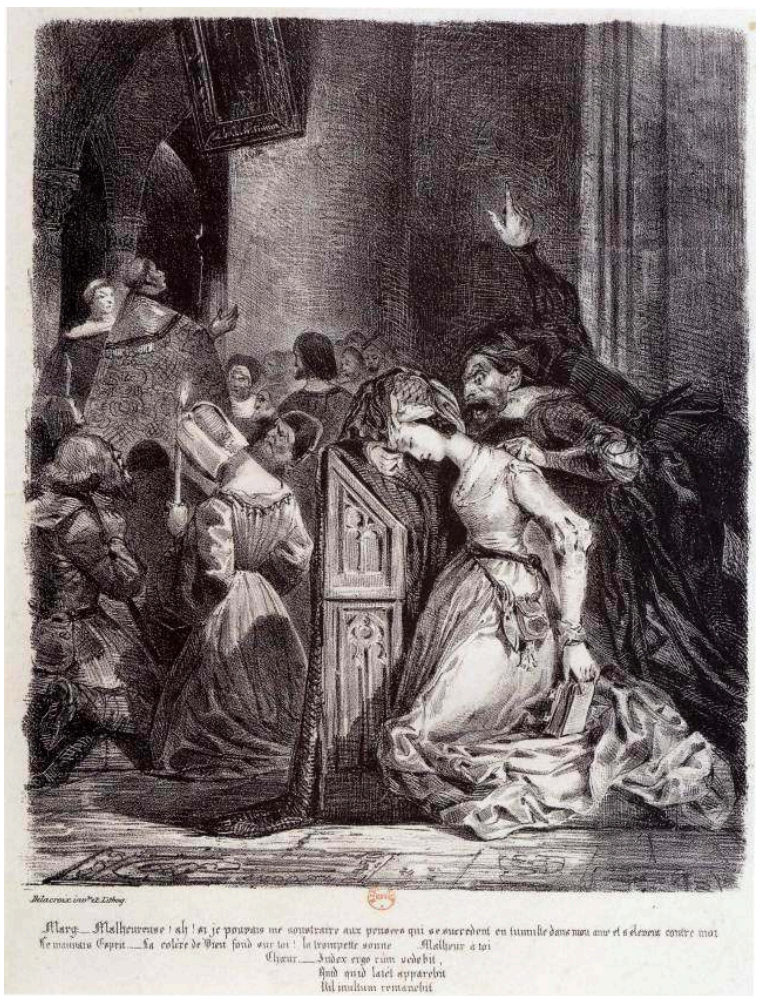

1828, lithographie, 260 × 220 mm, Paris, bibliothèque de l'École des beaux-arts.

10. Eugène Delacroix, Le Sac du château de Front-de-Bœuf [Rébecca enlevée par le Templier]

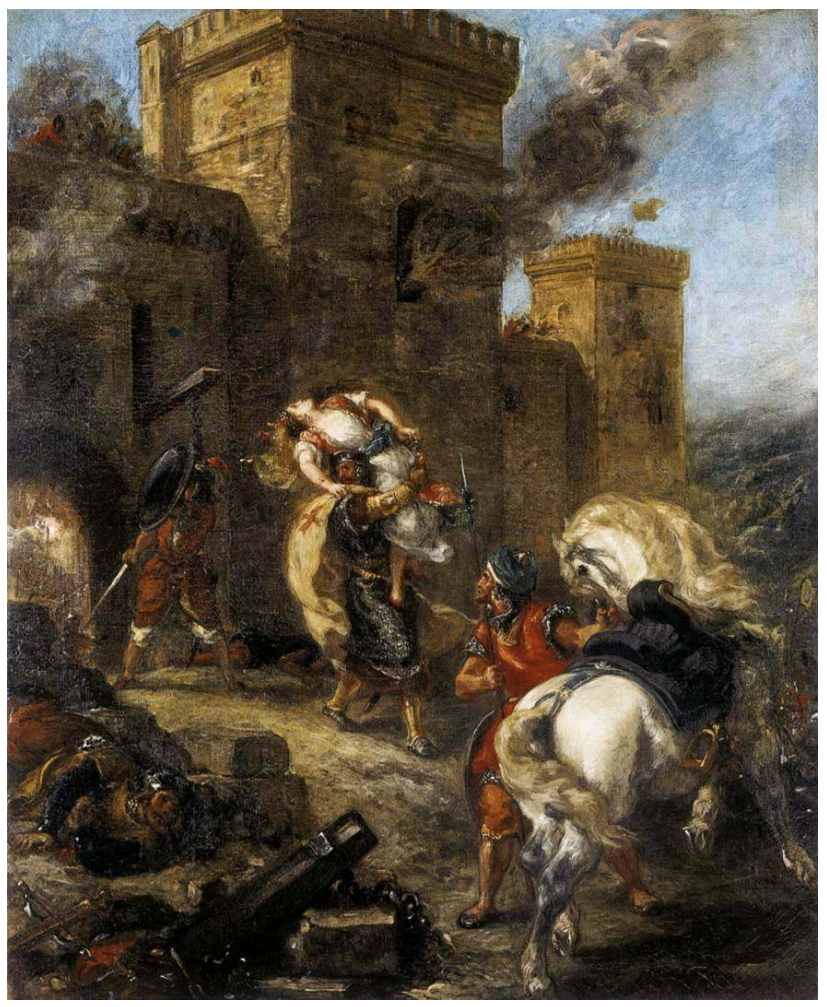

1846, huile sur toile, 105x 81 cm, Paris, musée du Louvre. 
11. Eugène Delacroix, Les Adieux de Roméo et de Juliette [Roméo et Juliette devant le tombeau des Capulet]

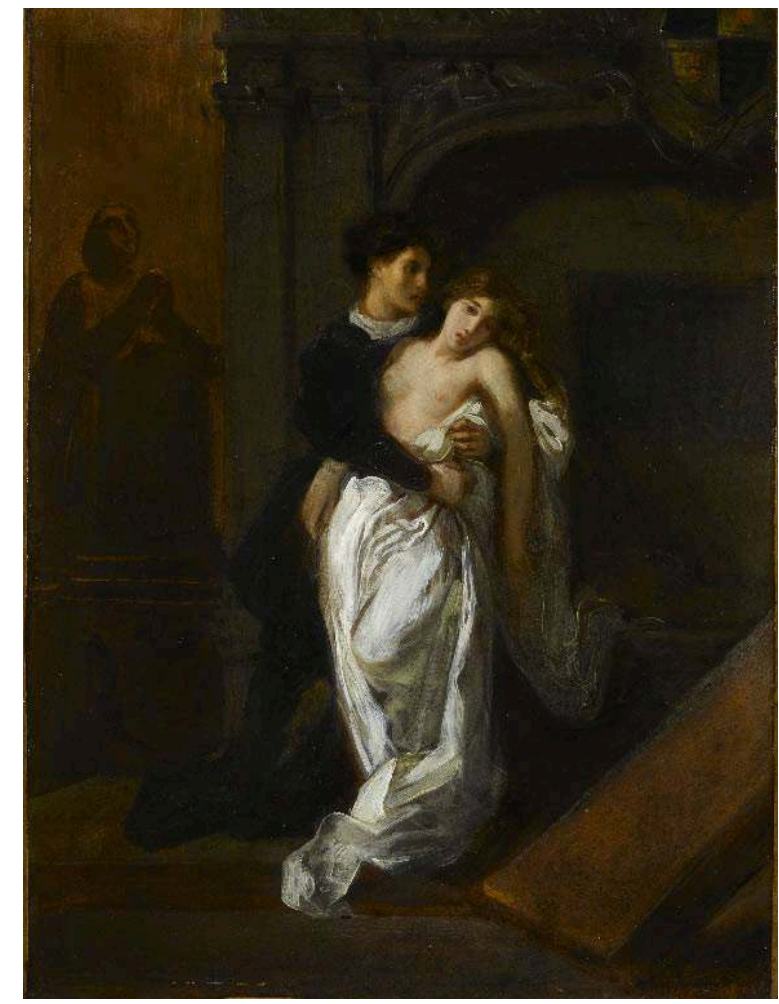

1846, huile sur papier, 35,2 × 25,5 cm, Paris, musée Eugène Delacroix.

11 Je vous parlerais bien encore des trois tableaux de M. Eugène Delacroix, Marguerite à l'église (fig. 9), Le Sac du château de Front-de-Bœuf (fig. 10) et Les Adieux de Roméo et de Juliette (fig. 11), si je pouvais prendre sur moi d'admirer les œuvres de cet artiste ; mais, que voulez-vous? Où ses admirateurs voient de la couleur, du dessin, des groupes bien disposés, je vois des tons faux ; là où la tradition indique que doit être la beauté, je vois une inconcevable laideur; et des compositions hardies comme les créations du cauchemar... Je prends donc le parti du silence. 


\section{« Deuxième article » (mai 1846)}

Journal des demoiselles, nº 5, mai 1846, $14^{\text {e }}$ année, 3 e série,

p. 153-156.

\section{Édouard Dubufe : Le Prisonnier de Chilon ; La Multiplication des pains}

12 Ces deux tableaux annoncent de la part de M. Dubufe des études sérieuses et un sentiment dramatique, caractère distinctif de la peinture moderne, où le drame et les effets de lumière qui le mettent en relief, préoccupent beaucoup plus les artistes que la forme et la couleur.

\section{$\mathrm{M}^{\mathrm{me}}$ Fanny Geefs : La Vierge consolatrice des affligés}

La reine du ciel s'avance dans toute sa gloire. Au-devant d'elle se pressent les veuves, les orphelins, représentés par des jeunes femmes que les pleurs n'ont pas encore flétries, et des petits enfants aussi beaux que les chérubins qui servent de cortège à Marie. Un guerrier vaincu vient aussi lui demander des consolations; un vieillard le soutient d'une main, et de l'autre implore la protectrice des affligés. Un autre vieillard traîne une chaîne et un boulet... Celui-là pourrait bien dire son Ave Maria aux galères... Mais il n'y a pas beaucoup souffert, car il est encore frais et vigoureux.

14 Cette grande page, d'un aspect très brillant et d'une composition plus vaste que celles auxquelles les femmes se livrent d'ordinaire, a l'éclat et le fini que recherchent les peintres belges ( $\mathrm{M}^{\mathrm{me}}$ Geefs est de Bruxelles.) Toutes les figures, et il y en a beaucoup, sont belles ou jolies... Mais je ne trouve pas qu'elles aient l'expression suprême que réclame un tel sujet.

\section{Biard : Le Droit de visite}

15 C'est à tout prendre une bonne chose que ce droit de visite dont on a tant parlé; il conduit de nos braves marins à délivrer toute une cargaison de nègres que l'on allait vendre aux colons, sous le titre frauduleux de marchandises quelconque. On les tire de l'entrepont où ils étaient entassés; les uns en se voyant libres se livrent à des joies insensées, les autres à des menaces terribles; une femme embrasse son mari avec une touchante effusion de bonheur; des enfants pressent dans leurs bras leur mère mourante. On va sans doute déposer ces infortunés sur la côte la plus voisine, où ils seront libres... De mourir de faim, si toutefois leurs aimables compatriotes ne les mangent pas, faute de pouvoir les vendre de nouveau... Mais espérons que, sauvés d'un malheur, ils ne retomberont pas dans un autre.

\section{Biard : Les Naufragés attaqués par un requin}




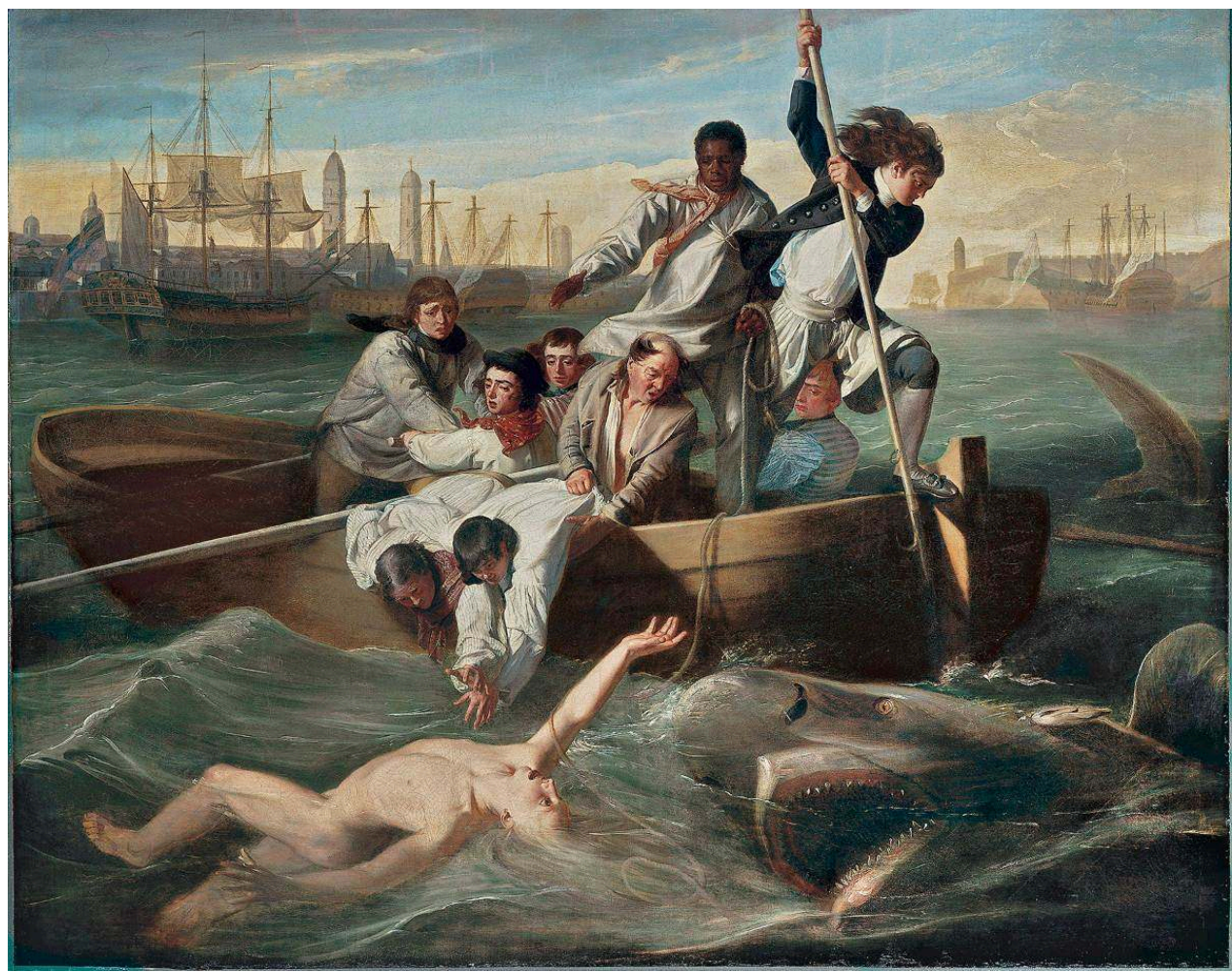

1846

16 Je ne vous parlerai pas de ce tableau, l'artiste ayant permis que l'on vous en donnât une esquisse dans ce journal (fig. 12).

\section{Biard : La Jeunesse de Linnée}

17 Linnée, pauvre enfant, avait la tête si dure pour apprendre à lire, que le maître d'école du village conseilla à son père de lui faire enseigner un état mécanique. On le mit chez un cordonnier, qui ne put lui apprendre à faire un soulier ; on le plaça domestique chez le docteur Rothman, qui se faisait accompagner par lui dans ses herborisations, et l'enfant prétendu stupide devint le premier législateur non seulement de la botanique, mais encore de toutes les sciences naturelles. Ce vieux docteur assis au bord d'une forêt, Linnée debout près de son maître étudiant une fleur, forment un tableau charmant.

18 M. Biard excelle encore dans les scènes grotesques qui l'ont rendu populaire et retiennent la foule devant ses cadres. [...]

\section{Claudius Jacquand : La Prise de Jérusalem par les Croisés}

19 Jérusalem sera bientôt au pouvoir des chrétiens (fig. 13), 


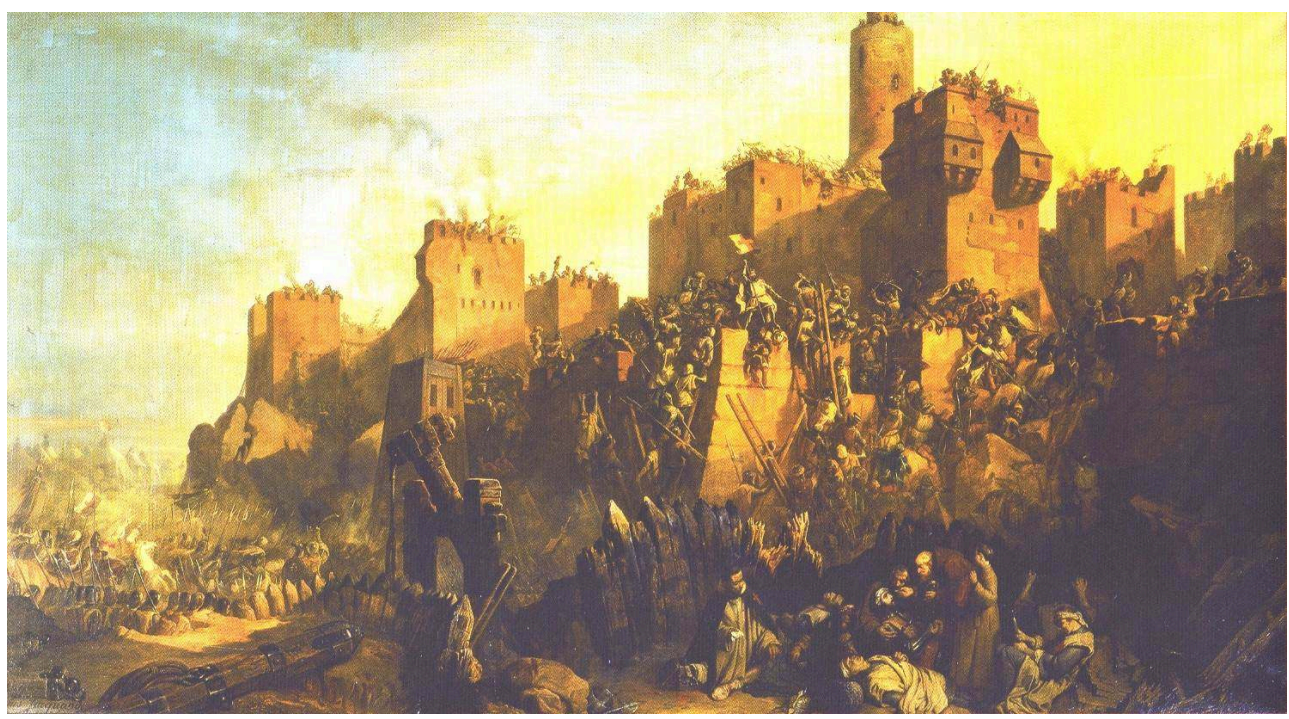

1846, huile sur toile, $173 \times 315$ cm, Versailles, musée national des châteaux de Versailles et de Trianon.

les palissades ont été forcées, le premier rempart est escaladé ; Jacques Molay, grand maître des Templiers, plante l'étendard de la croix sur un bastion; les musulmans éperdus courent à la défense des derniers remparts... Efforts inutiles! Le jour se lève à peine, et déjà ils sont à demi-vaincus. Ce tableau, destiné pour les galeries de Versailles, sera l'un des meilleurs de cette vaste collection.

\section{Claudius Jacquand : Les Orphelins}

Trois pauvres enfants sont chassés de leur demeure par un propriétaire impitoyable ; la fille aînée, protectrice maternelle de son petit frère et de sa jeune sœur, a à peine quinze ans; elle est bien belle! Mais la douleur vieillit vite! Cette charmante enfant se souviendra du noble père dont l'épée et le portrait sont l'unique héritage des orphelins, et elle ne fera rien d'indigne de lui. Vous verrez, mesdemoiselles, une esquisse de ce charmant tableau dans votre prochain journal, et votre attendrissement se mêlera certainement à nos éloges.

\section{Paysages, animaux}

Examinons maintenant les paysages. Nos artistes ont exposé des tableaux traités avec leur talent accoutumé, et chacun dans le système qu'il a adopté; car il ne faut pas croire que la nature soit vue du même œil par tout le monde : chaque peintre la voit et l'exprime à sa manière, et ce qu'il y a de plus étrange, c'est qu'il s'en trouve qui ne la voient pas du tout. Boucher refusait positivement d'aller étudier le paysage hors de Paris, et n'admettait que des arbres bleus et des ciels orange. Il me semble que M. Corot doit aussi tourner la tête de l'autre côté quand il voit un chêne ou un peuplier, et courir s'enfermer bien vite dans son atelier pour élaborer ses étranges productions. Messieurs Buttura, Desgolfe, Flandrin, donnent à la nature un aspect solennel; vous ne retrouverez jamais sur leurs toiles de ces bons petits paysages sans façon, qui commencent, au bord du cadre, par une mare couverte de canards, et finissent par une 
rangée de meules de blé, dans les gerbes desquelles se jouent les rayons du soleil. Ces artistes n'estiment que les montagnes imposantes, les belles ruines, les rochers et les arbres centenaires. Le jour, même, prend toutes sortes de précautions pour éclairer, selon les règles de l'art, ceci et pas cela. Franchement j'aime que la science se montre moins dans un tableau de paysage ; elle m'empêche de respirer librement, et je préfère me sauver à travers la campagne avec messieurs André Giroux, Christian Brune et tant d'autres qui évitent le style guindé du paysage historique.

\section{Auguste Lapito : Vue prise dans la forêt de Fontainebleau}

Nos paysagistes ne se repentent jamais de demander des inspirations aux sites de la France; la forêt de Fontainebleau vient de fournir à M. Lapito le sujet d'un superbe tableau : ce lieu, appelé Les Quatre Fils Aymon, a un aspect sauvage et grandiose ; une épopée du temps de la chevalerie a dû se passer là. Ce sont peut-être ces géants bardés de fer, lesquels voyageaient à quatre sur un seul cheval, qui ont ouvert cette route en brisant les roches dont les quartiers gisent çà et là.

\section{Mlle Rosa Bonheur}

On disait autour de moi que cette demoiselle compte à peine dix-huit ans, et cependant son talent est arrivé à sa maturité ; ses cinq tableaux représentant des animaux sont, sans contredit, les meilleurs du Salon; et celui où se voit un troupeau cheminant, mérite toutes les admirations possibles. Il y a là cinquante bêtes s'avançant par un sentier raboteux au-devant du spectateur. Ce troupeau, vu en raccourci, est serré, pourtant chaque bête se distingue des autres; le soleil glisse sur ces épaisses et graisseuses toisons ; ces têtes se soulèvent comme pour chercher de l'air et reconnaître la route. Il semble entendre les bêlements interrogatifs qui se répandent comme des échos. Les moutons marchent au pas accéléré, sans s'arrêter ni flâner. Pauvres créatures qui n'ont ni l'énergie qui prend l'initiative, ni la résignation que donne la confiance, et auxquelles $\mathrm{M}^{\mathrm{me}}$ Deshoulières n'a pas craint de dire : «Petits moutons, que vous êtes heureux ! » Heureux ! Entre le bâton du berger, la dent du chien et le couteau du boucher... Quelle cruelle raillerie !

\section{Charles Béranger : Animaux et Intérieurs}

Ce sont des délicieux chiens que ceux de M. le marquis d'Hertford; on conçoit qu'il y ait pour de telles bêtes des sièges de soie, des tapis de Turquie, un historiographe et un peintre. Merry, Fury, Duke sont deux Kings'Charles et un Stuart pur sang. Les premiers noir et feu, et l'autre feu et blanc. Tous les trois ont de longues soies, des oreilles qui touchent la terre, des queues comme des écureuils, des mines renfrognées, avec la truffe d'un noir pur; enfin des amours de chiens, gros comme le poing, et qui s'ébattent à l'aise sur un fauteuil de damas gris et cerise.

\section{Alfred Dedreux : Chasse anglaise}

Ceux-ci sont grands, vigoureux, bien découplés ; ils courent, ils crient, ils vont forcer à la course un pauvre renard qui ne saurait leur échapper plus longtemps. Cette meule 
est vive, animée; elle a du mouvement, de la vie; le dessin en est ferme, la couleur solide. La Chasse anglaise est à mon gré le meilleur des six tableaux de M. Dedreux.

\section{Alfred Dedreux : Étude de chiens}

Cependant je dois convenir que j'ai sympathisé avec la tristesse de ces deux autres chiens, un braque et un griffon; qu'ont-ils pour se tenir mélancoliquement assis, côte à côte, sur la paille du chenil ? Je l'ignore... Mais je me suis sentie toute prête à partager leur sombre chagrin, que ce soit la perte de la liberté ou la faim qui les fasse pleurer.

$M^{\text {me }}$ Alida de Savignac

\section{ANNEXES}

Lire des articles d'Alida de Savignac sur le Salon de 1837 parus dans le Journal des demoiselles

Lire des articles d'Alida de Savignac sur le Salon de 1844 parus dans le Journal des demoiselles

Lire l'introduction à Alida de Savignac écrite par Amandine Gorse 
Johanna von Haza (1794 - 1849) 


\title{
Introduction
}

\author{
France Nerlich
}

1 L'historiographie n'a retenu de Johanna von Haza qu'une vision morcelée, éclatée, qui correspond assez bien au caractère erratique de sa biographie et de sa carrière. Née en 1794 dans une famille aristocratique polonaise, elle grandit dans l'effervescence du milieu intellectuel, littéraire et musical de Dresde et Weimar sous la tutelle de son précepteur Adam Müller, grand théoricien politique du romantisme, promoteur de la littérature et de la poésie contemporaine, et rédacteur de la revue littéraire Phöbus. Il est probable que Johanna ait été marquée à cette époque par la lecture de Corinne ou l'Italie de Germaine de Staël à qui Müller consacra plusieurs articles et qu'il rencontra à Dresde en mai 1808. L'impossibilité pour la femme de génie de trouver une place dans la société contemporaine devient en effet un leitmotiv de la réflexion de Johanna von Haza qui allait elle-même mener une existence indépendante et itinérante à travers l'Europe.

2 Très liée à la famille de Goethe dont elle se revendiquait la fille spirituelle, elle évolua dans le cercle intellectuel «féminin » d'Ottilie von Goethe, mais aussi dans le milieu savant et littéraire de Dresde, Leipzig, Weimar, Paris, Londres, etc. Tout d'abord établie en Saxe, elle collabora à différentes revues avec des articles sur la musique, la littérature ou l'art de son temps sous le pseudonyme masculin de Heinrich Paris. Mais son horizon était déjà européen : elle recommandait ainsi des poètes français comme Charles Nodier au public allemand, collaborait à l'Encyclopédie des gens du monde de JeanHenri Schnitzler pour faire connaître des comédiennes allemandes aux Français, et élaborait un système didactique expérimental pour l'enseignement de la grammaire française dans un ouvrage financé par la duchesse d'Orléans. Très clairement, Johanna construisit sa carrière dans une dimension transnationale, s'établissant en France, en Suisse ou en Angleterre, signant ses publications tour à tour Heinrich ou Henri Paris, selon qu'elles paraissaient en allemand ou en français, se servant de recommandations d'amis français pour entrer en relation avec des intellectuels anglais. De fait, ses lettres révèlent un caractère intrépide, un humour caustique et une très grande lucidité sur les rouages du monde éditorial.

3 Alors qu'en Allemagne la plupart des comptes rendus d'exposition étaient encore publiés dans la presse, Johanna mit toute son énergie à publier ses Premières Impressions d'un dilettante [...] en un volume autonome. Publiés un an plus tôt, ses commentaires 
ironiques des tableaux de Düsseldorf exposés à Dresde (HAZA 1837) avaient agacé l'historien d'art Franz Kugler par leur outrecuidance à l'égard des grands noms de l'époque. C'est qu'en effet Johanna von Haza ne voulait pas soumettre son jugement aux autorités établies, mais porter sur les œuvres un regard spontané et sensible, plus proche du public que des érudits autoproclamés. Ce postulat de naïveté est - aussi dans sa dimension ironique et polémique - un héritage de la culture critique romantique, mais Johanna von Haza doublait sa réflexion sur la perception subjective et collective d'une réflexion sur la signification sociale des œuvres. Il était impossible pour elle d'oublier face aux œuvres ce qui se passait dans le monde. Aussi le commentaire consacré au Marché aux esclaves sur la côte-d'Or africaine de François Auguste Biard (1835, Hull, City Museums and Art Galleries, Wilberforce House) dépassait-il le seul commentaire esthétique pour s'interroger sur la condition des esclaves «blancs » dans les sociétés dites civilisées. Le conflit entre idéalisme esthétique et lucidité sociale qui s'exprime dans son discours traduit une forme de désenchantement postromantique. Quelques années plus tard, Johanna allait approfondir son constat de l'aliénation des femmes en réagissant à la naïveté des utopies émancipatrices saint-simoniennes (HAZA 1844). En attendant, son compte rendu de la première exposition de la Société d'art de Leipzig de 1837 participait à la fois de l'émergence du genre de la critique d'art autonome en Allemagne et de la transgression de ses codes par l'introduction d'une réflexion sociale sur l'art.

\section{BIBLIOGRAPHIE}

HAZA 1837

Johanna von Haza, Kreuz-und Quergedanken eines Dresdener Ignoranten vor den Düsseldorfer Bildern, Leipzig et Dresde, 1837.

HAZA 1844

Johanna von Haza, alias Heinrich Paris, Éphémères rhénanes, feuilles volantes, Strasbourg, G. Silbermann, 1844.

HEYTER-RAULAND 1997

Christine Heyter-Rauland, ,Jeannette von Haza alias Heinrich (Henri), Paris, Erste Spuren einer Mitarbeiterin von Gottfried Webers Cäcilia“, dans Axel Beer, Christina Pfarr et Wolfgang Ruf (éd.), Festschrift Christoph-Hellmut Mahling zum 65. Geburtstag, Tutzing, 1997, p. 553-560.

NERLICH 2010

France Nerlich, La Peinture française en Allemagne, 1815-1870, Paris, 2010, p. 155-160.

REUSS et STAENGLE 2003

Roland Reuss et Peter Staengle, ,,Das Schöne gehört jedem...' Zwei bisher unveröffentlichte Kleisthandschriften aus Kleists Dresdener Zeit", Berliner Kleist-Blätter, 2003, Bd. 15, p. 17-28. 


\section{ANNEXES}

Lire les extraits des Premières Impressions d'un profane à l'exposition d'art de Leipzig de l'automne 1837 de Johanna von Haza

Liste complète des œuvres d'arts commentées par Johanna von Haza à travers ses textes édités dans Plumes et pinceaux 


\section{Johanna von Haza, Premières Impressions d'un profane à l'exposition d'art de Leipzig de l'automne 1837}

[Heinrich Paris], Erste Eindrücke eines Laien auf der ersten Leipziger Kunstausstellung im Herbst 1837, Leipzig, 1838, extraits choisis. Traduction : Évelyne Sinnassamy depuis l'allemand

\section{Premier extrait}

Ce n'est que lorsque la bestialité tente de faire figure d'humanité, ou même de se faire admirer comme geste humanitaire, qu'il n'est plus possible de la passer sous silence ; et cela m'amène donc enfin à un tableau de cette exposition dont on a beaucoup parlé, dans lequel le bestial et l'humain sont mêlés de la façon la plus baroque et ironiquement sentimentale qui soit, raison pour laquelle il n'a pas manqué de provoquer toutes sortes de querelles critiques chez les belles âmes et les esprits forts: je parle du Marché aux esclaves sur la côte d'Or africaine de Biard à Paris, cette véritable pièce à effet française dans le style des mélodrames de potence et de galère de la porte Saint-Martin, devant laquelle, comme devant ceux-ci, tour à tour on se réjouit de l'art qui s'y dévoile indéniablement et on s'irrite de cette dépense artistique monstrueuse et inutile à travailler et à s'épuiser à un objet pourtant si totalement contraire à toutes les lois de l'art. 


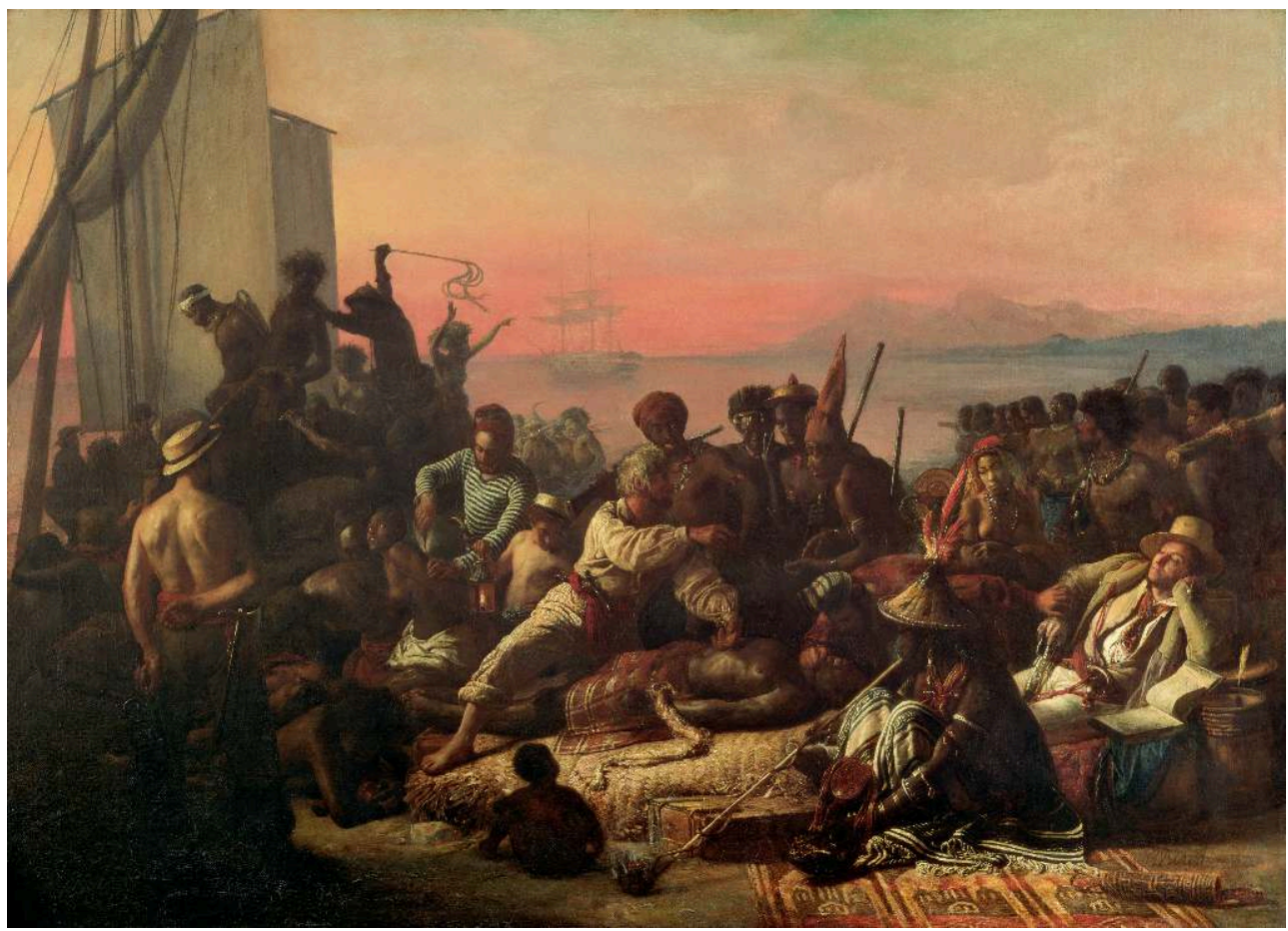

1835, huile sur toile, 162,5 × 228 cm, Wilberforce House, Hull City Museums and Art Galleries.

2 Ce tableau m'a montré à nouveau très clairement la confusion tragicomique des idées qui est le signe caractéristique de notre temps; et de ce point de vue, c'est à travers l'effet que je l'ai vu faire sur de nombreux milieux qu'il est devenu pour moi encore plus intéressant qu'à travers celui qu'il a produit sur moi-même.

3 Je ne fais pas partie de ces âmes belles ou libérales qui s'extasient devant le tableau de Biard, ni de ces esprits forts ou libres sous lesquels on m'a fait quelquefois l'honneur de me ranger; mais je fais partie tout simplement de ces personnes ingénues et un peu vieux jeu à qui tout ce qui est laid répugne, et en premier lieu tout ce qui est moralement laid, qu'il soit peint ou réel; et c'est pour cela que j'avoue que cette satire infernale du génial - comme on ne peut certes le nier - Apelle des nègres me fait véritablement horreur ; que j'y trouve quelque chose de blasphématoire, contre Dieu et l'humanité, contre l'art qui est aussi quelque chose de divin, et le bon goût qui est aussi quelque chose d'humain, et que dans cette horreur, rien d'autre de piquant ne m'est apparu que la malice méphistophélique du peintre que je crois deviner là-dedans, car il nous laisse, très rusé, complètement dans le doute: veut-il se moquer davantage des belles âmes, des âmes libérales pour lesquelles il peint leurs protégés ${ }^{1}$ noirs comme s'ils n'avaient jamais été des êtres humains, ou des esprits libres, des esprits forts pour lesquels il peint les prêtres de leur déesse, l'industrie vendeuse d'âmes, comme s'ils avaient depuis longtemps déjà cessé d'être des humains?

4 Car qu'on examine pourtant seulement en réalité le tableau avec précision : ne porte-til pas tout à fait la marque d'une mystification diaboliquement humoristique ? Mais au cas où cela n'aurait pas été l'intention de l'artiste, on devra cependant du moins admettre qu'il s'est trompé de la plus étrange façon dans le choix de ses moyens.

$5 \quad$ Il voulait peindre en quelque sorte un plaidoyer ${ }^{2}$ politique et philanthropique et mettre avec beaucoup d'insistance sous les yeux des Européens toute l'abomination du 
commerce des esclaves, dit-on ; et alors naturellement les amis extrémistes de la liberté se croient obligés au nom de leur parti de tomber dans l'extase libérale artistique indispensable devant ce noble début. Mais s'ils n'étaient malheureusement pour la plupart trop jeunes pour savoir ce qui s'est passé il y a quelques décennies plus tôt dans leur pays, ils pourraient se souvenir que leur compatriote Kotzebue, avant d'être poignardé en l'honneur de la liberté, et avant même que le libéralisme fût inventé, avait déjà réalisé une noble œuvre d'art analogue, et écrit, il y a déjà quarante ans, une pièce philanthropique, intitulée Les Esclaves nègres, qui ne le cède pas le moins du monde en noble et sentimentale laideur au tableau biardais. En ce temps-là cependant, les critiques étaient si arriérés dans la culture qu'ils n'approchaient pas une œuvre d'art au nom de la politique, mais uniquement au nom de l'art; et l'un d'eux qui en ce temps-là passait pour assez compétent en esthétique, à savoir Schlegel, fit contre les esclaves nègres de Kotzebue le distique suivant :

"Chassez vite du théâtre à coups de fouet les esclaves nègres,

Sinon ce sont tous les sentiments qu'on vous fouettera à coups d'orties ${ }^{3}$. »

6 J'aurais aimé appliquer cette vigoureuse expression, un peu barbare certes, mais excellente, au tableau biardais; car il m'a vraiment presque semblé que de telles créatures grotesques, simiesques, qui - telles que le peintre les a arrangées ici pour nous, ne font que caricaturer la forme humaine -, ne peuvent être destinées à rien d'autre en ce monde qu'à être fouettées. À qui peut-on demander de ressentir de la pitié quand il n'éprouve que du dégoût? Veut-on me faire croire que cet être grimaçant de toutes ses dents que l'on marque au fer soit une femme avec des sentiments féminins, que cet autre, à la semblance d'un homme, que l'on étend sur la natte, soit autre chose qu'une bête de somme à qui compter les dents doit ne m'apparaître que comme une action toute naturelle? Dans ce monstre ébouriffé qui se penche sur un petit monstre noir tout aussi répugnant, dois-je reconnaitre la douleur maternelle ? Il y a dans toutes ces figures qui ressemblent à des orangs outangs quelque chose de si déformé, de si exagéré, quelque chose de si absolument animal que l'intention prétendument philanthropique de l'artiste se perd complètement; qu'involontairement on se réconcilie presque avec le trafiquant d'hommes blanc, et qu'on trouve son impassibilité presque normale, puisque tout ce transport de marchandises vivantes qu'il passe en compte et embarque fait vraiment plutôt l'effet d'une ménagerie que d'une troupe d'hommes maltraités ; car jamais au grand jamais les nègres n'ont dans la réalité ressemblé à ces fantômes d'un vert moisi que noirs qui évoquent l'enfer de Dante.

7 Mais le plus méphistophélique dans la composition est sans conteste la représentation des vendeurs noirs de leurs propres frères, dont le spectacle révoltant détourne le dégoût que devraient inspirer les vendeurs blancs presque totalement de ces derniers et le dirige uniquement sur le digne chef noir qui, assis là devant cette scène affreuse avec un calme encore plus inhumain si possible que l'Européen déshumanisé, lave ainsi ce dernier en quelque sorte de tous ses péchés; car là où les gens vendent eux-mêmes les leurs et où les gens se laissent vendre par les leurs, quelle que soit l'horreur qui en résulte, on peut seulement dire : Tu l'as voulu, Georges Dandin ${ }^{4}$ : et lorsque par exemple on vendait encore des soldats allemands en Amérique, il ne venait au moins à l'idée de personne de bon sens de ne rejeter l'opprobre de ce commerce que sur ceux qui les payaient. 
8 D'ailleurs, je suis certainement un aussi vif ennemi de l'esclavage que les admirateurs de Biard; mais j'aime bien qu'on reste conséquent dans ses sentiments. Et enfin, puisque ce tableau a été pour ainsi dire élevé au rang d'une leçon de morale, je souhaiterais au moins maintenant aussi, pour le bien et l'intérêt de l'humanité, qu'un peintre de génie surgisse très bientôt sur Haïti pour donner une fois aux nègres, comme pendant, un tableau analogue du commerce d'esclaves auquel, sur nos côtes d'Europe, nous nous livrons quotidiennement avec nos prétendus hommes libres, et qui dans la chose même ne me semble pas bien différent, même si nous en varions un peu assurément la forme; oui, qui est même sûrement, dans une infinité de cas, encore infiniment plus dur pour ses victimes, parce que les souffrances morales de l'homme cultivé pénètrent toujours plus profondément que les souffrances plus physiques de celui qui vit dans l'état de nature ; car nous oublions toujours qu'avec nos exclamations humanistes nous lui supposons souvent des sentiments qu'il ne connaît pas du tout, et lui attribuons des humiliations qu'il ne peut pas du tout ressentir parce qu'il ne sait encore rien de nos besoins artificiels et de nos ambitions factices.

Qui de nos jours est déjà suffisamment vieux pour se souvenir de la gaieté sincère et de la joie exubérante des paysans européens d'autrefois, serfs et vilains, lors de leurs jours de fête, et pour les comparer avec les visages mécontents et moroses des "citoyens " actuels des classes inférieures abandonnés à eux-mêmes et à leur immaturité intellectuelle, court bien trop facilement le risque de presque se consoler devant les noirs de Biard avec cette pensée très peu libérale : « S'ils sont bien nourris la semaine par un maitre qui doit les entretenir et qu'ils ont le droit de danser librement le dimanche, ils ont finalement une vie encore plus supportable que ces esclaves blancs de la civilisation européenne qui au nom de la liberté et de l'honneur périssent dans la misère ou le crime, mais qui, s'ils vivent assez à l'aise pour pouvoir se divertir, ont besoin auparavant pour cela aussi d'une licence de la police. »

10 Sous combien de nombreuses variations un peintre ou un poète haïtien pourrait peindre à ses libres compatriotes noirs cette espèce d'esclave blanc! On a voulu affirmer que l'artiste français aurait immortalisé son propre portrait dans le marchand d'esclaves blanc; cette idée a souvent fait naître en moi, quand je me tenais devant le tableau, les plus étranges visions; il me semblait alors que le peintre regardait vraiment à travers le tableau ; comme si, confortablement étendu derrière son image, il laissait le public passer en revue devant lui; mais ensuite j'avais l'impression de l'entendre, avec sa physionomie impitoyable de Méphistophélès, apostropher les élégants spectateurs et spectatrices aux nerfs fragiles à peu près ainsi :

11 «Vous voyez ici, ô cœurs sensibles, une image fidèle de l'état de choses (comme vous avez coutume de vous exprimer selon la dernière mode) qui s'ensuit là où le faible doit servir le fort, l'idiot l'intelligent, le pauvre le riche, et où, conformément à votre religion actuelle, l'industrie, l'être humain n'est plus traité et évalué que comme machine de travail.»

12 « Regardez s'il vous plaît autour de vous, et ce spectacle cruel que j'ai pu vous montrer dans cette terre tropicale sauvage sous une forme unique bien établie, vous le reconnaîtrez tout près de vous, grâce à votre civilisation, dans les nuances les plus variées. [...]» 


\section{Deuxième extrait}

p. 27-32

"Vous soupirez, ô très chers, parce qu'au sucre et au café (dont vous ne voudriez pourtant pas vous passer) collent la sueur et les larmes de tant d'esclaves nègres. Cependant vous ne mangez pas une bouchée, vous n'enfilez pas un vêtement, vous ne lisez pas un journal, où ne s'accrochent pas tout autant de sueur et de larmes des esclaves blancs qui vous entourent, et dont je pourrais multiplier l'énumération par dix, oui, par cent !»

«Car qui compte d'abord toute la douleur intellectuelle qui s'enfonce tout au fin fond de l'âme plus profondément que le fer dans le dos du nègre, que les conditions sociales issues de votre civilisation imposent aux esclaves cultivés de la société européenne? »

« Mes noirs sont-ils plus affligeants à voir que ce sombre personnage pitoyable, maigre et blême, détonnant comme Don Quichotte au milieu des paysans de la noce bien nourris aux joues rouges, et qu'on appelle Monsieur le maître d'école - c'est sa seule gratification pour le sort affreux, bon an mal an, d'enseigner l'alphabet à la prometteuse jeunesse du village pour trois ou six pfennigs par tête et une saucisse au Nouvel An? Ou que le prédicateur de village qui a dû apprendre le grec et le latin et suivre une formation érudite pour, dans une Sibérie quelconque cachée dans la montagne ou la forêt, renoncer à nouveau à toute nourriture spirituelle parce qu'il peut à peine payer celle du corps qu'il doit péniblement collecter pour ainsi dire par portions auprès de ses ouailles? Ou que le professeur de leçons particulières qui a dépensé son petit capital pour des livres, des partitions ou des cartes, afin de les prêter à ses riches élèves qui n'ont pas envie de les acheter, et qui, courant de maison en maison, ne touche peut-être de leur part pour une heure d'enseignement intellectuel qu'autant que le pourboire qu'il doit glisser dans la main de leurs domestiques qui l'éclairent dans l'escalier, quand il a eu l'honneur d'être prié à un dîner qui a coûté six ou dix fois le salaire mensuel pour ses heures, salaire qu'il attend pourtant peut-être par-dessus le marché depuis déjà des mois pour payer son aubergiste qui le lui réclame? Ou que le jeune artiste dont l'imagination ébauche peut-être des figures raphaéliques mais qui, pour avoir du pain, doit peindre le visage gras de la grosse boulangère qui le dimanche l'enveloppe dans la poussière de sa voiture quand il doit marcher humblement à pied à côté de la chaussée pour pouvoir respirer un peu de l'air pur et libre de Dieu? Ou que le jeune érudit qui porte peut-être dans la tête un futur monde de pensées, qui, rien que pour apprendre à le mettre au jour, doit chanter aux portes de la bêtise pour une aumône, manger une aumône aux tables de l'arrogance, et aux thés de la frivolité transcrire ou traduire pour des aumônes les mauvaises pensées des autres, et pour enfin donner au monde ses propres bonnes pensées, doit en faire cadeau à un riche protecteur littéraire dans l'espoir de gagner après coup grâce à une seconde édition la redingote qui le rendra digne de l'honneur de s'asseoir à la table garnie par le gain de la première ? Ou que la femme géniale à qui la nature a donné le talent d'écrire, de faire des vers ou de peindre mieux que cent hommes, mais à qui pourtant cent auteurs, poètes ou peintres sans talent interdisent d'écrire, de faire des vers ou de peindre, ou à qui n'est offerte pourtant, du moins de ceux qui l'admirent, pour ses belles œuvres à peine la moitié de ce que les cent reçoivent pour leurs mauvaises œuvres, juste parce qu'il plut à Dieu de loger le plus grand génie dans un corps de femme? » [...] 


\section{Troisième extrait}

"Mais qui, ô chers cœurs sensibles, pourrait entièrement énumérer ces légions d'esclaves que la civilisation européenne met sur le marché sous le nom pompeux d'épouses? Toutes ces jeunes filles en fleur inexpérimentées, innocentes, que la vanité et la cupidité de parents déraisonnables ont privées de leur jeunesse, de leur beauté, de leur santé et de leur tranquillité d'esprit pour en faire au sens le plus strict les serves de tous ces tyrans domestiques sans cœur, usés, desséchés et hypocondriaques, tous ces tyrans stupides, vicieux, grossiers et infidèles, parmi lesquels par parenthèse les libéraux défenseurs des droits de l'homme ont l'habitude de se trouver en première position comme les plus despotiques? Qui compte toutes ces victimes que vos lois et coutumes humaines forcent à sacrifier aveuglément liberté et volonté, désirs et inclinations, sentiments et pensées, relations et habitudes, en un mot leur moi tout entier, à chaque humeur de leurs maris grincheux, grognons et querelleurs, ou buveurs, joueurs et marchandeurs, et à qui, pour qu'elles ressentent encore plus sûrement leur soumission à la force brutale, vous, très chers, donnez encore avec le plus grand soin possible la plus tendre éducation et la formation la plus raffinée, juste pour ensuite ne leur tendre la plus haute couronne de la féminité que lorsqu'elles se sont rendues vraiment elles-mêmes esclaves absolues et se sont une fois pour toutes résignées à tout accomplir sans rien réclamer, à tout supporter sans rien répliquer, à voir tous les mauvais exemples sans en suivre aucun, et sereines et gracieuses, souriantes et sans broncher, à accepter tous les mauvais traitements quotidiens qui dans l'amour et dans la vie de famille blessent plus profondément et brûlent plus ardemment que tous les fers rouges et toutes les verges du marchand de nègres?!"

17 C'est à peu près ainsi, me semblait-il, que ce malin, le peintre parisien, pourrait nous adresser la parole. Et j'aimerais maintenant demander, puisque nous sommes tous, donc, qui nous tenons face à son tableau, des esclaves, ou que nous avons des esclaves, oui même, comme presque tous en même temps nous sommes des esclaves et avons des esclaves, pourquoi au fond nous faisons un tel théâtre sentimental devant ces esclaves nègres. Et qu'avons-nous à nous pavaner devant nous-mêmes avec nos beaux sentiments et nos nobles convictions, alors que nous n'avons pourtant pas d'autre différence à présenter dans notre mode d'esclavage que le fait que les blessures que notre arrogance embrase et que notre égoïsme inflige ne laissent pas sur la peau des victimes maltraitées leurs balafres et leurs cicatrices!

Du reste, du point de vue de l'art, il m'a semblé que régnait aussi dans l'exécution technique de ce tableau le même mélange bizarre de beau et de laid qui se manifestait déjà si désagréablement dans sa composition.

Si l'on veut peindre un jour la même horreur, on ne peut cependant guère mieux ordonner les groupes, guère mieux caractériser les différentes figures que comme c'est effectivement réalisé ici ; il y a aussi beaucoup de réussites vraiment excellentes dans les accessoires, les tapis, nattes et autres choses de ce genre. Tout aussi approprié pour la scène d'épouvante est l'éclairage rouge sang qui lui donne tout à fait quelque chose de démoniaque, d'infernal. Toutefois, cette pénombre comme voilée de brume dans laquelle tout le tableau est par ailleurs plongé, les tonalités jaune verdâtre et terre blême dans les carnations noires et blanches (si tant est qu'on puisse parler de 
carnation), la négligence plus que schématique avec laquelle sont peints les groupes éloignés, tout cela lui donne au contraire au fond plus le caractère d'une fantasmagorie lugubre; cela ressemble à un morceau de décor pour un opéra devant lequel on chante $\mathrm{Au}$ secours, Samiel; ou cela rappelle plutôt ce qu'on appelait d'ordinaire ombres chinoises ${ }^{5}$.

Doit-on peindre, du reste, je pose enfin la question, une horreur pareille? Peut-on vraiment avec bonne conscience appeler œuvre d'art une telle composition? Il me semble que jusque-là pourtant, depuis qu'on peint et qu'on sculpte dans le monde, on s'accordait à peu près pour dire que seul le Beau peut être l'objet de l'art. Donc un tableau qui s'est emparé uniquement de la laideur pour sujet, dans lequel il n'est pas un personnage qui réponde simplement à l'exigence la plus pressante de toute représentation plastique, à savoir une quelconque beauté physique, et encore moins le plus léger souffle d'une beauté morale, pour former au moins un contraste à la hideur accumulée, un tel tableau, d'autres peuvent le qualifier de chef-d'œuvre de la philanthropie ; quant à moi qui réclame certes la philanthropie chez le législateur, mais en revanche seulement le sens de la beauté chez l'artiste, je prendrai toujours la liberté de ne voir dans un tel tableau que le plus grand égarement de l'esprit de l'artiste et de plaindre l'imagination qui est capable pendant toute la longueur de temps que réclame l'exécution d'une telle œuvre de s'attacher fermement avec une telle passion à une telle masse de laideur.

\section{ANNEXES}

Lire l'introduction à Johanna von Haza écrite par Franche Nerlich

\section{NOTES}

1. (NdT) En français dans le texte.

2. (NdT) En français dans le texte.

3. Voir les porches et les arcs de triomphe de Kotzebue.

4. (NdT) En français dans le texte.

5. (NdT) En français dans le texte. L'expression souvent reprise plaisamment „Samiel, hilf!" ou „Hilf, Samiel!" est tirée du livret de Friedrich Kind pour l'opéra de Carl Maria von Weber Der Freischütz, 1821. 
Marie d'Agoult (1805 - 1876) 


\title{
Introduction
}

\author{
Charlotte Foucher
}

1 En 1841, le retour d'Ingres en France à l'issue de son séjour romain déclencha chez Marie d'Agoult (1805-1876), salonnière, écrivaine et plus tard historienne, l'envie de s'essayer à la critique d'art. C'est aussi à cette époque de remise en question personnelle - elle venait de se séparer de son mari et entretenait une relation houleuse avec le compositeur Franz Liszt - que Marie d'Agoult fut encouragée par Émile de Girardin à publier un article sur les fresques de Paul Delaroche, qu'elle refusa de signer de son vrai nom pour lui préférer le pseudonyme masculin de Daniel Stern. Elle choisit vraisemblablement ce prénom en souvenir de son fils Daniel mort à vingt ans, et Stern, qui signifie étoile en allemand, comme un hommage à ses origines maternelles et à son pays natal. Elle débuta donc sa carrière d'écrivaine par le journalisme en publiant sous ce pseudonyme, entre 1841 et 1842, trois articles dans La Presse qui alimentèrent le culte d'Ingres et de ses élèves. Si le premier asseyait la supériorité de son héros en portant un jugement sévère sur l'art de Delaroche, l'un de ses principaux rivaux, les deux suivants faisaient plutôt l'éloge de son style et de celui de ses suiveurs (Flandrin, Lehmann, Chassériau...). Les discours sur l'art de Marie d'Agoult révèlent aussi le statut d'une femme qui, loin de se cantonner au seul rôle passif de muse et de salonnière, faisait paraître ses articles dans un grand quotidien français pour qu'ils soient lus par un large public. De même, elle prit soin d'éviter l'écueil d'une réception stéréotypée de ses critiques, par le camouflage de ses identités de femme et d'amie du peintre. Dans ses articles, Marie d'Agoult fit preuve d'un jugement personnel acéré et argumenté. Elle affirma et assuma toujours clairement ses positions, qui convergeaient toutes vers la promotion de la supériorité de l'esthétique ingresque. Raillant son culte de l'artiste qui frôlait parfois le dithyrambe, une critique anonyme, publiée en 1842 dans le journal satirique du Charivari, stigmatisa, via la parodie, le discours de Marie d'Agoult sur le Portrait de Cherubini par Ingres; critique anonyme qui prétendait ainsi défaire une « mystification qui dur[ait] depuis trop longtemps » (Charivari 1842, p. 1-2).

2 Dans la seconde partie de sa vie, ses activités de critique d'art laissèrent progressivement la place aux essais philosophiques et aux ouvrages historiques et littéraires. Elle publia notamment en 1846 un roman semi-autobiographique intitulé Nélida (anagramme de Daniel...), histoire d'un peintre que l'inspiration abandonne à la 
perte de l'être aimé, puis, quatre ans plus tard, une Histoire de la Révolution de 1848 en trois volumes qui lui valut l'estime et le respect de tous.

\section{BIBLIOGRAPHIE}

Charivari 1842

Le Charivari, « Salon de 1842. Charge et portraits », 8 mai 1842.

COLOMBO 1997

Laura Colombo, Marie d'Agoult. Autoritratto di un intelletuale romantica, Reggio Emilia, Diabasis, 1997.

STOCK-MORTON 2000

Phyllis Stock-Morton, The Life of Marie d'Agoult, alias Daniel Stern, Baltimore/Londres, The Johns Hopkins University Press, 2000.

TINTEROW, HALE et BERTIN 2000

Gary Tinterow, Charlotte Hale et Éric Bertin, “'Portraits by Ingres: Image of an Epoch':

Reflections, Technical Observations, Addenda, and Corrigenda," Metropolitan Museum Journal, 2000, vol. XXXV, p. 193-219.

WALTON 2000

Whitney Walton, Eve's Proud Descendants: Four Women Writers and Republican Politics in Nineteenth Century France, Stanford, Stanford University Press, 2000.

\section{ANNEXES}

Diaporama des œuvres d'arts commentées par Marie d'Agoult dans les articles publiés pour La Presse :

http://www.flickr.com//photos/73632227@N02/sets/72157629965180948/

Lire des articles de Marie d'Agoult, alias Daniel Stern, parus dans La Presse

Liste complète des œuvres d'arts commentées par Marie d'Agoult à travers ses textes édités dans Plumes et pinceaux 


\section{Daniel Stern [Marie d'Agoult], La Presse, 1841-1842 \\ [extraits choisis]}

\section{« La nouvelle salle de l'École des beaux-arts peinte par M. Paul Delaroche » (12 décembre 1841)}

p. 1-2

1 En dépit des préoccupations de toute sorte, des affaires, des intrigues, des intérêts et des amusements qui, à cette époque de l'année, emportent comme l'ouragan les heures de la vie parisienne, en dépit de cette « Bufera... chi mai non resta ${ }^{1}$ »où tournaient tous les esprits, une œuvre d'art, depuis longtemps annoncée, a fixé l'attention du public, et le nom d'un peintre qu'il affectionne l'attire chaque jour au Palais des beaux-arts.

M. Delaroche est un homme heureux. Dès ses premiers pas dans la carrière, il a rencontré le succès. La foule, dont il a tout d'abord charmé les yeux, l'a suivi comme d'instinct. Il a captivé cette grande majorité que j'appellerais volontiers les esprits sensibles. Il les a émus doucement, ainsi qu'ils se plaisent à l'être. Il ne s'est jamais élevé à ces régions supérieures de l'idéal, où ne respirent que les fortes intelligences : il est resté dans une sphère intermédiaire de facile abord, de lumière tempérée. Il a peu regardé en lui ; jamais, on pourrait le croire, au-dessus de lui, mais beaucoup et avec intelligence, au-dessous de lui. Ainsi que M. Delavigne, auquel il est semblable par plus d'un côté, il a eu de prudentes hardiesses, des douleurs aimables, une pathétique bien ordonnée, et surtout cette vérité de convention qui séduit le goût des masses dans les temps de civilisation avancée. Pour dire enfin notre pensée en peu de mots, $M$. Delaroche a été, est et restera l'homme de son temps, mais seulement de son temps ; l'expression habile, ingénieuse, d'une société qui n'a plus les fortes croyances des âges primitifs, ni la sérénité de la civilisation grecque, mais où règnent en toutes choses, dans les sentiments, dans la pensée et dans les actes qui en sont le produit, une sorte de médiocrité distinguée, d'éclectisme timide, de convenance sans grandeur, que le langage politique de nos jours a caractérisée par un mot barbare. M. Delaroche est un talent de juste milieu. Il n'a reçu en partage ni le génie qui crée et se fait, pour ainsi dire, 
contemporain de l'avenir; ni le sens profond du beau qui a ramené en ces derniers temps plusieurs artistes au culte du passé. Mais en revanche, toutes les facultés qui y suppléent jusqu'à un certain point, la réflexion, la persévérance, l'esprit et le jugement, lui ont été donnés avec abondance. Pour composer son œuvre, il n'a pas contemplé la nature, mais il a étudié l'histoire ; il n'a pas inventé, mais il a bien choisi ; il a fait de la peinture agréable et charmante sans trop se soucier ni d'idéal ni de vérité. Il a réussi. Comment et de quel droit lui dire qu'il a eu tort?

\section{Paul Delaroche, L'Hémicycle de l'École des beaux-arts de Paris}

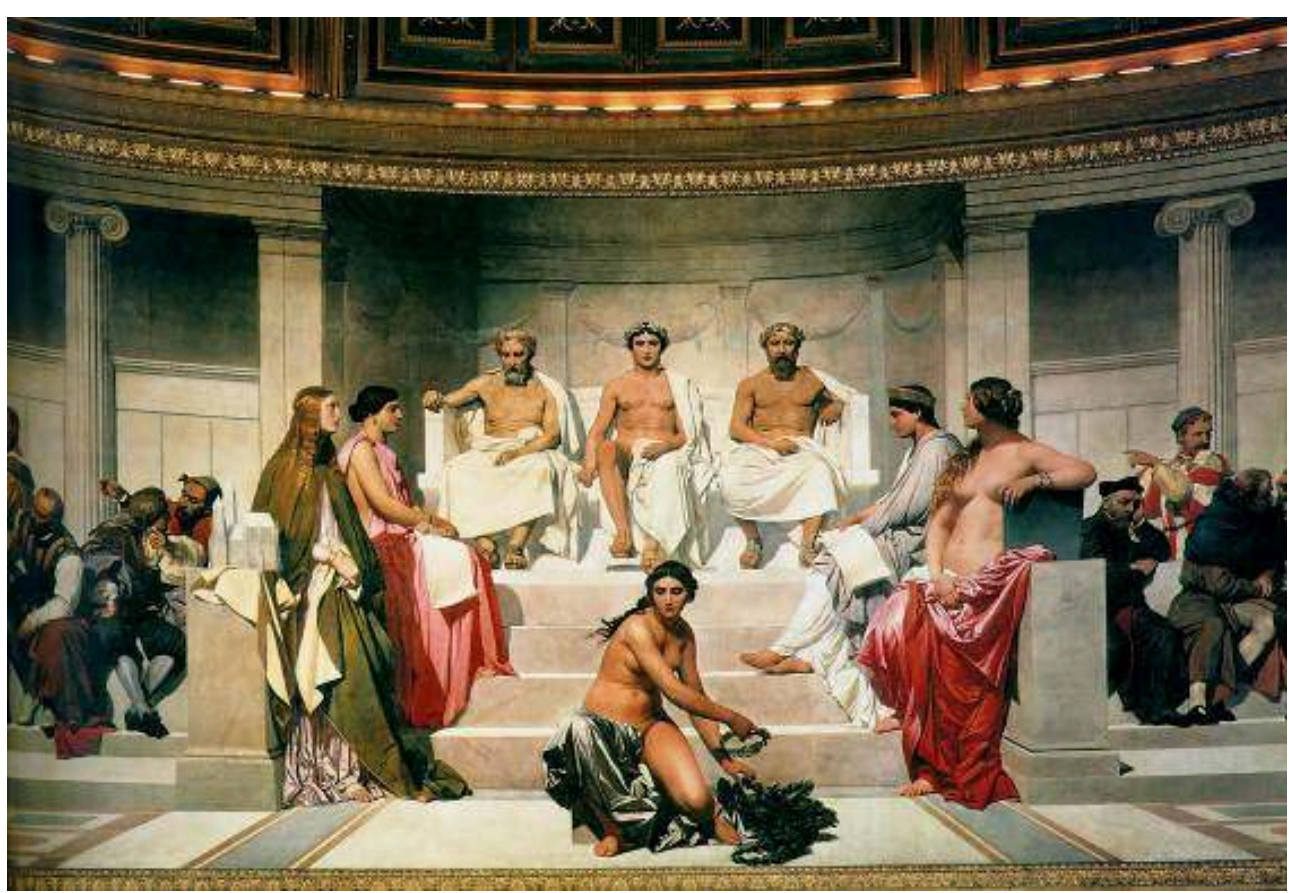

1836-1841, fresque, papier marouflé sur toile, Paris, École nationale des beaux-arts

3 La fortune que nous signalons dans la carrière de M. Delaroche l'a encore merveilleusement servi dans la circonstance présente. On lui a donné, pour y faire de la peinture monumentale, l'emplacement le plus propice: un hémicycle d'environ 45 mètres de long sur 4 de haut, admirablement éclairé par le jour qui tombe d'une demi-coupole et forme la décoration principale d'une salle située au fond de la troisième cour du Palais des beaux-arts (fig. 1). L'on y arrive déjà préparé au recueillement nécessaire pour contempler une œuvre sérieuse; on a traversé, en s'arrêtant souvent, trois cours de ce monument exquis dont toutes les lignes sont si harmonieuses et rappellent, sans imitation servile, les plus beaux édifices de l'Italie ; l'on est resté longtemps sous le gracieux péristyle orné des fragments antiques envoyés par M. Ingres; on a salué la Minerve grecque et ce torse de femme dont la délicatesse l'emporte peut-être encore sur la Vénus de Milo; enfin on se trouve en face de la composition de M. Delaroche et l'on en saisit du premier coup d'œil tout l'ensemble sur lequel descend une lumière égale et singulièrement favorable. On voit que toutes les conditions extérieures concourent à l'effet de la peinture et que le lieu n'eût pu être mieux choisi pour en rehausser le mérite.

4 Le sujet, à demi allégorique, semble avoir été, dans la pensée de M. Delaroche, une apothéose de l'art ou, moins ambitieusement, une distribution idéale de récompenses 
faites aux artistes modernes sous les auspices des grands maîtres de toutes les écoles. Voici quelle en est l'ordonnance: au centre du tableau, devant un édifice d'ordre ionique, sur trois fauteuils ou trônes sont assis Ictinos, Apelle et Phidias: le peintre, l'architecte, le statuaire. De chaque côté de ces trois personnages, mais sur un plan plus rapproché, sont quatre femmes figurant l'art à ses quatre périodes principales de développement: l'art grec, l'art romain, l'art au Moyen Âge et l'art à l'époque dite Renaissance. Au-devant de ces quatre figures, et tout près de la bordure du tableau, une jeune femme, assez peu caractéristique pour qu'on ne puisse deviner si ce doit être la Gloire, la Patrie, le Siècle, l'Opinion, est agenouillée auprès d'un monceau de couronnes et en lance une hors du tableau, vers le public. Ces huit figures principales forment le centre de la composition; elles en sont la partie mythologique et allégorique. Deux groupes très considérables occupent les deux côtés de l'hémicycle. À droite sont les architectes : Brunelleschi, Bramante, Erwyn de Steinbach, Sansovino, Palladio, Philibert Delorme, Mansart, etc., et les peintres qui, par l'élévation du style et leur tendance idéaliste, occupent le premier rang dans l'art. Là sont groupés Léonard de Vinci, Raphaël, Michel-Ange, Fra Bartolomeo, le Pérugin, Albrecht Dürer, Holbein, Orcagna, Giotto, Cimabue, Nicolas Poussin.

5 À gauche sont les sculpteurs: Puget, Benvenuto Cellini, Jean Goujon, Donatello, Ghiberti, Luca della Robbia, etc., puis les peintres des écoles naturalistes parmi lesquels se voient en première ligne Titien, Van Eyck, Giambellino [Giovanni Bellini], Paul Véronèse, Rubens, Murillo, Giorgione, Van Dyck, etc.

Dans ces deux groupes, M. Delaroche a montré son talent habituel et le genre de supériorité qu'on ne saurait lui contester. Il y a là de belles figures, des effets heureux, des détails exécutés avec une habileté rare, du mouvement, des costumes étudiés et reproduits avec une scrupuleuse fidélité historique. Un grave reproche à lui faire, c'est que la plupart de ses personnages sont représentés dans des attitudes trop familières pour une composition moins réelle qu'idéale, à laquelle président en quelque sorte trois grandes ombres du passé, et où le peintre fait intervenir des muses. Il eût fallu qu'une certaine tranquillité élyséenne, un calme presque surnaturel régnât dans tout le tableau. Des figures trop mouvementées, des lignes trop rompues, une trop grande profusion de couleurs forment un contraste fâcheux avec la solennité des figures antiques et le nu de l'allégorie.

7 Plusieurs des figures principales de ces deux groupes nous ont paru, il faut bien le dire, entièrement manquées. Qu'est-ce, par exemple, que ce Michel-Ange à l'air renfrogné, boudeusement assis, les mains sur les genoux ? Est-ce ainsi, sous ces traits mesquins, sous cet aspect de triviale mauvaise humeur, qu'on se représente le génie audacieux qui éleva dans les airs [sur le modèle de] la coupole du Panthéon [le dôme de Saint-Pierre de Rome] ? L'énergique vieillard qui faillit perdre la vue à peindre les colères divines ? Le puissant cerveau qui créa Moïse et la Pensiero ? Non, non; nous ne retrouvons point là ce vaste front éclairé du triple rayon de l'art. Le chagrin vulgaire qui a plissé ces joues n'est pas, à coup sûr, la tristesse sacrée d'un homme qu'écrasait sa propre pensée. Ce n'est point là Michel-Ange tel qu'il convenait de le montrer. Serait-ce ici Raphaël ? Encore moins peut-être ; car enfin nous le connaissons tous, ce jeune homme charmant, au profil pur, au regard limpide. Dès notre enfance, nous nous sommes familiarisés avec ce visage idéal qu'il a reproduit lui-même à son printemps. Le sentiment de la beauté, quand il s'est éveillé en nous, a pris les traits de ce fils d'un ange et d'une muse. 
8 De quel droit M. Delaroche ne respecte-t-il pas cette belle œuvre de Dieu? Pourquoi substituer à ce visage, déifié par l'admiration de trois siècles, un visage de keepsake, une chevelure brune, un lourd profil, un regard sans rayon? Était-ce bien le cas d'inventer? Et comment un artiste a-t-il pu parvenir à chasser de sa mémoire ces traits charmants, cet idéal de toutes les grâces, pour mettre à la place une figure sans caractère et sans beauté ? M. Delaroche eût dû suivre un exemple bien proche de lui : deux fois M. Vernet a peint Raphaël; il a toujours scrupuleusement reproduit ses traits et son costume traditionnel.

9 Nous ne reprendrons pas un à un tous les personnages de ces groupes, ce serait une critique trop minutieuse pour le lecteur; demandons pourtant encore à M. Delaroche pourquoi il a mis en évidence, sur le premier plan du groupe des coloristes, un profil aussi malheureux que celui de Giorgione ? Si M. Delaroche s'est fait esclave de la vérité historique, ce qui serait peu probable en considérant qu'il s'en est affranchi lorsqu'il s'agissait de Raphaël, pourquoi n'avoir pas perdu dans l'ombre une figure si disgraciée, ou pourquoi ne pas la peindre de face quand le profil était aussi ouvertement en guerre avec les principes de l'esthétique? Pourquoi Murillo ne vous offre-t-il pas le type de cette beauté espagnole, énergique et voluptueuse, qui eût si heureusement contrasté avec les visages flamands qu'il a mis tout auprès?

Mais laissons cette partie secondaire de la composition pour nous occuper de la partie principale. Ici, malheureusement, de graves défauts de style, des contresens nombreux, appellent la critique, et nous ne trouverons pas comme dans les groupes dont nous venons de parler la grâce des détails ou le mérite d'une exécution facile.

11 Il nous a été impossible, malgré tout notre bon vouloir, de ramener à l'unité le sens de ces figures allégoriques. Nous cherchons encore le rapport, la corrélation de ces trois artistes grecs avec les quatre muses et la figure agenouillée. Nous nous sommes vraiment demandé pourquoi ce tribunal suprême d'Apelle, Ictinos et Phidias, auquel semble se subordonner la muse elle-même qui devait au contraire les inspirer ? Et enfin pourquoi cette femme nue sur le bord du tableau pour représenter un siècle et un climat où le nu est inadmissible?

Les trois figures dominantes, Apelle, Ictinos et Phidias, n'ont rien d'antique ; à peine colorées, elles ressortent peu du mur et se perdent dans les fonds gris. Les quatre muses offraient à M. Delaroche une occasion admirable de faire de l'art noble et pur, des formes excellemment belles. Il pouvait, à son gré, inventer ou imiter, pourvu qu'il fût beau et qu'il traçât nettement les caractères divers de ces quatre types idéaux, faciles à saisir d'ailleurs, et d'où pouvaient naître des contrastes et des harmonies très agréables à l'œil. M. Delaroche ne nous semble pas avoir pénétré assez avant dans l'idée qu'il a voulu rendre; il a posé l'une vis-à-vis de l'autre la muse grecque et la muse romaine, toutes deux de fortes femmes aux lignes accusées, aux chairs épaisses et, sans la couleur de leur draperie qui est différente, on ne saurait à quoi les distinguer.

13 La muse du Moyen Âge, à laquelle il a donné en quelque sorte pour attribut une petite cathédrale gothique faite avec un soin extrême, manque, quoique belle, de l'expression mystique qui convenait. Pourquoi aucun détail ne doit être laissé au hasard: tous doivent concourir à rendre saisissable l'idée toujours assez obscure. M. Ingres l'a bien senti lorsqu'il a fait ces deux superbes figures de L'Iliade et de L'Odyssée, l'une vêtue de couleur de feu (allusion aux fureurs d'Achille), l'autre d'une teinte verdâtre qui transporte l'imagination sur la mer, où se passent les principales scènes du poème. L'azur, couleur du ciel, était indiqué pour la muse éminemment chrétienne du Moyen 
Âge ; nous aurions aimé également que, pour la caractériser davantage, elle eût le front ceint d'une auréole rappelant la multitude innombrable de bienheureux qu'elle a glorifiés et auxquels elle a élevé des temples. La muse qui devait personnifier l'art de la Renaissance, cet art prodigue de richesses et de voluptés, mais déjà moins primitif et enclin à la manière, est encore plus dépourvue de style. Une femme demi-nue, non de la nudité antique, chaste à force de noblesse et de beauté, mais d'une nudité toute charnelle, fait un geste sans motif et montre sous des draperies maladroites des formes d'un dessin contestable. Une couleur étrange, fausse, un ton de brique est répandu sur son visage et le haut de son corps. M. Delaroche semble avoir été satisfait de ces chairs de fantaisie, car il a remis les mêmes couleurs sur sa palette pour peindre la figure agenouillée. Quant à celle-ci, le dessin et la couleur en sont si déplorables, la pose si disgracieuse, le geste si peu noble, que nous avons peine à comprendre une pareille aberration chez un homme d'un talent éminent.

2. Jean Auguste Dominique Ingres, L'Apothéose d'Homère

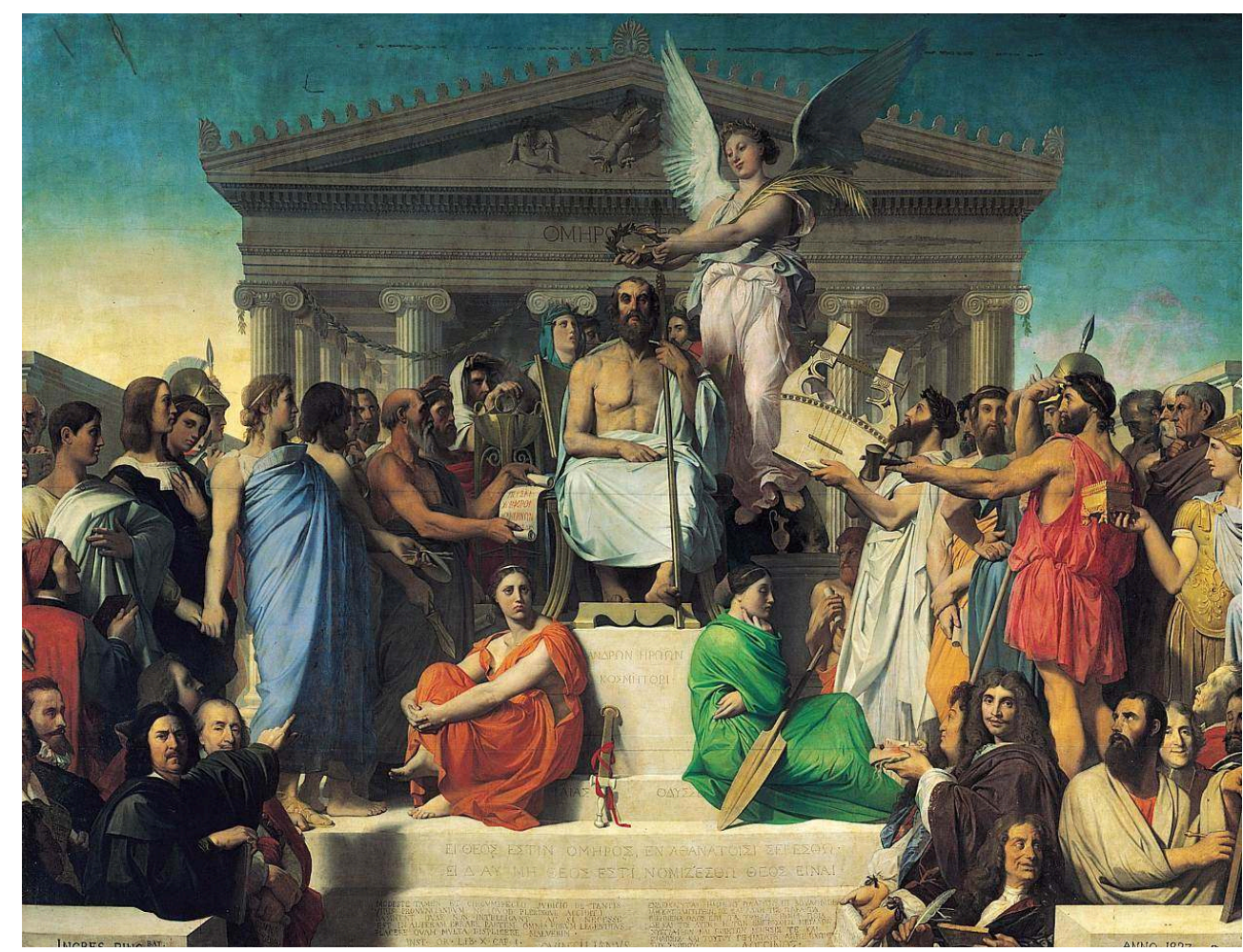

1827, huile sur toile, 386 × 512 cm, Paris, musée du Louvre. 


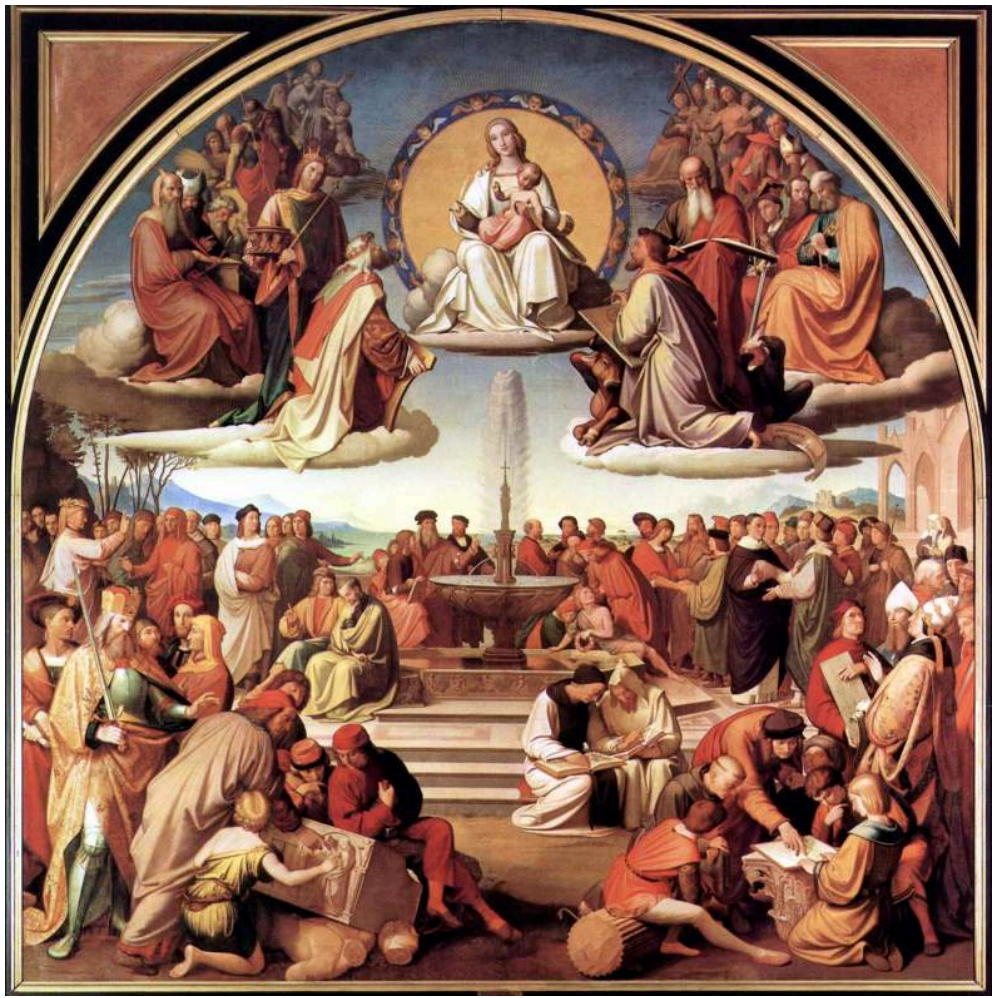

1840, huile sur toile, 389 × 390 cm, Francfort, Städelsches Kunstinstitut.

14 En résumé, la composition de M. Delaroche, quoique très remarquable sous plusieurs rapports, manque cependant aux conditions essentielles de l'art tel que l'ont compris et exercé les grands maîtres auxquels il a voulu rendre hommage. L'invention y est nulle. Non seulement la composition procède de l'École d'Athènes, ce dont nous ne lui ferions pas un reproche, mais encore elle rappelle le Plafond d'Homère [d'Ingres] (fig. 2) et Le Triomphe de la religion d'Overbeck (fig. 3), sans avoir toutefois en elle le principe supérieur qui, à des degrés différents, donne l'âme et la vie à ces deux œuvres. Dans le Plafond d'Homère, le sentiment antique domine la composition. On sent que le peintre était à l'aise, au sein de cette grécité qu'il a si profondément étudiée. Une beauté souveraine harmonise le tout, et l'exécution merveilleuse ne trahit pas un instant la grandeur de la conception. Devant le tableau d'Overbeck, la foi du chrétien, la sincérité et la conviction de l'artiste vous gagnent; et si peut-être on peut lui reprocher trop de recherche et d'esprit dans la poursuite de son symbolisme, toutefois il est impossible de ne pas étudier avec un intérêt réel une œuvre si évidemment sortie d'une intelligence élevée, d'un cœur plein d'amour pour l'art et la religion.

Le tableau de M. Delaroche, au contraire, nous laisse froid, parce qu'il ne s'adresse à aucun sentiment et n'éveille aucune idée. C'est un tableau qui n'est ni religieux, ni profane, ni antique, ni moderne, ni idéal, ni réel. Une confusion des éléments les plus contraires y trouble l'esprit, et surtout enfin, car c'est là la condamnation sans réplique d'une œuvre d'art, il est dépourvu de beauté. Or le beau manquant dans une composition où l'action et le drame sont nuls, où sera le principe de vie, l'élément de durée d'une pareille œuvre?

16 Ce n'est pas à dire que M. Delaroche, dans cette composition longuement méditée et exécutée avec le plus grand soin, soit resté au-dessous de ce qu'on avait droit 
d'attendre de lui. L'Hémicycle du Palais des beaux-arts doit, au contraire, agrandir et élever sa renommée. Si nous avons été sévère, peut-être jusqu'à la rigueur, envers cet habile artiste, c'est parce que la France a encore beaucoup à espérer du travail de ses mains et de sa pensée, et que ses consciencieuses recherches et ses études persévérantes invitent la critique à un examen sérieux, tandis que d'autres artistes qui importent moins lui arrachent sans tant de peine des encouragements bienveillants et de banales louanges.

Daniel Stern

\section{« Le portrait de Cherubini par M. Ingres » (7 janvier 1842)}

Tout au fond de la cour de l'Institut, à droite, un escalier en bois, jamais frotté, balayé avec distraction, véritable escalier de savant ou d'homme de génie, vous conduit à un palier dont il ne faudrait pas trop examiner les recoins (fig. 4).

4. Jean Auguste Dominique Ingres, Portrait de Cherubini [Le Compositeur Cherubini et la muse de la poésie lyrique]

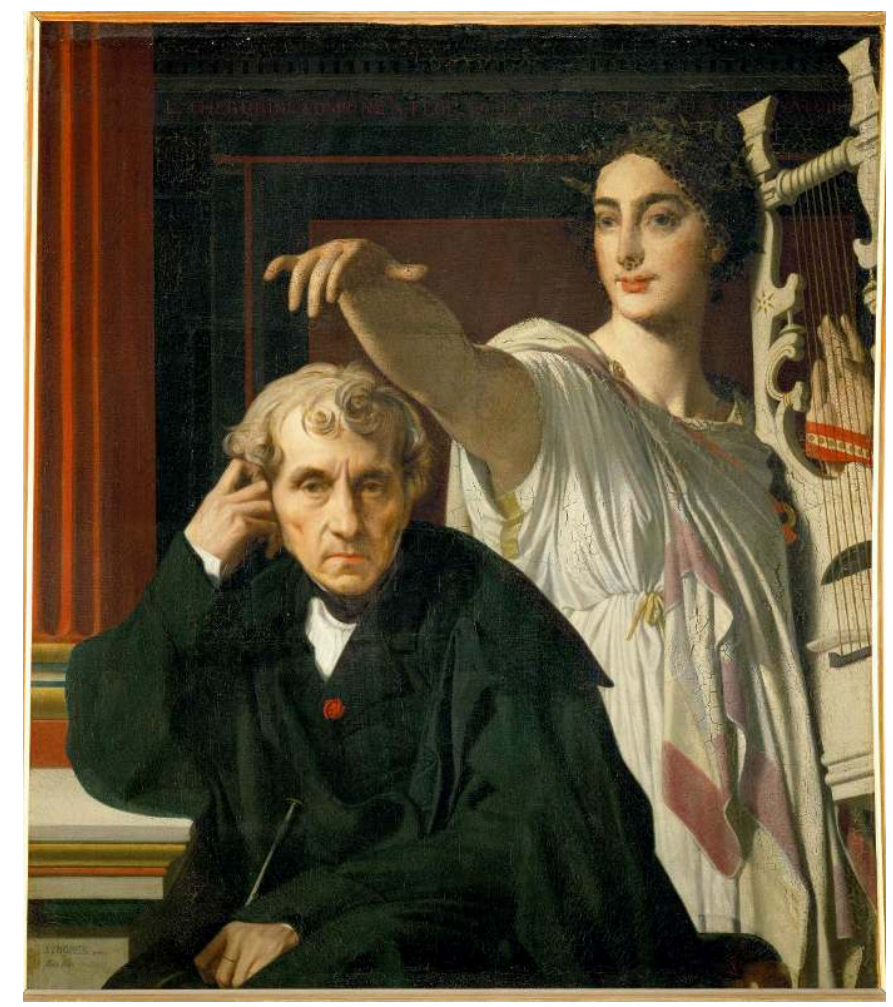

1841, huile sur toile, 105 × 94 cm, Paris, musée du Louvre.

Vous vous trouvez en face d'une porte numérotée (numéro $4:$ le hasard a quelquefois de l'esprit !). Vous sonnez. C'est une servante qui vient ouvrir. Elle vous précède dans un étroit couloir et vous introduit dans un cabinet sans tapis ni tenture. Là, vous êtes reçu avec cordialité par un homme de petite taille, négligemment vêtu, il vous fait asseoir sur un fauteuil en tapisserie, ouvrage de sa femme, et se met à causer sans prétendre le moins du monde à une attention particulière. D'où vient donc qu'au sein 
de ces mœurs bourgeoises, dans ce milieu prosaïque, vous êtes saisi de respect, et qu'en abordant cet homme, votre parole devient grave et déférente?

C'est que vous parlez tout simplement à l'un des premiers artistes de l'Europe, que cet artiste est une des gloires de la France ; qu'il a fait le Plafond d'Homère, et qu'il s'appelle Ingres (fig. 2).

Quoi qu'on ait pu dire de la décadence du goût et de l'indifférence des masses en matière d'art, jamais peut-être les grands peintres et les véritables artistes n'ont rencontré de plus respectueuses sympathies. Plus la société est entraînée par ses coutumes et ses tendances vers l'égalité dans le laid, plus les individus sentent le besoin d'honorer ces nobles selon l'esprit, ces patriciens de l'intelligence qui ont reçu tant d'en haut la connaissance du beau et le don de le révéler. Or, parmi ceux-là, nul n'a plus de droits à toutes sortes d'égards que M. Ingres. Aussi, voyez comme Paris a fêté son retour! Je m'étonne que le vieil escalier n'ait pas fléchi sous le poids de tant d'hommes d'État, de grands seigneurs, d'illustrations de tous genres accourus pour contempler la Vierge à l'hostie. Demandez au duc d'Orléans s'il ne regarde pas comme une faveur le droit de monter deux fois par semaine ces degrés sur lesquels l'imagination de l'architecte qui les a construits n'avait certes jamais posé un pied royal ? L'héritier du trône est heureux de se faire présenter à la France par la main du grand peintre. Mais songez-y, monseigneur, prendre un tel interprète auprès de la postérité, c'est presque s'engager à la gloire.

Bientôt, vous serez tous admis dans l'humble demeure de l'artiste. On ne fera aucuns frais extraordinaires pour vous recevoir. Les habitudes d'intérieur resteront les mêmes et dans ce petit cabinet où vous vous presserez en foule, rien ne sera changé. Il n'y aura qu'un chef-d'œuvre de plus: un portrait élevé à toute la hauteur d'un tableau d'histoire : Cherubini élu par la muse.

Il appartenait à $\mathrm{M}$. Ingres de faire le portrait de Cherubini. Son exquise organisation l'a de bonne heure rendu sensible aux effets de la musique. Prompt à tout concevoir, il a trouvé moyen, à ses heures perdues, de devenir un musicien consommé. Tout jeune encore il faisait partie des célèbres quatuors de Baillot; aujourd'hui Liszt se plaît à dire avec lui les sonates les plus difficiles de Beethoven; son goût en musique est empreint de la sévérité, de l'exclusion passionnée qui sont inhérentes à sa nature. M. Ingres n'admet que les grands stylistes. Il ne prononce jamais d'autres noms que ceux des compositeurs chez lesquels l'idée domine la forme. Il rejette avec horreur la musique sensualiste. Les plus heureux génies, s'ils ne sont forts de pensée, ne trouvent pas grâce devant lui. Ainsi Gluck, Haydn, Mozart, Beethoven, Cherubini sont à ses yeux les musiciens par excellence. Il les nomme les maîtres et leur rend des honneurs voisins du culte qu'il voue à ses dieux : Apelle et Raphaël.

Lié d'amitié avec Cherubini, M. Ingres a ressenti au cœur le silence qui, depuis quelques années, s'est fait autour du grand compositeur. Indigné d'un si prompt oubli, il s'est proposé de rappeler à la France l'auteur de Lodoïska, des Deux journées et de tant d'autres belles œuvres. Pour cela, il ne s'est pas borné à reproduire fidèlement les traits nobles, l'œil profond de Cherubini, il a voulu, afin de mieux rendre sa pensée, placer auprès de lui la muse Terpsichore indiquant du regard et du geste qu'elle le choisit, qu'elle le sacre devant le peuple.

23 Certes, c'était là une conception à faire trembler le pinceau en des mains moins fermes, à donner le vertige aux yeux les plus aguerris. Rapprocher ainsi l'idéal du réel ; évoquer 
l'Antiquité dans toute sa majesté pour la mettre en présence de notre actualité mesquine ; poser la jeune muse tenant la lyre auprès du vieillard, appuyé sur sa canne, c'était jeter un défi à l'impossible. Aborder en plein de pareilles difficultés, c'était l'œuvre d'un homme qui n'ignore aucune des ressources de l'art. Pour triompher dans une telle entreprise, l'audace de la jeunesse et la maturité de l'expérience étaient nécessaires. Il fallait joindre le libre essor d'une riche imagination à la plus haute puissance réflective. Il fallait posséder les secrets des maîtres grecs et n'avoir pas négligé l'observation de la réalité moderne. Il fallait savoir et oser. Que dirai-je encore? Il fallait être Ingres.

Voici quelle est la composition de ce tableau étrange et simple tout à la fois : Cherubini, dans le costume actuel, habit et manteau de drap, est assis tête nue sur un fauteuil en velours. Il tient d'une main sa canne, de l'autre son chapeau, dont on ne voit qu'une partie. Il regarde devant lui comme un homme qui cause ou qui rêve doucement. Debout, à sa gauche, un peu en arrière, est Terpsichore; vêtue de blanc, afin de rendre plus sensible le caractère sacerdotal qu'a voulu lui donner l'artiste, couronnée de lauriers, elle tient d'une main la lyre à sept cordes d'un geste dominateur; elle étend l'autre sur la tête de Cherubini, et regarde fièrement devant elle, comme pour indiquer au spectateur qu'elle prend possession de cet homme, que désormais il lui appartient. La figure de Cherubini ne trahit aucune émotion. On comprend qu'il n'a pas conscience de ce qui se passe auprès de lui. C'était à coup sûr la manière la plus philosophique d'exprimer la présence simultanée, sans relation apparente, dans un même individu, d'un génie élevé, d'une nature simple et naïve.

Mais pour faire admettre une donnée aussi neuve, la puissance d'exécution ne suffisait pas. Il fallait du bonheur. Car, et les grands artistes en conviennent tous, il y a encore du bonheur pour la main la mieux exercée; dans la vie de l'homme le plus maître de l'art, il est des heures propices où son travail devient en quelque sorte lumineux, s'anime au souffle d'un esprit invisible. Le portrait de Cherubini semble avoir été achevé à l'une de ces heures. La tête de ce musicien éminent est peut-être le plus beau portrait sorti du pinceau de $\mathrm{M}$. Ingres. On voit qu'il s'est plu à reproduire le froncement homérique de ces sourcils, ce front où Lavater eût reconnu les trois plis verticaux, signe certain d'un noble caractère. Il n'a pas craint de mettre en pleine lumière, sans en rien dissimuler, cette vieillesse au repos, à laquelle il a donné un aspect auguste. Ainsi qu'il l'avait déjà fait dans les portraits de M. Bertin et de Monsieur le comte Molé, il a tiré un parti merveilleux des étoffes rudes et cassantes dont se compose le costume moderne. Il est parvenu, en restant simple et même bourgeois comme il convenait, à donner au drap du manteau de larges plis, une ampleur presque romaine. Il a enfin résolu un des grands problèmes de l'art : ennoblir la vulgarité en la reproduisant avec exactitude.

26 La muse, également un portrait ${ }^{2}$, est un de ces types héroïques vers lesquels M. Ingres semble conduit par la pente invincible de son génie. Son œil noir, ses sourcils épais donnent à sa beauté un caractère de fierté que tempère la courbe gracieuse, la voluptueuse épaisseur de sa lèvre vermeille. La main étendue sur Cherubini est d'une délicatesse toute féminine, et pourtant on y sent une force souveraine : la force de la volonté, non celle des muscles. On devine que cette main est douée d'une puissance d'attraction surnaturelle.

L'autre main apparait à travers les cordes de la lyre sur laquelle elle est posée ; et c'est ici le lieu de remarquer le soin, le goût exquis qui relèvent tous les détails de cette composition sévère. La lyre, copiée sur un bas-relief antique, est suspendue à une 
bandelette rouge à filet blanc mat qui entoure la main et passe dans un anneau attaché à la ceinture. La tunique, retenue au-dessus du sein par un cordon de couleur d'or, dessine, sous ses plis mous et souples comme ceux d'une draperie grecque, des formes virginales, un beau corps dans toute la splendeur de la jeunesse. Une bordure lilas rompt avec bonheur l'uniformité toujours un peu aride des tons blancs.

5. Jean Auguste Dominique Ingres, Antiochus et Stratonice

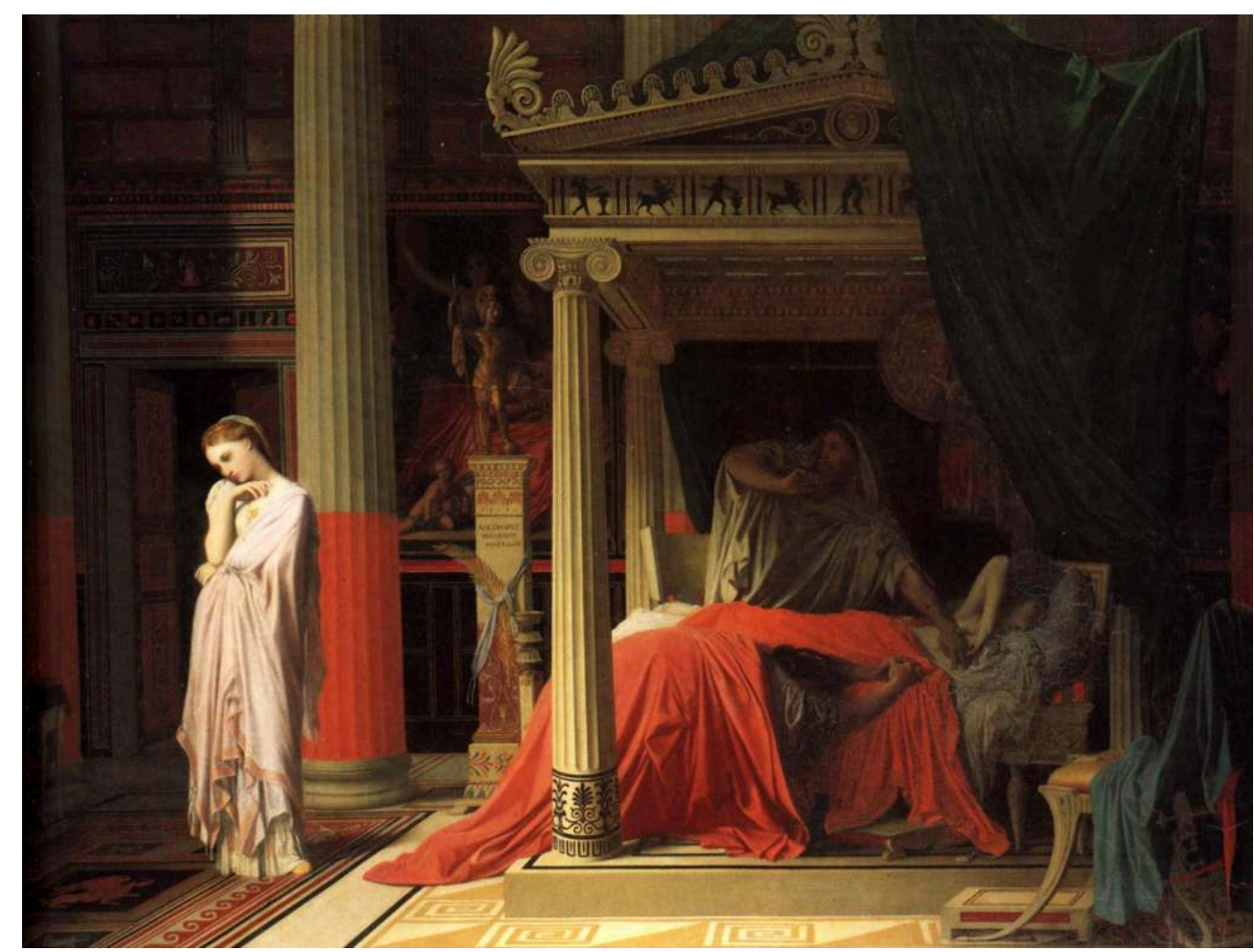

1840, huile sur toile, 57 × 98 cm, Chantilly, musée Condé 
6. Jean Auguste Dominique Ingres, La Vierge à l'hostie

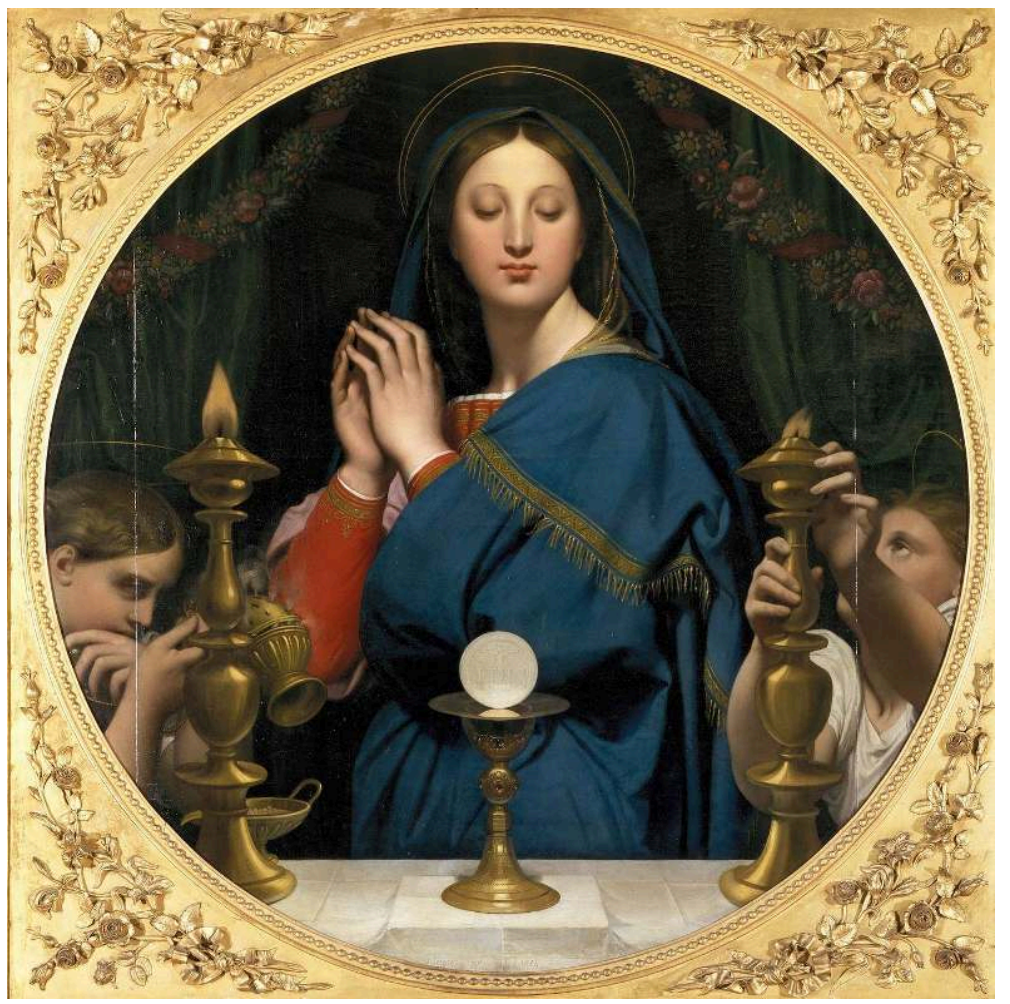

1841, huile sur toile, 116 × 84 cm, Moscou, musée Pouchkine.

28 Il était impossible de se montrer à la fois plus sobre et plus charmant. Nous ne nous étendrons pas sur les qualités matérielles de l'exécution. Tout le monde sait que M. Ingres dessine comme Raphaël. La Stratonice (fig. 5) et la Vierge à l'hostie (fig. 6) ont répondu à ceux qui lui refusaient la couleur.

Toutes les qualités qui font les grands coloristes se trouvent dans le portrait de Cherubini. Les ombres y sont ménagées; la lumière y est répartie avec un art entièrement dégagé de charlatanisme. Les tons des chairs sont chauds et vivants dans le visage de la muse, plus sérieux, plus assombris dans la figure du Cherubini. L'harmonie de l'ensemble est douce et suave. Que les jeunes peintres, que les élèves qui recherchent le beau avec ardeur et sincérité viennent étudier le tableau de M. Ingres. Ils trouveront chez le grand peintre le meilleur de tous les enseignements, l'exemple.

Que le public se presse sur leurs pas; il pourra admirer sans restriction une magnifique œuvre d'art. L'admiration est une des plus nobles jouissances de l'esprit. "C'est le sentiment de l'admiration qui distingue l'homme de la bête ", dit le théosophe SaintMartin. Admirons donc le plus souvent et le plus possible ; les occasions en sont rares, ne les laissons pas échapper.

Daniel Stern

\section{« Le Salon 1842. Deuxième article » (20 mars 1842)}

31 Tableaux d'histoire. MM. Flandrin, Lehmann, Chassériau, Bouchot, Gigoux, Mottez, Signol, etc. 
des choses les plus désagréables qu'on ait inventées depuis longtemps, c'est à coup sûr une exposition de tableaux. Après un concert monstre, et nous disons après, parce que la musique est de nature encore plus agressive que la couleur, nous ne connaissons rien de pire qu'une première visite au Salon. Lors même qu'il ne s'y trouverait que des chefs-d'œuvre, et Dieu sait que la supposition est hardie, ce serait encore un tourment pour un esprit paisible que de se voir ainsi tiraillé par mille objets divers; de se sentir le jouet de mille émotions opposées; de passer, en moins d'une seconde, de la pitié à la terreur, de la joie aux larmes; d'être poussé des ombrages d'Endymion dans la prison de Marguerite, des filets de Vulcain dans l'étable de Bethléem, de la galère de Cléopâtre dans l'intérieur d'une cuisine. On éprouve, ainsi ballotté, ahuri, dérouté, quelque chose d'analogue à ce que serait la lecture d'un volume rempli de la sorte, par exemple :

«C'était pendant l'horreur d'une profonde nuit ${ }^{3}$.

Clarisse aime mes vers, faisons-en pour Clarisse ${ }^{4}$.

Mur, ville

Et port,

Asile

De mort ${ }^{5}$.

Notre crime est d'être homme et de vouloir connaître ${ }^{6}$.

Dans ces prés fleuris

Qu'arrose la Seine ${ }^{7}$, etc. »

Aussi, dans cette grande mêlée de sainteté, de volupté, d'histoires, d'allégories et de fantasmagories, nous sommes-nous hâté de faire notre choix, pour nous y borner, y revenir sans cesse et l'étudier à loisir. C'est la seule manière d'échapper au vertige que ne peut manquer de donner une pareille masse de couleurs et de formes rapprochées, combinées de la façon la plus bizarre et la moins rationnelle.

Parmi les tableaux auxquels nous nous sommes tout d'abord arrêté, nous citerons en première ligne celui de M. Flandrin, Saint Louis dictant ses capitulaires. Cette composition se distingue, comme toutes celles du même artiste, surtout par la simplicité et la clarté. Assis sur un trône recouvert d'un dais, Saint Louis, revêtu des insignes de la royauté, indique par son air réfléchi, son regard sérieux et le geste significatif de sa main droite, qu'il exerce un acte grave de souveraineté. On comprend à l'attitude recueillie de ceux qui l'écoutent, à l'air de soumission attentive et reconnaissante du personnage qui écrit sous sa dictée, qu'il s'agit de consigner là l'expression d'une volonté auguste, de coopérer à une œuvre grande et utile. On devine que ce doit être l'établissement des capitulaires.

Cinq figures seulement remplissent la toile : le sujet n'en admettait guère davantage. Le roi de France, dans son conseil privé, ne devait être entouré que de ses plus éprouvés serviteurs; ceci est pour la vérité historique. Quant à la vérité de sentiment, elle exigeait tout aussi impérieusement la sobriété. La seule impression que le peintre pouvait espérer produire dans un sujet dénué de passion, sans aucun principe de lutte ni intérieure, ni extérieure, c'était une sorte de respect, de piété à la mémoire d'un grand mort, la satisfaction de l'intelligence dans une contemplation sérieuse. Or, la diversité des figures, la complication des groupes, des attitudes, des mouvements, les antithèses produites par cette diversité, eussent été nuisibles à l'harmonie solennelle qu'il fallait obtenir de préférence à tout. Sous ce rapport, nous approuvons entièrement M. Flandrin de n'avoir pas cherché une abondance hors de propos.

L'histoire ne précisait rien par rapport aux personnes présentes aux conseils du roi. Libre de choisir, M. Flandrin l'a fait avec sagacité. Derrière Guillaume de Nangis, qui 
écrit les Capitulaires, il a placé le sire de Joinville; de l'autre côté du trône, Mathieu, abbé de Saint-Denis, et Robert de Sorbon. Tous ces personnages ont les yeux fixés sur le roi, à l'exception de l'abbé de Saint-Denis qui, la tête appuyée sur sa main, semble méditer avec quelque appréhension les conséquences possibles de cette législation nouvelle. Il était difficile de tirer un meilleur parti d'un sujet aussi peu émouvant et qui ne touche aucune fibre du cœur. La tête de Saint Louis, fidèlement copiée d'après le masque traditionnel, cette tête sans beauté et sans caractère est habilement sauvée par une expression de bonté touchante rendue avec un rare talent.

La figure de l'abbé de Saint-Denis très bien drapée, et d'un dessin parfait, offre une silhouette d'un grand style; la distribution de la lumière est excellente. Malgré des ombres portées projetées franchement, elle est égale et douce comme il convenait. Le modèle est soigné ; nous y trouvons toutefois quelque mollesse. Les tons sont solides, mais trop mats; ce qui tient, nous le pensons, au peu d'empâtement et à l'absence complète de glacis. L'abus de la demi-teinte donne quelque chose de terne à tout le tableau; nous aurions aimé aussi moins d'aridité dans les accessoires. La tenture verte $\mathrm{du}$ fond, le dais et le tapis écarlate sans broderie, sans le plus léger ornement, ont un aspect pauvre qu'il fallait éviter. Nonobstant ces critiques de détail, la composition de M. Flandrin est une œuvre de conscience et de savoir ; c'est un tableau d'un sentiment élevé, rendu dans un style pur et sévère, exécuté avec habileté. Si cette œuvre ne saisit pas vivement et ne produit qu'une impression médiocre, cela tient à la froideur inévitable du sujet, et aussi à la nature du talent de M. Flandrin, talent calme, placide et noble, mais auquel manque peut-être une certaine flamme d'enthousiasme, une certaine vibration qui se communique.

La Flagellation, par M. Lehmann, présentait des difficultés d'un autre ordre, mais non moins grandes, que le Saint Louis. De tous les sujets empruntés à l'Évangile, c'est peutêtre celui qui blesse le plus l'imagination et qui convient le moins à la plastique. Outre ce désavantage inhérent au sujet, les dimensions de la toile données rendaient la tâche du peintre encore plus ingrate. Cette toile, très haute et très étroite, dans laquelle il était matériellement impossible de faire entrer un grand nombre de personnages, devenait un obstacle majeur au développement naturel, à la manifestation complète du fait historique. Tout sentiment, même le plus vil, acquiert une sorte de grandeur du moment où il anime une masse d'hommes. Ce qui est odieux dans l'individu devient terrible dans la foule. Ainsi, une vaste toile où l'on aurait pu représenter le mouvement et l'agitation du peuple juif se ruant sur Jésus eût été très propice. Au lieu de cela, M. Lehmann s'est vu contraint de résumer dans sept figures seulement les sentiments divers qui devaient animer la foule tout entière. De là le défaut capital du tableau: quelque chose de trop accentué en laideur, une antithèse trop marquée entre la sublimité du Christ et la brutalité de ses bourreaux.

L'ordonnance du tableau est grande et simple. Fidèle à la tradition, M. Lehmann a représenté le Christ dans le prétoire, au moment où il vient d'être livré par Pilate aux soldats. Il est debout devant un tronc de colonne qui repose sur un piédestal élevé de plusieurs marches. Deux colonnes de granit, supportant une arcade, laissent voir un ciel assombri très bien harmonisé à la scène qui se passe sur le premier plan. Cette disposition est ingénieuse, en ce qu'elle permet de supposer que la foule assiste du dehors à l'exécution, et étend pour l'imagination les bornes étroites du tableau.

Sur les degrés du piédestal, qu'on devine sans les voir, à droite et à gauche du Christ, sont groupés les quatre bourreaux. Un d'entre eux lui lie les mains; deux autres le 
flagellent; un quatrième lui crache à la face. Au second plan, dans l'ombre, un pharisien, enveloppé d'une draperie blanche, personnifie l'Envie. À gauche, un soldat et un jeune homme, par leurs gestes moqueurs, symbolisent l'ironie, cette forme cruelle de la haine intelligente.

La figure du Christ est noble et pure. La double nature de l'homme et du Dieu, la chair souffrante et l'esprit triomphant, y sont exprimés avec un talent remarquable. Le regard de Jésus levé au ciel où rayonne une bonté infinie résume admirablement cette parole de l'Écriture: "Mon père, pardonnez-leur, car ils ne savent ce qu'ils font »; tandis que les mains gonflées, les épaules nerveusement contractées dans un mouvement d'une vérité saisissante rendent on ne peut mieux la douleur du corps. Toutefois, nous reprocherons à M. Lehmann de s'être peut-être trop exclusivement inspiré de la mansuétude du fils de l'homme ; nous aurions voulu une résignation plus virile, une soumission plus manifestement volontaire. Après la figure de Jésus, la plus importante, quant à l'exécution, est le flagellateur de droite. Vu de dos et presque entièrement nu, il présente des raccourcis d'une grande hardiesse; il est d'un mouvement franc et énergique, d'un modelé vigoureux. C'est une étude savante de la nature. Nous donnerons toutes sortes d'éloges au porte-étendard qui lie les mains du Christ. L'expression de la tête est frappante ; la coiffure et le vêtement du Christ ont un caractère d'une très heureuse originalité.

Ainsi que nous l'avons dit, il y a de la grandeur dans les lignes d'ensemble de cette composition. L'air y circule bien; le peintre a su donner, dans un si petit espace, une surprenante liberté à toutes ses figures. Le coloris en est harmonieux, d'une transparence due à l'emploi habile de la demi-pâte et du glacis ; le ton des draperies est choisi avec goût et intelligence.

Nous ferons une exception critique pour celle du Christ. Le petit bout de tunique rouge qui passe sous la draperie blanche, non assez motivé, est d'un effort malheureux. Toute cette draperie manque d'ailleurs de souplesse et d'ampleur ; l'exécution en est lâchée. En résumé, cette composition révèle dans $M$. Lehmann des qualités que ses ouvrages précédents ne pouvaient faire supposer. Ce qui avait dominé jusqu'ici dans ses tableaux, c'était la délicatesse, un certain charme de naïveté. Dans La Flagellation, il a prouvé qu'il comprenait le mouvement, qu'il savait être énergique autant qu'il s'était montré gracieux. M. Lehmann a tenté, pour nous servir de l'expression d'un philosophe, de se réconcilier avec ses contraires. Aussi l'effort se fait-il encore sentir. La Flagellation est évidemment une œuvre de transition; mais le résultat en est tel, que nous sommes aujourd'hui certain d'une chose, c'est que lorsque M. Lehmann entreprendra un sujet de son choix, dont les conditions seront moins défavorables, nous pourrons le proclamer maitre de son art.

Ce sont deux vers

«[...] Cunctæque profundum

Pontum adspectabant flentes ${ }^{8}[. .$.$] »$

de Virgile qui ont inspiré à M. Chassériau une composition d'une grande originalité et qui renferme des beautés remarquables. Au bord d'une mer bleue, au pied d'un promontoire, sur une plage couverte de rochers où se joue l'écume des vagues, une vingtaine de femmes sont assemblées. Plusieurs sont couchées, d'autres debout regardent la mer, d'autres encore se voilent la face ou s'appuient sur leurs compagnes formant des groupes distincts et variés, mais tous conçus dans un même sentiment de pensive douleur. 

craindre et a été heureusement évitée. Le style de la composition est noble; un sentiment vrai de la Grèce s'y révèle. La critique pourrait y relever des réminiscences trop vives de Pompéi, peut-être, mais ce n'est pas nous qui reprendrons jamais un jeune artiste de trop se rapprocher de l'antique. Félicitons, au contraire, M. Chassériau d'aller si droit à ce qui est beau. Sa personnalité est assez fortement accusée, même dans les parties de son tableau qui semblent le produit d'une heureuse mémoire, pour que nous soyons assuré qu'elle ne tardera pas à se dégager. Le dessin des Troyens, généralement correct, est cependant répréhensible dans plusieurs figures, dont la tête et les membres manquent de proportion. Presque partout M. Chassériau a fait des bras démesurément forts pour des têtes délicates.

Nous signalerons particulièrement ce défaut dans la figure du premier plan qui a le bras levé et la main appuyée sur le front, et dans celle du troisième plan qui étend le bras vers la mer. Plusieurs parties du tableau sont d'une excellente couleur, mais l'ensemble manque d'une certaine fusion et trahit la méconnaissance des rapports. Certains tons très beaux, absolument parlant, deviennent criards par leur rapprochement trop heurté avec d'autres. Ainsi la draperie verte d'une figure au second plan à droite et le violet foncé d'une draperie qui enveloppe la tête et le corps d'une figure du premier plan sont d'un effet désagréable et jettent comme un son faux dans l'harmonie générale.

\section{Théodore Chassériau, La Descente de Croix}

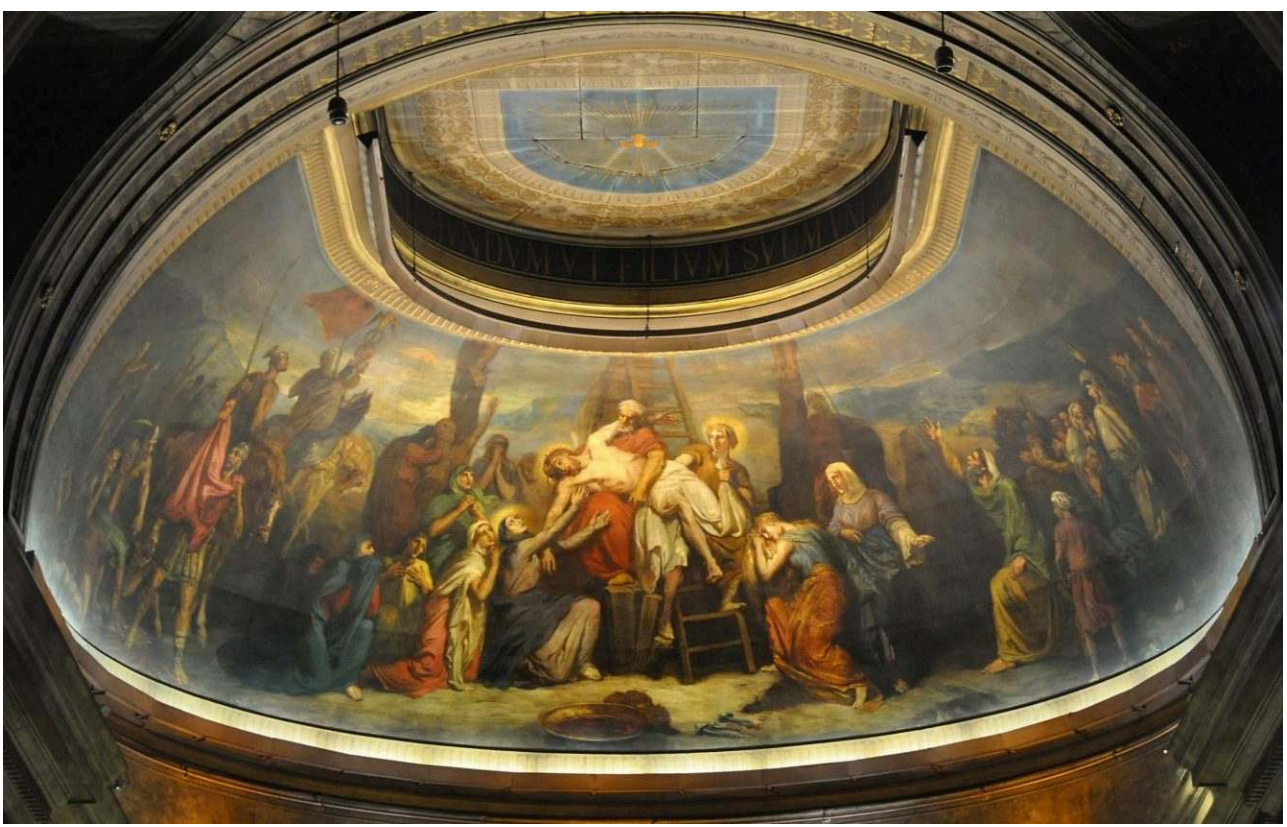

1842, huile sur toile, 300 × 220 cm, Saint-Étienne, église Notre-Dame.

Malgré ces défauts d'inexpérience et de jeunesse, le tableau des Troyennes et celui de la Descente de Croix (fig. 7), du même artiste, sont des œuvres où nous reconnaissons, quoique non encore développées, les qualités qui font les grands peintres. M. Chassériau a très poétiquement conçu ce dernier sujet. Au pied de la croix, dont on ne voit que la partie inférieure, le Christ mort est soutenu par Nicodème et saint Jean ; debout, derrière lui, sa mère enlève avec précaution la couronne d'épines; elle regarde le ciel avec l'expression d'une foi résignée. Sur le premier plan, Madeleine, également 
debout, étanche d'une main le sang de la plaie, tandis que de l'autre elle retient les draperies qui lui servent de vêtements. À la droite du tableau, une vieille femme tient un vase où elle baigne le bout du linceul; de l'autre côté, Joseph d'Arimathie est accroupi dans l'ombre. Sur le troisième plan, une femme, les bras levés vers le ciel, exprime l'étonnement, la stupeur où la jette cette scène de désolation.

Il y a dans cette composition, on le voit, de grandes beautés d'intention. La tête de la Vierge est d'un caractère noble et d'un bon style. La figure de la Madeleine est belle; le mouvement de son corps et de ses bras est très heureux, sa draperie riche est d'un éclat de couleur digne des maîtres. La figure de vieille est un souvenir assez bien déguisé de l'école vénitienne. Les accessoires, particulièrement le vase d'or où l'on voit une éponge imbibée de sang, sont remarquablement bien faits; mais ces qualités éminentes ne sauraient sauver les défauts nombreux du tableau. La tête et le torse du Christ sont non seulement dépourvus de beauté, mais encore ils pèchent gravement contre la vérité. Il est impossible de s'expliquer par quel artifice cette tête mortaise tient perpendiculairement sur le cou, et comment ce corps inanimé se tient debout. Le torse et les bras n'ont aucun relief; le modelé n'existe pas. La précipitation se fait sentir jusque dans des ombres et des clairs beaucoup trop tourmentés, [qui] manquent d'air et pèsent sur les personnages. En somme, la Descente de Croix est l'œuvre trop hâtée d'un artiste plein d'avenir. Jusque dans les défauts que nous y signalons, nous reconnaissons les indices d'une nature très douée à laquelle il ne faut que la volonté et la patience pour atteindre à tout.

Les amis de l'art déplorent la mort prématurée de M. Bouchot. Les tableaux inachevés qui sont à l'exposition témoignent que la France perd en lui un véritable artiste. La Vierge, dans une donnée qui n'est pas celle de la tradition, et qui suivant nous n'a pas toute la grandeur de style voulue, a des qualités remarquables. La composition est neuve et pleine de charme. L'Enfant Jésus est franchement posé et d'un excellent sentiment. Le contour tracé au crayon blanc, et qui indique d'heureux changements projetés, montre combien jusqu'au dernier moment de sa vie l'artiste poursuivait la perfection possible. Les draperies sont riches et disposées avec goût.

51 Nous plaçons encore au-dessus de la Vierge l'ébauche de l'armée française au passage du mont Saint-Bernard. Il y a là un sentiment dramatique profond, l'entente des masses, du mouvement sans confusion, une grande vérité et l'intelligence du paysage. La figure du général Bonaparte qui, la main étendue vers la plaine de la Lombardie, se tourne vers son armée et semble lui dire: "Voilà la récompense promise", est excellemment sentie. Le contraste de ce calme dominateur, de cette haute indifférence avec l'ardeur de curiosité, la convoitise exprimée sur les visages des soldats est un de ces efforts grandioses qui sont pris dans un sentiment de vérité idéale et dont les maitres seuls ont le secret. Si M. Bouchot avait pu exécuter ce tableau dans les dimensions de son Marceau, nous croyons qu'il eût excité peut-être à un plus haut degré encore l'enthousiasme et la sympathie.

Le tableau de M. Gigoux Saint Philippe guérissant une malade est complètement en dehors des conditions de style qui, à nos yeux, constituent une œuvre d'art. Toutefois nous en avons regardé longtemps et admiré l'ordonnance. Il y a dans la disposition architecturale, dans le fond où l'on entrevoit le paysage, dans la valeur relative assignée aux personnages, une intelligence remarquable de la ligne et quelque chose qui est très voisin de la grandeur. Cette disposition rappelle l'allure des maitres; elle 
nous a fait d'autant plus regretter ce qu'il y a d'éminemment commun dans le choix et de faible dans l'exécution des figures.

Nous signalerons, bien qu'il ait été relégué dans une galerie qui semble le destiner à l'obscurité, le tableau de M. Joyard, Les Druidesses invoquant la tempête. Cette composition se distingue par une individualité indépendante, un sentiment intime de la poésie du nord, des mouvements vifs, une exécution franche quoique incomplète et dépourvue de beauté.

Marthe et Marie, de M. Mottez, est un tableau d'un sentiment pur, d'une composition sage. La figure de Marie a quelque chose d'exquis dans son abandon; elle est comme pénétrée de la grâce divine. Nous aurons de plus particuliers éloges à donner à M. Mottez quand nous nous occuperons des portraits.

La Madeleine de M. Signol est un chef-d'œuvre du maniéré pleurnicheur. Il était difficile de pousser plus loin le mépris de la vérité, ni de se passer plus lentement de beauté.

Que dirons-nous d'une immense toile de M. Vinchon représentant la Séance royale en 1841 ? C'est une platitude officielle, un numéro du Moniteur illustré.

Devant un certain Damoclès, comme parle le livret, nous nous sommes dit que c'était là assurément une gageure. M. Léon Viardot aura parié qu'il dépasserait l'absurde et reculerait les bornes $\mathrm{du}$ ridicule. Nous le félicitons sincèrement d'avoir si complètement gagné son pari. Une Allégorie de M. Bézard occupe une place énorme dans le salon carré. Nous eussions préféré, nous le confessons, y voir les Troyennes de M. Chassériau, qu'on a placées à contre-jour tout au fond de la grande galerie. Un monsieur couché sur le dos représente l'Innocence. Il est devant le tribunal de la Crédulité, assistée de l'Ignorance ; la Calomnie, l'Envie, la Mauvaise Foi, l'accusent. Fort à propos, une dame, portant un miroir, laquelle se trouve être la Vérité, vient à son aide. Nous souhaitons à M. Bézard, qui semble fort innocent, de se laisser conduire par cette même vérité, au tribunal du sens commun; là il rencontrera l'expérience, la raison, la simplicité, qui ne sauraient manquer de lui donner des avis très utiles.

Des essais de fresques, par M. Brémont, nous paraissent destinés à fausser les notions des personnes assez malheureuses pour ne pas connaître les fresques du Vatican. Nous leur dirons avec le poète, non seulement à propos de ces fresques, mais encore à propos d'une multitude innombrable de tableaux de toutes dimensions et de tous genres, que nous avons été malheureusement forcés de regarder.

59 « Non ragioniam di lor, ma guarda e passa ${ }^{9}$.»

\section{ANNEXES}




\section{NOTES}

1. (NdÉ) « L'ouragan... qui jamais ne s'arrête » (Dante, La Divine Comédie, L'Enfer, chant V, vers 31).

2. $M^{\text {lle }}$ de R., fille de l'ambassadeur, a posé pour la Terpsichore.

3. (NdÉ) Jean Racine, Athalie, acte II, scène 5.

4. (NdÉ) Jean Regnault de Segrais, Éloges, « Timarète ».

5. (NdÉ) Victor Hugo, Les Orientales, «Les Djinns ».

6. (NdÉ) Alphonse de Lamartine, Méditations poétiques, «L'Homme ».

7. (NdÉ) Antoinette Deshoulière, Idylles, « Vers allégoriques ».

8. (NdÉ) « Regardent, en pleurant, l'immensité des flots. » (Virgile,Énéide, V, 614).

9. (NdÉ) «Ne discourons point d'eux, mais regarde et passe" (Dante, La Divine Comédie, «L'Enfer », chant III, vers 51). 
Edmée de Syva (? - ?) 


\section{Introduction}

Amandine Gorse 
1 Sous la monarchie de Juillet, la presse connut un essor considérable auquel participèrent les journaux dédiés aux femmes. Véhiculant les valeurs d'une bourgeoisie triomphante à l'ère industrielle, elle fut alors considérée comme un outil indispensable à l'éducation (BONVOISIN et MAIGNIEN 1986, p. 10 et CORROY 2004). C'est dans ce but que fut créé par Alfred Thiéry le Journal des demoiselles, dont le premier numéro parut le 15 février 1833 (LÉGER 1988 et BESSON-MOREL 1998). Pour satisfaire au mieux le besoin des jeunes lectrices, âgées de 14 à 18 ans et issues des couches aisées de la population, celuici s'entoura d'une équipe exclusivement féminine et spécialisée dans la rédaction d'ouvrages pédagogiques, menée par Jeanne-Justine Fouqueau de Pussy (1786-1863), avec à ses côtés Alida de Savignac, Coraly Thiéry et Flore Desinck. L'impression était assurée par une autre femme, la veuve Dondey-Dupré (MARCoIN 2006, p. 348-355).

2 L'une des rédactrices, Edmée de Syva, reste encore aujourd'hui une personnalité mystérieuse. Il semble qu'il s'agisse en fait de Jeanne-Justine Fouqueau de Pussy qui usait de ce pseudonyme pour ses articles sur l'art. Elle assurait au Journal des demoiselles un contenu diversifié, qui allait des contes moraux, de l'histoire, de la physique aux critiques littéraires et artistiques, en passant par la musique et les travaux de mode, le tout rédigé sur le ton de la conversation.

3 L'écriture de Jeanne-Justine Fouqueau de Pussy/Edmée de Syva dans ses critiques artistiques adoptait le même ton alerte et piquant que dans ses livres pour la jeunesse elle avait publié en $1832 \mathrm{chez}$ Firmin Didot Le Grand-Père et ses quatre petits-fils, livre de lecture à l'usage des écoles primaires. Laissant une grande place aux observations subjectives, à l'instar de la littérature romantique, elle offrait à la fois, dans ses contributions au Journal des demoiselles, des commentaires théoriques et une description vivante de l'atmosphère du Salon. Elle invitait ses lectrices à se familiariser avec le vocabulaire théorique et technique des beaux-arts : description, composition, touche, variation des teintes (HAUPAIS 2009), tout en rendant vivant le contenu iconographique des œuvres dont elle rendait compte. Ses écrits étaient donc adaptés aux convenances sociales en cours chez les lectrices du journal, mais s'éloignaient d'une revendication féministe émancipatoire.

\section{BIBLIOGRAPHIE}

BESSON-MOREL 1998

Anne Besson-Morel, La Presse enfantine sous la monarchie de Juillet, thèse de doctorat, université Paris IV-Sorbonne, 1998.

BONVOISIN et MAIGNIEN 1986

Samra-Martine Bonvoisin et Michèle Maignien, La Presse féminine, Paris, Presses universitaires de France, 1986. 
CORROY 2004

Laurence Corroy, La Presse des lycéens et des étudiants au XIX siècle : l'émergence d'une presse spécifique, Lyon, Institut national de recherche pédagogique, 2004.

HAUPAIS 2009

Coline Haupais, $L$ 'École des femmes. Représentations, définitions et apprentissage de la féminité dans les romans feuilletons $d u$ Journal des demoiselles, 1855-1870, mémoire de master d'histoire, université Paris I-Panthéon-Sorbonne, 2009.

LÉGER 1988

Christine Léger, Le Journal des demoiselles et l'éducation des filles au XIX ${ }^{e}$ siècle, thèse de doctorat, université Paris VII, 1988.

MARCOIN 2006

Francis Marcoin, Librairie de jeunesse et littérature industrielle au XIX siècle, Paris, H. Champion, 2006.

\section{ANNEXES}

Diaporama des œuvres d'art commentées par Edmée de Syva dans ses articles pour Le Journal des demoiselles :

http://www.flickr.com//photos/73632227@N02/sets/72157629965268380/

Lire les articles d'Edmée de Syva sur le Salon de 1848 parus dans le Journal des demoiselles

Liste complète des œuvres d'arts commentées par Edmée de Syva à travers ses textes édités dans Plumes et pinceaux 


\section{Edmée de Syva, Journal des demoiselles, 1848}

[extraits choisis]

\section{« Salon de 1848 - Premier article »}

Journal des demoiselles, $\mathrm{n}^{\circ} 5,1848,16^{\mathrm{e}}$ année, $4^{\mathrm{e}}$ série, p. 152-155.

1 Le 15 mars, à onze heures, ainsi qu'on l'avait annoncé, le Salon de 1848 a été ouvert. Une foule immense se pressait aux abords du musée; elle n'a pas tardé à envahir les galeries et les salles destinées cette année à l'exposition des ouvrages d'art. Grâce au nombre et à l'étendue de ces salles, la circulation a toujours été facile, excepté cependant lorsqu'on rencontrait des masses d'individus arrêtés devant des toiles d'un ridicule si burlesque, qu'elles excitaient l'hilarité générale. Un Amour sortant d'un buisson de roses, le Rachat d'une esclave, Napoléon avec un vieux de la vieille, justifiaient, de reste, les éclats de rire dont on les a salués. La verve moqueuse de certains jeunes gens ne s'est pas bornée à ces bruyantes manifestations. Ils ont décoré ces toiles de couronnes d'immortelles et d'inscriptions. Au Rachat d'une esclave était attachée celleci : Aux grands artistes la Patrie reconnaissante. À un Portrait d'homme inimaginable: L'homme est l'animal qui ressemble le plus au singe. À un portrait de femme qui paraissait être de carton-pierre: Femme condamnée à l'exposition. À un paysage vert épinard: Pâturages, par un peintre en herbe. Il faut espérer que cette critique d'une nouvelle espèce aura un bon effet et que, dorénavant, la crainte d'obtenir des suffrages si peu flatteurs sera un frein salutaire contre les prétentions ambitieuses de l'incapacité. Du reste, plusieurs toiles les plus bouffonnes ont été bien vite retirées par leurs auteurs.

Le nombre total des ouvrages exposés s'élève à 5 180. Il y a 4589 tableaux et dessins. Les tableaux à l'huile, les miniatures, occupent la petite salle d'entrée, le grand salon carré, la grande galerie des anciens maîtres, jusqu'au fond de la dernière travée des Raphaël. Les dessins sont exposés dans la galerie d'Apollon; les peintures sur porcelaine, comme toujours, dans la salle dite des Bijoux. On trouve réunis des pastels, des dessins et quelques peintures dans la salle des Sept Cheminées. Les galeries du bord de l'eau, habituellement consacrées à l'ancienne école française, contiennent aussi grand 
nombre de toiles nouvelles dans tous les genres; l'architecture est exposée dans la dernière de ces salles. Les marbres, les bronzes, les plâtres, sont placés dans les belles salles du Musée égyptien.

3 Beaucoup de nos peintres les plus renommés ont exposé cette année ; et néanmoins on compte les toiles vraiment remarquables, surtout celles dites historiques.

1. Auguste Couder, Le Serment du Jeu de paume (20 juin 1789)

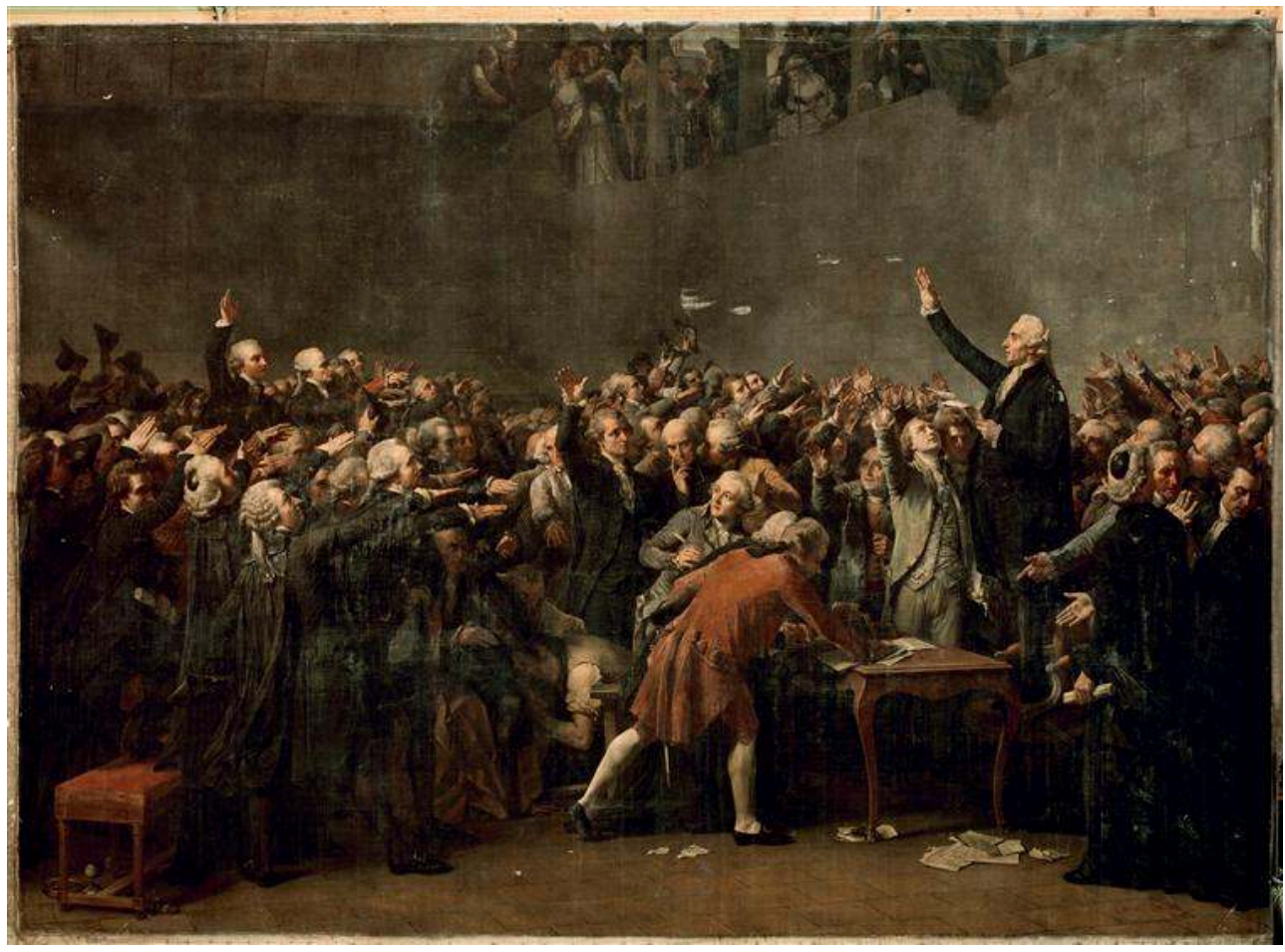

1848, huile sur toile, 421 x 580 cm, Versailles, musée national des châteaux de Versailles et de Trianon.

4 En entrant dans le grand salon, l'attention est d'abord attirée par Le Serment du Jeu de paume (20 juin 1789) de M. Couder (fig. 1). Ce tableau est destiné à orner les galeries du château de Versailles. La composition est bien ordonnée, l'effet en est satisfaisant. Quelques personnes critiquent les bras tendus, les mains levées des membres de l'assemblée des États généraux; mais là se trouve l'inévitable difficulté du sujet et il nous semble que l'artiste a réussi habilement à la surmonter. On s'arrêtera toujours avec intérêt devant la représentation de ce grand fait historique, car cette scène, si vive, si animée, $M$. Couder l'a rendue d'une manière franche et vraie ; l'exécution en est soignée, et laisserait peu à désirer si les carnations n'étaient pas par trop violacées. 


\section{Jean-Victor Schnetz, La Bataille d'Ascalon}

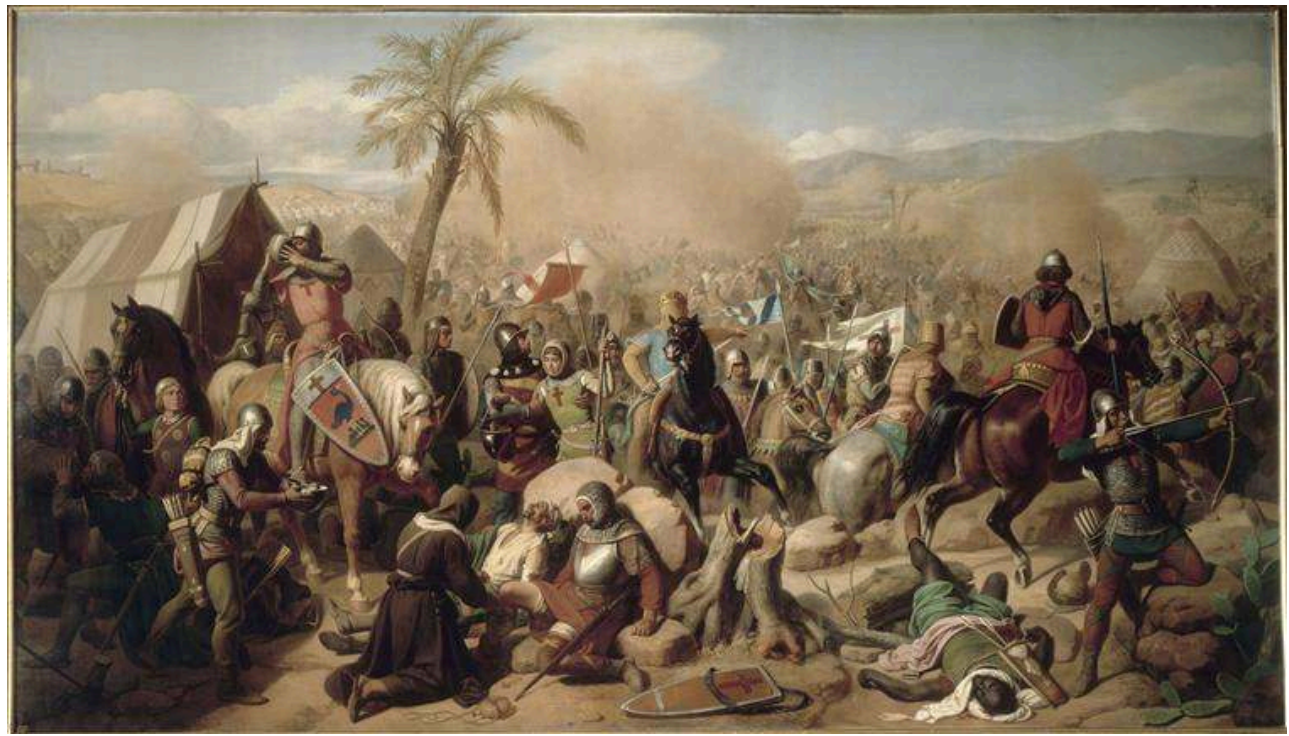

1847, huile sur toile, 315 × 556 cm, Versailles, musée national des châteaux de Versailles et de Trianon.

\section{Jean-Victor Schnetz, Les Funérailles d'une jeune martyre dans les catacombes de Rome}

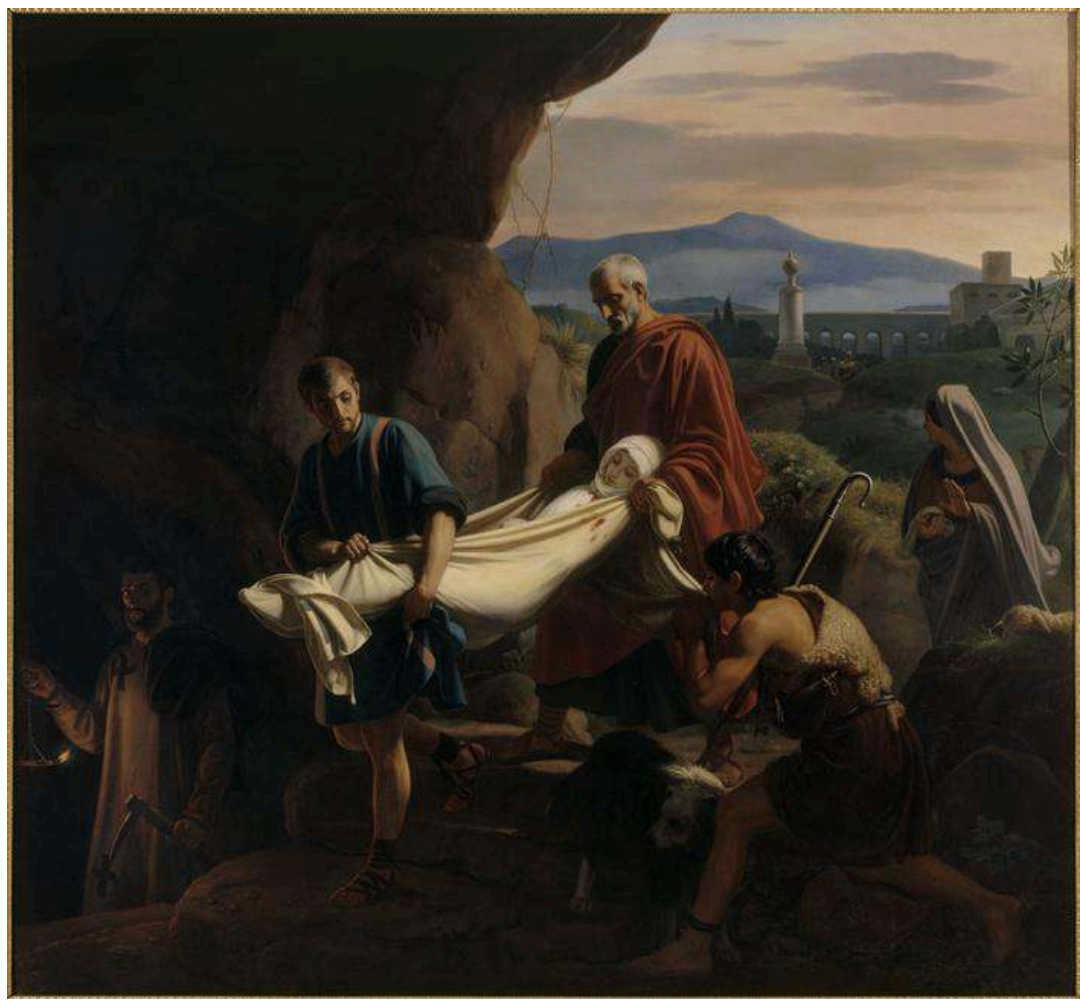

1847, huile sur toile, 338 x 382 cm, Nantes, musée des Beaux-Arts.

5 M. Schnetz a exposé deux ouvrages : La Bataille d'Ascalon (fig. 2), et les Funérailles d'une jeune martyre dans les catacombes de Rome (fig. 3).

6 Un vieillard et un jeune homme portent le corps de la jeune Vierge qui est placé sur un linceul. Un fossoyeur, un flambeau à la main, attend à l'entrée du souterrain le cortège 
funèbre, un jeune pâtre baise le linceul de la sainte martyre, et sur le second plan, on voit une femme portant une fiole remplie du sang de celle qui vient de mourir pour n'avoir pas voulu renier sa foi en Jésus-Christ. Dans le lointain d'un paysage sombre et sévère, on aperçoit des soldats cherchant la trace des chrétiens.

7 Ce sujet, plein de gravité et de tristesse, a été traité par M. Schnetz avec la plus noble simplicité. On est vivement ému en contemplant cette belle composition.

Dans la Bataille d'Ascalon, M. Schnetz a montré combien son talent est flexible et varié. Ce sujet exigeait des qualités bien différentes de celles dont il a donné des preuves dans la Jeune Martyre. Ces qualités ne lui ont pas manqué et il a rendu, sinon avec une scrupuleuse vérité, au moins d'une manière très pittoresque, le fait d'armes que Guillaume de Tyr raconte ainsi :

9 «En 1099, après la prise de Jérusalem, le khalife d'Égypte conçut le projet de couper la retraite aux croisés et de les exterminer au moment où ils penseraient mettre à la voile pour regagner leur patrie. En conséquence, il dirigea sur Ascalon une nombreuse armée, commandée par son émir l'apostat Élasdale. Le comte de Flandres, Baudoin, établi à Ramès, Ramla ou Ramala, envoya prévenir tous ses frères d'armes de l'arrivée des Égyptiens. Le comte de Toulouse, Raimond, et d'autres princes croisés, marchèrent contre les ennemis. À l'apparition soudaine des chrétiens, l'armée d'Élasdale, composée d'éléments hétérogènes, de nations inconnues les unes aux autres, imprévoyante, indisciplinée et ignorante, fut saisie de terreur. Le bruit courut parmi elle que l'Occident envoyait tous ses chevaliers ; alors la terreur s'empara de ces mécréants. Le fer acheva ce que la peur avait commencé. Raimond donna le signal de l'attaque et, après un engagement peu sérieux, 1200 cavaliers et 9000 hommes de pied mirent en fuite ces barbares, dont on ne pouvait même calculer le nombre, tant chaque jour ils avaient reçu de nouveaux renforts. "

10 Ce récit, un peu vague, laissait une grande latitude à l'imagination de l'artiste. M. Schnetz a été très heureusement servi par la science; il a su répandre un vif intérêt sur cette si vaste composition. Au premier plan se trouve un soldat apportant dans son casque de l'eau pour étancher la soif d'un pauvre blessé, qui est secouru par un moine. Ce groupe saisissant de vérité émeut profondément.

11 M. Debon a aussi traité un sujet historique, sur de très grandes dimensions. C'est la défaite d'Attila dans les plaines de Châlons qu'il a représentée. Le roi des Huns, après avoir traversé le Rhin, arrive jusqu'aux plaines de Châlons. Il y rencontre Aetius et Théodoric, qui marchaient vers lui avec un reste de légion, les Alains et les Bourguignons. Mérovée, le jeune roi des Francs, s'étant mis à la tête des Francs et des Gaulois, afin de repousser l'invasion, contribua pour beaucoup à la défaite des Barbares. La mêlée fut effroyable; 170000 morts couvrirent la plaine, Théodoric fut tué, mais Attila vaincu repassa le Rhin.

Il y a sans aucun doute beaucoup à louer dans l'œuvre de M. Debon. Elle atteste des efforts consciencieux, mais aussi il est impossible de ne pas reprocher à cet artiste la confusion qui règne sur sa toile : vainqueurs et vaincus sont enchevêtrés tellement qu'il n'y a pas moyen de les démêler; on ne peut se rendre compte de l'action, et l'intérêt ne se portant sur aucun groupe, sur aucun personnage, il advient qu'on demeure froid en face d'un tableau qui devrait remuer vivement le spectateur.

13 La Prise de Baruth par Amaury II en 1197, de M. Alexandre Hesse, est destinée, de même que la Bataille d'Ascalon, à la décoration de la salle des Croisades du musée de Versailles. 

donnèrent conseil d'aller assiéger Baruth. Les Sarrasins qui étaient sortis du château virent que les chrétiens approchaient rudement par mer et par terre; ils retournèrent en arrière et croyaient rentrer au château mais ils virent la porte fermée par les esclaves chrétiens, qui, pour favoriser les armes des croisés, étaient sur la porte ainsi que sur la maîtresse tour, et criaient : « Dieu, et Saint-Sépulcre! » Les Sarrasins, voyant qu'ils avaient perdu le château, s'enfuirent, et le château demeura aux chrétiens.

\section{Alexandre Hesse, Prise de Baruth par Amaury II en 1197 [La Reprise de Beyrouth occupée par les troupes du sultan Saladin, par Amaury de Lurisman et Henri ler Bratant, octobre 1197]}

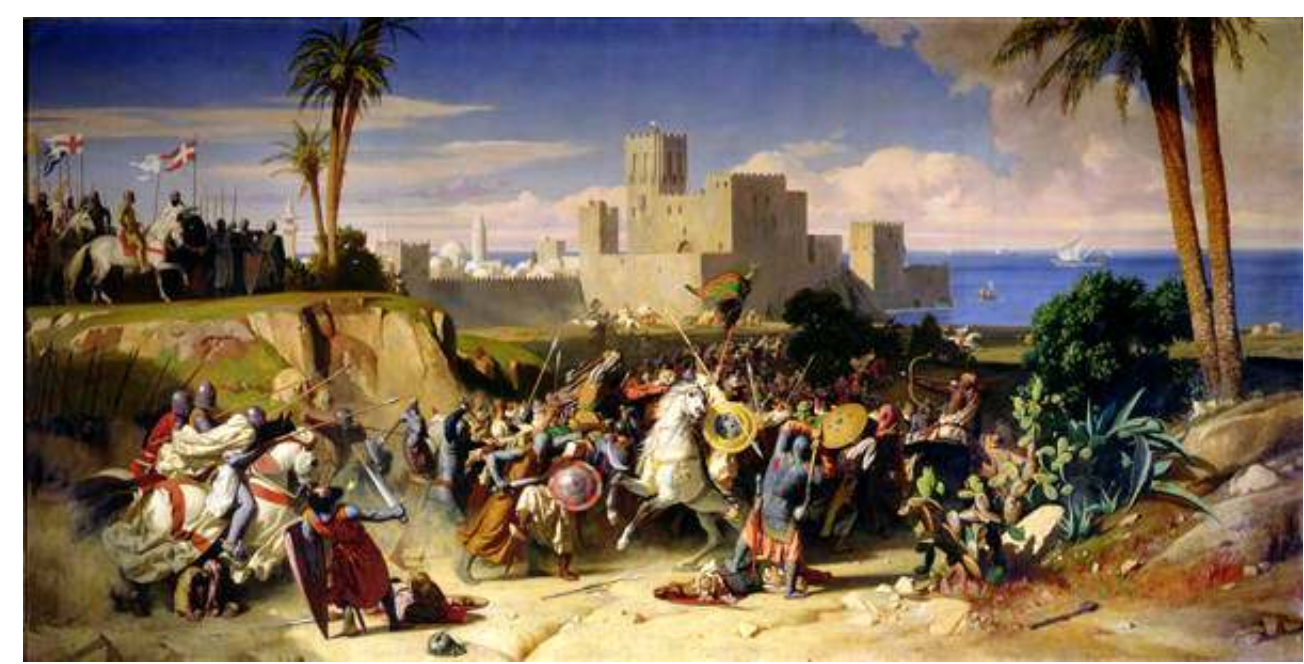

1842, huile sur toile, 173 × 383 cm, Versailles, musée national des châteaux de Versailles et de Trianon.

M. Alexandre Hesse a rendu avec une grande fidélité historique la prise de Baruth (fig. 4). Il y a beaucoup d'éclat et de vigueur dans son faire, peut-être même un peu trop; les contours sont arrêtés si nettement que cela approche de la dureté, et les ombres poussent au noir d'une manière presque exagérée.

La Sainte Cécile de M. Landelle est une œuvre de talent qui fait bien augurer de l'avenir de ce jeune artiste. Il a donné à la sainte une pose simple, gracieuse, et la figure a une expression pleine de noblesse. M. Landelle a bien voulu permettre que votre journal vous offrît une esquisse de son tableau. Vous la recevrez au mois de juin.

La Mort de saint Jean-Baptiste, de M. Gleize, est une œuvre très remarquable dont le dessin offre un mérite réel.

M. Duveau a représenté des émigrants bretons arrêtés par des républicains. Montés sur une faible barque, les émigrants sont parvenus, malgré la tempête, à s'éloigner du rivage. Ils vont bientôt atteindre le navire qui les attend. Tout à coup le passage leur est barré par un canot que dirigent les hommes à la mine sinistre et farouche. Les vieillards semblent frappés de stupeur, les femmes se tordent dans les angoisses du plus affreux désespoir, seul un jeune homme s'est élancé à l'avant de la barque, il tient un poignard à la main et combat corps à corps contre un des républicains. Le jeune émigrant est entièrement vu de dos. Néanmoins on sent qu'il est décidé à mourir s'il ne parvient à forcer le passage. M. Duveau a exprimé de la manière la plus énergique cette lutte suprême au milieu des vagues en fureur. L'aspect général de cette scène est terrifiant. 

rien que de gai, de brillant, de réjouissant dans le sujet qu'il a choisi : le jour du sabbat dans le quartier juif à Constantinople. On voit sur le premier plan les familles juives revêtues de leurs plus riches vêtements et réunies devant leur porte où elles se reposent tout le jour, selon l'usage. Des chefs arabes du désert de Biskra traversent dans le fond.

Les premiers ouvrages de M. Théodore Chassériau se faisaient remarquer par la pureté du dessin, le modelé des formes. Pourquoi le jeune artiste a-t-il complètement changé de manière ? C'est à regretter, car il possède des qualités essentielles, et le mépris qu'il affecte maintenant de la correction ne peut que lui être funeste.

\section{Rosa Bonheur, Taureau}

31

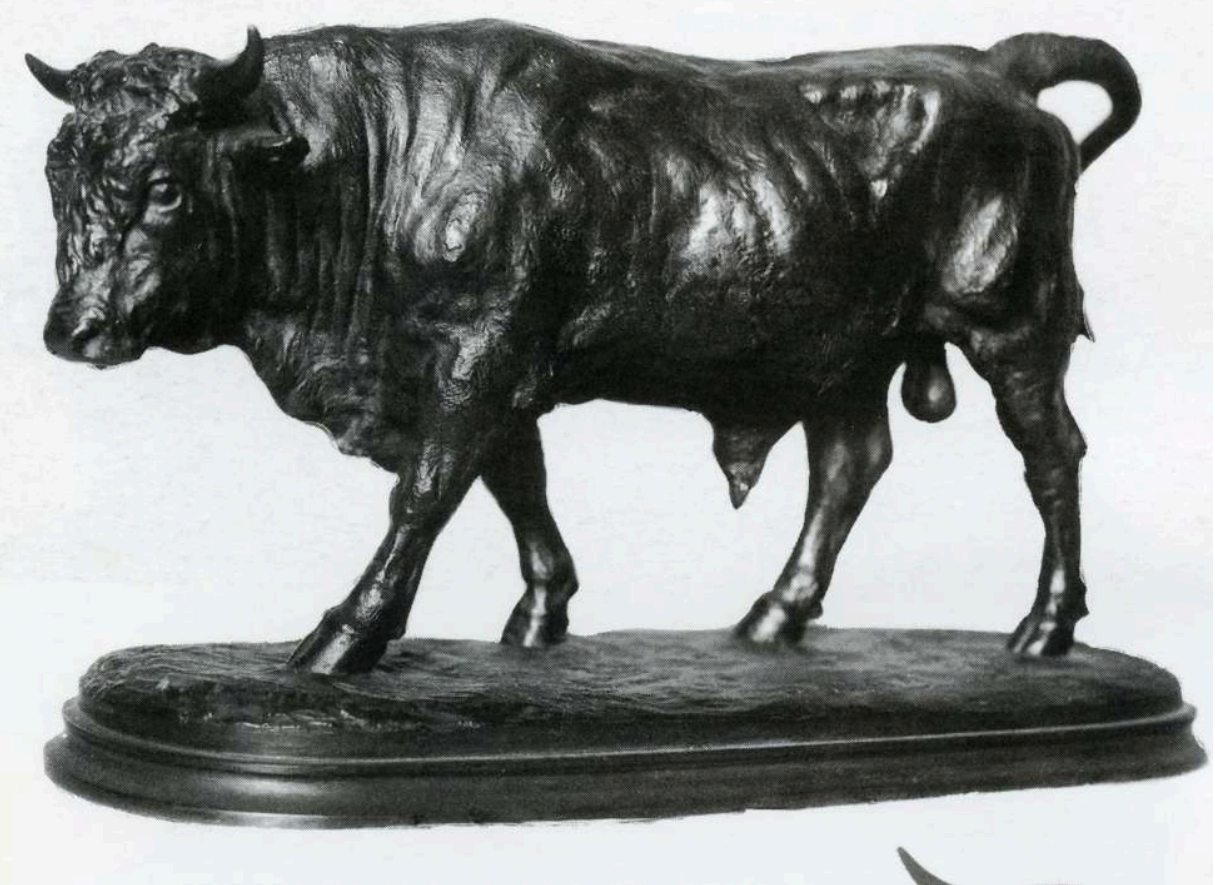

1848, sculpture, bronze, $18 \times 33 \times 11$ cm, Bordeaux, musée des Beaux-Arts 


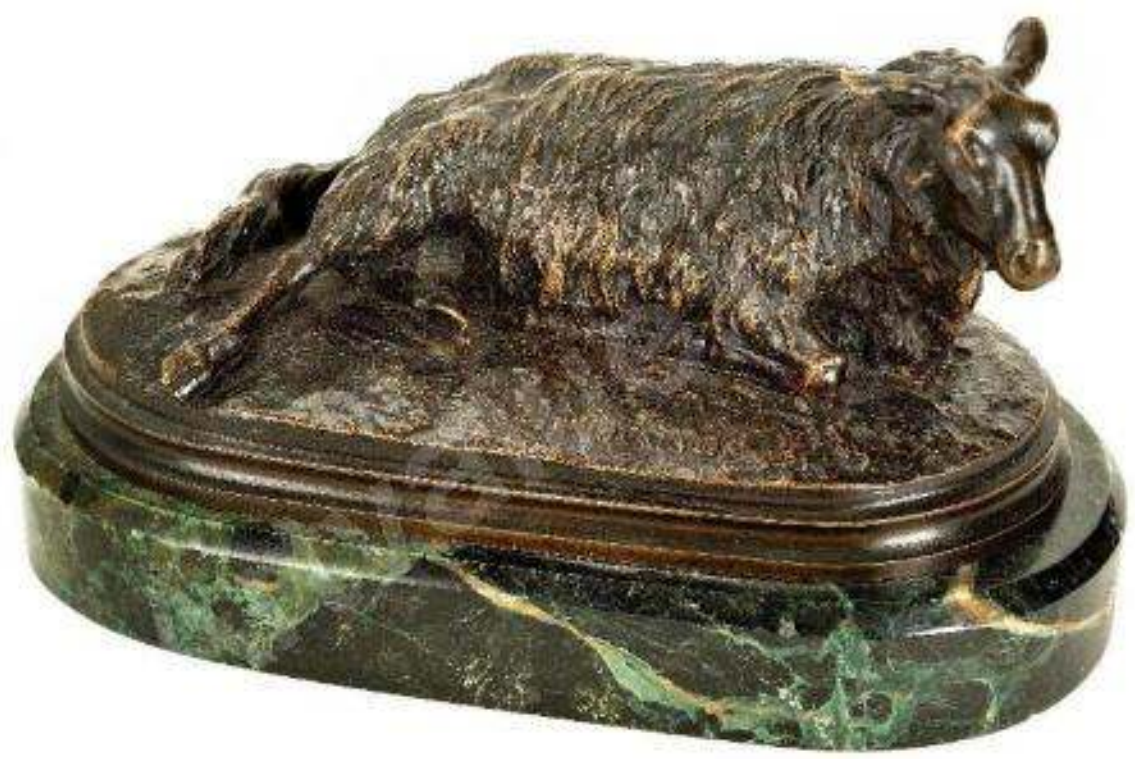

1848, sculpture, bronze, 9,9 × 22,1 x 11,7 cm, Fontainebleau, musée national du château.

21 Nous n'avons encore rencontré de M. Biard que sa Promenade sous le cercle polaire. C'est un beau et bon tableau, saisissant de vérité ; la mer est très belle : les personnages, parmi lesquels on remarque l'auteur, sont bien groupés; le dessin est soigné et l'ensemble offre un bel effet de couleur.

$\mathrm{M}^{\text {lle }}$ Rosa Bonheur a fait d'immenses progrès: ces Bœufs et Taureaux du Cantal sont assurément un de ses meilleurs tableaux de l'exposition de cette année. Il y a de la simplicité et de la vigueur dans sa touche. $\mathrm{M}^{\text {lle }}$ Rosa Bonheur a dû faire de consciencieuses études pour atteindre au degré de perfection qu'elle déploie dans ses paysages. Cette artiste a exposé un essai en sculpture ; son taureau (fig. 5) et sa brebis en bronze (fig. 6) ne sont pas sans mérite.

$M^{m e}$ Edmée de Syva

\title{
«Salon de 1848 - Deuxième article »
}

\author{
Journal des demoiselles, $\mathrm{n}^{\circ} 6,1848,16^{\mathrm{e}}$ année, $4^{\mathrm{e}}$ série, \\ p. 185-187.
}

Les tableaux religieux sont en grand nombre cette année à l'exposition. Parmi les plus remarquables, nous devons mentionner en première ligne la Descente de Croix de M. Achille Devéria (fig. 7). 


\section{Achille-Jacques-Jean-Marie Devéria, Descente de Croix}

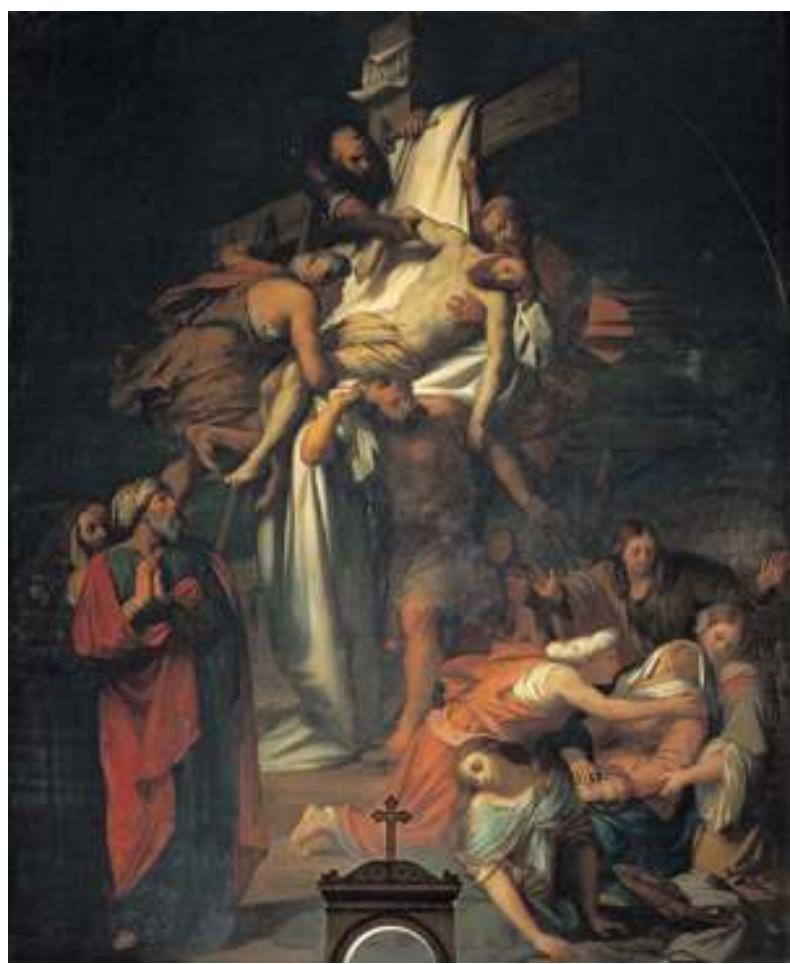

1848, huile sur toile, Chamagnieu, église paroissiale Saint-Christophe.

Cette grande composition est d'un excellent style, le sentiment évangélique y est traduit avec beaucoup d'habileté. La figure du Christ est belle et pleine de noblesse, la majesté divine y est empreinte à un haut degré. L'expression des têtes des autres personnages est d'une vérité parfaite, il est surtout impossible de rendre avec plus de naturel que ne l'a fait $\mathrm{M}$. Achille Devéria la douleur profonde sous laquelle la Vierge tombe affaissée.

24 M. Henri Lehmann possède des qualités éminentes; il est bon dessinateur, et il en a fait preuve dans les tableaux des Saintes Femmes au pied de la Croix. Ici nous ne voyons pas le Christ ; il vient d'être détaché et emporté par Joseph d'Arimathie et par Nicodème. Un lambeau de draperie blanche est demeuré accroché à l'instrument du supplice de celui qui a voulu mourir pour le salut du monde. Le groupe des saintes femmes, dans la toile de M. Lehmann, est disposé avec science, mais il manque de simplicité, la recherche s'y fait trop sentir. On pourrait aussi reprocher à cet artiste de n'avoir pas donné à la douleur de ses personnages un caractère assez élevé. 


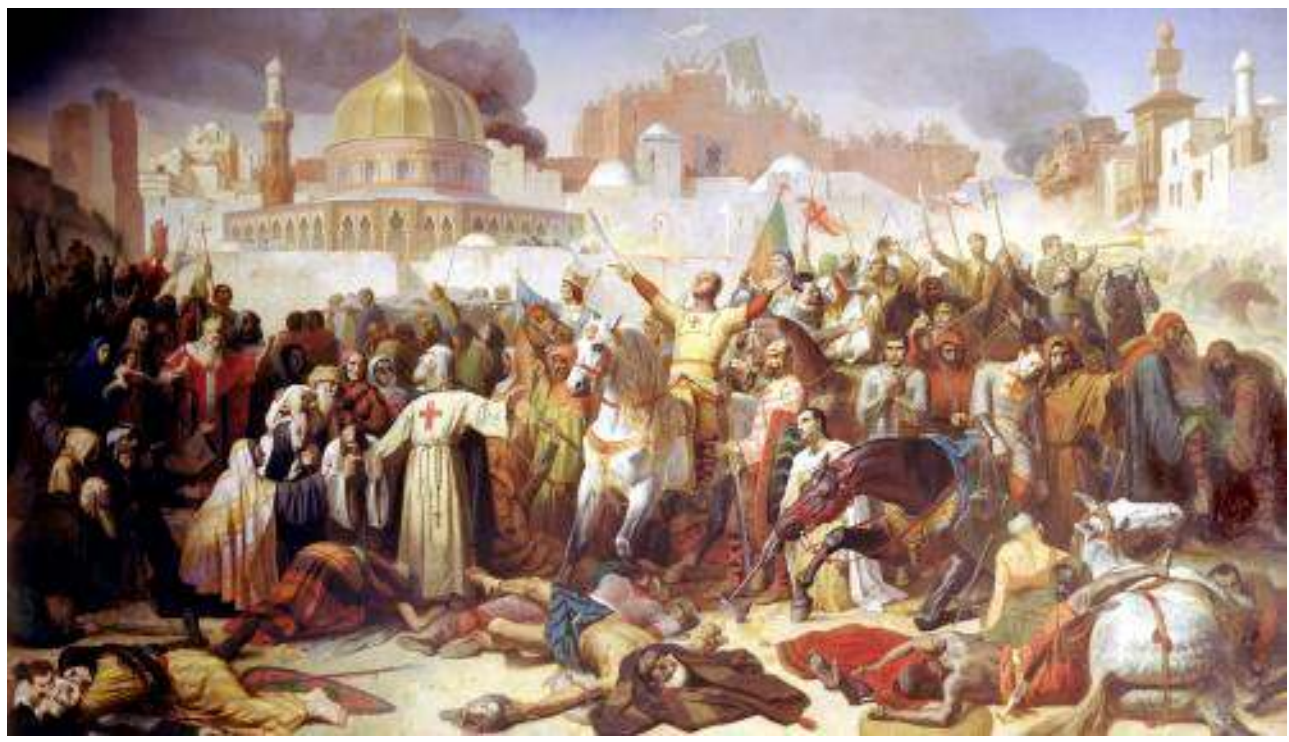

1847, huile sur toile, 324 × 556 cm, Versailles, musée national des châteaux de Versailles et de Trianon.

La Prise de Jérusalem en 1099, de M. Émile Signol, est une vaste composition traitée avec talent, et qui ne manque pas d'une certaine couleur locale (fig. 8). Voici le sujet de ce tableau. Les prédications de Pierre l'Ermite, appuyées par le pape Urbain II, avaient eu un succès inouï. Une multitude innombrable de chrétiens prirent l'engagement d'aller arracher le Saint-Sépulcre au pouvoir des infidèles. Comme signe de leur mission, ils attachèrent une croix à leur manteau. Des obstacles immenses devaient retarder l'accomplissement de la sainte entreprise des chrétiens. Leurs bandes indisciplinées eurent à supporter de grandes vicissitudes, si bien qu'au printemps de l'année 1099, les croisés n'étaient encore occupés qu'à conquérir les villes de la côte de Syrie. Ils furent puissamment secondés dans cette entreprise par les États commerçants d'Italie, surtout par ceux de Gênes et de Pise, fort intéressés à cette conquête dont ils attendaient de grands avantages. Mais au mois de mai, Godefroy de Bouillon et le légat du pape déclarèrent enfin qu'il était temps d'accomplir leur vœu. On réunit les débris de l'armée, et l'on se mit en marche contre Jérusalem. La conquête de la Ville sainte semblait être devenue impossible; les assiégés étaient en plus grand nombre que les assiégeants, qui d'ailleurs manquaient de machines de guerre, de bois et de vivres. Heureusement l'enthousiasme des chevaliers suppléa à leur petit nombre. De l'immense armée des croisés il ne restait que quarante mille hommes, et quoique la garnison égyptienne, jointe aux habitants, s'élevât à soixante mille, Jérusalem fut prise au mois de juillet 1099, et Godefroy de Bouillon fut élu roi de la Terre sainte reconquise.

C'est à la salle des Croisades du musée de Versailles qu'est destinée la Prise de Jérusalem de M. Émile Signol.

La grâce de la composition, le brillant et le charme du coloris distinguent Les Athéniens captifs à Syracuse, de M. Leloir ; Plutarque lui en a fourni le sujet. Dans la vie de Minus, il raconte que l'armée athénienne qui assiégeait Syracuse ayant été complètement battue, la plupart de ceux qui furent faits prisonniers moururent de maladies et de mauvais traitements. Quelques-uns seulement durent leur salut à Euripide; car les Siciliens, aimant passionnément les œuvres de ce poète, traitaient favorablement ceux de leurs 
captifs qui pouvaient leur apprendre de ses vers, et finirent même par leur rendre la liberté.

Il y a de charmantes têtes de femme dans le groupe de Siciliens et Siciliennes qui, assis en demi-cercle, écoutent attentivement et avec une naïve admiration un jeune Athénien réciter les vers de leur poète favori. L'exécution de M. Leloir se distingue par la finesse et l'élégance.

29 M. Jean-Louis Hamon a intitulé Dessus-de-porte une toile qui mérite une destination moins modeste. Où pourrait-on voir une réunion plus gracieuse que celle de ces trois jolies jeunes filles à la mine riante et éveillée? L'une joue du triangle, celle-ci de la guimbarde, l'autre d'un sistre placé près d'elle. Tout plaît, tout réjouit la vue dans cette œuvre d'une originalité remarquable.

On ne saurait trop louer la sobriété d'effet qui caractérise le tableau de M. Guichard, représentant Les Saints Patrons des principales églises de la ville de Japon, invoquant l'appui de la Sainte Vierge, afin que par son intercession notre divin Sauveur répande ses faveurs sur cette ville. La correction du dessin, l'harmonie de la couleur, la simplicité de la composition attestent que M. Guichard a fait de laborieuses études, et que, sans cesser d'être original, on peut s'inspirer des œuvres des grands maitres de l'art.

\section{Eugène Devéria, Femme des Pyrénées [Femme de la vallée d'Ossau et son enfant]}

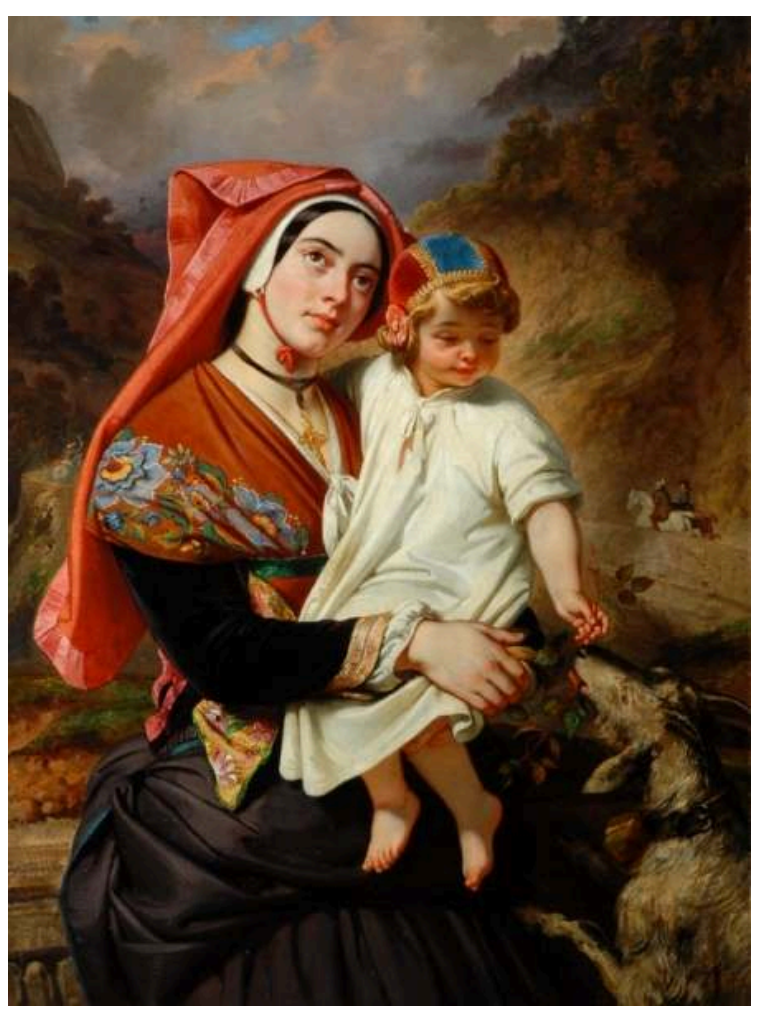

1847-1848, huile sur toile, 29,2 × 97,3 cm, Bowes Museum, Barnard Castle.

31 M. Eugène Devéria ne nous a donné qu'un seul tableau, représentant une Femme des Pyrénées, vue à mi-corps (fig. 9). Près d'elle est son enfant donnant à manger à une chèvre. L'aspect de ce groupe est très pittoresque ; la pose de la mère et de l'enfant a une grâce parfaite, et le tout est peint avec cette magie de couleur, cette verve étincelante, qualités distinctives du talent de $M$. Eugène Devéria. 

lequel les figures sont de grandeur naturelle, est remarquable par l'absence d'affectation, le ton doux et harmonieux du coloris, et la noble élégance des formes des personnages. Les deux autres tableaux de M. Schopin appartiennent à la peinture de genre. Les sujets sont également tirés de la Bible. C'est d'abord la Réception de Jacob dans la famille de Laban, puis la Première Entrevue de Rachel et de Jacob. M. Schopin excelle à rendre les scènes bibliques, qu'il empreint d'un sentiment très naif ; sa touche fine et brillante y répand une irrésistible séduction.

MM. Amaury-Duval, Henri Lehmann, Alexandre Hesse et Hippolyte Flandrin ont exposé des portraits qui, par le style, la pureté du dessin, la perfection du modèle, la vérité de la couleur, s'élèvent à la hauteur de la peinture historique. Au reste, M. Hippolyte Flandrin vient de se placer au premier rang des peintres contemporains par les belles fresques dont il a orné le chœur de Saint-Germain-des-Prés. Cette grande œuvre suffirait à illustrer un artiste.

Parmi les paysagistes habitués à obtenir les suffrages du public éclairé, nous citerons MM. Paul Flandrin, Philippe Rousseau, Cabat, François, Buttura, Lorot, Flers, Charles Leroux, Desgoffe, qui tous, cette année, ont parfaitement justifié leur réputation.

$M^{m e}$ Edmée de Syva

\section{«Salon de 1848 - Troisième et dernier article »}

Journal des demoiselles, $\mathrm{n}^{\circ} 7,1848,16^{\mathrm{e}}$ année, $4^{\mathrm{e}}$ série, p. 214-215.

La Condamnation de Jean Huss, de M. Martersteig, rend bien l'effet grave et sévère que comporte la situation. Au mérite d'une exécution très soignée cette toile réunit celui d'une grande fidélité historique. Condamné au feu pour crime d'hérésie, en 1415, par le concile de Constance, Jean Huss vient de s'agenouiller en présence de ses juges et il prie Dieu pour eux. Cette scène solennelle est retracée d'une manière saisissante par M. Martersteig.

Jean Huss monta sur le bûcher le 15 juillet 1415. Près de mourir, il s'écria : «Vous tuez une oie (huss signifie oie, en bohémien), mais dans cent ans vous verrez naître un cygne. » Luther commença ses prédications en 1516, et ses partisans ne manquèrent pas de rappeler la prédiction de Jean Huss.

Deux autres toiles de M. Martersteig retracent des traits de la vie du fondateur de la Réforme : dans l'une, on voit Luther brûlant la bulle du pape à Wittemberg et dans l'autre, Luther devant la diète assemblée à Worms.

En 1517, Luther afficha à la porte de l'église de Wittemberg les thèses qui servaient de bases à la Réforme, en invitant à venir les discuter avec lui ; ces thèses s'élevèrent à quatre-vingt-quinze. Jean Eck, célèbre théologien de ce temps et un des plus violents ennemis des doctrines de Luther, décida Léon $\mathrm{X}$ à prononcer une bulle qui condamnait quarante et un articles des écrits de son antagoniste. Les livres de Luther furent brûlés à Louvain, à Mayence et à Cologne. Luther, poussé par son caractère irascible, fit élever un bûcher le 10 décembre 1520, devant la porte de Wittemberg. En présence de l'université entière et du peuple assemblé, on y entassa par son ordre les rescrits et les décrétales des papes, les livres du droit canon et les écrits d'Eck, puis il y fit mettre le feu, et quand la flamme brilla, il y jeta de sa propre main la bulle d'excommunication 
lancée contre lui. C'était se mettre en guerre ouverte avec l'Église. Le pouvoir temporel se joignit bientôt au pouvoir spirituel; Charles Quint, récemment élu empereur d'Allemagne, intervint dans ce grand débat religieux; Luther fut cité à la diète de Worms, afin de rendre compte de ses écrits et de ses actions devant l'empereur luimême. Luther obéit, arriva à Worms le 16 avril 1521, et le lendemain, portant encore son habit de moine, il comparut devant l'empereur, qui était entouré de tout le corps germanique. Cette assemblée imposante parut l'éblouir un instant, mais elle n'ébranla pas sa résolution, et il présenta sa défense avec une fermeté inaccessible aux promesses et aux menaces. Il reconnut qu'il était l'auteur des écrits condamnés par le Saint-Siège, et refusa d'en rien rétracter. Les dernières paroles de sa défense furent celles-ci : «Me voilà devant vous ; je ne peux ni parler ni agir autrement. Mon Dieu, soyez-moi en aide ! Amen.»

M. Martersteig a dû étudier profondément le caractère de Luther, car il a rendu avec une vérité parfaite le fougueux prédicateur de la Réforme, ce moine obscur et pauvre, devenu si célèbre.

L'immortel ouvrage de Miguel de Cervantes, Don Quichotte, a fourni à M. Penguilly l'Haridon le sujet de deux charmantes toiles, empreintes d'une grande originalité. Sur l'une, on voit le noble Hidalgo, la lance en arrêt; une ardeur chevaleresque le transporte; il précipite Rossinante au galop, afin d'aller pourfendre les moulins à vent que son imagination transforme en autant de géants. Sur la seconde toile, c'est le retour de Don Quichotte. Quel contraste! Le malheureux chevalier, le corps brisé, la mort dans l'âme, est monté sur le grison de son écuyer; Rossinante, éreinté, suit derrière, et Sancho, qui dirige la triste cavalcade, frappe à la porte du manoir, qui ne verra plus sortir Don Quichotte que pour aller à sa dernière demeure.

41 L'aspect de ces deux compositions est attendrissant. Une mélancolie profonde y est répandue, et la touche fine et spirituelle de M. Penguilly leur a donné un charme indicible.

42 Il y a de la grâce, de la coquetterie, de la finesse dans la manière dont $\mathrm{M}$. Chevet a retracé la scène de Charles VII et Agnès Sorel chez l'astrologue.

43 Le roi Charles VII, voulant connaître le sort qui l'attend, consulte un astrologue en présence d'Agnès, qui veut aussi savoir quelle destinée lui est réservée. Le devin, probablement pour la flatter, lui prédit qu'elle régnera longtemps sur le cœur d'un grand roi. Agnès, saisissant cette occasion de faire entendre la vérité à Charles, se lève, lui fait une profonde révérence, et lui demande la permission de se rendre à la cour du roi d'Angleterre pour y remplir sa mission: "Sire, ajouta-t-elle, c'est lui, sans nul doute, que concerne la prédiction, puisque, bientôt, vous allez perdre votre couronne, et qu'il va la réunir à la sienne. " Ses paroles firent une telle impression sur le cœur du roi, que les larmes lui vinrent aux yeux. De là, il reprit courage, et renonçant à tous les divertissements, il fit si bien, par sa vaillance, qu'il chassa les Anglais de son royaume.

M. Peyronnet a rendu avec infiniment de bonheur et de talent Le Retour au village. Je m'abstiendrai de tout éloge, M. Peyronnet ayant permis qu'une gravure de cet intéressant tableau vous fût donnée dans votre journal.

$\mathrm{M}^{\text {lle }}$ Fabre d'Olivet a puisé le sujet d'un fort joli tableau de genre dans une nouvelle pleine d'intérêt de M. Töpffer. Il y a beaucoup de grâce et de sentiment dans la composition de $\mathrm{M}^{\text {lle }}$ Fabre d'Olivet. Ses deux femmes sont bien pesées, et il serait difficile, je crois, d'interpréter d'une manière plus heureuse les héroïnes de M. Töpffer. 
46 M. Auguste Moynier a parfaitement reproduit la douce et gracieuse physionomie de $\mathrm{M}^{\mathrm{me}} \mathrm{F}$. T. On ne saurait trop adresser de félicitations à l'artiste sur l'habileté dont il a fait preuve en rendant son modèle avec une si grande vérité.

$47 \quad \mathrm{M}^{\text {lle }}$ Anna Martin a exposé une Étude de jeune fille et plusieurs portraits d'un bon style, et qui font beaucoup d'honneur à son talent déjà si bien connu.

$M^{m e}$ Edmée de Syva

\section{ANNEXES}

Lire l'introduction à Edmée de Syva écrite par Amandine Gorse 


\section{Bibliographie générale}

\section{Sources}

Addison Joseph, Remarks on Several Parts of Italy \&c. In the Years 1701, 1702, 1703, Londres, Tonson, 1705.

Agoult Marie (d'), alias Daniel Stern, « Nouvelle Salle de l'École des beaux-arts, peinte par M. Paul Delaroche », La Presse, 12 décembre 1841.

Agoult Marie (d'), alias Daniel Stern, « Le portrait de Cherubini par M. Ingres », La Presse, 7 janvier 1842.

Agoult Marie (d'), alias Daniel Stern, «Le Salon. 1843 », La Presse, 25 mars 1843.

Agoult Marie (d'), alias Daniel Stern, «Les Salons de Paris », Allgemeine Zeitung. Beilage 133, 13 mai 1843.

Agoult Marie (d'), alias Daniel Stern, Histoire de la Révolution de 1848, 3 vol., Paris, G. Sandré, 1850-1853.

Agoult Marie (d'), alias Daniel Stern, Dante et Goethe, Paris, Didier et C $C^{\text {ie }}, 1866$.

Agoult Marie (d'), alias Daniel Stern, Mes Souvenirs 1806-1849, Paris, Calmann-Lévy, 1877.

[Anonyme], A Sketch of Modern France. In a Series of Letters to a Lady of Fashion. Written in the Years 1796 and 1797, during a Tour through France. By a Lady, C. L. Moody (éd.), Londres, Cadell and Davies, 1798.

[Anonyme], Alcune lettere inediti di donne illustri al Canova, Bassano, Tip. Bassegio, 1852.

[Anonyme], Description historique des tableaux de l'église de Paris [réparés en 1781], Paris, Imprimerie de la Veuve Herissant, 1781.

[Anonyme], Mélanges poétiques et littéraires dédiés à la jeunesse, Paris, A. Sirou et Desguers, 1846.

[Anonyme], „Miscellen“, Neue Jahrbücher für Philologie und Pädagogik, t.XLVII, nº 4, 1846, p. 448-450.

[Anonyme], « Salon de 1842. Charge et portraits », Le Charivari, 8 mai 1842.

[Anonyme], « Salon de 1843 », L'Artiste, $3^{\mathrm{e}}$ série, n 3, 2 avril 1843, p. 209-213.

[Anonyme], «Salon de 1846 », Journal des artistes et Bulletin de l'ami des arts, vol. 3, 26 avril 1846, p. 147-150. 
[Anonyme], „Venetianische Briefe über neudeutsche und altitalienische Malerei. Erster Artikel“, Blätter für die literarische Unterhaltung, $\mathrm{n}^{\circ}$ 214, 2 août 1839.

B., "Salon de l'an X », Journal des dames et des modes, $\mathrm{n}^{\circ}$ 9, 15 brumaire an 11 [6 novembre 1802], p. 67-70.

Baillie Marianne, First Impressions on a Tour Upon the Continent in the Summer of 1818 through Parts of France, Italy, Switzerland, the Borders of Germany and a Part of French Flanders, Londres, Murray, 1819.

Ballanche Pierre Simon, Lettres de Ballanche à Madame Récamier, 1812-1845, Agnès Kettler (éd.), Paris, Honoré Champion, 1996.

Barbey d'Aurevilly Jules, Les Bas-bleus. Les Euvres et les Hommes, t. V, Paris, Palmé, 1878 ; Genève, Slatkine reprints, 1968.

Balzac Honoré (de), Les Comédiens sans le savoir, Paris, E. Proux, 1846.

Bertuch Friedrich Justin, Allgemeine Literaturzeitung, n 207, t. II, 1807, p. 413-414.

Blagdon Francis, Paris as it was and as it is, 2 vol., Londres, Baldwin, 1803.

Briquet Fortunée, Dictionnaire historique, littéraire et bibliographique des Françaises et des étrangères naturalisées en France : connues par leurs écrits ou par la protection qu'elles ont accordée aux gens de lettres..., Paris, Indigo \& Côté-Femmes, [1804] 1997.

Briquet Fortunée, Ode sur la mort de Dolomieu, précédée d'une notice sur ce naturaliste, et suivie d'une lettre du secrétaire de la classe de littérature et beaux-arts de l'Institut national de France..., Paris, C. Pougens, 1802.

Briquet Marguerite, Ode à Lebrun, Paris, [s.n.], 1803.

Brun Sophie Christiane Friederike, Römisches Leben, 2 vol., Leipzig, Brockhaus, 1833.

Bury Richard, Histoire abrégée des philosophes et des femmes célebres, Paris, Chez Monory avec approbation \& privilege du roi, 1773.

Calonne Charles-Alexandre, Réponse de M. de Calonne à la dernière lettre de Madame Lebrun, [s.1.], [s.n.], 1789.

Candeille Julie, "De Girodet, et de ses ouvrages sur l'Anacréon et l'Énéide", Annales de la littérature, $\mathrm{VI}^{\mathrm{e}}$ année, 23, 1826, p. 298-305.

Candeille Julie, « Notice biographique sur Anne-Louis Girodet et Amélie-Julie Candeille pour mettre en tête de leur correspondance secrète », MS. Nouvelles acquisitions françaises 665, Bibliothèque nationale de France, 1829.

Candeille Julie, Lydie, ou les Mariages manqués, Paris, Barba, 1809.

Candeille Julie, Vaudeville de Catherine, ou la Belle fermiere : avec accompagnement de guittare, [Paris], [s.n.], 1793.

Candeille Julie, Souvenirs de Brighton, de Londres et de Paris, et quelques fragmens de littérature légère, Paris, Delaunay/Mongie/Lenormand/L'Huillier, 1818.

Canova Antonio, Edizione nazionale delle opere di Antonio Canova, vol. 1 et 2, Epistolario (1816-1817), Hugh Honour et Paolo Mariuz (éd.), Rome, Salerno, 2002-2003.

Carette $\left(\mathrm{M}^{\mathrm{me}}\right)$, Madame Vigée Le Brun par Madame Carette, Paris, Paul Ollendorff, 1894.

Carette $\left(\mathrm{M}^{\mathrm{me}}\right)$, Choix de mémoires et écrits des femmes françaises aux XVII ${ }^{e}$ XVIII et XIXe siecles avec leurs biographies par $M^{\text {me }}$ Carette, née Bouvet. $M^{\text {me }}$ de Staal-Delaunay, 6 e éd., Paris, Paul Ollendorff, 1895.

Carey Frances Jane, Journal of a Tour in France in the Years 1816 and 1817, Londres, Taylor and Hessey, 1823.

Carlyle Jane, Letters and Memorials of Jane Welsh Carlyle, New York, C. Scribner's Sons, 1883.

Carové Friedrich Wilhelm, Der Saint-Simonismus und die neuere französische Philosophie, Leipzig, T. C. Hinrichssche Buchhandlung, 1831. 
Carové Friedrich Wilhelm, Was ist der St. Simonismus? Oder Lehren, Grundsätze und Verfassung der in neuester Zeit entstandenen Simonistischen Religion, welche jetzt so großes Aufsehen erregt und in Frankreich bereits zahlreiche Anhänger gefunden hat [...], Quedlinburg/Leipzig, Basse, 1832.

[Carter Anne], Letters from a Lady to her Sister during a Tour to Paris in the Months of April and May 1814, Londres, Longman, 1814.

Catalogue des tableaux, dessins, bas-reliefs \& statues exposés dans les galeries du musée de la ville de Rennes, cat. expo., Jan Jules (éd.), Rennes, Le Roy, 1884.

Champsaur Félicien, «Les femmes au Salon de 1879 », Bas-bleu. Gazette mondaine, n² 2, 22 juin 1879.

Chateaubriand François-René (de), «Lettres à Madame Récamier ", Critique-Paris, nº 617, 1998, p. 635-643.

Chateaubriand François-René (de), Lettres à Madame Récamier, Maurice Levaillant et Emmanuel Beau de Loménie (éd.), Paris, Flammarion, 1951.

Chazet Alissan (de), Mémoires, souvenirs, œeuvres et portraits, Paris, Postel, 1837.

Chesnel de la Charbouclais Louis, Biographie des femmes auteurs contemporaines françaises : avec portraits, Paris, Armand-Aubrée, 1836.

Chézy Helmina (von), "Notice nécrologique », Magasin encyclopédique ou Journal des sciences, des lettres et des arts, t. I, 1808, p. 119-124.

Chézy Helmina (von), Leben und Kunst in Paris seit Napoleon I., Berlin, Akademie-Verlag, (1804) 2009.

Clément-Hémery Albertine, Souvenirs de 1793 et 1794, Cambrai, Leisne-Daloin, 1832.

Coicy Madame (de), Les Femmes comme il convient de les voir, Paris, Bacot, 1785.

Collin de Plancy Jacques-Albin-Simon, Almanach des femmes célèbres par leurs talents, leur courage, ou leurs vertus. [Par Gabrielle de Paban] 1823..., Paris, Ladvocat, 1823.

Collin de Plancy Jacques-Albin-Simon, Année des dames, ou Petite biographie des femmes célèbres pour tous les jours de l'année :... par Mme Gabrielle de $P^{* * * . . ., ~ P a r i s, ~ C r e v o t, ~} 1820$.

Colston Marianne, Journal of a Tour in France, Switzerland, and Italy, during the Years 1819, 20, and 21. Illustrated by Fifty Lithographic Prints, from original Drawings, taken in Italy, the Alps, and the Pyrenees, Paris, Galignani, 1822.

Comte Auguste, Lettres d'Auguste Comte à John Stuart Mill, 1841-1846, Paris, E. Leroux, 1877.

Constant Benjamin, Lettres à Madame Récamier (1807-1830), Paris, Slatkine Reprints, (1864) 1970.

Constant Benjamin, Lettres de Benjamin Constant à Madame Récamier, Dijon, université de Bourgogne, (1882) 1990.

Craven Elizabeth, A Journey Through the Crimea to Constantinople in a Series of Letters, Londres, Robinson, 1789.

Daumier Honoré, Intellectuelles : bas-bleus et femmes socialistes, préf. Françoise Parturier, catalogue et notices de Jacqueline Armingeat, Paris, Vilo, [s.d.] 1974.

Desbordes-Valmore Marceline, Correspondance intime de Marceline Desbordes-Valmore : publié par Benjamin Riviere..., Paris, A. Lemerre, 1896.

Desbordes-Valmore Marceline, Huit femmes, Genève, Librairie Droz, (1845) 1999.

Desbordes-Valmore Marceline, L'Atelier d'un peintre, rééd. Lille, Miroirs éd., (1833) 1992.

Desbordes-Valmore Marceline, La Jeunesse de Marceline ou l'Atelier d'un peintre. Avec une préface et des notes par A.-J. Boyer d'Agen. Édition illustrée d'un portrait et de 26 lithographies originales par Charles, Paris/Argenteuil, Éditions de la Nouvelle Revue française/impr. de Coulouma, 1922. 
Desbordes-Valmore Marceline, Le Salon de Lady Betty : mœurs anglaises, par $M^{m e}$ Desbordes-Valmore..., Paris, Charpentier, 1936.

Desbordes-Valmore Marceline, Lettres de Marceline Desbordes à Prosper Valmore, Paris, Éditions de la Sirène, 1924.

Desbordes-Valmore Marceline, Euvre poétique intégrale : textes versifiés, publiés \& inédits, Lyon, André, 2007.

Drohojowska Antoinette, Les Femmes illustres de la France, Paris, Lehuby, 1862.

Dufrénoy, Biographie des jeunes demoiselles, ou Vies des femmes célèbres, depuis les Hébreux jusqu'a nos jours..., Paris, D'Alexis Eymery, 1816.

Dupin A., La France illustrée par ses femmes, ou Beaux Exemples de l'amour filial de tendresse etc., Paris, [s.n.], 1833.

Duval Amaury, Monuments des arts du dessin chez les peuples tant anciens que modernes, Paris, Fermin Didot, 1829.

E.-J. C*** (abbé), Histoire des enfants célèbres, Limoges, E. Ardant, 1876.

Ellet Elizabeth, The Queens of American Society. [With illustrations], New York, [s.n.], 1867.

Ellet Elizabeth, The Women of the American Revolution, New York, Haskell House, 1969.

Ellet Elizabeth, Women Artists in all Ages and Countries, Londres, [s.n.], 1859.

Explication des ouvrages de peinture, sculpture, architecture et gravure, des artistes vivans, exposés au musée Napoléon, le $1^{\text {er }}$ novembre 1812, Paris, De l'Imprimerie des sciences et arts, 1812.

Explication des ouvrages de peinture, sculpture, architecture et gravure, des artistes vivans, exposés au Musée royal des arts, le $1^{\text {er }}$ novembre 1814, Paris, Dubray, 1815.

Fechner Gustav Theodor, alias $\mathrm{D}^{\mathrm{r}}$ Mises, Ueber einige Bilder der zweiten Leipziger Kunstausstellung, Leipzig, Voos, 1839.

Feller François-Xavier (de) et al., Biographie universelle, ou Dictionnaire des hommes qui se sont fait un nom par leur génie, leurs talents, leurs vertus [...], t. VIII, Lyon, J.-B. Pélagaud, 1851.

Fiorillo Johann, Geschichte der zeichnenden Künste, Göttingen, Rosenbusch, 1805.

Fouqueau de Pussy Jeanne-Justine, [« Nécrologie: Alida de Savignac »], Journal des demoiselles, 1847, p. 123.

Francia Ennio, Custine Delfina (de) et Stolberg Luisa, Guilietta Récamier a Canova. Lettere inedite, Rome, Edizioni di storia et letteratura, (« Quaderni di cultura francese », 13), 1972.

Friesen Hermann, Drei Briefe zu Widerlegung der Kreuz- und Quergedanken eines Dresdners Ignoranten vor d. Düsseldorf, Dresde, Blochmann, 1837.

Froude James Anthony (éd.), Letters and Memorials of Jane Welsh Carlyle, t. I, Londres, C. Scribner's Sons, 1883.

G. Marie-Camille (de), «Salon de 1834 », Tribune des femmes 2, n 10 , avril 1834, p. 158-164.

Gaudin Martin-Michel-Charles, Mémoires, souvenirs, opinions et écrits du duc de Gaëte (Martin-MichelCharles Gaudin), ancien ministre des finances, ex-député, gouverneur de la Banque de France, Paris, Baudouin frères, 1826-1834.

Gautier d'Agoty Jacques, Observations sur la peinture et sur les tableaux anciens et modernes, Paris, Jorry, 1753.

Genlis Caroline, Les Tableaux de M. le comte de Forbin, ou La Mort de Pline l'Ancien, et Inès de Castro : nouvelles historiques, Paris, Maradan, 1817.

Genlis Stéphanie-Félicité Du Crest (de), Adèle et Théodore, ou Lettres sur l'éducation, contenant tous les principes relatifs aux trois différens plans d'éducation des princes, des jeunes personnes, \& des hommes, Paris, Lambert \& F. J. Baudouin, 1782. 
Genlis Stéphanie-Félicité Du Crest (de), «Le Journal d'éducation de Pulchérie », Valence, Archives, 27 septembre 1783 (inédit).

Genlis Stéphanie-Félicité Du Crest (de), Les Veillées du chateau, ou Cours de morale à l'usage des enfants, Maestricht, Chez J.E. Dufour \& P. Roux, 1784.

Genlis Stéphanie-Félicité Du Crest (de), Nouveaux contes moraux et nouvelles historiques, Paris, Maradan, an XIII [1804].

Genlis Stéphanie-Félicité Du Crest (de), Les Monuments religieux, ou Description critique et détaillée des monuments religieux, tableaux et statues... qui se trouvent maintenant en Europe et dans les autres parties du monde..., Paris, Maradan, 1805.

Genlis Stéphanie-Félicité Du Crest (de), Arabesques mythologiques, ou Les Attributs de toutes les divinités de la fable : en 54 planches gravées d'après les dessins coloriés de madame de Genlis..., Paris, Chez Charles Barrois libraire Place du Carrousel $n^{\circ} 26,1810$.

Genlis Stéphanie-Félicité Du Crest (de), Les Annales de la vertu, ou Histoire universelle, iconographique et littéraire..., Vienne, [s.n.], 1814.

Genlis Stéphanie-Félicité Du Crest (de), Mémoires inédits de Madame la comtesse de Genlis, sur le dixhuitieme siècle et la Révolution française, depuis 1756 jusqu'à nos jours, Paris, Ladvocat, 1825.

Genlis Stéphanie-Félicité Du Crest (de), De l'influence des femmes sur la littérature française comme protectrices des Lettres ou comme auteurs, Paris, Lecointe et Durey, (1811) 1826.

Genlis Stéphanie-Félicité Du Crest (de), Contes moraux, Paris, Hachette, 1868.

Genlis Stéphanie-Félicité Du Crest (de), Choix de mémoires et écrits des femmes françaises aux XVII XVIII et XIX siecles, avec leurs biographies : par $M^{\text {me }}$ Carette, née Bouvet, $M^{m e}$ la Comtesse de Genlis..., Paris, P. Ollendorff, 1893.

Genlis Stéphanie-Félicité Du Crest (de), Mémoires de Madame de Genlis, Paris, Mercure de France, (1857) 2004.

Girodet-Trioson Anne-Louis, Lettres de Girodet à Julie Candeille, Orléans, Société archéologique et historique de l'Orléanais, 2003.

Godefroid Joseph-Ferdinand, Description historique des tableaux de l'église de Paris, Paris, Veuve Hérissant, 1781.

Goncourt Edmond et Jules, « Une revendeuse », dans Une voiture de masques, Paris, E. Dentu, 1856, p. 92-100.

Gouges Olympe (de), "Déclaration des droits de la femme et de la citoyenne », dans Opinions de femmes. De la veille au lendemain de la Révolution Française, Paris, Côté-Femmes éd., 1989 ; rééd. dans Évelyne Morin-Rotureau (dir.), Combats de femmes 1789-1799, Paris, Autrement, 2003, p. 223-226.

Granges de Surgères Anatole, Les Françaises du XVIII siecle : portraits gravés : ouvrage orné de douze portraits d'après les originaux, Paris, Dentu, 1887.

Guiffrey Jules et Académie de Saint-Luc, Livrets des expositions de l'Académie de Saint-Luc à Paris pendant les années 1751, 1752, 1753, 1756, 1762, 1764 et 1774, Paris, Baur et Détaille, 1976.

Guiffrey Jules, «Souvenirs de madame Vigée-Lebrun. Paris : Charpentier, 1869 », Revue critique d'histoire et de littérature, 12 février 1870, p. 109-112.

Guinot Eugène, Physiologie du provincial à Paris, Paris, Aubert, [1842].

Harlor, « Le Salon des femmes peintres et sculpteurs », La Fronde, nº 2109, 16 février 1905.

Haza Johanna (von), alias Heinrich Paris, Éphémères rhénanes, feuilles volantes, Strasbourg, G. Silbermann, 1844. 
Haza Johanna (von), alias Heinrich Paris, Tablettes grammaticales. Analyse généalogique des principes de la grammaire française. Atlas de seize tableaux avec texte explicatif et modèle d'exercices, Paris, Renouard, 1842.

Haza Johanna (von), alias Paris Heinrich, „Einige Worte der Fürsprache für einen zu wenig beachteten französischen Dichter", Ost und West, juillet 1841, p. 219, 226-227, 230-231.

Haza Johanna (von), alias Paris Heinrich, Erste Eindrücke eines Laien auf der ersten Leipziger Kunstausstellung im Herbste 1837, Leipzig, Teubner, 1838.

Haza Johanna (von), alias Paris Heinrich, Kreuz- und Quergedanken eines dresdener Ignoranten vor den düsseldorfer Bildern, üb. d. düsseldorfer Bilder u. manches Andere. Zur Erinnerung für Freunde, Dresde/Leipzig, [u.a.] Arnold , 1837.

Janin Jules, « Le Bas-bleu », dans Les Français peints par eux-mêmes. Encyclopédie morale du dixneuvième siècle, t. V, Paris, L. Curmer, 1840-1842, p. 200-231.

Joubert Solange, Une correspondance romantique: Madame d'Agoult, Liszt, Henri Lehmann, Paris, Flammarion, 1947.

Junot Laure, Abrantès (duchesse d'), Mémoires sur la restauration, ou Souvenirs historiques, Paris, Impr. Boulé et $C^{\text {ie }}, 1838$.

Junot Laure, Abrantès (duchesse d'), Salons révolutionnaires, présentation de Chotard Loïc, Paris, Ed. France-Empire, 1989.

Junot Laure, Abrantès (duchesse d'), Les Salons de Paris, [Paris], Balland, 1984.

Kant Emmanuel, Remarques touchant les observations sur le sentiment du beau et du sublime, Paris, J. Vrin, 1994.

Keralio $\left(\mathrm{M}^{\mathrm{lle}}\right)$, Collection des meilleurs ouvrages français, composés par des femmes, dédiée aux femmes françaises, Paris, l'auteur Lagrange, 1786.

Kugler Franz, Kleine Schriften und Studien zur Kunstgeschichte, Stuttgart, Ebner \& Seubert, 1854.

La Croix Jean, Dictionnaire historique portatif des femmes celebres, Paris, Chez L. Cellot..., 1769.

La Mésangère Pierre (de), alias Centyeux, «Paris », Journal des dames et des modes, 15 avril 1813, p. 162.

La Mésangère Pierre (de), alias Le Curieux, «Le Muséum », Journal des dames et des modes, $\mathrm{n}^{\circ} 2,10$ vendémiaire an XI [2 octobre 1802], p. 10-11.

La Mésangère Pierre (de), Galerie française de femmes célèbres : par leurs talens, leur rang ou leur beauté, Paris, Chez l'éditeur, 1827.

Ladimir Jules, Physiologie du pochard, Paris, W. Warée, 1842.

Lassels Richard, The Voyage of Italy: or Compleat Journey Through Italy in Two Parts, Paris, du Moutier, 1670.

Lebrun Jean, Precis historique de la vie de la citoyenne Lebrun, peintre, Paris, Gratis chez le citoyen Lebrun..., 1793.

Legouvé Gabriel, Poèmes de Legouvé, et de Vigée, $3^{\mathrm{e}}$ éd., Paris, Chez Louis rue S. Severin $n^{\circ} 110,1799$. Lemoine Edouard, Physiologie de la femme la plus malheureuse du monde, Paris, Aubert-Lavigne, 1841.

Lenormant Amélie, Madame Récamier, les amis de sa jeunesse et sa correspondance intime, Paris, M. Lévy Frères, 1872.

Lenormant Amélie, Souvenirs et correspondance tirés de papiers de Madame Récamier, 2 t., Paris, [s.n.], 1859.

Lenormant Charles, "M. Ingres. Portraits de Cherubini et de Monseigneur le duc d'Orléans », L'Artiste, série 3, 1, 20, 1842, p. 312-315. 
Lhéritier S.-D., Traité complet des maladies de la femme, étudiées sous les rapports physiologique, nosographique et thérapeutique, t. I, Paris, Au bureau du bulletin clinique, 1838.

Louyer Villermay Jean-Baptiste, Traité des maladies nerveuses en vapeurs, et particulièrement de l'hystérie et de l'hypocondrie, Paris, Méquignon l'aîné père, 1816.

Marchal Charles, Physiologie de la femme honnête, Paris, Lachapelle-Fiquet, 1841.

Marcucci Lorenzo, Saggio analitico-chimico sopra i colori minerali e mezzi di procurarsi gli artefatti, gli smalti e le vernici... di Lorenzo Marcucci ed osservazioni fatte dal medesimo sopra la pratica del dipingere, Rome, stamp. di L. Contedini, 1813.

Marquiset Alfred, Les Bas-bleus du Premier Empire..., Paris, H. Champion, 1913.

Mennessier-Nodier Marie, Charles Nodier : épisodes et souvenirs de sa vie, Paris, Didier, 1867.

Montagu Wortley Lady Mary, The Letters of the Right Honourable Lady M-yW-y M-e; Written during her Travels in Europe, Asia and Africa to Persons of Distinction, Men of Letters \&c. in different Parts of Europe. Which Contain, Among other Curious Relations, Accounts of the Policy and Manners of the Turks; Drawn from Sources that have been inaccessible to other Travellers, vol. 1, Londres, Bechet, 1763.

Mulier Léonier, "Le Salon", La Femme dans la famille et dans la société. Journal littéraire et scientifique, paraissant le samedi, $\mathrm{n}^{\circ}$ 3, 7 mai 1880, p. 6 .

Palmaroli Pietro, "Osservazioni sopra la pratica del dipingere ad olio tenuta dalle scuole fiorentina, venziana e fiamminga ne' loro migliori tempi con note », dans Lorenzo Marcucci (dir.), Saggio analitico-chimico sopra i colori minerali e mezzi di porcurarsi gli artefatti gli smalti e le vernici di lorenzo Marcucci ed osservazioni fatte dal medesimo sopra la pratica del dipingere ad olio tenuta dalle scuole fiorentina veneziana e fiamminga ne' loro migliori tempi colle note del sig. Pietro Palmaroli ristauratore di quadri antichi, Rome, Imprimerie Lino Contedini, 1813, p. 199-240.

Pernety Antoine-Joseph, Dictionnaire portatif de peinture, sculpture et gravure : avec un traité pratique des differentes manieres de peindre, dont la théorie est développée dans les articles qui en sont susceptibles, Paris, Bauche, 1757.

Piozzi Lynch Hester, Observations and Reflections Made in the Course of a Journey Through France, Italy and Germany, 2 vol., Londres, Strahan and Cadell, 1789.

Planche Gustave, « Salon de 1840 », Revue des deux mondes, t. XXII, 1840, p. 105-106.

Plumptre Anne, A Narrative of A Three Years' Residence in France, Principally in the Southern Departments, from the Year 1802 to 1805: Including Some Authentic Particulars Respecting the Early Life of the French Emperor, and a General Inquiry into his Character, 3 vol., Londres, Mawman, Ridgeway, Clarke, Crosby and Constable, 1810.

Plumptre Anne, Something New, or Adventures at Campbell-House, Deborah McLeod (éd.), Peterborough, Broadview Press, (1801) 1996.

Procès-verbaux de l'Académie royale d'architecture, 1671-1793, publiés pour la Société de l'histoire de l'art français par Henry Lemonnier, t. VI, Paris, Edouard Champion, 1920.

Récamier Juliette, Souvenirs et correspondance tirés des papiers de Madame Récamier..., $2^{\mathrm{e}}$ éd., Paris, Michel Lévy frères, 1860.

Reynolds Sir Joshua, Discours sur la peinture, Louis Dimier (éd.), Paris, ENSBA, (1776) 1991.

Riballier Charlotte-Catherine, De l'éducation physique et morale des femmes : avec une notice alphabétique de celles qui se sont distinguées dans les differentes carrières des sciences \& des beaux-arts, ou par des talens, Bruxelles/Paris, chez les frères Estienne, 1779.

Richardson Jonathan père et fils, Traité de la peinture et de la sculpture, Isabelle Baudino et Frédéric Ogée (éd.), Paris, ENSBA, 2008.

Richardson Jonathan, Senior and Junior, An Account of the Statues, Bas-Reliefs, Drawings and Pictures in Italy, France \& c. with Remarks, Londres, Knapton, 1722. 
Roux-Ferrand Hippolyte, Odyssée d'un bas-bleu, Meulan, imprimerie de la société philotechnique, 1880.

Sainte-Beuve Charles, Galerie des femmes célèbres, tirée des "Causeries du lundi " par Sainte-Beuve : illustrée de 12 portraits gravés au burin par Gouttière, Outhwaite, Geoffroy ... d'après les dessins de G., Paris, Garnier, 1862.

Sainte-Beuve Charles, Euvres, Paris, Gallimard, 1949.

Saint-Hilaire Émile Marco (de), Physiologie du troupier, Paris, Auvert et Cie-Lavigne, 1841.

Saisselin Rémy G., Le Bourgeois et le bibelot, New Brunswick, N.J., Rutgers University Press, 1985 ; trad. Jacqueline Degueret, Paris, Albin Michel, 1990.

Salm Constance (de), Vingt-quatre heures d'une femme sensible, Lettre IV, Paris, Phébus, (1824) 2007.

Salm Constance (de), Épittre aux femmes, Paris, Desenne, 1797.

Sand George, « Histoire de ma vie », dans Cuvres autobiographiques, t. II, Paris, Gallimard, (1854) 1971 , p. 5-465.

Sauvigny Bilardon, Parnasse des dames (ou choix de pièces de quelques femmes célèbres en littérature), Paris, Ruault, 1773.

Savary des Bruslons Jacques, Dictionnaire universel du commerce, Paris, J. Estienne, 1723.

Savignac Alida (de), « Salon de 1837 », Journal des demoiselles, n 3, mars 1837, p. 90-93 ; n 4, avril 1837, p. 21-124; $\mathrm{n}^{\circ}$ 5, mars 1837, p. 154-157.

Savignac Alida (de), « Salon de 1846 », Journal des demoiselles, n 6, juin 1846, p. 186-187.

Soulié Frédéric, Physiologie du Bas-bleu, Paris, Aubert-Lavigne, vers 1841.

Souvestre Émile, Les Drames parisiens, Paris, Michel-Lévy frères, 1859, p. 4-104.

Staël Auguste, Euvres posthumes de madame la baronne de Staël-Holstein. Précédées d'une notice sur son caractère et ses écrits, Paris, F. Didot, 1836.

Staël Germaine (de), Memoires de Madame de Staël (dix annees d'exil) : ouvrage posthume publié en 1818 par le duc de Broglie et le baron de Staël, nouvelle éd. précédée d'une notice sur la vie et les ouvrages de $\mathrm{M}^{\text {me }}$ de Staël par $\mathrm{M}^{\text {me }}$ Necker de Saussure, Paris, Charpentier, 1861.

Staël Germaine (de), Dante et Goethe : dialogues, Paris, Didier, 1866.

Staël Germaine (de), Lettres de Madame de Staël à Madame Récamier (première édition intégrale), Paris, Domat, 1952.

Staël Germaine (de), $M^{m e}$ de Staël. De l'Allemagne : nouvelle édition, publiée d'après les manuscrits et les éditions originales avec des variantes, une introduction, des notices et des notes par la Comtesse Jean, Paris, Hachette, 1959.

Staël Germaine (de), Correspondance générale..., Béatrice W. Jasinski (éd.), Paris, J.-J. Pauvert, 1960.

Staël Germaine (de), Choix de lettres : 1778-1817, Paris, Klincksieck, 1970.

Staël Germaine (de), Corinne ou l'Italie, Paris, Honoré Champion, (1807) 2000.

Stevens Mathilde, Impressions d'une femme au Salon de 1859, Paris, A. Bourdillat, 1859.

Tardieu [Alexandre], « Salon de $1842 »$, Courrier français, 16 mars 1842.

Texier Edmond-Auguste, Physiologie du poète, Paris, J. Laisné, 1842.

Thilda Jeanne, « Le dîner des Bas-Bleus », Gil Blas, $n^{\circ}$ 1696, 10 juillet 1884, p. 1-2.

Thoré Théophile, Le Salon de 1846, Paris, Alliance des arts, 1846.

Uzanne Octave, La Femme à Paris. Nos contemporaines. Notes successives sur les Parisiennes de ce temps dans leurs divers milieux, états et conditions, Paris, ancienne maison Quantin/Librairies-imprimeries réunies, 1894. 
V. C., "Statistique du Salon de 1827-1828», Journal des artistes, vol. 2, n 17, 27 avril 1828, p. 257-261.

V. R. d. [Alphonse Renaud de Vilback], «Salon de 1842 », Le Moniteur industriel, 20 mars 1842 ; 27 mars 1842.

Varnier Jules, « Portrait de Cherubini », L'Artiste, série 3, 1, 9, 1842, p. 154-155.

Vigée-Lebrun Élisabeth, Mémoires d'une portraitiste, préf. Jean-Pierre Cuzin, Paris, éditions Scala, (1835) 1989.

Vigée-Lebrun Élisabeth, Souvenirs de Madame Louise-Élisabeth Vigée-Lebrun, 3 vol., Paris, H. Fournier, 1835-1838.

Wiedenfeld Karl Wilhelm, Kritik des Saint Simonismus, ein Beitrag zur richtigern Würdigung dieser Sekte in ihren gefährlichen Folgen für Kirche und Stadt, Barmen/Schwelm, Falkenberg, 1832.

Williams Helen Maria, Letters Containing a Sketch of the Scenes which Passed in Various Departments of France during the Tyranny of Robespierre; and of the Events which Took Place in Paris on the 28th July 1794, Londres, Robinson, 1795.

\section{Littérature secondaire}

[Anonyme], Galerie des dames françaises distinguées dans les lettres et les arts ancienne monarchie empire restauration époque actuelle, Paris, Dussillon, (1843) 1918.

A. J., "L'amitié de George Sand et d'Eugène Delacroix ", Revue des deux mondes, t. XXI, 1934, p. 832-865.

Adhémar Jean, «L'éducation des fils de France et l'origine du musée de Versailles », La Revue des arts, 6, 1956, p. 29-34.

Adhémar Jean, "L'enseignement par l'image », Gazette des Beaux-Arts, vol. XCVII, février 1981, p. 53-60.

Adler Laure, À l'aube du féminisme, les premières journalistes : 1830-1850, Paris, Payot, 1979.

Allen Michael (éd.), An English Lady in Paris. The Diary of Frances Anne Crewe, St Leonards, OxfordStockley, (1786) 2006.

Ambrière Francis, Le Siècle des Valmore, 2 vol., Paris, Le Seuil, 1987.

Aragon Louis, «L'Atelier d'un peintre. Marceline Desbordes-Valmore romancière ", dans La Lumière de Stendhal, Paris, Denoël, 1954, p. 215-229.

Arendt Hannah, Rahel Varnhagen. Lebensgeschichte einer deutschen Jüdin aus der Romantik, Munich, Piper, 1959.

Aron Jean-Paul (éd.), Misérable et glorieuse la femme du XIXe siècle, Paris, Fayard, 1980.

Association Desbordes-Valmore, Études valmoriennes : publication de l'association Desbordes-Valmore, Lille, L'Association, 1983.

Au-delà du maître : Girodet et l'atelier de David, cat. expo., Richard Dagorne (éd.), (Montargis, musée Girodet, 2005), Paris, Somogy éd. d'art, 2005.

Auricchio Laura, "Eighteenth-Century Women Painters in France", dans Heilbrunn Timeline of Art History, New York, The Metropolitan Museum of Art, 2000. URL : http://www.metmuseum.org/ toah/hd/18wa/hd_18wa.htm. Consulté le 19 décembre 2011.

Auricchio Laura, Portraits of Impropriety: Adélaïde Labille-Guiard and the Careers of Professional Women Artists in Late Eighteenth-Century Paris, New York, Columbia University, 2000.

Auricchio Laura, Adélaïde Labille-Guiard: Artist in the Age of Revolution, Los Angeles, Getty Publications, 2009. 
Auricchio Laura, « Madame Récamier et les femmes de la haute société au temps du Directoire et du Consulat ", dans Juliette Récamier muse et mécène, cat. d'expo., (musée des Beaux-Arts de Lyon, du 27 mars au 29 juin 2009), Paris/Lyon, Hazan/Musée des beaux-arts, 2009, p. 97-104.

Bachelet Nicolas, Les Femmes et le droit des corporations d'Ancien Régime, mémoire de DEA, Nantes, université de Nantes, 1995.

Bakdach Safaa, Les Idées esthétiques de $M^{m e}$ de Staël d'après son roman Corinne ou l'Italie, Th. $3^{\mathrm{e}}$ cycle, Paris, [s.n.], 1976.

Balayé Simone, Madame de Staël. Lumières et liberté, Paris, Klincksieck, 1979.

Ballaster Ros et al., Women's Worlds: Ideology, Feminity and the Woman's Magazine, Londres, Macmillan, 1991.

Bann Stephen, “The Studio as a Scene of Emulation: Marceline Desbordes-Valmore's L'Atelier d'un peintre", French Studies, vol. 61, nº 1, 2007, p. 26-35.

Bann Stephen, Paul Delaroche: History Painted, Londres, Reaktion Books, 1997.

Barlow Margaret, Women Artists, New York, Universe, 2008.

Barnett Gérald, Richard and Maria Cosway, a Biography, Tiverton/Devon, Westcountry Books, 1995.

Batten Charles L., Pleasurable Instruction. Form and Convention in Eighteenth-Century Travel Literature, Berkeley, University of California Press, 1978.

Battersby Christine, Gender and Genius: towards a Feminist Aesthetics, Bloomington (Ind.), Indiana university press, 1989.

Baxa Jakob, „Adam Müllers literarische Tätigkeit“, Zeitschrift für Ganzheitsforschung, vol. neue Folge, 14. Jahrgang, $\mathrm{n}^{\circ}$ III, 1970, p. 129-154.

Baxa Jakob, Adam Müllers Lebenszeugnisse, Munich/Paderborn/Wien, F. Schöningh, 1966.

Bearne Catherine, Heroines of French Society in the Court, the Revolution, the Empire, and the Restoration (Madame Vigée-Lebrun. La Marquise de Montagu. Madame Tallien. Madame de Genlis)[...] Illustrated, Londres, T. Fisher Unwin, (1906) 1907.

Beasley Faith, Revising Memory: Women's Fiction and Memoirs in Seventeenth-Century France, New Brunswick, Rutgers University Press, 1990.

Beaunier André, Trois amies de Chateaubriand, Paris, Bibliothèque-Charpentier, 1910.

Beck Evelyn et Lanser Susan, "[Why] Are There No Great Women Art Critics? And What Difference Does It Make?", dans Julia Sherman et WRI of Wisconsin (éd.), The Prism of Sex: Essays in the Sociology of Knowledge: Proceedings of a Symposium, Madison, University of Wisconsin Press, 1979.

Becker Howard, Les Mondes de l'art, présentation de Pierre-Michel Menger, trad. Jeanne Bouniort, Paris, Flammarion, (1982) 2006.

Becq Annie, « Expositions, peintres et critiques. Vers l'image moderne de l'artiste », Dix-huitième siècle, $\mathrm{n}^{\circ} 14,1982$, p. 131-149.

Bellet Roger, « Masculin et féminin dans les pseudonymes des femmes de lettres au XIX ${ }^{\mathrm{e}}$ siècle », dans Femmes de lettres au XIX $X^{e}$ siècle. Autour de Louise Colet, Lyon, Presses universitaires de Lyon, 1982, p. 249-281.

Béraud Claire, Heim Jean-François et Heim Philippe, Les Salons de peinture de la Révolution française :1789-1799, Paris, CAC, 1989.

Berger Renate, „Und ich sehe nichts als die Malerei“, Autobiographische Texte von Künstlerinnen des 18.-20. Jahrhunderts, Francfort, Fischer, 1987.

Berger Renate, Malerinnen auf dem Weg ins 20. Jahrhundert, Cologne, Dumont, 1982.

Berger Vincent, « Où sont les femmes ? Pas dans l'université en tout cas », Libération, 8 juin 2011. 
Bergman-Carton Janis, “Conduct Unbecoming: Daumier and 'Les Bas-Bleus”', dans Kirsten Powell et Elizabeth C. Childs (éd.), Femmes d'esprit. Women in Daumier's Caricature, Hanovre/Londres, University Press of New England, 1990, p. 67-77.

Bergman-Carton Janis, The Woman of Ideas in French Art, 1830-1848, New Haven, Yale University Press, 1995.

Bermingham Ann, "The Aesthetics of Ignorance. The Accomplished Woman in the Culture of Connoisseurship", Oxford Art Journal, vol. 16, n² 2, 1993, p. 3-20.

Bertrand-Dorléac Laurence, "L'histoire de l'art et les cannibales", Vingtième Siècle. Revue d'histoire, $\mathrm{n}^{\circ}$ 45, janvier-mars 1995, p. 99-108.

Bertrand-Jennings Chantal, Masculin/féminin : le XIX siècle à l'épreuve du genre, Toronto, St Michael's College, Centre d'études du XIX ${ }^{\mathrm{e}}$ siècle, 1999.

Bertrand-Jennings Chantal, Un autre mal du siècle : le romantisme des romancières : 1800-1846, Toulouse, Presses universitaires du Mirail, 2005.

Bessire François et Reid Martine (dir.), Madame de Genlis. Littérature et éducation, Mont-SaintAignan, Publications des universités de Rouen et du Havre, 2008.

Besson-Morel Anne, La Presse enfantine sous la monarchie de Juillet, thèse de doctorat, université Paris IV-Sorbonne, 1998.

Betzer Sarah, Ingres and the Studio: Women, Painting, History, University Park, Penn State University Press, 2012.

Bitoun Carole, La Révolte au féminin : portraits de femmes exemplaires, Paris, Hugo \& Cie, 2007.

Blanc Olivier, Marie-Olympe de Gouges. Une humaniste à la fin du XVIII ${ }^{e}$ siècle, Cahors, Éditions René Viénet, 2003.

Blanc Olivier, Portraits de femmes : artistes et modèles à l'époque de Marie-Antoinette, Paris, éd. Didier Carpentier, 2006.

Blankenstein David et Lohmann Malte, «Helmina von Chézy », dans Michel Espagne et Bénédicte Savoy (dir.), Dictionnaire des historiens de l'art germaniques, Paris, éditions du CNRS, 2010, p. 35-42.

Bohls Elizabeth A., Women Travel Writers and the Language of Aesthetics, 1716-1818, Cambridge, Cambridge university press, 2004.

Boisserée Sulpiz et Klotz Heinrich, Briefwechsel Tagebücher, Göttingen, Vandenhoeck \& Ruprecht (Deutsche Neudrucke. Reihe Texte des 19. Jahrhunderts), 1970.

Bonnet Marie Jo, «Femmes peintres à leur travail: de l'autoportrait comme manifeste politique », Revue d'histoire moderne et contemporaine, 49: 3, 2002, p. 140-167.

Bonvoisin Samra-Martine et Maignien Michèle, La Presse féminine, Paris, Presses universitaires de France, 1986.

Borgonovi Chiara, Le Geste chez Madame de Staël : représentation littéraire et arts plastiques, Thèse de doctorat, université de Paris VIII, 2005.

Boudard Jacqueline, «L'Exil de $\mathrm{M}^{\text {me }}$ Vigée-Lebrun en Italie (1789-1792)», dans Voyage et Révolution. Viaggi di uomini e di idee al tempo della Rivoluzione, t. II, Genève, Slatkine, 2003, p. 2249-2269.

Boush Sara, Women Artists of the Eighteenth Century in France, a Compilation of Names and Works of forty-nine Artists, with a Consideration of some Problems of Social Context, Artistic Training, and Criticism, [s.l.], University of Wisconsin, 1976.

Brilliant Women. 18th-Century Bluestockings, cat. expo., Elizabeth Eger et Lucy Peltz (éd.), (Londres, National Portrait Gallery, 13 mars-15 juin 2008), Londres, National Portrait Gallery, 2008.

Broglie Gabriel (de), Madame de Genlis, Paris, Perrin, 1985. 
Brogniez Laurence, «La critique d'art au féminin au XIX siècle : Marc de Montifaud ou le discours (dé)voilé », Art \& Fact, n 24 (« Femmes et créations »), 2005, p. 15-23.

Brogniez Laurence, «Les femmes au Salon: propositions pour une étude de la critique d'art féminine au XIX ${ }^{e}$ siècle ", Christine Planté (dir.), Féminin/masculin. Écritures et représentations. Lieux littéraires/La revue. Corpus collectifs, $\mathrm{n}^{\circ}$ 7-8, juin 2005, p. 118-119.

Broude Norma et Garrard Mary D., Reclaiming Female Agency: Feminist Art History after Postmodernism, Berkeley, University of California Press, 2005.

Brunereau Jeanne, Presse féminine et critique littéraire de 1800 à 1830 : leurs rapports avec l'histoire des femmes, [Paris], EVE et son espace créatif, 2000.

Cabanis André, La Presse sous le Consulat et l'Empire, 1799-1814, Paris, Société des études robespierristes, 1975.

Cameron Vivian, “Two 18th-Century French Art Critics”, Woman's Art Journal, vol. V, n 1 , printemps-été 1984, p. 8-11.

Cameron Vivian, Woman as image and image-maker in Paris during the French Revolution, Michigan, UMI, 1999.

Cavallucci Giacomo et Guégan Bertrand, Bibliographie critique de Marceline Desbordes-Valmore d'après des documents inédits, Paris, A. Margraff, 1935.

Cazzulani Elena et Stroppa Angelo, Maria Hadfield Cosway : biografia, diari et scritti della fondatrice del Collegio delle dame inglesi in Lodi, Lodi, L'Immagine, 1989.

Certeau Michel (de), L'Invention du quotidien, 1. Arts de faire, Paris, Gallimard, (1980) 1990.

Chadwick Whitney, Women, Art, and Society, Londres,Thames \& Hudson, 1990.

Challice Annie, Illustrious Women of France..., Londres, Bradbury Agnew \& Co, 1873.

Chard Chloe, "Spectator and Spectacle. The Feminine and the Antique", dans Pleasure and Guilt on the Grand Tour: Travel Writing and Imaginative Geography 1600-1830, Manchester, Manchester University Press, 1999, p. 126-155.

Chatelus Jean, Peindre à Paris au XVIII ${ }^{e}$ siècle, Nîmes, Jacqueline Chambon, 1991.

Cheraft Céline, Les Bas-bleus : une série de caricatures de 1844 de Honoré Daumier (1808-1879). Une satire de la femme "intellectuelle ", mémoire de maîtrise, Paris, université Panthéon-Sorbonne, 2 vol., 2000-2001 (inédit).

Chicago Judy et Edward Lucie-Smith, Women and Art: Contested Territory, New York, Watson-Guptill Publications, 1999.

Clarke Meaghan, Critical Voices: Women and Art Criticism in Britain, 1880-1905, Aldershot/Hants, Ashgate, 2005.

Claude Moins, "George Sand et Delacroix », dans Marielle Caors (éd.), George Sand et les arts, actes du colloque international, (association Château d'Ars, Centre du Romantisme, 5-9 septembre 2004), Clermont-Ferrand, Presses universitaires Blaise Pascal, 2006, p. 215-225.

Colley Linda, Britons. Forging the Nation 1707-1837, Londres, Pimlico, (1992) 1994.

Colombo Laura, Marie d'Agoult. Autoritratto di un intelletuale romantica, Reggio Emilia, Diabasis, 1997.

Colwill Elizabeth, "Laws of Nature/Rights of Genius. The Drame of Constance de Salm", dans Elizabeth C. Goldsmith et Dena Goodman (dir.), Going Public. Women and Publishing in Early Modern France, Ithaca/Londres, Cornell University Press, 1995, p. 224-242.

Colwill Elizabeth, “Women's Empire and the Sovereignty of Man in La Décade philosophique, 1794-1807", Eighteenth-Century Studies, vol. 29, nº 3, 1996, p. 265-289.

Conti Alessandro, Storia del restauro e della conservazione delle opere d'arte, Milan, Electa, 1973. 
Contogouris Ersy, «Inspiration divine : Lady Hamilton en Sybille par Elisabeth Vigée-Lebrun », RACAR, 2010, p. 35-46.

Corbière-Gille Gisèle, «Les Bas-bleus et le féminisme ", La Revue des lettres modernes, $\mathrm{n}^{\circ}$ 351-354, 1973, p. 119-124.

Corroy Laurence, La Presse des lycéens et des étudiants au XIX siècle: l'émergence d'une presse spécifique, Lyon, Institut national de recherche pédagogique, 2004.

Coudert Allison P., « Ange du foyer ou idole de perversité, l'ésotérisme au féminin au XIX siècle », Politica Hermetica, $\mathrm{n}^{\circ} 20$ («L'ésotérisme au féminin »), 2006, p. 29-47.

Courajod Louis, "L'administration des Beaux-Arts au milieu du XVIII ${ }^{\mathrm{e}}$. La restauration des tableaux du roi », Gazette des Beaux-Arts, n 2, 1869, p. 372-376.

Crouzet Michel (éd.), Stendhal, Paris, Presses de l'université de Paris-Sorbonne, 1996.

Crow Thomas, Emulation: David, Drouais, and Girodet in the Art of Revolutionary France, New Haven/ Los Angeles, Yale University Press/The Getty Research Institute, 2006; trad. Roger Stuveras, L'Atelier de David: émulation et révolution, Paris, Gallimard, 1997.

Cuno James B., «Philipon et Desloges: éditeurs des “physiologies" (1841-1842)», Cahiers de l'Institut d'histoire de la presse et de l'opinion, 7, 1983, p. 137-162.

Dassas Frédéric, « Les enjeux d'une critique sentimentale : Diderot, Rousseau, madame de Staël », dans L'Invention du sentiment aux sources du romantisme, cat. expo., Philippe Bata et alii (dir.), (Paris, cité de la Musique, 2 avril - 30 juin 2002), Paris, cité de la Musique/RMN, 2002, p. 13-22.

Davidson Denise Zara, "Imagining the Readers of the Journal des dames et des modes", contribution à l'atelier More than Fashion: The Journal des dames et des modes (1797-1839), University of Michigan, Ann Arbor, 2009 (inédit).

Davidson Denise Zara, France after Revolution. Urban Life, Gender, and the New Social Order, Cambridge, Harvard University Press, 2007.

Décultot Élisabeth, « Friedrich Schlegel et "l'art divin de la peinture" ", Études germaniques, n 52, 1997, p. 629-648.

Deepwell Katy, «Défier l'indifférence à la différence: les paradoxes de la critique d'art féministe », dans Pierre-Henry Frangne et Jean-Marc Poinsot (dir.), L'Invention de la critique d'art, actes de colloque, (université Rennes 2, 24 et 25 juin 1999), Rennes, Presses universitaires de Rennes, 2002, p. 191-205.

Dekker Rudolf, “Jacques Presser's Heritage: Egodocuments in the Study of History", trad. Diederik van Werven, Memoria y Civilización (MyC), 5, 2002, p. 13-37.

Del Lungo Andrea et Louichon Brigitte (dir.), La Littérature en bas-bleus. Romancières sous la Restauration et la monarchie de Juillet, 1815-1848, Paris, Garnier, 2010.

Delon Michel et Mélonio Françoise, $M^{m e}$ de Staël, actes de colloque, (Sorbonne, 20 novembre 1999), Paris, Presses de l'Université de Paris-Sorbonne, 2000.

DeLorme Eleanor P., "The Courtly, Heroic, and Romantic. Joséphine's Patronage of Painting", dans Joséphine and the Arts of the Empire, Los Angeles [Calif.], J. Paul Getty Museum, 2005, p. 7-39.

Démoris René (dir.), Hommage à Élisabeth Sophie Chéron : texte et peinture à l'âge classique, Paris, Presses de la Sorbonne Nouvelle, 1992.

Derrida Jacques, "The Law of Genre" Glyph 7, Baltimore, The Johns Hopkins Press, 1980, p. 176-201 ; « La loi du genre », Parages, trad. Avital Ronell, Paris, Galilée, 2003.

Diaz Brigitte, Siess Jürgen, Centre culturel international (Cerisy-la-Salle Manche) et Centre de recherche Textes histoire, L'Épistolaire au féminin : correspondances de femmes, XVIII ${ }^{e}-\mathrm{XX}^{e}$ siècle, actes de colloque, (Cerisy-la-Salle, 1er-5 octobre 2003), Caen, Presses universitaires de Caen, 2006. 
Didi-Huberman Georges, Invention de l'hystérie. Charcot et l'iconographie photographique de la Salpêtrière, Paris, Macula, 1982.

Doy Gen, Seeing and Conciousness: Women, Class Representation, Oxford, Berg, 1995.

Doy Gen, "What do you say when you're looking? Women as makers and viewers of painting in early modern France”, Women's Art Magazine, juin-juillet 1996, p. 10-15.

Doy Gen, Women and Visual Culture in Nineteenth-Century France: 1800-1852, Londres, Leicester University Press, 1998.

Doy Gen, "Hidden from Histories: Women History Painters in Early Nineteenth-Century France", dans Rafael C. Denis (dir.), Art and the Academy in the nineteenth-century, Manchester, [s.n.], 2000, p. 71-85.

Dubé Pierre Hubert, Bibliographie de la critique sur Madame de Staël : 1789-1994, Genève, Droz, 1998.

Ducamp Emmanuel, L'Apothéose d'Hercule de François Lemoyne au château de Versailles : histoire et restauration d'un chef-d'œuvre, Paris, A. de Gourcuff, 2001.

Ducey Lynn, Issues in Representation: the Contrasting Reputations of Elisabeth Vigée-Lebrun and Adelaide Labille-Guiard, [s.l.], University of Illinois at Urbana-Champaign, 1997.

Edelman Nicole, Voyantes, guérisseuses et visionnaires en France, 1785-1914, Paris, Albin Michel, 1995.

Edelman Nicole, Les Métamorphoses de l'hystérique. Du début du XIXe siècle à la Grande Guerre, Paris, La Découverte, 2003.

Eger Elizabeth, Grant Charlotte, Ó Gallchoir Clíona et Warburton Penny, Women, Writing and the Public Sphere, 1700-1830, Cambridge, Cambridge University Press, 2001.

Eger Elizabeth, Bluestockings. Women of Reason from Enlightenment to Romanticism, New York, Palgrave Macmillan, 2010.

Espagne Michel et Savoy Bénédicte (éd.), Dictionnaire des historiens d'art allemands : 1750-1950, Paris, CNRS éd., 2010.

Étienne Noémie, «Édifier et instruire : une typologie des restaurations exposées à Paris autour de 1750 », CeROArt, 5, 2010, en ligne le 14 avril 2010. URL : http://ceroart.revues.org/index1466.html. Consulté le 19 décembre 2011.

Étienne Noémie, «Les peintures en pièces détachées : tableaux disloqués et critères de sélection en Europe (1775-1815) » dans A. R. Bazire et M. Drouin (dir.), La Sélection patrimoniale : $6^{e}$ Rencontre internationale des jeunes chercheurs en patrimoine, Montréal, Cahiers de l'Institut du patrimoine de l'UQAM/Multimondes, 2011, p. 275-288.

Étienne Noémie, « Polémique et politique. La réception des peintures restaurées à Paris après spoliation (1795-1815)», Histoire de l'art, $\mathrm{n}^{\circ}$ 68, 2011, p. 9-17.

Fabbricino Trivellini Gabriella, Cultura femminile tra ancien régime e restaurazione, Naples, Editoriale scientifica, 1992.

Fabritius Heinke, Die italienischen Landschaftszeichnungen Franz Hornys. Eine Studie zum bildnerischen Denken um 1820, Berlin, Böttcher/Frank, Dr. 2010.

Femmes peintres : 1550-1950, cat. expo., Ann Sutherland Harris et Linda Nochlin (éd.), (Los Angeles, Los Angeles County Museum, 1976), Paris, Des Femmes, 1981.

Fend Mechthild, Les Limites de la masculinité. L'androgynie dans l'art et la théorie de l'art (1750-1850), trad. Jean Torrent, Paris, INHA/CAHA/La découverte, (2003) 2011.

Fend Mechthild, Hyde Melissa et Lafont Anne (dir.), Plumes et Pinceaux. Discours de femmes sur l'art en Europe (1750-1850), Dijon, Les presses du réel/INHA, 2012.

Fétis François Joseph, Biographie universelle des musiciens et bibliographie générale de la musique, $10 \mathrm{t}$., $2^{\mathrm{e}}$ éd., Paris, Firmint-Didot, 1881-1889. 
Fitzgerald Colleen, “To Educate or Instruct? Du Bosc and Fénelon on Women”, dans Barbara J. Whitehead (dir.), Women's Education in Early Modern Europe-A History 1500-1800, New York/Londres, Garland Publishing, 1999.

Folger Collective on Early Women Critics (The), Women Critics 1660-1820. An Anthology, Bloomington, Indiana University Press, 1995.

Fort Bernadette, "Voice of the Public. Carnivalization of Salon Art in Prerevolutionary France", Eighteenth-Century Studies, vol. 22, n 3, 1989, p. 368-394.

Foucault Michel, «Qu'est-ce qu'un auteur?», dans Dits et écrits 1954-1975, t. I, Paris, Gallimard, 1994, p. 789-707.

Fraisse Geneviève, Muse de la raison : la démocratie exclusive et la différence des sexes, Aix-enProvence, Alinéa, 1989.

Fraisse Geneviève et Perrot Michelle (dir.), Histoire des femmes en Occident, IV. Le XIXe siècle, Paris, Plon, 1991.

Francia Ennio, « Delfina de Custine, Luisa Stolberg, Giulietta Récamier a Canova. Lettere inedite », Quaderni di cultura francese, $\mathrm{n}^{\circ} 13,1972$, p. 106-157.

Franklin Caroline, "Romantic Patriotism as Feminist Critique of Empire: Helen Maria Williams, Sydney Owenson and Germaine de Staël", dans Sarah Knott et Barbara Taylor (dir.), Women, Gender and Enlightenment, Basingstoke, Palgrave Macmillan, 2005.

Fraser Hilary, "Women and the Ends of Art History: Vision and Corporeality in NineteenthCentury Critical Discourse”, Victorian studies, vol. 42, nº 1, automne 1999-1998, p. 77-99.

Fripp Jessica L., Painting Community in Eighteenth-Century France: Labille-Guiard's Portraits of Artists, [s.l.], Williams College, 2005.

Füllner Bernd et Höhn Gerhard (éd.), Deutsch-französischer Ideentransfer im Vormärz, Bielefeld, Aisthesis, 2002.

Gallo Daniela (éd.), Les Vies de Dominique-Vivant Denon, actes de colloque, (musée du Louvre, du 8 au 11 décembre 1999), Paris, la Documentation française, 2001.

Gamboni Dario, “The Relative Autonomy of Art Criticism”, dans Michael Orwicz (éd.), Art Criticism and its Institutions in Nineteenth-Century France, Manchester/New York, Manchester University Press, 1994, p. 182-200.

Garb Tamar, "The Forbidden Gaze", Art in America, n 79, 1991, p. 146-152.

Garb Tamar, Sisters of the Brush. Women's Artistic Culture in Late Nineteenth-Century France, New Haven, Yale University Press, 1994.

Gaze Delia, Dictionary of Women Artists, Londres/Chicago, Fitzroy Dearborn Publishers, 1997.

Gelbart Nina Rattner, "The Journal des dames and its female editors: politics, censorship and feminism in the old regime press", dans J. Popkin et J. Censer (éd.), Press and Politics in PreRevolutionary France, Berkeley, University of California Press, 1987.

Gelbart Nina Rattner, «Les femmes journalistes et la presse (XVII ${ }^{\mathrm{e}}-\mathrm{XVIII}^{\mathrm{e}}$ siècle) ", dans Michèle Perrot et Georges Duby (éd.), Histoire des femmes en Occident 3. XVI $I^{e}-\mathrm{XVIII}{ }^{e}$ siècle, sous la direction de Natalie Zemon Davis et Arlette Farge, Paris, Plon, 1991, p. 491-512.

George Sand. Une nature d'artiste, cat. expo., Daniel Marchesseau et al. (dir.), (Paris, musée de la vie romantique, 29 juin - 28 novembre 2004), Paris, Paris musées, 2004.

Gipponi Tino, Maria e Richard Cosway, Turin, U. Allemandi, 1998.

Girard Marie-Hélène, "Corinne collectionneur, ou Le musée imaginaire de Madame de Staël », dans Art et littérature, acte de colloque, Société française de littérature générale et comparée (éd.), 
(Congrès de la Société française de littérature générale et comparée, Aix-en-Provence, 24-25-26 septembre 1986), Aix-en-Provence, université de Provence, 1988, p. 241-261.

Girodet, 1767-1824, cat. expo., Sylvain Bellenger (éd.), (Paris, musée du Louvre/Chicago, Art Institute of Chicago/New York, Metropolitan Museum of Art/Montréal, musée des Beaux-Arts, 2005-2006), Paris, Gallimard, 2005.

Godineau Dominique, Citoyennes tricoteuses: les femmes du peuple à Paris pendant la Révolution française, Paris, Alinéa, 1988.

Gothic Nightmares. Fuseli, Blake and the Romantic Imagination, cat. expo., Martin Myron (éd.), (Londres, Tate Britain, 2006), Londres, Tate Publishing, 2006.

Gougy-François Marie, Les Grands Salons féminins, Paris, Nouvelles Éditions Debresse, 1965.

Grigsby Darcy Grimaldo, "Nudity à la grecque in 1799", Art Bulletin, vol. 80, n² 2, juin 1998, p. 311-335.

Grigsby Darcy Grimaldo, Extremities: Painting Empire in Post-Revolutionary France, Londres, Yale University Press, 2002.

Grogan Susan K., French Socialism and Sexual Difference: Women and the New Society, 1803-44, New York, St. Martin's Press, 1992.

Grundy Isobel, Lady Mary Wortley Montagu. Comet of the Enlightenment, New York, Oxford University Press, 1999.

Guégan Stéphane, Théophile Gautier, la critique en liberté, Paris, Réunion des musées nationaux, 1997.

Guentner Wendelin A., “Seeking Aesthetic Expression: Mathilde Stevens' Impressions d'une femme au Salon de 1859 ", dans Rosemary Lloyd et Brian Nelson (dir.), Women Seeking Expression. France 1789-1914, Melbourne, Monash University, 2000, p. 24-41.

Guiffrey Jules, «Les expositions de l'Académie de Saint-Luc et leurs critiques (1751-1774) », dans Bulletin de la Société de l'histoire de l'art français, Paris, Jean Schemit, 1910, p. 77-124.

Gutwirth Madelyn, Madame de Staell, novelist: the Emergence of the Artist as Woman, Urbana, University of Illinois Press, 1978.

Hafter Daryl M., Women at Work in Preindustrial France, Pennnsylvania State University, University Park, 2007.

Hahn Barbara, „,Lernen Sie Europäisch!' Die Sprachen der Akkulturation um 1800“, Athenäum. Jahrbuch für Romantik, nº 5, 1995, p. 319-340.

Hahn Barbara, „Schriftstellerin zwischen allen Grenzen: Rahel Levin Varnhagen (1771-1833)“, dans Michel Espagne et Werner Greiling (éd.), Frankreichfreunde: Mittler des französisch-deutschen Kulturtransfers (1750-1850), Leipzig, Leipziger Universitätsverlag, 1996, p. 243-260.

Harcstark Myers Sylvia, The Bluestocking Circle. Women, Friendship, and the Life of the Mind in Eighteenth-Century England, Oxford, Clarendon Press, 1990.

Haroche-Bouzinac Geneviève, «Entre correspondance et autobiographie. Élisabeth VigéeLebrun ", dans Brigitte Diaz et Jürgen Siess (dir.), L'Épistolaire au féminin: correspondances de femmes, XVIII ${ }^{e}-\mathrm{XX}^{e}$ siècle, Caen, Presses universitaires de Caen, 2006, p. 51-64.

Haroche-Bouzinac Geneviève, Élisabeth Vigée-Lebrun, Souvenirs, 3 vol., Paris, H. Champion, 2009.

Harrison Charles, Gaiger Jason et Wood Paul, Art in Theory, 1815-1900: an Anthology of Changing Ideas, Malden, Wiley-Blackwell, 1998.

Harth Erica, "The Salon Woman Goes Public... Or Does She", dans Elizabeth Goldsmith et Dena Goodman (éd.), Going Public: Women and Publishing in Early Modern France, Ithaca, Cornell University Press, 1995, p. 179-193. 
Haskell Francis et Penny Nicholas, Pour l'amour de l'antique. La statuaire gréco-romaine et le goût européen, trad. F. Lissarrague, Paris, Hachette, (1981) 1988.

Hatin Eugène, Histoire politique et littéraire de la presse en France, vol. 7, Paris, Poulet-Malassis et De Broise, 1859-1861, p. 415-545.

Haupais Coline, L'École des femmes. Représentations, définitions et apprentissage de la féminité dans les romans feuilletons du Journal des demoiselles, 1855-1870, mémoire de master, université Paris I Panthéon-Sorbonne, 2009.

Heinz Korin, Between Life and Art: Germaine de Stael and the Discourse of Female Choice, Ph.D., Northern Illinois University, 1995.

Heller Deborah, "Bluestocking Salons and the Public Sphere", Eighteenth-Century Life, vol. XXII, mai 1998, p. 59-82.

Hénaut Léonie, « Montée en qualification et perte de contrôle. Les restaurateurs de tableaux et leur document de travail», dans Anne-Marie Arborio, Yves Cohen et Pierre Fournier (dir.), Observer le travail. Histoire, ethnographie, approches combinées, Paris, La Découverte, 2008, p. 95-112.

Herriot Edouard, Madame Récamier et ses amis, d'après de nombreux documents inédits, $3^{\mathrm{e}}$ éd., Paris, Plon-Nourrit et $C^{\mathrm{ie}}, 1905$.

Hesse Carla, "French Women in Print, 1750-1800. An Essay in Historical Bibliography", Studies in Voltaire and the Eighteenth Century, n ${ }^{\circ} 359,1998$, p. 65-82.

Hesse Carla, Publishing and Cultural Politics in Revolutionary Paris, 1789-1810, Berkeley, University of California Press, 1991.

Hesse Carla, The Other Enlightenment: how French Women Became Modern, Princeton N.J., Princeton University Press, 2001.

Heyter-Rauland Christine, „Jeanette von Haza alias Heinrich (Henri) Paris. Erste Spuren einer Mitarbeiterin von Gottfried Webers Cäcilia“, dans Axel Beer, Kristina Pfarr et Wolfgang Rud (éd.), Festschrift Christoph-Hellmut Mahling zum 65. Geburtstag, Tutzing, H. Schneider, 1997, p. 553-560.

Hoffmann-Curtius Kathrin et Wenk Silke (dir.), Mythen von Autorschaft und Weiblichkeit im 20. Jahrhundert, Marburg, Jonas Verlag, 1997.

Höhn Gerhard et Füllner Bernd, Deutsch-französischer Ideentransfer im Vormärz, Bielefeld, Aisthesis (Jahrbuch des Forum Vormärz Forschung ; 8/2002), 2002.

Holcomb Adele M., “Anna Jameson: The First Professional English Art Historian”, Art History, 6:2, 1983, p. 171-187.

Homans Margaret, Bearing the Word: Language and Female Experience in Nineteenth-Century Women's Writing, Chicago, University of Chicago Press, 1986.

Honegger Claudia, Die Ordnung der Geschlechter: die Wissenschaften vom Menschen und das Weib, 1750-1850, Campus, 1991.

Hubert René, Histoire de la pédagogie, Paris, PUF, 1949.

Hundt Irina, „,Wäre ich besonnen, ware ich nicht Helmina'. Helmina von Chézy (1783-1856). Porträt einer Dichterin und Publizistin“, dans Helga Brandes et Detlev Kopp (éd.), Autorinnen des Vormärz, Bielefeld, Aisthesis, 1997, p. 43-79.

Hundt Irina, „Geselligkeit im Kreise von Dorothea und Friedrich Schlegel in Paris in den Jahren 1802-1804“, dans Hartwig Schultz (éd.), Salons der Romantik: Beiträge eines Wiepersdorfer Kolloquiums $z u$ Theorie und Geschichte des Salons, Berlin/New York, W. de Gruyter, 1997, p. 83-133.

Hyde Melissa Lee et Milam Jennifer Dawn, Women, Art and the Politics of Identity in EighteenthCentury Europe, Ashgate, Aldershot/Hants, 2003. 
Ingres and the Comtesse d'Haussonville, cat. d'expo., Munhall Edgar (dir.), (New York, The Frick Collection, 19 novembre 1985-16 février 1986), New York, The Frick Collection, 1985.

Israël Lucien, L'Hystérique, le sexe et le médecin, Paris, Masson, 1976.

Jackson Joseph, «La Muse de Département [Julie Candeille] », dans Louise Colet et ses amis littéraires, New Haven/Londres, Yale university press/H. Milford Oxford university press, 1937, p. 20-32.

Jacobs Fredrika, Defining the Renaissance Virtuosa: Women Artists and the Language of Art History and Criticism, Cambridge/New York, Cambridge University Press, 1997.

James Cuno B., "Charles Philipon, La Maison Aubert, and the Business of Caricature in Paris, 1829-1841", Art Journal, 43, nº 4, hiver 1983.

Jasenas Éliane, Marceline Desbordes-Valmore devant la critique, Genève, E. Droz, 1962.

Jensen Belnap Heather, "Diversionary Tactics: Art Criticism as Political Weapon in Germaine de Staël's Corinne, or Italy (1807)", dans Waltraud Maierhofer, Gertrud Roesch et Caroline Bland (éd.), Women against Napoleon: Historical and Fictional Responses to his Rise and Legacy, Francfort/New York, Campus Verlag, 2007.

Jensen Belnap Heather, "The Journal des dames et des modes: Fashioning Women in the Arts, c. 1800-1815", Nineteenth Century Art Worldwide, vol. 5, $\mathrm{n}^{\circ} 1$, printemps 2006. URL: http://www. 19thc-artworldwide.org/index.php/spring06/172-the-journal-des-dames-et-des-modesfashioning-women-in-the-arts-c-1800-1815. Consulté le 2 juin 2010.

Jensen Belnap Heather, "Caroline Wuiet", dans Antoinette Fouque, Mireille Calle-Gruber et Béatrice Didier (éd.), Dictionnaire des femmes créatrices, Paris, éditions des femmes, à paraître.

Jensen Belnap Heather, “'C.W., académicienne': Caroline Wuiet and the Woman Art Critic in PostRevolutionary France", dans Wendelin Guentner (éd.), Vanishing Acts: Women Art Critics in Nineteenth-Century France, Newark, University of Delaware, à paraître.

Jensen Belnap Heather, Portraitistes à la plume. Women Art Critics in Revolutionary and Napoleonic France, [s.1.], University of Kansas, 2007.

Jensen Katharine, Writing Love: Letters, Women, and the Novel in France, 1605-1776, Carbondale, Southern Illinois University Press, 1995.

Jenson Deborah, Trauma and its Representations: the Social Life of Mimesis in Post-Revolutionary France, Baltimore, Johns Hopkins University Press, 2001.

Johns Christopher, Antonio Canova and the Politics of Patronage in Revolutionary and Napoleonic Europe, Berkeley, University of California Press, 1998.

Juliette Récamier, muse et mécène, cat. expo., Stéphane Paccoud (éd.), (Lyon, musée des Beaux-Arts, 2009), Paris, Hazan, 2009.

Juratic Sabine et Pellegrin Nicole, «Femmes, villes et travail en France dans la deuxième moitié du XVIII siècle : quelques questions ", Histoire, Économie, Société, nº 3, 1994, p. 477-500.

Kale Stephan D., "Women, the Public Sphere, and the Persistence of Salons", French Historical Studies, vol. 25, $\mathrm{n}^{\circ}$ 1, hiver 2002, p. 115-148.

Kermina Françoise, Madame Tallien : 1773-1835, Paris, Perrin, 2006.

Kettler Agnès, Lettres de Ballanche à Madame Récamier : 1812-1845, Paris, Honoré Champion, 1996.

Kleinert Annemarie, Le Journal des dames et des modes, ou la Conquête de l'Europe féminine (1797-1839), Stuttgart, J. Thorbecke, 2001.

Kleist Heinrich von, Sämtliche Werke. Brandenburger Ausgabe,t. III, Sämtliche Gedichte, Basel, Stroemfeld-Roter Stern, 2005. 
Kleist Heinrich, Briefe von und an Heinrich von Kleist, 1793-1811, Klaus Müller-Salget et Stefan Ormanns (éd.), vol. 4, 1. Aufl., Francfort-sur-le-Main, Deutscher Klassiker Verlag (Heinrich von Kleist Sämtliche Werke und Briefe), 1997.

Köster Christian, « Il Manuale di Christian Köster e il restauro in Italia e in Germania dal 1780 al 1830 », dans Sul restauro degli antichi dipinti ad olio, éd. et trad. par Giuseppina Perusini, Udine, Editrice Universitaria Udinese, 2001.

Köster Christian, Über Restauration alter Ölgemälde, Heidelberg, C. F. Winter, 1827-1830 ; réédité avec une introduction de Thomas Rudi, Bücherei des Restaurators (hrg. Ulrich Schiessl), Leipzig, Seeman, 2001.

L'Hôpital Madeleine, La Notion d'artiste chez George Sand, Paris, Boivin \& Cie, 1946.

La Femme artiste d'Élisabeth Vigée-Lebrun à Rosa Bonheur, cat. expo., musée Despiau-Wlérick (éd.), (Mont-de-Marsan, Donjon Lacataye, musée Despiau-Wlérick, 1981-1982), Mont-de-Marsan, Lacoste, 1981.

Laborde Alice M. , L'Euvre de Madame de Genlis, Paris, Éditions A.-G. Nizet, 1966.

Laffitte Pierre (éd.), «Matériaux pour servir à la biographie d'A. Comte. Correspondance avec $\mathrm{M}^{\mathrm{me}}$ Austin », La Revue occidentale philosophique, sociale et politique: organe du positivisme, seconde série, t. XX, 1900, p. 422.

Lafont Anne, Girodet, Paris, Biro-RMN, 2005

Lafont Anne, Foucher Charlotte et Gorse Amandine (dir.), Plumes et Pinceaux. Discours de femme sur l'art en Europe (1750-1850) - Anthologie, Dijon, Presses du réel/INHA, 2012.

Lafont Anne, « Comment peut-on être critique ? Jugement de goût et relativisme culturel », dans Marc Bayard, Jacqueline Lichtenstein et Christian Michel (dir.), De la quête des règles au discours sur les fins. Les mutations du discours sur l'art en France dans la seconde moitié du XVIII siècle, Rome, publications de la Villa Médicis, à paraître.

Lajer-Burcharth Ewa, Necklines: the Art of Jacques-Louis David after the Terror, New Haven, Yale University Press, 1999.

Landes Joan, Women and the Public Sphere in the Age of the French Revolution, Ithaca, Cornell University Press, 1988.

Langer Sandra L., "Women Artists in All Ages and Countries by Elisabeth Fries Lummis Ellet", Woman's Art Journal, vol. 1, n 2, [s.d.], p. 55-58.

Lanser Susan, Fictions of Authority: Women Writers and Narrative Voice, Ithaca, Cornell University Press, 1992.

Laqueur Thomas, La Fabrique du sexe. Essai sur le corps et le genre en occident, Paris, Gallimard, (1990) 1993.

Larsen Anne et Winn, Writings by Pre-Revolutionary French Women: from Marie de France to Élisabeth Vigée-Lebrun, New York/Londres, Garland publ., 2000.

Lassère Madeleine, Le Portrait double. Julie Candeille et Girodet, Paris, L'Harmattan, 2005.

Latour Bruno, La Science en action, trad. Michel Biezunski, Paris, La Découverte, (1987) 1989.

Lawrence Cynthia, Woman and Art in Early Modern Europe. Patrons, Collectors and Connoisseurs, University Park, The Pennsylvania State University Press, 1997.

Léger Christine, Le Journal des demoiselles et l'éducation des filles au XIXe siècle, thèse de doctorat, université Paris VII, 1988.

Lejeune-Resnick Évelyne, Les Femmes écrivains sous la monarchie de Juillet (société et littérature), thèse de doctorat, université Paris IV-Sorbonne, 1983. 
Lely Sandrine, «Peintresses ou artistes ? Les femmes dans la vie artistique de province au XVIII siècle ", dans Jean-Pierre Lethuillier (éd.), La Peinture en province : de la fin du Moyen Âge au début du XX ${ }^{e}$ siècle, Rennes, Presses universitaires de Rennes, 2002, p. 99-106.

Lemeux-Fraitot Sidonie, Ut poeta pictor. Les champs culturels et littéraires d'Anne-Louis GirodetTrioson, thèse de doctorat, Paris, université Panthéon-Sorbonne, 2003.

Letzer Jacqueline et Adelson Robert, "Women Opera Composers face the Parisian comités de lecture. Where Institutional Barriers meet Social Barriers to Performance", Studies on Voltaire and the Eighteenth Century, n ${ }^{\circ}$ 5, 2000, p. 355-369.

Letzter Jacqueline et Adelson Robert, Women Writing Opera: Creativity and Controversy in the Age of the French Revolution, Berkeley, University of California Press, 2001.

Levaillant Maurice, Une amitié amoureuse : Madame de Staël et Madame Récamier. Lettres et documents inédits, Paris, Hachette, 1956.

Leverson Wyndham Violet, Madame de Genlis, a Biography, Londres, Roy Publishers, 1958.

Levitine George, The dawn of Bohemianism: the Barbu Rebellion and Primitivism in Neoclassical France, University Park, Pennsylvania State University Press, 1978.

Levy Gayle A., “A Genius for the Modern Era: Madame de Staël's Corinne”, Nineteenth-Century French Studies, vol. 30, $\mathrm{n}^{\circ}$ 3\&4, 2002, p. 243-254.

Lew Laurie Kane, “Cultural Anxiety in Anna Jameson's Art Criticism”, Studies in English Literature, vol. 36, n 4, automne 1996, p. 839-856.

Lloyd Stephen, The Accomplished Maria Cosway: Anglo-Italian Artist, Musician, Salon Hostess and Educationalist (1759-1838), Msida, Malta University Press, 1992.

Lloyd Stephen, Richard \& Maria Cosway, Regency Artists of Taste and Fashion with Essays by Roy Porter \& Aileen Ribeiro, Edinburgh, Scottish National Portrait Gallery, 1995.

Longchamp Frédéric, L'Eeuvre imprimée de Madame Germaine de Staël : description bibliographique raisonnée et annotée de tous les ouvrages publiés par ses soins ou ceux de ses héritiers (1786-1821), Genève, [s.n.], 1949.

Losano Antonia, The Woman Painter in Victorian Literature, Columbus, Ohio State University Press, 2008.

Lotterie Florence, "Madame de Staël : la littérature comme "philosophie sensible" ", Romantisme. Revue du dix-neuvième siècle, $\mathrm{n}^{\circ}$ 124, 2004, p. 19-30.

Lotterie Florence, Szmurlo Karyna et Seth Catriona, Madame de Staël et les études feminines : autour de Madame Necker, Paris, Société des études staëliennes, 2006.

Louichon Brigitte, Romancieres sentimentales : 1789-1825, Saint-Denis, Presses universitaires de Vincennes, 2009.

Mallet Sylvie, "Tribune des Femmes: une éducation pour l'indépendance économique ", Romantisme, $\mathrm{n}^{\circ} 28,1980$, p. 203-211.

Mansfield Elizabeth, Art, History, and Authorship: The Critical Writings of Emilia Dilke (1840-1904), Ph.D., Harvard University, 1996.

Mansfield Elizabeth, Art History and its Institutions : foundations of a Discipline, Londres, New York, Routledge, 2002.

Marceline Desbordes-Valmore, cat. expo., Yvonne Duhamel et Julien Cain (éd.), (Douai, Bibliothèque municipale, 1959), Douai, éd. de la bibliothèque municipale, 1959.

Marcoin Francis, Librairie de jeunesse et littérature industrielle au XIX siècle, Paris, H. Champion, 2006.

Marot Pierre, «Les origines de la transposition en France », Annales de l'est, 1950, p. 241-282. 
Martin Sophie, George Sand et les milieux picturaux, thèse de doctorat, université Paris-Sorbonne, 1998 (inédit).

Matlock Jann, Scenes of Seduction. Prostitution, Hysteria and Reading Difference in Nineteenth-Century France, New York, Columbia University Press, 1994.

Matlock Jann, "Seeing Women in the July Monarchy Salon: Rhetorics of Visibility and the Women's Press", Art Journal, vol. 55, n 2, 1996, p. 73-84.

Matlock Jann, "Anatomies of Sociability", contribution au colloque Nineteenth-Century French Studies Colloquium, University of South Alabama, Mobile (Ala.), 2007 (inédit).

Matlock Jann, "Jeunes femmes à la mode: Anatomies of Sociability from Thermidor through the First Empire", dans le cadre de l'atelier international More than Fashion: The Journal des dames et des modes (1797-1839), University of Michigan, Ann Arbor, 2009 (inédit).

Maurer Shawn, Proposing Men: Dialectics of Gender and Class in the Eighteenth-Century English Periodical, Stanford, Stanford University Press, 1998.

May Gita, "Diderot and Burke, A study in Aesthetic Affinity", PMLA [Publications of the Modern Language Association of America], vol. 75, $\mathrm{n}^{\circ}$ 5, décembre 1960, p. 527-539.

Mazzocut-Mis Maddalena, Corpo e voce della passione. L'estetica di Jean-Baptiste Du Bos, Milan, Edizioni Universitarie di Lettere Economia Diritto, 2010.

McAlpin Mary, Gender, Authenticity and the Missive Letter in Eighteenth-Century France: Marie-Anne de La Tour, Rousseau's Real-Life Julie, Lewisburg, Bucknell University Press, 2006.

McCauley Elizabeth, A.A.E. Disdéri and the Carte de Visite Portrait Photograph, New Haven, Yale University Press, 1985.

McClellan Andrew, Inventing the Louvre: Art, Politics, and the Origins of the Modern Museum in Eighteenth-Century Paris, Cambridge/New York, Cambridge University Press, 1994.

McDermott Tara, Adélaïde Labille-Guiard and Elisabeth Vigée-Lebrun: Portraitists in the Age of the French Revolution, [s.l.], University of North Texas, 1996.

McWilliam Neil (dir.), A Bibliography of Salon Criticism in Paris from the July Monarchy to the Second Empire, 1831-1851, Cambridge, Cambridge University Press, 1991.

McWilliam Neil, Rêves de bonheur : l'art social et la gauche française (1830-1850), Dijon, Les Presses du réel, 2007.

Micale Mark, "Hysteria Male/Hysteria Female: Reflections on Comparative Gender Construction in Nineteenth-Century France and England”, dans Marian Benjamin (éd.), Science and Sensibility. Gender and Scientific Enquiry 1780-1945, Oxford, Blackwell Publishers, 1991, p. 200-239.

Michel Régis, Où en est l'interprétation de l'œuvre d'art ?, Paris, ENSBA, 2001.

Miller Daniel (dir.), “Introduction”, dans Materiality, Durham, Duke University Press, 2005.

Miller Nancy K., The Heroine's Text: Readings in the French and English Novel, 1722-1782, New York, Columbia University Press, 1980.

Miller Nancy K., "I's in Drag: The Sex of Recollection ", The Eighteenth Century, vol. 22, 1981, p. 47-57 ; nouvelle publication French Dressing: Women, Men and Ancien Régime Fiction, 1995, p. 93-103.

Mitchell Rosemary, "Baillie, Marianne (1795?-1831)”, dans Oxford Dictionary of National Biography, Oxford University Press, 2004. URL : http://www.oxforddnb.com/view/article/1065. Consulté le 9 décembre 2010.

Moreau Thérèse, «Le Bas-bleu : une monstruosité littéraire et sociale », dans Thérèse Vichy (éd.), Roman et société, actes du colloque international de Valenciennes, (université de Valenciennes et du Hainaut-Cambrésis, mai 1983), Cahiers de l'UER Froissart, nº 8, hiver 1983, p. 227-234. 
Morrissey Ann, Daumier on Women: the Lithographs, Los Angeles, University Art Galleries/ University of Southern California, 1982.

Moses Goldberg Claire, French Feminism in the Nineteenth Century, Albany, State University of New York Press, 1984.

Moses Goldberg Claire et Wahl Rabine Leslie, Feminism, Socialism, and French Romanticism, Bloomington, Indiana University Press, 1993.

Myers Nicole, "Women Artists in Nineteenth-Century France", Heilbrunn Timeline of Art History, 2000. URL : http://www.metmuseum.org/toah/hd/19wa/hd_19wa.htm. Consulté le 19 décembre 2011.

Naef Hans, Die Bildniszeichnungen von J.-A.-D. Ingres, vol. 3, Berne, 1979, p. 391-405; traduit dans Portraits by Ingres: Image of an Epoch, cat. expo., Gary Tinterow et al. (dir.), (Londres, National Gallery), Londres, Harry N. Abrams, 1999, p. 470-473.

Nel Philippe, «Émilie-Julie Candeille : un biscuit de Sèvres dit La Belle Provençale », conférence, (Société des amis du vieux Toulon, 21 mars 1930), Toulon, Impr. du Petit Var, 1930, p. 1-27.

Nerlich France, La Réception de la peinture française en Allemagne, 1815-1870, Paris, Maison des sciences de l'homme, 2010.

Nochlin Linda, “The Imaginary Orient”, Art in America, vol. 71, n 5, 1983, p. 119-131 et 187-191.

Nochlin Linda, "Why Have There Been No Great Women Artists?", ARTnews, janvier 1971, p. 22-39 et 67-71; trad. française d'Oristelle Bonis, « Pourquoi n'y a-t-il pas eu de grands artistes femmes ?", dans Femmes, art et pouvoir, et autres essais, Nîmes, Jacqueline Chambon, 1993, p. 201-244.

Nolhac Pierre (de), Madame Vigée-LeBrun, peintre de Marie-Antoinette, Paris, Goupil, 1912.

Nora Pierre, «Les mémoires d'État. De Commynes à de Gaulle», dans Les Lieux de mémoire, II. La Nation, Paris, Gallimard, 1986, chapitre 11.

Nunn Pamela Gerrish, "Critically Speaking”, dans Women in the Victorian Art World, Manchester/ New York, Manchester University Press, 1995, p. 107-124.

Ockman Carol, Ingres's Eroticized Bodies: Retracing the Serpentine Line, New Haven, Yale University Press, 1995.

Oliver Bette, Élisabeth Vigée-Lebrun, Jean-Baptiste Pierre Lebrun, and Marguerite Gérard and their Roles in the French Artistic Legacy, 1775-1825, Ph.D. Dissertation, University of Texas at Austin, 1997.

Oppenheimer Margaret Ann, “The Charming Spectacle of a Cadaver': Anatomical and Life Study by Women Artists in Paris, 1775-1815", Nineteenth Century Art Worldwide, printemps 2007. URL : http://www.19thc-artworldwide.org/index.php/spring07/142-qthe-charming-spectacle-of-acadaverq-anatomical-and-life-study-by-women-artists-in-paris-17751815. Consulté le 2 juin 2010. Oppenheimer Margaret Ann, «Nisa Villers, née Lemoine (1774-1821) », Gazette des Beaux-Arts, avril 1996, p. 165-180.

Oppenheimer Margaret Ann, Women Artists in Paris, 1791-1814, thèse de doctorat, [s. 1.], University Microfilms International, 1996.

Orwicz Michael, Art Criticism and its Institutions in Nineteenth-Century France, Manchester/New York, Manchester University Press, 1994.

Osterman Borowitz Helen, The Impact of Art on French Literature: from de Scudéry to Proust, Newark/ Londres, University of Delaware Press/Associated University Press, 1985.

Padiyar Satish, Chains: David, Canova, and the Fall of the Public Hero in Postrevolutionary France, University Park Pa., Pennsylvania State University Press, 2007.

Parker Rozsika et Pollock Griselda, Old Mistresses: Women, Art and Ideology, Londres, Pandora, 1981. 
Pascal Jean-Noël (dir.), «La "Muse de la Raison" : Constance de Salm (1767-1845) », numéro spécial des Cahiers Roucher-André Chénier, $\mathrm{n}^{\circ}$ 29, 2010.

Passez Anne, Adélaïde Labille-Guiard. 1749-1803. Biographie et catalogue raisonné de son œuvre. Prix de la fondation Paul Cailleux 1971, Paris, Arts et Métiers Graphiques, 1973.

Pavanello Giuseppe et Praz Mario, L'Opera completa del Canova, Milan, Rizzoli, 1976.

Pekacz Jolanta T., "The Salonnières and the Philosophies in Old Regime France: The Authority of Aesthetic Judgment", Journal of the History of Ideas, $n^{\circ}$ 60, février 1999, p. 277-297.

Pekacz Jolanta T., Conservative Tradition in Pre-Revolutionary France: Parisian Salon Women, New York, Peter Lang, 1999.

Petermann Thomas, Der Saint-Simonismus in Deutschland: Bemerkungen zur Wirkungsgeschichte, Francfort-sur-le-Main/New York, Peter Lang, 1983.

Peters Jennifer, The Culture of Eighteenth Century France and Its Impact on French Women Artists, Ph.D., California State University, Dominguez Hills, 1998.

Petteys Chris, Dictionary of Women Artists: an International Dictionary of Women Artists Born before 1900, Boston Mass., G.K. Hall, 1985.

Péty Dominique, «Le personnage du collectionneur au XIX siècle : de l'excentrique à l'amateur distingué ", Romantisme. Revue du dix-neuvième siècle, nº 112, 2001, p. 71-81.

Phelps William, The History and Antiquities of Somersetshire, Londres, Nichols, 1836, p. 470.

Plagnol-Diéval Marie-Emmanuelle, Madame de Genlis et le théâtre d'éducation au XVIII siècle, Oxford, Voltaire Foundation, 1997.

Plagnol-Diéval Marie-Emmanuelle, Madame de Genlis, Paris, Memini/diffusion CNRS éditions, 1996. Planté Christine, La Petite Sour de Balzac. Essai sur la femme auteur, Paris, éditions du Seuil, 1989.

Planté Christine, «Les Bas-bleus de Daumier : de quoi rit-on dans la caricature ? ", dans Philippe Régnier (dir.), La Caricature entre République et censure. L'imagerie satirique en France de 1830 à 1880 : un discours de résistance, Lyon, Presses universitaires de Lyon, 1996, p. 192-202.

Planté Christine, "L'Atelier d'un peintre de Marceline Desbordes-Valmore, le roman d'une poète », George Sand Studies, vol. XVII, nº 1 \& 2, 1998, p. 43-54.

Planté Christine, Pouzoulet Christine et Vaillant Alain (dir.), Une mélodie intellectuelle, Corinne ou l'Italie de Germaine de Staël, actes des journées d'études, (Lyon et Montpellier, 12 et 17 février 2000), Montpellier, université Paul Valéry, 2000.

Planté Christine et Thérenty Marie-Ève (dir.), "Masculin/féminin et presse au XIX siècle ", colloque international, Lyon, 24-26 novembre 2010, à paraître.

Pohl Nicole et Schellenberg Betty A. (éd.), Reconsidering the Bluestockings, San Marino, Huntington Library, 2003.

Polanyi Michael, The Tacit Dimension, New York, Anchor Books Doubleday, 1967.

Polanyi Michael, Personal Knowledge. Towards a Post Critical Philosophy, Londres, Routledge, 1998.

Pollock Griselda, “Artists, Mythologies, and Media Genius, Madness, and Art History”, Screen 21.3, 1980, p. 57-96.

Pollock Griselda, Differencing the Canon: Feminist Desire and the Writing of Art's Histories, Londres, Routledge, 1999.

Pollock Griselda, Vision and Difference: Feminism, Femininity and the Histories of Art, Londres/New York, Routledge, 2003.

Poortere Machteld (de), Les Idées philosophiques et littéraires de $M^{m e}$ de Staël et de $M^{\text {me }}$ de Genlis, New York, Peter Lang, 2004. 
Poovey Mary, The Proper Lady and the Woman Writer: Ideology as Style in the Works of Mary Wollstonecraft, Mary Shelley, and Jane Austen, Chicago, University of Chicago Press, 1984.

Portraits by Ingres: Image of an Epoch, cat. expo., Tinterow Gary, Conisbee Philip et Naef Hans (éd.), (Londres, National Gallery of Art/New York Metropolitan Museum of Art, 1999), New York, Metropolitan Museum of Art, 1999.

Potts Alex, "Political Attitudes and the Rise of Historicism in Art Theory", Art History, vol. 1, juin 1976, p. 191-215.

Pougetoux Alain, La Collection de peintures de l'impératrice Joséphine, Paris, Réunion des musées nationaux, (« Notes et documents des musées de France», n 37), 2003.

Praz Mario, On Neoclassicism, Londres, Thames \& Hudson, 1969 ; Goût Néoclassique, trad. Constance Thompson Pasquali, Paris, éditions du Promeneur, 1974.

Presser Jacques, Ashes in the Wind: the Destruction of Dutch Jewry, Londres, Souvenir Press, 2010.

Preziosi Donald, The Art of Art History: A Critical Anthology, Oxford, Oxford University Press, 2009.

Proctor Candice, Women, Equality, and the French Revolution, New York, Greenwood Press, 1990.

Prudhomme Louis, Répertoire universel, historique, biographique des femmes célèbres, mortes ou vivantes..., Paris, [s.n.], 1826.

Pullan Ann, “'Conversations on the Arts': Writing a Space for the Female Viewer in the Repository of Arts, 1809-1815", Oxford Art Journal, vol. 15, n² 2, 1992, p. 15-26.

Raaphorst M. R., “Adele versus Sophie: the Well-Educated Woman of $\mathrm{M}^{\mathrm{me}}$ de Genlis", Rice University Studies, vol. 64, 1978.

Rabaut Jean, Féministes à la Belle Époque, Paris, France Empire, 1985.

Rahel Varnhagen. Eine jüdische Frau in der Berliner Romantik, 1771-1833, cat. expo., Carola Gerlach et François Melis (éd.), Berlin, Beratungsstelle für Frauen und Familien, 1993.

Reid Martine, Des femmes en littérature, Paris, Belin, 2010.

Rennolds Margaret B. (éd.), National Museum of Women in the Arts, New York, H.N. Abrams, 1987.

Rétif de la Bretonne Fr., Les Nuits révolutionnaires : impressions et récits contemporains, Paris, [s.n.], 1910.

Reuss Roland et Staengle Peter, „Das Schöne gehört jedem...' Zwei bisher unveröffentliche Kleisthandschriften aus Kleists Dresdener Zeit“, Berliner Kleist-Blätter, vol. 15, 2003, p. 17-28.

Richter Sherman Claire (éd.), Women as Interpreters of the Visual Arts, 1820-1979, Westport/Londres, Greenwood Press, 1981.

Rièse Laure, Les Salons littéraires parisiens : du Second Empire à nos jours, Toulouse, Privat, 1962.

Rimbault Caroline, La Presse féminine française au XVIII ${ }^{e}$ siècle, Amsterdam/Maarsen, APA/Holland University Press, 1988.

Riot-Sarcey Michèle, Histoire du féminisme, Paris, La Découverte, 2002.

Riviere Joan, « La féminité en tant que mascarade (1929) », dans Marie-Christine Hamon (dir.), Féminité mascarade : études psychanalytiques, Paris, Seuil, 1994, p. 197-214.

Robb Bonnie, Félicité de Genlis: Motherhood in the Margins, Newark, University of Delaware Press, 2008.

Robert-Jones Philippe, "Les femmes dans l'œuvre lithographique de Daumier », Médecine de France, 23, 1951, p. 29-32.

Roland Michel Marianne et Kahng Eik, Anne Vallayer-Coster. Peintre à la cour de Marie-Antoinette, Paris, Somogy, 2003. 
Rooses Max, L'Euvre de P. P. Rubens. Histoire et descriptions de ses tableaux et dessins, vol. II, Soest, Davaco, 1977.

Rosen Julia (von), Le Transfert culturel comme transformation de discours : $M^{\text {me }}$ de Staël interprète de l'esthétique kantienne, thèse de doctorat, Caen, université de Caen, 2003 (inédit).

Rossi Henri, «La cour de Vienne dans les Souvenirs de $\mathrm{M}^{\text {me }}$ Vigée-Lebrun », dans Mémorialistes de l'exil : émigrer, écrire, survivre, Paris, L'Harmattan, 2003, p. 153-172.

Rotman Deborah L., Separate Spheres: Beyond the Dichotomies of Domesticity, Chicago, University of Chicago Press, 2006.

Rouff Marcel et Casevitz Thérèse, «Une actrice femme de lettres au dix-huitième siècle : $\mathrm{M}^{\text {lle }}$ Candeille ", Revue hebdomadaire, décembre 1923, p. 185-199, p. 300-317 et p. 446-463.

Salomon Nanette, "The Art Historical Canon: Sins of Omission", dans J. Hartman et E. MesserDavidow (dir.), (En)Gendering Knowledge, Knoxville, University of Tennessee Press, 1991, p. 222-236.

Schaeffer Jean Owens, "The Souvenirs of Elisabeth Vigée-Lebrun: The Self-Imaging of the Artist and the Woman", International Journal of Woman's Studies, vol. 4, 1981, p. 35-49.

Schazmann Paul-Émile, Bibliographie des œuvres de $M^{m e}$ de Stä̈l et description d'après les exemplaires originaux des éditions françaises publiées de son vivant et des inédits posthumes avec 12 reproductions, Paris, V. Attinger, 1938.

Schiebinger Londa, The Mind Has No Sex? Women in the Origins of Modern Science, Cambridge, Harvard University Press, 1989.

Schmidt am Busch Hans-Christoph (éd.), Hegelianismus und Saint-Simonismus, Paderborn, Mentis, 2007.

Schmidt-Linsenhoff Victoria (éd.), Sklavin oder Bürgerin. Französische Revolution und Neue Weiblichkeit 1760-1830, Marburg, Jonas, 1989.

Schneider René, "L'art anachréontique et alexandrin sous l'Empire", Revue des études napoléoniennes, t. II, novembre 1916, p. 257-271.

Schroder Anne L., "Learning to Look: $\mathrm{M}^{\mathrm{me}}$ de Genlis and Art as a Pedagogical Tool”, conférence présentée devant l'American Society for Eighteenth-Century Studies, Notre Dame (IN), 1998.

Schroder Anne L., "Going Public Against the Academy in 1784. $\mathrm{M}^{\mathrm{me}}$ de Genlis Speaks Out on Gender Bias and Élisabeth Vigée-Lebrun”, Eighteenth Century Studies, vol. 32, n 3, 1999, p. 376-382. Schwab Clothilde, Marie-Jacob van Merle, appelée la Veuve Godefroid, restauratrice des tableaux du roi de 1741 à 1775, restauratrice pour les particuliers et marchande de tableaux, mémoire de master 1, Paris, École du Louvre, 2004.

Sennett Richard, Ce que sait la main. La culture de l'artisanat, trad. Pierre-Emmanuel Dauzat, Paris, Albin Michel, (2008) 2010.

Serebrjakova Galina, Nine Women, Drawn from the Epoch of the French Revolution, Freeport N.Y., Books for Libraries Press, 1969.

Shaffer Elinor, "Plumptre, Anne (1760-1818)", dans Oxford Dictionary of National Biography, Oxford University Press, 2004. URL : http://www.oxforddnb.com/. Consulté 5 septembre 2010.

Shelton Carrington Andrew, “Art, Politics, and the Politics of Art. Ingres's Saint Symphorien at the 1834 Salon”, Art Bulletin, LXXXIII, nº 4, 2001, p. 711-739.

Shelton Carrington Andrew, From Making History to Living Legend: The Mystification of M. Ingres (1834-1855), Ph.D. Dissertation, New York University, 1997.

Shelton Carrington Andrew, Ingres and his Critics, Cambridge/New York, Cambridge University Press, 2005. 
Sheriff Mary, The Exceptional Woman: Élisabeth Vigée-Lebrun and the Cultural Politics of Art, Chicago, University of Chicago Press, 1996.

Sheriff Mary, Moved by Love: Inspired Artists and Deviant Women in Eighteenth-Century France, Chicago, University of Chicago Press, 2004.

Sherman Claire, Women as Interpreters of the Visual Arts, 1820-1979, Westport Conn., Greenwood Press, 1981.

Showalter Elaine, "Feminist Criticism in the Wilderness", Critical Inquiry, vol. 8, n² 2, hiver 1981, p. 243-270.

Siebers-Gfaller Stefanie, Deutsche Pressestimmen zum Saint-Simonismus 1830-1836: eine frühsozialistische Bewegung im Journalismus der Restaurationszeit, Francfort-sur-le-Main/New York, Peter Lang, 1992.

SIEFAR, Dictionnaire des femmes de l'Ancien Régime, 2004. URL : http://www.siefar.org/dictionnaire/ fr/Accueil. Consulté le 19 décembre 2011.

Siegfried Susan L., "The Politicization of Art Criticism in the Post-Revolutionary Press", dans Michael R. Orwicz (éd.), Art Criticism in Nineteenth-Century France, New York/Manchester University Press, 1994.

Siegfried Susan L., "Engaging the Audience: Sexual Economies of Vision in Joseph Wright", Representations, $\mathrm{n}^{\circ}$ 68, automne 1999, p. 34-58.

Siegfried Susan L., Ingres' Painting Reimagined, New Haven, Yale University Press, 2009.

Simons-Candeille Amélie, Souvenirs de Brighton, de Londres et de Paris, Paris, Delaunay, 1818.

Slama Béatrice, «Femmes écrivains », dans Jean-Paul Aron (éd.), Misérable et glorieuse : la femme du XIX siècle, [Paris], Fayard, 1980, p. 216-218.

Snell Robert, Théophile Gautier: A Romantic Critic of the Visual Arts, Oxford, Oxford University Press, 1982.

Société Chateaubriand, Madame Récamier et son entourage, journée-colloque, (Lyon, 3 décembre 1777 ; Paris, 11 mai 1849), La Vallée-aux-loups/Le Plessis-Robinson, 1978.

Société d'agriculture, sciences et arts de Douai, Marceline Desbordes-Valmore et son temps, actes de colloque (Douai, bibliothèque municipale, 26 avril 1986), Douai, Imprimerie Lefebvre-Lévêque, 1986.

Sofio Séverine, «La vocation comme subversion. Artistes femmes et anti-académisme dans la France révolutionnaire ", Actes de la recherche en sciences sociales, $n^{\circ} 3 / 168,2007$, p. 34-49.

Solomon-Godeau Abigail, "Genre, Gender and Géricault", dans Théodore Géricault. The Alien Body: Tradition in Chaos, Vancouver, University of British Columbia, 1997, p. 94-116.

Solomon-Godeau Abigail, Male Trouble: a Crisis in Representation, Londres/New York, Thames \& Hudson, 1997.

Solovieff Georges, « Une irréductible : Helmina de Chézy (1783-1856) », dans Cinq figures féminines méconnues du romantisme allemand, Paris, L'Harmattan, 2005, p. 233-299.

Sonolet Louis, Madame Tallien, d'après des témoignages contemporains et des documents inédits, Paris, L'Édition, 1909.

Spencer Clifford Michael, The Art Criticism of Théophile Gautier, Genève, Librairie Droz, 1969.

Stafford Barbara, Artful Science: Enlightenment, Entertainment, and the Eclipse of Visual Education, Cambridge Mass., MIT Press, 1994.

Stock-Morton Phyllis, The Life of Marie d'Agoult, alias Daniel Stern, Baltimore/Londres, The Johns Hopkins University Press, 2000. 
Struckmeyer Nina et Blankenstein David, « Saisir la vie, transférer des savoirs : Helmina de Chézy à Paris sous le Premier Empire ", Histoire de l'art, $n^{\circ}$ 64, 2009, p. 95-102.

Sullerot Évelyne, La Presse féminine, Paris, A. Colin, 1963.

Sullerot Évelyne, Histoire de la presse féminine en France, des origines à 1848, préf. de Jacques Godechot, Paris, Armand Colin, 1966.

Swain Gladys, «L'âme, la femme, le sexe et le corps. Les métamorphoses de l'hystérie à la fin du dix-neuvième siècle ", Le Débat, n 24, mars 1983, p. 107-127.

Teotochi Albrizzi Isabella, Opere di scultura e di plastica di Antonio Canova, Pise/Bassano del Grappa, Istituto di Ricerca per gli Studi su Canova e il Neoclassicismo, (1824) 2003.

Terrin Charles, «Julie Candeille. Actrice, musicienne, femme de lettres », Revue des deux mondes, mai 1936, p. 403-425.

The Three Graces. Antonio Canova, cat. expo., Timothy Clifford et al. (dir.), (Édimbourg, National Gallery of Scotland), Édimbourg, National Gallery of Scotland, 1995.

Therrien Lyne, L'Histoire de l'art en France, genèse d'une discipline universitaire, Paris, Éditions du CTHS, 1998.

Thomann Tewarson Heidi, Rahel Levin Varnhagen, mit Selbstzeugnissen und Bilddokumenten, Hambourg, Rowohlt, 1988.

Thuillier Jacques, Rubens, la galerie Médicis au palais du Luxembourg, appendice historique et documentaire de Jacques Foucart, Paris/Milan, Laffont/Rizzoli, 1969.

Tinterow Gary, Hale Charlotte et Bertin Éric, “'Portraits by Ingres: Image of an Epoch': Reflections, Technical Observations, Addenda, and Corrigenda", Metropolitan Museum Journal, vol. XXXV, 2000, p. 193-219.

Tourneux Maurice, «Lettre de $\mathrm{M}^{\mathrm{me}}$ de Vandeul, née Diderot, sur le Salon de l'an X », Bulletin de la Société d'histoire de l'art français, 1912, p. 124-140.

Toussaint du Wast Nicole, Laure Junot, duchesse d'Abrantès, Paris, Fanval, 1985.

Trebitsch Michel et Blum Françoise (dir.), Intellectuelles: du genre en histoire des intellectuels, Bruxelles/Paris, Éd. Complexe/IHTP-CNRS, 2004.

Trouille Mary Seidman, “The influence of Class and Politics on Women's Response to Rousseau: Stéphanie de Genlis and Olympe de Gouges", dans Sexual Politics in the Enlightenment. Women Writers Read Rousseau, Albany/New York, University of New York Press, 1997.

Turquan Joseph, A Great Coquette: Madame Récamier and her Salon, New York, Brentano's, 1913.

Vailleton Laure, "Les Salons de $\mathrm{M}^{\text {me }}$ de Vandeul ou l'histoire d'une filiation littéraire», Recherches sur Diderot et sur l'Encyclopédie, vol. 13, octobre 1992, p. 79-105.

Van Dijk Suzan, «Le Journal des dames, 1759-1778 : les journalistes-dames et les autres », dans Traces de femmes, présence féminine dans le journalisme français du XVIII ${ }^{e}$ siècle, Amsterdam/Maarsen, APA/Holland University press, 1988, p. 134-186.

Varnhagen von Ense Rahel, Rahel Varnhagen: eine jüdische Frau in der Berliner Romantik 1771-1833 Ausstellung zum 160. Todestag, Berlin, [s.n.], 1993.

Vier Jacques, La Comtesse d'Agoult et son temps, avec des documents inédits, 2. Recommencement d'une vie (1839-1848), Paris, A. Colin, 1959.

Vier Jacques, La Comtesse d'Agoult et son temps, avec des documents inédits, 6. Dernières années (1870-1876), Paris, A. Colin, 1963.

Villeneuve Roland (de), Le Musée de la bestialité, Paris, H. Veyrier, 1973. 
Violin-Savalle Maryse, Images croisées de la femme romantique à travers la littérature et la peinture, en France de 1765 à 1833 : esquisse, genèse et développement d'une typologie imaginaire, Villeneuve d'Ascq, Presses universitaires du Septentrion, 1998.

Virolle Roland, «Madame de Genlis, Mercier de Compiègne : gothique anglais ou gothique allemand ? ", Europe, n 659, mars 1984, p. 29-38.

Wagener Françoise, Madame Récamier 1777-1849, Paris, éd. Jean-Claude Lattès, 1986.

Walker John, Maria Cosway, an Undervalued Artist, Londres, Apollo, 1986.

Walker Lesley H., A Mother's Love: Crafting Feminine Virtue in Enlightenment France, Lewisberg, Bucknell University Press, 2008.

Waller Margaret, The Male Malady: Fictions of Impotence in the French Romantic Novel, New Brunswick, Rutgers University Press, 1993.

Waller Margaret, "Disembodiment as a Masquerade: Fashion Journalists and Other 'Realist' Observers in Directory Paris", Esprit créateur, vol. 37, n 1, printemps 1997, p. 44-54.

Walton Whitney, Eve's Proud Descendants: four Women Writers and Republican Politics in NineteenthCentury France, Stanford, Stanford University Press, 2000.

Weder Katharine, Kleists magnetische Poesie: Experimente des Mesmerismus, Göttingen, Wallstein, 2008.

Wehinger Brunhilde, Conversation um 1800: Salonkultur und literarische Autorschaft bei Germaine de Stä̈l, 1. Aufl., Berlin, ed. tranvía Verl. Frey, 2002.

Welschinger Henri, La Censure sous le Premier Empire, avec documents inédits, Paris, Perrin, 1997.

Winn Colette et Kuizenga Donna, Women Writers in Pre-Revolutionary France: Strategies of Emancipation, New York, Garland Pub., 1997.

Winock Michel, Madame de Staël, Paris, Fayard, 2010.

Wyndham Violet, Madame de Genlis. A biography [With plates, including portraits.], Londres, Andre Deutsch, 1958.

Yeldham Charlotte, Women Artists in Nineteenth-Century France and England: their Art Education, Exhibition Opportunities and Membership of Exhibiting Societies and Academies, with an Assessment of the Subject Matter of their work and summary biographies, New York, Garland, 1984. 


\section{Liste des œuvres évoquées}

Source : Anne Lafont, Charlotte Foucher, Amandine Gorse et al. (dir.), Plumes et Pinceaux. Discours de femmes sur l'art en Europe (1750-1850) - Anthologie, Paris, INHA-Presses du réel, 2012.

\section{Marie d'Agoult}

Bézard Jean-Louis, Allégorie ["Devant le triomphe de la Crédulité, assistée du Soupçon et de l'Ignorance, la Calomnie, la Mauvaise Foi et l'Envie traînent et accusent l'homme innocent qui implore la Vérité ", dit aussi La Calomnie d'Apelle], 1842, huile sur toile, 350 x $460 \mathrm{~cm}$

Bouchot François, L'Armée française au passage du mont Saint-Bernard

Bouchot François, La Vierge

Brémont Jean-François, Essais de fresques [L'Architecture, la Peinture et la Sculpture], 1842 , peinture à fresque

Brémont Jean-François, Essais de fresques [Tête d'homme], 1842, peinture à fresque

Chassériau Théodore, La Descente de Croix, 1842, huile sur toile, 300 x $220 \mathrm{~cm}$, Saint-

Étienne, église Notre-Dame

Chassériau Théodore, Les Troyennes [Les Troyennes regrettant leur patrie], 1842 [tableau détruit ; esquisse conservée à Beauvais, musée départemental de l'Oise]

Delaroche Paul, L'Hémicycle de l'École des beaux-arts de Paris, 1836-1841, fresque, papier marouflé sur toile, Paris, École nationale des beaux-arts

Flandrin Hippolyte, Saint Louis dictant ses capitulaires, 1842, huile sur toile, 316 x $251 \mathrm{~cm}$, Paris, palais du Sénat

Gigoux Jean-François, Saint Philippe guérissant une malade

Ingres Jean Auguste Dominique, Antiochus et Stratonice, 1840, huile sur toile, 57 x $98 \mathrm{~cm}$, Chantilly, musée Condé

Ingres Jean Auguste Dominique, L'Apothéose d'Homère, 1827, huile sur toile, 386 x $512 \mathrm{~cm}$, Paris, musée du Louvre

Ingres Jean Auguste Dominique, Portrait de Cherubini [Le Compositeur Cherubini et la muse de la poésie lyrique], 1841, huile sur toile, 105 x $94 \mathrm{~cm}$, Paris, musée du Louvre 
Ingres Jean Auguste Dominique, La Vierge à l'hostie, 1841, huile sur toile, 116 x $84 \mathrm{~cm}$, Moscou, musée Pouchkine

Joyard Angel, Les Druidesses invoquant la tempête

Lehmann Henri, La Flagellation [La Flagellation de Jésus-Christ], 1842, huile sur toile, $272 \mathrm{x}$ $185 \mathrm{~cm}$, Boulogne-sur-Mer, église Saint-Nicolas

Mottez Victor, Marthe et Marie, 1842, Nogent-Le-Rotrou, église

Overbeck Friedrich, Le Triomphe de la Religion [Le Triomphe de la Religion dans les arts], 1840, huile sur toile, 389 x $390 \mathrm{~cm}$, Francfort, Städelsches Kunstinstitut

Signol Émile, Madeleine [peut-être La Mort de la Madeleine, peinture commandée en 1836, Paris, église de la Madeleine]

Viardot Léon, Damoclès [Le Festin de Damoclès], 1842, huile sur toile, 363 x $176 \mathrm{~cm}$, Moulins, musée Anne de Beaujeu

Vinchon Auguste, Séance royale [peut-être Louis XVIII préside l'ouverture de la session des Chambres, le 4 juin 1814], 1841, huile sur toile, 421 x $576 \mathrm{~cm}$, Versailles, musée national des châteaux de Versailles et de Trianon

B.

Auzou Pauline, L'Amour dissipant les larmes, 1802 (an X)

Auzou Pauline, Deux jeunes filles lisant une lettre, 1802 (an X)

Bounieu ( $\left.\mathrm{M}^{1 \mathrm{ll}}\right)$, L'Amour endormi rêve que Psyché est près de lui, 1802 (an X)

Bounieu $\left(\mathrm{M}^{11 \mathrm{e}}\right)$, Portrait en pied du cit. Lafond, étudiant devant une glace le rôle de Tancrède, 1802 (an X)

Bounieu $\left(\mathrm{M}^{\mathrm{ll}}\right)$, Psyché sortant des enfers et venant d'ouvrir la boîte de fard de Proserpine, 1802 (an X)

Bounieu ( $\left.\mathrm{M}^{\mathrm{lle}}\right)$, Un Amour traçant un serment de fidélité sur le sable, 1802 (an X)

Bounieu $\left(\mathrm{M}^{\mathrm{Ile}}\right)$, Une jeune femme surprise par un orage

Garnier, Dédale et Icare, 1802 (an X)

Gérard François, Bélisaire, 1797, huile sur toile, 91 x 74 cm, Los Angeles, J. Paul Getty Museum Collection

Gérard Marguerite, Tableau représentant des bergers qui se disputent le prix du chant devant des jeunes filles, 1802 (an X)

Gérard Marguerite, Une jeune femme embrassant son enfant, 1802 (an X)

Girodet Anne-Louis, L'Apothéose des héros français morts pour la patrie pendant la guerre de la Liberté : les ombres des héros morts pour la patrie conduites par la Victoire viennent habiter l'Élysée aérien où les ombres d'Ossian \& de ses valeureux guerriers s'empressent de leur donner dans ce séjour d'immortalité \& de gloire la fête de la Paix \& de l'Amitié, 1801 (an IX), huile sur toile, $192 \times 182 \mathrm{~cm}$, Rueil-Malmaison, musée national des Châteaux de Malmaison et de Bois-Préau

Guérin Pierre-Narcisse, Phèdre et Hippolyte, 1802 (an X), huile sur toile, 257 x $335 \mathrm{~cm}$, Paris, musée du Louvre

Isabey Jean-Baptiste, Miniatures, 1790, aquarelle sur ivoire, 6,6 x 6,5 cm, Philadelphia Museum of art 
Isabey Jean-Baptiste, Portrait du Premier consul [peut-être Le Premier Consul Bonaparte à la Malmaison, 1797, crayon noir, estompe, blanc (rehaut), 69 x 47,5 cm, Rueil-Malmaison, musée national des Châteaux de Malmaison et de Bois-Préau]

Mongez Angélique, Astyanax arraché à sa mère, 1802 (an X)

Mongez Angélique, Bataille du mont Tabor, esquisse, 1802 (an X)

Mongez Angélique, Le Duel, 1802 (an X)

Mongez Angélique, Éros ou l'Amour débrouillant le Chaos, 1802 (an X)

Mongez Angélique, Jupiter et Io, 1802 (an X)

Mongez Angélique, Molière lisant le Tartuffe chez Ninon de l'Enclos, 1802 (an X)

Mongez Angélique, Un enfant dans son berceau, entraîné par les eaux de l'inondation de l'an $X$ Regnault Jean-Baptiste, Hercule et Alceste [Hercule enlevant Alceste des enfers], 1802 (an X)

Vernet Horace, Le Premier Consul passant une revue dans la cour des Tuileries, 1802 (an X), dessin, encre de chine, estompe, lavis gris, mine de plomb sur papier brun, 25,8 $\times 43 \mathrm{~cm}$, Paris, musée du Louvre

\section{Mme de Beaumer}

[Anonyme], Nymphe, sculpture, Salon de 1761

Cazenove, Bataille, Salon de 1761

Deshays de Colleville Jean-Baptiste Henri, dit le Romain, Saint Benoît mourant reçoit le viatique, 1761, huile sur toile, 292 x $191 \mathrm{~cm}$, Orléans, musée des Beaux-Arts

Doyen Gabriel-François, Portrait d'une jeune Indienne, Salon de 1761

Doyen Gabriel-François, Vénus blessée par Diomède [Mars blessé par Diomède ?], Salon de 1761, huile sur toile, Poitiers, musée municipal

Dumont Jacques, dit le Romain, Allégorie en l'honneur de la publication de la paix d'Aix-laChapelle, le 13 février 1749, 1761, huile sur toile, 320 x $430 \mathrm{~cm}$, Paris, musée Carnavalet

Girouard $\left(\mathrm{M}^{\mathrm{ll}}\right)$, Deux filles qui se font dire la bonne aventure

Girouard $\left(\mathrm{M}^{1 \mathrm{ll}}\right)$, Vénus d'une grande beauté qui désarme l'Amour

Girouard ( $\left.\mathrm{M}^{1 \mathrm{ll}}\right)$, Vierge et l'Enfant Jésus, 1761, huile sur toile, Marchéville, église

Girouard $\left(\mathrm{M}^{\mathrm{ll}}\right)$, Vierge et l'Enfant Jésus, pastel

Greuze Jean-Baptiste, La Jeune Blanchisseuse, Salon de 1761, huile sur toile, 40,6 x 32,4 $\mathrm{cm}$, Los Angeles, J. Paul Getty Museum Collection

La Tour Maurice Quentin (de), Portrait de M. Laideguive, Salon de 1761, huile sur toile, Barcelone, musée d'Art moderne

Lisle ( $\left.\mathrm{M}^{\mathrm{me}} \mathrm{de}\right)$, Suzanne au bain

Trunque ( $\left.\mathrm{M}^{\mathrm{Ile}}\right)$, Portrait de la reine d'Espagne, pastel

Trunque $\left(\mathrm{M}^{\mathrm{ll}}\right)$, Portrait de Sa Majesté prussienne, pastel

Van Loo Charles André, dit Van Loo Carle, La Lecture, 1761, huile sur toile, 164 x $129 \mathrm{~cm}$, SaintPétersbourg, musée de l'Ermitage

Van Loo Charles André, dit Van Loo Carle, La Magdeleine dans le désert, Salon de 1761, huile sur toile, $200 \times 156 \mathrm{~cm}$, coll. part. 
Van Loo Louis Michel, Portrait du roi [Louis XV, roi de France et de Navarre], Salon de 1761, huile sur toile, 271 x $196 \mathrm{~cm}$

Vernet Claude Joseph, Marines, Salon de 1761

Vien Joseph-Marie, Saint Germain revêtu de ses habits pontificaux et donnant une médaille à sainte Geneviève, Salon de 1761

\section{Julie Candeille}

Girodet Anne-Louis, Atala [Les Funérailles d'Atala], 1808, huile sur toile, 207 x $267 \mathrm{~cm}$, Paris, musée du Louvre

Girodet Anne-Louis, Déluge [Scène de Déluge], Salon de 1806, huile sur toile, 441 x $331 \mathrm{~cm}$, Paris, musée du Louvre

Girodet Anne-Louis, Endymion, 1792, huile sur toile, $198 \times 261 \mathrm{~cm}$, Paris, musée du Louvre

\section{Helmina von Chézy}

Bartolini Lorenzo, Cléobis et Biton, 1802, plâtre, 54 x 31 cm, Rimini, Fondo Fagnani Pani Cardi

Bartolini Lorenzo, Tête colossale de l'empereur Napoléon [Napoléon I Ir], 1805, bronze, 155 x 91 x76 cm, Paris, musée du Louvre

Bergeret Pierre-Nolasque, Raphaël sur son lit de mort [Honneurs rendus à Raphaël après sa mort, 8 avril 1520], 1806, huile sur toile, $108 \times 197 \mathrm{~cm}$, Oberlin, Ohio

Chaudet Jeanne Élisabeth, Portrait de la princesse Laetitia [Marie-Laetitia Murat portant le buste de Napoléon $I^{2 r}$ ], 1806, huile sur toile, 125 x $98 \mathrm{~cm}$, Ajaccio, musée Fesch [il existe une autre version conservée au-musée national du Château de Fontainebleau].

David Jacques-Louis, Bonaparte au pied du mont Cenis [Bonaparte franchissant les Alpes au Grand

Saint-Bernard], 1801, huile sur toile, Rueil-Malmaison, musée national des châteaux de Malmaison et Bois-Préau

Drouais Jean-Germain, Les Gracques [Caius Gracchus sortant de sa maison pour apaiser la sédition dans laquelle il périt, ou Départ de Tiberius Gracchus pour aller demander l'exécution de la loi agraire], plume et encre noire, traits à la mine de plomb sur papier blanc, 199 x 428 cm, Lille, musée des Beaux-Arts

Drouais Jean-Germain, La Femme adultère devant le Christ [peut-être Le Christ et la Cananéenne], 1784, huile sur toile, 114 x $146 \mathrm{~cm}$, Paris, musée du Louvre

Gérard François, Bélisaire [Bélisaire portant son guide piqué par un serpent], 1797, huile sur toile, 91 x $74 \mathrm{~cm}$, Los Angeles, J. Paul Getty Museum

Gérard François, Ossian [Ossian évoque les fantômes au son de la harpe sur les bords du Lora ?], 1801-1802, huile sur toile, 125 x $98 \mathrm{~cm}$, Malmaison, château de Malmaison et Bois Préau OU [Ossian ou L'Apothéose des Héros français morts pour la patrie pendant la guerre de la Liberté], commandé par Bonaparte en 1800, 192,5 x $184 \mathrm{~cm}$, Rueil-Malmaison, musée national des châteaux de Malmaison et de Bois-Préaux 
Gérard François, Portrait d'Alexandrine Émilie Brongniart, en buste, en robe blanche, 1795, huile sur toile, $50 \times 38 \mathrm{~cm}$

Gérard François, Psyché [Amour et Psyché], 1797, huile sur toile, 186 x $132 \mathrm{~cm}$, Paris, musée du Louvre

Girodet Anne-Louis, Endymion [Le Sommeil d'Endymion], 1791, huile sur toile, 198 x 261 $\mathrm{cm}$, Paris, musée du Louvre

Gros Antoine-Jean, La Bataille d'Aboukir, 1806, huile sur toile, 578 x $968 \mathrm{~cm}$, musée des châteaux de Versailles et de Trianon

Gros Antoine-Jean, Bonaparte dans l'hôpital de Jaffa [Bonaparte visitant les pestiférés...], 1804, huile sur toile, $73 \mathrm{~cm} \times 59 \mathrm{~cm}$, Paris, musée du Louvre

Guérin Pierre-Narcisse, Hippolyte [Phèdre et Hippolyte], 1802, huile sur toile, 257 x $335 \mathrm{~cm}$, musée du Louvre

Hennequin Philippe-Auguste, diverses toiles

Ingres Jean Auguste Dominique, Portrait de l'Empereur [Napoléon I ${ }^{\text {er }}$ sur le trône impérial], 1806, huile sur toile, 260 x $163 \mathrm{~cm}$, Paris, musée de l'Armée

Ingres Jean-Auguste Dominique, Portrait de Napoléon en Premier consul, 1804, huile sur toile, 227 x $147 \mathrm{~cm}$, Liège, musée des Beaux-Arts

Lefebvre Robert, Un portrait de l'Empereur grandeur nature [Napoléon en habits impériaux], 1807, Paris, musée de la Légion d'honneur

Léonard de Vinci, La Joconde, 1503-1506, huile sur bois, 77 x $53 \mathrm{~cm}$, Paris, musée du Louvre

Meynier Charles, Calypso

Raphaël, La Diane

Raphaël, La Madonna del donatorio

Regnault Jean-Baptiste, Jeunesse d'Achille [L'Éducation d'Achille par le centaure Chiron], 1782 , huile sur toile, $261 \times 215 \mathrm{~cm}$, Paris, musée du Louvre

Riesener Henri-François, Portraits

Vernet Carle, Tableaux de batailles (?)

Vincent François André, Esquisse d'un tableau de bataille des Pyramides [La Bataille des Pyramides], vers 1800, huile sur toile, 80 x $125 \mathrm{~cm}$, Paris, musée du Louvre

\section{Marianne Colston}

[Anonyme], Vénus de Milo, env. ${ }_{\mathrm{I}}$ er siècle avant J. C., sculpture, marbre, $202 \mathrm{~cm}$, Paris, musée du Louvre

Agasias d'Éphèse, Gladiateur au combat [Gladiateur au combat dit Gladiateur Borghèse], ${ }_{\text {III }}^{\text {e }}$ II siècle avant J.C., sculpture, marbre, 199 cm, Paris, musée du Louvre

Cellini Benvenuto, Figure de bronze en relief

Dael Jan Frans (van), dit François Van Dael, Un tableau représentant des fleurs

Dubufe Claude-Marie, Un Christ calmant la tempête, 1819, huile sur toile, $344 \times 443 \mathrm{~cm}$, Riom, église Saint-Amable

Forbin [Fortin?], Chasseur de l'Apennin 
Fragonard Jean-Honoré, L'Adoubement de François $I^{\text {er }}$ [François I ${ }^{\text {er }}$ armé chevalier par Bayard], Salon de 1819, huile sur toile, 85,5 x 115,5 cm, Paris, musée du Louvre

Génillion Jean-Baptiste-François, Vue de l'église des Invalides

Gérard François, Corinne au cap Misène, 1819-1821, huile sur toile, 256,5 x 277 cm, Lyon, musée des Beaux-Arts

Goujon Jean, Quatre cariatides supportant la tribune de la salle des Cariatides du musée du Louvre

Granet François-Marius, Vue du chœur de l'église des Capucins à Rome [Chøur de la chapelle des Capucins place de Barberini à Rome], 1808, huile sur toile, 66 x $50 \mathrm{~cm}$, Grenoble, musée des BeauxArts

Gros Antoine-Jean, David charmant et chassant l'esprit mauvais qui habite Saul

Gros Antoine-Jean, Un paysage

Guillois François-Pierre, Enfant nourrissant un serpent [Enfant couché donnant à manger à un serpent], 1822, marbre, 57 × 95 x $35 \mathrm{~cm}$, Douai, hôtel de la sous-préfecture

Lejeune Louis-François (général), Tableau représentant l'attaque d'un convoi français par l'armée espagnole

Lemoyne Paul, Faune dérobant un fruit à une bacchante endormie [Bacchante et jeune faune], 1821, marbre, 98 x 131 x 63 cm, Bordeaux, musée des Beaux-Arts

Lemoyne Paul, La Nymphe Écho, 1821, marbre, 70 x 140 x 50 cm, Paris, musée du Louvre

Lescot Pierre, Dessins pour la salle des Cariatides du musée du Louvre

Picot François-Édouard, Cupidon quittant Psyché [L'Amour et Psyché], Salon de 1819, huile sur toile, 234 x 291,5 cm, Paris, musée du Louvre

Ponce Paul, Ornements de la salle des Cariatides du musée du Louvre

Raphaël, La Belle Jardinière, 1507-1508, huile sur toile, 122 x $80 \mathrm{~cm}$, Paris, musée du Louvre

Raphäl, Une Sainte Famille

Rubens Pierre-Paul, Le Débarquement de Marie de Médicis à Marseille, 1622-1625, Paris, musée du Louvre

Vernet Horace, Joseph Vernet, attaché à un mât, étudie les effets de la tempête, Salon de 1822, huile sur toile, 275 x $336 \mathrm{~cm}$, Avignon, musée Calvet

Vernet Joseph, Vue de Bayonne, Salon de 1761, huile sur toile, 165 x $263 \mathrm{~cm}$, Paris, musée national de la Marine

Watelet, Paysage

\section{Maria Cosway}

Fuseli, Henry Johann Heinrich Füssli, dit, Visions

Raphaël, La Transfiguration, 1516-1520, huile sur bois, 405 x $218 \mathrm{~cm}$, cité du Vatican, musées du Vatican

Vigée-Lebrun Élisabeth, Portrait du prince Lubormirski, 1789, huile sur toile, 105 x $83 \mathrm{~cm}$, Berlin, Gemäldegalerie 


\section{Marceline Desbordes-Valmore}

Delacroix Eugène, Un Christ [Christ en croix], 1846, Salon de 1847, huile sur toile, 80 x 64,2 $\mathrm{cm}$, Baltimore, The Walters Art Museum

Girodet Anne-Louis, Atala [Les Funérailles d'Atala], 1808, huile sur toile, 207 x $267 \mathrm{~cm}$, Paris, musée du Louvre

Girodet Anne-Louis, Déluge [Scène de Déluge], Salon de 1806, huile sur toile, 441 x $331 \mathrm{~cm}$, Paris, musée du Louvre

Haudebourt-Lescot Hortense, Le Baisement des pieds à Rome [Le Baisement des pieds de la statue de Saint-Pierre dans la Basilique Saint-Pierre de Rome], 1812, huile sur toile, 148 x 196 $\mathrm{cm}$,

Fontainebleau, musée national du château

Haudebourt-Lescot Hortense, Le Condamné à mort [Un condamné exhorté par un moine capucin au moment de partir au supplice, Salon de 1819, huile sur toile, 55 x $69 \mathrm{~cm}$, Paris, musée du Louvre

Haudebourt-Lescot Hortense, Le Meunier et son fils [Le Meunier, son fils et l'âne], huile sur toile, 41 x 32,5 cm, Château-Thierry, musée Jean de La Fontaine

Haudebourt-Lescot Hortense, La Prière pendant l'orage [peut-être Le Vœu à la Madone après la tempête], Salon de 1817, Châteauroux, musée Bertrand de Châteauroux

\section{Félicité de Genlis}

[Anonyme], Apollon du Belvédère, copie romaine réalisée vers 130-140 après J. C., marbre, $224 \mathrm{~cm}$, cité du Vatican, musée Pio Clementino

[Anonyme], Laocoon, ${ }_{\mathrm{I}}^{\mathrm{er}}$ siècle avant J.-C., marbre, $242 \mathrm{~cm}$, cité du Vatican, musées du Vatican

Canova Antonio, Madeleine [Madeleine pénitente], 1809, sculpture, marbre, 95 x 70 x 77 $\mathrm{cm}$, SaintPétersbourg, musée de l'Ermitage

Carrache Annibal, Descente de Croix [peut-être Descente de Croix, Londres, Bridgewater Gallery]

Chaudet Antoine-Denis, Petite naïade, sculpture, marbre

Cignani Carlo, Psyché avec sa lampe regardant l'Amour endormi

Cignani Carlo, Une Vierge

Cima Conegliano [Cima da Conegliano], Une Résurrection du Christ

Corrège (Le), L'Ascension de Jésus-Christ, 1520-1524, fresque, Parme, église Saint-Jean l'évangéliste

Corrège (Le), L'Assomption de la Vierge, 1526-1530, fresque, 1093 x $1530 \mathrm{~cm}$, Parme, cathédrale

Corrège (Le), Un amour adolescent

Corrège (Le), La Vierge, l'Enfant Jésus, la Madeleine, saint Jérôme [Madone de saint Jérôme ou Le Jour], huile sur bois, $235 \times 141 \mathrm{~cm}$, Parme, Galerie nationale

Crespi Daniele, Saint Joseph embrassant l'Enfant Jésus

Cuyp, Le Baptême de l'Eunuque de la reine Candace 
David Jacques-Louis, La Mort de Socrate, 1789, huile sur toile, 323 x $422 \mathrm{~cm}$, New York, The Metropolitan Museum of Art

David Jacques-Louis, Psyché [L'Amour et Psyché], 1817, huile sur toile, $184 \times 241 \mathrm{~cm}$, Cleveland, The Cleveland Museum of Art

David Jacques-Louis, Le Serment des Horaces, 1784, huile sur toile, 330 x $425 \mathrm{~cm}$, Paris, musée du Louvre

Dominiquin (Le), Ascension de la Vierge

Dominiquin (Le), Communion de saint Jérôme, 1614, huile sur toile, 419 x $256 \mathrm{~cm}$, cité du Vatican, musées du Vatican

Dou Gérard, La Femme hydropique [La Femme hydropique ou Docteur examinant les urines d'une femme], 1663, huile sur bois, 83 x $67 \mathrm{~cm}$, Paris, musée du Louvre

Drolling Michel Martin, La Mort d'Abel, Salon de 1817

Gérard François, Bélisaire [Bélisaire portant son guide piqué par un serpent], 1797, huile sur toile, 91 x $74 \mathrm{~cm}$, Los Angeles, J. Paul Getty Museum

Gérard François, Le Duc de Bellegarde saluant d'un air d'intelligence la belle Gabrielle à une fenêtre

Girodet Anne-Louis, Pygmalion et Galatée, Salon de 1819, huile sur toile, 253 x $202 \mathrm{~cm}$, Paris, musée du Louvre

Granger Jean-Pierre, Apollon et Cyparisse mourant, 1816, huile sur toile, $240 \times 189 \mathrm{~cm}$, Leipzig, Museum der Bildenden Künste

Greuze Jean-Baptiste, La Dame de charité, vers 1772-1775, huile sur toile, 112 x $146 \mathrm{~cm}$, Lyon, musée des Beaux-Arts

Greuze Jean-Baptiste, La Malédiction du père de famille [La Malédiction paternelle. Le Fils ingrat], 1777, huile sur toile, $130 \times 162 \mathrm{~cm}$, Paris, musée du Louvre

Greuze Jean-Baptiste, La Noce de village [L'Accordée de village], Salon de 1761, huile sur toile, $92 \times 117 \mathrm{~cm}$, Paris, musée du Louvre

Greuze Jean-Baptiste, Petite fille pleurant son serin [Petite fille pleurant son oiseau mort ou L'Oiseau mort], vers 1759, huile sur toile, $68 \times 55 \mathrm{~cm}$, Paris, musée du Louvre; il existe une autre version aux National Galleries of Scotland

Grollier $\left(\mathrm{M}^{\mathrm{me}}\right)$, Tableau de fleurs

Guérin Pierre Narcisse, L'Aurore et Céphale, 1810, huile sur toile, 257 x $178 \mathrm{~cm}$, Paris, musée du Louvre

Guide (Le), L'Enfant Jésus endormi sur une croix, 28 x $45 \mathrm{~cm}$

Guide (Le), Saint Pierre dans la prison pleurant son péché

Kauffmann Angelika, Andromaque dans l'attitude d'un profond accablement appuyée sur la tombe d'Hector [peut-être Hector prenant congé d'Andromaque, 1768, huile sur toile, $134 \mathrm{x}$ $176 \mathrm{~cm}$, Plympton, The National Trust, The Morley Collection, Saltram House]

Kauffmann Angelika, Cléopâtre ornant fastueusement d'une guirlande de fleurs le tombeau d'Antoine, vers 1770, huile sur toile, 127 x $100 \mathrm{~cm}$, San Diego, université de Californie

Kauffmann Angelika, La Dernière Pensée de Virgile

L'Albane, Hercule entre le vice et la vertu

Le Boulanger de Boisfrémont Charles Pompée, Vénus enlevant Ascagne, Salon de 1817

Mengs Anton Raphaël, plafond du cabinet des manuscrits, cité du Vatican 
Metsu Gabriel, La Veille des rois, 1650-1655, huile sur toile, 80 x $97 \mathrm{~cm}$, Munich, Alte Pinakothek

Michel-Ange, Moïse descendant du mont Sinaï, 1513-1515, marbre, $235 \mathrm{~cm}$, Rome, église SaintPierre-aux-liens

Michel-Ange, Saint Michel terrassant le diable

Migliara Giovanni, Cathédrale de Milan [peut-être L'Intérieur de la cathédrale de Milan avec une procession et de nombreuses figures, 1816, huile sur toile, $61 \times 52 \mathrm{~cm}$ ]

Pérugin (Le), Présentation de Jésus au Temple

Poussin Nicolas, Les Bergers d'Arcadie, vers 1638-1640, huile sur toile, 85 x $121 \mathrm{~cm}$, Paris, musée du Louvre

Prud'hon Pierre-Paul, Portrait de M. de Sommariva, 1814, Milan

Prud'hon Pierre-Paul, Psyché enlevée par les zéphyrs, eau-forte et burin, $64,9 \times 48,3 \mathrm{~cm}$, Zurich, Ecole polytechnique fédérale

Puget Pierre, Alessandro Sauli, 1663-1668, terre cuite, $70 \mathrm{~cm}$, Cleveland, The Cleveland Art Museum of Art [il existe une autre version au musée Granet]

Puget Pierre, Saint Sébastien, terre cuite, 93 x 34 × 28 cm, Paris, musée du Petit Palais

Raphaël, Jonas, sculpture

Raphaël, Madonna della seggiola [Vierge à la chaise], 1513-1514, huile sur panneau, diamètre $71 \mathrm{~cm}$, Florence, palais Pitti

Raphaël, La Messe de Bolsena, 1514, fresque, base $660 \mathrm{~cm}$, chambre d'Héliodore Cité du Vatican, musées du Vatican

Raphaël, La Messe de Bolsena, 1514, fresque, chambre d'Héliodore, cité du Vatican, musées du Vatican

Raphaël, Saint Jean dans le désert [Saint Jean-Baptiste dans le désert], 1515-1516, huile sur bois transposé sur toile, 135 x $142 \mathrm{~cm}$, Paris, musée du Louvre

Raphaël, La Transfiguration, 1516-1520, huile sur bois, 405 x $218 \mathrm{~cm}$, cité du Vatican, musées du Vatican

Reynolds Joshua (Sir), Miss Sydons [Mrs Siddons en muse tragique], 1784, huile sur toile, 236 x $146 \mathrm{~cm}$, California, San Marino, Huntington Library and Art Gallery

Romain Jules, Jésus dans le Temple au milieu des docteurs de la Loi

Rubens Pierre-Paul, L'Accouchement de Marie de Médicis [La Naissance de Louis XIII], vers 16221625, huile sur toile, 394 x $295 \mathrm{~cm}$, Paris, musée du Louvre

Rubens Pierre-Paul, La Descente de Croix, 1611-1614, huile sur bois, triptyque, panneau central, 420 x $310 \mathrm{~cm}$, panneaux latéraux, $420 \times 150 \mathrm{~cm}$ chacun, Anvers, cathédrale Notre-Dame

Rubens Pierre-Paul, L'Entrée d'Henri IV à Paris [L'Entrée triomphale de Henri IV à Paris], 1617-1630, huile sur toile, 380 x $692 \mathrm{~cm}$, Florence, musée des Offices

Rubens Pierre-Paul, Jugement dernier [Le Grand Jugement dernier], 1615-1616, huile sur bois, 604 x $474 \mathrm{~cm}$, Munich, Alte Pinakothek

Timanthe de Cythnos, Sacrifice d'Iphigénie, entre 10 et 79 av. J.-C., fresque, 138 x $140 \mathrm{~cm}$, Naples, Musée national archéologique

Timomaque de Byzance, Médée tue ses enfants, entre 62 et 79 av. J.-C., fresque, 120 x 97 $\mathrm{cm}$, Naples, Musée national archéologique 
Titien (Le), La Gardeuse de cassette ou La Femme à la cassette [Jeune Femme à la cassette, dit Lavinia à la cassette]

Van Dyck Antoine, Bélisaire

Vernet Horace, Un cheval arabe

Véronèse Paolo, L'Apparition des anges à Abraham [Le Sacrifice d'Abraham], vers 1529, huile sur toile, 129 x $95 \mathrm{~cm}$, Madrid, musée du Prado

Véronèse Paolo, Léda et le cygne [peut-être huile sur toile, 121 x 100 cm, Ajaccio, musée Fesch] Cuvre évoquée par

\section{Johanna von Haza}

Biard François-Auguste, Marché aux esclaves sur la côte d'Or africaine, 1833, huile sur toile, 162,5 x 228,6 cm, Hull, City Museum and Art Galleries Wilberforce House

\section{Catherine-Michelle de Maisonneuve}

Adam Nicolas-Sébastien, Prométhée attaché sur le mont Caucase, un aigle lui dévore le foie

[Prométhée], 1762, sculpture, marbre, $115 \mathrm{~cm}$, Paris, musée du Louvre

Audran, Portrait de Sa Majesté, gravure exécutée en haute lisse d'après le tableau original de M.

Louis-Michel Van Loo qui fut exposé en 1761 au Salon du Louvre

Bachelier Jean-Jacques, L'Europe savante, 1762, huile sur toile, 329 x $178 \mathrm{~cm}$, Paris, musée du Louvre

Boizot Louis-Simon, La Sculpture, Salon de 1763

Caffieri Jean-Jacques, Portrait de M. le Prince de Condé, sculpture

Challe Charles Michel Ange, Esther évanouie aux pieds d'Assuerus, Salon de 1763

Challe Charles Michel Ange, Vénus endormie, Salon de 1763

Challe Simon, Vierge avec l'Enfant Jésus, sculpture, marbre

Chevalier Antoine de Favray, Dames maltaises se faisant visite, 1751, huile sur toile, 49 × 63 $\mathrm{cm}$, Paris, musée du Louvre

Danzel Jacques-Claude, La Blanchisseuse, gravée par M. Danzel, d'après une huile sur toile de

M. Greuze présentée au Salon en 1759, 1765, gravure en taille douce, 39,8 x 32,3 cm, Paris, Bibliothèque nationale de France

Danzel Jacques-Claude, La Charité Romaine, d'après une huile sur toile de feu M. Coypel, 1763, gravure en taille douce, 42,7 x 31,6 cm, Paris, Bibliothèque nationale de France

Danzel Jacques-Claude, Vénus et Adonis, 1761, gravure en taille douce

Danzel Jacques-Claude, Vénus et Énée, d'après un tableau de M. Boizot, 1762, gravure en taille douce

Deshays de Colleville Jean-Baptiste Henri, dit le Romain, Danaé, 1763, huile sur toile

Deshays de Colleville Jean-Baptiste Henri, dit le Romain, Le Mariage de la Sainte Vierge, 1763 , huile sur toile, $104 \times 62 \mathrm{~cm}$ 
Drouais François-Hubert, Jeune fille jouant avec un chat, 1763, huile sur toile, 61 x 49,5 cm, coll. part.

Drouais François-Hubert, $M^{\text {Iles }}$ de Lorraine et d'Elbeuf

Drouais François-Hubert, Portrait de Madame et de Monsieur le comte d'Artois jouant ensemble [Charles Philippe de France, comte d'Artois et sa sceur, $M^{m e}$ Clothilde], 1763, huile sur toile, 129,5 x 97,5 cm, Paris, musée du Louvre

Falconet Étienne Maurice, La Douce Mélancolie, sculpture, marbre

Fessart Mathieu, Une fête flamande, gravure

Flipart Jean-Jacques, Jeune fille pleurant son serin, d'après le tableau de M. Greuze, 1767, estampe

Flipart Jean-Jacques, Le Paralytique servi par ses enfants, lithographie gravée d'après le tableau de M. Greuze, 1767, 55,5 x 66 cm, Dijon, Hôpital général

Flipart Jean-Jacques, Une jeune fille qui pelotte du coton, gravure

Greuze Jean-Baptiste, Jeune Fille pleurant son serin [Une Jeune fille qui pleure son oiseau mort], 1765, huile sur toile, $52 \times 45,6 \mathrm{~cm}$, Édimbourg, National Galleries of Scotland

Greuze Jean-Baptiste, Le Paralytique servi par ses enfants ou La Piété filiale, huile sur toile, 115 x $146 \mathrm{~cm}, 1763$, Saint-Pétersbourg, musée de l'Ermitage

Greuze Jean-Baptiste, Portrait de $M^{m e}$ Greuze [peut-être $M^{m e}$ Greuze enceinte dans un fauteuil, 1763, dessin à la sanguine, 39,9 x $32,3 \mathrm{~cm}$, Saint-Pétersbourg, musée de l'Ermitage]

Greuze Jean-Baptiste, Portrait de $M^{\text {ell }}$ de Chartres

Greuze Jean-Baptiste, Portrait de $M^{\text {elle }}$ de Pange

Greuze Jean-Baptiste, Portrait de M. le duc de Chartres

Greuze Jean-Baptiste, Une jeune fille qui a cassé son miroir [Le Miroir cassé], 1763, huile sur toile, 56 x $46 \mathrm{~cm}$, Londres, Wallace Collection

Guérin François ou Louis, Portrait de $M^{\text {me }}$ la comtesse de l'Isle-Bonne avec $M^{\text {lle }} d^{\text {'Harcourt sa }}$ fille, Salon de 1763

Hallé Noël, Vierge avec l'Enfant Jésus, Salon de 1763

Ingouf [Pierre Charles ?], Gravure représentant une petite fille qui tient d'un air boudeur une poupée habillée en capucin

Jeaurat Étienne, Peintre faisant chez lui le portrait d'une jeune dame [peut-être Intérieur du studio d'un artiste, 1715, huile sur toile, 117,1 x 88,3 cm, Hull, Ferens Art Gallery], Salon de 1763

La Tour Maurice Quentin (de), Portrait de la princesse Marie-Christine de Saxe, 1763, dessin au pastel, $32 \times 22 \mathrm{~cm}$, Saint-Quentin, musée Antoine Lécuyer

La Tour Maurice Quentin (de), Portrait de $M^{\text {me }}$ la Dauphine [peut-être Portrait de MarieJosèphe de Saxe, dauphine, 1761, , dessin au pastel, 64 x $52 \mathrm{~cm}$, Paris, musée du Louvre], Salon de 1763

Lagrenée Louis Jean François, La Douce Captivité, Salon de 1763

Lagrenée Louis Jean François, Le Lever de l'Aurore, 1763, huile sur toile, 121 x $170 \mathrm{~cm}$, Vicence, coll. part.

Lagrenée Louis Jean François, Suzanne surprise au bain par les deux vieillards, 1763, huile sur toile, Tampere (Finlande), coll. part. 
Le Bas Jacques Philippe, La Charité Romaine, gravure d'après un tableau de Coypel Le Bas Jacques Philippe, La Récompense villageoise, gravure

Lemoyne Jean-Baptiste II, Un buste représentant la belle Madame la comtesse de Brionne, sculpture

Lempereur Louis Simon, Les Baigneuses, d'après Carle Van Loo, 1763, gravure à l'eau forte et au burin, $42,2 \times 34,7 \mathrm{~cm}$

Loutherbourg Jacques Philippe (de), Quatre tableaux représentant les quatre heures du jour

Machy Pierre-Antoine (de), Statue équestre de Louis XV

Mansart Jules Hardouin, Sainte Thérèse, 1676-1708, sculpture d'autel, Paris, hôtel des Invalides

Mignot Pierre-Philippe, Quatre Médaillons en marbre pour être placés à l'Hôtel de Ville de Paris [M. le duc de Chevreuse, M. le prévôt des Marchands, M. Mercier et M. Babil, échevins], sculpture

Nattier Jean-Marc, Indienne [peut-être Portrait d'une jeune femme en vestale, 1759, huile sur toile, 115,6 x 135,9 cm, Raleigh, North Carolina Museum of art], Salon de 1763

Pajou Jacques-Augustin-Catherine, La Peinture, sculpture

Perronneau Jean-Baptiste, Portrait de $M^{m e}$ de Tourolle, 1763, dessin au pastel, 59 x $49 \mathrm{~cm}$, Orléans, musée des Beaux-Arts

Perronneau Jean-Baptiste, Portrait de $M^{\text {me }}$ Perronneau faisant des nœuds, 1763, dessin au pastel

Perronneau Jean-Baptiste, Portrait de $M^{\text {me }}$ Trudaine de Montigny, 1763, dessin au pastel

Pierre Jean Baptiste Marie, Le Massacre des innocents, 1762, dessin à la plume et encre noire, lavis brun avec rehauts de gouache blanche sur traits de pierre noire, sur papier bleu, 33,9 x 55,7 cm, Paris, musée du Louvre

Restout Jean (?), Orphée descendu aux enfers pour demander Eurydice ou La Musique, 1763, huile sur toile, 355 x $575 \mathrm{~cm}$, Paris, musée du Louvre

Roland de la Porte Henri-Horace, Les Apprêts d'un déjeuner rustique, 1763, huile sur toile, $92 \times 73 \mathrm{~cm}$, Paris, musée du Louvre

Roland de la Porte Henri-Horace, Bas-relief avec la bordure imitée, représentant une tête d'empereur [Portrait de Louis XV en médaillon], ${ }^{\mathrm{de}}$ moitié $\mathrm{du}{ }_{\mathrm{xvIII}}{ }^{\mathrm{e}}$ siècle, huile sur toile en camaïeu, $49,5 \times 40,5 \mathrm{~cm}$, coll. part.

Roslin Alexandre, Portrait de $M^{m e}$ la comtesse d'Egmont, fille de M. le duc de Richelieu [JeanneSophie-Élisabeth-Louise-Septimanie du Plessis-Richelieu, comtesse d'Egmont-Pignatelli], 1763, huile sur toile, Paris, université de la Sorbonne

Valade Jean, Portait de $M^{m e}$ de Bourgogne, 1763

Van Loo Charles André, dit Van Loo Carle, L'Amour faisant faire l'exercice à ses soldats

Van Loo Charles André, dit Van Loo Carle, Les Trois Grâces enchainées par l'Amour, 1763, huile sur toile, château de Chenonceaux

Van Loo Louis-Michel, L'Evanouissement d'Esther, Salon de 1763

Van Loo Louis-Michel, Louis-Michel Van Loo accompagné de sa søur Marie-Anne et travaillant au portrait de son père Jean-Baptiste Van Loo, 1763, huile sur toile, $245 \times 162 \mathrm{~cm}$, Versailles, musée national des châteaux de Versailles et de Trianon 
Vassé Louis Claude, Femme couchée sur un socle carré, pleurant sur une urne, 1763 (?), petite figure en plâtre, Saint-Pétersbourg, Laure Alexandre Nevski, tombeau de la Princesse de Galitzin

Vernet Joseph, La Bergère des Alpes, 1763, huile sur toile, 119 x 80 cm, Tours, musée des Beaux-Arts

Vernet Joseph, Vue du port de La Rochelle, 1763, huile sur toile, 165 x $263 \mathrm{~cm}$, Paris, musée national de la Marine

Vernet Joseph, Vue du port de Rochefort, 1762, huile sur toile, Paris, musée national de la Marine

Vien Joseph-Marie, Glycère ou la Marchande de fleurs, 1763, huile sur toile, 91 x $67 \mathrm{~cm}$, Troyes, musée d'Art, d'Archéologie et de Sciences naturelles

Vien Joseph-Marie, La Marchande à la toilette [La Marchande d'Amours], 1763, huile sur toile,

140 x $117 \mathrm{~cm}$, Fontainebleau, musée national du Château

Vien Joseph-Marie, Une femme qui arrose un pot de fleurs, Salon de 1763

Vien Joseph-Marie, Une femme qui sort des bains, 1763, huile sur toile, 95 x $68 \mathrm{~cm}$, coll. part.

Vien Marie-Thérèse, Deux pigeons, Salon de 1763, miniature

Vien Marie-Thérèse, Oiseaux, Salon de 1763, miniature

Vien Marie-Thérèse, Un bouquet de roses dans un gobelet, Salon de 1763, miniature

Vien Marie-Thérèse, Un émouchet terrassant un petit oiseau, Salon de 1763, miniature

Vien Marie-Thérèse, Une tige de renoncules dans un pot de terre, Salon de 1763, miniature

Wille Jan Georges, La Fileuse, gravure

\section{Marie-Camille de G.}

Decamps Alexandre Gabriel, La Bataille que Marius gagna sur les Cimbres en Provence [Marius défait les Cimbres], 1834, huile sur toile, 130 x 195 cm, Paris, musée du Louvre

Delacroix Eugène, Bataille de Nancy, 1831, huile sur toile, 237 x 350 cm, Nancy, musée des BeauxArts

Delacroix Eugène, Femmes d'Alger dans leur appartement, 1834, huile sur toile, 180 x 229 $\mathrm{cm}$, Paris, musée du Louvre

Delaroche Paul, Jeanne Grey [L'Exécution de Jeanne Grey], 1834, huile sur toile, 180 x 155 $\mathrm{cm}$, Londres, The National Gallery

Granet François Marius, La Mort de Poussin, 1834, huile sur toile, Florence, Villa Demidoff Ingres Jean-Auguste-Dominique, Le Martyre de saint Symphorien, 1834, huile sur toile, 405 x $337 \mathrm{~cm}$, Autun, cathédrale Saint-Lazare

Laure Jules, Lélia agenouillée près du cadavre de Sténio, 1834

Scheffer Ary, L'Eberhad, comte de Wurtemberg, dit Le Larmoyeur [Le Larmoyeur], 1834, huile sur toile, 26,5 x 21,5 cm, Dijon, musée Magnin 
Vernet Horace, L'Entrée du duc d'Orléans au Palais-Royal [Le Duc d'Orléans quitte le Palais Royal pour se rendre à l'hôtel de ville, 31 juillet 1830], 1833, huile sur toile, $228 \times 258 \mathrm{~cm}$, Versailles, musée national des châteaux de Versailles et de Trianon

Vernet Horace, Une scène d'Arabes dans leur camp [Chefs arabes en conseil ou Le Négociateur], 1834, huile sur toile, Chantilly, musée Condé

\section{Marie-Émilie de Montanclos}

Charpentier P., Marchand de melons

Charpentier P., Marchande bouquetière

Charpentier P., Portraits

Filleul $\left(\mathrm{M}^{\mathrm{me}}\right)$, Portrait de Madame sa mère [ $\mathrm{M}^{\mathrm{me}}$ - ], 1774, pastel, Montbouy, châte u de evi res

Greuze Jean-Baptiste, La Cruche cassée, 1771, huile sur toile, 109 x 87 cm, Paris, musée du Louvre

L i e- ui rd dé de, Portraits, Salon de Saint-Luc, 1774

Le Mire Noël, $A g[$ [ $v$ à 'vè $m d L$ XVI ô, estampe

Le Mire Noël, Médaillon de la Reine, soutenu par [la B]onté et la Tendresse, estampe

Lorges (chevalier de) ou Delorge Jean-Joseph, Portrait de Marie-Antoinette en Diane chasseresse, 1774, huile sur toile

Montpetit Arnauld Vincent (de), Allégorie charmante, qui nous peint notre reine dans une rose et ombragée de lys [Marie-Antoinette], 1770, peinture éleudorique (huile sur taffetas), exposition de ' c démie de S i t-Luc à ' ôtel de Jabac, 1774

Navarre Marie Geneviève, Femme, 1774, pastel sur papier, 61 x 49,5 cm, Washington, National Museum of Women in the Arts

Navarre Marie Geneviève, Tête d'une jeune personne, miniature

Navarre Marie Geneviève, Une tête d'enfant, miniature, Paris, musée du Louvre

Vigée $\left(\mathrm{M}^{\mathrm{me}}\right)$, $\mathrm{M}^{\text {lle }}$ Dumesnil

Vigée $\left(\mathrm{M}^{\mathrm{me}}\right)$, Portrait de $\mathrm{M}^{\mathrm{me}}$ de... [Vigée-Lebrun Élisabeth, $\mathrm{M}^{\text {lle }}$ de ${ }^{* * *}$ en buste, pastel, exposition de 'c démie de S i t-Luc, 1774, $\mathrm{n}^{\circ}$ 174]

\section{Anne Plumptre}

[Anonyme], Apollon du Belvédère, copie romaine réalisée vers 130-140 après J.-C., marbre, $224 \mathrm{~cm}$, cité du Vatican, musée Pio Clementino

[Anonyme], Diane, Paris, musée du Louvre

[Anonyme], Laocoon, $\underset{\mathrm{I}}{\mathrm{er}}$ siècle av. J.-C., marbre, $242 \mathrm{~cm}$, cité du Vatican, musées du Vatican

[Anonyme], Le Tombeau d'Héloïse et d'Abélard, Paris, cimetière du Père Lachaise

[Anonyme], Vénus Médicis

Bernin (Le) et Girardon François, Statue équestre de Louis XIV sous les traits de Marcus Curtius, 1688, marbre blanc, Versailles, jardins du château

Cloissens Antoine, Un bronze de Mercure, Paris, musée du Louvre (?) 
David Gérard, Le Jugement de Cambyse, 1498, Bruges, Groeningemuseum

Mansart Jules-Hardouin, Bassin de Neptune, 1682, Versailles, jardins du château

Puget Pierre, Milon de Crotone, 1683, marbre, 270 x 140 cm, Paris, musée du Louvre

Puget Pierre, Persée et Andromède, 1684, marbre, 320 x 106 x $114 \mathrm{~cm}$, Paris, musée du Louvre

Tuby, Jean-Baptiste, Bassin d'Apollon, Versailles, jardins du château

Van Loo, Tableau représentant un paysage enneigé

\section{Alida de Savignac}

Alophe Marie-Alexandre, Charité, vertu du riche ; Résignation, vertu du pauvre, 1844

Beaume Joseph, Éducation de la Vierge, 1844, Luxembourg

Beaume Joseph, Enfants surpris par la marée, 1844

Bendemann Eduard Julius Friedrich, Jérémie pleurant sur les ruines de Jérusalem, 1837

Béranger Charles, Animaux et intérieur [peut-être Stilleben mit Kupferkanne und erlegten Rebhühnern, 1846, huile sur bois, 18 x 13,5 cm, coll. part.]

Biard François-Auguste, Bivouac de la garde nationale en 1832 [Louis-Philippe au milieu de la Garde nationale], 1836, huile sur toile, $78 \times 100 \mathrm{~cm}$, Versailles, musée national des châteaux de Versailles et de Trianon

Biard François-Auguste, Le Droit de visite, 1846

Biard François-Auguste, La Jeunesse de Linnée, 1846

Biard François-Auguste, Les Naufragés attaqués par un requin, 1846

Bigot Isaure $\left(\mathrm{M}^{\mathrm{lle}}\right)$ [Isaure Alexandrine Bigot de la Presle, marquise de Las Cases], Etude de Judith, 1837

Bonheur Rosa, Cinq tableaux représentant des animaux, 1846

Bordier Dubignon Jacques-Olivier, Bal donné à l'hôtel de ville de Paris à l'occasion du mariage du roi de Westphalie, 1844

Boulanger Clément, La Procession de la gargouille, 1837, huile sur toile, $320 \times 227 \mathrm{~cm}$, Toulouse, musée des Augustins

Boulanger Louis, Portrait d'Honoré de Balzac, vers 1836, huile sur toile, 610 x $500 \mathrm{~cm}$, Tours, musée des Beaux-Arts

Brascassat Jacques Raymond, Paysages, 1837

Brune-Pagès Aimée, La Fille de Jephté, 1846

Chassériau Théodore, Ruth et Booz, 1837

Colin Alexandre, Les Quatre Saisons, 1844

Couder Louis-Charles-Auguste ou Couder Auguste, Fédération de 1790 [Fête de la Fédération nationale au Champ-de-Mars, le 14 juillet 1790], vers 1838, huile sur toile, $451 \times 847 \mathrm{~cm}$, Versailles, musée national des châteaux de Versailles et de Trianon

Court Joseph-Désiré, Mariage de la reine des Belges [Mariage de Léopold I Ir, roi des Belges, et de Louise d'Orléans le 9 août 1832], 1837, huile sur toile, $90 \times 116 \mathrm{~cm}$, Compiègne, musée national du château de Compiègne 
Couture Thomas, Amour de l'or [La Soif de l'or ou l'Amour de l'or], 1844, huile sur toile, 154 x $188 \mathrm{~cm}$, Toulouse, musée des Augustins

Decamps Alexandre Gabriel, École turque, 1846

Decamps Alexandre Gabriel, Souvenir de la Turquie d'Asie : enfants turcs jouant avec une tortue, 1836, huile sur toile, $72,5 \times 91 \mathrm{~cm}$, Chantilly, musée Condé

Dedreux Pierre-Alfred, Chasse anglaise [peut-être Le Départ pour la chasse, 1846, huile sur toile, $24 \times 32.5 \mathrm{~cm}$, coll. part.]

Dedreux Pierre-Alfred, Cheval abandonné sur un champ de bataille, 1844

Dedreux Pierre-Alfred, Étude de chiens, 1846

Deharme Élisa-Apollina, Portraits, 1837

Delacroix Eugène, Les Adieux de Roméo et de Juliette [Roméo et Juliette devant le tombeau des Capulet], 1846, huile sur papier, 35,2 x 25,5 cm, Paris, musée Eugène Delacroix

Delacroix Eugène, Marguerite à l'église, 1828, lithographie, $260 \times 220 \mathrm{~cm}$, Paris, bibliothèque de l'École des beaux-arts

Delacroix Eugène, Le Sac du château de Front-de-Bœuf [Rébecca enlevée par le Templier], 1846, huile sur toile, $105 \times 81 \mathrm{~cm}$, Paris, musée du Louvre

Delaroche Paul, Charles I ${ }^{e r}$ insulté par les soldats de Cromwell, 1836, huile sur toile, $300 \mathrm{x}$ $400 \mathrm{~cm}$, Londres, National Gallery

Delaroche Paul, Lord Strafford marchant au supplice, 1837, huile sur toile, coll. part.

Delaroche Paul, Sainte Cécile et les anges, 1836, huile sur toile, $202 \times 162 \mathrm{~cm}$, Londres, Victoria \& Albert Museum

Desnos Marie-Louise [Desnos Louise Adélaïde, née Robin ?], Interrogatoire et condamnation de la princesse de Lamballe. 1792, 1846

Desnos Marie-Louise [Desnos Louise Adélaïde, née Robin ?], Le Journal du soir ou l'Appel des condamnés. 1793, 1846

Dubufe Édouard Louis, La Multiplication des pains, 1846

Dubufe Édouard Louis, Le Prisonnier de Chilon, 1846

Geefs Fanny, La Vierge consolatrice des affligés, 1846, huile sur toile, Schaerbeek (Belgique), église de la Sainte Famille

Giroux André, Vue prise des Alpes françaises [Paysage montagneux. Vue prise dans les Alpes françaises, au lieu-dit le Bout du monde, dans le ravin], 1837, huile sur toile, $326 \times 262 \mathrm{~cm}$, Paris, musée du Louvre

Gosse Nicolas, Louis XI aux pieds de saint François de Paule, 1844, huile sur toile, 64 x 86 $\mathrm{cm}$, Paris, musée du Louvre

Hérain ( $\left.\mathrm{M}^{\mathrm{me}} \mathrm{de}\right)$, La Foi et l'Espérance remontant au ciel, 1837

Hesse Alexandre, Henri IV rapporté au Louvre [Le Corps d'Henri IV exposé au Louvre], 1837, huile sur toile, 172 x $135 \mathrm{~cm}$, Pau, musée national du château de Pau

Jacquand Claudius, Les Orphelins, 1846

Jacquand Claudius, La Prise de Jérusalem par les Croisés [Jacques Molay, grand maître de l'ordre du

Temple en 1298, prend Jérusalem par surprise en 1299], 1846, huile sur toile, 173 x $315 \mathrm{~cm}$, Versailles, musée national des châteaux de Versailles et de Trianon

Johannot Alfred, La Veuve de François de Guise et ses enfants à la cour de Charles IX, 1837 
Juillerat Clothilde, Deux pastels, 1837

Labouchère Pierre-Antoine, Luther, Melanchton, Pomeranus et Cruciger traduisant la Bible, 1846

Lagache Mathilde, Le Chapelet, 1844

Lapito Louis Auguste, Vue prise dans la forêt de Fontainebleau, 1846, huile sur panneau, 33 $\mathrm{x} 41 \mathrm{~cm}$, coll. part.

Lehmann Henri, La Fille de Jephté, 1835, huile sur toile, 128 x $161 \mathrm{~cm}$, Bourron-Marlotte, mairie

Lehmann Henri, Le Mariage de Tobie

Mauvoisin, Le Neuf Thermidor, 1837

Murat Jean-Gilbert, Lamentations de Jérémie, 1844, huile sur toile, 306 x $450 \mathrm{~cm}$, SaintLéonard-deNoblat, collégiale Saint-Léonard

Murillo Bartolomé Esteban, Sainte Élisabeth de Hongrie, duchesse de Thuringe, lave et soigne les blessures des malades de la teigne, 1672, huile sur toile, 35,9 x 27,6 cm, Séville, hôpital de la SainteCharité

Norblin Sébastien, Les Trois Parques, 1846, cire sur bois

Philippoteaux Henri Félix Emmanuel, Avant-poste arabe, 1844

Philippoteaux Henri Félix Emmanuel, Le Rapt, 1844

Philippoteaux Henri Félix Emmanuel, La Razzia, 1844

Robert Léopold, Moissonneurs [L'Arrivée des moissonneurs dans les marais Pontins], 1830, huile sur toile, 141,7 x $212 \mathrm{~cm}$, Paris, musée du Louvre

Rouget Georges, Mariage de l'empereur Napoléon et de Marie-Louise [Mariage religieux de Napoléon $I^{\text {er }}$ et de Marie-Louise dans le salon carré du Louvre, le 2 avril 1810], 1837, huile sur toile, $185 \times 182 \mathrm{~cm}$, Versailles, musée national des châteaux de Versailles et de Trianon

Scheffer Ary, La Bataille de Tolbiac, 1836, huile sur toile, 415 x $465 \mathrm{~cm}$, Versailles, musée national des châteaux de Versailles et de Trianon

Scheffer Ary, Le Christ consolateur, 1837, huile sur toile, 184 x $248 \mathrm{~cm}$, Amsterdam, Historisch Museum

Scheffer Ary, Le Christ et les Saintes Femmes, 1846, huile sur bois, 108,8 x 86 cm, Manchester, Art Gallery

Scheffer Ary, L'Enfant charitable, 1840, huile sur toile, 118 x $74 \mathrm{~cm}$, Nantes, musée des Beaux-Arts Scheffer Ary, Marguerite et Faust au jardin, 1846, huile sur toile, 218 x $135 \mathrm{~cm}$, coll. part.

Scheffer Ary, Marguerite sortant du tombeau et apparaissant à son séducteur [peut-être Marguerite quittant l'église, 1838, huile sur toile, 222,3 x 144,8 cm, Detroit, Institute of Arts]

Scheffer Ary, La Plainte de la jeune fille, 1827, huile sur toile, $33 \times 25 \mathrm{~cm}$, ClermontFerrand, musée d'art Roger-Quilliot

Scheffer Ary, Prière de Rachel

Scheffer Ary, Sainte Monique et saint Augustin [Saint Augustin et sa mère sainte Monique], 1846, huile sur toile, 147 x $114 \mathrm{~cm}$, Paris, musée du Louvre

Scheffer Henry, La Bataille de Cassel, 1837, huile sur toile, 465 x $543 \mathrm{~cm}$, Versailles, musée national des châteaux de Versailles et de Trianon 
Vernet Horace, La Bataille d'Isly [Victoire de l'Isly], 1846, huile sur toile, 514 x $1040 \mathrm{~cm}$, Versailles, musée national des châteaux de Versailles et de Trianon

Vernet Horace, Un traîneau russe [De retour du marché], 1843, huile sur toile, 36 x $31 \mathrm{~cm}$, coll. part.

Winterhalter Franz Xaver, Le Décaméron, 1837, huile sur toile, 190.5 x 254 cm, coll. part.

Winterhalter Franz-Xavier, Salon du château de Windsor [Réception de Louis-Philippe, roi de France, au château de Windsor le 8 octobre 1844], 1844-1845, huile sur toile, 345 x $480 \mathrm{~cm}$, Versailles, musée national des châteaux de Versailles et de Trianon

\section{Germaine de Staël}

[Anonyme], Alexandre mourant, Rome, palais Justiniani

[Anonyme], Apollon du Belvédère, copie romaine réalisée vers 130-140 après J. C., marbre, $224 \mathrm{~cm}$, cité du Vatican, musée Pio Clementino

[Anonyme], Apollon musagète

[Anonyme], Castor et Pollux

[Anonyme], Cincinnatus invité par les consuls à quitter sa charrue pour commander les armées romaines

[Anonyme], Colosse nerveux de l'Hercule

[Anonyme], Colosses de Monte Cavallo

[Anonyme], Énée dans les Champs-Élysées

[Anonyme], Le Fils de Caïrbar endormi sur la tombe de son père

[Anonyme], Laocoon, $\mathrm{I}^{\mathrm{er}}$ siècle avant J.-C., marbre, $242 \mathrm{~cm}$, cité du Vatican, musées du Vatican

[Anonyme], Minerve guerrière

[Anonyme], Les Muses

[Anonyme], Niobé

[Anonyme], Pied de Jupiter, cité du Vatican, musées du Vatican

[Anonyme], Statue de Tibère

[Anonyme], Tête d'Apollon, Rome, palais Justiniani

[Anonyme], Torse d'Hercule, cité du Vatican, musées du Vatican

Brunn Ida, Althée prête à brûler le tison auquel est rattachée la vie de son fils Méléagre

Canova Antonio, Génie de la Douleur appuyé sur un lion

Corrège (Le), La Sainte Nuit, vers 1522-1530, huile sur bois, 190 x $295 \mathrm{~cm}$, Dresden, Gemäldegalerie

David Jacques-Louis, Les Licteurs rapportent à Brutus les corps de ses fils, 1789, huile sur toile, $323 \times 422 \mathrm{~cm}$, Paris, musée du Louvre

Dominiquin (Le), Communion de saint Jérôme, 1614, huile sur toile, 419 x $256 \mathrm{~cm}$, cité du Vatican, musées du Vatican

Drouais Jean-Germain, Marius épargné par le Cimbre [Marius prisonnier à Minturnes], 1786, huile sur toile, 271 x $365 \mathrm{~cm}$, Paris, musée du Louvre 
Gagnereaux Bénigne, Clorinde mourante et Tancrède [Le Baptême de Clorinde par Tancrède], 1789, huile sur toile, 76 x $98 \mathrm{~cm}$, Paris, musée du Louvre

Gérard François, Bélisaire [Bélisaire portant son guide piqué par un serpent], 1797, huile sur toile, 91 x $74 \mathrm{~cm}$, Los Angeles, J. Paul Getty Museum

Gérard François, Ossian [Ossian évoque les fantômes au son de la harpe sur les bords du Lora], 1801-1802, huile sur toile, 180,5 x 198,5 cm, Rueil-Malmaison, château de Malmaison et de Bois-Préau

Guérin Pierre-Narcisse, Thésée protège son épouse [Phèdre et Hippolyte], vers 1802, huile sur toile, 257 x $335 \mathrm{~cm}$, Paris, musée du Louvre

Hartmann, Visite de Madeleine et de deux femmes nommées Marie au tombeau de J.-C.

L'Albane, Le Christ endormi sur la croix [peut-être Le Christ en croix, première moitié du ${ }_{\mathrm{xvII}}{ }^{\mathrm{e}}$ siècle, huile sur toile, $63,3 \mathrm{~cm}$ de diamètre, Troyes, musée des Beaux-Arts]

Raphaël, L'École d'Athènes, 1510, fresque, base $700 \mathrm{~cm}$, cité du Vatican, musées du Vatican

Raphaël, La Messe de Bolsena, 1512, fresque, base $660 \mathrm{~cm}$, cité du Vatican, musées du Vatican

Raphaël, Sainte Cécile levant les yeux au ciel [Sainte Cécile], 1514, huile sur bois transposé sur toile, 220 x $136 \mathrm{~cm}$, Bologne, Pinacoteca Nazionale

Raphaël, La Transfiguration, v. 1517-1520, huile sur bois, 405 x 278 cm, cité du Vatican, musées du Vatican

Raphaël, Une Vierge contemplée par deux enfants

Rosa Salvator, Cincinnatus commande les armées romaines [peut-être Cincinnatus labourant son champ au moment qu'on lui apporte les faisceaux et les autres marques consulaires]

Rosa Salvator, Le Fils de Caïrbar endormi sur la tombe de son père

Rosa Salvator, trois tableaux de paysage

Schick, Premier Sacrifice de Noé après le déluge

Thorwaldsen Bertel, Jason [Jason et le veau d'or], modelé à Rome en 1802-1803, complété en marbre en 1828, $242 \mathrm{~cm}$, Copenhague, musée Thorwaldsen

Titien (Le), Jésus succombant sous le fardeau de la Croix

\section{Edmée de Syva}

[Anonyme], Amour sortant d'un buisson de roses, 1848

[Anonyme], Napoléon avec un vieux de la vieille, 1848

[Anonyme], Le Rachat d'une esclave, 1848

Biard François-Auguste, Promenade sous le cercle polaire [Promenade artistique au rocher d'Hesmandoë par le travers du cercle polaire, en 1839], 1848

Bonheur Rosa, Bœufs et taureaux du Cantal, 1848

Bonheur Rosa, Brebis couchée (?), 1848, sculpture, bronze, Fontainebleau, musée national du château

Bonheur Rosa, Taureau, 1848, sculpture, bronze, 18 x 33 x $11 \mathrm{~cm}$, Bordeaux, musée des Beaux-Arts

Chassériau Théodore, Jour du sabbat dans le quartier juif à Constantinople, 1848 
Chevet, Charles VII et Agnès Sorel chez l'astrologue, 1848

Couder Auguste, Le Serment du Jeu de paume (20 juin 1789), 1848, huile sur toile, 421 x 580 $\mathrm{cm}$, Versailles, musée national des châteaux de Versailles et de Trianon

Debon Hippolyte François, Défaite d'Attila dans les plaines de Châlons, 1848, huile sur toile, 445 x $592 \mathrm{~cm}$, Marseille, musée des Beaux-Arts

Devéria Achille-Jacques-Jean-Marie, Descente de Croix, 1848, huile sur toile, Chamagnieu, église paroissiale Saint-Christophe

Devéria Eugène, Femme des Pyrénées [Femme de la vallée d'Ossau et son enfant], 1847-1848, huile sur toile, 29,2 x 97,3 cm, Bowes Museum, Barnard Castle

Duveau Louis, Émigrants bretons arrêtés par des républicains, 1848

Fabre d'Olivet $\left(\mathrm{M}^{\mathrm{lle}}\right)$, tableau inspiré d'une nouvelle de $\mathrm{M}$. Töpffer, 1848

Gleize, Mort de saint Jean-Baptiste, 1848 [peut-être Glaize Auguste-Barthélémy, Mort de saint Roch, 1847, huile sur toile, Montpellier, église Saint-Roch]

Guichard Joseph-Benoît, Les Saints Patrons des principales églises de la ville de Japon [Lyon ?], 1848, Sées, église Saint-Pierre

Hamon Jean-Louis, Dessus-de-porte, 1848

Hesse Alexandre, Prise de Baruth par Amaury II en 1197 [La Reprise de Beyrouth occupée par les troupes du sultan Saladin, par Amaury de Lurisman et Henri I ${ }^{\text {er }}$ Bratant, octobre 1197], 1842, huile sur toile, 173 x $383 \mathrm{~cm}$, Versailles, musée national des châteaux de Versailles et de Trianon

Landelle Charles, Sainte Cécile, 1848, huile sur toile, Paris, église Saint-Nicolas-desChamps

Lehmann Henri, Saintes Femmes au pied de la Croix, 1848

Leloir Jean-Baptiste Auguste, Les Athéniens captifs à Syracuse, 1848

Martin Anna, Étude de jeune fille, 1848

Martersteig, La Condamnation de Jean Huss, 1848

Martersteig, Luther brûlant la bulle du pape à Wittemberg, 1848

Martersteig, Luther devant la diète assemblée à Worms, 1848

Moynier Auguste, Portrait de $M^{m e}$ F. T., 1848

Penguilly L'Haridon Octave, deux toiles inspirées de Don Quichotte, 1848

Peyronnet Joseph Gustave, Le Retour au village, 1848

Schnetz Jean-Victor, La Bataille d'Ascalon, 1847, huile sur toile, 315 x $556 \mathrm{~cm}$, Versailles, musée national des châteaux de Versailles et de Trianon

Schnetz Jean-Victor, Les Funérailles d'une jeune martyre dans les catacombes de Rome, 1847, huile sur toile, 338 x $382 \mathrm{~cm}$, Nantes, musée des Beaux-Arts

Schopin Henri-Frédéric, Le Jugement de Salomon, 1842, huile sur toile, 280,4 x 341,6 cm, coll. part.

Schopin Henri-Frédéric, Première Entrevue de Rachel et de Jacob, 1848

Schopin Henri-Frédéric, Réception de Jacob dans la famille de Laban, 1848, huile sur toile, 82 x 65,5 cm, Morez, musée de la Lunette

Signol Émile, Prise de Jérusalem par les croisés, 15 juillet 1099, 1847, huile sur toile, 324 x 556 $\mathrm{cm}$, Versailles, musée national des châteaux de Versailles et de Trianon 


\section{Élisabeth Vigée-Lebrun}

Adrien, Le Faune qui dort, sculpture

Andrea del Sarto, Madone del Sacco, 1525, fresque, $191 \times 403 \mathrm{~cm}$, Florence, église SS Annunziata

Andrea del Sarto, La Vierge, Jésus et saint Jérôme [peut-être La Sainte Famille, huile sur bois, 130 x $98 \mathrm{~cm}$, Florence, palais Pitti]

[Anonyme], Apollon

[Anonyme], Belle Cléopâtre mourante

[Anonyme], Gladiateur mourant

[Anonyme], Laocoon, ${ }_{\mathrm{I}}^{\mathrm{er}}$ siècle av. J.-C., sculpture, marbre, $242 \mathrm{~cm}$, cité du Vatican, musées du Vatican

Bellini Giovanni, Baptême de Jésus, vers 1502, huile sur bois, 400 x $263 \mathrm{~cm}$, Vicence, église SainteCorone

Bernin (Le), Sainte Thérèse [L'Extase de sainte Thérèse], 1647-1651, sculpture, marbre, 350 $\mathrm{cm}$, Rome, église Sainte-Marie-de-la-Victoire

Bologne Jean (de), Alexandre mourant

Bologne Jean (de), Les Deux Lutteurs

Bologne Jean (de), Euphrosyne couchée

Bologne Jean (de), Fontaine de Neptune, sculpture, marbre, $348 \mathrm{~cm}$, Florence, jardins du Boboli

Bologne Jean (de), Niobé

Bologne Jean (de), Le Rémouleur

Bologne Jean (de), Le Satyre et le Bacchus

Bologne Jean (de), Un jeune faune

Bologne Jean (de), La Vénus de Médicis [Vénus agenouillée], vers 1560, sculpture, bronze, $25,5 \mathrm{~cm}$, Florence, musée national du Bargello

Canova Antonio, Mausolée de Ganganelli

Carrache Annibal, Déposition du Christ [peut-être Mise au tombeau, 1595, huile sur cuivre, 438 x $349 \mathrm{~cm}$, New York, The Metropolitan Museum of Art]

Carrache Louis, Portrait de Louis Carrache [Autoportrait], 71 x 56,5 cm, Florence, galerie des Offices

Corrège (Le), La Crèche ou Nativité [peut-être Nativité avec sainte Élisabeth et saint JeanBaptiste, Milan, pinacothèque de Brera]

Dominiquin (Le), Martyre de sainte Agnès, huile sur toile, $533 \times 342 \mathrm{~cm}$, Bologne, Pinacothèque

Dou Gérard, La Femme hydropique [La Femme hydropique ou Docteur examinant les urines d'une femme], 1663, huile sur bois, 83 x $67 \mathrm{~cm}$, Paris, musée du Louvre

Ghiberti Lorenzo, Portes du baptistère [Les Portes du Paradis], 1429-1452, porte en bronze doré, Florence, cathédrale

Guerchin (Le), Départ d'Agar [Abraham renvoie Agar], 1652, huile sur toile, 193 x $229 \mathrm{~cm}$, Londres, collection de Sir Denis Mahon 
Guerchin (Le), Hercule qui étouffe Antée, 1631, fresque, Bologne, palais Sampieri

Guerchin (Le), Sibylle de Cumes [La Sibylle de Cumes avec un putto], 1651, huile sur toile, 222 x 168,5 cm, Londres, collection de Sir Denis Mahon

Guide (Le), La Charité, vers 1620, huile sur toile, 107 x $88 \mathrm{~cm}$, Florence, palais Pitti

Guide (Le), Enfant endormi

Guide (Le), Les Evangélistes dans le désert

Guide (Le), Magdeleine, 1633, huile sur toile, 231 x $152 \mathrm{~cm}$, Rome, galerie nationale d'Art antique, palais Barberini

Guide (Le), Saint Pierre et saint Paul causant ensemble, 1605, huile sur toile, 197 x $140 \mathrm{~cm}$, Milan, pinacothèque de Brera

Kauffmann Angelika, Autoportrait, 1787, huile sur toile, $128 \times$ x 93, $5 \mathrm{~cm}$, Florence, galerie des Offices

Léonard de Vinci, La Cène, 1494-1498, peinture murale à la tempera, Milan, église Santa Maria delle Grazie

Michel-Ange, Le Jugement dernier, 1534-1541, fresque, 146 x $134 \mathrm{~cm}$, Vatican, chapelle Sixtine

Michel-Ange, Mausolée de Jules II, 1505-1535, sculpture, marbre, Rome, Saint-Pierre-auxliens Notte Gérard (de la), L'Ombre de Samuel

Poussin Nicolas, La Mort de Germanicus, 1626-1627, huile sur toile, 148 x $198 \mathrm{~cm}$, Minneapolis, The Minneapolis Institute of Art

Raphaël, Autoportrait, vers 1504-1506, huile sur bois, 47, 5 x 33 cm, Florence, galerie des offices

Raphaël, L'École d'Athènes, 1509-1510, fresque, 500 x 700 cm, cité du Vatican, musées du Vatican

Raphaël, L'Incendie du Borgo, 1514-1517, fresque, base 770 cm, cité du Vatican, musées du Vatican

Raphaël, Jules II [Le Pape Jules II], 1512, tempera sur bois, 108, 5 x $80 \mathrm{~cm}$, Florence, galerie des Offices

Raphaël, Léon X [Le Pape Léon X avec les cardinaux Giulio de Médicis et Luigi de Rossi], vers 1518 , huile sur panneau, $154 \times 119 \mathrm{~cm}$, Florence, galerie des Offices

Raphaël, Madonna della seggiola [Vierge à la chaise], 1513-1514, huile sur panneau, $71 \mathrm{~cm}$, Florence, palais Pitti

Raphaël, La Messe de Bolsena, 1512, fresque, base $660 \mathrm{~cm}$, cité du Vatican, musées du Vatican

Raphaël, Sainte Famille assise sur des ruines

Raphaël, La Transfiguration, 1516-1520, huile sur bois, $405 \times 218 \mathrm{~cm}$, cité du Vatican, musées du Vatican

Raphaël, Vision d'Ézéchiel, 1518, huile sur bois, 40, 7 x 29, 5 cm, Florence, palais Pitti

Rembrandt, Portrait d'un philosophe

Romain Jules et Primatice, fresques, 1526-1534, Mantoue, Palazzo Té

Rubens Pierre-Paul, Fête de village [peut-être Ronde de paysans dite La Ronde, vers 1640, huile sur toile, 73 x $106 \mathrm{~cm}$, Madrid, musée du Prado]

Rubens Pierre-Paul, Henri IV et Gabrielle 
Tintoret (Le), Le Crucifiement, 1565, huile sur toile, 536 x $1224 \mathrm{~cm}$, Venise, Scuola di San Rocco

Tintoret (Le), La Fuite en Égypte, 1582-1587, huile sur toile, 422 x $580 \mathrm{~cm}$, Venise, Scuola di San Rocco

Titien (Le), Paul III [existent trois versions : huile sur toile, $98 \times 79 \mathrm{~cm}$, SaintPétersbourg, musée de l'Ermitage ; 1543, huile sur toile, 107 x $83 \mathrm{~cm}$, Naples, Museo nazionale ; vers 1549, huile sur toile, 89 x $78 \mathrm{~cm}$, Vienne, Kunsthistorisches Museum]

Titien (Le), Portrait d'une femme habillée en satin cramoisi [peut-être Giulia Varano, vers 1545-1547, huile sur toile, 113, 5 x $88 \mathrm{~cm}$, Florence, palais Pitti]

Van Dyck Antoine, Une famille de bourgmestres [peut-être Portrait de Rockox avec sa nièce et un fils de celle-ci, Turin, galerie royale]

Volterra Daniele (da), Descente de Croix, 1545, fresque, Rome, église de la Trinité-desMonts

\section{Caroline Wuiet}

[Anonyme], Oreste

[Anonyme], Portrait de Giovanni Battista Martini

[Anonyme], Portrait de Jacques-Henri Bernardin de Saint-Pierre

[Anonyme], Portrait de l'abbé Jacques Delille [peut-être Portrait de Jacques Delille, poète, gravure en couleur, 37 x 25,5 cm, Versailles, musée national des châteaux de Versailles et de Trianon]

[Anonyme], Portrait de la cit. Lange (cit. Simon)

Barbier-Walbonne Jacques-Luc, Othryade, Spartiate, 1798, huile sur toile

Barbier-Walbonne Jacques-Luc, Un portrait de la famille du c. $C^{* * *}, 1798$, huile sur toile

Bosio Jean Baptiste François, Homère chez le berger Glocus, 1798, huile sur toile

Bouchet Louis André Gabriel, Le Portrait de la citoyenne de Saint-Aubin dans le rôle de Lisbeth, 1798, huile sur toile, $33,5 \times 25 \mathrm{~cm}$

Bouton Joseph-Marie, Portrait d'une jeune personne, peinte en Érigone [Joséphine Raoulx en Érigone], 1798, gouache sur ivoire, $18 \times 14,5 \mathrm{~cm}$, Paris, collection de la comtesse de Milleville

Chinard Joseph, Deux bustes, sculpture

Coste L., Clair de lune, 1798, peinture sur porcelaine

Coste L., Paysage, effet de neige, 1798, peinture sur porcelaine

Delafontaine Pierre Maximilien, Le Patineur (portrait du graveur Jean Bertrand Andrieu), 1798, huile sur toile, 179 x $130 \mathrm{~cm}$, Paris, musée de la Monnaie

Desoria Jean-Baptiste François, Portrait de la citoyenne Pipelet, 1798, huile sur toile, $130 \mathrm{x}$ $99,1 \mathrm{~cm}$,

Chicago, The Art Institute

Gauffier Pauline, Deux tableaux, sujets champêtres représentant des paysannes des environs de Terracine, nommés L'Horoscope tiré et L'Horoscope réalisé, 1798, huile sur toile, 69 x 54 cm, Dijon, musée Magnin 
Gérard François, L'Amour et Psyché, 1797-1798, huile sur toile, 186 x 132 cm, Paris, musée du Louvre

Gonet, Portrait en miniature d'André-Ernest-Modeste Grétry (1741-1813), 1798, aquarelle et lavis de gris sur papier, $80 \times 60 \mathrm{~mm}$, Londres, British Museum

Honnet Alexandre Romain, Séparation de Télémaque et Mentor en Égypte, 1798, huile sur toile Huin ( $\left.\mathrm{M}^{\mathrm{lle}}\right)$, Hébé, 1798

Huin $\left(\mathrm{M}^{\mathrm{lle}}\right)$, Un cadre renfermant divers portraits en miniatures

Isabey Jean-Baptiste, Isabey et sa famille, dessiné par lui-même [La Barque d'Isabey], 1798, dessin au crayon noir, 64,5 x 87,7 cm, Paris, musée du Louvre

Isabey Jean-Baptiste, Portrait du c. Roche, marchand du palais Égalité [peut-être Portrait d'un jeune homme de profil, début ${ }_{\mathrm{XIX}}{ }^{\mathrm{e}}$ siècle, dessin, pierre noire, 17,5 x 15,3 cm, Boston, Museum of fine arts]

Labille-Guiard Adélaïde, Portrait du c. Charles, professeur de physique, membre de l'Institut national, faisant une démonstration d'optique et tenant un réflecteur solaire, 1798, huile sur toile, 86,5 x $69 \mathrm{~cm}$, Paris, bibliothèque de l'Institut de France

Labille-Guiard Adélaïde, Portrait du c. Janvier, mécanicien astronome, traçant la projection graphique d'un passage de Vénus sur le soleil : on aperçoit sur la table plusieurs figures de planètes et de constellations, 1798, huile sur toile

Leguay Étienne Charles, Deux portraits peints sur ivoire [peut-être Portrait d'Adam Hippolyte de Fabrioni, âgé de 12 ans, vers 1797, miniature sur ivoire, $71 \mathrm{~cm}$, Paris, musée du Louvre, et Portrait de femme blonde, 1797, miniature sur ivoire, $78 \mathrm{~cm}$, Paris, musée du Louvre]

Leguay Étienne Charles, Quatre portraits en miniature peints sur de la porcelaine

Lemoine Marie-Victoire, Tableau représentant une jeune Frescatane écoutant un jeune homme qui joue de la guitare, 1793, huile sur toile, 92,5 x 78,3 cm

Leroy de Liancourt François, Tableau représentant un vieillard aveugle jouant de la vielle et trois enfants qui l'écoutent, 1798, huile sur toile

Lethière Guillaume Guillon, Philoctète dans l'île déserte de Lemnos gravissant les rochers pour avoir un oiseau qu'il a tué, 1798, huile sur toile, Paris, musée du Louvre

Malard Sermaise [ou Sarmaise], Vénus et Endymion [peut-être Vénus et Adonis], 1798, huile sur toile

Martin Guillaume, L'Enlèvement d'Hélène, 1798, huile sur toile

Monsiau Nicolas André, Dessin d'après le tableau de Zeuxis, 1798, dessin, mine de plomb, plume et encre brune, lavis brun, $26 \times 40 \mathrm{~cm}$, coll. part.

Monsiau Nicolas André, Socrate et Alcibiade chez Aspasie [Aspasie s'entretenant avec les hommes illustres], 1798, huile sur toile, 146,5 x 106,5 cm, Chambéry, musée des BeauxArts

Monsiau Nicolas André, Zeuxis choisissant des modèles, 1798, huile sur toile, 96 x $129 \mathrm{~cm}$, Toronto, Art Gallery of Ontario

Morin Eulalie, Portrait d'homme, 1798, dessin au crayon

Myron, Tête de Jupiter, ${ }_{\mathrm{v}}^{\mathrm{e}}$ siècle av. J.-C., sculpture, bosquet du château de Versailles puis Muséum 
Pajou Jacques-Augustin-Catherine, Orphée perdant son Eurydice pour la seconde fois, 1798 [peut-être Bas-reliefs de jeux d'enfants avec Orphée et Eurydice, 1770, bois doré, Versailles, musée national des châteaux de Versailles et de Trianon]

Stouf Jean-Baptiste, Vincent de Paule, fondateur des hospices des enfants trouvés, considéré comme un philosophe, 1798, sculpture, plâtre, $150 \mathrm{~cm}$, Paris, église Saint-Thomas-d'Aquin Vallayer-Coster Anne, Des fleurs dans un vase de porcelaine garni de bronze, 1798

Vernet Horace, Fidélité des hussards français, 1798, dessin

Vernet Horace, Une femme à cheval (Amazone), 1798, huile sur toile

Vincent François André, L'Agriculture, nommé La Leçon de labourage, 1798, huile sur toile, 213 x $313 \mathrm{~cm}$, Bordeaux, musée des Beaux-Arts 